PROGRAMA DE DOCTORADO EN ESPAÑOL: LINGÜÍSTICA, LITERATURA Y COMUNICACIÓN

TESIS DOCTORAL

\title{
EL PROGRAMA TELEVISIVO COMO RECURSO PARA LA ENSEÑANZA/APRENDIZAJE DE ESPAÑOL LENGUA EXTRANJERA
}

\author{
Presentada por \\ SARA DEL VALLE REVUELTA
}

para optar al grado de Doctora por la

Universidad de Valladolid

Dirigida por

NIEVES MENDIZÁBAL DE LA CRUZ

MARÍA ÁNGELES SASTRE RUANO 



\section{AGRADECIMIENTOS}

En primer lugar, quiero mostrar mi más sincero agradecimiento a las profesoras Nieves Mendizábal y Mariángeles Sastre, las directoras de esta tesis doctoral. Siempre os estaré muy agradecida por haberme dado la oportunidad de ser vuestra doctoranda y por haberme ofrecido todo vuestro apoyo y ayuda desde el principio hasta el final. A ti, Nieves, también me gustaría agradecerte tu constante atención, motivación, dedicación, paciencia y confianza durante estos tres años. Siempre estaré en deuda contigo.

Hago extensible mi agradecimiento a la profesora María Amores, mi coordinadora y tutora en West Virginia University. María, tu atención, disponibilidad y apoyo me han permitido continuar y finalizar esta tesis en Estados Unidos y, con ello, optar a la mención de doctorado internacional. Siempre te estaré enormemente agradecida.

También quiero mostrar mi gratitud a todos los docentes de ELE que tan amablemente respondieron al cuestionario para profesores incluido en esta tesis; a los alumnos de West Virginia University que participaron en los dos estudios empíricos que realicé en esa universidad; y a mis compañeras y amigas Evangeline Cade y Shelby Concepción, por revisar mis traducciones al inglés.

Por otro lado, esta tesis no habría sido posible sin la oportunidad que mis padres me han dado para poder llegar hasta aquí. Les agradezco el esfuerzo — tanto personal como económico- que me han dedicado y los valores que me han inculcado. Con tu permiso, mamá, me gustaría dedicarle una líneas más a papá: muchísimas gracias por todo el tiempo y dedicación que le has prestado a esta tesis; poder contar con tu ayuda siempre que la he necesitado me ha proporcionado un apoyo y una tranquilidad enormes.

Y quedas tú, Bastian. Por supuesto que esta tesis ha llegado a feliz término también gracias a ti. Gracias por escucharme, por apoyarme, por animarme, por cuidarme y por divertirme durante todo el proceso de realización de esta tesis. Y por hacerme feliz siempre.

Finalmente, también tengo que dar las gracias a mis amigos, en especial a aquellos que han recorrido conmigo algún tramo de este camino.

¡Muchas gracias a todos! 


\section{RESUMEN}

Esta tesis doctoral se propone estudiar y demostrar la rentabilidad del programa televisivo como recurso para la enseñanza/aprendizaje de español como lengua extranjera. El programa televisivo ofrece la posibilidad de trabajar varios de los componentes de la competencia comunicativa. Una de las principales ventajas de trabajar con este formato es su gran contenido cultural. Este es destacable porque se trata de formatos elaborados en el país para cuya población están destinados. A diferencia de otro tipo de formatos audiovisuales, el uso del programa de televisión en la clase de español como lengua extranjera no es tan habitual, quizás por no ser considerado un material educativo. Sin embargo, es lo más cercano a la realidad que el docente puede introducir en su aula.

Los objetivos de esta investigación han sido: analizar y explicar, a través de instrumentos de recogida y de análisis de datos, las razones por las que el programa televisivo aún no se rentabiliza como recurso para la enseñanza/aprendizaje de español como lengua extranjera; y demostrar la rentabilidad didáctica de este formato audiovisual a través del diseño de propuestas didácticas y de su aplicación práctica en un contexto educativo real.

Esta investigación nos ha permitido obtener datos recientes y extraer conclusiones sobre el uso que se le da a este recurso. Por un lado, se han analizado las actividades basadas en programas televisivos que aparecen en los manuales de ELE; y, por otro lado, se ha realizado un cuestionario a una muestra de profesores de ELE, cuyas preguntas nos han permitido sondear cómo y con qué frecuencia los docentes de ELE trabajan con programas televisivos en sus clases, así como su opinión acerca de dicho recurso.

Para demostrar la rentabilidad didáctica de este recurso en diferentes niveles y confirmar cómo el uso de programas televisivos en clase favorece la adquisición de ciertas competencias y destrezas, además de ser un material muy motivador para los alumnos, se han diseñado diez propuestas didácticas con actividades para realizar antes, durante y después del visionado, utilizando un formato televisivo diferente para cada una de ellas. Finalmente, se han realizado dos estudios empíricos en una universidad norteamericana con el objetivo de poner en práctica dos de estas propuestas didácticas y de llevar a cabo un análisis de resultados de los datos obtenidos a través de los cuestionarios completados por los alumnos participantes. 
Los resultados de esta investigación nos han permitido demostrar que es posible elaborar una propuesta didáctica basada en el uso de programas televisivos que permita a los alumnos mejorar la comprensión y expresión oral, la comprensión y expresión escrita, aprender gramática, vocabulario, expresiones en español y rasgos de la pronunciación del español, conocer la cultura española, e incluso motivar a los alumnos tanto a ver programas de televisión en español fuera de clase como a intentar expresarse en la lengua que están aprendiendo.

\section{PALABRAS CLAVE}

Enseñanza de español, aprendizaje de español, competencia comunicativa material audiovisual, programa televisivo, recurso didáctico, aplicación didáctica. 


\section{ABSTRACT}

This doctoral thesis approaches the use of television programs as a teaching resource in the Spanish-as-a-second-language classroom. Television programs offer the possibility to work on several aspects of the communicative competence. One of the main advantages of using these programs when teaching is their high cultural content. This is significant because these programs are made within a cultural context aimed at a specific population. Unlike other audiovisual productions, television programs are not yet so utilized in the Spanish-as-a-second-language classroom. A reason may be that they are still considered to have no educative value. However, it is the most real linguistic sample that teachers can bring to their students.

The aim of this study has been: to analyze and explain, through data collection instruments and data analysis tools, the reasons why television programs are not yet so utilized in the Spanish-as-a-second-language classroom; and to demonstrate the usefulness of television programs for teaching a foreign language by presenting and putting into practice, in a real academic context, a learning proposal for Spanish-as-a-second-language students based on this resource.

This study has allowed us to collect recent data and draw conclusions about the use of this resource by means of two diagnostic tests. On the one hand, we have analyzed several activities based on television programs in Spanish-as-asecond-language manuals. On the other hand, we have distributed a questionnaire among several Spanish teachers. Its questions have allowed us to sound out how and how often Spanish teachers use television programs in their classes, as well as their opinion on this teaching resource.

In order to prove the teaching profitability of this resource in different levels and to confirm how the use of television programs in class favors the acquisition of certain competences and skills, in addition to being a very motivating material for the students, we have designed ten teaching proposals with activities to do before, during and after the viewing, using a different television program format for each of them. Finally, we have carried out two empirical studies in a North American university with the aim of putting into practice two of these teaching proposals and to perform an analysis of the data obtained through the questionnaires completed by the participating students. 
The results of this study have allowed us to demonstrate that it is possible to create a teaching proposal based on the use of television programs, which allows students to improve their listening, speaking, reading and writing skills, as well as to learn grammar, vocabulary, Spanish expressions and features of Spanish pronunciation, to get to know the Spanish culture and even to motivate the students to watch Spanish television programs outside of class as well as to attempt expressing themselves in the language.

\section{KEY WORDS}

Teaching Spanish, learning Spanish, comunicative competence, audiovisual content, television program, teaching resource, learning proposal. 
EL PROGRAMA TELEVISIVO COMO RECURSO PARA LA ENSEÑANZA/APRENDIZAJE DE ESPAÑOL LENGUA EXTRANJERA 


\section{ÍNDICE}

INTRODUCCIÓN __ 1

JUSTIFICACIÓN DE LA INVESTIGACIÓN 2

OBJETIVOS 4

METODOLOGÍA_ 7

ESTRUCTURA DE LA TESIS _ 13

1. LA COMPETENCIA COMUNICATIVA EN LA ENSEÑANZA DE SEGUNDAS LENGUAS

1.1 ADQUISICIÓN Y APRENDIZAJE DE SEGUNDAS LENGUAS ___ 18

1.2 LA COMPETENCIA COMUNICATIVA 25

1.3 LA COMPETENCIA LINGÜÍSTICA __ 34

1.3.1 La competencia léxica 36

1.3.2 Competencia gramatical _ 38

1.3.3 Competencia semántica___ 42

1.3.4 Competencia fonológica _ 44

1.3.5 La competencia ortográfica _ 45

1.3.6 Competencia ortoépica 46

1.4 LA COMPETENCIA SOCIOLINGÜÍSTICA 48

1.4.1 Los contrastes socioculturales _ 50

1.4.2 Los marcadores lingüisticos de relaciones sociales___ 51

1.4.3 Las normas de cortesía $\quad 53$

1.4.4 Las expresiones de sabiduría popular___ 56

1.4.5 Diferencias de registro _ 58

1.4.6 Los dialectos y acentos __ 61

1.5 LA COMPETENCIA DISCURSIVA 65

1.6 LA COMPETENCIA ESTRATÉGICA $\quad 70$

1.7 LA COMPETENCIA PRAGMÁTICA 78

1.7.1 Los factores pragmáticos: elementos y relaciones __ 79

1.7.2 Los aspectos pragmáticos: los actos de habla y la cortesía ___ 81

2. DIDÁCTICA DE LOS MEDIOS AUDIOVISUALES

2.1 PRINCIPIOS PARA LA SELECCIÓN-EVALUACIÓN _ 86

2.2 PRINCIPIOS PARA LA UTILIZACIÓN E INTEGRACIÓN DIDÁCTICA___ 87

2.3 PRINCIPIOS PARA EL DISEÑO DE MATERIALES DIDÁCTICOS __ 89

2.4 MARCO METODOLÓGICO Y ENFOQUE PEDAGÓGICO ___ 92

3. EL PROGRAMA DE TELEVISIÓN COMO RECURSO PARA LA ENSEÑANZA/APRENDIZAJE DE ELE__ 96

3.1 El MATERIAL AUDIOVISUAL EN LA CLASE DE ELE _ 97

3.2 VENTAJAS DEL RECURSO DEL PROGRAMA DE TELEVISIÓN PARA TRABAJAR EL

ENFOQUE COMUNICATIVO 99 
EL PROGRAMA TELEVISIVO COMO RECURSO PARA LA

ENSEÑANZA/APRENDIZAJE DE ESPAÑOL LENGUA EXTRANJERA

3.3 LA INTEGRACIÓN DEL PROGRAMA DE TELEVISIÓN EN LA ENSEÑANZA DE ELE.

VENTAJAS E INCONVENIENTES 101

3.4 CRITERIOS DE SELECCIÓN DE PROGRAMAS DE TELEVISIÓN PARA LA

ENSEÑANZA DE ELE 104

4. ASPECTOS DE LA COMPETENCIA COMUNICATIVA QUE SE PUEDEN

TRABAJAR CON PROGRAMAS DE TELEVISIÓN _ 109

4.1 LA ELECCIÓN DEL INPUT _ 110

4.2 LA TIPOLOGÍA DE LAS ACTIVIDADES __ 114

4.3 EL DISEÑO DE LAS ACTIVIDADES __ 120

4.4 ASPECTOS GRAMATICALES ___ 122

4.5 ASPECTOS LÉXICOS _ 124

4.6 ASPECTOS SOCIOCULTURALES _ 130

4.7 ASPECTOS PRAGMÁTICOS _ 132

4.8 ASPECTOS ESTRATÉGICOS 136

4.9 ASPECTOS DISCURSIVOS _ 145

5. ANÁLISIS DE MANUALES Y EXTRACCIÓN DE DATOS _

5.1 CRITERIOS PARA EL ANÁLISIS DE MANUALES 152

5.2 ANÁLISIS DE MANUALES _ 153

5.3 CONCLUSIONES _ 165

5.4 METODOLOGÍA PARA LA EXTRACCIÓN DE DATOS ___ 166

5.5 DATOS EXTRAÍDOS DEL CUESTIONARIO REALIZADO POR LOS PROFESORES 167

5.6 ANÁLISIS DE LOS DATOS EXTRAÍDOS DEL CUESTIONARIO REALIZADO POR LOS

PROFESORES

5.7 CONCLUSIONES 180

6. DETERMINACIÓN DEL CORPUS DE PROGRAMAS TELEVISIVOS

EMPLEADO COMO RECURSO DIDÁCTICO _ 182

6.1 METODOLOGÍA Y CRITERIO DE SELECCIÓN DE LOS PROGRAMAS TELEVISIVOS

INCLUIDOS EN LAS PROPUESTAS DIDÁCTICAS

6.2 DESCRIPCIÓN DE LOS PROGRAMAS TELEVISIVOS INCLUIDOS EN LAS

PROPUESTAS DIDÁCTICAS 184

7. PROPUESTAS DIDÁCTICAS PARA LA EXPLOTACIÓN DE PROGRAMAS DE TELEVISIÓN EN LA CLASE DE ELE 189

7.1 RECOMENDACIONES PARA LA UTILIZACIÓN DE ESTE FORMATO EN LOS DIFERENTES NIVELES DEL MCER 190

7.2 PARÁMETROS DE CLASIFICACIÓN DE LAS PROPUESTAS DIDÁCTICAS 191

7.3 PROPUESTA DE ACTIVIDADES PARA LA EXPLOTACIÓN DE UN PROGRAMA DE INFORMACIÓN METEOROLÓGICA 193

7.3.1 Actividades de previsionado 193

7.3.2 Actividades durante el visionado 197

7.3.3 Actividades de posvisionado 198 
7.4 PROPUESTA DE ACTIVIDADES PARA LA EXPLOTACIÓN DE UN PROGRAMA INFORMATIVO 200

7.4.1 Actividades de previsionado _ـ 200

7.4.2 Actividades durante el visionado _ 203

7.4.3 Actividades de posvisionado 205

7.5 PROPUESTA DE ACTIVIDADES PARA LA EXPLOTACIÓN DE UN PROGRAMA DE

INFORMACIÓN DEPORTIVA _ 206

7.5.1 Actividades de previsionado _ـ 206

7.5.2 Actividades durante el visionado 209

7.5.3 Actividades de posvisionado __ 211

7.6 PROPUESTA DE ACTIVIDADES PARA LA EXPLOTACIÓN DE UN PROGRAMA DE

COCINA 212

7.6.1 Actividades de previsionado _ 212

7.6.2 Actividades durante el visionado _ 214

7.6.3 Actividades de posvisionado _ـ 216

7.7 PROPUESTA DE ACTIVIDADES PARA LA EXPLOTACIÓN DE UN PROGRAMA

DOCUMENTAL 217

7.7.1 Actividades de previsionado _ـ 217

7.7.2 Actividades durante el visionado _ 219

7.7.3 Actividades de posvisionado 221

7.8 PROPUESTA DE ACTIVIDADES PARA LA EXPLOTACIÓN DE UN PROGRAMA DE

FICCIÓN $\quad 222$

7.8.1 Actividades de previsionado _ 222

7.8.2 Actividades durante el visionado _ 224

Ahora vas a ver un vídeo de uno de los programas de Camera Café emitidos

en España. 224

7.8.3 Actividades de posvisionado __ 225

7.9 PROPUESTA DE ACTIVIDADES PARA LA EXPLOTACIÓN DE UN PROGRAMA DE ENTRETENIMIENTO $\quad 227$

7.9.1 Actividades de previsionado _ـ 227

7.9.2 Actividades durante el visionado _ 230

7.9.3 Actividades de posvisionado _ـ 232

7.10 PROPUESTA DE ACTIVIDADES PARA LA EXPLOTACIÓN DE UN CONCURSO DE

TELEVISIÓN $\quad 234$

7.10.1 Actividades de previsionado _ـ 234

7.10.2 Actividades durante el visionado _ 237

7.10.3 Actividades de posvisionado _ـ 239

7.11 PROPUESTA DE ACTIVIDADES PARA LA EXPLOTACIÓN DE UNA EMISIÓN

PUNTUAL $\quad 242$

7.11.1 Actividades de previsionado_ 242

7.11.2 Actividades durante el visionado 245

7.11.3 Actividades de posvisionado __ 247 
EL PROGRAMA TELEVISIVO COMO RECURSO PARA LA

ENSEÑANZA/APRENDIZAJE DE ESPAÑOL LENGUA EXTRANJERA

7.12 PROPUESTA DE ACTIVIDADES PARA LA EXPLOTACIÓN DE UN PROGRAMA DE HUMOR

7.12.1 Actividades de previsionado 249

7.12.2 Actividades durante el visionado 252

7.12.3 Actividades de posvisionado 254

8. ESTUDIOS EMPÍRICOS 255

8.1 ESTUDIO EMPÍRICO DE LA PROPUESTA DIDÁCTICA PARA LA EXPLOTACIÓN DE UN PROGRAMA DE COCINA 256

8.1.1 Datos extraídos del cuestionario realizado por los alumnos 258

8.1.2 Análisis de los datos extraídos del cuestionario realizado por los alumnos 271

8.1.3 Conclusiones 275

8.2 ESTUDIO EMPÍRICO DE LA PROPUESTA DIDÁCTICA PARA LA EXPLOTACIÓN DE UN PROGRAMA DOCUMENTAL __ 278

8.2.1 Datos extraidos del cuestionario realizado por los alumnos ___ 280

8.2.2 Análisis de los datos extraídos del cuestionario realizado por los alumnos 293

8.2.3 Conclusiones 298

CONCLUSIONES 302

BIBLIOGRAFÍA 318

MANUALES ANALIZADOS 330

ANEXO I 334

ANEXO II 339

ANEXO III 345

ANEXO IV 351

ANEXO V 353

ANEXO VI 354 
EL PROGRAMA TELEVISIVO COMO RECURSO PARA LA

ENSEÑANZA/APRENDIZAJE DE ESPAÑOL LENGUA EXTRANJERA

\section{ÍNDICE DE TABLAS}

TABLA 1 PROCESOS COMUNICATIVOS DE LA LENGUA SEGÚN EL MCER (2002)..............23

TABLA 2 DESCRIPCIÓN DE LA ORGANIZACIÓN GRAMATICAL SEGÚN EL MCER (2002) ....40

TABLA 3 TIPOS DE MARCADORES DISCURSIVOS SEGÚN EL MECR (2002) .......................52

TABLA 4 EJEMPLOS DE CORTESÍA POSITIVA, CORTESÍA NEGATIVA Y DESCORTESÍA SEGÚN

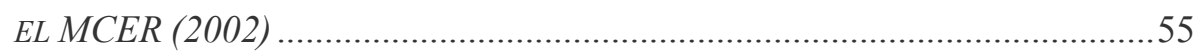

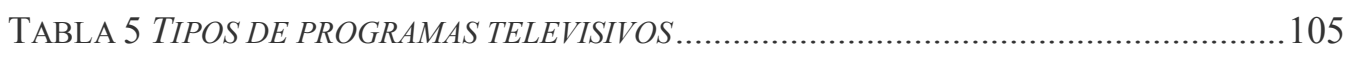

TABLA 6 ESTRATEGIAS FOMENTADAS MEDIANTE ACTIVIDADES POR REBECCA OXFORD

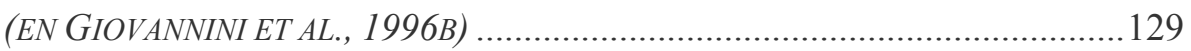

TABLA 7 TIPOS KINÉSICOS DE COMUNICACIÓN NO VERBAL SEGÚN POYATOS (1994) ......140

TABLA 8 ESCALA PARA VER TELEVISIÓN Y CINE EN CLASE DE ELE SEGÚN EL MCER

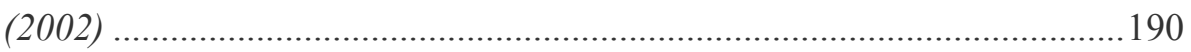

TABLA 9 TABLA MODELO DE CLASIFICACIÓN DE LAS PROPUESTAS DIDÁCTICAS .............192

TABLA 10 CLASIFICACIÓN DE LA PROPUESTA DE ACTIVIDADES PARA LA EXPLOTACIÓN DE UN PROGRAMA DE INFORMACIÓN METEOROLÓGICA

TABLA 11 CLASIFICACIÓN DE LA PROPUESTA DE ACTIVIDADES PARA LA EXPLOTACIÓN DE UN PROGRAMA INFORMATIVO

TABLA 12 CLASIFICACIÓN DE LA PROPUESTA DE ACTIVIDADES PARA LA EXPLOTACIÓN DE UN PROGRAMA DE INFORMACIÓN DEPORTIVA. 206

TABLA 13 CLASIFICACIÓN DE LA PROPUESTA DE ACTIVIDADES PARA LA EXPLOTACIÓN DE UN PROGRAMA DE COCINA 212

TABLA 14 CLASIFICACIÓN DE LA PROPUESTA DE ACTIVIDADES PARA LA EXPLOTACIÓN DE UN PROGRAMA DOCUMENTAL.

TABLA 15 CLASIFICACIÓN DE LA PROPUESTA DE ACTIVIDADES PARA LA EXPLOTACIÓN DE UN PROGRAMA DE FICCIÓN.

TABLA 16 CLASIFICACIÓN DE LA PROPUESTA DE ACTIVIDADES PARA LA EXPLOTACIÓN DE UN PROGRAMA DE ENTRETENIMIENTO

TABLA 17 CLASIFICACIÓN DE LA PROPUESTA DE ACTIVIDADES PARA LA EXPLOTACIÓN DE UN CONCURSO DE TELEVISIÓN

TABLA 18 CLASIFICACIÓN DE LA PROPUESTA DE ACTIVIDADES PARA LA EXPLOTACIÓN DE UNA EMISIÓN PUNTUAL

TABLA 19 CLASIFICACIÓN DE LA PROPUESTA DE ACTIVIDADES PARA LA EXPLOTACIÓN DE UN PROGRAMA DE HUMOR 


\section{ÍNDICE DE FIGURAS}

FIGURA 1. PORCENTAJE DE PROFESORES QUE TRABAJA CON DOCUMENTOS AUDIOVISUALES EN EL AULA DE ELE.

FIGURA 2. MOTIVOS POR LOS QUE LOS PROFESORES DECLARAN NO TRABAJAN CON DOCUMENTOS AUDIOVISUALES EN EL AULA DE ELE. 168

FIGURA 3. FRECUENCIA CON LA QUE LOS PROFESORES DECLARAN TRABAJAR CON DOCUMENTOS AUDIOVISUALES EN EL AULA DE ELE.

FIGURA 4. PORCENTAJE APROXIMADO DEL TIEMPO DE CLASE QUE LOS PROFESORES DECLARAN DEDICAR A QUE LOS ALUMNOS REALICEN ACTIVIDADES CON DOCUMENTOS AUDIOVISUALES.

FIGURA 5. FRECUENCIA CON LA QUE LOS PROFESORES DECLARAN UTILIZAR PROGRAMAS TELEVISIVOS EN EL AULA DE ELE.

FIGURA 6. FRECUENCIA CON LA QUE LOS PROFESORES DECLARAN UTILIZAR ANUNCIOS PUBLICITARIOS EN EL AULA DE ELE.

FIGURA 7. FRECUENCIA CON LA QUE LOS PROFESORES DECLARAN UTILIZAR PROGRAMAS TELEVISIVOS EN EL AULA DE ELE

FIGURA 8. FRECUENCIA CON LA QUE LOS PROFESORES DECLARAN UTILIZAR TRÁILERES EN EL AULA DE ELE.

FIGURA 9. FRECUENCIA CON LA QUE LOS PROFESORES DECLARAN UTILIZAR CORTOMETRAJES EN EL AULA DE ELE.

FIGURA 10. FRECUENCIA CON LA QUE LOS PROFESORES DECLARAN UTILIZAR PROGRAMAS TELEVISIVOS INFORMATIVOS EN EL AULA DE ELE.

FIGURA 11. FRECUENCIA CON LA QUE LOS PROFESORES DECLARAN UTILIZAR PROGRAMAS TELEVISIVOS CULTURALES EN EL AULA DE ELE.

FIGURA 12. FRECUENCIA CON LA QUE LOS PROFESORES DECLARAN UTILIZAR PROGRAMAS TELEVISIVOS DE FICCIÓN EN EL AULA DE ELE..

FIGURA 13. FRECUENCIA CON LA QUE LOS PROFESORES DECLARAN UTILIZAR PROGRAMAS TELEVISIVOS DE ENTRETENIMIENTO EN EL AULA DE ELE.....172

FIGURA 14. FRECUENCIA CON LA QUE LOS PROFESORES DECLARAN UTILIZAR PROGRAMAS TELEVISIVOS DE DEPORTES EN EL AULA DE ELE.

FIGURA 15. FRECUENCIA CON LA QUE LOS PROFESORES DECLARAN TRABAJAR CON DOCUMENTOS RADIOFÓNICOS EN EL AULA DE ELE.

FIGURA 16. FRECUENCIA CON LA QUE LOS PROFESORES DECLARAN TRABAJAR CON PERIÓDICOS EN EL AULA DE ELE.

FIGURA 17. FRECUENCIA CON LA QUE LOS PROFESORES DECLARAN TRABAJAR CON REVISTAS EN EL AULA DE ELE.

FIGURA 18. FRECUENCIA CON LA QUE LOS PROFESORES DECLARAN TRABAJAR CON REDES SOCIALES EN EL AULA DE ELE.

FIGURA 19. PORCENTAJE DE PROFESORES QUE CONSIDERARÍA ÚTIL TRABAJAR CON PROGRAMAS TELEVISIVOS. 
EL PROGRAMA TELEVISIVO COMO RECURSO PARA LA

ENSEÑANZA/APRENDIZAJE DE ESPAÑOL LENGUA EXTRANJERA

FIGURA 20. ASPECTOS QUE LOS PROFESORES CONSIDERAN QUE SE PODRÍAN TRABAJAR MEDIANTE LA EXPLOTACIÓN DIDÁCTICA DE UN PROGRAMA TELEVISIVO. . 175

FIGURA 21. COMPETENCIAS DE LA LENGUA QUE LOS PROFESORES CONSIDERAN QUE SE PODRÍAN TRABAJAR MEDIANTE LA EXPLOTACIÓN DIDÁCTICA DE UN PROGRAMA TELEVISIVO.

FIGURA 22: PORCENTAJE DE PROFESORES QUE CONSIDERA QUE SE PODRÍA DESARROLLAR LA CAPACIDAD DE AUTOAPRENDIZAJE DEL ALUMNO MEDIANTE LA EXPLOTACIÓN DIDÁCTICA DE UN PROGRAMA TELEVISIVO. . 176

FIGURA 23. FRECUENCIA CON LA QUE LOS ALUMNOS DECLARAN VER PROGRAMAS DE TELEVISIÓN. .258

FIGURA 24. FRECUENCIA CON LA QUE LOS ALUMNOS DECLARAN VER ANUNCIOS PUBLICITARIOS. .258

FIGURA 25. FRECUENCIA CON LA QUE LOS ALUMNOS DECLARAN VER PELÍCULAS.....259

FIGURA 26. FRECUENCIA CON LA QUE LOS ALUMNOS DECLARAN VER TRÁILERES.....259

FIGURA 27. FRECUENCIA CON LA QUE LOS ALUMNOS DECLARAN VER CORTOMETRAJES.

FIGURA 28. NÚMERO DE PROGRAMAS DE TELEVISIÓN QUE LOS ALUMNOS DECLARAN VER EN SU LENGUA MATERNA. ......

FIGURA 29. FRECUENCIA CON LA QUE LOS ALUMNOS DECLARAN VER PROGRAMAS TELEVISIVOS INFORMATIVOS. 260

FIGURA 30. FRECUENCIA CON LA QUE LOS ALUMNOS DECLARAN VER PROGRAMAS TELEVISIVOS CULTURALES. 260

FIGURA 31. FRECUENCIA CON LA QUE LOS ALUMNOS DECLARAN VER PROGRAMAS TELEVISIVOS DE FICCIÓN. 261

FIGURA 32. FRECUENCIA CON LA QUE LOS ALUMNOS DECLARAN VER PROGRAMAS TELEVISIVOS DE ENTRETENIMIENTO.

FIGURA 33. FRECUENCIA CON LA QUE LOS ALUMNOS DECLARAN VER PROGRAMAS TELEVISIVOS DE DEPORTES.

FiguRA 34. PORCENTAJE DE ALUMNOS QUE DECLARA VER PROGRAMAS TELEVISIVOS EN ESPAÑOL.

FIGURA 35. PORCENTAJE DE ALUMNOS QUE DECLARA HABER TENIDO ALGUNA VEZ UNA CLASE DE ESPAÑOL QUE INCORPORARA PROGRAMAS TELEVISIVOS. ..263

Figura 36. VALORACIÓN GENERAL DE LOS ALUMNOS (DE 1 A 10) DE LA ClASE RECIBIDA EN ESTE ESTUDIO EMPÍRICO.

FIGURA 37. VALORACIÓN DE LOS ALUMNOS (DE 1 A 10) DE LA UTILIDAD DE LA CLASE RECIBIDA EN ESTE ESTUDIO EMPÍRICO.

FIGURA 38. VALORACIÓN DE LOS ALUMNOS (DE 1 A 10) DE LAS ACTIVIDADES DE PREVISIONADO DE LA PROPUESTA DIDÁCTICA EMPLEADA EN ESTE ESTUDIO EMPÍRICO.

FIGURA 39. ASPECTOS QUE LOS ALUMNOS CONSIDERAN QUE SE PODRÍAN TRABAJAR MEDIANTE LA VISUALIZACIÓN DE PROGRAMAS TELEVISIVOS EN LA CLASE DE ESPAÑOL 
FIGURA 40. VALORACIÓN DE LOS ALUMNOS (DE 1 A 10) DE LA ACTIVIDAD DE POSVISIONADO CONSISTENTE EN ESCRIBIR UNA RECETA DE COCINA. ........267

FIGURA 41. NÚMERO DE ALUMNOS QUE DECLARÓ HABER LEÍDO ALGUNAS RECETAS EN ESPAÑOL ANTES DE ESCRIBIR SU RECETA.

FIGURA 42. VALORACIÓN DE LOS ALUMNOS (DE 1 A 10) DE LA ACTIVIDAD DE POSVISIONADO CONSISTENTE EN GRABAR UN VÍDEO DE SÍ MISMOS EXPLICANDO UNA RECETA DE COCINA.

FIGURA 43. NÚMERO DE ALUMNOS QUE DECLARÓ HABERSE GRABADO POR PRIMERA VEZ HABLANDO EN OTRO IDIOMA AL REALIZAR ESTA ACTIVIDAD DE POSVISIONADO.

FIGURA 44. ASPECTOS QUE LOS ALUMNOS CONSIDERAN HABER TRABAJADO A TRAVÉS DE LAS ACTIVIDADES DE POSVISIONADO DE LA PROPUESTA DIDÁCTICA DE ESTE ESTUDIO EMPÍRICO.

FIGURA 45. FRECUENCIA CON LA QUE LOS ALUMNOS DECLARAN VER PROGRAMAS DE TELEVISIÓN.

FIGURA 46. FRECUENCIA CON LA QUE LOS ALUMNOS DECLARAN VER ANUNCIOS PUBLICITARIOS.

FIGURA 47. FRECUENCIA CON LA QUE LOS ALUMNOS DECLARAN VER PELÍCULAS.....281

FIGURA 48. FRECUENCIA CON LA QUE LOS ALUMNOS DECLARAN VER TRÁILERES.....281

FIGURA 49. FRECUENCIA CON LA QUE LOS ALUMNOS DECLARAN VER CORTOMETRAJES.

FIGURA 50. NÚMERO DE PROGRAMAS DE TELEVISIÓN QUE LOS ALUMNOS DECLARAN VER EN SU LENGUA MATERNA.

FIGURA 51. FRECUENCIA CON LA QUE LOS ALUMNOS DECLARAN VER PROGRAMAS TELEVISIVOS INFORMATIVOS

FIGURA 52. FRECUENCIA CON LA QUE LOS ALUMNOS DECLARAN VER PROGRAMAS TELEVISIVOS CULTURALES.

FIGURA 53. FRECUENCIA CON LA QUE LOS ALUMNOS DECLARAN VER PROGRAMAS TELEVISIVOS DE FICCIÓN.

FIGURA 54. FRECUENCIA CON LA QUE LOS ALUMNOS DECLARAN VER PROGRAMAS TELEVISIVOS DE ENTRETENIMIENTO.

FIGURA 55. FRECUENCIA CON LA QUE LOS ALUMNOS DECLARAN VER PROGRAMAS TELEVISIVOS DE DEPORTES.

FIGURA 56. PORCENTAJE DE ALUMNOS QUE DECLARA VER PROGRAMAS TELEVISIVOS EN ESPAÑOL.

FIGURA 57. PORCENTAJE DE ALUMNOS QUE DECLARA HABER TENIDO ALGUNA VEZ UNA CLASE DE ESPAÑOL QUE INCORPORARA PROGRAMAS TELEVISIVOS. ..285

FIGURA 58. VALORACIÓN GENERAL DE LOS ALUMNOS (DE 1 A 10) DE LA CLASE RECIBIDA EN ESTE ESTUDIO EMPÍRICO.

FigURA 59. VALORACIÓN DE LOS ALUMNOS (DE 1 A 10) DE LA UTILIDAD DE LA ClASE RECIBIDA EN ESTE ESTUDIO EMPÍRICO. 
EL PROGRAMA TELEVISIVO COMO RECURSO PARA LA

ENSEÑANZA/APRENDIZAJE DE ESPAÑOL LENGUA EXTRANJERA

Figura 60. VALORACIÓN DE LOS ALUMNOS (DE 1 A 10) DE LAS ACTIVIDADES DE PREVISIONADO DE LA PROPUESTA DIDÁCTICA EMPLEADA EN ESTE ESTUDIO EMPÍRICO. .288

FIGURA 61. ASPECTOS QUE LOS ALUMNOS CONSIDERAN QUE SE PODRÍAN TRABAJAR MEDIANTE LA VISUALIZACIÓN DE PROGRAMAS TELEVISIVOS EN LA CLASE DE ESPAÑOL. 289

FIGURA 62. VALORACIÓN DE LOS ALUMNOS (DE 1 A 10) DE LA ACTIVIDAD DE POSVISIONADO CONSISTENTE EN ESCRIBIR UNA RECETA DE COCINA. .290

FIGURA 63. NÚMERO DE ALUMNOS QUE DECLARÓ HABER LEÍDO ALGUNAS RECETAS EN ESPAÑOL ANTES DE ESCRIBIR SU RECETA 290

FigURA 64. VALORACIÓN DE LOS ALUMNOS (DE 1 A 10) DE LA ACTIVIDAD DE POSVISIONADO CONSISTENTE EN GRABAR UN VÍDEO DE SÍ MISMOS EXPLICANDO UNA RECETA DE COCINA.

FIGURA 65. NÚMERO DE ALUMNOS QUE DECLARÓ HABERSE GRABADO POR PRIMERA VEZ HABLANDO EN OTRO IDIOMA AL REALIZAR ESTA ACTIVIDAD DE POSVISIONADO.

FIGURA 66. ASPECTOS QUE LOS ALUMNOS CONSIDERAN HABER TRABAJADO A TRAVÉS DE LAS ACTIVIDADES DE POSVISIONADO DE LA PROPUESTA DIDÁCTICA DE ESTE ESTUDIO EMPÍRICO 
EL PROGRAMA TELEVISIVO COMO RECURSO PARA LA ENSEÑANZA/APRENDIZAJE DE ESPAÑOL LENGUA EXTRANJERA

\section{INTRODUCCIÓN}




\section{JUSTIFICACIÓN DE LA INVESTIGACIÓN}

Esta tesis doctoral tiene por objeto en estudiar y demostrar la rentabilidad del programa televisivo como recurso para la enseñanza/aprendizaje de español como lengua extranjera. Consideramos que el aprendizaje de lenguas extranjeras en situaciones de no inmersión no dispone de suficientes recursos para que los estudiantes desarrollen una competencia comunicativa, fundamentalmente oral, adecuada para obtener un nivel óptimo de la lengua meta. En esta tesis doctoral partimos de la hipótesis de que los recursos audiovisuales, en concreto los programas televisivos, son una herramienta idónea como soporte para el aprendizaje de segundas lenguas y lenguas extranjeras. Esta hipótesis se fundamenta en los estudios previos que reclaman una enseñanza de lenguas enfocada en contextos de aprendizaje más naturales o enfoques metodológicos menos artificiales. La falta de contextos ecológicos nos lleva a tener que dirigir la enseñanza de lenguas a través de recursos auténticos. Por ello, el programa de televisión se puede considerar como una herramienta y como un recurso óptimo. Nuestra hipótesis de partida será corroborada a través de la investigación que llevaremos a cabo. Se tratará de una investigación no experimental $^{1}$, transversal ${ }^{2}$, comparativa $^{3}$ y metodológica, que aportará evidencias acerca de la optimización de la enseñanza/aprendizaje de lenguas a través de este tipo de formato audiovisual.

En los programas televisivos se ven reflejados de manera natural varios de los componentes de la competencia comunicativa (aspectos gramaticales, léxicos, socioculturales, pragmáticos, estratégicos y discursivos). Por ello, queremos demostrar, a través de la metodología que adoptaremos dentro del enfoque comunicativo, que es posible utilizar este formato para trabajar de forma integrada distintas habilidades comunicativas, como la comprensión oral, la comprensión escrita, la expresión oral, la expresión escrita, la interacción oral, la interacción escrita, la mediación oral y la mediación escrita. Dado que su uso en la clase de ELE no parece habitual, creemos que este recurso, quizá por

\footnotetext{
${ }^{1}$ Aquella que se realiza sin manipular deliberadamente variables. Se basa fundamentalmente en la observación de fenómenos tal y como se dan en su contexto natural para analizarlos con posterioridad.

${ }^{2}$ Aquella que se centra en analizar el estado de una o diversas variables o la relación entre un conjunto de variables en un momento dado.

${ }^{3}$ Aquella en la que se lleva a cabo un procedimiento sistemático de contrastación de uno o más fenómenos, a través del cual se busca establecer similitudes y diferencias entre ellos.
} 


\section{EL PROGRAMA TELEVISIVO COMO RECURSO PARA LA \\ ENSEÑANZA/APRENDIZAJE DE ESPAÑOL LENGUA EXTRANJERA}

rechazo, por desconocimiento o por falta o escasez de propuestas didácticas o de ideas, se sigue desaprovechando.

Esta tesis doctoral pretende justificar y demostrar por qué este género audiovisual se debería emplear y explotar como recurso para la enseñanza/aprendizaje de español como lengua extranjera. Nos proponemos elaborar una propuesta didáctica innovadora, dentro del enfoque comunicativo de la enseñanza de lenguas, dirigida a todos aquellos profesores que quieran utilizar este recurso en sus clases. Hay que recordar que una de las tareas del profesor de una lengua extranjera consiste en exponer a los alumnos a muestras de lengua auténtica, tanto si los estudiantes están aprendiendo el idioma en el extranjero como si se encuentran en un contexto de inmersión lingüística, así como el hecho de que el uso de los documentos audiovisuales es una necesidad y una práctica de consumo actual.

Desde el punto de vista personal, los programas televisivos siempre me han sido de gran ayuda para aumentar mis conocimientos - tanto lingüísticos como culturales - en otras lenguas, para mejorar mis habilidades comunicativas, y para habituarme al ritmo de habla de los hablantes nativos. Hace unos años, como estudiante y profesora de idiomas, comencé a preguntarme por qué casi nunca alguno de mis profesores de idiomas había mostrado en clase un fragmento de un programa televisivo del país o países correspondientes a la lengua estudiada. Estaba convencida de que, con las actividades adecuadas, se podía aprender mucho con ellos, de forma amena y entretenida. No dejaba de sorprenderme el hecho de que de vez en cuando proyectaran en clase películas en versión original, pero no fragmentos de programas televisivos. Fue así como en 2014, tras cursar el Máster en Enseñanza de Español como Lengua Extranjera, decidí enfocar mi Trabajo de Fin de Máster en el desarrollo de las competencias sociocultural y pragmática en español a través de programas televisivos. Esto me llevó, un año más tarde, a comenzar mis estudios de doctorado con el objetivo de continuar, profundizar y expandir este estudio hacia el desarrollo no solo de las competencias sociocultural y pragmática, sino también de las competencias gramaticales, léxicas, estratégicas y discursivas, así como de elaborar una propuesta didáctica innovadora dentro del enfoque comunicativo de la enseñanza de lenguas que pudiera servir de guía e inspiración a otros profesores de ELE. 


\section{OBJETIVOS}

\section{Objetivos generales}

Esta investigación tiene como objetivos generales los siguientes: analizar y explicar, a través de instrumentos de recogida y de análisis de datos, las razones por las que el programa televisivo aún no se rentabiliza como recurso para la enseñanza/aprendizaje de español como lengua extranjera; y demostrar la rentabilidad didáctica de este formato audiovisual a través del diseño de propuestas didácticas y de su aplicación práctica en un contexto educativo real.

\section{Objetivos específicos}

Los objetivos específicos de esta investigación son los siguientes.

i. Aportar una base metodológica para dar coherencia y sentido a la propuesta de técnicas docentes para la explotación del programa televisivo.

Con el objetivo de conocer el estado de la cuestión, se estudiará la competencia comunicativa, uno de los conceptos más importantes en lingüística aplicada, tanto en el estudio de la adquisición de segundas lenguas como, a un nivel más práctico, en la enseñanza de lenguas. Este estudio nos permitirá obtener la siguiente información: en qué consiste adquirir una lengua; qué conocimientos, capacidades o destrezas se necesitan para hablar una lengua; y cuál es el objetivo de la enseñanza de lenguas.

ii. Establecer un diagnóstico de la presencia y de la explotación del programa televisivo como recurso didáctico en los manuales más actuales de español como lengua extranjera.

Los objetivos de dicho diagnóstico serán: determinar con qué finalidad se utiliza el programa televisivo; determinar qué contenidos se trabajan a través de este formato; comprobar si otros formatos relativos a los medios de comunicación — como la radio, la prensa, la publicidad o las TIC - u otros formatos de tipo audiovisual, como el cine, están más didácticamente explotados y/o cuentan con mayor presencia en los manuales de ELE; y determinar en qué nivel o niveles se trabaja con 


\section{EL PROGRAMA TELEVISIVO COMO RECURSO PARA LA ENSEÑANZA/APRENDIZAJE DE ESPAÑOL LENGUA EXTRANJERA}

este formato. En cuanto a la selección de los programas televisivos incluidos en los diferentes manuales, este análisis nos permitirá recopilar información sobre qué programas televisivos se utilizan como soporte para las actividades, con el objetivo de reflexionar posteriormente sobre su adecuación.

iii. Hacer un diagnóstico de la situación en la que se encuentra el uso del programa televisivo en el panorama de la enseñanza de español lengua extranjera.

Los objetivos de este diagnóstico serán: en primer lugar, conocer los hábitos de los profesores de ELE en cuanto al uso de documentos audiovisuales en general, así como del programa televisivo en particular; $\mathrm{y}$, en segundo lugar, determinar si los profesores consideran el programa televisivo como un posible recurso con el que trabajar en el aula de ELE, así como los objetivos con los que utilizan o utilizarían este formato, en caso de no hacerlo.

iv. Demostrar la rentabilidad didáctica de los programas televisivos en un contexto de enseñanza de una lengua extranjera.

Con el objetivo de demostrar la rentabilidad didáctica de los programas televisivos, estudiaremos la competencia audiovisual y sus implicaciones en la enseñanza; argumentaremos qué ventajas presenta el uso de este formato como recurso para trabajar el enfoque comunicativo; discutiremos cuáles son las ventajas y las posibles desventajas de la integración de este formato en la enseñanza de ELE; y analizaremos qué criterios se deben tener en cuenta a la hora de seleccionar y utilizar este material. Seguidamente, con el fin de demostrar que el programa televisivo permite trabajar no solo uno sino varios aspectos de la competencia comunicativa, argumentaremos qué tipo de actividades son susceptibles de ser diseñadas para trabajar cada uno de estos aspectos: gramaticales, léxicos, socioculturales, pragmáticos, estratégicos y discursivos.

v. Presentar actividades de explotación didáctica para estudiantes de español como lengua extranjera a partir de este tipo de programas.

Con el objetivo de demostrar que es posible trabajar varios aspectos de la competencia comunicativa utilizando diversos formatos televisivos, 
se diseñarán diez propuestas didácticas y se utilizará un programa de televisión diferente para cada una de ellas: un programa de información meteorológica, un programa informativo, un programa de información deportiva, un programa de cocina, un programa documental, un programa de ficción, un programa de entretenimiento, un concurso de televisión, una emisión puntual y un programa de humor. Para confirmar que es posible encontrar vídeos en los que tanto el contenido como la duración no requieren ninguna modificación, en todas las propuestas didácticas diseñadas se utilizarán vídeos completos a los que se pueda acceder de forma fácil y gratuita a través de internet. Asimismo, para demostrar que no es necesario recurrir a una película de dos horas o a un cortometraje de veinte minutos cuando se quiere utilizar un recurso audiovisual en clase para trabajar uno o varios aspectos de la competencia comunicativa, la duración media de los vídeos que se seleccionarán será de dos minutos y medio. Por último, dado que otro de nuestros objetivos es demostrar que el programa televisivo es un recurso que se puede utilizar en todos los niveles, se diseñarán propuestas didácticas dirigidas a niveles diferentes, desde básicos hasta avanzados. Para ello, se seleccionarán los vídeos y diseñarán las actividades teniendo en cuenta la duración, los temas, la variedad, la velocidad de habla, la dificultad general y los posibles contenidos y destrezas que se pueden trabajar, así como los descriptores establecidos en el MCER (2002).

vi. Llevar a la práctica, en un contexto educativo real, actividades de explotación didáctica para estudiantes de español como lengua extranjera a partir de este tipo de programas.

Con el fin de demostrar la efectividad de las propuestas didácticas que presentaremos en esta tesis, dos de ellas serán llevadas a la práctica en una universidad norteamericana. Una se utilizará en dos cursos de nivel básico y otra en dos cursos de nivel intermedio-alto. Esto permitirá, por un lado, demostrar la rentabilidad didáctica del programa televisivo en diferentes niveles y, por otro, corroborar cómo el uso de programas televisivos en clase favorece la adquisición de varias competencias y destrezas, además de ser un material muy motivador para los alumnos. 


\section{METODOLOGÍA}

De entre todos los posibles enfoques y teorías sobre competencia comunicativa, esta investigación se centrará en la división de competencias establecida por Canale y Swain (1980) y Bachman (1990), ya que en su clasificación se incluyen las cinco competencias más esenciales y representativas de este enfoque: la competencia lingüística, la competencia sociolingüística, la competencia discursiva, la competencia estratégica y la competencia pragmática. Este enfoque metodológico será la base que aporte coherencia y sentido a la propuesta de técnicas docentes presentada en esta investigación porque el enfoque comunicativo propone que se utilicen documentos auténticos -como son los programas televisivos-durante el proceso de aprendizaje con el objetivo de capacitar al alumno a que consiga una comunicación real.

Para el desarrollo del análisis de manuales, la metodología de investigación que se adoptará será la que Grotjahn (1987: 54-81) define como exploratoriacuantitativa-interpretativa. ${ }^{4}$ Se trata de una metodología mixta a menudo utilizada en la lingüística aplicada para el análisis de métodos y materiales. A través de esta metodología se pretende recoger datos acerca de la frecuencia y la forma con la que los manuales más actuales de ELE integran el recurso del programa televisivo en sus propuestas didácticas. Para esta investigación, será necesaria la localización de una cantidad representativa de manuales de enseñanza de español como lengua extranjera. La muestra se compondrá de veintidós de los manuales más actuales y utilizados para la enseñanza/aprendizaje de ELE, publicados en España entre los años 2003 y $2014^{56}$.

\footnotetext{
${ }^{4}$ R. Grotjahn considera solo dos paradigmas como "formas puras": el paradigma analíticonomológico, que no genera hipótesis sino que las comprueba; y el paradigma exploratoriointerpretativo, que permite formar hipótesis y comprobarlas en un mismo proceso. Por otra parte, señala que por el tipo de datos, y también por el método de análisis, pueden establecerse seis "formas mixtas": paradigmas experimental-cualitativo-interpretativo, experimentalcualitativo-estadístico, exploratorio-cualitativo-estadístico, exploratorio-cuantitativo-estadístico, exploratorio-cuantitativo-interpretativo y experimental-cuantitativo-interpretativo. Por ello, R. Grotjahn justifica y defiende el carácter polimetodológico de la investigación, que recurre a diferentes métodos para obtener datos de diferente tipo. (Grotjahn, 1987: 54-81)

${ }^{5}$ Estos manuales son los que se encontraron disponibles en la biblioteca de la sede del Instituto Cervantes en Madrid durante la fase de análisis.

${ }^{6}$ Véase el apartado Manuales Analizados dentro de la BiBLIOGRAFÍA.
} 
Se analizarán las actividades cuyo soporte sea algún programa televisivo. Los parámetros de análisis de cada una de las actividades que cumplan con esta condición serán: objetivo/s (p. ej.: comprender un texto humorístico), contenido/s (p. ej.: el sentido de humor español) soporte/s (p. ej.: audición de un monólogo extraído del programa $\mathrm{El} \mathrm{Club}$ de la Comedia) y destreza/s (p. ej.: comprensión oral, expresión oral e interacción oral). Este análisis permitirá la extracción de datos acerca de los contenidos gramaticales, léxicos, socioculturales y pragmáticos trabajados en los manuales actuales de ELE a través del recurso del programa televisivo, así como su posterior análisis e interpretación.

La metodología en la que se integrará el procedimiento elegido para acceder a las consideraciones, valoraciones y opiniones de profesores de ELE acerca del uso del programa televisivo como recurso para la enseñanza/aprendizaje de ELE y de su presencia en el aula, será la cuantitativa. La técnica de toma de datos será el cuestionario (Sierra Bravo, 1994). El cuestionario es un instrumento de investigación a menudo utilizado en el campo de las ciencias sociales y, por ello, en la educación. El cuestionario facilita la consulta a una población amplia, de manera rápida, sistemática, ordenada y fiable, y permite obtener datos cuantificables a través de los que se puede llegar a una serie de conclusiones estadísticas.

El método que se seguirá será no paramétrico. Los métodos no paramétricos permiten la recogida de muestras no aleatorias, escogidas por el investigador, que se caracterizan por ofrecer resultados que no pueden ser extrapolados al conjunto de la población, aunque sí pueden resultar de gran valor. La elección de un método paramétrico sería lo ideal, pero nos enfrentamos a la imposibilidad de seleccionar una muestra aleatoria representativa de profesores, ya que se desconoce la cantidad total de profesores de ELE que imparten clases en todo el mundo.

En este caso, la muestra constará de una media de cincuenta profesores que trabajen en distintos contextos profesionales, todos ellos con formación especializada en la didáctica de ELE y, preferiblemente, con varios años de experiencia profesional. Los cuestionarios serán distribuidos a través de la herramienta de software libre distribuida por Google, Google Docs, que permitirá que los encuestados completen los cuestionarios en línea. Los cuestionarios se distribuirán a través de correo electrónico y de varios grupos dedicados a la enseñanza de ELE organizados en la red social Facebook. Dentro de los métodos no paramétricos existentes, este es el denominado "bola de 


\section{EL PROGRAMA TELEVISIVO COMO RECURSO PARA LA ENSEÑANZA/APRENDIZAJE DE ESPAÑOL LENGUA EXTRANJERA}

nieve" (Goodman, 1961), que consiste en la selección de miembros dentro de uno o varios grupos, en este caso, de profesores de español como lengua extranjera. Este método será el más adecuado para conocer la opinión de un número elevado de profesores que trabajen en diferentes centros educativos y países a los que, de otro modo, no sería posible acceder. La recopilación y análisis de datos se llevará a cabo utilizando la aplicación de hojas de cálculo de Microsoft Excel.

Para el diseño del cuestionario se partirá de la elaboración de una lista de las variables que se quieren medir. Esto permitirá seleccionar el tipo de preguntas más adecuadas para medir cada una de ellas. Habrá algunas preguntas categorizadas con diferentes niveles de medición (frecuencia, porcentaje de tiempo de la clase...), así como preguntas cerradas y abiertas. Las cuestiones serán relativamente breves y exhaustivas, e irán de lo general a lo particular, lo que se denomina la "técnica embudo" (Pardinas, 1991).

Las preguntas planteadas en el cuestionario de profesores estarán dirigidas a sondear, en primer lugar, los hábitos de los profesores en cuanto al uso en el aula de ELE de documentos audiovisuales en general (preguntas 1 a 5), y el uso del programa televisivo en particular (preguntas 6 y 7) y, en segundo lugar, se centrarán en averiguar si los profesores consideran el programa televisivo como un posible recurso con el que trabajar en el aula de ELE (pregunta 8), así como los objetivos con los que utilizan o utilizarían este formato, en caso de no hacerlo (pregunta 9). Al comienzo del cuestionario se incluirán tres preguntas destinadas a conocer la siguiente información sobre cada uno de los sujetos (variables del sujeto): tipo de centro y país en el que trabaja, años de experiencia en la enseñanza de ELE y formación especializada en la didáctica de ELE.

El enfoque que adoptaremos a la hora de diseñar las propuestas didácticas será el enfoque por tareas ${ }^{7}$. Se optará por este enfoque debido, esencialmente, a la enorme diversidad de tratamientos, propuestas, ejemplos, etc., que permite. Asimismo, todas las propuestas didácticas que se presentarán en esta investigación obedecerán a las observaciones y necesidades diagnosticadas, por un lado, a través del análisis de manuales y, por otro, de la información proporcionada por la muestra encuestada de docentes de ELE. Por último, se

\footnotetext{
7 La enseñanza mediante tareas no es un método, si no que se trata de una propuesta del Enfoque Comunicativo. (CVC, 1997-2018)
} 
pretenderá que las propuestas didácticas cumplan con las siguientes condiciones:

- tener como soporte programas televisivos diferentes y variados;

- incluir actividades de previsionado, durante el visionado y posvisionado;

- ser ejemplos de tarea ${ }^{8}$ para el desarrollo de varios aspectos de la competencia comunicativa;

- estar dirigidas a diferentes niveles, desde básicos hasta avanzados;

- respetar los descriptores de la escala ilustrativa para Ver televisión y cine del MCER (2002: 73);

- ser adecuadas para jóvenes y adultos ${ }^{9}$, alfabetizados, ya sea en situación de inmersión o no, tanto en grupos monoculturales como multiculturales.

$\operatorname{Dos}^{10}$ de las propuestas didácticas que diseñaremos serán llevadas a la práctica en dos cursos de español, uno de nivel básico y otro de nivel intermedio-alto, en la universidad West Virginia University ${ }^{11}$. Para realizar este estudio empírico en Estados Unidos será necesario contar con la aprobación del Institutional Review Board (IRB) ${ }^{12}$ y del Department of World Languages, Literatures, and

${ }^{8}$ En el Diccionario de términos clave de ELE del CVC (1997-2018). Una TAREA se define de la siguiente manera:

a) una tarea es una iniciativa para el aprendizaje,

b) que consiste en la realización en el aula de actividades de uso de la lengua representativas de las que se llevan a cabo fuera de ella

c) y que posee las siguientes propiedades:

1. Tiene una estructura pedagógicamente adecuada.

2. Está abierta, en su desarrollo y en sus resultados, a la intervención activa y a las aportaciones personales de los alumnos

3. Requiere de ellos, en su ejecución, una atención prioritaria al contenido de los mensajes.

4. Les facilita al propio tiempo ocasión y momentos de atención a la forma lingüística. 9 Algunas de las propuestas didácticas incluidas en esta tesis doctoral podrían ser adecuadas para trabajar con niños. No obstante, dado que su puesta en práctica se realizará en una universidad, se dirigirán principalmente a aprendientes jóvenes y adultos.

${ }^{10}$ Debido a la obligación de cumplir con la programación establecida por del departamento de español de la universidad West Virginia University, solo será posible realizar un estudio empírico por cada año de estancia en dicha universidad.

${ }^{11}$ Universidad pública, fundada en 1887, ubicada en Morgantown, Virginia Occidental, Estados Unidos.

12 En Estados Unidos, comité encargado de la aprobación y seguimiento de cualquier investigación que involucre a personas. 


\section{EL PROGRAMA TELEVISIVO COMO RECURSO PARA LA ENSEÑANZA/APRENDIZAJE DE ESPAÑOL LENGUA EXTRANJERA}

Linguistics ${ }^{13}$ de la universidad, así como con el consentimiento de los alumnos a participar en este estudio.

Dado que en esta universidad los cursos de español se imparten tres días a la semana en clases de cincuenta minutos, será necesario adaptar el estudio empírico a dicha duración. Los cincuenta minutos de la clase se distribuirán de la siguiente forma: durante los cinco primeros minutos, los alumnos completarán un cuestionario online, diseñado a través de Google Docs, cuyas preguntas intentarán sondear, en primer lugar, su nivel de consumo habitual de programas televisivos en su lengua materna, y en segundo, lugar, sus hábitos y experiencia en cuanto al visionado ${ }^{14}$ de programas televisivos en español. Durante los cuarenta minutos siguientes se llevará a cabo la propuesta didáctica, en concreto las actividades de previsionado y las actividades durante el visionado. Finalmente, durante los últimos cinco minutos de clase, los alumnos rellenarán un segundo cuestionario en el que se les pedirá que valoren la formación que acaban de recibir y su reciente experiencia trabajando con programas televisivos en la clase de español. En cuanto a las actividades de posvisionado, estas se propondrán como práctica optativa para realizar fuera de clase $^{15}$. Los alumnos que las lleven a cabo completarán, posteriormente, un tercer y último cuestionario en el que se les pedirá que valoren estas actividades.

Se intentará que la muestra total de alumnos conste de al menos ochenta participantes. La metodología en la que se integrará el procedimiento elegido para acceder a las experiencias, valoraciones y opiniones de estos alumnos de español como lengua extranjera acerca del uso del programa televisivo como recurso para la enseñanza/aprendizaje de ELE y de su presencia en la clase de español será, de nuevo, la cuantitativa. Como en el caso anterior, la técnica de toma de datos será el cuestionario (Sierra Bravo, 1994) y el método que se seguirá será no paramétrico.

Para el diseño del cuestionario se partirá nuevamente de la elaboración de una lista de las variables que se quieren medir. Esto permitirá seleccionar el tipo de preguntas más adecuadas para medir cada una de ellas. Habrá algunas preguntas categorizadas con diferentes niveles de medición (frecuencia, valoración...), así

\footnotetext{
${ }^{13}$ Departamento de Lenguas del Mundo, Literaturas y Lingüística.

14 VISIONAR: examinar técnica o críticamente, en una sesión de trabajo, un producto cinematográfico, televisivo, etc. (RAE, Diccionario de la lengua española, 23. a ed., 2014, s.v.)

${ }^{15}$ De nuevo, debido a las limitaciones que implica seguir la programación del departamento.
} 
como preguntas cerradas y abiertas. Las preguntas abiertas permitirán a los participantes justificar sus respuestas, esta información será fundamental para conocer en profundidad la perspectiva del alumno: sus razones tanto de aceptación como de rechazo para trabajar con programas televisivos en la clase de español.

Las preguntas planteadas en el cuestionario de alumnos estarán dirigidas a sondear, en primer lugar, sus hábitos de consumo de programas televisivos (preguntas 1 a 3); en segundo lugar, sus hábitos de consumo de programas televisivos en español y su experiencia como estudiantes de español en cuanto al uso de programas televisivos en español (preguntas 8 y 9); en tercer lugar tras realizar las actividades de previsionado y durante el visionado en clase- su reciente experiencia como estudiantes de español en cuanto al uso de programas televisivos en clase (preguntas 12 a 15); y, por último - tras realizar las actividades de posvisionado fuera de clase- su reciente experiencia como estudiantes de español en cuanto al uso de programas televisivos fuera de clase. Al comienzo del cuestionario se incluirán seis preguntas destinadas a conocer la siguiente información sobre cada uno de los sujetos (variables del sujeto): tipo de centro y país en el que estudia, nacionalidad, sexo, edad, tiempo (en meses o años) estudiando español y nivel de español ${ }^{16}$.

\footnotetext{
${ }^{16}$ Dado que en EEUU no se aplica el MCER (2002), nos basaremos en el criterio de admisión y
} en la programación del curso para determinar su nivel de correspondencia con el MCER. 


\section{ESTRUCTURA DE LA TESIS}

Esta tesis doctoral está estructurada en ocho capítulos: los cuatro primeros capítulos abordan el estado de la cuestión, que en este caso se centra en los estudios previos sobre la competencia comunicativa en la enseñanza de segundas lenguas, en la didáctica a través de los medios audiovisuales, en el programa de televisión como recurso para la enseñanza/aprendizaje de ELE y en los aspectos de la competencia comunicativa que se pueden trabajar con programas de televisión. El quinto capítulo consiste en un análisis de manuales de ELE y de datos procedentes de una muestra representativa de profesores de ELE acerca del uso y la rentabilidad del programa televisivo como herramienta para la enseñanza/aprendizaje de español como lengua extranjera. El sexto y séptimo capítulo lo conforma una serie de propuestas didácticas originales destinada a demostrar la rentabilidad del programa televisivo como recurso para trabajar varios de los componentes de la competencia comunicativa, a través de un posterior estudio empírico, desarrollado en el capítulo octavo, realizado con estudiantes de español en una universidad norteamericana ${ }^{17}$.

En la INTRODUCCIÓN, aparecen distintos apartados, cuya función es la de justificar esta tesis doctoral, presentar los objetivos planteados, explicar la metodología de la investigación y describir la estructura de la tesis.

En el CAPÍTULO 1 se revisan dos conceptos: uno es el de adquisición de segundas lenguas y otro es el de aprendizaje de segundas lenguas. Para abordar este tema, se comienza estableciendo una distinción entre los términos lengua materna, lengua extranjera y lengua segunda. Esto lleva a estudiar uno de los conceptos más importantes en lingüística aplicada, tanto en el estudio de la adquisición de segundas lenguas como, a un nivel más práctico, en la enseñanza de lenguas: la competencia comunicativa. A partir de la recopilación de bibliografía específica, se estudia y se analiza esta competencia, así como las distintas subcomptencias en las que se fundamenta. Este conocimiento previo es necesario para la argumentación y defensa de la rentabilidad didáctica del programa televisivo como recurso para trabajar varios de los componentes de la competencia comunicativa.

\footnotetext{
${ }^{17}$ El estudio empírico se ha realizado en la universidad West Virginia University, situada en el estado de West Virginia, EE. UU.
} 
En el CAPÍTULO 2 se exponen algunos principios generales para la selección, evaluación, utilización e integración didáctica de los medios audiovisuales, así como para el diseño de materiales didácticos. En este capítulo también se justifican el marco metodológico y el enfoque pedagógico adoptados en el diseño de propuestas didácticas, es decir, los elementos que las definen.

En el CAPÍTULO 3 se parte del estudio de las implicaciones que el material audiovisual tiene en la enseñanza de lenguas extranjeras, para proceder a argumentar las ventajas que el programa televisivo presenta como recurso para trabajar el enfoque comunicativo. En uno de los apartados, no obstante, se analizan tanto las ventajas como los inconvenientes que su uso presenta. El capítulo concluye con una breve presentación de los tipos de formatos de programas televisivos y de los criterios de selección que pueden aplicarse a la hora de trabajar con este material audiovisual en la clase de ELE.

En el CAPÍTULO 4 se ofrece una explicación detallada, acompañada de referencias bibliográficas y de ejemplos concretos, de cómo utilizar los programas televisivos para trabajar el enfoque comunicativo: criterios de selección del material, aspectos que se pueden abordar — aspectos gramaticales, léxicos, socioculturales, pragmáticos, estratégicos y discursivos-y actividades de lengua que se pueden diseñar y realizar.

En el CAPÍTULO 5 se incluyen dos pruebas diagnósticas. Su función es proporcionar datos recientes sobre la utilización del programa televisivo como herramienta para la enseñanza/aprendizaje de español como lengua extranjera. La primera prueba consiste en un análisis de algunos de los manuales más actuales y utilizados en el aula de ELE para los diferentes niveles, teniendo en cuenta los siguientes parámetros: objetivos, contenidos, soportes y destrezas. Este análisis está enfocado en los contenidos gramaticales, léxicos, socioculturales y pragmáticos trabajados exclusivamente en las actividades cuyo soporte es el programa televisivo. La segunda comprende un cuestionario, dirigido una muestra de profesores de ELE, compuesto por una serie de preguntas acerca de los hábitos de los profesores en cuanto al uso en el aula de ELE de documentos audiovisuales en general, y el uso del programa televisivo en particular. Cada una de estas pruebas diagnósticas incluye el conjunto de datos extraídos, un análisis detallado de los datos, y una serie de conclusiones parciales, previas a las conclusiones finales.

En el CAPÍTULO 6 se presenta el corpus de programas televisivos empleados en el diseño y elaboración de las propuestas didácticas incluidas en el capítulo 


\section{EL PROGRAMA TELEVISIVO COMO RECURSO PARA LA ENSEÑANZA/APRENDIZAJE DE ESPAÑOL LENGUA EXTRANJERA}

7. Se ofrece una explicación justificada de la metodología empleada y de los criterios aplicados. Finalmente, se incluye una descripción de los programas televisivos utilizados en dichas propuestas.

En el CAPÍTULO 7 se presentan una serie de propuestas didácticas con actividades para realizar antes, durante y después del visionado del recurso audiovisual que nos ocupa, utilizando una selección de programas de televisión que constituyen una muestra de diferentes formatos televisivos: un programa de información meteorológica: Agencia EFE; un programa informativo: RT en español; un programa de información deportiva: Informe Robinson; un programa de cocina: Karlos Arguiñano en tu cocina; un programa documental: Españoles en el Mundo; un programa de ficción: Camera Café; un programa de entretenimiento: El Hormiguero; un concurso de televisión: MasterChef; una emisión puntual: Campanadas de fin de año; y un programa de humor: El club de la comedia. Al principio de cada una de estas propuestas didácticas hay una tabla en la que se clasifica la propuesta de acuerdo con los siguientes parámetros: el nivel del MCER para el que está dirigida, las competencias de la lengua que se trabajan y las actividades comunicativas de la lengua que se llevan a cabo.

En el CAPÍTULO 8 se describen los dos estudios empíricos realizados con el fin de poner en práctica dos de las propuestas didácticas diseñadas, incluidas en el capítulo anterior. El primer estudio empírico se basa en la propuesta didáctica para la explotación de un programa de cocina, dirigida a estudiantes de español de nivel básico; mientras que el segundo estudio empírico parte de la propuesta didáctica para la explotación de un programa documental, dirigida a estudiantes de español de nivel intermedio-alto. Cada uno de estos estudios incluye el conjunto de datos extraídos del cuestionario realizado por los alumnos, un análisis detallado de los datos, y una serie de conclusiones parciales.

Tras este capítulo aparecen las CONCLUSIONES finales, en las que se exponen los resultados obtenidos en esta investigación.

La tesis incluye una BIBLIOGRAFÍA, con un apartado para las referencias de los manuales analizados, y seis ANEXOS. El primer anexo es el cuestionario distribuido entre los docentes de ELE; el segundo anexo lo compone la versión original, en inglés, del cuestionario completado por los alumnos que participaron en cada uno de los dos estudios empíricos en la universidad estadounidense West Virginia University, el tercer anexo es la traducción al español de dicho cuestionario; en el cuarto anexo se incluye la autorización 
expedida por el Institutional Review Board (IRB), necesaria para poder llevar a cabo esta investigación en Estados Unidos; el quinto anexo recoge el documento informativo, previo a ambos estudios empíricos, proporcionado a los alumnos participantes, y por último, el sexto anexo consiste en una recopilación de las propuestas didácticas presentadas. 
LA COMPETENCIA COMUNICATIVA EN LA ENSEÑANZA DE SEGUNDAS LENGUAS

1. LA COMPETENCIA COMUNICATIVA EN LA ENSEÑANZA DE SEGUNDAS LENGUAS 


\section{EL PROGRAMA TELEVISIVO COMO RECURSO PARA LA \\ ENSEÑANZA/APRENDIZAJE DE ESPAÑOL LENGUA EXTRANJERA}

\subsection{Adquisición y aprendizaje de segundas lenguas}

Para abordar este tema, conviene comenzar haciendo una distinción entre los términos lengua materna, lengua extranjera y lengua segunda. Por lengua materna o L1 se entiende la primera lengua que aprende un ser humano en su infancia y que de forma natural se convierte en su instrumento de pensamiento y comunicación. Con este sentido también se emplean los términos lengua nativa y, con menor frecuencia, lengua natal. Como su etimología indica, esta suele ser la lengua de la madre - dado que en las comunidades primitivas era la madre quien se ocupaba de la crianza de los niños-, aunque también puede ser la de cualquier otra persona: padre, abuelos, niñera, etc. Quienes comparten una lengua materna son considerados hablantes nativos de la lengua en cuestión; en el caso de la lengua española, se denominan hispanohablantes nativos. El término lengua materna se suele emplear en contraposición a lengua extranjera (LE) o a lengua segunda (L2) (CVC, 1997-2018).

En didáctica de las lenguas se emplea el término lengua meta ${ }^{18}$ (LM) para denominar a la lengua que constituye el objeto de aprendizaje, ya sea en un contexto de aprendizaje formal o natural. Este término engloba los conceptos de lengua extranjera (LE) y de lengua segunda (L2), aunque, en ocasiones, los tres términos se emplean como sinónimos ${ }^{19}$. En cualquier caso, el término lengua meta excluye al de lengua materna (L1), al que normalmente se contrapone. En teoría de la traducción y en informática, el término se emplea para aludir a la lengua (natural o computacional) a la que se traduce un texto. Aunque el aprendizaje de lenguas extranjeras o segundas es prácticamente tan antiguo como el propio lenguaje, el término lengua meta o LM no empieza a aparecer con frecuencia en el ámbito del español como lengua extranjera hasta la década de los 80 del siglo XX (CVC, 1997-2018).

Algunos de los motivos que llevan a una persona a aprender una LM pueden ser de tipo personal, social, educativo, profesional, etc. La decisión sobre qué LM aprender puede estar, en cierta manera, condicionada por el espacio que abarca y el prestigio que posee en la sociedad y en la época en cuestión, por ejemplo, en la enseñanza, en los medios de comunicación, en la política, en la administración, etc. En la actualidad, las lenguas meta más estudiadas en el mundo son el inglés, el francés, el español, el alemán y el chino, entre otras,

\footnotetext{
18 Traducción del inglés target language.

${ }^{19}$ A lo largo de este trabajo se utilizarán estos tres términos como sinónimos.
} 
pues son las lenguas que protagonizan las relaciones internacionales en la cultura, el comercio, la política, etc. (CVC, 1997-2018).

De acuerdo con las situaciones y circunstancias en las que se aprende la LM, se suele distinguir entre lengua extranjera (LE) y lengua segunda (L2). Cuando la LM se aprende en un país donde no es ni oficial ni autóctona, se considera una LE; por ejemplo, el español en Brasil. Cuando la LM se aprende en un país donde coexiste como oficial y/o autóctona con otra(s) lengua(s), se considera una L2; por ejemplo, el guaraní para aquellos niños paraguayos cuya L1 es el español, o bien el español para los niños paraguayos cuya L1 es el guaraní. Otra situación cada vez más frecuente de L2 es la que se produce cuando los emigrantes con una L1 común llegan a constituir una comunidad de habla relevante en el país de acogida, como ocurre con los hispanos en EE. UU. En estos casos, desde un punto de vista estrictamente lingüístico, parece pertinente empezar a considerar que la lengua de esa comunidad de habla (el español en este ejemplo) puede dejar de ser una LE y convertirse en una L2, al margen de su posible cooficialidad (CVC, 1997-2018).

Por otro lado, los procesos de aprendizaje de una LE y de una L2 también presentan algunas características comunes; por ejemplo, en ambos casos el aprendiente $^{20}$ posee un cierto conocimiento del mundo y una determinada competencia comunicativa en su L1. Así, parece lógico que, independientemente del modo de enseñanza, el aprendiente tienda a relacionar la LM y su cultura con su L1 y su propia cultura, es decir, se sirve de sus conocimientos previos para facilitarse el aprendizaje de los nuevos conocimientos léxicos, gramaticales, socioculturales, etc. Debido también a estos conocimientos previos, el aprendiente de una LM es más consciente de su propio proceso de aprendizaje que en el caso de la L1. Por último, cabe mencionar que, generalmente, no se alcanza el mismo nivel de corrección y de

\footnotetext{
${ }^{20}$ El término de aprendiente abarca otros como los de estudiante, alumno, discente o aprendiz pero no es, en sentido estricto, sinónimo de ninguno de ellos; los tres primeros suelen asociarse, generalmente, a la existencia de un plan de estudios, un centro de enseñanza, un profesor, unos materiales didácticos, etc., por lo que no resultan idóneos para referirse a aquellas personas que aprenden la lengua en contexto natural (p. ej., los inmigrantes que no siguen ningún curso pero aprenden la lengua en la interacción con otros en su medio social y laboral). Por su parte, el término de aprendiz suele aplicarse habitualmente a quien se inicia en un arte o profesión manual (tiene, pues, la connotación de principiante en el oficio y una clara indicación de pertenecer a un nivel inferior en la escala profesional); eso lo hace inapropiado para aquellos individuos que ya tienen un buen nivel de lengua extranjera, pero que siguen motivados por mejorarlo; de hecho, toda persona que ha iniciado el aprendizaje de una segunda lengua puede considerarse de por vida aprendiente de esa lengua (CVC, 1997-2018).
} 


\section{EL PROGRAMA TELEVISIVO COMO RECURSO PARA LA ENSEÑANZA/APRENDIZAJE DE ESPAÑOL LENGUA EXTRANJERA}

fluidez en la LM que en la L1, si bien es cierto que en el caso de la L2 se suelen alcanzar mejores resultados que en el de la LE (CVC, 1997-2018).

La expresión enseñanza de segundas lenguas hace referencia a toda actividad didáctica en el ámbito del aprendizaje de lenguas no maternas, cuyo objetivo es la adquisición de dichas lenguas por parte de los aprendientes. A lo largo de los años, este concepto ha experimentado importantes cambios. Los métodos tradicionales, provenientes de la enseñanza de las lenguas clásicas, dominaron durante años. Su método de enseñanza se basaba en el aprendizaje y la aplicación de las reglas gramaticales, la traducción de una lengua a otra y el aprendizaje de un vocabulario aislado. En la segunda mitad del siglo XX, aumenta el interés por la investigación del aprendizaje de idiomas, debido a los resultados insatisfactorios obtenidos hasta entonces. A partir de aquel momento, se decide estudiar qué procesos influyen en la adquisición de lenguas. La tendencia a desplazar sus planteamientos desde una visión 'externa' o 'de arriba-abajo' hacia un enfoque que busque comprender los procesos de adquisición internamente 'de abajo-arriba' desemboca en una nueva visión. Se considera que los factores que desempeñan un papel en la adquisición deben dirigir la enseñanza y no al revés. Así surge el que probablemente es el enfoque de mayor relevancia y el más considerado en la enseñanza actual de segundas lenguas: el enfoque comunicativo (CVC, 1997-2018).

Pastor Cesteros (2008: 68-69) defiende que el rasgo más definitorio de la enseñanza de segundas lenguas es el de favorecer el aprendizaje de una lengua no nativa por parte de alumnos que no la dominan por completo, o incluso en absoluto, y el consecuente desarrollo de la competencia comunicativa en esa nueva lengua. Por tanto, ante la pregunta de qué significa aprender una segunda lengua, coincidimos con la respuesta que ofrece Cesteros: ser capaz de usar esa lengua de un modo lo más similar posible al de un nativo, para lo que se requiere tanto el dominio del sistema lingüístico a través de las cuatro destrezas, como el dominio del uso pragmático de la lengua; y conocer también la cultura en la que dicha lengua se inserta y desenvuelve. En este sentido, y como veremos a lo largo de esta tesis, el programa televisivo es un recurso totalmente válido y adecuado para la enseñanza/aprendizaje de segundas lenguas.

Se debe distinguir también entre los términos aprendizaje y adquisición. E1 término adquisición es utilizado algunas veces en contraposición al de aprendizaje y otras como sinónimo. En la actualidad, hay una mayor tendencia 
a utilizarlo para referirse conjuntamente a los procesos de adquisición y a los de aprendizaje $^{21}$. No obstante, la investigación sobre adquisición de segundas lenguas acuñó este término para designar el conjunto de procesos inconscientes a través de los que el aprendiente desarrolla la capacidad de utilizar estructuras y formas lingüísticas para comunicarse en una segunda lengua. Este desarrollo consiste en la superación de unos estadios, que siguen un orden de adquisición natural. Para que ese proceso sea posible, el input ${ }^{22}$ tiene que superar ligeramente el nivel actual de competencia del aprendiente. Este input resulta comprensible gracias a la situación, el contexto, la información extralingüística y el conocimiento del mundo por parte del aprendiente. La producción verbal que resulta del procesamiento del input constituye el output ${ }^{23}$ (CVC, 19972018).

Por su parte, el término aprendizaje designa el conjunto de procesos conscientes e inconscientes mediante los cuales el aprendiente alcanza un determinado nivel de competencia en una segunda lengua. Lo consigue ejercitando las distintas estrategias de aprendizaje mediante la realización de actividades. En estos procesos influyen factores de aprendizaje externos e internos: son factores internos la motivación, las necesidades y el estilo de aprendizaje del aprendiente; son factores externos el contexto en el que se produce el aprendizaje y la enseñanza que lo promueve. Los primeros intentos por explicar el aprendizaje se produjeron en el marco del conductismo. Desde entonces, se han sucedido muchas otras propuestas, entre las que destacan las del cognitivismo, el enfoque humanístico, el interaccionismo social y el constructivismo. Los diferentes enfoques y métodos de enseñanza y aprendizaje de lenguas tienen su fundamento teórico en alguna de estas corrientes de la psicología. Como veremos a continuación, Krashen (1981) fue el primero en distinguir entre adquisición y aprendizaje.

La hipótesis de la distinción entre adquisición y aprendizaje sirve de fundamento teórico al Enfoque natural, una propuesta de enseñanza de lenguas que incorpora los principios naturalistas identificados en los estudios sobre la adquisición de segundas lenguas. Esta propuesta fue presentada por Terrell en 1977 a partir de su experiencia como profesora de español en California.

\footnotetext{
${ }^{21}$ Así será principalmente utilizado a lo largo de este trabajo.

${ }^{22}$ El vocablo inglés input, también conocido como caudal lingüístico o aducto, hace referencia a las muestras de lengua meta, orales o escritas, que el aprendiente encuentra durante su proceso de aprendizaje y a partir de las cuales puede realizar ese proceso (CVC, 1997-2018).

${ }^{23}$ El vocablo inglés output, también conocido como salida de datos o educto, hace referencia a la lengua que el aprendiente produce (CVC, 1997-2018).
} 


\section{EL PROGRAMA TELEVISIVO COMO RECURSO PARA LA \\ ENSEÑANZA/APRENDIZAJE DE ESPAÑOL LENGUA EXTRANJERA}

Terrell, junto a Krashen, publica The Natural Approach ${ }^{24}$ en 1983. Según Krashen (1983), la adquisición de una segunda lengua consiste en el conjunto de procesos de carácter natural e inconsciente mediante los que el aprendiente desarrolla - tal y como lo hacen los niños en la lengua primera- la competencia para la comunicación; por otro lado, el aprendizaje se refiere al conjunto de procesos conscientes en el marco de una enseñanza formal, donde se produce la corrección de errores, que permite al alumno alcanzar el conocimiento explícito de las reglas gramaticales y de uso lingüístico de la lengua segunda, y la capacidad de expresar verbalmente ese conocimiento.

Krashen (1983), quien considera que el aprendizaje no conduce a la adquisición, fundamenta su mencionada teoría en torno a cinco hipótesis: la hipótesis de la distinción entre adquisición y aprendizaje, la hipótesis del monitor, la hipótesis del orden natural, la hipótesis del input comprensible y la hipótesis del filtro afectivo. Otros autores, manteniendo la distinción teórica entre procesos de aprendizaje y procesos de adquisición, y admitiendo que los conocimientos obtenidos como resultado de ambos procesos se almacenan por separado, sostienen, sin embargo, que entre ellos existen ciertas conexiones y que los mecanismos de enseñanza de conocimientos explícitos pueden contribuir favorablemente al desarrollo de los procesos de adquisición.

Conviene hacer una distinción entre los tipos de procesos a los que venimos haciendo referencia. Se entiende por proceso a una sucesión de acciones físicas o mentales que realizan los hablantes cuando usan comunicativamente la lengua, la adquieren o la aprenden. Así, por una parte se habla de procesos comunicativos de la lengua, por otra parte de procesos de adquisición de lenguas y por último, de procesos de aprendizaje (CVC, 1997-2018).

Se entiende por procesos comunicativos de la lengua un conjunto de acciones que un hablante tiene que dominar para usar la lengua de forma competente. El Marco Común Europeo de Referencia para las Lenguas ${ }^{25}$ (en adelante, MCER) (2002: 88) identifica los siguientes procesos según la actividad de la lengua que se esté llevando a cabo. Así queda recogido en la siguiente tabla.

\footnotetext{
${ }^{24}$ Krashen, S. D. y Terrel, T. D. (1983). The Natural Approach: Language Acquisition in the Classroom. Oxford: Pergamon.

25 Documento publicado por el Consejo de Europa en 2001 que nace con la intención de reflexionar sobre los objetivos y metodología de la enseñanza y aprendizaje de lenguas y de ofrecer una base común para el desarrollo curricular, la elaboración de programas, exámenes y criterios de evaluación.
} 
Tabla 1

Procesos comunicativos de la lengua según el MCER (2002)

$\begin{array}{ll}\text { Expresión oral } & \begin{array}{l}\text { Planear y organizar un mensaje; formular un enunciado } \\ \text { lingüístico; articular el enunciado. }\end{array} \\ \text { Expresión escrita } & \begin{array}{l}\text { Organizar y formular un mensaje; escribir el texto a mano } \\ \text { o teclearlo. }\end{array} \\ \begin{array}{l}\text { Comprensión } \\ \text { auditiva }\end{array} & \begin{array}{l}\text { Percibir el enunciado; identificar el mensaje lingüístico; } \\ \text { comprender el mensaje; interpretar el mensaje. }\end{array} \\ \text { Comprensión } & \begin{array}{l}\text { Percibir el texto escrito; reconocer la escritura; identificar } \\ \text { el mensaje; comprenderlo; interpretarlo. }\end{array} \\ \text { lectora } & \begin{array}{l}\text { Se ponen en práctica los procesos ya mencionados que } \\ \text { intervienen en la expresión oral y la comprensión }\end{array} \\ & \begin{array}{l}\text { auditiva. Sin embargo, en este caso los procesos no se } \\ \text { suceden linealmente, sino que interactúan y los } \\ \text { interlocutores los superponen en el transcurso de la } \\ \text { conversación. }\end{array} \\ \text { Interacción escrita } & \begin{array}{l}\text { Los procesos de comprensión y de expresión permanecen } \\ \text { diferenciados. Sin embargo, en los chat los efectos del } \\ \text { discurso acumulativo son parecidos a los de la interacción } \\ \text { oral, ya que consisten en una interacción en tiempo real. }\end{array}\end{array}$

Datos obtenidos del MCER (2002)

En cuanto a los procesos que intervienen en la adquisición de lenguas, se ha identificado una serie de procesos cognitivos que guían el aprendizaje en general y el aprendizaje de lenguas en particular. Se distinguen los procesos de aprendizaje (cognitivos), y los reguladores del aprendizaje (metacognitivos). Aunque la identificación de estos procesos varía según los autores (Faerch y Kasper, 1983; McLaughlin, 1990; Ellis, R., 1992), se pueden enumerar los siguientes:

- Imitación de algunos de los elementos que componen la lengua que se percibe.

- Formulación de hipótesis sobre el funcionamiento de la lengua, posterior comprobación y reajuste, si es necesario. 


\section{EL PROGRAMA TELEVISIVO COMO RECURSO PARA LA ENSEÑANZA/APRENDIZAJE DE ESPAÑOL LENGUA EXTRANJERA}

- Percepción e identificación del elemento lingüístico nuevo en la lengua que se percibe.

- Contraste del elemento lingüístico nuevo con el de la propia lengua u otras lenguas conocidas.

- Incorporación del nuevo elemento lingüístico.

- Reestructuración, pues la incorporación del nuevo elemento lingüístico provoca una reorganización del conocimiento.

Finalmente, se distinguen tres procesos metacognitivos que afectan al control del aprendizaje:

- Planificación de lo que se va aprender.

- Control del aprendizaje durante su transcurso.

- Evaluación de los logros obtenidos.

Como recoge Muñoz (2000), el aprendizaje y la adquisición de segundas lenguas es un proceso que puede tener lugar en diferentes contextos sociolingüísticos y educativos. En este complejo proceso intervienen directa o indirectamente un gran número de variables individuales y contextuales que también pueden estar relacionadas entre sí. Igualmente, presenta una gran diversidad en lo que se refiere a las condiciones en que tiene lugar y a sus objetivos.

La adquisición o el aprendizaje de segundas lenguas puede tener lugar en contextos naturales o formales, aunque también existen los contextos mixtos. En el contexto natural, más parecido al contexto de adquisición de primeras lenguas, la adquisición ocurre como resultado de la interacción con hablantes de la L2 y la observación de la interacción entre hablantes de L2 en distintas situaciones sociales. Estas situaciones varían según las características de los interlocutores y los objetivos de la propia interacción. En contextos formales, el estudiante suele recibir algún tipo de explicación sobre el funcionamiento de la segunda lengua, así como una valoración sobre aspectos específicos y/o generales de los avances y resultados de su aprendizaje. En estos contextos, la exposición a la segunda lengua es el resultado de un proceso de intervención educativa que programa y regula la cantidad y el tipo de input y de interacción al que tendrá acceso el estudiante. En la mayoría de los casos, la adquisición de segundas lenguas en contextos formales tiene lugar en el aula, pero también 
existe la posibilidad de que se dé por medio de autoinstrucción con la ayuda de materiales didácticos específicos (Muñoz, 2000).

Consideramos que el recurso del programa televisivo puede ser útil para el aprendiente de español, tanto si se encuentra en un contexto natural como formal o mixto. Mediante la visualización de programas televisivos, el aprendiente puede, tanto de forma autónoma como en una clase, observar, analizar y comprender cómo se desarrolla la interacción entre hablantes nativos $^{26}$ o no nativos ${ }^{27}$ de español en distintas situaciones, según el tipo de programa que esté viendo, ya que las características de los interlocutores y los objetivos de la interacción serán diferentes. La principal ventaja de utilizar este recurso en el aula reside en que esto permite aprovechar aún más su potencial educativo — tanto a nivel cultural como lingüístico- pues a través de actividades de previsionado, durante el visionado y de posvisionado, el profesor puede trabajar, como demostraremos más adelante en esta tesis, diferentes aspectos de la competencia comunicativa.

\subsection{La competencia comunicativa}

En la actualidad, la competencia comunicativa se considera un conjunto de saberes, capacidades, habilidades o aptitudes - que participan en el desarrollo de las relaciones interpersonales e intergrupales - necesario para conseguir una comunicación eficaz (Cenoz, 1996).

La competencia comunicativa es uno de los conceptos más importantes en lingüística aplicada, tanto en el estudio de la adquisición de segundas lenguas como, a un nivel más práctico, en la enseñanza de lenguas. En efecto, la competencia comunicativa es un concepto clave al tratar de responder a las siguientes preguntas: ¿en qué consiste adquirir una lengua?; ¿qué conocimientos, capacidades o destrezas se necesitan para hablar una lengua?; ¿cuál es el objetivo de la enseñanza de lenguas?

La lingüística aplicada muchas veces ha tomado como base teorías de la lingüística teórica o de otras áreas de conocimiento, como la psicología o la

\footnotetext{
${ }^{26}$ Tanto de España como de otros países hispanohablantes.

${ }^{27}$ La observación de una situación comunicativa en la que participa un hablante no nativo resulta especialmente interesante para trabajar la competencia estratégica, como explicamos en el apartado Aspectos estratégicos que se pueden trabajar con programas de televisión.
} 


\title{
EL PROGRAMA TELEVISIVO COMO RECURSO PARA LA \\ ENSEÑANZA/APRENDIZAJE DE ESPAÑOL LENGUA EXTRANJERA
}

antropología, para desarrollar modelos teóricos y constructos que puedan resultar apropiados a sus propios fines. El concepto de competencia comunicativa tiene su origen en el concepto de competencia de la lingüística teórica en el marco de la gramática generativa, pero también ha recibido la influencia de teorías de la antropología y la sociolingüística. Por lo tanto, se trata de un concepto que, del mismo modo que los de adquisición de segundas lenguas o enseñanza de lenguas, tiene un carácter interdisciplinar (Cenoz, 1996).

La importante difusión del concepto de competencia comunicativa en los estudios de adquisición y enseñanza de lenguas está relacionada directamente con la distinción realizada por Chomsky (1965) entre competencia y actuación:

\begin{abstract}
Linguistic theory is concerned primarily with an ideal speaker-listener, in a completely homogeneous speech-community, who knows its language perfectly and is unaffected by such grammatically irrelevant conditions as memory limitations, distractions, shifts of attention and interest, and errors (random or characteristic) in applying his knowledge of the language in actual performance ${ }^{28}$ (Chomsky, 1965: 3).
\end{abstract}

Por lo tanto, para Chomsky, la competencia es el conocimiento que el hablanteoyente tiene de la lengua, y la actuación es el uso real de la lengua en situaciones concretas. Chomsky se muestra más interesado en estudiar la competencia que la actuación. Su interés se dirige al desarrollo en una teoría lingüística centrada principalmente en las reglas gramaticales.

Aunque en un principio Chomsky aceptó que todos los aspectos relacionados con el uso se incluían en la actuación, más tarde reconoció que algunos aspectos del uso son sistemáticos y están gobernados por reglas. Así, en 1980, reconoció que, además de la competencia gramatical, también existe la competencia pragmática. Esta última está referida al conocimiento de las condiciones y al modo de uso apropiado conforme a varios fines, mientras que la primera se refiere al conocimiento de la forma (Chomsky, 1980: 224).

Además de centrarse en el conocimiento y no en la capacidad o habilidad para utilizarlo en la comunicación interpersonal, el concepto de competencia lingüística está unido al conocimiento de la lengua por parte de los hablantes

\footnotetext{
${ }^{28}$ La teoría lingüística se centra principalmente en el hablante-oyente ideal de una comunidad de habla completamente homogénea que conoce su lengua perfectamente y al que no le afectan condiciones irrelevantes a nivel gramatical como las limitaciones de memoria, las distracciones, los cambios de atención y de interés y los errores al aplicar su conocimiento de la lengua a la actuación real (Traducción de CVC, 1997-2018).
} 
monolingües nativos. El concepto de hablante nativo ideal es difícil de aceptar puesto que no todos los hablantes de una lengua son competentes y pueden distinguir oraciones gramaticales de oraciones no gramaticales. Además, hablantes no nativos pueden distinguir ciertos tipos de oraciones gramaticales y no gramaticales con más exactitud que algunos hablantes nativos.

El concepto de competencia de Chomsky provocó reacciones importantes entre los investigadores situados fuera del marco de la gramática generativa (Lyons, 1970; Campbell y Wales, 1970; Hymes, 1972). Se considera inadecuado porque se limita a la competencia lingüística del hablante-oyente ideal en una sociedad homogénea y no considera aspectos centrales del uso de la lengua. En efecto, el concepto de competencia propuesto por Chomsky supone una abstracción e idealización, que no tiene una relación directa con la capacidad y habilidad para utilizar una o varias lenguas en la comunicación interpersonal por parte de hablantes monolingües y plurilingües en sociedades multiculturales. Es un concepto útil dentro de la gramática generativa, pero que se torna demasiado reduccionista si se aplica a la adquisición y enseñanza de lenguas.

Sin embargo, es preciso reconocer, como considera Llurdá (2000: 86), que la definición de Chomsky representa el punto de partida de otros enfoques posteriores y que, además, la controversia sobre el concepto de competencia lingüística ha favorecido la aceptación del concepto de competencia comunicativa como concepto fundamental en la adquisición y enseñanza de lenguas.

La reacción al concepto de competencia de Chomsky se centró en resaltar el carácter social de la competencia y la importancia de que los enunciados sean apropiados al contexto en el que tiene lugar la comunicación. De este modo, Lyons (1970: 287) considera que: «la habilidad de utilizar la lengua con corrección en una variedad de situaciones determinadas socialmente es una parte tan central de la competencia lingüística como la habilidad de producir oraciones gramaticalmente correctas»».

Campbell y Wales también insisten en la idea de que la gramaticalidad de las oraciones no es suficiente: «la habilidad de producir o comprender enunciados que no son tanto gramaticales sino algo más importante, apropiados al contexto en el que tienen lugar» (Campbell y Wales, 1970: 247).

Los investigadores que critican el concepto de competencia lingüística consideran que el concepto de competencia en la gramática generativa es 


\title{
EL PROGRAMA TELEVISIVO COMO RECURSO PARA LA ENSEÑANZA/APRENDIZAJE DE ESPAÑOL LENGUA EXTRANJERA
}

reduccionista porque en él no se consideran elementos del contexto sociolingüístico. Sin duda alguna, la reacción contraria de mayor importancia ha sido la de Hymes (1972), quien considera que la competencia lingüística es insuficiente porque los enunciados deben ser también apropiados y aceptables en el contexto en el que se utilizan:

\begin{abstract}
There are rules of use without which the rules of grammar would be useless. Just as syntax can control aspects of phonolgy, and just as semantic rules perhaps control aspects of syntax, so rules of speech acts enter as a controlling factor for linguistic forms ${ }^{29}$ (Hymes, 1972: 278).
\end{abstract}

Hymes propuso el concepto de competencia comunicativa, que incluye las reglas de uso a las que hace referencia. En él incluye el significado referencial y social del lenguaje, y no solo se refiere a la gramaticalidad de las oraciones, sino también a si estas son apropiadas o no en el contexto. Para Hymes la competencia comunicativa presenta cuatro dimensiones: el grado en que algo resulta formalmente posible (gramaticalidad), el grado en que algo resulta factible, el grado en que algo resulta apropiado y el grado en que algo se da en la realidad. Por lo tanto, podemos ver que conceptos como ser apropiado o aceptable forman parte, al igual que ser gramaticalmente correcto, de la competencia comunicativa. Hymes afirma que la competencia es el conocimiento subyacente general y la habilidad para el uso de la lengua que posee el hablante-oyente. Según este autor, los hablantes consideran factores que intervienen en la comunicación cuando usan la lengua. Estos factores incluyen las características de los interlocutores o las relaciones que nos unen al interlocutor. Dependiendo de las distintas situaciones, los hablantes pueden utilizar diferentes registros.

El concepto de competencia comunicativa propuesto por Hymes tiene gran fuerza como herramienta organizadora en las ciencias sociales y es utilizado con gran frecuencia en la lingüística y psicolingüística, especialmente en relación con la adquisición de la primera y la segunda lengua. Sin embargo, son muchos los investigadores que han complementado algunos aspectos de la definición de competencia comunicativa. Por ejemplo, Gumperz (1972) considera que esta es lo que necesita el hablante para comunicar en contextos que son significativos culturalmente. Saville-Troike (1989: 21) opina que la

\footnotetext{
${ }^{29}$ Hay reglas de uso sin las cuales las reglas gramaticales serían inútiles. Del mismo modo que las reglas sintácticas pueden controlar aspectos de la fonología, y las reglas semánticas quizá controlar aspectos de la sintaxis, las reglas de los actos de habla actúan como factores que controlan la forma lingüística en su totalidad (Traducción de CVC, 1997-2018).
} 
competencia comunicativa incluye, además, aspectos de la comunicación, tales como hablar con personas de distintos estatus, conocer rutinas en la alternada de turnos u otros relacionados con el uso de la lengua en contextos sociales específicos.

La competencia comunicativa no es solamente una extensión de la competencia lingüística, a la que se le han añadido las reglas relacionadas con el uso. No se trata únicamente de una adición cuantitativa; es también, y sobre todo, una ampliación cualitativa. El concepto de competencia lingüística se refiere al conocimiento de determinadas reglas mientras que la competencia comunicativa incluye además la habilidad o la destreza para utilizar ese conocimiento. Esta habilidad para usar el conocimiento puede distinguirse de la actuación, aunque solamente la actuación sea observable. La competencia es, en este sentido, conocimiento y habilidad, mientras que la actuación es lo que el hablante hace en el acto de comunicación.

Otra diferencia importante entre las competencias lingüística y comunicativa corresponde al carácter dinámico de la segunda frente al carácter estático de la primera. La competencia lingüística es innata, tiene base biológica, es estática, tiene un carácter absoluto y no implica comparación. La competencia comunicativa es un concepto dinámico que depende de la negociación del significado entre dos o más personas que comparten hasta cierto punto el mismo sistema simbólico. Como Savignon (1983) propone, tiene un carácter interpersonal y no intrapersonal. Además, la competencia comunicativa tiene un carácter relativo y no absoluto y los diferentes usuarios de la lengua pueden presentar distintos grados de competencia comunicativa. La competencia comunicativa, por lo tanto, tiene base social y es específica del contexto en el que tiene lugar la comunicación.

Las perspectivas desde las que se han propuesto los conceptos de competencia lingüística y comunicativa difieren porque las líneas de investigación para las que estos conceptos son necesarios son diferentes. La gramática generativa se centra principalmente en el estudio de los aspectos sintácticos de la lengua como sistema, mientras que otras perspectivas, relacionadas con la lingüística aplicada y la antropología, necesitan de este concepto porque refleja una perspectiva más amplia del estudio de la lengua e incluye otras áreas contextuales e interdisciplinares relacionadas con el uso de la lengua.

Taylor (1988) considera que cada gran confusión conceptual se debe a que Chomsky está interesado en la competencia como estado y no como proceso, y 


\title{
EL PROGRAMA TELEVISIVO COMO RECURSO PARA LA \\ ENSEÑANZA/APRENDIZAJE DE ESPAÑOL LENGUA EXTRANJERA
}

en el conocimiento y no en la habilidad. Widdowson (1995: 84) expresa las diferencias entre los dos conceptos:

\begin{abstract}
Para Chomsky, entonces, la competencia es el conocimiento gramatical como un arraigado estado mental por debajo del nivel de lengua. No es una habilidad para hacer nada. Ni siquiera es la habilidad para formar o comprender oraciones, porque el conocimiento puede existir sin que sea accesible [...]. Para Hymes, por otro lado, la competencia es la habilidad para hacer algo: para usar la lengua. Para él el conocimiento gramatical es un recurso, no una configuración cognitiva abstracta existente por propio derecho como una estructura mental. El modo en que este conocimiento se convierte en uso es, por tanto, una cuestión central, y es necesariamente un componente de la competencia comunicativa.
\end{abstract}

La confluencia de estudios, tanto en el área del lenguaje como en el de la psicología y la cognición, permitió la expansión del concepto de competencia comunicativa. Es así como a partir de la década de los años ochenta del siglo $\mathrm{XX}$ surgen algunos modelos.

Varios autores coinciden en que la competencia comunicativa es el resultado de la suma de varias competencias y subcompetencias, denominadas dimensiones. Mientras que Canale y Swain (1980: 1-47) consideran que la competencia sociolingüística incluye a la pragmática y Bachman (1990) entiende que la competencia pragmática incluye a la sociolingüística, el MCER (2002: 13) las considera competencias diferentes dentro de la competencia comunicativa.

Como recogen Bermúdez y González (2011), podemos concluir entonces que el estudio de la competencia comunicativa requiere de una visión holística alejada de posturas mecanicistas y rígidas. Como variable de estudio y partiendo del hecho de que la competencia comunicativa ha sido abordada por diferentes ciencias, su análisis adquiere dos dimensiones básicas: la dimensión lingüística y la dimensión estratégica.

La dimensión lingüística abarca inicialmente lo referente a la gramática tradicional, con sus niveles: morfología, sintaxis, fonética, fonología y semántica (Chomsky, 1965). A estos elementos Hymes (1971) agrega la capacidad y el entendimiento de relacionarlos con el contexto sociohistórico y cultural en el que se lleva a cabo la comunicación. Según la visión de este autor, no basta solo con saber las reglas gramaticales del uso de la lengua, sino que es sumamente importante tener la capacidad de relacionarlas con el contexto.

Como categoría de análisis, la dimensión lingüística incluye la competencia discursiva y la competencia sociolingüística. La competencia discursiva es la capacidad de una persona para comunicarse de manera eficaz y adecuada en 
una lengua, dando un uso adecuado a las reglas gramaticales y significado a un texto oral o escrito. La competencia sociolingüística implica todos los componentes sobre los aspectos socioculturales o convenciones sociales del uso del lenguaje. Esta consta de tres elementos básicos: el saber, conceptos teóricos y empíricos; el saber hacer, procedimientos, habilidades y destrezas; saber ser o querer hacer, actitudes que abarca la competencia existencial del ser.

La competencia sociolingüística posee, según la perspectiva de Hymes (1971), las reglas de interacción social y la competencia cultural que llevan a comprender las normas de comportamiento de los miembros de una cultura específica, la asimilación de todos los aspectos de la cultura, específicamente los que se refieren a la estructura social, los valores, y creencias. Por su parte, Van Dijk (1980) defiende que los esquemas mentales, las actitudes y los valores son el resultado de la interacción de las mentes de una comunidad, es decir, un hecho social. Los miembros de una comunidad tienen la base común para calificar situaciones, eventos y actos de habla y, por supuesto, interpretar la ausencia de otros.

La dimensión estratégica de la competencia comunicativa abarca los factores relacionados con el uso efectivo de la lengua. Es la capacidad de hacer uso de recursos verbales y no verbales para favorecer la comunicación y compensar errores derivados de falta de conocimiento o de otras condiciones. Tal como señala Bachman (1990), la competencia estratégica es una habilidad que permite a un individuo hacer un uso más efectivo de las habilidades disponibles, al llevar a cabo una tarea determinada, tanto si esa tarea está relacionada con el uso comunicativo de la lengua como con tareas no verbales.

De entre todos los posibles enfoques y teorías sobre competencia comunicativa, en este trabajo nos centramos en la división de competencias establecida por Canale y Swain (1980: 1-47) y Bachman (1990), pues consideramos que en su clasificación se incluyen las cinco competencias más esenciales y representativas de este enfoque: la competencia lingüistica, la competencia sociolingüística, la competencia discursiva, la competencia estratégica y la competencia pragmática. A continuación, analizamos cada una de ellas.

La competencia lingüística, también llamada competencia gramatical, está relacionada con el dominio del código lingüístico (verbal o no verbal). Se incluyen aquí características y reglas del lenguaje como el vocabulario, la formación de palabras y frases, la pronunciación, la ortografía y la semántica. Esta competencia se centra directamente en el conocimiento y la habilidad 


\section{EL PROGRAMA TELEVISIVO COMO RECURSO PARA LA \\ ENSEÑANZA/APRENDIZAJE DE ESPAÑOL LENGUA EXTRANJERA}

requeridos para emprender y expresar adecuadamente el sentido literal de las expresiones (Canale, 1983).

La competencia sociolingüística se ocupa de en qué medida las expresiones son producidas y entendidas adecuadamente en diferentes contextos sociolingüísticos dependiendo de factores contextuales como la situación de los participantes, los propósitos de la interacción y las normas y convenciones. La adecuación de los enunciados está relacionada con la adecuación del significado y la forma. La adecuación del significado tiene que ver con el alcance hasta el cual funciones comunicativas determinadas (por ejemplo, ordenar, quejarse e invitar), actitudes (incluyendo la cortesía y la formalidad) e ideas son juzgadas como características de una situación dada. La adecuación de la forma trata de la medida en que un significado dado (incluidas funciones comunicativas, actitudes y proposiciones/ideas) se representa por medio de una forma verbal y/o no verbal, que es característica en un contexto sociolingüístico (Canale, 1983).

Como señala Canale (1983), hay una tendencia en muchos programas de segunda lengua a tratar la competencia sociolingüística como si fuese menos importante que la competencia gramatical. Esta tendencia resulta extraña por dos razones. Primero, da la impresión de que la corrección gramatical de las expresiones es más importante que su adecuación a la comunicación real. Segundo, esta tendencia ignora el hecho de que la competencia sociolingüística es necesaria en la interpretación de enunciados por su significado social, por ejemplo, función comunicativa y actitud (cuando no queda claro por el significado literal de las expresiones o a partir de indicaciones no verbales, por ejemplo, contexto sociocultural y gestos). Sin duda, hay aspectos universales respecto al uso adecuado de la lengua que no necesitan ser nuevamente aprendidos para comunicarse de manera adecuada en una segunda lengua (Canale y Swain, 1980: 1-47); pero también hay aspectos específicos de las lenguas y las culturas.

La competencia discursiva está relacionada con el modo en que se combinan formas gramaticales y significados para lograr un texto hablado o escrito en diferentes géneros. Por género se entiende el tipo de texto: por ejemplo, una narración oral o escrita, un ensayo argumentativo, un artículo científico, una carta comercial, un conjunto de instrucciones... La unidad de un texto se alcanza por medio de la cohesión en la forma y la coherencia en el significado. La cohesión implica el modo en que las frases se unen estructuralmente y facilita la interpretación de un texto. Por ejemplo, el uso de mecanismos de 
cohesión como pronombres, sinónimos, elipsis, conjunciones y estructuras paralelas sirve para establecer conexiones entre frases individuales y para indicar cómo un grupo de frases ha de entenderse como un texto (por ejemplo, lógica o cronológicamente). La coherencia hace referencia a las relaciones entre los diferentes significados en un texto, donde estos significados pueden ser literales, funciones comunicativas y actitudes (Canale, 1983).

La competencia estratégica se compone del dominio de las estrategias de comunicación verbal y no verbal que pueden utilizarse por dos motivos principalmente. Primero, para compensar los fallos en la comunicación debidos a condiciones limitadoras en la comunicación real (por ejemplo, la incapacidad momentánea para recordar una idea o una forma gramatical) o a insuficiente competencia en una o más de las otras áreas de competencia comunicativa. Segundo, para favorecer la efectividad de la comunicación (por ejemplo, hablar de forma lenta y baja deliberadamente con una intención retórica). Por ejemplo, cuando alguien no recuerda una forma gramatical concreta, una estrategia compensatoria que puede usarse es la paráfrasis. Naturalmente, tales estrategias no se limitan a resolver problemas gramaticales: la comunicación real también requerirá que los aprendientes se enfrenten con problemas de naturaleza sociolingüística (por ejemplo, cómo dirigirse a extraños cuando se está inseguro de su posición social) y de naturaleza discursiva (por ejemplo, cómo conseguir la coherencia en un texto cuando no se tiene seguridad sobre los elementos de cohesión) (Canale, 1983).

Canale (1983) explica que el valor potencial de tales estrategias para el estudiante de una lengua extranjera quizá se puede demostrar más fácilmente si pensamos en el profesor de la segunda lengua como un aprendiente de la primera. Por ejemplo, un profesor de francés como segunda lengua que solo habla francés a un grupo de alumnos anglófonos, desde el punto de vista de los estudiantes, puede ser visto como un aprendiente que casi no sabe inglés; sin embargo, consigue comunicarse de manera eficaz. Si el profesor es entendido gracias al uso de estrategias comunicativas, queda claro que estas son cruciales para que la comunicación tenga lugar. Canale se pregunta por qué, si los profesores son formados en el uso de técnicas para hacerse entender en la segunda lengua de los alumnos, los alumnos no deberían también ser instruidos en las mismas técnicas.

La competencia pragmática se centra en el uso de los recursos lingüísticos (producción de funciones del lenguaje y de actos de habla) sobre la base de guiones o escenarios de intercambios comunicativos. También está relacionada 


\section{EL PROGRAMA TELEVISIVO COMO RECURSO PARA LA ENSEÑANZA/APRENDIZAJE DE ESPAÑOL LENGUA EXTRANJERA}

con el dominio del discurso, la cohesión y la coherencia, la identificación de tipos y formas de texto, la ironía y la parodia. Se refiere a las precondiciones situacionales que deben ser satisfechas para realizar una función comunicativa determinada (por ejemplo, para dar una orden, una persona debe tener derecho a hacerlo). Las reglas de adecuación social se ocupan de si una función dada sería normalmente expresada o no y, en caso afirmativo, hasta qué punto podría ser directa (por ejemplo, al preguntarle a un extraño cuánto dinero gana). Las reglas de realización lingüística incluyen una serie de aspectos que han de ser tenidos en cuenta, como la frecuencia con la que una forma gramatical dada se usa para realizar una determinada función, el número y rango estructural de formas asociadas con cada función, la generalización de formas en funciones $y$ situaciones, y los medios para modular el tono de una función.

\subsection{La competencia lingüística}

La competencia lingüística, también llamada competencia gramatical, es la capacidad de una persona para producir enunciados gramaticales en una lengua, es decir, enunciados que respeten las reglas de la gramática de dicha lengua en todos sus niveles (vocabulario, formación de palabras y oraciones, pronunciación y semántica). Se define como el conocimiento implícito que un hablante posee sobre su propia lengua, el cual le permite no solo codificar mensajes que respeten las reglas de la gramática, sino también comprenderlos y emitir juicios sobre su gramaticalidad.

El concepto de competencia gramatical fue propuesto por Chomsky en la obra Estructuras sintácticas ${ }^{30}$ (1957), y constituye un concepto fundamental en la tradición de la llamada Gramática Generativa, que se propone como fin último hacer explícito el conocimiento implícito sobre la propia lengua que tienen los hablantes. Sin embargo, desde otras disciplinas lingüísticas que atienden a aspectos relacionados con la lengua en uso, se ha puesto en entredicho que el mero conocimiento de la gramática de una lengua permita usarla siempre de manera adecuada. Hymes, en sus trabajos de sociolingüística y de etnografía de la comunicación, propuso hacia los años 70 del siglo $\mathrm{XX}$ el concepto de competencia comunicativa como una capacidad de alcance más amplio, que

30 Chomsky, N. (1957). Syntactic Structures (Estructuras sintácticas), Buenos Aires: Siglo XXI, 1999. 
permite a un hablante comportarse comunicativamente de forma adecuada. Para ello, este no debe poseer únicamente un dominio sobre las reglas gramaticales de buena formación de oraciones, sino también sobre las reglas que determinan el uso de la lengua en la producción de enunciados adecuados en el contexto discursivo.

Canale (1983) es uno de los primeros autores en relacionar el concepto de competencia comunicativa definido por Hymes con la enseñanza de segundas lenguas y en analizar los componentes que la integran, a saber: la competencia gramatical, la competencia discursiva, la competencia sociolingüística y la competencia estratégica. Describe la competencia gramatical como aquella que «se centra directamente en el conocimiento y la habilidad requeridos para emprender y expresar adecuadamente (cursiva en el original) el sentido literal de las expresiones».

Con posterioridad a Canale, otros autores del campo de la enseñanza de segundas lenguas han publicado trabajos sobre la competencia comunicativa y sus componentes. Todos ellos incluyen entre estos la competencia gramatical. Aunque se refieren a un mismo concepto, lo describen de manera parcialmente diferente, de acuerdo con la aproximación que subyace en sus trabajos al propio concepto de gramática. Así, J. van Ek (1991), que adopta una postura muy próxima a la de Canale, habla de la capacidad de referirse al significado convencional de las expresiones, el cual define como aquel significado que una persona nativa atribuiría a una expresión si esta apareciera aislada de cualquier texto, contexto y situación de uso. Para Bachman (1990), en cambio, la competencia gramatical junto con la competencia textual conforman la competencia organizativa; esta competencia organizativa, a su vez, conforma junto con la competencia pragmática la competencia lingüística (que en el modelo de Bachman equivale en gran medida a lo que el resto de autores llama competencia comunicativa).

En el MCER (2002: 107) la competencia lingüística está integrada, a su vez, por la competencia léxica, la competencia gramatical, la competencia semántica, la competencia fonológica, la competencia ortográfica y la competencia ortoépica, como explicaremos en los apartados siguientes. En una detallada descripción de cada una de estas competencias y subcompetencias, el MCER ofrece unas escalas — no incluidas en esta tesis - con seis niveles de dominio para cada una de ellas; así, describe en esos seis niveles la competencia lingüística general, la riqueza de vocabulario, el dominio del vocabulario, la 


\section{EL PROGRAMA TELEVISIVO COMO RECURSO PARA LA \\ ENSEÑANZA/APRENDIZAJE DE ESPAÑOL LENGUA EXTRANJERA}

corrección gramatical, el dominio de la pronunciación y el dominio de la ortografía.

\subsubsection{La competencia léxica}

Desde finales de los setenta, el concepto de competencia léxica ha recibido una gran atención manifestada especialmente en intentos de definir qué significa conocer una palabra. Sin embargo, como señala Maiguashca (1993), faltan modelos integrados de competencia léxica en los que se describan las reglas sistemáticas que subyacen a la misma, del mismo modo que se ha hecho para otros componentes de la lengua como el fonológico o el sintáctico.

El interés por la competencia léxica se fundamenta en el hecho de que su definición permite: analizar los principios que regulan la adquisición del vocabulario; descubrir si existe un orden sistemático reflejado en etapas de adquisición de este componente; comprobar si dichas etapas son diferentes en la lengua materna y en la L2; averiguar si en dicho aprendizaje influyen determinados factores contextuales e individuales como el tipo de input, el modo de enseñanza, la edad, el sexo, la motivación o la aptitud lingüística.

Asimismo, como han señalado diversos investigadores (Richards, 1976; Nation, 1990; Sanjuan, 1991; Maiguashca, 1993; Schmitt, 1995), la definición de la competencia léxica es de gran utilidad para el profesorado de idiomas puesto que, por un lado, le aporta criterios de referencia para evaluar el aprendizaje y le ayuda a diagnosticar las dificultades de aprendizaje del léxico; y, por otro, le permite evaluar no solo los contenidos de los libros de texto, libros de actividades y test, sino también planificar adecuadamente la enseñanza en un determinado nivel.

La competencia léxica, que es el conocimiento del vocabulario de una lengua y la capacidad para utilizarlo, se compone de elementos léxicos y elementos gramaticales.

Los elementos léxicos comprenden:

a) Expresiones hechas, que se componen de varias palabras que se utilizan y se aprenden como un todo. Las expresiones hechas incluyen:

- Fórmulas fijas, que comprenden: 


\section{LA COMPETENCIA COMUNICATIVA EN LA ENSEÑANZA DE}

SEGUNDAS LENGUAS

- Exponentes directos de funciones comunicativas, como, por ejemplo, saludos: encantado de conocerle, buenos dias, etc.

- Refranes, proverbios, etc.

- Arcaísmos residuales; por ejemplo: desfacer entuertos, válgame Dios.

- Modismos; a menudo:

- Metáforas lexicalizadas, semánticamente opacas; por ejemplo: estiró la pata (murió), se quedó de piedra (se quedó asombrado), estaba en las nubes (no prestaba atención).

- Intensificadores, ponderativos o epítetos. Su uso es a menudo contextual y estilísticamente restringido; por ejemplo: blanco como la nieve (= 'puro'), como opuesto a blanco como la pared (= 'pálido').

- Estructuras fijas, aprendidas y utilizadas como conjuntos no analizados, en los que se insertan palabras o frases para formar oraciones con sentido; por ejemplo: «Por favor, ¿sería tan amable de + infinitivo...?».

- Otras frases hechas, como:

- Verbos con régimen preposicional; por ejemplo: convencerse de, alinearse con, atreverse a.

- Locuciones prepositivas; por ejemplo: delante de, por medio de.

- Régimen semántico: expresiones que se componen de palabras que habitualmente se utilizan juntas; por ejemplo: cometer un crimen/error, ser culpable de (algo malo), disfrutar de (algo bueno).

b) Polisemia: una palabra puede tener varios sentidos distintos; por ejemplo: tanque, un recipiente de líquido, o un vehículo armado y blindado; o banco, lugar para sentarse o entidad financiera. Estas palabras incluyen miembros de las clases abiertas de palabras: sustantivo, verbo, adjetivo, adverbio, aunque estas pueden incluir conjuntos léxicos cerrados (por ejemplo: días de la semana, meses del año, pesos y medidas, etc.). Se pueden establecer otros conjuntos léxicos con fines gramaticales y semánticos.

Los elementos gramaticales pertenecen a clases cerradas de palabras; por ejemplo:

- $\quad$ artículos (el, la, los, las...); 


\section{EL PROGRAMA TELEVISIVO COMO RECURSO PARA LA \\ ENSEÑANZA/APRENDIZAJE DE ESPAÑOL LENGUA EXTRANJERA}

- cuantificadores (algo, poco, mucho...);

- demostrativos (este, esta, estos, estas);

- pronombres personales (yo, tú, él, ella, nosotros...);

- pronombres relativos y adverbios interrogativos (qué, cuál, quién, dónde, cómo, cuándo);

- $\quad \operatorname{posesivos}(m i, t u, s u \ldots)$;

- preposiciones (a, ante, bajo, con, contra...);

- verbos auxiliares (ser, estar, haber...);

- conjunciones (y, o, pero, aunque...).

Uno de los rasgos fundamentales de la competencia léxica es su capacidad de poder establecer relaciones entre las palabras. A estas características hay que añadir que la competencia léxica es distinta en cada persona en función de la edad, sexo, desarrollo cognitivo, y experiencia del mundo. Por último, como ya señalaba Vygotsky (1962) en relación a la lengua materna, la competencia léxica es dinámica en tanto que existe una reconstrucción continua del conocimiento. Cada vez que aprendemos una nueva palabra, o cada vez que aprendemos un nuevo significado de una palabra, no lo hacemos desde el vacío sino apoyándonos en nuestro conocimiento previo, de tal modo que no solo aprendemos nuevas palabras o nuevos significados de palabras ya conocidas sino que además, nuestro conocimiento de otras palabras también se reconstruye.

\subsubsection{Competencia gramatical}

La competencia gramatical se puede definir como el conocimiento de los recursos gramaticales de una lengua y la capacidad de utilizarlos.

Como explica Sánchez Pérez (1992), en la historia de las diversas metodologías del aprendizaje de lenguas extranjeras, la relación entre conocer una lengua y conocer la gramática de la lengua siempre fue muy próxima. Hasta los años sesenta y setenta del siglo XX, los estudiantes aprendían reglas gramaticales y listas de vocabulario y aplicaban estos conocimientos en traducciones directas e inversas. En los años setenta, los métodos audio-orales hicieron que el aprendizaje de una lengua se restringiera a utilizar los contenidos lingüístico- 
gramaticales aprendidos en prácticas orales previas. Los ejercicios que se proponía resultaban monótonos, pues consistían en la mera repetición de estructuras lingüísticas.

Con la llegada del enfoque comunicativo, se propuso un gran cambio en la forma de afrontar la gramática en la clase de ELE. De acuerdo con este enfoque, la habilidad de componer oraciones no es suficiente para que haya comunicación. Esta solo tiene lugar cuando se aplican los conocimientos lingüísticos en contexto. No basta con que los estudiantes sepan un conjunto de reglas y estructuras de la lengua extranjera analizadas y organizadas conscientemente en un sistema, necesitan saber cómo funcionan las normas y estructuras gramaticales del español, en una gran variedad de contextos, niveles sociales e incluso ámbitos profesionales, para verificar los diversos usos y funciones del lenguaje.

Gómez y Zanón (1999) señalan que los aprendices elaboran dos tipos de conocimiento gramatical a partir de los datos de entrada que reciben: el conocimiento gramatical explícito y el conocimiento gramatical implícito. Así, la gramática explícita es importante para un aprendiz porque es la encargada de monitorizar y, por lo tanto, puede ser una aliada a la hora de enfrentarse a la fosilización o la interferencia - entre otros problemas que surgen en el proceso de enseñanza/aprendizaje de una lengua extranjera - pero, sin lugar a dudas, cuando el estudiante necesita comunicarse de forma espontánea, recurre a su conocimiento implícito. De este modo, el alumno utiliza ambos conocimientos gramaticales, el explícito y el implícito.

Formalmente, la gramática de una lengua se puede considerar como un conjunto de principios que rigen el ensamblaje de elementos en compendios (oraciones) con significado, clasificados y relacionados entre sí. La competencia gramatical es la capacidad de comprender y expresar significados expresando y reconociendo frases y oraciones bien formadas, de acuerdo con estos principios (como opuesto a su memorización y reproducción en fórmulas fijas). La gramática de cualquier lengua en este sentido es enormemente compleja, y hasta ahora se resiste a un tratamiento concluyente o exhaustivo. Hay varias teorías y modelos en conflicto sobre la organización de palabras en oraciones. El MCER (2002: 110) no valora ni preconiza el uso de ninguna, sino más bien procura que los usuarios manifiesten cuál han decidido adoptar y qué consecuencias tiene esa elección para su práctica. En él se señalan algunos parámetros y categorías que se han utilizado ampliamente en la descripción gramatical. 
La descripción de la organización gramatical supone la especificación de elementos, categorías, clases, estructuras, procesos y relaciones, como puede apreciarse en la siguiente tabla:

Tabla 2

Descripción de la organización gramatical según el MCER (2002)

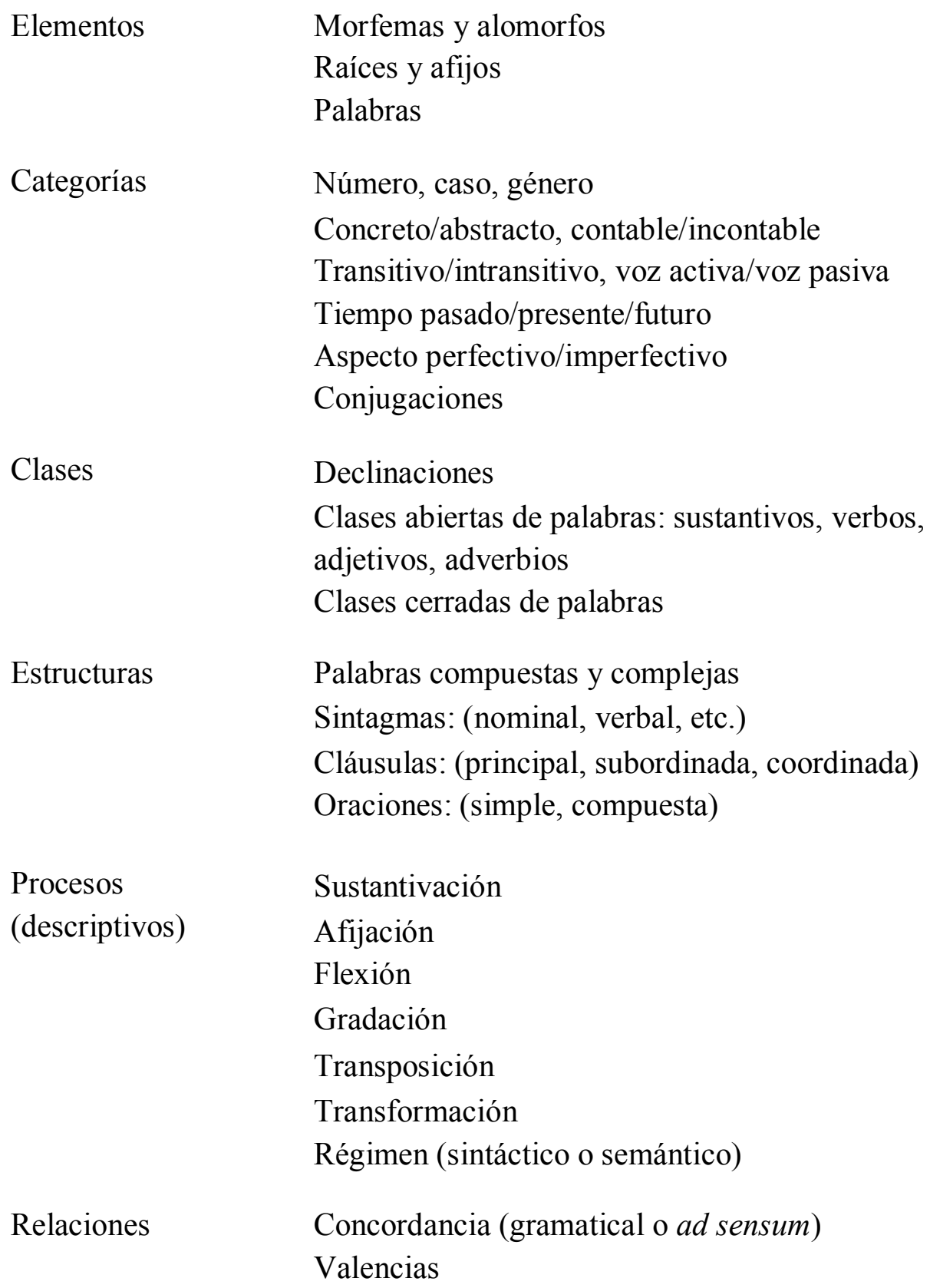

Clases

Declinaciones

Clases abiertas de palabras: sustantivos, verbos, adjetivos, adverbios

Clases cerradas de palabras

Estructuras

Palabras compuestas y complejas

Sintagmas: (nominal, verbal, etc.)

Cláusulas: (principal, subordinada, coordinada)

Oraciones: (simple, compuesta) 
Tradicionalmente, se establece una distinción entre la morfología y la sintaxis:

a) La morfología se ocupa de la organización interna de las palabras. Las palabras se pueden analizar como morfemas, clasificados de la siguiente forma:

- Raíces.

- Afijos (prefijos, sufijos, infijos), que comprenden:

- Afijos de derivación (por ejemplo: re-, -mente, -dad).

- Afijos de flexión (por ejemplo: -aba, -ase).

Formación de palabras:

Las palabras se pueden clasificar en:

- Palabras simples (solo la raíz; por ejemplo: seis, árbol, romper).

- Palabras complejas (raíz + afijos; por ejemplo: irrompible, seises).

- Palabras compuestas y lexías complejas (que contienen más de una palabra; por ejemplo: rompehielos, cascanueces, vestido de noche, cuello de botella).

La morfología también se ocupa de otras maneras de modificar formas de palabras; por ejemplo:

- Alternancia de vocales (dormir/duermo, demostrar/demuestro).

- Modificación de las consonantes (escoger/escojo).

- Formas irregulares (andar/anduve, voy/iba/fui).

- Flexión (tengo/tienes/tiene/tenemos/tenéis/tienen).

- Formas invariables (crisis/crisis, amamos/amamos).

La morfofonología, por su parte, se ocuparía de la variación condicionada fonéticamente de morfemas. Se ocuparía, por lo tanto, de estudiar los casos en los que un mismo morfema se pronuncia de dos maneras diferentes por vulgarismo (como, por ejemplo, el morfema de participio en -ado > -ao: se ha acabao ya), o por ultracorrección (el morfema tras- $>$ trans-: *estaba transtornado). 


\section{EL PROGRAMA TELEVISIVO COMO RECURSO PARA LA \\ ENSEÑANZA/APRENDIZAJE DE ESPAÑOL LENGUA EXTRANJERA}

b) La sintaxis, por su parte, se ocupa de la organización de palabras en forma de oraciones en función de las categorías, los elementos, las clases, las estructuras, los procesos y las relaciones que conlleva, y a menudo se presenta en forma de conjunto de reglas. La sintaxis de la lengua de un hablante nativo y maduro es enormemente compleja y en gran parte inconsciente. La capacidad de organizar oraciones que transmitan sentido es un aspecto fundamental de la competencia comunicativa.

\subsubsection{Competencia semántica}

La competencia semántica comprende la conciencia y el control de la organización del significado con que cuenta el alumno:

La semántica léxica trata asuntos relacionados con el significado de las palabras:

- Relación de las palabras con el contexto general:

- Referencia.

- Connotación.

- Exponencia de nociones específicas generales.

- Relaciones semánticas, como, por ejemplo:

- Sinonimia/antonimia.

- Hiponimia/hiperonimia.

- Régimen semántico.

- Relaciones de la parte por el todo (metonimia).

- Análisis componencial.

- Equivalencia de traducción.

La semántica gramatical trata el significado de los elementos, las categorías, las estructuras y los procesos gramaticales.

La semántica pragmática se ocupa de relaciones lógicas, como, por ejemplo, la vinculación, la presuposición, la implicación, etc. 
Las cuestiones de significado son, naturalmente, fundamentales para la comunicación, y el MCER se ocupa de ellas en diversas ocasiones.

Como se explica en el MCER (2002: 113), la competencia lingüística se trata aquí en un sentido formal. Desde el punto de vista de la lingüística teórica o descriptiva, una lengua es un sistema simbólico enormemente complejo. Cuando, como aquí ocurre, se intentan separar los numerosos y distintos componentes de la competencia comunicativa, resulta legítimo señalar que el conocimiento (en gran parte inconsciente) de las estructuras formales y la capacidad de manejarlas constituye uno de esos componentes. Un asunto distinto es determinar qué cantidad, si acaso, de análisis formal debería introducirse en el aprendizaje o en la enseñanza de idiomas.

El enfoque nocional/funcional adoptado en las publicaciones Waystage (1991), Threshold Level (1991) y Vantage Level (1997), del Consejo de Europa, ofrece una alternativa al tratamiento que de la competencia lingüística se hace en el MCER. En vez de comenzar partiendo de las formas lingüísticas y sus significados, comienza partiendo de una clasificación sistemática de funciones y de nociones comunicativas, divididas en generales y específicas, y de forma secundaria trata las formas, léxicas y gramaticales, como sus exponentes. Los enfoques son formas complementarias de tratar la doble articulación de la lengua. Las lenguas se basan en una organización de la forma y en una organización del significado. Los dos tipos de organización se cruzan entre sí de una forma en gran parte arbitraria. La descripción basada en la organización de las formas de expresión atomiza el significado, y la basada en la organización del significado atomiza la forma. Cuál sea la que el usuario prefiera depende de la finalidad para la que se ha producido la descripción.

El éxito del enfoque de Threshold Level indica que a muchos profesionales les resulta más ventajoso ir del significado a la forma, y no seguir la práctica más tradicional de organizar la progresión en términos puramente formales. Por el contrario, algunos pueden preferir la utilización de una gramática comunicativa, como, por ejemplo, en Un niveau-seuil (1975). Lo que está claro es que el estudiante de lenguas tiene que adquirir tanto las formas como los significados. 


\section{EL PROGRAMA TELEVISIVO COMO RECURSO PARA LA \\ ENSEÑANZA/APRENDIZAJE DE ESPAÑOL LENGUA EXTRANJERA}

\subsubsection{Competencia fonológica}

La competencia fonológica se refiere a la articulación del discurso hablado. Es inherente y consustancial a la comunicación oral $\mathrm{y}$, por tanto, un elemento totalmente relevante en la adquisición y el uso de una lengua. Además, las investigaciones en el campo de la psicolingüística han demostrado que es también relevante para los procesos mismos de aprendizaje. Tal y como recoge Vivian Cook (2001: 86), de acuerdo con la teoría de la memoria operativa, la pronunciación es vital para procesar y aprender una lengua. La incapacidad de pronunciar los sonidos rápidamente limita la memoria a corto plazo $\mathrm{y}$, en consecuencia, crea dificultades para procesar y almacenar la lengua en la memoria a largo plazo. Además, prosigue, la falta de énfasis en la pronunciación en la enseñanza de la lengua pone trabas al aprendizaje del estudiante.

La competencia fonológica supone el conocimiento y la destreza en la percepción y la producción de:

- Las unidades de sonido (fonemas) de la lengua y su realización en contextos concretos (alófonos).

- Los rasgos fonéticos que distinguen fonemas (rasgos distintivos; por ejemplo: sonoridad, nasalidad, oclusión, labialidad).

- La composición fonética de las palabras (estructura silábica, la secuencia acentual de las palabras, etc.).

- Fonética de las oraciones (prosodia):

- Acento y ritmo de las oraciones.

- Entonación.

- Reducción fonética:

- Reducción vocal.

- Formas fuertes y débiles.

- Asimilación.

- Elisión.

Conviene señalar que el objetivo último no es, necesariamente, la consecución de una pronunciación igual o semejante a la de un hablante nativo, sino una que permita en todo momento la inteligibilidad y una comunicación fluida. El 
objetivo es alcanzar el umbral de inteligibilidad, un requisito mínimo e indispensable. Para alcanzar dicho objetivo, sí es imprescindible dedicar atención a esta competencia mediante actividades y herramientas adecuadas. Asumir que la pronunciación no es importante equivale a asumir que la comunicación oral tampoco lo es.

A pesar de su relevancia, ha recibido una atención fluctuante y desigual en los diversos métodos de enseñanza. La obra de Celce-Murcia ${ }^{31}$ (1996) ofrece una síntesis sobre esta cuestión.

\subsubsection{La competencia ortográfica}

Como explica el MCER (2002: 114-115), la competencia ortográfica supone el conocimiento y la destreza en la percepción y la producción de los símbolos de que se componen los textos escritos. Los sistemas de escritura de todas las lenguas europeas se basan en el principio alfabético, aunque los de algunas otras lenguas siguen el principio ideográfico (por ejemplo, el chino) o el principio consonántico (por ejemplo, el árabe). Para los sistemas alfabéticos, los alumnos deben saber y ser capaces de percibir y producir lo siguiente:

- Las formas de las letras en sus modalidades normal y cursiva, tanto mayúsculas como minúsculas.

- La correcta ortografía de las palabras, incluidas las formas de contracción aceptadas.

- Los signos de puntuación y sus normas de uso.

- Las convenciones tipográficas y las variedades de tipos de letra, etc.

- Los signos no alfabetizables de uso común (por ejemplo: @, \&, \$, etc.).

Algunos autores consideran que la ortografía es un aspecto complejo dentro de la didáctica de la lengua, que tradicionalmente se ha abordado de forma marginal en la programación de la clase de ELE, desplazado quizá por la abundancia de temas prioritarios en otros niveles del aprendizaje de la lengua. Esto es motivado, en parte, a que otros errores prioritarios para la comunicación

\footnotetext{
31 Celce-Murcia, M.; Brinton, D. y Goodwin, J. (1996). "The History and Scope of Pronunciation Teaching". Teaching Pronunciation: A Reference for Teachers of English to Speakers of other Languages, pp. 2-13. Cambridge: CUP.
} 


\section{EL PROGRAMA TELEVISIVO COMO RECURSO PARA LA \\ ENSEÑANZA/APRENDIZAJE DE ESPAÑOL LENGUA EXTRANJERA}

pueden causar mayores malentendidos que la ortografía.

No hay que olvidar que el correcto uso de la ortografía en la lengua que se está aprendiendo es tan importante como en la lengua propia. Por ello, lo mejor es explicar las repercusiones semánticas, significativas y expresivas que su uso implica para la pronunciación, la entonación y la comunicación. Resulta imprescindible que los conocimientos ortográficos se integren en el aprendizaje de un modo global para que resulten significativos y relevantes.

\subsubsection{Competencia ortoépica}

La competencia ortoépica comprende tanto el conocimiento de los nombres de las grafías, necesario para el deletreo, como el correcto establecimiento de correspondencias entre grafías y sonidos.

Por lo que respecta al primero, y aunque pueda parecer una cuestión banal, saber cómo deletrear es imprescindible para evitar ambigüedades y conseguir una comunicación efectiva. Pensemos, por ejemplo, en un intercambio de información ante un órgano administrativo donde al hablante no nativo se le pida que deletree alguno de sus datos personales; o en una conversación telefónica, en el transcurso de la cual sea necesario deletrear algún dato.

Con respecto a las correspondencias entre grafías y sonidos, en comparación con otras lenguas que disponen también de sistemas de escritura alfabéticos, como el inglés o el francés por ejemplo, el español presenta una frecuencia más alta de univocidad. No obstante, ello no significa que tenga una ortografía fonética, ya que no todas las correspondencias son unívocas.

Como es sabido, hay casos en que una sola grafía se corresponde con más de un sonido. Por ejemplo, la grafía $g$ representa dos fonemas: $/ \mathrm{x} /$ cuando va seguida de /e, i/ y $g$ cuando va seguida de /a, o, u/. Del mismo modo, la grafía $c$ representa dos fonemas en algunas variedades del español: $\theta$ / cuando va seguida de /e, i/ y / $/$ / cuando va seguida de /a, o, u/. A la inversa, un mismo sonido puede estar representado por diversas grafías. Tal es el caso del fonema / $\theta$ / (que existe en algunas variedades), representado por las grafías $c$ y $z$. El fonema $/ \mathrm{k} /$ está representado por $c, k$ y por el dígrafo $q u$. El fonema $/ \mathrm{b} /$ está representado por las grafías $b$ y $v$. Además, existen los dígrafos, como $g u$ y el ya mencionado $q u$; la grafía $h$, que no corresponde a ningún sonido; y las grafías que 
representan diptongos. Todos estos casos sí requieren atención explícita en el proceso de enseñanza-aprendizaje. Además, tanto los nombres de las grafías como las reglas ortoépicas de la primera lengua u otras de los aprendices pueden interferir con las del español.

Como expone el MCER (2002: 115), los usuarios a los que se les pide que lean en alto un texto preparado o que utilicen en el habla palabras que han aprendido en su forma escrita necesitan saber articular una pronunciación correcta partiendo de la forma escrita. Esto puede suponer lo siguiente:

- El conocimiento de las convenciones ortográficas.

- La capacidad de consultar un diccionario y el conocimiento de las convenciones utilizadas en los diccionarios para la representación de la pronunciación.

- El conocimiento de la repercusión que las formas escritas, sobre todo, los signos de puntuación, tienen en la expresión y en la entonación.

- La capacidad de resolver la ambigüedad (palabras homónimas, ambigüedades sintácticas, etc.) en función del contexto.

La relevancia de esta competencia queda avalada no solo por las exigencias estrictamente pragmáticas del aula y de la comunicación cotidiana, sino también por estudios empíricos en el campo de la psicolingüística. Por ejemplo, tal y como muestran Ellis y Beaton (1993), para aprender vocabulario activamente (productive learning), decir las palabras en voz alta conduce a un aprendizaje más rápido y con un índice más alto de retención que la repetición silenciosa. Según los resultados de diversos estudios empíricos mencionados por estos autores, aprender la pronunciación de las palabras de una lengua extranjera constituye tanto una cuestión de habilidad motriz como de memoria auditiva y es imposible memorizar palabras sin haberlas articulado. De ello se deriva la importancia de conocer la correcta correspondencia grafía-sonido, ya que, en caso de que el estudiante aprenda una nueva palabra a partir de su forma escrita, el conocimiento de las reglas ortoépicas es el que posibilitará una efectiva y correcta memorización de la misma.

A pesar de ello, entre los profesores y los diseñadores de materiales didácticos existe el riesgo de que prevalezca la asunción de que el alumno captará fácilmente estas normas de forma implícita. Ello lleva a descuidar, e incluso a no tratar dichas reglas en el aula, o en los materiales didácticos, o en ambos. 


\subsection{La competencia sociolingüística}

Como indica Sánchez Sarmiento (2005: 588), algunos autores prefieren dejar el término Pragmática para designar una de las ciencias del lenguaje que se propone estudiar la lengua como acción social (Balboni, 1999: 77) y reservar el término de competencia sociopragmática para la competencia que resulta de la unión de tres componentes que en el plano teórico van separados y que incluye:

- el aspecto pragmático, que se identifica con la capacidad de perseguir los propios fines a través de la comunicación;

- el aspecto sociolingüístico, que identifica la capacidad de elegir la variedad de registro adecuada a la situación comunicativa;

- el aspecto cultural, que hace referencia a la capacidad de interactuar y perseguir los propios fines de manera adecuada según la escena cultural en la que tiene lugar el intercambio comunicativo.

Los patrones sociales y culturales implícitos en la mente de los estudiantes de una lengua extranjera también influyen en la interpretación que hacen de situaciones comunicativas y del lenguaje utilizado en dichas situaciones. Esta distinción ha dado lugar a los conceptos de interferencia pragmalingüística e interferencia sociopragmática (Thomas, 1983; Kasper, 1992). Estas se producen porque los aprendices reconocen tipos de actos de habla, contextos, fórmulas fijas y datos extralingüísticos que les guían en la interpretación, ya que tienen intuiciones sobre el tipo de cultura en la que están y sobre el comportamiento de los miembros de esa sociedad, pero los principios socioculturales y sociolingüísticos de su lengua materna o de otras lenguas siguen influyendo en la producción de enunciados en la lengua extranjera.

Se ha propuesto ampliar esta clasificación añadiendo otros dos tipos de errores causados por interferencia pragmática: los incoativos y los no lingüísticos (Riley, 1989). De los últimos se ocupan los estudios de comunicación no verbal, mientras que los primeros, relacionados con el reconocimiento del valor del discurso y del silencio en cada lengua/cultura, pueden ser estudiados como parte de los errores por transfer sociopragmático. 
A partir de la distinción original de Leech (1983) entre pragmalingüística y sociopragmática, Thomas (1983) estableció la diferencia entre errores o interferencias pragmalingüísticos y errores o interferencias sociopragmáticos.

- Las interferencias pragmalingüísticas se dan cuando hay una transferencia de estrategias de los actos de habla de una lengua a otra, así como de enunciados sintáctica o semánticamente equivalentes, pero cuya fuerza ilocutiva e implicaciones en la comunicación son diferentes. Este tipo de errores afecta especialmente a los aspectos más convencionalizados y más ritualizados de la comunicación interpersonal, que están íntimamente relacionados con la cortesía verbal: saludos, despedidas, felicitaciones, dar las gracias, hacer cumplidos, decir piropos, etc.

- Las interferencias sociopragmáticas no se asocian al uso de fórmulas específicas, sino a la manera en que los miembros de cada cultura conceptualizan la conducta adecuada y las relaciones sociales entre los participantes en la interacción. Las interferencias de este tipo consisten en trasladar de una lengua a otra las percepciones sociales y las expectativas de comportamiento que son propias de otra cultura.

Lo ideal para asimilar los datos culturales y comunicativos de una lengua extranjera es aprenderlos en situaciones de comunicación lingüística, pues dicho proceso se lleva a cabo mucho más rápido. Pero si no es posible, existen otras formas de adquirir la competencia comunicativa y pragmática. Las estrategias más eficaces consisten en exponer al alumno a interacciones reales (vídeos, películas, programas de televisión, obras de teatro, conversaciones e intercambios con hablantes nativos, etc.) el mayor tiempo posible. La labor del profesor en este sentido será ayudar a desarrollar la habilidad de los estudiantes para analizar usos, finalidades e intenciones de sus diferentes actos comunicativos. Como explicaremos más adelante, el programa televisivo es uno de los formatos que mejor permite transmitir a los alumnos de la lengua extranjera estos datos culturales y comunicativos, a falta de una situación de inmersión lingüística.

Como señalan Corral y Fernández (2009: 121-137), lo más apropiado es que el alumno reciba este tipo de información desde el inicio, aunque lo cierto es que uno de los principales problemas en el aula es que las situaciones comunicativas auténticas que surgen se reducen a áreas muy determinadas. Sin embargo, cabe destacar la división que Meyer (1991) realiza de las etapas en la adquisición de la competencia intercultural: 


\section{EL PROGRAMA TELEVISIVO COMO RECURSO PARA LA ENSEÑANZA/APRENDIZAJE DE ESPAÑOL LENGUA EXTRANJERA}

- nivel monocultural: el alumno ve e interpreta según las reglas de su propia cultura, por lo que los tópicos, prejuicios y estereotipos prevalecen;

- nivel intercultural: el conocimiento que se tiene de la cultura extranjera permite comenzar a comparar con la propia y ya se poseen recursos para explicar las diferencias;

- nivel transcultural: el alumno se sitúa ya por encima de ambas culturas y se erige como mediador, gracias a su conocimiento adquirido de los principios fundamentales de cooperación y comunicación.

En este sentido, la enseñanza de la pragmática es fundamental para que nuestros alumnos cambien de estadio y alcancen la competencia intercultural.

Como afirma Kasper, «language teaching therefore has the important task to help students situate L2 communicative practices in their sociocultural context and appreciate their meanings and functions within the L2 community ${ }^{32}$ 》 (Kasper, 1997).

\subsubsection{Los contrastes socioculturales}

Es evidente que existen contrastes socioculturales y pragmáticos entre las diferentes lenguas y culturas. A veces solo somos conscientes de ellos cuando se dan entre culturas o lenguas muy diferentes; sin embargo, existen incluso entre lo que podemos considerar lenguas o culturas cercanas. Tomaremos como ejemplo algunos de los contrastes socioculturales y pragmáticos que se pueden apreciar entre las lenguas francesa y española.

El francés, como el español, emplea dos formas de tratamiento diferentes: una informal y familiar (tú) y otra formal y de distancia (usted). El tipo de relación determina la distancia lingüística que se establece entre los interlocutores, y que se manifiesta, entre otras cosas, en la elección de fórmulas de tratamiento.

Como señala Escandell (2004: 179-198), conocer las condiciones de uso de las diferentes formas es una necesidad fundamental para los alumnos que provienen de lenguas en las que tal distinción no existe, pero esta tarea a veces

\footnotetext{
32 La enseñanza de lenguas tiene, por tanto, la importante tarea de ayudar a los estudiantes a situar las prácticas comunicativas de la L2 en su contexto sociocultural y a apreciar sus significados y funciones dentro de la comunidad de la L2 (Traducción propia).
} 
resulta aún más difícil para los alumnos en cuya lengua hay también dos formas parecidas a las nuestras, ya que las condiciones según las cuales se establece el uso de una u otra forma varían de una sociedad a otra.

En España, el tuteo se permite más que en Francia; por ejemplo, en Francia es obligatorio tratar de usted a los profesores y dirigirse a ellos como Monsieur y Madame $^{33}$ seguido de su apellido. Sin embargo, en España, a no ser que el profesor especifique lo contrario, se permite tanto el tuteo al profesor como dirigirse a él por su nombre, sin resultar esto un comportamiento irrespetuoso.

Por otro lado, en España, lo normal es saludar con un hola cuando, por ejemplo, entramos en una tienda o establecimiento público, tanto el cliente como el dependiente. Sin embargo, en Francia, el equivalente de hola es salut y esta fórmula solo se utiliza para saludar a personas muy cercanas, como amigos o familiares. Lo mismo ocurre con la fórmula de despedida hasta luego. En España no se considera descortés, mientras que en Francia su equivalente es à tout à l'heure y solo debe ser utilizada en un contexto muy familiar. Lo correcto en este país en un contexto no familiar sería despedirse siempre diciendo au revoir, en español adiós.

También encontramos diferencias entre ambas culturas en cuanto a cierta forma de saludar que implica contacto físico: el beso en la mejilla. Por un lado, en España se da un beso primero en la mejilla derecha y después en la mejilla izquierda, mientras que en Francia se comienza por el lado contrario. Además, hay que saber que este gesto es muy común en Francia entre dos hombres que tienen una relación cercana, no necesariamente amorosa, mientras que en España no está tan socialmente aceptado y puede ser considerado como un comportamiento homosexual. Para evitar malentendidos, en este país el saludo más adecuado entre dos hombres sería el apretón de manos.

Por todo esto, «no basta con que los profesores de segundas lenguas o lenguas extranjeras enseñen las formas, sino que se hace necesario especificar los parámetros de acuerdo a los cuales se decide qué forma usar» (Escandell, 2004: 179-198).

\subsubsection{Los marcadores lingüísticos de relaciones sociales}

\footnotetext{
${ }^{33}$ Señor y Señora.
} 


\section{EL PROGRAMA TELEVISIVO COMO RECURSO PARA LA ENSEÑANZA/APRENDIZAJE DE ESPAÑOL LENGUA EXTRANJERA}

Los asuntos tratados en el apartado de competencia sociolingüística del MCER (2002: 116) — que como venimos defendiendo, también deberían ser trabajados en la clase de ELE - son los que se relacionan específicamente con el uso de la lengua y que no se abordan en otra parte: los marcadores lingüísticos de relaciones sociales, las normas de cortesía, las expresiones de sabiduría popular, las diferencias de registro, el dialecto y el acento.

Aunque reciben un tratamiento separado en el MCER, los marcadores de relaciones se inscriben también en el ámbito de la cortesía. Sin embargo, siguiendo la división propuesta por el MCER, esta será tratada en el apartado siguiente, así como en la sección dedicada a la competencia pragmática.

Por lo que respecta a los marcadores lingüísticos, naturalmente, estos difieren ampliamente según las distintas lenguas y culturas, dependiendo de factores tales como: el estatus relativo, la cercanía de la relación, el registro del discurso, etc.

\section{Tabla 3}

Tipos de marcadores discursivos según el MECR (2002)
Uso y elección del saludo Al llegar a un sitio; por ejemplo: hola, buenos días...
Presentaciones; por ejemplo: encantado, ¿cómo estás?...
Despedidas; por ejemplo: adiós, hasta luego, hasta mañana...

Uso y elección de formas de tratamiento

Convenciones para los
Solemne; por ejemplo: usía, su ilustrísima...

Formal; por ejemplo: señor, señora, señorita + apellido, doctor, profesor + apellido.

Informal; por ejemplo: Juan, Susana, solo el nombre de pila, sin forma de tratamiento.

Familiar; por ejemplo: cariño, amor, mi vida.

Perentorio; por ejemplo: solo el apellido, como:

¡Sánchez, tú, aqui!

Insulto ritual; por ejemplo: idiota, tonto (a menudo, de forma cariñosa).

La alternancia de los turnos de habla, las 
turnos de palabra reformulaciones y el valor de los solapamientos o interrupciones en la conversación.

Actos iniciativos; por ejemplo: preguntas, solicitudes, mandatos e informaciones (relatos, juicios, actos expresivos).

Actos reactivos; por ejemplo: respuestas, asentimientos o rechazos.

Uso y elección de interjecciones y frases interjectivas
Por ejemplo, ¡Dios mío!, ;Venga ya!, ¡Hayque ver!...

Datos obtenidos del MECR (2002)

\subsubsection{Las normas de cortesía}

Como acabamos de comentar, tanto la competencia sociolingüística como la competencia pragmática tratan el tema de la cortesía, por lo que más adelante, en el apartado de Competencia Pragmática, volveremos a hacer referencia a este concepto.

Por cortesía solemos entender el conjunto de normas que regulan el trato social de los miembros de una sociedad determinando los comportamientos adecuados y sancionando las conductas inadecuadas.

Generalmente se entiende la cortesía verbal como el conjunto de mecanismos o habilidades lingüísticas al servicio de las relaciones sociales. Su finalidad no es garantizar una mejor transmisión de la información, sino regular el comportamiento de los interlocutores en la conversación, suavizando o salvando posibles conflictos de interés y permitiendo una relación basada en la cordialidad y la cooperación mutuas.

La cortesía de los enunciados se rige por ciertas reglas que los lingüistas formulan como normas o máximas. Las de ámbito más general fueron propuestas por Lakoff (1973), quien define ser cortés en las siguientes máximas: 


\section{EL PROGRAMA TELEVISIVO COMO RECURSO PARA LA ENSEÑANZA/APRENDIZAJE DE ESPAÑOL LENGUA EXTRANJERA}

1) «No impongas tu voluntad al interlocutor»; lo que hace preferible el enunciado iQué bien si pudieras llevarme en coche! al más imperativo ¡Llévame en coche!

2) «Ofrécele opciones»: esta máxima halla su mejor expresión en enunciados disyuntivos como Vamos a trabajar, ¿o prefieres quedarte?

3) «Sé amable; procura que tu interlocutor se sienta cómodo»: ¡Hombre, don Antonio! De paseito, ¿eh? ¿Qué periódico nos compramos hoy?

Las máximas (1) y (2) se aplican fundamentalmente en contextos exhortativos, y persiguen la formulación del mandato como si se tratara de un ruego. Con ello le damos a entender a nuestro interlocutor, sobre el que pretendemos actuar para que realice una acción en nuestro beneficio, que somos conscientes de que invadimos su ámbito intencional y que deseamos suavizar el mandato. Evitamos con ello que se sienta comprometido y amenazado en su libertad de acción. Representan la cortesía negativa.

La aplicación de la máxima (3) abarca actos verbales más variados que las anteriores. Aspira a crear en nuestro interlocutor la impresión de que es una persona respetada y apreciada por el hablante, cultivando y fortaleciendo los lazos que nos unen a él. Representa la cortesía positiva.

Según el tipo de acto verbal, estas estrategias pueden ser matizadas y desarrolladas por otras de ámbito más específico. Así, los actos de petición y comisivos (prometer) se asocian con las máximas de:

- Tacto: «supón que eres tú el que solicitas algo y tu interlocutor quien debe conceder la autorización».

- Generosidad: «minimiza tu beneficio y maximiza el de tu interlocutor».

Con los actos expresivos (agradecer, felicitar, etc.) y asertivos se suelen asociar las de:

- Aprobación: «minimiza el desprecio hacia el interlocutor, pero maximiza el aprecio».

- Modestia: «minimiza el aprecio hacia ti mismo y maximiza el aprecio hacia el otro»».

- Unanimidad: «minimiza el desacuerdo con el otro, pero maximiza el acuerdo». 
- Simpatía: «minimiza la antipatía y maximiza la simpatía».

Las normas de cortesía proporcionan una de las razones más importantes para alejarse de la aplicación literal del principio de cooperación (principio general que guía a los interlocutores en la conversación). Varían de una cultura a otra y son una fuente habitual de malentendidos interétnicos, sobre todo, cuando las normas de cortesía se interpretan literalmente (MCER, 2002: 116-117). En la siguiente tabla podemos ver ejemplos de cortesía positiva, cortesía negativa y descortesía.

Tabla 4

Ejemplos de cortesía positiva, cortesía negativa y descortesía según el MCER (2002)

Cortesía positiva

Uso apropiado de por favor, gracias, etc.

Mostrar interés por el bienestar de una persona, etc.

Compartir experiencias y preocupaciones, «charlar sobre problemas», etc.

Expresar admiración, afecto, gratitud, etc.

Ofrecer regalos, prometer futuros favores, hospitalidad, etc.

Cortesía negativa Evitar el comportamiento amenazante (dogmatismo, órdenes directas, etc.).

Expresar arrepentimiento, disculparse por comportamiento amenazante (corrección, contradicción, prohibiciones, etc.).

Utilizar enunciados evasivos, etc. (por ejemplo: «Creo que...», preguntas cortas de confirmación, etc.).

Descortesía

Brusquedad, franqueza.

(incumplimiento

Expresión de desprecio, antipatía.

deliberado de las

Queja fuerte y reprimenda.

normas de cortesía)

Descarga de ira, impaciencia.

Afirmación de la superioridad.

Datos obtenidos del MCER (2002) 


\section{EL PROGRAMA TELEVISIVO COMO RECURSO PARA LA ENSEÑANZA/APRENDIZAJE DE ESPAÑOL LENGUA EXTRANJERA}

\subsubsection{Las expresiones de sabiduría popular}

El MCER (2002: 117) llama expresiones de sabiduría popular a lo que también podría llamarse unidades fraseológicas, ya que se refiere a fórmulas o combinaciones de palabras estables o fijas (Penadés, 1999). Se trata, por tanto, de expresiones metalingüísticas en las que la comunicación social práctica se convierte en objeto de interacciones comunicativas. Son actos de habla que no solo constituyen un tipo de acto, sino que además lo describen. Entre estas unidades pueden incluirse las paremias, efectivamente, a las que se presta especial atención, pero también los modismos y otros giros.

Estas fórmulas fijas - que incorporan a la vez que refuerzan actitudes comunes - contribuyen de forma significativa a la cultura popular. Se utilizan a menudo, por ejemplo, en los titulares de los periódicos. El conocimiento de esta sabiduría popular acumulada, expresado en un lenguaje que se supone conocido, es un componente importante del aspecto lingüístico de la competencia sociocultural.

- Refranes; por ejemplo: No por mucho madrugar amanece más temprano.

- Modismos; por ejemplo: A troche y moche, A la pata la llana.

- Comillas coloquiales; por ejemplo: To' $p a^{\prime}$ na', Me voy pa' casa.

- Expresiones de:

- Creencias como, por ejemplo, refranes sobre el tiempo atmosférico: En abril, aguas mil.

- Actitudes como, por ejemplo, frases estereotipadas del tipo: De todo hay en la viña del Señor.

- Valores como, por ejemplo: Eso no es juego limpio.

Los graffiti, los lemas de las camisetas, las frases con gancho de la televisión como veremos más adelante en esta tesis-, las tarjetas y los carteles de los lugares de trabajo a menudo tienen ahora esa función.

Hasta hace poco la enseñanza de la fraseología se limitaba a la presentación de listas de expresiones elaboradas sin criterios claros de ordenación que el alumno debía memorizar no con poco esfuerzo. En la última década, el número de publicaciones referidas a la enseñanza de la fraseología española en clase de 
ELE se ha incrementado considerablemente. Algunos de los últimos trabajos publicados (García-Page Sánchez, 2008; Leal Riol, 2013), además, empiezan a contemplar las directrices generales referentes a la fraseología recogidas en el MCER (2002) y el Plan Curricular del Instituto Cervantes (2006).

La enseñanza de fraseología en clase de ELE resulta un interesante punto de encuentro de las distintas competencias comunicativas: así, en primer lugar, los fraseologismos, - $-\mathrm{y}$ esencialmente las locuciones - son considerados como un subcomponente del nivel léxico (tal como se explicita en MCER: 108-109) por lo que si, en palabras de Gómez Molina (2000: 112):

\footnotetext{
procuramos la enseñanza-aprendizaje de estas unidades pluriverbales como un aspecto más en el desarrollo de la competencia comunicativa del aprendiz, [...] el dominio léxico se ejercita en los cuatro componentes de la competencia comunicativa y de forma integrada en cada una de las áreas concretas de conocimiento y capacidad.
}

Además, el estudio de tales fraseologismos y, sobre todo, de las relaciones semánticas que se puedan manifestar entre ellos y otras clases de palabras (Penadés, 2000), quedaría estrechamente relacionado con el desarrollo de la competencia semántica. En segundo lugar, la mayoría de los fraseologismos $\mathrm{y}$ especialmente las fórmulas rutinarias y las locuciones que actúan como marcadores discursivos - conllevan determinados significados connotativos (Corpas Pastor, 1996: 125-131) y valores pragmáticos (Ruiz Gurillo, 2001: 6588; García-Page Sánchez, 2008: 433-451) cuyo trabajo en clase ejercitaría también las competencias sociolingüística y pragmática del aprendiz. En tercer lugar, este tipo de conocimiento popular acumulado (MCER: 117) resulta un fiel reflejo de la sociedad y de los aspectos socioculturales y económicos de esta, al tratarse de combinaciones pluriverbales capaces de condensar la forma de vivir y sentir la vida de un pueblo, su organización social y laboral, su cultura y pautas de conducta, tanto individual como social (Olaeta Rubio, 1997: 454), por lo que a través de los fraseologismos se pueden trabajar contenidos culturales, y se desarrolla la competencia sociocultural del aprendiz.

El objetivo del proceso de enseñanza-aprendizaje de unidades fraseológicas en el aula de español se ha de contemplar, siguiendo a Gómez Molina (2000: 112), como un aspecto más en el desarrollo de la competencia comunicativa del alumno, de manera que la finalidad última de dicho proceso ha de ser que el alumno emplee los fraselogismos aprendidos «de la misma manera que lo haría un hablante nativo que está aprendiendo a usarlas por primera vez, es decir, experimentando cómo funcionan y deducir las reglas por las que se rigen» (Gómez Molina, 2000: 120). Del mismo modo, como afirma González Rey 


\section{EL PROGRAMA TELEVISIVO COMO RECURSO PARA LA \\ ENSEÑANZA/APRENDIZAJE DE ESPAÑOL LENGUA EXTRANJERA}

(2006: 124), el empleo efectivo de las unidades fraseológicas es una competencia verdaderamente activa, pues la comunicación efectiva con los hablantes nativos de una lengua se fundamenta precisamente en el dominio de la fraseología de esta, que el alumno necesitará emplear en el uso cotidiano de la L2.

En la actualidad, existe un consenso en cuanto a la necesidad de hacer una selección de unidades fraseológicas con fines didácticos. Ningún hablante nativo domina la totalidad del corpus fraseológico de su lengua, pero no por ello se siente limitado al comunicarse. Por una parte, su competencia fraseológica se va ampliando conforme lo exigen sus necesidades e intereses y, por otra, dispone de recursos lingüísticos y extralingǘsticos suficientes para compensar esa carencia idiomática. El objetivo en la clase de ELE debe ser que el alumno aprenda solo algunas unidades fraseológicas: aquellas que tienen un eco en su propia lengua, así como otras que no lo tienen pero presentan una gran transparencia de imagen o una base metafórica muy clara; también aquellas que cumplen las funciones comunicativas más frecuentes; finalmente, las que, por la edad e intereses de los aprendices, motiven su aprendizaje y actualización dentro y fuera del aula (Leal Riol, 2013).

\subsubsection{Diferencias de registro}

Como se explica en el Diccionario de términos clave de ELE del CVC (19972018), la noción de registro se entiende como el uso lingüístico determinado por el contexto inmediato de producción de un discurso. El registro se considera una variedad lingüística funcional - también denominada variedad diafásicacondicionada por cuatro factores contextuales fundamentalmente: el medio de comunicación (oral o escrito), el tema abordado, los participantes y la intención comunicativa. La forma de expresión lingüística - cuidada o informal, general o específica, etc. - que escoge el hablante responde a cada uno de estos factores. Como veremos más adelante, todos estos rasgos se pueden apreciar, comparar y analizar mediante el visionado de diferentes formatos televisivos, por ejemplo, en un programa informativo predominará el registro formal, mientras que en un programa de entretenimiento lo hará el informal.

La teoría del registro incorpora el contexto al estudio de la lengua. Fue formulada por la sociolingüística y la lingüística sistémico-funcional anglosajona en los años 60 del siglo XX. Halliday, McIntosh y Strevens (1964) 
plantean en primer lugar estas relaciones entre uso de la lengua y situación extralingüística, perspectiva reformulada posteriormente en trabajos como el de Gregory y Carroll (1978). En español, la teoría de la variación situacional ha sido aplicada por diversos lingüistas especialmente al análisis del registro coloquial de la lengua y al estudio de los lenguajes de especialidad.

Según Halliday (1978), la lengua se adecua a la situación en función de tres categorías o parámetros contextuales:

1. El campo, en el sentido tanto del marco social en que se desarrollan las prácticas comunicativas (juzgado, casa familiar, administración, hospital, iglesia, etc.) como en el sentido del tema tratado (derecho, ciencia, venta de un producto, religión, etc.). El campo determina el grado de especificidad de un texto, estableciendo una gradación desde textos técnicos o de especialidad a textos más corrientes.

2. El modo, entendido como el medio o canal escogido para la comunicación (oral, escrito, audiovisual, comunicación mediatizada por ordenador, dialogado o monologado, etc.). En cada medio se fijan unas prácticas discursivas o géneros discursivos que toman unos rasgos característicos debidos a su función social. Este factor determina el grado de planificación y espontaneidad de un discurso.

3. El tenor, como factor de la situación relacionado con los interlocutores y con la función perseguida en la comunicación:

El denominado tenor interpersonal o tono determina el grado de formalidad de los textos (solemne, neutral, informal, íntimo, etc.), las formas de tratamiento escogidas (corteses o no), y las marcas de subjetividad $\mathrm{u}$ objetividad. La identidad social de los participantes en la comunicación, su estatus y el tipo de relación que mantienen (de jerarquía o solidaridad) son rasgos decisivos en la configuración del registro escogido en un texto.

El tenor funcional remite a la forma en la que la función comunicativa influye en la expresión de los textos. Los propósitos estéticos, por ejemplo, identifican los registros literarios, diferenciándolos del resto. Las instrucciones de uso de un electrodoméstico tienen un tenor funcional explicativo y descriptivo, pero la publicidad que se haga de él seguramente escogerá un tenor persuasivo.

Estos tres factores o parámetros de la situación de comunicación influyen en la forma final del mensaje: en el tipo de pronunciación escogida (más o menos 


\section{EL PROGRAMA TELEVISIVO COMO RECURSO PARA LA \\ ENSEÑANZA/APRENDIZAJE DE ESPAÑOL LENGUA EXTRANJERA}

relajada, más o menos cuidada), en el léxico seleccionado (más formal o coloquial, más general o especializado), en la combinación de las palabras en patrones sintácticos fijados o más libres, en la preferencia por un estilo sintáctico determinado (nominal o verbal), en la organización de los contenidos en el discurso (según una superestructura preestablecida o no, orientada hacia la narración o la argumentación, etc.), en las convenciones para los turnos de habla o en el uso de elementos paralingüísticos (la entonación, los gestos, la gestión del espacio en el discurso oral; el formato elegido, el requerimiento de recursos visuales o no, por ejemplo, en el escrito). El concepto de registro, pues, da cuenta de las posibilidades que ofrece el uso de la lengua, de su especificidad, formalidad y planificación. El hablante competente sabe elegir, en los distintos planos de la lengua y del discurso, las expresiones lingüísticas más apropiadas para cada situación (CVC, 1997-2018).

En el Diccionario del CVC (1997-2018) se precisa que los registros no constituyen entidades con fronteras claras, sino que dependen del mayor o menor grado de presencia de rasgos singulares; así pues, entre los extremos (de formalidad, de especialidad, etc.) se sitúan registros lingüísticos intermedios entre lo oral y lo escrito, entre lo formal y lo informal, entre lo general y lo especializado. Además, si bien el uso de la lengua viene determinado por el contexto, a su vez el uso lingüístico tiene capacidad para configurar una singular situación de comunicación; esto es, la elección de un registro por parte del hablante puede crear un contexto intencionado: una relación particular con el destinatario (de cercanía o lejanía), una perspectiva concreta (de especialidad o más corriente), un marco de interacción ajustado a sus intereses, etc. Este aspecto pone en cuestión la correspondencia entre variables contextuales y variables lingüísticas; por otro lado, un mismo hablante, en la misma situación, puede recurrir a rasgos asociados a distintos registros para conseguir determinados efectos.

En didáctica de las lenguas el fin último de la enseñanza-aprendizaje de los registros es que los alumnos adquieran la competencia sociolingǘstica, para tomar conciencia de la diversidad funcional de la lengua y saber modular el mensaje según las circunstancias. Disponer de competencia sociolingüística significa ser capaz de poder elegir — según el asunto, la audiencia, el medio, el objetivo- entre distintas palabras, entre un repertorio amplio de construcciones sintácticas, entre varias formas de pronunciación, entre distintos géneros discursivos de un mismo ámbito de comunicación, etc. Saber adaptarse lingüísticamente a cada situación (cotidiana, académica, profesional) contribuye al éxito comunicativo (CVC, 1997-2018). 
En lo que se refiere a los registros, el MCER, aun ajustándose a la definición de Halliday (1982) (variedades según el uso), los interpreta desde las diferencias en el nivel de formalidad y se limita a proponer una pequeña clasificación de doce registros, que a continuación incluimos. Este es un concepto amplio del que se destacan dos aspectos: los hablantes de una lengua extranjera han de acceder a un registro que les permita una comunicación adecuada socialmente, y deben poner especial atención en el manejo de elementos lingüísticos que se relacionen con los registros más formales y con los más familiares, pues su uso inadecuado puede afectar a la eficacia de la comunicación.

La clasificación propuesta en el MCER en cuanto a las diferencias en el nivel de formalidad es la siguiente:

- Solemne, por ejemplo: Hace entrega del premio Su Alteza Real, las Princesa de Asturias.

- Formal, por ejemplo: ¡Orden en la sala, por favor! Tiene la palabra el fiscal.

- Neutral, por ejemplo: ¿Podemos comenzar?

- Informal, por ejemplo: ¡Venga! ¿Empezamos ya, o qué?

- Familiar, por ejemplo: ;Vale! Al grano.

- Íntimo, por ejemplo: ¿Ya, cariño?

De acuerdo con el MCER (2002: 117), en el aprendizaje temprano (hasta el nivel B1), lo apropiado es un registro relativamente neutral, a menos que haya alguna razón que justifique lo contrario. Es este registro el que los hablantes nativos probablemente utilicen con extranjeros y desconocidos, y el que esperan de ellos. Es probable que se adquiera un conocimiento de registros más formales o más corrientes con el paso del tiempo, quizá mediante la lectura de distintos tipos de texto, sobre todo, novelas, al principio como una competencia de comprensión. Se debe tener cierta precaución al utilizar registros más formales o más corrientes, ya que su uso inapropiado puede provocar una interpretación errónea y, en su caso, el ridículo.

\subsubsection{Los dialectos y acentos}

La competencia sociolingüística también comprende la capacidad de reconocer 


\section{EL PROGRAMA TELEVISIVO COMO RECURSO PARA LA \\ ENSEÑANZA/APRENDIZAJE DE ESPAÑOL LENGUA EXTRANJERA}

marcadores lingüísticos relativos a la procedencia geográfica, la extracción social, la etnia de origen o los grupos sociales a los que los hablantes pertenecen.

Dichos marcadores comprenden:

- Léxico; por ejemplo: la palabra «miaja» (de «migaja») se utiliza en determinadas zonas de España para significar una parte muy pequeña de algo.

- Gramática; por ejemplo: la expresión jergal «currarse algo» para significar que se ha puesto mucho empeño en la ejecución o resolución de algo.

- Fonología; por ejemplo: la voz andaluza «quillo», por «chiquillo».

- Características vocales (ritmo, volumen, etc.).

- Paralingüística. De acuerdo con Cesteros (1991) - que no se aleja demasiado de la clasificación de Poyatos (1994)— aquí se incluyen:

1. Las cualidades y los modificadores fónicos. El tono, el timbre, la cantidad y la intensidad, además de ser fonológicamente relevantes en el ámbito estrictamente lingüístico, se consideran elementos paralingüísticos. Son cualidades físicas del sonido y nos pueden indicar el sexo, la edad y determinados estados físicos (un resfriado) o anímicos (nerviosismo) del interlocutor. Igualmente, pueden determinar o matizar la información del enunciado, por ejemplo, dependiendo del tono con que se emita el enunciado «ya han llegado» podemos expresar alegría, sorpresa, desilusión, etc.

2. Los indicadores sonoros de reacciones fisiológicas y emocionales. Algunos de ellos son el llanto, la risa, un suspiro, un grito, un bostezo o el carraspeo de la garganta. Son signos que se emiten de manera consciente o inconsciente y que tienen un gran rendimiento funcional; por ejemplo, la risa puede manifestar alegría y miedo, indicar acuerdo o seguimiento al interlocutor o marcar un suceso anecdótico, entre otras muchas manifestaciones. Poyatos (1994) considera que el jadeo, el hipo, el eructo, el escupir, el estornudo, las flatulencias y el castañeteo de dientes son también diferenciadores paralingüísticos porque sus emisiones tienen un significado y unas repercusiones culturales.

3. Los elementos cuasi-léxicos. Aquí se incluyen las vocalizaciones y las consonantizaciones convencionales. Estos elementos tienen un 
contenido léxico bastante limitado, pero poseen gran valor funcional. Algunos de estos elementos son: la mayoría de las interjecciones y de las onomatopeyas, algunas emisiones sonoras del tipo chistar, roncar o gemir y otros muchos sonidos que se utilizan convencionalmente con valor comunicativo, como por ejemplo, «hm» de asentimiento.

4. Las pausas y silencios. La ausencia de sonido también comunica. Hay que distinguir entre pausa y silencio:

- Las pausas son la ausencia de habla durante un intervalo breve de tiempo comprendido. Su principal función es regular los cambios de turno, pero también pueden presentar distintos tipos de actos comunicativos verbales (una pregunta) o tener carácter reflexivo o fisiológico.

- Los silencios pueden ser la consecuencia de un fallo comunicativo (en situaciones de duda) o de un fallo en los mecanismos que regulan la interacción (cuando no se emite respuesta alguna a una pregunta). Al igual que las pausas, pueden presentar actos comunicativos, enfatizar el contenido de un enunciado o confirmarlo.

Algunos componentes del sistema paralingüístico son comunes en diferentes culturas; sin embargo, existen otros muchos (por ejemplo algunos sonidos onomatopéyicos) que varían de una cultura a otra y que los estudiantes de una lengua extranjera desconocen.

- Lenguaje corporal o cinésica. Según Poyatos (1994) podemos distinguir entre gestos, maneras y posturas.

Ninguna comunidad de lengua europea es totalmente homogénea. Las distintas regiones tienen sus peculiaridades lingüísticas y culturales. Estas peculiaridades suelen estar más marcadas en las personas que viven una vida puramente local, y guardan relación, por tanto, con la clase social, la ocupación y el nivel educativo. El reconocimiento de dichos rasgos dialectales ofrece, pues, claves significativas respecto a las características del interlocutor. Los estereotipos desempeñan un papel importante en este proceso que se puede reducir con el desarrollo de destrezas interculturales. Con el paso del tiempo, los alumnos también entrarán en contacto con hablantes de varias procedencias; antes de que puedan adoptar ellos mismos las formas dialectales, deberían ser conscientes de sus connotaciones sociales y de la necesidad de coherencia y de constancia (MCER, 2002: 118). 


\section{EL PROGRAMA TELEVISIVO COMO RECURSO PARA LA \\ ENSEÑANZA/APRENDIZAJE DE ESPAÑOL LENGUA EXTRANJERA}

Como explica Moreno Fernández (2007: 55-70), también se convierte en crucial la elección del modelo de lengua por parte del profesorado de ELE que, en el caso de lenguas con una geografía tan extensa como la del español, se refleja en preguntas como esta: ¿qué español enseñar? La cuestión es de un interés evidente ya que en la mayoría de los países, no solo hispanos, conviven hispanohablantes de España y de otros países hispánicos, como consecuencia de los movimientos migratorios.

En la extensa geografía del español pueden identificarse al menos ocho grandes variedades cultas de referencia (castellana, andaluza, canaria, caribeña, mexicano-centroamericana, andina, rioplatense y chilena). Cada una de esas áreas tiene fronteras con otras lenguas que hacen que las demandas de enseñanza y aprendizaje de español sean diferentes y que ponen sobre la mesa, de un modo constante, la cuestión del modelo que debe ser la base de la enseñanza. Parece lógico que se trabaje siempre a partir de un modelo de norma culta, pero, dependiendo de las circunstancias, puede tratarse de cualquiera de las ocho variedades citadas.

Esa información es de una enorme utilidad en campos muy distintos, como el de la redacción de materiales de enseñanza o el de la elaboración de los test o exámenes para medir las habilidades lingüísticas de las personas que están adquiriendo una lengua. $\mathrm{Si}$ los especialistas saben cómo es la conducta lingüística normal o correcta en una comunidad lingüística o en un grupo social, estos materiales ganarán en adecuación y realismo.

Como puede imaginarse, la información sobre lo que es normal o correcto dentro de una comunidad depende de las características específicas de cada norma culta, por más que muchas características se compartan. Por debajo de ese nivel de «normalidad», hay formas de hablar que se van alejando del modelo y que suelen entrar, bien en la categoría del dialecto, que es como se interpreta el habla de la gente de otras regiones, bien en la categoría de los «errores», que es como se interpreta el habla de los extranjeros (Preston, 2000). Por eso, los aprendices suelen considerar como demeritorio hablar con «acento extranjero», porque creen que revela su incapacidad para acceder a la lengua «normal».

Sin embargo, como defiende Moreno Fernández (2007: 55-70), «el acento no es un obstáculo para la comunicación ni para la integración, siempre que no sea tan marcado que impida la inteligibilidad». Recordemos que la pauta de lo que es normativo y correcto nos va a venir dada por la información sobre la 
variación geolingüística, sociolingüística y estilística que se haya reunido a propósito de la lengua que se quiere enseñar.

\subsection{La competencia discursiva}

La competencia discursiva consiste en el dominio tanto de géneros discursivos como de secuencias textuales; en la definición de esta competencia destaca la capacidad de dirigir y estructurar el discurso, ordenar las frases en secuencias coherentes y organizar el texto según las convenciones de una comunidad determinada para explicar historias, construir argumentaciones o disponer en párrafos los textos escritos. El MCER (2002: 120) propone cuatro criterios para la evaluación de la competencia discursiva:

- la flexibilidad ante las circunstancias en que se desarrolla la comunicación;

- el manejo de los turnos de palabra (en la interacción oral);

- el desarrollo temático;

- la coherencia y cohesión de los textos (orales y escritos) que produce.

El Diccionario de términos clave de ELE del CVC (1997-2018) denomina géneros a formas de discurso estereotipadas, es decir, que se han fijado por el uso y se repiten con relativa estabilidad en las mismas situaciones comunicativas. Por ello, son formas reconocibles y compartidas por los hablantes, quienes identifican los géneros sobre todo por su formato externo y por el contexto en que se suelen producir; cada género discursivo responde a la necesidad de conseguir de forma satisfactoria una intención comunicativa determinada. Son los géneros discursivos los que distinguen una carta comercial de un sermón, una noticia periodística, una receta, una conferencia, un brindis, un contrato o una entrevista radiofónica, por ejemplo.

Los textos que pertenecen a un mismo género discursivo se han desarrollado históricamente en una comunidad de hablantes, dentro de un ámbito social o profesional, y comparten una misma forma de organizar la información y un mismo conjunto de recursos lingüísticos (registro, fraseología, etc.). El uso de los conocimientos lingüísticos y discursivos típicos de un género es convencional, esto es, está estandarizado y viene establecido por la tradición (CVC, 1997-2018). 


\section{EL PROGRAMA TELEVISIVO COMO RECURSO PARA LA ENSEÑANZA/APRENDIZAJE DE ESPAÑOL LENGUA EXTRANJERA}

La noción de género se remonta a la Antigüedad clásica. La retórica griega establecía, como respuesta a las necesidades de administrar la vida de la ciudad y los conflictos comerciales, tres grandes géneros de discurso: el género deliberativo para la asamblea, el género judicial para el tribunal y el género epidíctico para las ceremonias. En la tradición de la crítica literaria se han elaborado clasificaciones para los textos literarios, atendiendo a criterios diversos: según la composición, la forma y el contenido (se distingue entre poesía, teatro, novela y ensayo); según el modo de concebir la representación de la realidad (géneros románticos, realistas, naturalistas, surrealistas, etc.); o según la organización enunciativa de los textos (géneros fantásticos, autobiográficos, novela histórica, etc.) (CVC, 1997-2018).

En el análisis del discurso y la lingüística del texto se aplica el concepto de género para la descripción de los textos en general, y no solo los literarios. Bajtín (1952-53), desligándose de la tradición literaria, plantea de forma novedosa el estudio de los géneros discursivos en relación con las que él llama esferas de actividad social de cada comunidad de hablantes. Según este lingüista, la riqueza y diversidad de los géneros discursivos es inmensa, porque las posibilidades de la actividad humana son inagotables y en cada ámbito de uso (comercial, científico, familiar, etc.) existe un amplio repertorio de géneros discursivos que se diferencia y crece a medida que se desarrolla y se hace más compleja cada situación de comunicación. En este sentido, Swales (1990) y Adam (1999) han destacado el carácter histórico y cultural de los géneros discursivos: por un lado, los géneros pueden cambiar y desarrollarse para responder a los cambios sociales. Esto explica, por ejemplo, la aparición de géneros nuevos, como los géneros electrónicos: chat, foro de discusión, etc. Por otro lado, en cada cultura, las características discursivas y lingüísticas de un mismo género pueden variar. Este es el caso de la entrevista televisiva, un género muy marcado culturalmente y que, como explicamos más adelante en esta tesis, nos permite trabajar la competencia discursiva en la clase de ELE.

Los criterios que se han utilizado en la lingüística del texto y el análisis del discurso para clasificar los géneros discursivos varían según el punto de vista teórico adoptado. Una distinción establecida en la lingüística textual es la que diferencia entre géneros discursivos (también llamados clases textuales en la lingüística germánica) y tipos de texto. Los tipos de texto son formas textuales definidas por sus características internas (estructurales y gramaticales), resultado de una conceptualización que persigue clasificar los textos en un sistema tipológico cerrado. En cambio, los géneros discursivos se definen pragmáticamente según parámetros externos, es decir, contextuales (propósito 
comunicativo, papel y estatus del emisor y del receptor, tipo y modo de interacción) y, a diferencia de los tipos de texto, no constituyen un repertorio cerrado de formas, sino que los géneros están abiertos a los cambios sociales y culturales (CVC, 1997-2018).

Como se explica en el Diccionario de términos clave de ELE del CVC (19972018), para la didáctica de segundas lenguas, dos tipos de descripción son relevantes:

- caracterizar rasgos textuales típicos o convencionales de cada género discursivo (tipo de información, organización del contenido, marcas de emisor y receptor, registro, etc.), rasgos recurrentes y reconocidos por los participantes en una determinada actividad comunicativa; ello permite identificar correlaciones entre forma lingüística-función discursiva pedagógicamente útiles;

- explicar esta caracterización en el contexto tanto de las restricciones socioculturales como de las restricciones cognitivas que operan en cada ámbito de uso, en el sentido de que en cada cultura y comunidad de hablantes un mismo género discursivo (un testamento, una entrevista televisiva, un examen, por ejemplo) puede presentar unas normas o reglas formales y temáticas distintas a las fijadas por el uso en otro contexto sociocultural.

En la aplicación docente, el aprendizaje de una L2 a partir de los géneros discursivos tiene ya una tradición en el campo de la enseñanza de la lengua para fines específicos. Se han llevado a cabo propuestas de programas concretos relacionados con actividades sociales y profesionales determinadas, como la actividad comercial, científica o económica.

En el MCER (2002: 15) se especifican las situaciones que el aprendiente habrá de resolver lingüísticamente y también los lugares, instituciones/organismos, personas, objetos, acontecimientos y acciones en que podrá estar implicado. En función de estos factores caracterizadores de los géneros discursivos, el MCER establece para la enseñanza-aprendizaje de una L2 cuatro ámbitos de uso:

- el ámbito personal, en el que los hablantes se comunican con géneros como la conversación, las cartas personales, la publicidad comercial, el diario, etc.; 


\section{EL PROGRAMA TELEVISIVO COMO RECURSO PARA LA \\ ENSEÑANZA/APRENDIZAJE DE ESPAÑOL LENGUA EXTRANJERA}

- el ámbito público, caracterizado por el uso de avisos públicos y carteles, etiquetas y envases, anuncios, reglamentos, contratos, etc.;

- el ámbito profesional, en el que la comunicación se realiza a través de cartas comerciales, notas e informes, instrucciones de uso, tarjetas de visita, etc.;

- y el ámbito educativo, en el que las formas típicas de comunicación son, entre otras, los libros de texto, artículos de investigación, resúmenes, diccionarios, etc.

Por su parte, el Plan curricular del Instituto Cervantes (2006) sigue como criterio de clasificación de los géneros la forma a través de la cual se transmite la lengua (oral, escrita); en el caso de los géneros intermedios entre la oralidad y la escritura, se tiene en cuenta la vía por medio de la cual llegan a la audiencia. Aparte de las listas alfabéticas de géneros que abordar en cada uno de los niveles de aprendizaje, el Instituto Cervantes también proporciona muestras de géneros analizados (conversaciones, trabajos escolares y académicos, presentaciones públicas, cartas, etc.) en sus distintas partes textuales (secciones y subsecciones o movimientos). El enfoque basado en los géneros discursivos para el aprendizaje del español queda, por lo tanto, ilustrado de forma muy detallada.

Como hemos enunciado, la competencia discursiva también consiste en el dominio de lo que se denomina secuencia textual: la unidad de composición, de un nivel inferior al texto constituida por un conjunto de proposiciones que presentan una organización interna que les es propia. Es un concepto cercano al de superestructura textual - estructura formal que representa las partes en que se organiza el contenido de un texto-, pero hace referencia a un esquema de organización del contenido intermedio entre la frase y el texto.

El concepto de secuencia parte de la lingüística del texto (Werlich, 1975) y en la última década del siglo XX es objeto de un gran desarrollo teórico en los trabajos del lingüista francés Adam (1992). La teoría de las secuencias ha sido elaborada como reacción a la teoría demasiado general de las tipologías textuales - forma de organizar la diversidad textual y de clasificar los distintos textos-. Adam considera que no puede hablarse de tipos de texto porque no existen textos puros en cuanto al tipo al que pertenecen, sino que precisamente los textos se caracterizan por su complejidad en la forma de composición y su heterogeneidad tipológica. Es decir, no se puede hablar de un texto, por ejemplo, como puramente narrativo, pues como unidad comunicativa presentará, además de fragmentos narrativos, fragmentos descriptivos, 
dialogados, etc. Por ello, es más preciso y adecuado hablar de secuencias textuales, y definir el texto como «una estructura jerárquica compleja que comprende $n$ secuencias -elípticas o completas - del mismo tipo o de tipos diferentes». La secuencia, pues, se presenta como un modo de segmentación que permite articular la complejidad textual.

Adam distingue cinco secuencias textuales prototípicas: narrativa, descriptiva, argumentativa, explicativa, y dialogal. Lo más habitual es que un texto integre diversas secuencias. Para explicar cómo se combinan las secuencias en los textos, este lingüista propone distinguir entre secuencia dominante $y$ secundaria, por un lado, y envolvente e incrustada, por otro:

- La secuencia dominante es aquella que se manifiesta con una presencia mayor en el conjunto del texto. Si tomamos como ejemplo el relato biográfico, por más variadas que resulten sus formas de construcción, hay siempre una secuencia narrativa dominante: se presenta una sucesión de acciones encadenadas sobre un eje temporal que permite ubicar una situación inicial y una final, y una serie de transformaciones entre la primera y la segunda; pero, además, esta secuencia narrativa puede combinarse con secuencias descriptivas, dialogadas, explicativas, etc. De todos modos, como la secuencia narrativa sería el modo de organización típico al que se apela para producir y leer biografías, se considera el relato biográfico como texto narrativo. Por lo tanto, un texto será de tipo narrativo, descriptivo, explicativo o argumentativo si las secuencias dominantes lo son. La secuencia secundaria es aquella que está presente en el texto sin ser la dominante.

- Por otro lado, si una secuencia constituye el marco en que otras secuencias pueden aparecer incrustadas, se le llama secuencia envolvente: por ejemplo, en un artículo de opinión, pueden dominar secuencias como la narrativa o la explicativa, que serían secuencias incrustadas, porque la secuencia que enmarca y da sentido al conjunto del texto es la argumentativa, que sería la secuencia envolvente.

La dominancia y la inserción son los dos tipos de heterogeneidad textual, esto es, de combinación de secuencias diferentes en un texto, que distingue Adam.

Por consiguiente, las secuencias se caracterizan por estos rasgos: 


\section{EL PROGRAMA TELEVISIVO COMO RECURSO PARA LA \\ ENSEÑANZA/APRENDIZAJE DE ESPAÑOL LENGUA EXTRANJERA}

- son autónomas con respecto al texto, con el que mantienen una relación de dependencia (se realizan en el texto) e independencia (se pueden aislar del texto);

- presentan una organización interna propia, que puede descomponerse en partes;

- se combinan de forma jerárquica dentro del texto con otras secuencias.

En el plano de la didáctica, las secuencias textuales son de gran utilidad para el desarrollo de las habilidades de lectura y escritura. Es posible extraer de los textos formas diversas de organización textual que los estudiantes deberán conocer y dominar, puesto que cada tipo de secuencia se caracteriza por unos rasgos particulares, de carácter funcional, textual y lingüístico. Algunos materiales organizan las unidades didácticas a partir de la enseñanzaaprendizaje de secuencias textuales (la argumentación, la descripción, etc.), que se caracterizan por presentar regularidades en el uso de la lengua. Además, en el nivel secuencial de un texto pueden establecerse paralelismos entre dos lenguas determinadas, igual que el que se establece en otros niveles de la descripción lingüística (el léxico, el morfológico, el sintáctico o el semántico) (CVC, 19972018).

\subsection{La competencia estratégica}

El concepto de estrategias de aprendizaje forma parte de la explicación que la psicología cognitiva proporciona sobre el proceso de aprender. Dicha disciplina destaca la implicación activa del aprendiente en este proceso. En el éxito del aprendizaje, junto a otros factores personales como la motivación, las aptitudes o la experiencia acumulada, desempeña un importante papel la habilidad de cada persona para aplicar todos sus recursos de la manera más efectiva posible a cada situación de aprendizaje. Estos recursos incluyen los necesarios procesos mentales, pero también otras formas de comportamiento y actuación, tanto de orden psicológico (emociones, actitudes, etc.) como de orden social (experiencias y contactos sociales, etc.) (CVC, 1997-2018).

No existe unanimidad de criterios sobre el concepto y su definición, puesto que las estrategias de aprendizaje constituyen un conjunto de técnicas, habilidades, procedimientos y destrezas. Las hay conscientes e inconscientes, innatas o adquiridas, observables y no observables, etc. Algunos autores como Nisbet y 
Shucksmith (1991), establecen una distinción entre destrezas y estrategias. Según ellos, una destreza es una habilidad que se tiene (por ejemplo, recordar palabras haciendo asociaciones mentales con imágenes, o con sonidos, o mediante procedimientos mnemotécnicos); una estrategia consiste en seleccionar las destrezas más apropiadas para cada situación y aplicarlas adecuadamente. En consecuencia, caracterizan a las estrategias por su intencionalidad y por su orientación a una meta. Otros autores hablan de estrategias generales y específicas, de macrodestrezas y microdestrezas, etc.

Las estrategias de aprendizaje fueron descritas por vez primera en el marco de los estudios sobre el aprendizaje en general. Desde entonces, el interés por estas ha provocado un gran desarrollo de su estudio en el campo del aprendizaje de lenguas. Las primeras investigaciones se realizaron en el ámbito de la adquisición de segundas lenguas, más en concreto, en el proyecto sobre El buen aprendiente de lenguas (The Good Language Learner), llevado a cabo a mediados de los años 60 del siglo XX en el OISE (Ontario Institute for Studies in Education), en Toronto, Canadá. Durante los años 70 y 80 la investigación sobre este componente del aprendizaje cobra un creciente interés y se publican numerosos estudios tanto teóricos como aplicados a la enseñanza, que incluyen extensas taxonomías de estrategias (Naiman, Fröhlich, Stern, y Todesco, 1978).

Se han establecido también diversas tipologías de estrategias. La más difundida es la que las agrupa en cuatro tipos (Wenden, 1987; Oxford, 1990):

1. Estrategias de comunicación. Estas estrategias permiten al aprendiente mantener la comunicación en lugar de abandonarla ante dificultades imprevistas, proporcionándole así un mayor contacto con la L2 y más ocasiones de práctica y aprendizaje. En las estrategias de los aprendientes, los autores distinguen entre las estrategias de evitación y las de compensación.

Las primeras conducen a un empobrecimiento de la comunicación, puesto que el hablante, con el fin de evitar problemas en el uso de la lengua o de cometer errores, renuncia a abordar determinados temas: o bien abandona total o parcialmente un tema iniciado, o bien reduce el contenido de su mensaje. Las segundas consisten en la búsqueda de procedimientos alternativos, que permitan al hablante conseguir su propósito comunicativo: parafrasear, explicar mediante ejemplos, usar un término inventado que se considera comprensible por el receptor, etc. 


\section{EL PROGRAMA TELEVISIVO COMO RECURSO PARA LA \\ ENSEÑANZA/APRENDIZAJE DE ESPAÑOL LENGUA EXTRANJERA}

Desde el punto de vista de las aplicaciones didácticas, las más importantes son las estrategias de compensación. Muchas de ellas son comunes a los procesos de comunicación entre nativos competentes: recurrir a claves extralingüísticas, ayudarse de los datos contextuales, pedir aclaraciones al interlocutor, etc., para asegurarse de la correcta comprensión de los mensajes; paradójicamente, estas estrategias que el aprendiente aplica espontáneamente en su propia lengua quedan bloqueadas en el uso de una L2, especialmente en contextos de aprendizaje escolarizado.

2. Estrategias cognitivas. Consisten en actividades y procesos mentales que los aprendientes realizan de manera consciente o inconsciente; con ellas mejoran la comprensión del lenguaje, su asimilación, su almacenamiento en la memoria, su recuperación y su posterior utilización. El estudio de este tipo de estrategias nace del interés de la psicología cognitiva por la forma en que las personas comprenden el mundo que les rodea, aprenden de su experiencia y resuelven problemas.

En el aprendizaje de una nueva lengua el aprendiente tiene que llegar a comprender, por un lado, el contenido de los mensajes que recibe y los textos que lee y, por otro, nuevas reglas y nuevos patrones lingüísticos. En ambos casos la mente del aprendiente realiza una actividad y experimenta unos procesos muy similares de procesamiento y almacenamiento de la información obtenida; además, en el primer caso, la aplicación de estrategias cognitivas se combina eficazmente con la de estrategias comunicativas. Oxford (1990) señala que las estrategias cognitivas «siendo muy diversas, comparten todas una misma función: la manipulación de la lengua meta, o su transformación, por parte del aprendiente».

Ejemplos de estrategias cognitivas pueden ser: la comparación entre una estructura de la nueva lengua y la equivalente en la lengua propia; la elaboración de un esquema de lo que se ha aprendido; el subrayado de los pasajes principales de un texto.

3. Estrategias metacognitivas. Consisten en los diversos recursos de que se sirve el aprendiente para planificar, controlar y evaluar el desarrollo de su aprendizaje.

A diferencia de las cognitivas, estas estrategias permiten al aprendiente observar su propio proceso, son externas al mismo y comunes a todo tipo de aprendizaje. Conforman un tipo especial de conocimiento por parte del aprendiente, que algunos autores han caracterizado como un triple conocimiento: referido a la tarea de aprendizaje, referido a las estrategias de aprendizaje y referido al sujeto del aprendizaje. En otras palabras, saber en 
qué consiste aprender, saber cómo se aprenderá mejor y saber cómo es uno mismo, sus emociones, sus sentimientos, sus actitudes, sus aptitudes.

Ejemplos de estrategias metacognitivas pueden ser: el detenerse a reconocer el objetivo y finalidad de un ejercicio o tarea que se vaya a realizar (distinguiendo, por ejemplo, entre uno que sirve para el enriquecimiento del vocabulario mediante la lectura de un texto y otro que sirve para el perfeccionamiento de la comprensión lectora); la autoevaluación de una actividad ya realizada; la búsqueda de ocasiones de práctica para consolidar lo aprendido en la clase.

4. Estrategias socioafectivas. Consisten en aquellas decisiones que los aprendientes toman y aquellas formas de comportamiento que adoptan con el fin de reforzar la influencia favorable de los factores personales y sociales en el aprendizaje.

La importancia de estas estrategias radica en el hecho de que el aprendizaje se desarrolla no solo a partir de procesos cognitivos, sino que entre estos y las emociones, actitudes, etc. del aprendiente se establecen fuertes vínculos de interdependencia. Por otra parte, en su vertiente social, mediante estas estrategias se incrementa el contacto del aprendiente con la lengua y se potencian sus efectos positivos en el aprendizaje.

Ejemplos de estrategias socioafectivas pueden ser: realizar actividades de diverso tipo para superar inhibiciones y bloqueos en el uso de la nueva lengua; cooperar con otros aprendientes o con hablantes nativos en prácticas de aprendizaje y uso de la nueva lengua; desarrollar actitudes positivas ante las diferentes convenciones sociales entre la cultura propia y la de la nueva lengua.

En el ámbito de las segundas lenguas se distingue también entre estrategias directas e indirectas, según el modo en que ejercen su influencia en el desarrollo del proceso de aprendizaje. Dado el carácter social y comunicativo del lenguaje, las estrategias comunicativas y las sociales son estrategias indirectas que adquieren una gran relevancia en el aprendizaje de lenguas (Wenden, 1987; Oxford, 1991).

Su importancia para la didáctica radica en la posibilidad de incluirlas en un programa de estudio que permita un entrenamiento más efectivo de los alumnos. De ese modo, entre los objetivos del programa se fijan no solo los de aprender la lengua sino también los de aprender a aprender. Esta orientación didáctica ha venido a coincidir con las propuestas de programas y currículos. 


\section{EL PROGRAMA TELEVISIVO COMO RECURSO PARA LA \\ ENSEÑANZA/APRENDIZAJE DE ESPAÑOL LENGUA EXTRANJERA}

Las propuestas de entrenamiento de estrategias se dividen entre aquellas que incorporan su tratamiento integrado en las actividades de aprendizaje de la lengua, y aquellas otras que ofrecen un programa específico de aprendizaje de estrategias. Entre las segundas destaca la de O'Malley y Chamot (1990), conocida como Cognitive Academic Language Learning Approach o CALLA, un programa de entrenamiento de estrategias para el aprendizaje del inglés.

Como resume Pinilla (2000), el foco de interés de las estrategias de aprendizaje se centra en el aprendizaje de la lengua, y el de las estrategias de comunicación, en su uso. El motivo principal que condiciona el uso de una estrategia de aprendizaje no es el deseo inmediato de comprender o comunicar un mensaje, sino el de aprender la L2. Así, el uso de reglas nemotécnicas para aprender vocabulario o la memorización y repetición de algunas estructuras problemáticas de la L2 se consideran estrategias de aprendizaje y no estrategias de comunicación. Las estrategias de comunicación son mecanismos usados para resolver los problemas comunicativos, como son, por ejemplo, el desconocimiento de una palabra o de una expresión que se necesita en una situación concreta o la imposibilidad de seguir la línea argumental de un mensaje por el desconocimiento de los conectores discursivos que le dan forma.

Según el MCER (2002: 59), las estrategias de comunicación son un medio que utiliza el usuario de la lengua para movilizar y equilibrar sus recursos, poner en funcionamiento destrezas y procedimientos con el fin de satisfacer las demandas de comunicación que hay en el contexto y completar con éxito la tarea en cuestión, de la forma más completa o más económica posible, dependiendo de su finalidad concreta.

A lo largo del proceso de aprendizaje y, especialmente, durante las etapas iniciales, el estudiante hace frente a diferentes tipos de interacciones en las que se evidencian sus deficiencias comunicativas, ya sean de tipo lingüístico, discursivo o sociolingüístico. Es entonces, al resolver ese problema, cuando hace uso de su componente estratégico, es decir, cuando recurre a estrategias que le permiten salvar esas deficiencias.

En esta tesis nos centraremos en las estrategias de comunicación orales, ya que son estas las que intentaremos optimizar a través del recurso de los programas televisivos. Además, como venimos argumentando, es un hecho que la mayor parte de los intercambios comunicativos con hablantes nativos en los que el estudiante se verá inmerso son y serán conversaciones, en el amplio sentido de la palabra. 
Como recoge Pinilla (2006), por lo que respecta a las estrategias de comunicación en el plano oral, podemos hablar de dos tipos teniendo en cuenta las destrezas señaladas: estrategias de expresión y estrategias de interacción. Las estrategias de expresión suponen movilizar recursos y buscar el equilibrio entre distintas competencias, distinguimos entre las estrategias de evitación (el hablante evita utilizar expresiones o abordar temas que no controla) y de aprovechamiento (el hablante se siente capaz de utilizar ciertas expresiones o abordar ciertos temas). En cuanto a las estrategias de interacción, hay que considerar que se encuentran implicadas tanto las de comprensión como las de expresión. Destacan las de planificación de la interacción, las de control de los turnos de palabra, las de colaboración y cooperación y las de petición de ayuda.

Resultan especialmente relevantes aquellas estrategias que tienen que ver con el control del proceso. En el plano de las competencias lingüísticas del estudiante, y más relacionadas con la expresión, se encuentran las estrategias de paráfrasis, es decir, los procesos de reestructuración lingüística llevados a cabo por el estudiante, mediante los que recurre a un plan alternativo para referirse a la palabra que se desconoce, mediante aproximaciones (uso de cuasi sinónimos, por ejemplo) y descripciones y comparaciones. En este sentido, son fundamentales para el alumno la competencia léxica y la capacidad neológica que se derivan del conocimiento de las reglas de formación de palabras (conocimiento morfosintáctico). Por otra parte, y más en el plano de las competencias propiamente comunicativas, y por tanto, de la interacción, podemos resaltar la estrategia de comunicación de petición de ayuda al interlocutor, que supone una evidencia directa de que el estudiante necesita ayuda explícita para solucionar el problema que le surge durante la comunicación (Pinilla, 2006).

Los estudiantes disponen de un potencial estratégico que pueden desarrollar siempre que se enfrenten a un problema en cualquiera de las otras áreas de la competencia comunicativa. Así, por ejemplo, en relación con problemas de tipo discursivo, podemos pensar en aquellos casos en los que el estudiante olvida la línea argumental de lo que está exponiendo o no sabe cómo conseguir la cohesión de un texto porque desconoce los conectores discursivos necesarios en la L2. En ese caso, normalmente, realizará un resumen rápido para volver a ordenar las ideas, o bien recurrirá a diferentes tipos de entonación o rasgos prosódicos, como silencios o pausas, para marcar las partes del discurso. En el caso de problemas de tipo sociolingüístico, también encontramos ejemplos de aplicación de recursos estratégicos: el estudiante se enfrenta a un problema de esta clase cuando no sabe cómo formular correctamente sus intenciones 


\section{EL PROGRAMA TELEVISIVO COMO RECURSO PARA LA ENSEÑANZA/APRENDIZAJE DE ESPAÑOL LENGUA EXTRANJERA}

comunicativas y advierte que estas han sido malinterpretadas; en estas situaciones, puede reformular su discurso e introducirlo con expresiones del tipo bueno, es decir, etc. A veces, el problema reside en no saber si adoptar un registro informal o formal (uso de tú o usted), por desconocimiento de las reglas de uso que afectan a la relación entre los interlocutores. En estos casos, por ejemplo en los saludos, puede optar por utilizar una forma neutra (Pinilla, 2000).

Parece que el principal motivo por el que se desencadena el uso de una estrategia de comunicación es el de compensar fallos en la comunicación, debidos, fundamentalmente, a deficiencias en la competencia comunicativa. Sin embargo, a veces estos fallos comunicativos se originan por otros motivos, como las variables que se producen en la producción lingüística, del tipo de lapsus, problemas de memoria, falta de concentración, etc. Así se pone de manifiesto en la definición que realizan Canale y Swain (1980: 1-47) de las estrategias de comunicación: «La competencia estratégica estará compuesta de las estrategias de comunicación verbales y no verbales a las que se puede recurrir para compensar los fallos en la comunicación debidos a variables en la realización o a una competencia insuficiente ${ }^{34} \gg$.

En el recurso a una estrategia de comunicación siempre subyacen, por parte del hablante, dos tipos de procesos que, normalmente, tienen lugar de forma simultánea: un análisis del concepto y un control del código formal (Bou, 1992). El análisis del concepto supone un acercamiento reflexivo a los rasgos semánticos y significativos de una palabra, mientras que el control del código significa la elaboración lingüística del estudiante, que se sirve de sus conocimientos formales del sistema. Las estrategias de comunicación que subyacen a las producciones orales de nuestros estudiantes de ELE se pueden clasificar de la siguiente manera: a) paráfrasis, b) acuñaciones léxicas, c) recursos a la lengua materna, d) peticiones de ayuda al interlocutor y e) recursos no verbales.

a) Paráfrasis. Es el resultado de una estrategia procesal de análisis del concepto. Bajo esta estrategia agrupamos los procesos de reestructuración

\footnotetext{
${ }^{34}$ En el artículo de CANALE (1983) se recoge esta doble consideración de los motivos para usar una estrategia de comunicación: Competencia estratégica: dominio de las estrategias verbales y no verbales para (a) compensar los fallos en la comunicación debidos a una incompetencia insuficiente o a limitaciones en la realización y (b) aumentar o realzar el efecto retórico de los enunciados (traducción al español de J. Lahuerta en Pinilla, 2000).
} 
lingüística llevados a cabo por el estudiante, que suponen la puesta en marcha de un plan alternativo para referirse a la palabra que se desconoce. La manera de poner en marcha ese plan da lugar a dos tipos de estrategia de paráfrasis: aproximaciones y descripciones. Un ejemplo de aproximación es el uso de «parte» por sale de en la frase «Cuando mi, yo e mi amigo hablamos alto, siempre, siempre después de comida, Franz parte habitación» ... Un caso de descripción sería el ejemplo de camarera aérea por azafata ${ }^{35}$.

b) Acuñaciones léxicas. La estrategia de acuñación léxica consiste en la creación de una nueva palabra en la interlengua del estudiante, que puede existir o no en el español, pero que para el estudiante es una palabra nueva, cuyo significante desconocía. Esta estrategia supone un análisis del concepto, pero también una elaboración del código lingüístico, que supone la aplicación de características morfológicas de la lengua meta. Las estrategias de acuñación léxica se clasifican en función de la lengua sobre la que se elabora y acuña la forma léxica: 1) basadas en la lengua materna, como «oñonas» por cebollas — del francés, oignon-, y 2) basadas en la L2, como «gasolinista» por empleado de gasolinera o palabrar por deletrear ${ }^{36}$.

c) Recursos a la lengua materna. Esta estrategia consiste en una transferencia no elaborada de la lengua materna del estudiante y responde a una estrategia de control del código. Agrupamos aquí todos aquellos enunciados en los que subyace el recurso directo, por parte del estudiante, a su lengua nativa, o incluso, a otra lengua añadida que conozca, total o parcialmente. Se ha aplicado esta estrategia en el siguiente caso, en el que el estudiante desconoce la expresión española tomar decisiones y recurre, directamente, a su correspondiente en inglés: "es necesario al final a decidir a determinar el, el make decisions $»^{37}$.

d) Peticiones de ayuda al interlocutor. La estrategia de petición de ayuda es el resultado de una estrategia de control del código y supone una evidencia directa de que el estudiante necesita ayuda explícita para solucionar un problema que le ha surgido durante la comunicación. La petición de ayuda puede responder a una necesidad del estudiante de suministro de información, o bien de confirmación de una información que él mismo

\footnotetext{
${ }^{35}$ Ejemplos tomados de Pinilla (2000).

${ }^{36}$ Ejemplos tomados de Pinilla (2000).

${ }^{37}$ Ejemplo tomado de Pinilla (2000).
} 


\section{EL PROGRAMA TELEVISIVO COMO RECURSO PARA LA ENSEÑANZA/APRENDIZAJE DE ESPAÑOL LENGUA EXTRANJERA}

proporciona. Un ejemplo del primer caso sería el siguiente: «Sí, pero es que, me perdone..., ¿cómo se dice mess?», en el que el estudiante desconoce la palabra desorden, y la pregunta. Hay una petición de confirmación en el siguiente enunciado: «...en nuestro diploma es una exigen..., ¿obligación?.... $\rangle^{38}$.

e) Recursos no verbales. Esta estrategia consiste en el paso del código verbal al código no verbal (mímica, gestos). Normalmente, suelen utilizarse de forma conjunta palabras y gestos para aludir a rasgos característicos del concepto que se pretende expresar; por ejemplo, el estudiante indica la idea cuando era niño mediante un gesto con la mano indicando la altura de un niño ${ }^{39}$.

Las estrategias de comunicación desempeñan un papel fundamental en el desarrollo de las habilidades y las prácticas comunicativas de los estudiantes de ELE, y así lo reconoce también el MCER cuando dice que «son una base adecuada para la elaboración de escalas de capacidad lingüística» (2002: 59). Sin embargo, parece que no son suficientemente tenidas en cuenta ni en la práctica real en las aulas ni en los procesos de evaluación en general.

\subsection{La competencia pragmática}

En los últimos treinta años, la competencia comunicativa se ha convertido en el objetivo central al que debe aspirar la enseñanza de una segunda lengua o una lengua extranjera. Uno de los componentes básicos que se reconocen dentro de la competencia comunicativa es precisamente la competencia pragmática (Escandell, 2004: 179-198).

El MCER (2002: 14) nos dice que las competencias pragmáticas tienen que ver con el uso intencionado de los recursos lingüísticos (producción de funciones de lengua, de actos de habla) sobre la base de guiones o escenarios de intercambios lingüísticos. También tienen que ver con el dominio del discurso, la cohesión y la coherencia, la identificación de tipos y formas de texto, la ironía y la parodia. Respecto a este componente, el gran impacto que ejercen las interacciones y los entornos culturales en que se desarrollan estas capacidades, es aún más importante que en el caso del componente lingüístico.

\footnotetext{
${ }^{38}$ Ejemplo tomado de Pinilla (2000).

${ }^{39}$ Ejemplo tomado de Pinilla (2000).
} 
Cuando comunicamos, para seleccionar la lengua que producimos, debemos tener en cuenta el contexto y los interlocutores. Es importante que transmitamos esto a los aprendices de una lengua extranjera. La tarea de enseñar a nuestros alumnos a comportarse y comunicarse en todas las situaciones, en todos los contextos, con todas las personas que pueden aparecer en su vida puede parecer inabarcable, pero probablemente la respuesta esté en analizar «qué factores determinan sistemáticamente el modo en que funcionan nuestros intercambios comunicativos» (Corral y Fernández, 2009: 121-137).

Aquí aparece uno de los elementos fundamentales de la pragmática: la intención. Esta debe ser entendida por el oyente para conseguir el éxito comunicativo y evitar los malentendidos.

Como recoge Escandell (2004: 179-198), los humanos, además de saber interpretar eficazmente los símbolos convencionales de un código aprendido (entre ellos, los signos lingüísticos), somos capaces de obtener información a partir de indicios e iconos; y no solo eso, somos capaces de explotar esta capacidad con fines comunicativos, es decir, sabemos producir intencionalmente indicios para que los demás los interpreten. Esto indica que el proceso de descodificación no es la única fuente de la que obtenemos contenidos; también la inferencia (el razonamiento que nos permite deducir nuevas informaciones a partir de otras ya existentes) desempeña un papel decisivo en la comunicación. Este papel es todavía más importante de lo que pudiera parecer en un principio, ya que también lo comunicado verbalmente recibe una interpretación inferencial. Lo que hace que el modo en que nos comunicamos sea creativo, y no puramente mecánico, es precisamente nuestra capacidad de superar el código y de transmitir contenidos por medios no convencionales.

El ser consciente de la estructura interna de los diferentes tipos de actos de habla y de la diversidad de secuencias que pueden integrarlos es decisivo para el profesor de una lengua extranjera. «No se trata de enseñar a los alumnos una forma que en su lengua no existe, sino de que aprendan a utilizar las formas disponibles en una proporción cercana a la que muestran los hablantes nativos» (Escandell, 2004: 179-198).

\subsubsection{Los factores pragmáticos: elementos y relaciones}




\section{EL PROGRAMA TELEVISIVO COMO RECURSO PARA LA \\ ENSEÑANZA/APRENDIZAJE DE ESPAÑOL LENGUA EXTRANJERA}

Hay variables clásicas, como la relación interpersonal y el tipo de acto de habla; y variables menos estudiadas, pero igualmente importantes, como el tema, los sentimientos, el registro y la dinámica interna del discurso (Landone, 2009).

Como recoge Escandell (2004: 179-198), en cualquier intercambio comunicativo intervienen como piezas clave cuatro elementos básicos.

- Emisor (E): es un hablante que produce intencionalmente una expresión lingüística en un momento dado, ya sea oralmente o por escrito. La noción de emisor está construida sobre la de hablante (persona que posee el conocimiento de la lengua), pero está sujeta a dos condiciones más: por un lado, se es emisor cuando se hace uso de la palabra; por otro, se es emisor cuando se comunica intencionalmente.

- Destinatario (D): es el hablante al que se dirige el emisor. Se excluye de la condición de destinatario a los oyentes ocasionales que captan por casualidad un mensaje. En las interacciones dialogales, emisor $\mathrm{y}$ destinatario van intercambiando sus papeles.

- Situación (S): incluye todo aquello que, física o culturalmente, rodea al acto mismo de enunciación.

- Enunciado (e): es la expresión lingüística que produce el emisor. Funciona como la unidad mínima de comunicación y está delimitada por el cambio de emisor, sin que se tomen en consideración otros factores estructurales como la complejidad sintáctica o la longitud.

Tan importantes como los elementos son las relaciones que se establecen entre ellos.

- La intención: es el propósito o el objetivo que el emisor quiere conseguir por medio de su enunciado. Guía al emisor a utilizar los medios que considere más adecuados para alcanzar sus fines. Además, la intención no solo es decisiva desde el punto de vista del emisor y de la producción del enunciado; también es central desde el punto de vista del destinatario y de la interpretación: por ello, el reconocimiento de la intención del emisor es un paso imprescindible para que no se produzcan malentendidos.

- La distancia social: es la relación entre los interlocutores de acuerdo con los patrones sociales de cada cultura. Se establece en virtud de diversos 
factores, tales como los roles que a cada uno corresponden, la edad o el grado de conocimiento previo.

Una vez presentadas las herramientas básicas que utiliza la Pragmática para describir y explicar el uso de la lengua en la comunicación, nos disponemos a explicar dos de los muchos aspectos de interés que pueden identificarse. Estos están especialmente relacionados con las tareas de quien enseña una lengua extranjera: los actos de habla y la cortesía.

- Los actos de habla catalogan las intenciones y analizan los medios lingüísticos que se usan para expresarlas.

- La cortesía estudia los parámetros que determinan la distancia social y sus manifestaciones lingüísticas.

Estos dos ámbitos son de gran interés para los profesores de ELE porque son los dos campos en que se hacen más evidentes las diferencias culturales en lo que a normas de uso de la lengua se refieren, y, por tanto, son los campos en que se manifiestan de manera más clara los fenómenos de interferencia pragmática (Escandell, 2004: 179-198).

\subsubsection{Los aspectos pragmáticos: los actos de habla y la cortesía}

La idea de los actos de habla desarrollada en principio por Austin en 1962 va a tratar de diferenciar las intenciones y a analizar los medios lingüísticos usados para expresarlas. De esta forma encontraremos:

- actos locutivos: aquellos que llevamos a cabo al hablar;

- actos ilocutivos: que superan la literalidad, por qué decimos algo;

- y actos perlocutivos: que persiguen conseguir un efecto en el oyente, los decimos para algo.

La pragmática se centra en el estudio de los actos ilocutivos. De acuerdo con Searle (1975), podemos agrupar y clasificar los diferentes tipos de acción, según su intención, en cinco categorías básicas. 


\section{EL PROGRAMA TELEVISIVO COMO RECURSO PARA LA ENSEÑANZA/APRENDIZAJE DE ESPAÑOL LENGUA EXTRANJERA}

- Asertivos (o representativos): el emisor pretende reflejar el estado de cosas del mundo. Comprende actos como afirmar, referir, explicar, sugerir, presumir, quejarse... Estos actos se evalúan en términos de verdadero/falso.

- Directivos: el emisor pretende que el destinatario lleve a cabo una determinada acción. Son actos directivos ordenar, pedir, rogar, aconsejar, recomendar...

- Compromisivos: el emisor manifiesta su compromiso de realizar una determinada acción: prometer, asegurar, garantizar, ofrecer,...

- Expresivos: el emisor manifiesta su estado de ánimo con respecto a algo: felicitar, agradecer, complacerse, perdonar, insultar,...

- Declarativos: el emisor produce cambios en el mundo en virtud de la autoridad que le ha sido otorgada. El acto de habla debe hacerse según unas fórmulas ritualizadas: bautizar, casar, inaugurar, dictar sentencia, contratar...

Junto a la idea de intencionalidad, otro elemento fundamental a tener en cuenta es el de la distancia social entre los interlocutores. Esto es lo que conocemos por cortesía. En este punto, y siguiendo a Escandell (1998: 45-57), vamos a considerar la cortesía no como un conjunto de normas sociales sino como un conjunto de estrategias conversacionales gracias a las cuales lograremos evitar o mitigar conflictos entre los objetivos del hablante y del oyente.

Como explica Escandell (2004: 179-198), los estudios sobre la distancia social y sus repercusiones sobre el modo en que usamos la lengua miden la distancia con respecto a dos ejes fundamentales.

- Jerarquía: está determinada por la relación vertical entre los interlocutores en función tanto de las características físicas inherentes de cada individuo (edad, sexo, parentesco...) como de los roles sociales que tienen atribuidos y que resultan relevantes para el intercambio (jefe, secretario, botones...). Tanto las características inherentes como los roles sociales pueden dar lugar a relaciones simétricas (coetáneos, compañeros de estudios, colegas de trabajo...) o asimétricas (viejo/joven, cliente/empleado, médico/paciente, profesor/alumno...).

- Familiaridad: es una relación simétrica determinada por la relación horizontal que establece el grado de conocimiento previo (desconocidos, conocidos, amigos íntimos...). 
El interés de los estudios de cortesía no se limita a estos aspectos. Una de las líneas de investigación más desarrolladas y fructíferas es la que se ocupa de analizar la interacción entre las dos relaciones básicas: la distancia social y las intenciones comunicativas.

- Acciones que apoyan (o mejoran) la relación social existente entre emisor y destinatario, es decir, que suponen un beneficio para el destinatario y un coste para el emisor: agradecer, felicitar, saludar, ofrecer, invitar...

- Acciones indiferentes, es decir, aquellas en las que no hay un desequilibrio claro entre coste y beneficio para los interlocutores: afirmar, informar, anunciar...

- Acciones que entran en conflicto con la relación social, esto es, que implican algún tipo de coste para el destinatario: pedir, ordenar...

- Acciones dirigidas frontalmente contra la relación entre los interlocutores, es decir, acciones que pretenden acrecentar la distancia o destruir las relaciones existentes: amenazar, acusar, maldecir...

El tratamiento lingüístico que se da a un determinado tipo de acto verbal estará, pues, en función de la relación previa existente entre los interlocutores y de los efectos (positivos o negativos) que pueda tener el acto sobre dicha relación. Se habla, en estos casos, de usos estratégicos de la cortesía, en el sentido de que la formulación lingüística empleada puede utilizarse para amortiguar o para potenciar los efectos no deseados de un determinado acto. Los parámetros de acuerdo a los que se evalúa lo que es costoso o beneficioso para el destinatario varían considerablemente de cultura a cultura (Escandell, 2004: 179-198). «Así, se distingue entre la imagen positiva que nos permite ser aceptados socialmente; y la imagen negativa que nos lleva a no inmiscuirnos en la vida privada de los demás» (Corral y Fernández, 2009: 121-137).

Se ha observado que los actos verbales de cortesía se realizan mediante ciertos mecanismos lingüísticos que a continuación se esquematizan como recoge Albelda (2007: 200). Se clasifican en dos grupos, según si la cortesía se origina por la existencia o no de amenazas a la imagen.

- Cortesía mitigadora: se suele realizar mediante estrategias de atenuación. Se mitiga la fuerza ilocutiva de los enunciados, de modo que se atenúa la posible amenaza a la imagen. 


\section{EL PROGRAMA TELEVISIVO COMO RECURSO PARA LA \\ ENSEÑANZA/APRENDIZAJE DE ESPAÑOL LENGUA EXTRANJERA}

- Cortesía valorizante: se suele realizar mediante estrategias de intensificación.

- Refuerzo directo de la imagen del otro interlocutor mediante halagos, alabanzas, cumplidos, etc.

- Refuerzo indirecto de la imagen del otro interlocutor, apoyando lo dicho por este último:

- colaborando con el tema: proargumentos, intervenciones colaborativas, afirmaciones, ratificaciones;

- $\quad$ manifestando el acuerdo;

- colaborando a la producción del enunciado del otro interlocutor.

El refuerzo social entre los interlocutores se logra especialmente mediante cortesía valorizante, como ocurre, por ejemplo, con los cumplidos; pero también evitando las amenazas mediante cortesía mitigadora. No obstante, puede darse el caso de situaciones en que la cortesía valorizante no refuerce los lazos sociales, sino que dé lugar a un distanciamiento entre los interlocutores o mantenga la distancia presente entre ellos (Albelda, 2007: 213).

Sin embargo, como señala Albelda (2007: 214), no podemos concluir que atenuación e intensificación sean estrategias opuestas, sino que se trata de categorías complementarias $\mathrm{y}$, en ocasiones, se hace uso de ambas para sintonizar las relaciones sociales.

Para concluir, y citando de nuevo a Escandell,

Enseñar una lengua lleva asociado, por tanto, enseñar a percibir y a evaluar las situaciones y las relaciones sociales tal y como las perciben y las evalúan los nativos, para poder adaptar el comportamiento lingüístico propio a los mismos parámetros que ellos. Enseñar a interactuar de manera adecuada y fluida es tan importante como enseñar a producir enunciados gramaticalmente correctos, con la diferencia de que la incorrección gramatical se enmienda inconscientemente en la interpretación, mientras que la inadecuación pragmática no se detecta ni se corrige con la misma facilidad. Cuando hay fallos de esta clase, se originan malentendidos, y estos crean estereotipos negativos sobre las personas de otra cultura («son fríos»; «son bruscos»;...). Para evitar que la lengua nos separe, es necesario tratar de desterrar estos malentendidos por medio de una adecuada instrucción (Escandell, 2004: 179-198). 
LA COMPETENCIA COMUNICATIVA EN LA ENSEÑANZA DE SEGUNDAS LENGUAS

\section{DIDÁCTICA DE LOS MEDIOS AUDIOVISUALES}




\section{EL PROGRAMA TELEVISIVO COMO RECURSO PARA LA ENSEÑANZA/APRENDIZAJE DE ESPAÑOL LENGUA EXTRANJERA}

A la hora de integrar didácticamente los medios audiovisuales en un proceso de formación hay que tener en cuenta una serie de principios para proceder de forma adecuada a su selección-evaluación y/o utilización. Los diferentes principios y recomendaciones generales deben interpretarse como válidos para todas las etapas, áreas de conocimiento y procesos formativos, por lo que deben contextualizarse y adaptarse en función de las necesidades que se vayan a atender y de las acciones que se vayan a realizar. (Ballesteros, 2016: 66)

\subsection{Principios para la selección-evaluación}

El proceso de selección-evaluación de los medios audiovisuales debe estar condicionado por los siguientes principios generales (Cabero, 2004 y 2007; Ballesteros, 2013 y 2016), los cuales tendremos en cuenta a la hora de seleccionar los programas televisivos o los fragmentos de programas televisivos a partir de los que diseñaremos las propuestas didácticas que presentaremos en esta tesis:

a) ¿A quién va dirigido? Las características de los receptores potenciales: edad, nivel socio-cultural y educativo, necesidades, carencias $\mathrm{y}$ conocimientos previos: ideas y expectativas.

b) ¿Cuándo se utilizará? Momento del proceso de formación en el que se aplicará.

c) ¿Qué se pretende? La selección debe hacerse teniendo en cuenta los objetivos y contenidos que se deseen alcanzar y desarrollar.

d) ¿Cómo se utilizará? Función que desempeñará durante en el proceso formativo: introducción-motivación, evaluación inicial de conocimientos previos, desarrollo-profundización, refuerzo-recuperación o síntesisevaluación final.

e) La predisposición de los alumnos y profesores hacia los medios audiovisuales como recurso didáctico: sus intereses, preferencias, deseos y motivaciones.

f) El contexto de enseñanza y aprendizaje donde se inserten los medios audiovisuales también será un elemento condicionante para su puesta en práctica. Por lo tanto, deberán atenderse tanto los aspectos socio-culturales como los organizativos y funcionales del centro. 
g) Las diferencias cognitivas entre los alumnos también pueden condicionar los resultados que se alcancen y su forma de utilización, facilitando o dificultando la integración de los medios audiovisuales seleccionados.

h) Debe facilitar la participación e intervención de los alumnos y profesores para que se conviertan en procesadores activos de información y participen en la construcción de nuevo conocimiento: generándolo, consolidándolo y/o reelaborándolo.

i) Las características técnicas: su calidad de imagen y sonido, adecuación de los textos, gráficos e ilustraciones, interactividad, relación costedurabilidad, etc.

j) Las características semánticas-expresivas: el tipo de información, conocimientos, procedimientos, actitudes, valores y normas culturales que presente.

k) Su versatilidad para poder desempeñar diferentes funciones y tareas dentro del mismo proceso formativo.

1) En la medida de lo posible, seleccionar documentos audiovisuales que puedan complementarse e interaccionar con otros medios-TIC.

\subsection{Principios para la utilización e integración didáctica}

Una vez seleccionado el medio audiovisual, se procede a su utilización e integración didáctica teniendo en cuenta las características del proceso de enseñanza/aprendizaje. A este respecto, Cabero (2004: 77-104 y 2007: 129149) ofrece una serie de recomendaciones generales que tendremos presentes a lo largo del proceso de diseño de propuestas didácticas que llevaremos a cabo, así como en el momento de su puesta en práctica.

a) Debemos entender los medios audiovisuales simplemente como un recurso tecnológico más. Su funcionalidad didáctica estará condicionada por la estrategia metodológica que se aplique sobre ellos puesto que por sí mismos no pueden generar aprendizaje.

b) El profesor se convierte en el elemento más significativo para su integración didáctica. Tanto su formación y experiencia técnico-didáctica como sus necesidades, carencias, actitudes y expectativas personales-profesionales determinarán el papel que los medios audiovisuales puedan desarrollar durante el proceso formativo. 


\section{EL PROGRAMA TELEVISIVO COMO RECURSO PARA LA ENSEÑANZA/APRENDIZAJE DE ESPAÑOL LENGUA EXTRANJERA}

c) Los medios audiovisuales seleccionados no funcionarán en el vacío, sino en un complejo contexto-aula donde se combinan diferentes variables (como el profesor, los alumnos, los objetivos y contenidos propuestos, los factores organizativos, el ambiente de clase, de centro y el propio contexto sociocultural), que deberán ser tenidos en cuenta para que la propuesta didáctica que se plantee a los alumnos sea significativa.

d) El profesor debe asignar a los alumnos un rol participativo que les permita participar como receptores-procesadores activos de la información y del conocimiento que se quiera desarrollar. Asimismo, se debe potenciar un modelo interactivo de comunicación bidireccional entre el profesor y los alumnos.

e) Antes de la aplicación de los medios audiovisuales el profesor debe realizar las siguientes tareas:

- Planificar las actividades de extensión que los alumnos realizarán una vez visionado el documento audiovisual.

- Ensayar su puesta en práctica para, por una parte, comprobar que todos los dispositivos técnicos y materiales que se vayan a necesitar estén disponibles y operativos; y, por otra, coordinar-evaluar-adaptar, si fuera necesario, la secuencia, temporalización y desarrollo de las actividades propuestas.

f) Durante la puesta en práctica de los medios audiovisuales se deben tener en cuenta una serie de aspectos:

- Proponer un modelo de utilización estructurado donde se puedan experimentar todas las posibilidades técnicas (pausa, avance rápido, cámara lenta, etc.) y didácticas (formulación de preguntas previas a su visionado, intercambio de información entre alumnos, revisión de las partes más significativas, producción de algún material o documento de síntesis, etc.) de este recurso tecnológico.

- Evitar los modelos lineales tradicionales caracterizados por la típica presentación inicial del profesor, la observación completa y continuada de los medios audiovisuales y la posterior formulación de preguntas sobre las dudas que se hayan generado.

- Cuando se presenten los medios audiovisuales, se debe explicar a los alumnos los motivos por los que se observan y los objetivos que se persiguen. También se deben explicar los conceptos que puedan aparecer y generar alguna dificultad de comprensión a los alumnos, y se 
les debe ayudar a centrar su atención informándoles sobre las partes más significativas del mismo.

- Observar las reacciones de los alumnos durante el visionado del documento.

- No olvidar que el comportamiento del profesor durante la emisión del audiovisual condicionará, por una parte, la actitud e implicación de los alumnos sobre los contenidos presentados en el mismo y, por otra, la actividad cognitiva que desarrollen durante la observación. En este sentido, comportamientos como la ausencia de clase, la realización de otras actividades o mantener conversaciones con algún compañero tendrán una repercusión negativa en la interacción cognitiva y actitudinal que los alumnos realicen con el documento audiovisual.

g) Después del visionado se finalizará con la realización de diferentes actividades orientadas a la identificación de los errores adquiridos durante la observación y al análisis-profundización de la información recibida: entrevistas a especialistas, debates en grupo, presentación de los materiales elaborados durante el visionado, experimentos, maquetas, esquemas, dibujos, relatos, fichas, murales, búsqueda de ejemplos en su contexto real, descripción de los distintos personajes y situaciones presentadas, identificación de los conceptos clave, explicación y/o resumen de los contenidos tratados e incluso la creación de un nuevo guion complementario o alternativo.

\subsection{Principios para el diseño de materiales didácticos}

El Diccionario de términos clave de ELE del CVC (1997-2018) define los materiales didácticos, también denominados materiales curriculares, como recursos de distinto tipo - impresos como los libros de texto, audiovisuales como un vídeo, multimedia como un DVD, etc. - que se emplean para facilitar el proceso de aprendizaje. La elaboración de materiales didácticos se concibe en función de diversos factores: los objetivos de aprendizaje, las necesidades de los alumnos, los procesos mentales que se quieren fortalecer o el medio social en que se utilizan. En consecuencia, no puede hablarse de materiales didácticos buenos ni malos a priori, sino de materiales más o menos adecuados a la propuesta docente que se persigue desarrollar. Los principios que se deben tener en cuenta y que nos servirán de guía durante el proceso de creación de 


\section{EL PROGRAMA TELEVISIVO COMO RECURSO PARA LA \\ ENSEÑANZA/APRENDIZAJE DE ESPAÑOL LENGUA EXTRANJERA}

materiales didácticos a partir de programas televisivos son los siguientes (CVC, 1997-2018):

- coherencia con el proyecto educativo, es decir, con las opciones metodológicas (papel que el profesor desea asumir), con los objetivos, contenidos y procedimientos de aprendizaje;

- adecuación a las necesidades de los aprendientes y del contexto de aprendizaje;

- significatividad, de tal forma que los materiales consideren los conocimientos, intereses y valores de los estudiantes;

- impulso de la autonomía tanto de enseñanza como de aprendizaje;

- flexibilidad y adaptabilidad a la multiplicidad de acontecimientos que tienen lugar en el proceso de enseñanza-aprendizaje y a la diversidad de aprendientes, en el sentido de que los materiales no han tomado de antemano todas las decisiones propias del desarrollo curricular;

- equilibrio en el tratamiento de los distintos contenidos del currículo: conceptos, habilidades y actitudes; espacio dedicado a cada destreza lingüística; etc.

- gradación didáctica del material a lo largo del proceso de aprendizaje;

- autenticidad de las muestras de lengua y de las actividades de comunicación;

- contextualización por referencia a una situación de comunicación;

- claridad en la formulación lingüística de las instrucciones.

En cuanto al formato de los materiales, estos se clasifican en: auditivos, como los casetes y los discos compactos; de imagen fija como, por ejemplo, las fotografias; gráficos, como los carteles y diagramas; impresos, como los libros y las revistas; audiovisuales como, por ejemplo, las películas; tridimensionales, como los objetos reales; y electrónicos, como el ordenador. (Ogalde, 2000: 22)

Por otro lado, por material auténtico se entiende aquel que no ha sido manipulado con fines pedagógicos; el tipo de material que un hablante nativo de una lengua escucharía, leería o utilizaría en su vida ordinaria. Los materiales pedagógicos, por el contrario, se podrían definir como aquellos que se elaboran intencionalmente con el fin de facilitar procesos de enseñanza y aprendizaje de la lengua extranjera. (Palacios, 2009: 242) 
Por último, según el aspecto de la lengua que el material ayuda a desarrollar, los materiales se clasifican en manuales y materiales complementarios (Fernández López, 2004: 724). Los manuales son los instrumentos de trabajo que buscan integrar y presentar todos los aspectos relacionados con una lengua. Por otro lado, los materiales complementarios son instrumentos complementarios que se elaboran con el fin de proporcionar al alumno y al profesor un mayor apoyo teórico o práctico relacionado con un aspecto puntual y específico del aprendizaje de una lengua. La clasificación de Fernández López (2004: 724) para los materiales complementarios incluye materiales de apoyo gramatical, materiales para el desarrollo de la comprensión y la expresión escrita, para la ampliación de vocabulario, para la práctica de la fonética, para la comprensión y expresión oral, para fines específicos, materiales centrados en la enseñanza de la literatura y la cultura y materiales para la preparación de exámenes, entre otros.

Por lo que respecta a la elaboración de materiales que llevaremos a cabo, las propuestas didácticas que diseñaremos se pueden catalogar: por su formato, como un material audiovisual; por su autenticidad, como un material pedagógico que incluye muestras de lengua auténticas; y por el aspecto de la lengua que ayuda a desarrollar, como un material complementario que sirve de apoyo para trabajar varios aspectos y habilidades de la competencia comunicativa en el contexto de enseñanza y aprendizaje de ELE.

Una vez establecida la definición y los criterios de clasificación de nuestras propuestas didácticas, presentaremos algunos elementos relacionados con su diseño. De acuerdo con Brian Tomlinson (1998: 2), el desarrollo de materiales para la enseñanza de lenguas extranjeras se refiere a «cualquier cosa que hacen los diseñadores, profesores o aprendices para proporcionar fuentes de input de lengua y para explotar esos recursos de manera que se maximice la posibilidad de apropiación» ${ }^{40}$. Tomlinson (1998) establece dieciséis características que los materiales deben reunir, y que procuraremos que nuestros materiales reúnan, para lograr el objetivo de facilitar a los estudiantes el aprendizaje de una lengua:

- tener un impacto positivo en los estudiantes;

- ayudarlos a sentirse cómodos aprendiendo;

\footnotetext{
${ }^{40}$ En el original: «anything which is done by writers, teachers or learners to provide sources of language input and to exploit those sources in ways which maximize the likelihood of intake». (Tomlinson, 1998: 2)
} 


\section{EL PROGRAMA TELEVISIVO COMO RECURSO PARA LA ENSEÑANZA/APRENDIZAJE DE ESPAÑOL LENGUA EXTRANJERA}

- ayudarlos a desarrollar confianza en sí mismos;

- ser percibidos por los estudiantes como relevantes y útiles;

- facilitarles el autodescubrimiento;

- presentarlos cuando los estudiantes estén preparados;

- exponerles al uso auténtico de la lengua;

- enfocarlos hacia las características lingüísticas del input;

- brindarles oportunidades para que usen la lengua con propósitos comunicativos;

- tener en cuenta que los efectos positivos de la instrucción tardan en manifestarse;

- tener presentes los diferentes estilos de aprendizaje de los estudiantes;

- tener en cuenta sus diferentes actitudes afectivas;

- permitir un periodo de silencio al comienzo de la instrucción;

- estimularlos a nivel intelectual, estético y emocional;

- no depender mucho de la práctica controlada;

- otorgarles oportunidades para la retroalimentación.

\subsection{Marco metodológico y enfoque pedagógico}

Como marco metodológico, en esta tesis doctoral seguiremos las etapas para el diseño de materiales establecidas por Jolly y Bolitho en Tomlinson (1998: 9899). Estos autores enumeran siete etapas para el diseño de un material didáctico: la identificación de la necesidad de un material, la exploración de esta necesidad, la realización contextual del material, la realización pedagógica, la producción física del material, la etapa de uso, y la evaluación del material. A continuación, explicaremos brevemente a qué hace referencia cada una de ellas.

1. Etapa de identificación: consiste en descubrir la existencia de una necesidad en la enseñanza o en el aprendizaje de una lengua, que se puede solucionar por medio del diseño de un material didáctico. En nuestro caso, se trata de la falta de contextos ecológicos que lleva a tener que dirigir la enseñanza de lenguas a través de recursos auténticos. 
2. Etapa de exploración: el investigador determina la forma en la que va a dar solución al problema identificado, teniendo en cuenta diversos aspectos como la lengua y la cultura que va a enseñar mediante el material. En este caso nos proponemos dar solución al problema identificado mediante el diseño de propuestas didácticas dirigidas a la explotación didáctica de los programas televisivos en español.

3. Etapa de realización contextual: consiste en encontrar ideas adecuadas, contextos y textos con los que trabajar o los que desarrollar en el material didáctico. En esta etapa será necesario visualizar una amplia variedad de fragmentos de programas televisivos en español con el objetivo de elegir aquellos con los que trabajaremos y en torno a los que desarrollaremos nuestros materiales didácticos.

4. Etapa de realización pedagógica: en ella se lleva a cabo la planificación y elaboración pedagógica del material didáctico, a partir de aspectos como la realización de la secuencia de actividades y de las instrucciones. Una vez elegidos los fragmentos de programas televisivos, procederemos a la planificación de las secuencias de actividades antes del visionado, durante el visionado y tras el visionado.

- Etapa de producción física: se refiere al material como producto físico y a aspectos como el uso de imágenes, la distribución y organización de las actividades y las muestras de lengua, el uso de determinados colores, iconos y el tamaño de la letra. Una vez planificadas las actividades, nos centraremos en su diseño, distribución y organización para que el material resulte estimulante tanto intelectual como visualmente.

5. y 7. Etapas de uso y evaluación del material: estas etapas se refieren a la utilización del material por parte del estudiante y a la evaluación que profesores y estudiantes hacen del mismo. Esto puede ser de gran utilidad para modificarlo y mejorarlo. En nuestro caso, esta etapa será llevada a cabo en los cursos de español de la universidad West Virginia University.

En cuanto al enfoque pedagógico, se privilegiarán los enfoques comunicativos. Optaremos por el enfoque por tareas por poseer varias características adecuadas para potenciar los aspectos más interesantes de un documento auténtico como es el programa televisivo: la implicación de los estudiantes, la similitud de las tareas con las realizadas por los hablantes nativos, la práctica global de las cuatro destrezas, el favorecimiento de aspectos lúdicos y afectivos en las actividades, el uso del documento con objetivos claros y concretos, etc. 


\section{EL PROGRAMA TELEVISIVO COMO RECURSO PARA LA ENSEÑANZA/APRENDIZAJE DE ESPAÑOL LENGUA EXTRANJERA}

No obstante, creemos que del mismo modo que no existe un enfoque 'ideal' para la enseñanza de lenguas, tampoco lo hay a la hora de explotar estos documentos. Consideramos que elegir el método o métodos más adecuado o adecuados en cada situación es una labor más del profesor, en ocasiones con la cooperación de los alumnos. Deben tenerse en cuenta las características del grupo, el nivel, los objetivos, el contexto académico, el documento utilizado, etc.

En este caso, las actividades que diseñaremos estarán dirigidas al aula de clase y muchas se podrán adaptar para trabajar en grupos, parejas o individualmente, según el criterio del profesor. De igual manera, las actividades posibilitarán el aprendizaje autónomo, principalmente de aquellos que deseen continuar con su proceso de aprendizaje sin la asistencia constante del profesor. La organización de las actividades en cada secuencia será la siguiente:

- Actividades de previsionado. Plantearemos la fase de calentamiento previo a la audición de diferentes maneras. Nuestro objetivo será comenzar por atraer la curiosidad y el interés por parte de los alumnos para que la proyección sea fructífera. Algunas de estas actividades serán:

- el planteamiento de preguntas que hagan al alumno reflexionar antes de la escucha y activar el conocimiento previo sobre el tema en cuestión;

- la lectura de un breve texto o diagrama relativo al tema de la audición para anticipar al alumno la información que recibirá;

- la presentación del vocabulario con cierta dificultad para la comprensión del documento, mediante la explicación de su significado o la realización de un ejercicio de emparejamiento entre las palabras y su significado, en ocasiones con ayuda de imágenes.

- Actividades durante el visionado. En esta fase todas las actividades estarán directamente relacionadas con el vídeo en cuestión. Primará no solo la comprensión del mensaje (del sentido global y de detalles concretos) sino también la explotación de cualquier otro aspecto de la competencia comunicativa que el documento permita tratar. Para que los aprendientes puedan realizar todas las actividades, se podrá pasar varias veces el fragmento e incluso interrumpirlo. Las actividades no se corresponderán propiamente con la destreza de comprensión auditiva, sino que estarán centradas en trabajar otros aspectos de la competencia comunicativa y consistirán en:

- la práctica de algún aspecto gramatical, léxico, cultural, pragmático, estratégico o discursivo, explicado o practicado en el marco de la 
actividad, por ejemplo, a partir de un fragmento de la transcripción, o transformando algunas frases de la misma;

- la práctica de la identificación de formas lingüísticas de manera inductiva, a partir de fragmentos de la transcripción de la audición.

- Actividades de posvisionado. Nuestro objetivo en esta fase será diseñar actividades con las que el aprendiente pueda trabajar y mejorar la expresión oral y escrita, a partir de lo aprendido y practicado en las dos fases previas. Estas actividades podrán llevarse a cabo dentro o fuera del aula, dependiendo de factores como la duración de la clase o el número de alumnos:

- la práctica de la expresión oral consistirá en una videograbación similar a la del vídeo visualizado. Esto permitirá al estudiante expresarse con un objetivo comunicativo, observarse a sí mismo hablando en la lengua meta, tener acceso directo a los errores y trabajar en ellos.

- la práctica de la expresión escrita consistirá en la redacción de un breve texto relacionado con el tema del programa televisivo visualizado. Esto ayudará al alumno a retener los conocimientos adquiridos en las dos fases anteriores, y le permitirá aplicarlos a través de la reflexión, la organización y la redacción.

Junto con los principios generales de selección-evaluación de los medios audiovisuales de Cabero (2004 y 2007) y Ballesteros (2013 y 2016), las recomendaciones generales para la utilización e integración didáctica de los medios audiovisuales de Cabero (2004 y 2007), los principios de creación de materiales didácticos descritos en el CVC (1997-2018), las etapas para el diseño de materiales didácticos establecidas por Jolly y Bolitho en Tomlinson (1998), y las características que los materiales didácticos deben reunir para facilitar a los estudiantes el aprendizaje de una lengua establecidas por Tomlinson (1998), como fuentes de referencia a la hora de diseñar todas las actividades de esta tesis doctoral también se tendrán en cuenta: los descriptores para Ver televisión y cine incluidos en el apartado Actividades de comprensión audiovisual del MCER (2002: 73), los descriptores de los niveles comunes de referencia para la comprensión auditiva, la comprensión de lectura, la interacción oral, la expresión oral y la expresión escrita, incluidos en el capítulo Niveles Comunes de Referencia del MCER (2002: 30 y 31), y el Plan Curricular del Instituto Cervantes (2006). 
EL PROGRAMA DE TELEVISIÓN COMO RECURSO PARA LA ENSEÑANZA/APRENDIZAJE DE ESPAÑOL LENGUA EXTRANJERA

\section{EL PROGRAMA DE TELEVISIÓN COMO RECURSO} PARA LA ENSEÑANZA/APRENDIZAJE DE ELE 


\section{EL PROGRAMA TELEVISIVO COMO RECURSO PARA LA \\ ENSEÑANZA/APRENDIZAJE DE ESPAÑOL LENGUA EXTRANJERA}

\subsection{El material audiovisual en la clase de ELE}

Los materiales auténticos pueden ser muy variados: periódicos, revistas, folletos publicitarios, catálogos, prospectos, grabaciones de la radio o de la televisión, etc. «Lo más importante es que este tipo de materiales muestran ejemplos de lengua usada de manera natural, no en el sentido de realista, sino de verdadera» (Ruiz Fajardo, 1994: 143).

De entre todos ellos, nos gustaría destacar el papel del material audiovisual. El vídeo nos permite presentar situaciones comunicativas en contexto y mostrar aspectos culturales. Además, posibilita la presencia e integración de las cuatro destrezas lingüísticas en una misma actividad. Igualmente, cabe destacar que, gracias a Internet, se ha hecho mucho más fácil conseguir este tipo de material, pues este medio permite el acceso directo a todo tipo de documentos auténticos de diferente carácter y nivel de dificultad.

Según Lonergan (1985: 18-21), «la característica principal de los vídeos es su capacidad para presentar situaciones comunicativas completas». De acuerdo con este autor, la combinación de sonido e imagen resulta dinámica, inmediata y accesible, lo que significa que muestra la comunicación en contexto y que los espectadores —en este caso alumnos de lenguas - perciben con facilidad los diversos componentes que entran en juego en la comunicación. Los alumnos ven y oyen a los interlocutores de un diálogo y demás participantes en la situación; advierten la edad de los personajes, su sexo, el tipo de relación entre ellos, condición social, actividad... e incluso su estado de ánimo o sus sentimientos.

Además, disponen de información paralingüística, como las expresiones del rostro o los gestos de las manos, que acompañan a los indicadores orales de la entonación, así como de información lingüística. Es un hecho que aquellos alumnos que alguna vez han estado «enganchados» a telenovelas, series, dibujos animados, etc. suelen presentar un mayor nivel de la lengua en cuestión.

El uso de documentos audiovisuales está recogido en el capítulo 6 (Aprendizaje y evaluación) del MCER, cuando se tratan las formas en las que se espera que los alumnos aprendan una lengua: «viendo y escuchando la televisión, vídeos, etc.» (MCER, 2002: 141). Por otro lado, el MCER menciona las actividades de comprensión audiovisual, en las que el usuario recibe información simultánea a través de dos canales, el auditivo y el visual. 


\section{EL PROGRAMA DE TELEVISIÓN COMO RECURSO PARA LA ENSEÑANZA/APRENDIZAJE DE ESPAÑOL LENGUA EXTRANJERA}

En el MCER se proponen unas escalas que sirven de medida de la capacidad lingüística, es decir, que muestran el nivel concreto que tiene cada alumno en las actividades comunicativas de comprensión. Entre ellas, encontramos unas para ver televisión y Cine (MCER, 2002: 73). Una cuestión importante en la comprensión audiovisual son los materiales que se emplean —el formato (tipo de soporte, extensión, calidad acústica, etc.), el contenido (tema, tratamiento, etc.), el nivel (léxico, gramatical, cultural, etc.) - y las tareas que el profesor propone que se hagan con ellos (Soriano Fernández, 2009: 37).

Como señala Soriano Fernández (2009:35), muchos profesores de ELE son reticentes a trabajar con materiales audiovisuales en sus clases por motivos como los siguientes:

- los alumnos (y algunos profesores) no se toman en serio las actividades con este tipo de material;

- los profesores no saben cómo explotar el material ni cuál es el objetivo de este tipo de tareas;

- el trabajo con materiales audiovisuales se sale del currículo;

- se considera una pérdida de tiempo.

Sin embargo, hay una serie de argumentos que apoyan la inclusión de este tipo de material en la clase de ELE:

- se ha demostrado que a través del visionado de la televisión en dicho idioma se permite aprehender información lingüística. Parece que aquellos alumnos que alguna vez han estado «enganchados» a telenovelas, series, dibujos animados, etc. suelen presentar un mayor nivel de la lengua en cuestión;

- es un material muy motivador, ameno, sugerente y la imagen, en general, es algo a lo que están acostumbrados todos los estudiantes. Esta motivación garantiza la participación de toda la clase (Soriano Fernández, 2009: 35).

El lema que debe guiarnos es el siguiente: «lo visual, lo tangible siempre llama la atención y mantiene vivo el interés de los alumnos» (Ferrer Plaza, 2008: 2365). 


\subsection{Ventajas del recurso del programa de televisión para trabajar el enfoque comunicativo}

El MCER propone un enfoque comunicativo centrado en la acción, es decir, un aprendizaje y uso de la lengua en un contexto social amplio y en el que se realizan tareas que activan competencias comunicativas y que requieren el uso de estrategias. Un aprendizaje más global y dinámico. Como señalan Leontaridi, Ruiz Morales y Peramos Soler (2009), lograr que los alumnos estén más desinhibidos y que se relajen en clase está estrechamente relacionado con hacerles sentir que, de alguna forma, se disminuye la formalidad del contexto educativo. Esto se puede conseguir incorporando un componente lúdico, como es el programa televisivo, en la clase de ELE.

Como resume Soriano Fernández (2009: 36), el enfoque comunicativo es un enfoque metodológico con el que se pretende capacitar al alumno para que consiga una comunicación real, oralmente y por escrito, con otros hablantes de la lengua meta. Con este objetivo, durante el proceso de aprendizaje se utilizan documentos auténticos y se realizan actividades que intentan imitar fielmente la realidad fuera del aula.

En los enfoques comunicativos, la interacción oral entre los alumnos es muy habitual y muy diversa: en parejas, en tríos, en grupos mayores o entre toda la clase. El libro de texto es el apoyo material, pero no la base de la enseñanza. También se emplean otros tipos de materiales didácticos (cartulinas, tarjetas, fotos, dados) y auténticos (periódicos, anuncios publicitarios, menús de restaurantes, etc.). El profesor ya no es el centro del aula. Su función se ha ampliado: analizar las necesidades de los alumnos, crear situaciones de comunicación, organizar actividades, asesorar, participar como un compañero más, observar el desarrollo de las tareas en el aula, elaborar materiales, etc. El docente es un guía que facilita el aprendizaje y fomenta la cooperación entre los alumnos. Ahora son estos los verdaderos protagonistas. Se trata de un enfoque centrado en el alumno (Soriano Fernández, 2009: 36).

Según Aparici y García Mntilla (1987), «el vídeo sirve tanto para la enseñanza de la imagen como para la enseñanza con imágenes». Este último tipo de enseñanza se refiere a la utilización en clase de una cámara de vídeo que grabe y muestre después al alumno sus actividades. Este es uno de los numerosos recursos de que disponemos para trabajar el enfoque comunicativo mediante el uso del programa televisivo. Podríamos pensar que este tipo de material no involucra al receptor en el acto comunicativo que muestra. Sin embargo, el 


\section{EL PROGRAMA DE TELEVISIÓN COMO RECURSO PARA LA ENSEÑANZA/APRENDIZAJE DE ESPAÑOL LENGUA EXTRANJERA}

vídeo nos permite utilizar dos tipos de textos que sí involucran al aprendiz. En primer lugar, los textos televisivos, que exigen del estudiante una actitud pasiva, una respuesta desde el entusiasmo al aburrimiento, pasando por toda la gama de reacciones y seguimientos que son los mismos que pueden provocar en los hablantes nativos, pues están pensados para eso. En segundo lugar, las videograbaciones, donde el estudiante se observa a sí mismo tomando parte en una interacción en la lengua objeto (Ruiz Fajardo, 1994: 144).

Como propone Ruiz Fajardo (1994: 158), una manera de trabajar el enfoque comunicativo a través de un programa de televisión puede ser la siguiente: elaborando en grupo programas (role play) a partir de otros programas auténticos grabados de la televisión en la lengua objeto. Es decir, a partir de modelos que proporcionen el caudal de lengua (input) necesario. Cada grupo decide, de acuerdo con las preferencias de sus miembros, el número de actores, sus roles, si algunos estudiantes se quedan tras la cámara, etc. Así, se fomenta el trabajo en grupo, lo que favorece la adquisición de la competencia comunicativa.

A propósito de la elaboración de estos programas y, sobre todo, de la grabación de los vídeos, no hay que dejar de mencionar que la presencia de una cámara puede producir ansiedad en los estudiantes. Como solución a este problema, Lonergan (1984: 113) cree que es suficiente hacer ver a los aprendices el propósito pedagógico de la actividad: la vergüenza debe suplirse con el interés por aprender a través de la representación y, sobre todo, por el interés de verse a uno mismo actuando en la lengua objeto (Ruiz Fajardo, 1994: 158). No obstante, dado que el uso de grabaciones de actuaciones de los alumnos en el aula de L2 está ya bastante extendido, este problema es cada vez menos frecuente.

Ruiz Fajardo (1994: 159-160) sostiene que para evitar interrumpir el desarrollo de la actividad, la corrección de errores no debe hacerse durante la actuación de los estudiantes. Lo más adecuado es que el profesor anote los errores cometidos y programe otro tipo de actividades destinadas a corregirlos. La grabación es la que permite al profesor y a los alumnos tener un acceso directo a los errores. Además, permite a los estudiantes enfrentarse a ellos y reconocerlos personalmente durante la sesión de clase en la que los estudiantes vean las reproducciones de sus trabajos. Esta autoevaluación por parte de los propios estudiantes puede ayudarles mucho, sobre todo, al darles la oportunidad de observarse a sí mismos hablando español. 


\section{EL PROGRAMA TELEVISIVO COMO RECURSO PARA LA \\ ENSEÑANZA/APRENDIZAJE DE ESPAÑOL LENGUA EXTRANJERA}

Por último, nos gustaría hacer un breve comentario sobre papel del docente a la hora de realizar este tipo de actividades. Compartimos la opinión de Pardo Díaz (2000: 876), quien sostiene que el profesor debe cooperar con los estudiantes y guiarlos en la producción del vídeo. Para ello, debe perder el miedo a las «máquinas», familiarizarse con el uso de la cámara y ser capaz de resolver cualquier problema técnico que pueda surgir, para que este tipo de actividades se lleven a cabo con éxito.

\subsection{La integración del programa de televisión en la enseñanza de ELE. Ventajas e inconvenientes}

Como hemos mencionado anteriormente, una de las principales ventajas del recurso del programa de televisión es que el material audiovisual motiva a los estudiantes y los moviliza como espectadores audiovisuales expertos. Esta motivación también viene dada por la aportación de variedad a la dinámica de la clase para salir de la monotonía. Como afirma Ferrés Prats (1994: 127), la mayoría de las imágenes televisivas pueden servir como programa motivador. Bastará que tengan capacidad de seducción y que el profesor las sepa integrar en una unidad didáctica. Además, como hemos señalado, el alumno tiene la posibilidad de seguir mejorando su capacidad de comprensión audiovisual de manera autónoma con un producto fácilmente adquirible. En este sentido, conviene subrayar la diferencia de uso del medio que hace un nativo respecto a un alumno de lengua extranjera que, en la fase de aprendizaje y bajo la guía de un docente, utiliza los medios de comunicación como una herramienta más para obtener su fin: ampliar su competencia comunicativa.

Otra ventaja del programa de televisión es que estimula el interés del alumno por adquirir nuevos contenidos de todo tipo. Al ser un material auténtico, incluye contenidos sociales, culturales, políticos, pragmáticos, etc. del país originario de la lengua que se estudia. Así, nos permite conocer esta cultura de una forma amena y dinámica.

Asimismo, al transmitir ejemplos de comunicación auténtica y espontánea, les presenta muestras reales de lengua. La íntima relación de los programas televisivos con el contexto social y cultural conlleva que normalmente el lenguaje utilizado sea muy coloquial y expresivo, reflejo de lo que el alumno se 


\section{EL PROGRAMA DE TELEVISIÓN COMO RECURSO PARA LA ENSEÑANZA/APRENDIZAJE DE ESPAÑOL LENGUA EXTRANJERA}

va a encontrar en la calle. También ofrece al espectador diversos registros lingüísticos, una amplia tipología textual y pone en contacto al estudiante con diferentes variantes lingüísticas del español. Del mismo modo, ofrece la posibilidad de tratar en la clase de ELE cuestiones como los estereotipos, los clichés uniformados, las costumbres idealizadas, los modelos contraculturales, etc.

\footnotetext{
Los gustos y las preferencias de los espectadores se han ido polarizando en una doble dirección, dependiendo del contenido de la información que desean recibir. Según esta bipolarización, el espectador acude al cine cuando busca la evasión, cuando atrae la ficción, el ensueño y la fantasía, cuando siente la necesidad de identificarse con los héroes y - por el contrario - contempla la TV cuando desea acercarse a la realidad conocer el suceso inmediato, la noticia. El espectador identifica realidad con TV e imaginación con cine (Soler, 1988:120).
}

Soler (1988: 120) explica una de las claves diferenciales de la televisión frente a su más inmediato competidor: el cine. Los géneros, espacios y modos de trabajo más propiamente televisivos se caracterizan por ser en directo, lo que origina una forma de lenguaje que, de entrada, rehúye la narrativa sincopada propia del relato fílmico, ya que carece de un guion estricto. El programa televisivo refleja no solo los momentos interesantes de la acción, sino también los tiempos muertos, las transiciones, las interrupciones, etc. Además, posee el interés adicional de presentar los hechos en el mismo momento en que se están produciendo, lo que exculpa a su lenguaje de ciertas limitaciones y hasta de cierta pobreza y monotonía.

Otra ventaja es su corta duración, que nos permite trabajar con agilidad y rapidez, variando las actividades y practicando varias destrezas. La mayoría tienen pocos diálogos, lo que nos permite realizar actividades sencillas de audición. Igualmente, no implica el esfuerzo de atención y comprensión, por parte de los alumnos, que exigen otro tipo de materiales audiovisuales como los documentales o las películas. Estos últimos, además, no muestran actos comunicativos espontáneos, sino que están a caballo entre la lengua hablada y la escrita, ya que proceden de guiones (Ruiz Fajardo, 1994: 152).

Como señalan Marques Branco y de Amorim Barbieri (2003), también cabe mencionar el beneficio que se puede obtener del empleo de la televisión como recurso didáctico para la enseñanza de español como lengua extranjera en países con grandes desigualdades sociales. En este sentido, la transmisión de programas educativos puede ser una salida ante las dificultades de algunos para acceder a una formación educativa en su país. En algunos países la desigualdad social es un factor que lleva a que un gran número de personas se vea obligado 


\section{EL PROGRAMA TELEVISIVO COMO RECURSO PARA LA \\ ENSEÑANZA/APRENDIZAJE DE ESPAÑOL LENGUA EXTRANJERA}

a interrumpir sus estudios, ya sea por su situación económica o por la distancia existente para poder llegar a un gran centro educativo.

Por otro lado, pueden señalarse algunos inconvenientes. El primero, que el material audiovisual requiere un equipo de vídeo para su reproducción, y esto supone una inversión para los centros de enseñanza. Además, como señala Aguaded Gómez (1993: 123), conviene contar también con óptimos aparatos de recepción de la imagen, puesto que el visionado de grandes grupos de alumnos con pequeños monitores no facilita un aprendizaje en óptimas condiciones. Sin embargo, creemos que hoy en día esto supone una inversión de escasa cuantía para cualquier centro de enseñanza, ya que existe en el mercado una amplia oferta de reproductores, cámaras y material editado a precios muy económicos.

El segundo inconveniente puede resultar quizás más relevante: el vídeo puede promover la pasividad de los alumnos. Ahora bien, esto solo ocurre cuando nos limitamos a utilizarlo como medio de presentación de la lengua objeto, pues existen multitud de recursos de explotación para convertirlo en una fuente de auténtica actividad (Ruiz Fajardo, 1994: 142). Por ejemplo, como hemos explicado, la organización de representaciones (role play) y la elaboración de programas por parte de los estudiantes.

En el ámbito de la enseñanza del español, Sierra Plo (1990), aunque valora mucho la utilidad de este recurso, advierte de un peligro, que podríamos considerar el tercer inconveniente: un apoyo excesivo en la imagen, aun siendo beneficioso para la comprensión, puede perjudicar el desarrollo de la competencia comunicativa del alumno, al distraer su atención de los elementos verbales de la comunicación. Para evitarlo, como sostiene Ruiz Fajardo (1994: 142) el visionado debe ser activo, sirviendo como punto de partida para discusiones, comentarios y búsqueda de soluciones a problemas que surjan en la pantalla, y el profesor debe programar actividades para que así sea.

Por último, como señala Aguaded Gómez (1993: 119), la televisión ha hecho más cercana la realidad y la diversidad cultural y social de la humanidad. Pero además, junto a esta faceta positiva, la televisión es también canal de transmisión de estereotipos, clichés uniformados, costumbres idealizadas, modelos contraculturales, etc. Sin embargo, no creemos que esto sea un inconveniente, sino una cuestión más que tratar en la clase de ELE a través del programa televisivo. 


\subsection{Criterios de selección de programas de televisión para la enseñanza de ELE}

La cantidad de material disponible puede ser uno de los grandes problemas a la hora de elegir adecuadamente: ¿qué tipo de documentos seleccionar?, ¿qué características deben tener para ser documentos auténticos?, ¿qué variedad del español han de mostrar?, ¿qué cultura hispánica tienen que representar? Además, el profesor se encuentra con la cuestión de cómo explotarlos didácticamente (Ferrer Plaza, 2009: 2363).

Una frase clásica referida dice que la televisión pretende informar, formar y entretener. Esto es así, pero con un mayor predominio de los programas de entretenimiento y de información, pues los programas meramente formativos son menos atractivos para los telespectadores -entre los que podemos incluir, en este caso, a los estudiantes de español como lengua extranjera-.

Con respecto a los formatos de programas, existe cierta tendencia a la hibridación, por ello, el formato magazine es uno de los más explotados. Este puede albergar todo tipo de contenidos: entrevistas, tertulias, secciones de información, reportajes, humor, etc. En este sentido, creemos y, más adelante en este trabajo, demostraremos que también es uno de los formatos que más se puede explotar didácticamente como material complementario para la enseñanza de idiomas.

Sin embargo, como mostramos en la siguiente tabla, hay muchos otros formatos de programas televisivos que también deberían tenerse en cuenta a la hora de trabajar con material audiovisual en la clase de ELE. 
Tabla 5

Tipos de programas televisivos

Informativos

Culturales/Divulgativos

Ficción

Entretenimiento
Flash informativo y avances informativos.

Telediario: programa informativo por excelencia.

Ediciones especiales: eventos deportivos, políticos (elecciones), etc.

Opinión: tertulias, debates.

Reportajes de actualidad.

Entrevistas a personajes de interés social, cultural, político, etc.

El tiempo, Deportes: secciones incluidas dentro de un Telediario, y que normalmente se presentan en bloques diferenciados.

Documental: de cierto carácter informativo pero no necesariamente actual.

Musicales: programas para divulgar la música.

Educativos: pueden estar asociados a un programa de educación formal y reglada.

Otros: especializados en libros, arte, viajes, etc.

Series: con tramas específicas por capítulo y tramas de larga duración.

Miniseries: series de corta duración.

Telenovelas: tramas continuadas entre capítulos.

$T V$ movies: películas producidas específicamente para televisión. No se estrenan en cine.

Cine: películas que se emiten en televisión después de un tiempo de explotación comercial en los cines.

Magazines: engloban géneros diversos y sirven como formato contenedor.

Galas: suelen incluir actuaciones musicales, de humor, etc.

Concursos: de azar, de méritos, etc.

Talk-shows: entrevistas y testimonios.

Reality-shows: hay distintas variedades y suelen incluir algún tipo de concurso: de famosos, de 
convivencia, de méritos, etc.

Deportes

Programas específicos de programación regular.

Retransmisiones de competiciones: fútbol, motos,

Fórmula1, ciclismo, etc.

Eventos especiales: Juegos Olímpicos, Campeonatos

del Mundo, etc.

Fuente: elaboración propia

El alumno está acostumbrado a ver la televisión o el cine como medio de entretenimiento y relajación. La actitud del alumno es por lo tanto pasiva. Si vamos a utilizar el vídeo en clase con fines didácticos, la actitud del alumno deberá ser activa. Para ello, debemos preparar una serie de materiales complementarios que despierten su interés y le motiven a participar en la actividad (Pardo Díaz, 2000: 876). Esto es lo que nos proponemos conseguir con la propuesta de actividades presentada al final de esta tesis doctoral.

Para aprovechar este potencial motivador, los textos con que se va a trabajar deben despertar el interés del alumno. Del mismo modo que en la vida real solo escuchamos lo que nos interesa, nuestros alumnos solo se implicarán en comprender el mensaje si sienten alguna curiosidad por la información que van a recibir (Soriano Fernández, 2009: 38-39). Por ello, el punto de partida ideal a la hora de seleccionar un programa de televisión y diseñar con él una unidad didáctica sería el realizar encuestas a nuestros alumnos para conocer sus gustos, pues de esta manera tendríamos ganado su interés desde el principio. Por supuesto, el profesor valorará el potencial didáctico del programa televisivo elegido, y decidirá la apropiada secuencia de trabajo, la tipología de actividades que se va a aplicar, así como la adecuación de la actividad a la situación docente.

Al contrario de lo que podríamos pensar, no es imprescindible que los programas televisivos sean didácticos. Como afirma Ferrés Prats (1994: 128), cualquier imagen puede serlo si se sabe integrar en una unidad didáctica. Tanto 


\section{EL PROGRAMA TELEVISIVO COMO RECURSO PARA LA \\ ENSEÑANZA/APRENDIZAJE DE ESPAÑOL LENGUA EXTRANJERA}

en las noticias como en los anuncios y en los programas de variedades, hay ejemplos de neologismos, de variaciones dialectales, de utilización de un lenguaje de argot, de incorrecciones o deficiencias expresivas, de variación en los registros expresivos...

Por otra parte y de acuerdo con Ferrer Plaza (2009: 2366-2367), los profesores debemos tener muy en cuenta que los documentos auténticos pueden presentar estructuras, vocabulario o contenidos culturales aún desconocidos para el alumno. Esto puede provocar que la pretendida motivación que tendría que despertar en ellos el documento se convierta en desmotivación al verse incapaces de comprender lo que se les presenta. Para evitar que esto ocurra, el profesor deberá tener en cuenta lo siguiente:

- El documento auténtico debe ser seleccionado de acuerdo con el nivel de lengua de los alumnos.

- Se realizarán una serie de actividades previas que tendrán como objetivo practicar y resolver las posibles dificultades que el profesor presupone que los alumnos tendrán a la hora de usar el documento. Estas dudas pueden ser gramaticales, de vocabulario, socioculturales, etc.

- Las actividades estarán siempre centradas en el documento que estemos usando en ese momento en la clase y las tareas estarán relacionadas con las destrezas comunicativas que utilizaría un nativo al usar ese documento.

- Se privilegiarán los enfoques comunicativos a la hora de explotar didácticamente el documento. Quizá el más apropiado sea el enfoque por tareas por poseer varias características adecuadas para potenciar los aspectos más interesantes del documento auténtico: la implicación de los estudiantes, la similitud de las tareas con las realizadas por los hablantes nativos, la práctica global de las cuatro destrezas, el favorecimiento de aspectos lúdicos y afectivos en las actividades, el uso del documento con objetivos claros y concretos, etc.

- Por otra parte, del mismo modo que no existe un enfoque 'ideal' para la enseñanza de lenguas, tampoco lo hay a la hora de explotar estos documentos. Será la elección personal del profesor (o en ocasiones con la cooperación de los alumnos) en función de las características del grupo, el nivel, los objetivos, el contexto académico, el documento utilizado... la que finalmente determine qué método o métodos usará para cumplir los objetivos planteados. 


\section{EL PROGRAMA DE TELEVISIÓN COMO RECURSO PARA LA ENSEÑANZA/APRENDIZAJE DE ESPAÑOL LENGUA EXTRANJERA}

El profesor debe, por tanto, explotar adecuadamente estos documentos con una secuencia didáctica cuyo fin se identifique de una forma natural con la respuesta comunicativa que daría un hispanohablante, intentando en todo momento salvaguardar la característica esencial que los hacen tan útiles para la clase de ELE: su autenticidad (Ferrer Plaza, 2008: 2368). 
ASPECTOS DE LA COMPETENCIA COMUNICATIVA QUE SE PUEDEN

TRABAJAR CON PROGRAMAS DE TELEVISIÓN

4. ASPECTOS DE LA COMPETENCIA COMUNICATIVA QUE SE PUEDEN TRABAJAR CON PROGRAMAS DE TELEVISIÓN 


\section{EL PROGRAMA TELEVISIVO COMO RECURSO PARA LA \\ ENSEÑANZA/APRENDIZAJE DE ESPAÑOL LENGUA EXTRANJERA}

Si el objetivo principal en el proceso de enseñanza y aprendizaje de una lengua extranjera es conseguir que los alumnos aprendan a comunicarse en una lengua que no es la propia, se hace necesario desarrollar su competencia comunicativa de una manera total, de tal modo que trabajen por igual tanto en la expresión oral y escrita como en la comprensión auditiva y de lectura, es decir, las cuatro destrezas lingüísticas, en un determinado contexto social y cultural (Instituto Cervantes 1994:90)

Antes de abordar qué aspectos de la competencia comunicativa se pueden trabajar con programas de televisión, es necesario presentar una breve tipología de actividades susceptibles de ser diseñadas y realizadas para ser trabajadas mediante el uso de un documento audiovisual, así como algunos criterios necesarios a la hora de elegir los programas televisivos o los fragmentos de estos con que podemos trabajar.

\subsection{La elección del input}

A la hora de elegir el input, recomendamos seguir los diez criterios que propone Wilson (2008:33) y que se relacionan tanto con el contenido del texto oral, como con la retransmisión del mismo:

1. Interés: ¿Será interesante para mis alumnos?

2. Accesibilidad cultural: ¿Comprenderán el contexto y las ideas?

3. Actos de habla/estructuras del discurso: ¿Se discuten conceptos abstractos o se basa en transacciones cotidianas?

4. Densidad: ¿La información se da de manera concentrada y rápida o hay momentos en los que el alumno se puede relajar?

5. Nivel lingüístico: ¿La mayoría del léxico y de la gramática es apropiada para mis estudiantes?

6. Duración: ¿Necesito cortarlo porque es demasiado largo? ¿Es suficientemente largo?

7. Calidad de la grabación: ¿Es clara? ¿Los ruidos de fondo afectan a la comprensión?

8. Velocidad: ¿Hablan demasiado rápido para mis alumnos?

9. Número de hablantes: ¿Las numerosas voces son una potencial causa de confusión?

10. Acento: ¿Es familiar el acento? ¿Es comprensible? 
A estos criterios podemos añadir que el tipo de texto resulte relevante para ejercitar las habilidades que necesita desarrollar el aprendiz, que se varíen las tipologías textuales (canciones, noticias, películas, conversaciones, etc.), que se respeten los rasgos prosódicos genuinos de la LE, y que se considere la dificultad no solo del input, sino también de la tarea que debe realizarse a partir de él y de las instrucciones de esta.

Estamos de acuerdo con Brandimonte (2003) en que normalmente los telediarios son los programas más adecuados para empezar, ya que no plantean mucha dificultad incluso para los alumnos de nivel elemental, dadas las directrices impuestas a los locutores cuyo objetivo primario es comunicar, con lo cual asistimos a una perfecta dicción, vocalización y ritmo lento, adoptando la norma culta estándar enriquecida con algunos rasgos típicos de la lengua especializada del periodismo. Otros programas que presentan las mismas características son los informativos, cuyo planteamiento a base de entrevistas puede servir para introducir muestras auténticas de habla cotidiana. Como señala Brandimonte, la visión de documentales generalmente no suele despertar gran interés, tanto por su contenido lingüístico como por los argumentos tratados.

Todos los programas de tertulias, magazines y de entretenimiento se adaptan perfectamente para empezar a profundizar en los fenómenos fonéticos que se apartan de la norma estándar, y que representan uno de los principales obstáculos para la comprensión. Aquí ya se pueden analizar las pronunciaciones irregulares debidas a supresión y adición de sonidos, por influencia de sonidos próximos, por articulaciones de difícil ejecución, las pronunciaciones descuidadas debidas a la tendencia a la economía y relajación, típicas de las interacciones llevadas a cabo en forma de charla amigable. Además, si se trata de programas emitidos en varios países, se pueden hacer, al mismo tiempo, interesantes comparaciones entre unas culturas y otras. Por su parte, los concursos relacionados con la lengua y la cultura general, que también suelen tener sus exactos correspondientes en otros países, se prestan para el análisis y la ampliación del léxico.

Las teleseries suelen ser de gran utilidad y logran cierta aceptación entre los alumnos, aunque a veces presentan cierto grado de enfatización y afectación que no se suele apreciar en las películas de cine. La mayoría de las series españolas representa una buena muestra de la vida y del habla cotidiana de España. Estas sirven, además, como preparación para la visión de las historias más elaboradas de las películas. 


\section{EL PROGRAMA TELEVISIVO COMO RECURSO PARA LA \\ ENSEÑANZA/APRENDIZAJE DE ESPAÑOL LENGUA EXTRANJERA}

Otro aspecto importante de cada cultura y que merece un espacio en el aula de lenguas extranjeras es el relativo al humorismo. Los programas de humor, de chistes o de monólogos resultan más adecuados para los niveles más avanzados, pues este lenguaje es uno de los más complicados de entender e interpretar para un extranjero, debido a sus múltiples implicaciones culturales. Es un género mixto, monologal (externamente) y al mismo tiempo dialogal (internamente). En cuanto al registro, el estilo es coloquial, el discurso es referido, hay expresiones idiomáticas, polisemia, símiles, metáforas, hipérboles, ironía, personificaciones y, sobre todo, humor.

También algunas emisiones puntuales, como el Programa de Fin de Año o la Gala de los Goya, pueden servir de muestra para explicar algunos aspectos culturales del país, como la tradición de las doce uvas, la celebración anual de premios cinematográficos que tiene lugar en España, etc. Los programas de medicina, gastronomía, derecho, cine, música y deporte, entre otros, también se pueden utilizar para trabajar en clase las lenguas especializadas y la terminología relativa a ese campo.

Por último, cabe señalar que no se debe confundir lo oral con lo coloquial. El programa televisivo supone una muestra real tanto del registro coloquial como del formal. Sin embargo, consideramos importante resaltar la necesidad de trabajar adecuadamente el registro coloquial, pues destaca el hecho de que, desde hace varios años, hay una tendencia a hacer más coloquiales ciertos géneros, por lo que su dominio puede ayudar, en gran parte, a dominar el resto de registros. Además, este registro se da en todas las edades y se combina con otras variedades. Sin embargo, parece que cuando se enseña el registro coloquial se pone especial énfasis en el léxico, cuando esto no es lo único que lo diferencia del registro formal. Los modelos coloquiales que se ofrecen a los alumnos en clase de ELE no siempre son los más representativos, pues muchos de ellos no reflejan algunas de sus características (dubitación, reformulación, repetición, vacilación...). Enseñar todo esto al estudiante con muestras reales, como es el caso de los programas televisivos, contribuye a reducir su ansiedad ante el miedo a no realizar un «discurso perfecto». No obstante, como venimos anunciando, la propuesta didáctica presentada al final de esta tesis supone una muestra de actividades enfocadas a trabajar tanto el registro coloquial como el formal.

Respecto al diseño de las actividades, ofrecemos diez pautas que suponen la aplicación de los fundamentos teóricos anteriormente expuestos: 
1. Las actividades deben servir para identificar por qué el alumno entiende lo que entiende y no entiende lo que no entiende, esto es, constituyen un diagnóstico para el profesor.

2. Han de ser significativas para el desarrollo del aprendiz como oyente, es decir, ejercitarán las habilidades que deba desarrollar para desenvolverse en las situaciones comunicativas a las que debe enfrentarse. Por ejemplo, no necesita las mismas habilidades de comprensión oral un alumno de ELE que se está preparando para ser intérprete simultáneo, que otro que aprende español para participar en reuniones de negocios.

3. Dirigir algunas actividades a la detección de problemas para reducir la ansiedad ante la tarea de la comprensión oral.

4. Requerir que el alumno active los mismos procesos de comprensión que pondría en práctica en una situación similar fuera del contexto académico de uso de la lengua.

5. Las actividades de preaudición deben incluir la planificación del proceso de comprensión oral, fijando los propósitos de la escucha, orientando la atención, y facilitando estrategias de apoyo.

6. Interrumpir la escucha cuando sea necesario por alguna dificultad concreta - de manera que el alumno pueda aplicar sus estrategias con cierto grado de control- y repetir la escucha tantas veces como sea necesario, ya que el objetivo no es evaluar la comprensión oral, sino ejercitarla.

7. Permitir que el alumno responda en su lengua materna cuando el modo de respuesta pueda interferir negativamente en la comprensión auditiva.

8. Fomentar la selección de objetivos del propio aprendiz para fomentar su autonomía como oyente.

9. Dirigir la atención del alumno primero al contenido del mensaje y luego a la forma lingüística.

10. Escuchar nuevamente el texto oral en la corrección de la actividad, y dirigir esta nueva audición a detectar dónde y por qué se han producido los problemas de comprensión, y a dar una orientación al alumno para solucionarlos. Esto servirá para que el alumno tenga la oportunidad de ejercitar de nuevo su habilidad de comprensión oral, poniendo esta vez a prueba los consejos del profesor, y para reflexionar conscientemente sobre sus procesos y estrategias de escucha. 


\section{EL PROGRAMA TELEVISIVO COMO RECURSO PARA LA \\ ENSEÑANZA/APRENDIZAJE DE ESPAÑOL LENGUA EXTRANJERA}

\subsection{La tipología de las actividades}

Antes de explicar la tipología de actividades, hay que comentar las distintas variables que intervienen en su diseño: el tipo de proceso de comprensión que se requiere, el tipo de labor que se fija en cada una, el modelo pedagógico en que se basa el diseño, o el nivel lingüístico que se quiere trabajar. Dado que el programa televisivo es un documento de tipo audiovisual, la destreza de la que partiremos para posteriormente diseñar actividades con las que trabajar los diferentes aspectos de la competencia comunicativa - aspectos gramaticales, léxico, socioculturales, pragmáticos, estratégicos y discursivos-, será la comprensión auditiva.

En primer lugar, respecto a los tipos de procesos que intervienen en la comprensión auditiva, Richards $(1983,2008)$ distingue dos: procesamiento ascendente (bottom-up processing) y descendente (top-down processing). E1 procesamiento ascendente parte del análisis de los sonidos para identificar palabras, y a su vez sintagmas, oraciones, el discurso... Para desarrollar este tipo de destreza es preciso el reconocimiento de palabras clave, el acento y la entonación, las relaciones gramaticales entre partes clave de las oraciones, etc., y para ello se plantean ejercicios como dictados, actividades de rellenar huecos, de selección de respuestas múltiples, de identificación de conectores oracionales... En el procesamiento descendente, el estudiante requiere conocimiento previo acerca del tema del discurso o la situación comunicativa, que activa una serie de esquemas o guiones sobre esta (qué formulas o vocabulario usar, por ejemplo, en una tienda). Se requieren habilidades de inferencia (de la situación comunicativa, detalles no mencionados acerca del contenido, etc.) o de anticipación de cuestiones relacionadas con lo que va a escuchar, y para ello se suele pedir a los estudiantes que escriban una serie de ideas o palabras antes de escuchar, que intenten predecir el final de una historia, etc. Cada tipo de procesamiento requiere ciertas estrategias y habilidades cognitivas y comunicativas, de las cuales existen taxonomías para planificar actividades (vid. Gil-Torresano, 2004: 909).

En segundo lugar, el diseño, como indica Richards (1983), puede centrarse en la manipulación de la grabación que recibe el alumno (el input) o en la tarea que tiene que realizar. Respecto a la tarea, las actividades pueden variar según se quiera practicar la comprensión global (el significado del documento en su conjunto) o la comprensión parcial (de detalles específicos). Igualmente, según la respuesta que requiera por parte del alumno, la tarea puede ser mecánica (en la que no es necesario comprender el significado; por ejemplo, discriminar un 
sonido entre dos palabras), significativa (en la que se necesita comprender, sin creatividad por parte del alumno; por ejemplo, ordenar un diálogo) o comunicativa (en la que se requiere comprender y además interpretar y actuar de algún modo: reaccionar, proponer una solución, recomendar algo...).

En tercer lugar, el tipo de actividad puede depender del modelo pedagógico para la comprensión auditiva, que según Bonch-Bruevich (2006) puede ser uno de estos cuatro:

- emparejamiento o armonización por patrones: es propio de los métodos audiolinguales de los años 40-60 del siglo XX y se dirige a la repetición mecánica de estructuras, sin atender al mensaje. No suele emplearse más allá de los niveles iniciales;

- procesamiento de la información discreta: propio del método nociofuncional de los años 70-80, ofrece actividades sin una dimensión interactiva con el alumno: cuestiones de verdadero o falso, selección múltiple, relacionar...;

- instrucción por tareas: se practica desde los años 70 en adelante y el alumno emplea la información escuchada para realizar una tarea o resolver un problema;

- comunicación interactiva: el modelo más actual, incorpora a la comprensión del mensaje destrezas propias de la competencia cultural, sociolingüística o estratégica. Se lleva a cabo generalmente en niveles avanzados.

Finalmente, el nivel de la lengua que se quiera practicar influirá en el tipo de diseño. Como indican A. Giovannini, E. Martín Peris, M. Rodríguez y T. Simón (1996a: 12-13), la actividad de comprensión auditiva puede trabajar los siguientes niveles:

- palabras: por ejemplo, completar las palabras eliminadas de la transcripción;

- frases: responder con acciones (por ejemplo, instrucciones o consejos), dibujar...;

- organización de la información: reconstruir una historia desordenada, ordenar los elementos de un mensaje...;

- discurso: tomar apuntes de una conferencia, rellenar una ficha...; 


\section{EL PROGRAMA TELEVISIVO COMO RECURSO PARA LA \\ ENSEÑANZA/APRENDIZAJE DE ESPAÑOL LENGUA EXTRANJERA}

- comprensión inferencial: deducir las actitudes de un intercambio de opiniones, la situación comunicativa o la información sobre los participantes en un discurso...

Además de estos niveles, las actividades deben trabajar también el conocimiento lingüístico del ritmo y la melodía del habla oral (entonación, pausas, etc.) o de las variaciones de pronunciación debidas a la coarticulación (Gil-Torresano, 2004: 903).

A continuación se detallan algunos de los posibles tipos de actividades de comprensión auditiva que se pueden realizar utilizando como base, en nuestro caso, programas televisivos. Hay que tener en cuenta que los límites entre las categorías no son nítidos en todos los casos. Algunas de estas actividades se incluyen en las propuesta didácticas originales que presentamos en esta tesis.

- Selección de información:

- preguntas de verdadero/falso;

- rellenar huecos: puede ser a partir de la transcripción de la grabación o de frases literales sueltas;

- rellenar tablas: por ejemplo, completar los verbos en la persona de la conjugación que se indica, clasificar los datos en cada columna de características, ventajas o inconvenientes, o extraer del texto escuchado los recursos que emplea el hablante para presentar los contenidos de una conferencia, agradecer al auditorio, etc.;

- completar información: por ejemplo, para concertar una cita, un cuadro con la hora y el medio de transporte; o indicar la información económica a la que pertenecen los datos que se presentan. Marcar las casillas con la opción correcta, entre varias que se presentan;

- ordenar los diálogos que se ofrecen desordenados o los fragmentos de un párrafo;

- ordenar elementos: por ejemplo, los diferentes destinos de un viaje, las etapas de la vida de alguien o las fases de fabricación de algo; la actividad también puede apoyarse en ilustraciones.

- Transferencia de información: 
- con ilustraciones se pueden realizar actividades como escuchar y seguir una ruta, marcar en un mapa qué ciudades se mencionan o los fenómenos climáticos de cada región;

- dibujar un plano de una casa a partir de los datos escuchados...

- Relación o distinción de información:

- relacionar datos: por ejemplo, los titulares de varias noticias con sus subtítulos correspondientes, a partir de la información económica de la radio; o unas gráficas de datos económicos con la información que proporcionan los hablantes;

- distinguir la información escuchada y la que se ofrece en forma de texto: por ejemplo, seleccionar el mejor resumen de un fragmento de conferencia o de noticia que se ha escuchado; decidir cuál es el correo electrónico más apropiado para pedir cierta información; o cuál es el mejor esquema relacionado con una presentación corporativa, etc.;

- corregir un texto que presenta errores o que carece de ciertas palabras;

- de entre varias ideas clave que se presentan sobre un documento, marcar las que se escuchan o en qué orden aparecen. Como variante, se puede pedir al alumno que marque qué palabras se escuchan en el texto de entre varias que se presentan.

- Sintetizar información: se trata de actividades que consisten en resumir los contenidos en un breve texto, empleando un título o completando una frase.

- Reacción y respuesta: por ejemplo, responder a preguntas de respuesta abierta o cerrada, de selección múltiple, etc. También se puede plantear que el alumno escuche una información y a partir de ella formule un consejo.

- Actividades de inferencia: en estos ejercicios el hablante escucha una grabación y deduce los datos necesarios para realizar una tarea, por ejemplo:

- Interpretar información, por ejemplo, a partir de los datos que proporciona un hablante, considerar si la actitud ante los mismos es positiva o negativa o si el enfoque de una información va a ser irónica, realista, bromista, etc.

- Inferir datos desconocidos de la grabación: por ejemplo, detalles sobre los hablantes o la situación comunicativa, deducir de qué se habla o en qué contexto se desarrolla. 


\section{EL PROGRAMA TELEVISIVO COMO RECURSO PARA LA \\ ENSEÑANZA/APRENDIZAJE DE ESPAÑOL LENGUA EXTRANJERA}

En cuanto a los posibles tipos de actividades de posvisionado — una vez visto y tratado el formato y el contenido del vídeo del programa televisivo en cuestión, mediante las actividades realizadas durante el visionado - creemos que las más adecuadas y rentables para trabajar con este formato son las actividades de expresión e interacción orales, ya que el input del que partimos es de tipo oral. En esta clasificación, podemos incluir los diálogos, las entrevistas y encuestas, los monólogos, los debates, y los relatos y anécdotas (Pinilla, 2010). No obstante, como veremos en las propuestas didácticas incluidas en esta tesis, también es posible realizar actividades de otro tipo.

- El diálogo, la conversación en general, corresponde al tipo de discurso más emblemático en el desarrollo, las técnicas y las estrategias de la interacción. Los interlocutores alternan el papel de emisor y receptor y codifican y descodifican mensajes en un tiempo récord. La conversación se caracteriza por el dinamismo, la alternancia de papeles, la cooperación, la espontaneidad, la relación entre los interlocutores y todos aquellos factores que hemos señalado como parte del contexto.

La conversación que solemos presentar en el aula suele producirse en el nivel correspondiente al registro informal, aunque también hay conversaciones, relacionadas con entornos situacionales como el profesional o el institucional - especialmente practicadas en el ámbito de español para fines específicos-, que son más formales y que responden a una mayor estructuración discursiva.

Por supuesto, los diálogos pueden ser más dirigidos o más libres por parte del profesor en función del nivel de competencia comunicativa alcanzado por los estudiantes.

- Las entrevistas y las encuestas son dos tipos de discurso en los que los papeles están muy bien definidos: el que pregunta y el que responde, el entrevistador/encuestador y el entrevistado/encuestado, respectivamente. Aunque en la vida real el estudiante suele enfrentarse a más situaciones en las que él es el entrevistado/encuestado, en clase conviene trabajar ambas facetas.

Como señala Pinilla (2010), la diferencia básica entre la entrevista y la encuesta la encontramos en las definiciones que de ellas da el Diccionario de la lengua española de la RAE. La entrada léxica entrevista aparece con dos acepciones básicas: a) conversación acerca de ciertos extremos para informar al público de sus respuestas; y b) concurrencia de dos o más personas que tratan de resolver un negocio. 
En el primer sentido, pensamos en una entrevista radiofónica a un personaje famoso y, en el segundo, en una entrevista de trabajo, por ejemplo, o si nos centramos en el ámbito institucional, en la capacidad de responder ante la acción de poner una denuncia.

La encuesta, por su parte, es un conjunto de preguntas tipificadas dirigidas a una muestra representativa, para averiguar estados de opinión o diversas cuestiones de hecho.

- Los monólogos son situaciones en las que el estudiante actúa como emisor. El objetivo es que el estudiante hable e intervenga. El monólogo responde a una necesidad subjetiva de expresión — normalmente estos monólogos están dentro de una interacción más amplia, ya sea un diálogo o un debate-.

- El debate es una de las actividades de interacción oral más utilizadas en clase de ELE. Sin embargo, no siempre se practica de forma correcta por su complejidad - las destrezas y habilidades específicas que requiere por parte de los estudiantes - y por el tiempo que normalmente lleva su preparación y su puesta en escena en el aula.

El debate es la actividad de interacción oral —en este caso sí podemos utilizar de manera más precisa el término interacción en lugar de expresión - que supone un mayor despliegue de técnicas argumentativas: opinar, ejemplificar, argumentar, rebatir, tomar o quitar la palabra, y retomarla cuando te la quitan.

Conviene añadir que el debate es una actividad que se suele practicar con estudiantes que tienen un cierto nivel lingüístico y que normalmente es necesaria la figura de un moderador, normalmente el profesor.

- Las actividades comunicativas que se incluyen en el grupo de relatos y anécdotas tienen en común el género, correspondiente a la narración y también a la exposición en el caso de las exposiciones orales en el aula actividad muy relacionada con el mundo académico y con el profesional-. Se trata de un tipo de discurso monogestionado, como lo define Mercè Pujol (2002). También se corresponde con la actividad denominada monólogo sostenido: descripción de experiencias (MCER: 213). Entre las muestras más habituales cabría destacar, por ejemplo, contar y relatar biografías, sueños, chistes, anécdotas, relatos, microrrelatos, cuentos, historias (extrañas, divertidas, inolvidables), hábitos, etc. (Pinilla, 2010). 


\section{EL PROGRAMA TELEVISIVO COMO RECURSO PARA LA \\ ENSEÑANZA/APRENDIZAJE DE ESPAÑOL LENGUA EXTRANJERA}

\subsection{El diseño de las actividades}

Diseñar actividades de comprensión auditiva no es una tarea fácil si se quieren cumplir los criterios de adecuación que expone Richards (1983: 233):

- lograr que la actividad desarrolle la comprensión auditiva y no el conocimiento de la materia que aborda el documento $u$ otras destrezas relacionadas con la inteligencia;

- no realizar actividades que más bien se dirijan a la práctica de la memoria;

- aproximar el propósito de la actividad de comprensión auditiva al de cualquiera de la vida real, no complicar las actividades con ejercicios artificiosos;

- diseñar la actividad según el propósito elegido para la misma: enseñar a escuchar o evaluar;

- autenticidad de los materiales.

En cada propuesta didáctica presentada en esta tesis, se incluyen actividades de previsionado, de durante el visionado y de posvisionado, como las que se describen a continuación.

La fase de calentamiento previo a la audición puede plantearse de diferentes maneras. Esta fase resulta de gran importancia, pues con el simple visionado no se alcanzarían los mismos resultados. Hay que comenzar por atraer la curiosidad y el interés por parte de los alumnos para que la proyección sea fructífera.

- El planteamiento de algunas preguntas que hagan al alumno reflexionar antes de la escucha, activar el conocimiento previo sobre el tema principal del discurso, o preparar y refrescar vocabulario sobre el asunto o las posibles fórmulas para expresar una función comunicativa. En otros casos, también se le pide al alumno que lea el título y piense de qué tratará el documento antes de la audición, para que tras la visualización, pueda contrastar sus hipótesis. Igualmente, para activar el conocimiento previo del alumno se pueden utilizar ilustraciones.

- La lectura de un breve texto o diagrama relativo al tema de la audición; de este modo, se prepara el conocimiento que recibirá el alumno. 
- La presentación del vocabulario con cierta dificultad para la comprensión del documento, mediante la explicación de su significado, lectura o la realización de un ejercicio de emparejamiento entre las palabras y su significado, ofreciendo también a veces una actividad previa de relación entre imágenes y vocabulario. Es evidente que, como señalan varios autores (Martín Peris: 1991; Cabello, 1998: 9), lo importante en la comprensión auditiva no es entenderlo todo, por lo que no es necesario presentar o explicar todas las palabras, sino solo aquellas que podrían ser problemáticas.

En la fase de visualización prima la comprensión del mensaje (bien del sentido global o de detalles concretos) por encima del trabajo sobre la forma, pues, como afirma Richards (1983: 221), la memoria a largo plazo trabaja con el significado, no con la forma, de modo que los mecanismos léxicos o gramaticales del discurso escuchado no se retienen, sino su significado proposicional. Dependiendo del tiempo a disposición, la fase de proyección no debería extenderse en exceso para dejar espacio a la actividad de ejercicio. Gracias a la gran flexibilidad del medio y a la facilidad de uso, es posible pasar varias veces el fragmento, interrumpirlo para realizar una actividad, pasar la imagen sin sonido, en definitiva, manipularlo para lograr nuestros objetivos. El subtitulado es otro aspecto importante en una fase inicial o intermedia donde los estudiantes muestran todavía algunas carencias en la comprensión auditiva.

Por lo general, los ejercicios de posvisualización no corresponden propiamente a la destreza de comprensión auditiva y se convierten más bien en ejercicios centrados en la forma para trabajar otros aspectos de la competencia comunicativa. De ahí que defendamos que, a través del recurso del programa televisivo, es posible ejercitar varias destrezas. Estos ejercicios pueden consistir en:

- la práctica de algún aspecto gramatical, léxico, cultural, pragmático, estratégico o discursivo, explicado o practicado en el marco de la actividad, por ejemplo, a partir de un fragmento de la transcripción, o transformando algunas frases de la misma;

- la práctica de la identificación de formas lingüísticas de manera inductiva, a partir de la transcripción de la audición.

Si el material se dirige a niveles intermedios y avanzados, se pueden diseñar abundantes actividades de posvisualización para la reflexión y la práctica sobre 


\section{EL PROGRAMA TELEVISIVO COMO RECURSO PARA LA \\ ENSEÑANZA/APRENDIZAJE DE ESPAÑOL LENGUA EXTRANJERA}

aspectos léxicos como las expresiones fraseológicas (modismos, por ejemplo, «estar verde»; fórmulas rutinarias, por ejemplo, "ifaltaría más!», etc.) o las colocaciones (brindar una posibilidad, administrar una vacuna...). Asimismo, también se pueden presentar actividades de posvisualización para la práctica de aspectos pragmáticos; por ejemplo, los marcadores discursivos: conectores y ordenadores como por un lado, por otro lado, etc.; marcadores conversacionales como pues, mira, ¿sabes?...

Otro tipo de actividad de posvisualización consiste en centrar la atención en algún tema relacionado con el documento escuchado, para la práctica de la expresión oral — como detallamos más arriba - o la expresión escrita. Si el alumno trabaja de manera autónoma, puede proporcionarle un motivo para escribir un pequeño texto. Si la actividad se lleva a cabo en una clase, puede proporcionar un motivo de debate entre grupos de alumnos.

\subsection{Aspectos gramaticales}

Como explicamos en apartados anteriores, el Enfoque Comunicativo tiene como objetivo que los alumnos alcancen una competencia comunicativa teniendo en cuenta el contexto en el que se produce la comunicación, así como la intención comunicativa de sus protagonistas. Para este objetivo, es necesario, entre otros, el conocimiento gramatical, ya que como parte fundamental de la competencia comunicativa se encuentra la competencia gramatical.

Gómez del Estal y Zanón (1999) señalan que los aprendices elaboran dos tipos de conocimiento gramatical a partir de los datos de entrada que reciben: por un lado, un tipo de conocimiento gramatical explícito, compuesto por un conjunto de reglas y estructuras de la LE que han sido analizadas y organizadas de manera consciente por el alumno, a las que puede acceder sin esfuerzo y cuya función principal es la de monitorizar; por otro lado, un conocimiento gramatical implícito, compuesto por un conjunto de unidades (frases-fórmula del tipo «qué tal»; y reglas intuitivas — que forman la gramática que subyace cuando el alumno habla o escribe en la lengua de forma espontánea-), de naturaleza intuitiva y no accesibles conscientemente.

Los profesores de ELE deben tener en cuenta ambos conocimientos gramaticales, y el papel de la enseñanza de la gramática debe tender a activar ambos tipos de conocimientos, utilizando para ello actividades centradas en la 
forma, en el uso, y en la forma y en el uso al mismo tiempo, como por ejemplo, la comprensión oral de los diferentes formatos televisivos.

Dentro de esta visión comunicativa y a la vez pragmática en la enseñanza de ELE, podemos constatar que los textos, tanto orales como escritos, extraídos de situaciones comunicativas reales como ocurre con los programas televisivos - resultan ser un material adecuado para trabajar también la competencia gramatical. Así, a través del texto, el estudiante extrae desde una situación discursiva las intenciones comunicativas con sus exponentes funcionales, además de las estructuras gramaticales.

En este sentido, se pueden realizar actividades de dos tipos: que contribuyan a desarrollar las nociones gramaticales en los alumnos de manera inconsciente; o que estén orientadas a trabajar y practicar en contexto las nociones ya aprendidas.

En cuanto a las actividades del primer tipo, estas pueden organizarse de acuerdo con las siguientes fases: en la primera etapa del trabajo, los estudiantes, sin ningún tipo de input, leen en clase el texto elegido por el profesor; a partir de esta lectura, los alumnos y los profesores reflexionan sobre el elemento lingüístico (gramatical), previamente planeado por el profesor, que se quiere presentar a los estudiantes; después de la lectura, los estudiantes intentan inferir en qué pueden consistir el elemento - y la correspondiente regla gramaticalobservados; en la segunda etapa, el profesor procede a la explicación detallada de la regla gramatical y a la consulta de las posibles dudas que esta nueva información haya suscitado en los alumnos. Finalmente, mediante el debate actividad de expresión oral - sobre el tema planteado en el texto, los estudiantes proceden a emplear el tópico gramatical analizado.

La enseñanza de la subcompetencia gramatical es uno de los retos fundamentales que los profesores de español encuentran en su práctica cotidiana. Su proceso de enseñanza/aprendizaje siempre ha recibido, y aún recibe, una especial atención por parte de todos los métodos de enseñanza de ELE, incluso del enfoque comunicativo. Por ello, creemos que es importante tener en cuenta diferentes recursos a la hora de trabajar esta subcompetencia, entre ellos, el programa televisivo. 


\section{EL PROGRAMA TELEVISIVO COMO RECURSO PARA LA \\ ENSEÑANZA/APRENDIZAJE DE ESPAÑOL LENGUA EXTRANJERA}

\subsection{Aspectos léxicos}

Es un hecho que muchos profesores, cada vez que deben explicar qué significa una palabra, recurren a gestos o a dibujos. Por este motivo, resulta contradictorio el poco provecho que se obtiene de los recursos audiovisuales para el aprendizaje del léxico. Estamos de acuerdo con Miguel García (2005), como indica en su artículo sobre la metodología aplicada en el aula de ELE a la hora de enseñar el léxico, en que parece que los profesores no prestan la suficiente atención a la enseñanza del léxico en clase, en ocasiones porque piensan que los alumnos terminarán aprendiéndolo con el tiempo. Sin embargo, no debemos olvidar que para referirnos a la realidad y comunicar aquello que queremos hay que conocer los términos adecuados.

Parece que la razón de este problema es la dificultad que conlleva su enseñanza comparada con la de otros ámbitos lingüísticos, viéndose esta relegada, en numerosas ocasiones, a la simple y cómoda facilitación de una lista de palabras que, más que facilitar, dificulta bastante la adquisición del léxico. Una de las dificultades para su enseñanza es, sin duda, el carácter inconmensurable del léxico de una lengua, pues en él se incluyen no solo palabras, sino también expresiones idiomáticas, frases hechas o modismos. Cervero y Pichardo (2000: 9) reflexionan sobre la enseñanza del léxico en estos términos: «Nuestra tarea como profesores/as consistirá en ofrecerles una selección o parcelación del léxico que les permita alcanzar objetivos comunicativos»».

En el ámbito de la enseñanza se emplea cada vez más el término de unidad léxica frente al de palabra. Esta expresión haría referencia a:

[...] una secuencia con significado unitario que remite globalmente a un concepto, constituye un sistema arbitrario y puede estar integrada también por una o más palabras: expresiones prepositivas y conjuntivas, frases hechas, combinaciones sintagmáticas bimembres o trimembres y expresiones lexicalizadas (Cervero y Pichardo, 2000: 44).

De esta manera, una unidad léxica puede comprender una o varias palabras, entendiendo por este término una secuencia de letras y/o sonidos limitados que tiene uno o varios significados. A la hora de formular un mensaje empleamos palabras, pero en nuestra mente lo que se almacena son unidades léxicas que, tras un proceso, lograrán combinarse en la lengua.

Como vimos en uno de los apartados previos de esta tesis, en el MCER no se hace distinción entre palabra y unidad léxica, sino que se emplean los términos 
elementos léxicos y elementos gramaticales. Los primeros se refieren al conjunto léxico más abierto (incluyen expresiones idiomáticas, modismos, palabras polisémicas...), mientras que los segundos pertenecen a grupos cerrados y su función es principalmente sintáctica (artículos, pronombres, adverbios...).

A pesar de esta diferencia en la terminología, podemos observar que, en cualquier caso, en la actualidad se entiende que la adquisición de léxico no se basa únicamente en el hecho de asimilar palabras, sino que consiste en aprender las relaciones entre formas y significados.

A la hora de enseñar vocabulario a nuestros alumnos debemos tener en cuenta determinados criterios (Giovannini et al., 1996b: 46-48).

- Rentabilidad/utilidad. Aprendemos una palabra cuando creemos necesario utilizarla. Esto no implica solamente el hecho de incluirla en un mensaje, también el de reconocerla y comprenderla dentro del texto, ya sea oral o escrito, al que el alumno se enfrenta. En este sentido, por tanto, no se trata de dar a conocer el mayor número posible de palabras, sino de proporcionar al estudiante unas herramientas básicas para que, a partir de estas y con determinadas palabras clave, pueda entender y generar mensajes. Así, por ejemplo, como señalan Giovannini et al. (1996b: 46-48), será más útil que nuestros alumnos conozcan la palabra enfermedad en lugar del nombre de diversas enfermedades más específicas.

- Frecuencia. Muy a menudo, se han tomado como punto de partida para determinar qué léxico enseñar las listas de frecuencia. Sin embargo, aunque esto pueda tener cierto sentido en determinados niveles, hay que considerar cuáles son las necesidades de nuestros alumnos y qué palabras, debido a tales necesidades o intereses, utilizarán más. Evidentemente, si nos encontramos en un curso de español para fines específicos, el alumno valorará más aprender léxico relacionado con su especialidad que aprender los nombres de algunos alimentos.

- Acepciones más frecuentes. En este caso también convendrá conocer cuáles son los intereses de nuestros estudiantes, en qué registros deberán interactuar, con el fin de evaluar qué acepciones será más provechoso que aprendan. Así, un alumno que estudie español jurídico deberá conocer expresiones de uso específico y un léxico muy concreto, como por ejemplo, la acepción precisa de palabras como enajenación o enjuiciar dentro del ámbito del derecho. 


\section{EL PROGRAMA TELEVISIVO COMO RECURSO PARA LA ENSEÑANZA/APRENDIZAJE DE ESPAÑOL LENGUA EXTRANJERA}

- Necesidades e intereses de los alumnos. Como hemos comentado, este es un criterio muy importante. Así, no necesitará aprender el mismo tipo de léxico un estudiante que realiza un curso de Erasmus que un especialista en medicina que tiene relaciones con instituciones de habla española. Por tanto, ambos deberán aprender una serie de palabras clave o vocabulario base que irán enriqueciendo poco a poco dependiendo de sus propias necesidades.

En cuanto a la forma de enseñarlo, debemos tener en cuenta cuál es el proceso de adquisición de unidades léxicas, que según Aitchinson (en Morante, 2005: 46) se compone de tres pasos.

1. La etiquetación o reconocimiento de la unidad léxica. En este paso el alumno retiene la grafía y empieza la retención entre forma y significado.

2. El empaquetado. Se descubren los posibles significados de la unidad léxica (denotativos, connotativos, figurativos, rasgos dialectales o de registro, etc.), así como sus posibilidades morfológicas y sintácticas.

3. La construcción de redes. La unidad léxica pasa a incluirse en el lexicón mental del alumno y a formar parte de su vocabulario pasivo a largo plazo, permitiendo la organización del léxico mediante redes semánticas y jerárquicas.

Cervero y Pichardo (2000: 97) añaden un paso más a este proceso: el uso de la unidad léxica, es decir, cuando esta ya forma parte del vocabulario activo del alumno, puesto que este es capaz de recuperarla cuando lo necesita.

Todo esto, evidentemente, supone tener en cuenta una serie de premisas a la hora de diseñar las actividades que han de realizar los alumnos. Baralo propone cinco implicaciones básicas (2000: 172-173):

- El vocabulario en contexto; es decir, proporcionar la mayor cantidad y calidad de información posible, para facilitar el establecimiento implícito de una asociación firme y certera entre la estructura fonológica y la estructura léxico-conceptual de la nueva unidad léxica.

- La selección del vocabulario, atendiendo tanto al nivel de dificultad como al conocimiento previo que tengan los alumnos del tema.

- La utilización de técnicas de descubrimiento e información referencial.

- La importancia del uso de diferentes tipos de diccionarios. 
- Tipología de actividades para promover y facilitar la adquisición del léxico, mediante la puesta en marcha de estrategias de asociación, formales y semánticas del tipo de: derivación y composición; hiponimia e hiperonimia; sinonimia y antonimia; polisemia; campos semánticos y asociativos; expresiones idiomáticas; cognados.

Estos autores plantean una cuestión muy importante: ¿las palabras clave, habrá que presentarlas antes o después de exponer al alumno frente al input? Estamos de acuerdo con ellos en que esto dependerá de los objetivos que se fijen a la hora de diseñar la actividad.

Por otro lado, tenemos que tener claro que no bastará con presentar el vocabulario una única vez, pues el aprendizaje del léxico, como ya hemos visto, se desarrolla de modo progresivo y gradual. Como indica Baralo, es fundamental tener conciencia de que:

En el aula necesitamos, por lo tanto, destinar tiempo para realizar tareas que ayuden a los alumnos a reciclar el léxico que ya conocen, por lo que el profesor necesita disponer de una tipología muy variada de tareas y de técnicas que faciliten ese reciclado del léxico y que eviten su desgaste o pérdida (Baralo, 2007: 40).

Son numerosas las tipologías de actividades que se pueden usar para la enseñanza del léxico: desde las más formales, en las que se suelen relacionar determinadas palabras con sus correspondientes definiciones, hasta aquellas con un fuerte carácter lúdico, como pueden ser las adivinanzas, versiones de algunos juegos famosos como Tabú, ejercicios de escritura creativa, etc.

El objetivo de estas actividades siempre será propiciar la adquisición de léxico por parte de los alumnos pero de una manera más motivadora. Además, mediante el uso de actividades del último tipo, favoreceremos el desarrollo de las distintas destrezas. Mediante ejercicios de escritura creativa mejorará la expresión escrita de nuestros alumnos, al mismo tiempo que se verán obligados a procesar semánticamente el nuevo léxico que han aprendido. Los juegos, como los nombrados anteriormente, ponen en marcha diversas operaciones mentales: se facilita el acceso al lexicón mental, recuperando, indirecta y lúdicamente, el léxico almacenado, al mismo tiempo que se desarrolla la interacción oral y se entrenan en estrategias de comunicación y aprendizaje.

En este sentido, también nos parece muy importante el papel que puede ejercer un material como el audiovisual en la adquisición del léxico. Como ampliaremos más adelante, el programa televisivo aporta una gran información 


\section{EL PROGRAMA TELEVISIVO COMO RECURSO PARA LA \\ ENSEÑANZA/APRENDIZAJE DE ESPAÑOL LENGUA EXTRANJERA}

contextual, fundamental para la comprensión. Además, presenta otros elementos no lingüísticos que, sin embargo, son fundamentales en toda interacción, como los gestos y las características suprasegmentales, la entonación y el acento.

Así, llevando a la clase de ELE un recurso como el programa televisivo, estaremos ofreciendo a nuestros alumnos información contextualizada del léxico —reducción y selección del léxico común; palabras comodines o proformas; léxico formal y coloquial; léxicos especiales, argóticos, extranjerismos...; metáforas de la vida cotidiana; expresiones intensificadoras (y todo ello de acuerdo con la variación geográfica) - y estaremos integrando el factor de la motivación, pues este formato posee la capacidad de atraer fácilmente el interés. Evidentemente, estará en nuestras manos, mediante la creación de tareas significativas en las que se integre el nuevo léxico, el buen desarrollo del proceso de adquisición.

Morante (2004) propone una serie de ejemplos cuyos objetivos generales responden en gran medida a las implicaciones sugeridas por Baralo, anteriormente nombradas. Así, encontramos ejemplos de actividades donde relacionar las unidades léxicas con sus respectivos sinónimos, antónimos, merónimos, etc., o bien en las que se tengan que construir mapas semánticos, de manera que se trabajen las relaciones entre las distintas unidades; otra tipología de ejercicios, que pretende trabajar con todos los sentidos de la unidad léxica sería la de seleccionar ocurrencias según la definición o bien la de seleccionar entre distintos sinónimos el más correcto según el contexto; se plantean, por último, diversas actividades para trabajar con expresiones idiomáticas $\mathrm{y}$ colocaciones.

Finalmente, consideramos también importante que las actividades planteadas proporcionen a los alumnos una serie de estrategias y técnicas que les ayuden, ya no solo a la hora de comprender y aprender, sino también en el momento de la comunicación. Esto facilitará en gran medida la adquisición del léxico pues, en cualquier caso, pueden favorecer cada uno de los pasos que, según Aitchinson (en Morante, 2005: 46), se dan en el proceso de aprendizaje del léxico.

Recogemos a continuación el cuadro propuesto por Rebecca Oxford (en Giovannini et al., 1996b: 68), en el que se cataloga una serie de estrategias fomentadas mediante actividades concretas y que, creemos, es importante tener en cuenta: 
Tabla 6

Estrategias fomentadas mediante actividades por Rebecca Oxford (en Giovannini et al., 1996b)

Crear redes Agrupar mentales

Aplicar imágenes Emplear imágenes y sonidos

Revisar

Emplear la acción

\section{Asociar}

Incorporar palabras en un contexto

Mapa semántico

Usar palabras clave

Representar sonidos en la memoria

Revisión estructurada

Usar una respuesta física o una sensación
Agrupar el vocabulario por temas o tipos de palabras para poder memorizar mejor. Por ejemplo: palabras relacionadas con el tiempo: calor, frío, etc.

Asociar palabras, o la nueva información, a los conceptos que ya están memorizados. Dicha asociación ha de ser significativa para el alumno.

Las nuevas palabras se vinculan al contexto, ya sea oracional o discursivo.

Las palabras nuevas se incorporan a imágenes o se relacionan con otras. Asociar una palabra abstracta a un dibujo concreto.

A partir de una palabra clave, hacer un mapa con todas las palabras que están relacionadas con esta.

Recordar una palabra usando claves, ya sean visuales o auditivas.

Recordar una palabra nueva por su sonido.

Repasar a intervalos temporales para poder ir reactivando la memoria. (Por la mañana, al cabo de dos horas, etc.)

Representar físicamente la palabra o expresión que se ha aprendido. 


\author{
Emplear técnicas \\ mecánicas
}

Por ejemplo, escribir las palabras en tarjetitas e ir revisándolas u organizándolas según la actividad memorística.

Datos obtenidos en Giovannini et al., 1996b

De lo expuesto en este cuadro, podemos destacar la importancia que tienen la imagen y el sonido a la hora de adquirir el léxico, tanto en la incorporación y etiquetación de este en el lexicón mental del alumno como en su posterior recuperación y uso. En este sentido, como mostraremos más adelante en nuestras propuestas didácticas, debemos aprovechar las facilidades que el material audiovisual nos ofrece. Desde un primer momento, el alumno realiza asociaciones entre las palabras que se le presentan y las imágenes que ve y que, de un modo u otro, pasan a formar parte de su propia experiencia. Al mismo tiempo, se le ofrece un contexto en el que aparecen y se usan tales palabras. Los medios audiovisuales, por tanto, acompañados de las actividades adecuadas, contribuyen a reforzar y enriquecer los procesos de adquisición de léxico.

\subsection{Aspectos socioculturales}

$\mathrm{Si}$, desde una perspectiva comunicativa, queremos que el estudiante sea competente, es decir, que no tenga solo conocimientos sobre la sociedad, sino que estos conocimientos le sirvan para actuar en ella o con los individuos que hacen uso de la lengua-meta, es necesario abordar la competencia cultural.

Algunos pensarán que esto no es demasiado importante, que los alumnos lo aprenderán cuando vayan al país y lo vean, o que el sentido común les ayudará a desenvolverse en las diferentes situaciones. Puede que tengan razón, pero creemos que es mejor no dejar todos estos aspectos al azar y trabajarlos con anticipación en el aula.

Como afirma Ruiz Fajardo (1994: 154), las diferencias entre lo que distintas culturas y distintos grupos sociales consideran descortés o maleducado llenan el anecdotario de cualquier persona que haya viajado. Y, aunque muchas comunidades suelen ser más permisivas con el extranjero que con los miembros propios, las situaciones que acarrean el desconocimiento de estas reglas pueden ser muy molestas. 
Miquel y Sans (1992: 15-21) explican que el concepto de cultura abarca todo lo pautado, lo no dicho, aquello que todos los individuos, adscritos a una lengua y cultura, comparten y dan por sobreentendido. En España, por ejemplo, los extranjeros necesitarán una serie de propuestas didácticas que les permitan comprender las cosas que suceden a su alrededor (que el luto se simboliza a través del negro; que el 6 de enero se celebra la fiesta de los Reyes Magos; que la gente 'toca madera' para evitar la mala suerte...) que les permitan actuar adecuadamente (que se suele comer entre dos y tres; que muchos productos, como, por ejemplo, los huevos, se compran en docenas o en medias docenas...) $y$, por último, información para interactuar (que no se habla de lo que la gente realmente gana salvo en relaciones de mucha confianza; que, cuando se recibe un elogio, hay que reaccionar quitándole importancia; que no solo está permitido tutear a personas con las que se tiene una estrecha relación, etc.)

Podemos concluir que enseñando la lengua, entendida como un instrumento de comunicación, se enseñan, aun sin ser consciente de ello, una serie de prácticas sociales y de valores culturales. Difícilmente se llegará a potenciar en el estudiante la competencia comunicativa en una lengua extranjera si no se considera la competencia cultural como uno de sus componentes básicos.

Como señalan Miquel y Sans (1992: 15-21), con esto no estamos diciendo que el extranjero que aprende una lengua deba pretender comportarse en todo momento como un miembro de la comunidad que habla esa lengua, sino que tiene derecho a tener un máximo de información para, de una forma consciente, elegir en todo momento entre transgredir o respetar las pautas culturales esperadas.

Para conseguir transmitir todos estos contenidos socioculturales a los alumnos, es importante que el profesor de ELE sea capaz de «hacerlos visibles». Creemos que el programa televisivo es una buena herramienta para lograr este fin. El alumno valorará el hecho de trabajar en clase con materiales que forman parte de la vida cotidiana de los hablantes nativos; este aspecto acercará su aprendizaje a la realidad: al uso auténtico del lenguaje. El profesor puede realizar un trabajo de comparación y contraste sociocultural a través de los programas televisivos, por ejemplo, entre la versión del país de origen de los estudiantes y la versión española del mismo formato, pues cada una de ellas estará adaptada al público del país donde se retransmiten. 


\section{EL PROGRAMA TELEVISIVO COMO RECURSO PARA LA \\ ENSEÑANZA/APRENDIZAJE DE ESPAÑOL LENGUA EXTRANJERA}

\subsection{Aspectos pragmáticos}

A través de los programas televisivos podemos ofrecer a nuestros estudiantes de ELE muestras de las diferentes modalidades discursivas orales: podemos trabajar tanto el registro coloquial como el formal mediante el visionado y análisis de debates, entrevistas, reportajes, anuncios, reality-shows, etc. Entre otros aspectos pragmáticos, a través de este formato se puede facilitar la comprensión por parte del alumno de la cortesía; la ironía; la toma de turno, la dinámica de la conversación; la atenuación; la intensificación y las estrategias conversacionales en español.

Dentro del grupo de los géneros del discurso orales están las conversaciones, cara a cara o telefónicas, y también las que se han desarrollado a partir de la cibertecnología, como el chat, los foros de opinión o los blogs (Albelda y Fernández, 2006: 3). Desde un enfoque comunicativo, la conversación coloquial posibilita la práctica del componente pragmático: el ejercicio de la lengua oral, el proceso de enseñanza/aprendizaje contextualizado, el uso de la lengua como instrumento de comunicación y no como producto, y el trabajo de las funciones comunicativas.

La conversación cara a cara constituye lo que se ha denominado la situación canónica de la comunicación. Es la forma más directa, natural y espontánea del lenguaje. Muchas de las categorías lingüísticas (temporalidad, modalidad, referencia, deixis...) están ligadas a esta situación comunicativa. Al margen de sus valores lingüísticos, conversar es una actividad regida por principios comunicativos que trascienden las puras reglas gramaticales. Se trata también de normas de buena conducta comunicativa que el usuario de la lengua nativa va adquiriendo (Gutiérrez Ordóñez, 2004: 33). Por su parte, Briz (2010) señala que, cuando hablamos, por ejemplo, coloquialmente, afloran más ${ }^{41}$ las características dialectales (variedades geográficas) y las sociolectales de edad, sexo y las del medio oral y las de género, que en ese caso es más conversacional; $\mathrm{y}$, al contrario, se ven neutralizadas o niveladas las sociolectales de nivel sociocultural.

En la mayoría de programas televisivos, la conversación espontánea está muy presente. Por tanto, la utilización de este tipo de material en el aula de ELE puede facilitar la tarea del profesor de familiarizar al estudiante con el valor

\footnotetext{
${ }^{41}$ Briz (2010) utiliza cursiva en el original para resaltar el carácter gradual de la variación lingüística.
} 


\section{ASPECTOS DE LA COMPETENCIA COMUNICATIVA QUE SE PUEDEN \\ TRABAJAR CON PROGRAMAS DE TELEVISIÓN}

que, en nuestra cultura, asumen determinados actos de habla en la conversación coloquial: insultos empleados como vocativos, que no insultan; actos directivos sin atenuar, que no ofenden; halagos y cumplidos aceptados; consejos ofrecidos sin previa petición; insistencia en los actos de ofrecimiento; situaciones que requieren cortesía y formas de expresarla, situaciones que resultan conflictivas o pueden amenazar la imagen de los interlocutores y, por supuesto, los grados de formalidad que cada momento exige en función de los rasgos situacionales (Albelda y Fernández, 2006: 6).

En la audición de la conversación real con frecuencia, se pueden encontrar los fenómenos de habla con los que se enfrentan los estudiantes en sus intercambios comunicativos reales: solapamientos de habla, variedades en la curva de entonación, entonaciones expresivas, alargamientos fonéticos, contextualización de las interjecciones, identificación de ironías, elementos paralingüísticos (risas, gritos), interrupciones, desambiguación de malentendidos, equivocaciones y reinicios, etc. (Albelda y Fernández, 2006: 7).

Trabajar con una conversación es trabajar en un contexto. La conversación se realiza en un marco físico y temporal particular en el que se reconocen las características de los interlocutores (edad, sexo, profesión,...), los factores que rodean la situación comunicativa y las intenciones de los actos de habla emitidos.

\footnotetext{
Enseñar mediante conversaciones implica múltiples ventajas derivadas de su contextualización: se aprenden no solo las estructuras sino también sus funciones comunicativas, se amplía la capacidad de entender los significados e inferir sus sentidos y usos, y en consecuencia, se aumenta la capacidad de procesamiento de lengua de los estudiantes, se aprecia la adecuación de las formas lingüísticas a una situación, se interpretan más fácilmente fenómenos semánticos como el doble sentido, la ironía, las metáforas, etc. Además, se posibilita un aprendizaje crítico y reflexivo, realizado de forma inductiva: se enfrenta al estudiante con muestras de habla a través de las que inducen tanto las reglas del sistema lingüístico, como los significados y las licencias interaccionales permitidas en nuestra cultura conversacional (Albelda y Fernández, 2006: 6).
}

A la hora de trabajar la pragmática en clase de ELE mediante programas televisivos, es conveniente especificar cada uno de los rasgos situacionales que caracterizan las secuencias comunicativas presentadas. Los registros, según Briz y el Grupo Val.Es.Co. (Briz, coord., 1995; Briz y grupo Val.Es.Co., 2002), se definen por dos tipos de rasgos: situacionales y primarios, detallados a continuación:

- Rasgos situacionales: 


\section{EL PROGRAMA TELEVISIVO COMO RECURSO PARA LA \\ ENSEÑANZA/APRENDIZAJE DE ESPAÑOL LENGUA EXTRANJERA}

- tipo de relación social y funcional entre los interlocutores: igualdad/desigualdad;

- relación vivencial: de proximidad o de distancia;

- marco de interacción en que se desarrolla la comunicación: ajeno, familiar; cotidiano/no cotidiano;

- tipo de temática: especializada/ no especializada; cotidiana/no cotidiana.

- Rasgos primarios:

- finalidad de la interacción: transaccional o interpersonal;

- presencia o ausencia de una planificación del discurso;

- tono formal o informal.

Como explican Albelda y Fernández (2006: 5), el registro formal presentará principalmente los siguientes rasgos: relación social $\mathrm{y} / \mathrm{o}$ funcional de desigualdad entre los interlocutores, relación vivencial de distancia, marco de interacción no familiar o no cotidiano, temática especializada, finalidad transaccional, planificación discursiva y tono formal.

Por su parte, el registro informal se caracterizará normalmente por los rasgos contrarios: relación social y/o funcional de igualdad entre los interlocutores, relación vivencial de proximidad, marco de interacción familiar o cotidiano, temática no especializada y/o cotidiana, finalidad interpersonal, ausencia de planificación y tono informal.

Se ha hablado de que los rasgos anteriores caracterizan prototípicamente un registro u otro. Sin embargo, puede ocurrir que algunos de los rasgos anteriores no estén presentes y la situación siga reconociéndose como formal o informal.

Albelda y Fernández (2006: 16) recomiendan que las entrevistas se trabajen en niveles de lengua A2 (según el MCER), y que, a partir del nivel B1, se introduzcan las conversaciones coloquiales. Según el nivel de lengua de los estudiantes, puede que sea necesario que el profesor explique algunas palabras nuevas para los alumnos: por su concreta procedencia geográfica, por su valor excesivamente coloquial o técnico... Conviene hacerlo, especialmente, si se trata de términos o estructuras que aparecen con frecuencia en el texto oral presentado. 
En cuanto al modo de trabajar las diversas posibilidades didácticas que ofrece la conversación, Albelda y Fernández (2006: 18) aconsejan actuar de lo general a lo particular. Es decir, el objetivo es que los alumnos primero alcancen una idea general del contenido de la conversación y después vayan comprendiendo y asimilando los diferentes términos y estructuras.

Una vez presentado el ejemplo de la modalidad discursiva que se trabajará a través del visionado de uno o varios programas televisivos, las tareas que mejor propician el dominio de la competencia pragmática dentro del aula son normalmente aquellas que se llevan a cabo en grupos pequeños, que requieren un intercambio de información, y cuyos participantes tienen un objetivo común (Sánchez Sarmiento, 2005: 592):

- actividades de interacción oral centradas en la negociación del significado;

- actividades de interacción oral centradas en el vacío de información;

- actividades sobre el uso de determinadas estrategias de comunicación;

- actividades que incluyan cierto nivel de reflexión sobre las normas y convenciones sociales en diferentes situaciones de comunicación;

- actividades que lleven al conocimiento de las normas sociales que rigen los usos lingüísticos;

- actividades con simulaciones y juegos de roles que supongan variaciones de registros de los interlocutores;

- actividades basadas en la presentación de muestras de la lengua oral y escrita que incluyan variación de registros.

En todas ellas el componente pragmático de la lengua está presente a través de:

- las implicaturas;

- el lenguaje coloquial;

- las estrategias de cortesía;

- la pragmática intercultural.

La pragmática intercultural somete a estudio, en un sentido amplio, las diferencias lingüístico-culturales en los mecanismos que regulan la interacción conversacional y en los principios con los que se valoran las praxis comunicativas. Recoge muchos de los aspectos sometidos a examen por la etnografía de la comunicación, por los estudios de adquisición de segundas lenguas con orientación pragmática, y aborda temas 


\section{EL PROGRAMA TELEVISIVO COMO RECURSO PARA LA \\ ENSEÑANZA/APRENDIZAJE DE ESPAÑOL LENGUA EXTRANJERA}

clásicos en la tradición de la sociolingüística interaccional (Hernández Sacristán, 1999).

Cuanto más variado y más diverso sea el input, más fácil será alcanzar los objetivos (Sánchez Sarmiento (2005: 592). Los programas televisivos deben presentar variaciones de registro, de acentos regionales, de género..., para potenciar la capacidad sociolingüística del alumno. De cara a la competencia sociopragmática esto supone la presencia de actividades basadas en esa amplia variedad de muestras orales en las que el alumno se verá obligado a reflexionar sobre lo que se dice, el cómo se dice, y sobre cuál es la intención comunicativa de los hablantes.

\subsection{Aspectos estratégicos}

A través de un medio audiovisual, como es el programa televisivo, se puede ayudar al aprendiente de español a desarrollar varias estrategias, en especial, estrategias de comprensión y expresión orales — estas últimas también llamadas estrategias comunicativas-.

En cuanto a la tarea de la comprensión auditiva, las investigaciones de referencia coinciden en que el oyente activa diversos tipos de conocimiento para procesar con éxito la información escuchada. La clasificación más detallada, que aquí presentamos, es la de Flowerdew y Miller (2005: 30), que recoge el conocimiento fonológico (sistema sonoro), el sintáctico (modo de unir las palabras), el semántico (conocimiento de las palabras y sus relaciones), el pragmático (significado de enunciados en situaciones particulares) y el cinésico (expresión facial y corporal del hablante).

- Fonológico. Es el primero en activarse al percibir un mensaje y contribuye a la segmentación de este en los sonidos que lo componen. Los fonemas de dos lenguas no son siempre iguales, de manera que, por una parte, el oyente no nativo tiene que adquirir un nuevo conjunto de fonemas $\mathrm{y}$, por otra, su percepción de la LE pasaría por lo que Trubetzkoy (1939) denomina criba fonológica. Por esta razón, conviene tener en cuenta las diferencias de los sistemas fonéticos de las lenguas materna y meta, de cara a predecir y analizar los errores de comprensión de los alumnos.

A la hora de pasar de la identificación de fonemas al reconocimiento de sílabas y la formación de palabras hasta llegar al enunciado, se suman los 
elementos suprasegmentales como la acentuación, la entonación y el ritmo. $\mathrm{Su}$ importancia radica en que cumplen el papel de integradores de los diversos factores que inciden en la pronunciación, con lo que también afectan a la audición (Poch, 1993). En consecuencia, el profesor debe proporcionar muestras lingüísticas en las que los sonidos no aparezcan aislados, sino ofrecer curvas entonativas representativas de sus distintas realizaciones. Del mismo modo, convendría presentar a los alumnos un contraste de las características propias de los elementos suprasegmentales en ambas lenguas, con objeto de evitar, por ejemplo, la transferencia de la entonación de un idioma a otro.

En el nivel del enunciado confluyen otro tipo de dificultades, derivadas de las modificaciones en la realización de los hablantes en función de la situación comunicativa, como puedan ser la asimilación y la elisión. Debido a esto, de acuerdo con Poch (2001), el oyente debe restituir todo lo que no está presente físicamente en la onda sonora, pero sí en la intención de realización del hablante; en este caso, la activación de otros tipos de conocimiento declarativo y la aplicación de estrategias contribuirán al éxito de la comprensión.

- Sintáctico. A pesar de que las reglas combinatorias del sistema lingüístico son limitadas, los enunciados que a partir de ellas pueden crearse son infinitos. Por ello, el significado de un enunciado no puede limitarse a la suma de los significados de las palabras que lo componen y se necesita de la sintaxis para establecer relaciones entre las palabras de un enunciado y los significados que tales relaciones conllevan (Flowerdew y Miller, 2005).

De acuerdo con Anderson (1985), el oyente procesa un enunciado analizándolo en proposiciones e interpretando el significado de cada una de ellas. Las proposiciones serían, por tanto, las unidades básicas de significado implicadas en la comprensión y el material con el que trabaja la memoria (Richards, 1983), dado que los enunciados son demasiado largos y complejos. En este sentido, la comprensión del enunciado requiere la descomposición de este en las proposiciones que lo constituyen, una habilidad derivada de la competencia gramatical que se vería facilitada por el apoyo léxico, fonológico (entonación del enunciado) y del conocimiento contextual.

Las señales sintácticas sirven para relacionar la información nueva a la ya existente en la memoria; de esta forma, el empleo de un artículo determinado, por ejemplo, indicaría al oyente una información conocida. Por otra parte, las unidades lingüísticas de orden superior al enunciado 


\section{EL PROGRAMA TELEVISIVO COMO RECURSO PARA LA \\ ENSEÑANZA/APRENDIZAJE DE ESPAÑOL LENGUA EXTRANJERA}

(párrafo y texto) se estructuran jerárquicamente de acuerdo con ciertas relaciones que el oyente debe identificar para comprender la organización del texto $y$, consecuentemente, su significado.

La perspectiva de Anderson (1985), Richards (1983) y Rost (2002) es de carácter funcional, dada la limitación de recursos del oyente. En este sentido, consideran que el individuo atiende principalmente a la función comunicativa y, solo de forma secundaria, a las manifestaciones formales de esta, por lo que, después de aplicar el conocimiento sintáctico a la interpretación de un constituyente, la palabras exactas de este ya no se necesitan más; es decir, la memoria almacenaría significados y no formas, lo que explicaría que un individuo no sea capaz de recordar las palabras textuales de un enunciado que ya ha sido procesado en el momento en el que está procesando el siguiente.

Las implicaciones didácticas que de aquí se derivan afectan tanto a la transmisión de los conocimientos sintácticos como al diseño de las actividades de comprensión oral y la selección del input para ellas. Por una parte, convendrá considerar la distancia existente entre los sistemas sintácticos de las lenguas materna y meta del aprendiz, de cara a facilitar la formación de los patrones proposicionales habituales más complejos en la LE, tal y como recomienda Glisan (1985); por otra parte, habrá que exponer a los estudiantes a un input que permita el reconocimiento de tales patrones y la asignación de un valor semántico a los mismos, sin pretender con ello que los alumnos reproduzcan las formas textuales que están escuchando.

- Semántico. El conocimiento sintáctico del que acabamos de hablar se combina con el semántico para lograr una correcta comprensión lingüística, de forma que la preferencia por cada tipo de señales podría variar de un idioma a otro (Anderson, 1985). Con este término se hace referencia al conocimiento tanto del significado de las palabras, como de las relaciones entre las palabras que forman un enunciado y entre los enunciados individuales que conforman un discurso (Flowerdew y Miller, 2005).

Respecto al significado de las palabras, la forma que el oyente tiene de acceder al léxico para reconocerlas viene determinada por la manera en la que se almacena tal información en la memoria. Al parecer, el ser humano cuenta con un lexicón mental en el cual guarda el vocabulario de las distintas lenguas que conoce, estableciendo vínculos de unos términos con otros en forma de esquemas.

En cuanto a la relación de las palabras entre sí dentro de los enunciados, y de estos en el discurso, se entiende que existe una jerarquía proposicional; 
para reconocerla, es necesario tanto un conocimiento de la cohesión (nivel superficial), como de la coherencia (nivel subyacente) del texto (Flowerdew y Miller, 2005: 39). La coherencia, por su parte, abarca dos tipos principales de relaciones entre las proposiciones, la de secuencia lógica y la de equiparación. En la primera de ellas se distinguirían las relaciones de fenómeno-razón, causa-consecuencia e instrumento-logro, mientras que, en la segunda, entrarían las de compatibilidad y contraste.

A la hora de interpretar un enunciado, el oyente debe elegir un único significado de entre todos los posibles, es decir, ha de salvar la ambigüedad propia del lenguaje y decantarse por un solo sentido. La presencia de la ambigüedad obliga al oyente a un constante control de la comprensión para elegir el significado más acorde a la situación comunicativa.

De cara al diseño de la enseñanza de LE, se acepta de manera generalizada la utilidad de activar el conocimiento léxico mediante actividades de preaudición. Sin embargo, para fomentar la seguridad del oyente no nativo en ocasiones reales de uso lingüístico, convendría presentarle, además, situaciones en las que se vea obligado a tratar con la ambigüedad de manera consciente y a elegir un único significado razonadamente, es decir, atendiendo a las señales de cohesión y coherencia presentes en los enunciados.

- Pragmático. La importancia concedida recientemente a la habilidad pragmática del aprendiz como componente de la competencia comunicativa en LE ha llevado a los autores a considerar más de cerca la manera en que el conocimiento pragmático afecta a cada una de las destrezas tradicionales de uso lingüístico. De este modo, en los últimos estudios sobre comprensión auditiva, encontramos un amplio desarrollo de este asunto, como es el caso de Rost (2002), quien lo considera no ya un nivel de conocimiento, sino un tipo de procesamiento que transcurre paralelamente al lingüístico. Según Flowerdew y Miller (2005: 41), el conocimiento pragmático está relacionado con el significado y uso del lenguaje en situaciones específicas, y contribuye, principalmente, a la desambiguación. La unidad de análisis en este caso sería el enunciado entendido como la realización lingüística específica de una proposición en una situación determinada.

Los componentes que entran en juego, de acuerdo con Rost (2002), son la inferencia de la intención del hablante a partir de convenciones conversacionales e inferencias; el establecimiento de un marco de relaciones sociales y la percepción que tiene el oyente del papel de cada participante; 


\section{EL PROGRAMA TELEVISIVO COMO RECURSO PARA LA ENSEÑANZA/APRENDIZAJE DE ESPAÑOL LENGUA EXTRANJERA}

el tipo de respuesta que el oyente puede dar en la conversación, así como sus maneras de colaboración.

El fomento del conocimiento pragmático en la clase de ELE cuenta con el principal inconveniente de que, en la mayoría de las ocasiones, los aprendientes se ven enfrentados a un input que no permite su respuesta o colaboración como oyentes en los términos conversacionales propios de la vida real. Igualmente, muchas veces deben escuchar mensajes sin apoyo visual, lo que limita considerablemente la información contextual y les obliga a reconstruirla a partir tan solo de las señales prosódicas y paralingüísticas.

Una forma de subsanar este vacío de información sería la presentación de actividades de preaudición de anticipación sobre el contexto y establecimiento de hipótesis acerca de las características de los participantes y sus relaciones. En el caso de tratarse de un documento audiovisual como el programa televisivo, el ejercicio podría partir del visionado de un fragmento sin sonido, para favorecer las especulaciones de los alumnos a partir de las imágenes. Asimismo, resulta evidente que todo input destinado a contribuir al conocimiento pragmático del estudiante debe consistir en material auténtico, de manera que refleje fielmente el comportamiento de hablantes y oyentes en la cultura meta.

- Cinésico o kinésico. Se refiere al significado de las señales no verbales que intervienen en la comunicación, tales como la expresión facial, el contacto visual, los movimientos corporales y la posición, que apoyan o encubren el sentido de lo que dice el hablante (Flowerdew y Miller, 2005). Según Poyatos (1994), podemos distinguir entre gestos, maneras y posturas; desde los movimientos que acompañan los saludos hasta aplausos o chasquidos, desde rascarse la cabeza hasta un levantamiento de cejas. Así, Poyatos (1994) llega a proponer diecisiete tipos kinésicos de comunicación no verbal, como se muestra en la siguiente tabla:

Tabla 7

Tipos kinésicos de comunicación no verbal según Poyatos (1994)

\begin{tabular}{ll}
\hline Emblemas & Gestos por palabras \\
Metadiscursos & Los movimientos del hablar \\
Marcaespacios & Señalando lo presente y lo ausente
\end{tabular}




\begin{tabular}{ll}
\hline Marcatiempos & Pasado, presente y futuro \\
Deícticos & Señalando a personas y cosas \\
Pictografías & Dibujando con las manos \\
Ecoicos & Imitando todo lo que suena \\
Kinetografías & Imitando todo lo que se mueve \\
Kinefonografías & Imitando movimiento y sonido \\
Ideografías & Dando forma visual a los pensamientos \\
Marcasucesos & Cómo pasaron las cosas \\
Identificadores & La forma visual de los conceptos \\
Exteriorizadores & Nuestras reacciones a la vista \\
Autoadaptadores & Tocándonos a nosotros mismos \\
Alteradaptadores & Tocando a los demás \\
Somatoadaptadores & Los íntimos de nuestro cuerpo \\
Objetoadaptadores & Interacción con los objetos \\
\hline
\end{tabular}

Datos obtenidos de Poyatos (1994)

Las dificultades de transmitir este tipo de conocimiento en el aula son similares a las del pragmático. Además, conviene tener en cuenta que, en ocasiones, los estudiantes solo cuentan con el modelo del profesor para crearse una imagen del comportamiento comunicativo no verbal propio de los hablantes de la LE, con lo que se corre el peligro de adquirir una representación equivocada. La exposición, de nuevo, a un input visual como el del programa televisivo, sin apoyo auditivo, resulta adecuada para destacar la gestualidad y la distancia física entre los hablantes propias de la LE.

Teniendo en cuenta los tipos de conocimiento que el oyente activa para procesar con éxito la información escuchada cuando realiza una tarea de comprensión oral, sugerimos las siguientes estrategias de apoyo propuestas por Martín Leralta (2009). 


\section{EL PROGRAMA TELEVISIVO COMO RECURSO PARA LA ENSEÑANZA/APRENDIZAJE DE ESPAÑOL LENGUA EXTRANJERA}

- Avance de la organización. El establecimiento previo de los objetivos de la tarea facilita la búsqueda consciente del input relevante. No consiste en realizar una actividad de preaudición de anticipación de léxico, sino en orientar a los aprendices sobre el tipo de texto que van a escuchar y los propósitos de la audición.

- Atención dirigida. Se ofrece esta estrategia con el fin de mantener la concentración durante la exposición al input y reducir la tensión. Una forma de aplicarla es fijarse en las palabras familiares, sin desviar la atención a las desconocidas.

- Atención selectiva. Se trata de orientar la atención específicamente a los aspectos situacionales básicos para comprender la situación comunicativa dada, como, por ejemplo, atender al tono de voz y al uso de las formas de tratamiento (tú/usted) para establecer posteriormente la relación entre los hablantes.

- Inferencia por repetición. Cuando el aprendiz conoce la mayor parte del léxico presente en el mensaje, la selección de los términos conocidos desechando los nuevos se realiza de manera automática y sin dificultad; en estas ocasiones, ni siquiera da importancia a la información que ha pasado por alto. Sin embargo, frente a enunciados de vocabulario mayoritariamente extraño para él, intenta atender conscientemente a más palabras de las que permite su capacidad, ante la imposibilidad de discriminar las que son esenciales. Aquí resultaría indicado motivarle a que eligiera tan solo los términos que se repiten.

- Inferencia de voces y paralingüística. Dado que las palabras clave vienen, muchas veces, enfatizadas por el tono de voz y otras señales paralingüísticas, estos rasgos pueden emplearse para la selección de aquellos términos desconocidos que, por su especial acentuación, se revelan esenciales para la reconstrucción del mensaje.

- Inferencia cinestésica. Cuando se cuenta con apoyo visual, se puede entrenar a los aprendices en la lectura de la gestualidad que marca el input relevante. Al igual que la estrategia anterior, el lenguaje corporal puede llevar a que el oyente no nativo perciba la relevancia de determinados términos desconocidos.

- Transferencia. La selección de palabras desconocidas a las que se atribuye un significado por su parecido con otra lengua que habla el aprendiz es una estrategia de fácil aplicación para este estadio, sobre todo, porque se retienen en la memoria con más facilidad. 
- Toma de notas. La anotación de los términos y marcas gramaticales relevantes puede resultar de gran utilidad en el caso de la exposición a un input prolongado, aunque, como explica Vogely (1995), la acción de escribir puede interferir negativamente en el proceso de escucha.

Por lo que se refiere a las estrategias de expresión oral, constantemente, en el proceso de intercambio comunicativo, los estudiantes se ven en la necesidad de dar solución a los problemas comunicativos que se les presentan a partir de activar, de forma más o menos consciente, mecanismos o estrategias en una búsqueda de negociación externa e interna, que permita la efectividad de estos mecanismos de uso. Si a esto se suma la imposibilidad de predecir las diversas situaciones comunicativas en las que se verán inmersos los alumnos, lo que se traduce en no poder ofrecer todos los recursos lingüísticos necesarios para ello; entonces, «la razón de incentivar el uso de estrategias comunicativas en las clases de ELE encuentra toda justificación» (Manchón, 1993).

Entre las estrategias de expresión oral o estrategias comunicativas que el aprendiente de una lengua extranjera suele emplear, podemos destacar: el uso de perífrasis; la gestualidad; la petición de cooperación; la demanda de clarificación; la invención de palabras y otras estrategias de compensación; las estrategias de aproximación y rodeo para soslayar una dificultad; la petición de repetición; la aproximación al mensaje del interlocutor; y la indicación explícita de comprensión (Villanueva et al.,1997).

Para desarrollar este tipo de estrategias en la clase de ELE es necesario que el profesor realice determinadas actividades de interacción oral. Littlewood (1981) clasifica estas actividades en dos tipos: actividades de comunicación funcional y actividades de interacción social. Entre las primeras, este autor incluye aquellas en las que los estudiantes tengan que resolver problemas, «obtener información y en las que lo más importante es transmitir significados del modo más eficaz posible (...) con cualquier recurso que tengan a su alcance» (Littlewood, 1981). En cuanto al segundo tipo de actividades, se remite al tema de la adecuación, en tanto crear actividades que hagan que el estudiante seleccione la lengua teniendo en cuenta el contexto social en el que se desarrolla la interacción.

A partir de considerar esta división, sobresale la importancia de convertir las clases de ELE en contextos propicios para lograr armonizar la funcionalidad y la adecuación sobre la base del empleo de estrategias comunicativas, en un trabajo coherente que contemple la inclusión de habilidades que potencien este 


\section{EL PROGRAMA TELEVISIVO COMO RECURSO PARA LA \\ ENSEÑANZA/APRENDIZAJE DE ESPAÑOL LENGUA EXTRANJERA}

uso estratégico. El éxito de la comunicación no depende solo de cuánto conocimiento lingüístico se posea de la lengua meta, sino también de cómo de eficaz se sea a la hora de maniobrar y guiar la conversación de acuerdo a la situación específica.

Es conveniente, por tanto, convertir la clase en un contexto de interacción social donde se propicien actividades lúdicas que potencien el trabajo con estrategias comunicativas: "cómo maniobrar con largos turnos de conversación, saber cómo se interrumpe a otra persona, cómo se cambia de tema» (Barroso, 2000), o cómo percibir si lo que se dice está siendo comprendido correctamente. De la misma forma, el tratamiento de situaciones disímiles en las que los estudiantes se verán inmersos en el entorno social implica que hay que valerse, inteligentemente, de actividades de simulación, juegos de roles, situaciones auténticas y dramatizaciones, que además de propiciar el dinamismo y la creatividad al proceso, permitan la puesta en práctica, de manera espontánea, de los recursos comunicativos para conseguir entender y ser entendido, sin prestar atención a que el discurso pueda o no ser correcto lingüísticamente en términos de lengua extranjera. «También son muy efectivos los debates, como otro tipo de actividad que utiliza el contexto docente como espacio interactivo» (Barroso, 2000), que se orienten de forma tal que los estudiantes ofrezcan sus opiniones, experiencias, criterios, aprovechando las oportunidades que tienen a su disposición, de utilizar, siempre que lo necesiten, recursos alternativos estratégicos para paliar las dificultades lingüísticas, que le permitan expresarse y hacerse comprender.

En este sentido, se puede aplicar el enfoque por tareas, que consiste en diseñar las unidades didácticas a través de tareas. Existen diversas definiciones del concepto tarea; por ejemplo, para Nunan (1989) se trata de: «(..) una parte del trabajo de clase que hace que los alumnos comprendan, manipulen, produzcan y se comuniquen con la lengua meta centrando su atención más en el significado que en la forma»; mientras que para Zanón (1990) la tarea «es representativa de procesos de comunicación de la vida real, también es identificable como unidad de actividad en el aula, está dirigida intencionalmente hacia el aprendizaje del lenguaje y está diseñada con un objetivo, estructura y secuencia de trabajo».

Todas estas propuestas pueden ser adaptadas a los diferentes niveles de enseñanza y pueden ser elaboradas utilizando el recurso del programa televisivo. A través del visionado de este tipo de formato audiovisual, se pueden percibir, analizar, y comentar en clase las estrategias comunicativas a las que los propios hablantes nativos, y también no nativos, recurren en unas u otras 
situaciones comunicativas. Se trata de estimular a los alumnos a que aprendan y usen la lengua sin miedo, de la manera que les resulte más útil y efectiva, en un esfuerzo por conocer y aplicar las estrategias comunicativas más adecuadas para posibles situaciones y contextos problemáticos. Con el empleo de estos recursos, los alumnos activan su propio aprendizaje y adquieren cada vez más autonomía para desenvolverse eficazmente en la lengua meta.

\subsection{Aspectos discursivos}

Los programas televisivos, sobre todo los no guionados, como las entrevistas, suponen una buena muestra de cómo los hablantes nativos de español se sirven de la entonación, los alargamientos silábicos, la pronunciación enfática y marcada, las partículas discursivas y los conectores pragmáticos, los deícticos y el orden de las palabras, entre otros aspectos discursivos, para favorecer y enriquecer la comunicación oral.

Tradicionalmente, se ha insistido en el dominio de la morfología, sintaxis, fonología y léxico; el enfoque nociofuncional ha intentado, además, un acercamiento a la pragmática, sobre todo en relación al lenguaje oral y algunos de los métodos comunicativos se han preocupado también de estudiar los conectores que consiguen la cohesión y la adecuación de los diálogos en situación. Con todo, las actividades enfocadas a trabajar los aspectos discursivos de la lengua oral deben consistir en capacitar a los alumnos para formar frases, comprender mensajes, seguir el hilo de una conversación o contar de forma comprensible una experiencia o una película, es decir, a defenderse discursivamente sobre un tema, incluso con escasos recursos lingüísticos.

Según Bygate (1987), hay dos aspectos fundamentales para que se produzca una comunicación satisfactoria.

1. Organización de la interacción: saber cuándo y cómo tomar la palabra; cómo invitar a otra persona a hablar; cómo hacer fluir una conversación; cuándo y cómo terminar una conversación.

2. Negociación del significado: habilidad de asegurarse de que la persona con la que se está hablando le ha entendido a uno, y que uno le ha entendido a ella; es decir, que los dos están hablando de lo mismo. 


\section{EL PROGRAMA TELEVISIVO COMO RECURSO PARA LA ENSEÑANZA/APRENDIZAJE DE ESPAÑOL LENGUA EXTRANJERA}

En el discurso oral, la complejidad sintáctica puede ser mayor o menor según el tipo de evento de que se trate. Entre un discurso y una conversación espontánea encontraremos diferencias notables, ya que el primero, probablemente, habrá sido preparado y responderá a determinados patrones elaborados; en el caso de la conversación, la propia espontaneidad de la situación lleva consigo expresiones de duda, repeticiones, titubeos, cambios de estrategia sintáctica, discordancias, uso de muletillas o coletillas, piezas de relleno y completadores, etc. (Cortés, 1991).

Debido a la copresencia de los interlocutores y al hecho de que comparten una localización espacial y temporal, es muy común y característico el uso de elementos deícticos. La deixis - referencia, por medio de unidades gramaticales de la lengua, a elementos del contexto de la comunicaciónpersonal, espacial, temporal y social permite referirse a esos parámetros contextuales e ir construyendo cooperativamente el marco en el que se desarrolla el evento. En general, puesto que se tiende a facilitar la comprensión por parte de la audiencia, en las formas más comunes y habituales de discurso oral se tiende al uso abundante de la yuxtaposición y la coordinación para relacionar oraciones y a un menor uso de nexos de subordinación. El orden de las palabras también sirve en muchos casos para señalar el foco informativo. Del mismo modo, la selección sintáctica sirve como marcador de la variedad funcional o registro que se utiliza. En general, una menor complejidad sintáctica se corresponde con un registro más coloquial, y una mayor complejidad sintáctica, con un registro más formal o culto (Calsamiglia y Tusón, 1999: 59).

Dado el grado de imprevisibilidad y de improvisación característico del discurso oral, es común que quien habla modalice muy a menudo aquello que dice, ya sea para mostrar duda o seguridad o para señalar su actitud respecto al contenido de sus palabras (yo creo, yo diría, a mí me parece...). También la utilización del condicional, de la modalidad interrogativa o de marcadores de aspecto sirve a estos fines. Del mismo modo, la apelación al «otro», la demanda de validación o evaluación de lo que estamos diciendo o el uso de retroalimentación se usan con fines claramente interactivos (Schiffrin, 1987).

Como explican Calsamiglia y Tusón (1999: 60), desde el punto de vista del discurso oral y dependiendo del evento, la variación léxica sirve para marcar el registro, el tono de la interacción, las finalidades que se pretenden conseguir, a la vez que puede ser una indicadora de las características socioculturales de los participantes. Podemos hablar de un léxico más o menos culto, cuidado, 
técnico-jergal, relajado, común, formal, barriobajero, marginal, argot, etc. El léxico está, así pues, en estrecha relación con la diversidad sociocultural en el seno de una misma cultura. Así, se puede estudiar el léxico característico de diferentes grupos dentro de una misma sociedad, por ejemplo, las diferencias entre el léxico de: hombres/mujeres, medio rural/medio urbano, diferentes profesiones, argot. El léxico es un marcador de pertenencia a un grupo; por ello, saber utilizar el léxico adecuado en el momento preciso puede ayudar al estudiante de ELE a sentirse parte del grupo con el que esté realizando el intercambio comunicativo en ese momento.

Otra de las características del discurso oral en este nivel tiene que ver con el bajo grado de densidad léxica y el alto grado de redundancia. Como consecuencia de que se comparta el contexto y de que los participantes vayan construyendo conjuntamente el sentido de la interacción se producen repeticiones, paráfrasis, se utilizan palabras comodín, deícticos, proformas léxicas (del tipo hecho, cosa, etc.). Si alguien no entiende, puede pedir aclaraciones o repeticiones y quien estaba hablando tendrá que acceder a esas peticiones para poder continuar la conversación (Calsamiglia y Tusón (1999: 61).

Por su parte, Cortés (1991) establece correlaciones entre el uso de conectores y los grupos de edad o niveles socioculturales. En su estudio, recogido en la obra Sobre conectores, expletivos y muletillas en el español hablado, este autor concluye que la edad es determinante en el mayor o menor uso de las formas claro y bueno, mientras que el nivel sociocultural influye en el uso del conector vamos. Resultan especialmente interesantes la correlación entre edad y uso de la forma bueno —que, según su análisis, aumenta significativamente cuanto más joven es el encuestado-, o la alta frecuencia de uso de estos cinco conectores que, de acuerdo con sus datos, se da en el grupo de mayor nivel sociocultural, pues esto hace que nos planteemos hasta qué punto es cierto el mito de que los llamados expletivos son recursos propios de las personas de bajo nivel cultural.

En la intersección entre las vocalizaciones, el léxico y la morfosintaxis se observa el uso de expresiones que muestran la actitud y que tienen unas funciones modalizadoras, interactivas y expresivas muy evidentes. Por todo ello, el estudio de la sintaxis de la lengua oral a partir de documentos auténticos, como los programas televisivos, resulta de gran interés. Mediante la visualización de, por ejemplo, una entrevista televisiva, los estudiantes pueden apreciar, analizar y asimilar cómo la organización de la interacción y la 


\section{EL PROGRAMA TELEVISIVO COMO RECURSO PARA LA ENSEÑANZA/APRENDIZAJE DE ESPAÑOL LENGUA EXTRANJERA}

negociación del significado se llevan a cabo en la cultura de su lengua de estudio, el español en este caso.

Por otro lado, es un hecho que en el discurso oral la expresividad también viene, en gran parte, determinada por la función paralingüística de la entonación, por medio de la cual mostramos nuestras reacciones hacia las cosas que percibimos o nuestros sentimientos. En opinión de Poch (1999: 34), el hecho de que esta ejerza dicha función ha de tenerse especialmente en cuenta durante el proceso de enseñanza de la lengua extranjera, ya que «está íntimamente relacionado con el concepto pragmático de intención de comunicación».

Como recogen Calsamiglia y Tusón (1999: 56), uno de los primeros aspectos del discurso oral que debe llamar la atención es la variedad en la pronunciación. Cuando se describe el plano fónico de una lengua se explica sobre todo su sistema fonológico y las variantes fonéticas que resultan por contacto de unos sonidos con otros. Sin embargo, como se viene demostrando desde hace tiempo, las realizaciones fonéticas están en correlación con variables de todo tipo, de ahí la heterogeneidad en la pronunciación. Básicamente se habla de cuatro tipos de variedades.

1. Variedad dialectal, geográfica o diatópica (dialectos geográficos)

2. Variedad social o diastrática (dialectos sociales o sociolectos).

3. Variedad situacional, funcional o diafásica (registros).

4. Variedad individual o estilo (idiolecto).

Cada una de estas variedades se caracteriza por unos rasgos fonéticos, además de otros léxicos y algunos morfosintácticos. El habla nos informa sobre características psicosociales y culturales: sobre el origen geográfico, sobre el origen social, sobre elementos de la situación o sobre algunas características personales. La manera de pronunciar genera actitudes hacia los hablantes, actitudes positivas o negativas que pueden derivar o provenir de prejuicios o de estereotipos. Es importante mostrar al aprendiente de ELE, mediante ejemplos reales, que esta o aquella persona no «se come las letras» o «habla mal», sino que su forma de pronunciar corresponde a la de la mayoría de la población del lugar donde ha vivido o vive (Calsamiglia y Tusón, 1999: 57).

La prosodia (entonación, intensidad, ritmo) constituye otro de los aspectos específicos de la oralidad. Utilizamos la entonación para organizar la 
información, tanto por su función sintáctica para señalar la modalidad oracional (enunciativa, interrogativa, exclamativa) como por su función enfática $y$ modalizadora, ya que nos permite marcar el foco temático o destacar determinados elementos estructurales (Hidalgo, 1997).

En lenguas como el español, llamadas de acento libre, la intensidad, además de distinguir significados, sirve también, como en el caso de la entonación, para marcar énfasis. También el ritmo, en el interior de los grupos tonales o la presencia/ausencia de pausas más o menos largas, tienen funciones sintácticas $\mathrm{y}$, además, nos sirven para señalar e interpretar actitudes; por ejemplo, un ritmo rápido se asocia con un cierto estado de nerviosismo, mientras que un ritmo lento se asocia con un estado más relajado, más seguro. Las pausas también se utilizan con valor enfático, pues funcionan como recursos para crear expectación o para marcar quién tiene el poder en cierta situación comunicativa (Calsamiglia y Tusón, 1999: 58).

A través de las muestras de lengua extraídas de programas televisivos, el profesor de ELE también puede trabajar con los alumnos, mediante análisis comparativos y contrastivos, las características psicosociales y culturales de diferentes hispanohablantes. De esta forma, el aprendiente aprenderá a distinguir, comprender y respetar las diferentes variedades del español. 
EL PROGRAMA TELEVISIVO COMO RECURSO PARA LA ENSEÑANZA/APRENDIZAJE DE ESPAÑOL LENGUA EXTRANJERA 
ANÁLISIS DE MANUALES Y EXTRACCIÓN DE DATOS

5. ANÁLISIS DE MANUALES Y EXTRACCIÓN DE DATOS 
Es verdad que, aunque la utilización del material audiovisual en la enseñanza de ELE es de máxima actualidad como material rentable, la presencia del programa televisivo en los manuales es aún muy escasa. A pesar de ser un material disponible en línea, son pocos los libros que incluyen en sus páginas una dirección de Internet o un código $\mathrm{QR}^{42}$ para visualizarlo.

Sin embargo, no podemos pasar por alto el hecho de que en este tema no partimos de cero, pues ciertos recursos didácticos enfocados, especialmente en los últimos años, en otros materiales audiovisuales como el cine o la publicidad; o relativos a otros medios de comunicación, como la prensa y la radio, pueden ser también aplicados a los programas televisivos. De ahí que nos parezca importante realizar un análisis de los manuales más actuales y de sus propuestas.

A lo largo de nuestro análisis, veremos y concluiremos que este soporte solo es utilizado para tratar de forma general los programas televisivos emitidos en España, pero no como herramienta didáctica para trabajar alguna o varias destrezas comunicativas. Especialmente, las actividades relacionadas con programas de televisión se destinan a trabajar los contenidos de tipo léxico, es decir, la ampliación del vocabulario. Efectivamente, veremos que, en la mayoría de los casos, el programa televisivo se utiliza como excusa para iniciar una unidad o proponer simplemente una conversación, sin profundizar en el estudio de ninguno de los aspectos - lingüísticos, culturales, pragmáticos, estratégicos y discursivos - que se pueden presentar en clase para su explicación y análisis.

\subsection{Criterios para el análisis de manuales}

Nos propusimos analizar algunos de los manuales más actuales y utilizados en el aula de ELE para los diferentes niveles. Nuestro análisis centró su atención en los contenidos gramaticales, léxicos, socioculturales y pragmáticos trabajados en las actividades cuyo soporte es el programa televisivo.

\footnotetext{
${ }^{42}$ Un código QR (del inglés Quick Response code, "código de respuesta rápida") es la evolución del código de barras. Es un módulo para almacenar información en una matriz de puntos o en un código de barras bidimensional. La matriz se lee en el dispositivo móvil por un lector específico (lector de QR) y de forma inmediata nos lleva a una aplicación en internet.
} 
Analizamos las actividades que aparecen en los libros teniendo en cuenta los siguientes parámetros: objetivos, contenidos, soportes y destrezas.

\subsection{Análisis de manuales}

\section{PRISMA}

Este método está estructurado en seis niveles según el MCER y el Plan curricular del Instituto Cervantes y está enfocado desde una perspectiva comunicativa.

El libro del alumno consta de doce unidades con dos repasos. En el índice, las lecciones se presentan con el siguiente desglose: Funciones comunicativas, Contenidos gramaticales, Contenidos léxicos y Contenidos culturales, que también aparecen al inicio de cada lección.

\section{Prisma B1 Progresa ${ }^{43}$}

En todo el manual, no hay ninguna referencia ni actividad relacionada con los programas televisivos. Sin embargo, sí se incluyen contenidos relacionados con el cine (Unidad 6), la radio (Revisión 1), y la publicidad en España (Revisión 2).

\section{Prisma B2 Avanza ${ }^{44}$}

En este manual tampoco hay ninguna referencia ni actividad relacionada con los programas de televisión. No obstante, sí encontramos contenidos relacionados con los nuevos medios de comunicación: foro, chat, correo electrónico y SMS (Unidad 2), Internet (Revisión 6-10), el cine (Unidad 4), y la música (Unidad 5).

NUEVO PRISMA

43 VV. AA. (2003). Prisma B1 Progresa. Método de español para extranjeros. Madrid: Edinumen.

44 VV. AA. (2003). Prisma B2 Avanza. Método de español para extranjeros. Madrid: Edinumen. 


\section{EL PROGRAMA TELEVISIVO COMO RECURSO PARA LA ENSEÑANZA/APRENDIZAJE DE ESPAÑOL LENGUA EXTRANJERA}

Como su edición anterior, este método está estructurado en seis niveles, según el MCER y el Plan curricular del Instituto Cervantes, y también sigue un enfoque comunicativo.

El libro del alumno consta de doce unidades y de una prueba de examen del nivel correspondiente. Esta colección supone una evolución de Prisma, con una reorganización y renovación de contenidos, así como de nuevas herramientas interactivas y multimedia. En el índice, las lecciones se presentan con el siguiente desglose: Tipos de texto y léxico, El componente estratégico, Contenidos culturales y Ortografia y fonética (para los niveles A1-A2) o Contenidos funcionales y Contenidos lingüísticos (para los niveles C1-C2), que también aparecen al inicio de cada lección.

\section{Nuevo Prisma A1 $1^{45}$}

A lo largo del manual no encontramos ninguna referencia ni actividad relacionada con los programas televisivos. Sin embargo, se incluyen contenidos sobre personajes famosos del mundo hispano (Unidad 4), y diferentes contenidos léxicos y tipos de texto: periodístico y Facebook (Unidad 3), informativo y entrevista (Unidad 8), y reportaje (Unidad 9).

\section{Nuevo Prisma $A 2^{46}$}

En este manual, la única actividad en la que se menciona el programa televisivo se encuentra en la Unidad 1, en los apartados 1.2 y 1.3. En ella, se pide a los alumnos que anoten las estrategias que utilizan para aprender español y se les pregunta si creen que para ello es útil escuchar la radio, ver la televisión, etc. Sin embargo, esta actividad solo menciona el programa televisivo como posible recurso para el aprendizaje del español, pero no incluye ningún ejercicio para su explotación didáctica. Por el contrario, sí encontramos actividades en las que se trabaja con entrevistas de radio, artículos de prensa y publicidad (Unidades 1, 7,10, 11 y 12), Facebook (Unidad 2), revistas de ocio (Unidad 5), y Twitter (Unidad 9). Por ejemplo, en el apartado Contenidos culturales de la Unidad 10, se presentan los principales periódicos y cadenas de radio de los países hispánicos, y se les pide a los alumnos que escriban una noticia de prensa y que preparen un programa de radio.

\footnotetext{
${ }^{45}$ VV. AA. (2012). Nuevo Prisma A1. Curso de español para extranjeros. Madrid: Edinumen. ${ }^{46}$ VV. AA. (2013). Nuevo Prisma A2. Curso de español para extranjeros. Madrid: Edinumen.
} 


\section{Nuevo Prisma $C 1^{47}$}

En este manual hay una actividad relacionada con los programas televisivos. En el apartado Tipos de texto y léxico, se trabaja el texto humorístico: chiste, caricatura, tira cómica y monólogo (Unidad 1), y se presenta el programa televisivo El Club de la Comedia ${ }^{48}$ :

Unidad 1, actividades 1,2 y 3

$\begin{array}{ll}\text { Objetivo } & \text { Comprender un texto humorístico } \\ \text { Contenido } & \text { El sentido de humor español } \\ \text { Soporte } & \begin{array}{l}\text { Audición de un monólogo extraído del programa El Club de la } \\ \text { Comedia }\end{array}\end{array}$

Destrezas Comprensión oral, expresión oral e interacción oral

Sin embargo, encontramos más actividades relacionadas con otros medios de comunicación, tales como la entrevista radiofónica (Unidad 2) y el anuncio publicitario (Unidad 4).

\section{Nuevo Prisma $C 2^{49}$}

Este manual presenta una actividad relacionada con los programas televisivos. En el ejercicio 2 de la Unidad 2, se pregunta al alumno si conoce algún programa de televisión de divulgación científica en español. A continuación, hay un ejercicio de comprensión oral en que el alumno escucha un fragmento del programa Redes $2.0^{50}$. Sin embargo, no se da la opción de reproducir el programa en vídeo, sino solo en audio:

Unidad 2, actividad 2

\footnotetext{
${ }^{47}$ VV. AA. (2011). Nuevo Prisma C1. Curso de español para extranjeros. Madrid: Edinumen.

${ }^{48}$ Formato de televisión del género stand up comedy, en el que monologuistas profesionales y actores invitados se enfrentan al público en directo con un monólogo de entre 8 y 10 minutos de duración.

${ }^{49}$ VV. AA. (2012). Nuevo Prisma C2. Curso de español para extranjeros. Madrid: Edinumen.

${ }^{50}$ Programa de televisión de divulgación científica que trata diversos temas científicos como la sociología, la biología o la astronomía.
} 
Objetivo Predecir el contenido de un texto auditivo: formato y contenido

Contenidos Léxico relacionado con los sentidos

Soporte Audición y texto sinopsis del programa televisivo en cuestión

Destrezas Comprensión oral

En la Unidad 8, en el apartado Contenidos culturales, hay dos ejercicios relacionados con el programa televisivo Tengo una pregunta para usted ${ }^{51}$. El ejercicio 4 pretende trabajar la comprensión oral, y el ejercicio 5 se centra en la expresión oral. Sin embargo, una vez más, solo es posible la reproducción del programa en formato audio.

Unidad 8, actividades 4 y 5

Objetivo Responder a consultas formales, contraargumentar, expresar compromiso

Contenidos Léxico relacionado con las formas de gobierno, instituciones, etc.

Soporte Audición

Destrezas Comprensión oral y expresión oral

Podemos señalar que, como en otros manuales, también en este hay más actividades que utilizan como soporte otros medios de comunicación: se tratan el texto periodístico y radiofónico (Unidades 2, 3, 5), la conversación tecnológica (el chat) y los mensajes cortos en Internet (Twitter, Facebook) (Unidades 7 y 10); por otro lado, también se hace referencia a la literatura y el cine (Unidad 10).

GENTE HOY

${ }^{51}$ Programa de televisión en el que un grupo de cien ciudadanos anónimos entrevistan a líderes
políticos invitados. 
Este método está disponible en cuatro de los seis niveles establecidos el MCER y el Plan curricular del Instituto Cervantes y está basado en el enfoque por tareas.

El libro del alumno consta de doce unidades, un consultorio gramatical y un consultorio verbal. Es una nueva edición de la colección Gente, en la que se han revisado contenidos, objetivos y tareas. Cada unidad está dividida de la siguiente manera:

- Entrar en materia: es el primer contacto con los temas y el vocabulario; se presenta el objetivo de la unidad y lo que el alumno va a aprender;

- En contexto: se presentan algunos documentos que el alumno puede encontrar en situaciones reales de la vida diaria;

- Formas y recursos: se abordan los aspectos gramaticales;

- Tareas: se proponen actividades en grupo para que el alumno practique intercambios comunicativos similares a los de la vida real;

- Mundos en contacto: se ofrece información sobre el mundo hispanohablante.

Gente Hoy $1(A 1-A 2)^{52}$

Al comienzo de varias unidades se incluye un vídeo disponible en línea, extraído de un programa televisivo relacionado con el contenido de la unidad para Entrar en materia, tal y como el nombre del apartado indica. Sin embargo, no se explota el programa televisivo como recurso didáctico en sí: en las Unidades 1 y 10, se presenta un vídeo de un concurso televisivo; en la Unidad 5 , se trata de un programa de televisión que ofrece consejos para estar en forma; en la Unidad 6, el vídeo muestra la elaboración de una paella; y en las Unidades 7 y 8 , hay reportajes.

Por otro lado, en el apartado En contexto de las Unidades 1 y 10, se incluye un texto de un concurso televisivo para trabajar la CO y la CE. En otras unidades, los textos se centran en la entrevista radiofónica y periodística, y en las revistas.

Unidad 1, actividad 4

${ }^{52}$ VV. AA. (2012). Gente Hoy 1 (A1-A2). Curso de español. Barcelona: Difusión. 


\section{Objetivo Identificar países}

Contenidos Vocabulario de los países y los números

Soporte Audio de un concurso musical en el que se dan votaciones

Destrezas Comprensión oral

Unidad 10, actividad 2

$\begin{array}{ll}\text { Objetivo } & \text { Referir y situar acontecimientos pasado, conocer el cine español } \\ \text { e hispanoamericano }\end{array}$

Contenidos Pretérito indefinido

Soporte

Audio de un concurso televisivo, imágenes de paneles con preguntas

Destrezas Comprensión oral, comprensión escrita y expresión oral

Gente Hoy $2(B 1)^{53}$

Como en anterior manual de Gente Hoy que acabamos de analizar, al comienzo de varias unidades se presenta un vídeo disponible en línea, extraído de un programa televisivo relacionado con el contenido de la unidad para Entrar en materia, que es el título del apartado. Sin embargo, no se explota el programa televisivo como recurso didáctico en sí: en las Unidades 1, 4 y 6, se trata de una entrevista; en la Unidad 5, de un anuncio; y en la Unidad 7, se presenta un documental.

La Unidad 2, sí dedica una parte del contenido al programa televisivo, pues uno de los objetivos establecidos consiste en describir y valorar películas, programas de TV y espectáculos. También se aborda el vocabulario relacionado con el cine y la televisión (géneros, características...). En otras unidades, los tipos de texto trabajan la entrevista, el anuncio publicitario y la tertulia radiofónica.

${ }^{53}$ VV. AA. (2014). Gente Hoy 2 (B1). Curso de español. Barcelona: Difusión. 
Unidad 2, actividad 9

Objetivo Describir y valorar películas, programas de TV y espectáculos

Contenidos Adjetivos para valorar, vocabulario relativo al cine y la televisión

Soporte Imágenes representativas de programas de televisión españoles

Destrezas Expresión oral e interacción oral

Igualmente, la Unidad 10 comienza con un vídeo de un concurso en la calle y, como tipo de texto, se vuelve a incluir el concurso de televisión.

Unidad 10, actividades 2 y 3

Objetivo Dar información con diferentes grados de seguridad, discutir datos, comprobar la validez de la información

Contenidos La expresión de grados de seguridad, la expresión del acuerdo y el desacuerdo

Soporte Cuestionario y audio de un concurso de televisión

Destrezas Compresión oral e interacción oral

\section{AULA INTERNACIONAL (NUEVA EDICIÓN)}

Este método está disponible para cuatro de los seis niveles incluidos el MCER y el Plan curricular del Instituto Cervantes y está basado en el enfoque por tareas.

Es una nueva edición de la colección Aula Internacional, en la que se han introducido nuevos contenidos y secciones. Los manuales de los diferentes niveles están divididos en seis (Aula Internacional 4 y 5) nueve o diez unidades didácticas. Los contenidos se indican en el índice y al comienzo de cada unidad, y están estructurados del siguiente modo:

- Comprender: contenidos lingüísticos y comunicativos contextualizados;

- Explorar y reflexionar: observación de lengua a partir de muestras; 


\section{EL PROGRAMA TELEVISIVO COMO RECURSO PARA LA ENSEÑANZA/APRENDIZAJE DE ESPAÑOL LENGUA EXTRANJERA}

- Practicar y comunicar: práctica lingüística y comunicativa;

- Viajar: materiales con contenido cultural.

Aula Internacional $1(A 1)^{54}$

En este manual no aparece ninguna referencia o actividad relacionada con los programas televisivos ni tampoco con otros medios de comunicación.

Aula Internacional 2(A2) 55

Aquí podemos encontrar una unidad dedicada al cine (Unidad 2) y alguna otra actividad relativa a este campo (Unidades 8 y 10), pero nada relacionado con los programas televisivos.

Aula Internacional 3(B1) 56

En el apartado Recursos Léxicos de la Unidad 4 se tratan los géneros narrativos: cine, televisión, novelas... así como el léxico del cine y la televisión. No obstante, la tarea final está enfocada al género cinematográfico. Del mismo modo, en la Unidad 9, la tarea final consiste en escribir una discusión de pareja para el guion de una película. Por otro lado, como en manuales anteriores, en este también se hace referencia a la publicidad y a los tipos de texto (móvil, correo electrónico...).

Unidad 4, actividad 2

Objetivo Escribir la sinopsis de una película

Contenidos Relatar en presente, utilizar el léxico del cine y la televisión

Soporte Fotogramas

Destrezas Expresión oral y expresión escrita

\footnotetext{
54 VV. AA. (2013). Aula Internacional 1 (A1). Curso de español. Nueva Edición. Barcelona: Difusión.

${ }^{55}$ VV. AA. (2013). Aula Internacional 2 (A2). Curso de español. Nueva Edición. Barcelona: Difusión.

${ }^{56}$ VV. AA. (2014). Aula Internacional 3 (B1). Curso de español. Nueva Edición. Barcelona: Difusión.
} 


\section{Aula Internacional 4(B2.1 $)^{57}$}

La Unidad 1 se titula Buenas noticias y propone como tarea final convertirnos en la redacción de un medio de comunicación. En esta unidad se trabajan los recursos léxicos relativos a los medios de comunicación. También se hace referencia a este soporte en la Unidad 3, pues la tarea final consiste en decidir qué compañeros pueden participar en un reality-show.

Unidad 1, actividad 12

Objetivo Inventar y presentar una noticia de prensa, radio o televisión

Contenidos Tiempos del pasado, uso de la voz pasiva, construcciones impersonales

Soporte Previa muestra de noticias de prensa y radio

Destrezas Expresión escrita y expresión oral

Unidad 3, actividad 13

Inventar un concurso de televisión y entrevistar a otros

Objetivo compañeros para decidir si estos podrían ser seleccionados como concursantes

Contenidos Algunos usos del condicional y del subjuntivo

Soporte Información previa sobre un concurso de televisión

Destrezas Expresión oral e interacción oral

\section{Aula Internacional $5(B 2.2)^{58}$}

La Unidad 3 se titula Así pasó y la tarea final está directamente relacionada con el programa televisivo, ya que consiste en hacer un programa de televisión con historias sobre una ciudad o un barrio. En el apartado Recursos léxicos, se trabaja el vocabulario del ámbito de la crónica en los medios de comunicación.

\footnotetext{
${ }^{57}$ VV. AA. (2013). Aula Internacional 4 (B2.1). Curso de español. Nueva Edición. Barcelona: Difusión.

${ }^{58}$ VV. AA. (2014). Aula Internacional 5 (B2.2). Curso de español. Nueva Edición. Barcelona: Difusión.
} 


\section{EL PROGRAMA TELEVISIVO COMO RECURSO PARA LA \\ ENSEÑANZA/APRENDIZAJE DE ESPAÑOL LENGUA EXTRANJERA}

Unidad 3, actividad 12
Objetivo
Hacer un programa de televisión con historias sobre una ciudad o un barrio, grabarlo y mostrarlo en clase
Contenidos Combinar tiempos del pasado, referir eventos pasados, contar relatos

Soporte Imagen de muestra

Destrezas Expresión oral

\section{NUEVO AVANCE}

Este método está disponible en cuatro de los seis niveles establecidos en el MCER y el Plan curricular del Instituto Cervantes y sigue el enfoque comunicativo.

Los libros del alumno constan de un número diferente de unidades: Nuevo Avance Básico está divido en dieciséis, con un repaso cada tres unidades; Nuevo Avance 3 y 5 incluyen seis unidades con un repaso cada dos unidades; y Nuevo Avance Superior está dividido en doce unidades con un repaso cada tres. En el índice, las lecciones se presentan con el siguiente desglose: Contenidos temáticos, Contenidos gramaticales, Contenidos léxicos y Contenidos funcionales y socioculturales, Contenidos pragmáticos y Tipología textual.

Nuevo Avance Básico (A1-A2) 59

En este manual, únicamente la Unidad 15, en sus apartados dedicados a los contenidos temáticos y léxicos, aborda el tema de la publicidad y de los medios de comunicación. Por otra parte, en la Unidad 9, se presentan algunos productos del mundo hispano, como la revista Muy Interesante ${ }^{60}$ y la película Amores Perros $^{61}$, pero no se dice nada sobre programas televisivos. Tampoco se tratan

\footnotetext{
${ }^{59}$ Moreno, C.; Zurita, P.; Moreno, V. (2010). Nuevo Avance Básico A1-A2. Curso de español. Madrid: SGEL.

${ }^{60}$ Revista mensual española de divulgación y ciencia popular.

${ }^{61}$ Primer largometraje del director mexicano Alejandro González Iñárritu.
} 
demasiado otros temas que podríamos relacionar con los medios de comunicación, como las TICs (Unidad 17) y el formato entrevista (Unidad 6).

Unidad 15, actividad 4

\section{Objetivo Aprender nuevo vocabulario}

Contenidos Léxico de la publicidad y los medios de comunicación

Soporte Imágenes

Destrezas Comprensión escrita

Nuevo Avance $3(B 1.1)^{62}$

En este manual no aparece ninguna referencia o actividad relacionada con los programas televisivos. Sin embargo, dedica una unidad completa al cine y a los espectáculos (Unidad 5). También hay alguna referencia a las entrevistas y revistas de moda (Unidad 3).

Nuevo Avance 5 (B2.1) 63

Aquí tampoco encontramos ninguna referencia o actividad relacionada con el programa de televisión. Tan solo podríamos mencionar la Unidad 5, que está dedicada a la publicidad y a los anuncios.

Nuevo Avance Superior (B2) ${ }^{64}$

Tampoco en este manual hay ninguna referencia o actividad relativa a los programas televisivos. De nuevo, solo la Unidad 5 podría estar ligeramente relacionada, pues trata sobre la publicidad y los anuncios; y la Unidad 9, que trata la literatura, la música y el cine.

\section{PASAPORTE}

\footnotetext{
62 Moreno, C.; Zurita, P.; Moreno, V. (2010). Nuevo Avance 3 (B1.1). Curso de español. Madrid: SGEL.

${ }^{63}$ Moreno, C.; Zurita, P.; Moreno, V. (2011). Nuevo Avance 5 (B2.1). Curso de español. Madrid: SGEL.

${ }^{64}$ Moreno, C.; Zurita, P.; Moreno, V. (2014). Nuevo Avance Superior (B2). Curso de español. Madrid: SGEL.
} 


\section{EL PROGRAMA TELEVISIVO COMO RECURSO PARA LA \\ ENSEÑANZA/APRENDIZAJE DE ESPAÑOL LENGUA EXTRANJERA}

Este método está estructurado en cuatro de los seis niveles incluidos en el MCER y el Plan curricular del Instituto Cervantes y está basado en el enfoque comunicativo.

El libro del alumno está constituido por seis módulos. Cada módulo está formado por los cuatro ámbitos de uso de la lengua (Ámbito personal, Ámbito público, Ámbito profesional y Ámbito académico) para poder utilizar la lengua de una manera más adecuada a cada situación. En cada uno de los ámbitos se incluyen contenidos para trabajar las competencias gramaticales, léxicas, funcionales, fonéticas y ortográficas, y sociolingüísticas en español. También incluye una sección de cultura hispánica en cada unidad.

Pasaporte Nivel $1(A 1)^{65}$

En este manual no hay ninguna referencia o actividad relativa a los programas televisivos.

Pasaporte Nivel $2(A 2)^{66}$

En la Unidad 1, titulada Hablar de las personas, en la sección Ámbito público, la actividad principal que se propone consiste en elegir programas de televisión.

Unidad 1, actividad 1

Objetivo Expresar preferencias

Contenidos Léxico de los deportes

Soporte Audio de una entrevista de televisión

Destrezas Comprensión oral, expresión oral e interacción oral

Pasaporte Nivel $3(B 1)^{67}$

\footnotetext{
${ }^{65}$ Cerrolaza Aragón, M.; Cerrolaza Gili, O.; Justo Muñoz, P. (2007). Pasaporte Nivel 1 (A1). Español Lengua Extranjera. Madrid: Edelsa.

${ }^{66}$ Cerrolaza Aragón, M.; Cerrolaza Gili, O.; Llovet Barquero, B. (2008). Pasaporte Nivel 2 (A2). Español Lengua Extranjera. Madrid: Edelsa.

${ }^{67}$ Cerrolaza Aragón, M.; Cerrolaza Gili, O. Llovet Barquero, B. (2008). Pasaporte Nivel 3 (B1). Español Lengua Extranjera. Madrid: Edelsa.
} 
En este manual no hay ninguna referencia o actividad relativa al programa de televisión. Solo en el Módulo 5 se incluyen algunos contenidos relacionados con la prensa y la publicidad en España.

Pasaporte Nivel $4(B 2)^{68}$

Aquí tampoco encontramos ninguna referencia o actividad relativa a los programas televisivos.

\section{VÍA RÁPIDA}

Curso intensivo de español en un volumen que cubre los niveles A1, A2 y B1 del MCER dirigido a jóvenes y adultos, y basado en el enfoque comunicativo.

El libro del alumno se compone de 15 unidades y cada una de ellas incluye las siguientes secciones: Comprensión oral y escrita, Expresión oral y escrita e interacción oral y Recursos léxicos y gramaticales. También incluye algunos contenidos relativos a las culturas española y latinoamericana.

Vía Rápida $(A 1-B 1)^{69}$

En este manual no aparece ninguna referencia o actividad relacionada con los programas televisivos. Sin embargo, sí se trabaja la comprensión de lo esencial de textos auténticos, como la sinopsis de películas en una cartelera de cine, de un programa de radio y de entrevistas (Unidades 12 y 14).

\subsection{Conclusiones}

Este análisis de manuales nos permitió determinar que en la mayoría de las actividades cuyo soporte es el programa de televisión este solo es utilizado como herramienta para introducir los contenidos temáticos de una unidad; trabajar contenidos léxicos, especialmente aquellos relativos a los medios de comunicación; o gramaticales, como los tiempos del presente, el pasado o el condicional. Solo en un manual de los veintidós analizados, vimos que este

\footnotetext{
${ }^{68}$ Cerrolaza Aragón, M.; Cerrolaza Gili, O. Llovet Barquero, B. (2010). Pasaporte Nivel 4 (B2). Español Lengua Extranjera. Madrid: Edelsa.

${ }^{69}$ VV. AA. (2011). Vía Rápida (A1-B1). Curso intensivo de español. Barcelona: Difusión.
} 


\section{EL PROGRAMA TELEVISIVO COMO RECURSO PARA LA \\ ENSEÑANZA/APRENDIZAJE DE ESPAÑOL LENGUA EXTRANJERA}

formato se utilizara para trabajar contenidos pragmáticos: la valoración positiva y negativa, y la expresión del acuerdo y el desacuerdo; o como recurso para trabajar varios aspectos de la expresión y la interacción orales: hacer un programa de televisión. Sin embargo, comprobamos que otros formatos relativos a los medios de comunicación — como la radio, la prensa, la publicidad o las TIC - u otros formatos de tipo audiovisual, como el cine, están más didácticamente explotados y se incluyen en la gran mayoría de manuales de todos los niveles.

Por otra parte, en cuanto a la selección de los programas televisivos con los que se trabaja en los diferentes manuales, observamos que no se trata de programas especialmente motivadores para los alumnos. Por ejemplo, en el manual Nuevo Prisma $C 2$ las actividades giran en torno a un programa de divulgación científica y a otro de entrevistas sobre política. Además, en algunas de las actividades no se ofrece la posibilidad de ver el vídeo, sino solo de escuchar el audio del programa televisivo en cuestión. Este también es un factor que contribuye a disminuir la motivación, la atención y el interés por parte de los alumnos.

\subsection{Metodología para la extracción de datos}

Con el objetivo de conocer la opinión de la comunidad de profesores de español acerca del uso y de la rentabilidad del programa televisivo en el aula de ELE, diseñamos unos cuestionarios ${ }^{70}$ que sirvieran para realizar la observación. Para su diseño, distribución y análisis cuantitativo de los datos recurrimos a la herramienta de software libre distribuida por Google, Google Docs, que permite que los encuestados completen los cuestionarios en línea. Esta aplicación también facilita la organización de la recogida de datos en tablas de Excel. Los cuestionarios se distribuyeron a través de correo electrónico y de varios grupos dedicados a la enseñanza de ELE organizados en la red social Facebook. La muestra total recogida consiguió analizar la respuesta de 55 profesores que trabajan en distintos contextos profesionales ${ }^{71}$, todos ellos con formación

\footnotetext{
${ }^{70}$ Véase Anexo I.

71 De ellos, 21 profesores declararon trabajar en una universidad y/o centro de idiomas universitario, y 34 en colegios, institutos y academias privadas. Por lo que respecta al país, 24 de ellos trabajan en España, mientras que el resto se encuentran en Inglaterra, Italia, Francia, Alemania, Finlandia, Eslovaquia, Bulgaria, Marruecos, Túnez, Argentina, Canadá, y China.
} 
especializada en la didáctica de ELE y, en su mayoría, con varios años de experiencia profesional.

Entre las cuestiones básicas destacamos aquellas que hacen referencia al desarrollo de tipos de competencias y actividades comunicativas de la lengua a las que iría encaminada la explotación didáctica del programa televisivo, los niveles en que los profesores utilizarían este recurso, la relación que podría establecerse entre el uso de este material y el desarrollo de la competencia cultural, así como su posible uso para favorecer la capacidad de autoaprendizaje del alumno.

Los datos obtenidos nos llevaron a inferir que una gran mayoría de profesores considera que el programa televisivo es un recurso de utilidad para el aprendizaje y la enseñanza de ELE por varios y diversos motivos. La lectura de los datos obtenidos en el análisis de los cuestionarios de profesores nos sirvió para reflexionar sobre la incorporación de propuestas de aula y técnicas docentes que ayuden a los profesores de ELE a utilizar este formato en sus clases. Del mismo modo, la información extraída se tuvo en cuenta a la hora de establecer los criterios de diseño de la propuesta didáctica que presentamos como fruto de la presente tesis doctoral.

\subsection{Datos extraídos del cuestionario realizado por los profesores}

\section{1. ¿Trabaja con documentos audiovisuales en el aula de ELE?}

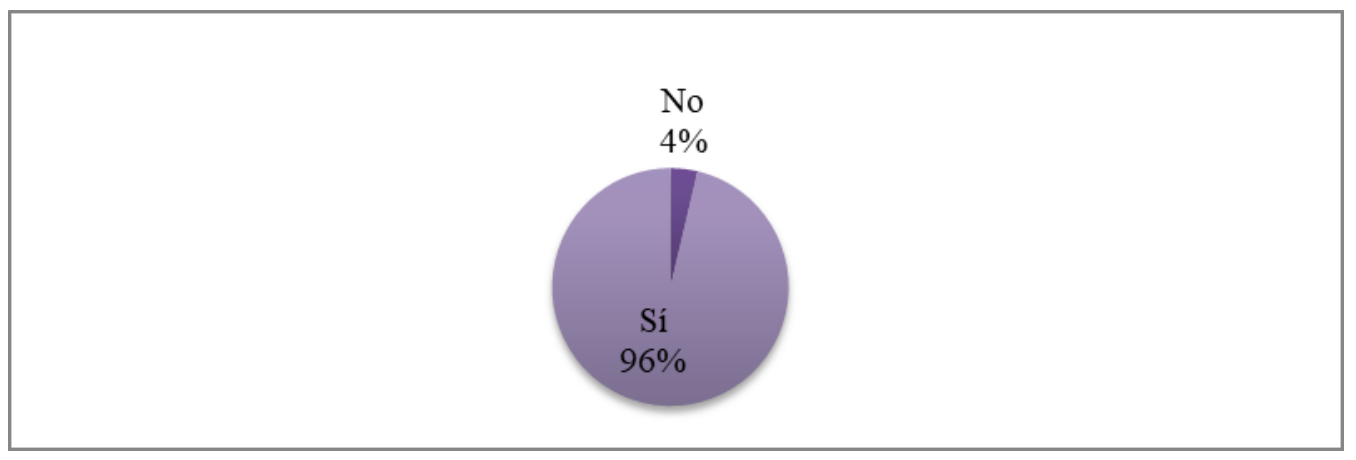

Figura 1. Porcentaje de profesores que trabaja con documentos audiovisuales en el aula de ELE. 


\section{En caso de respuesta negativa en la pregunta 1 , por favor, señale sus motivos:}

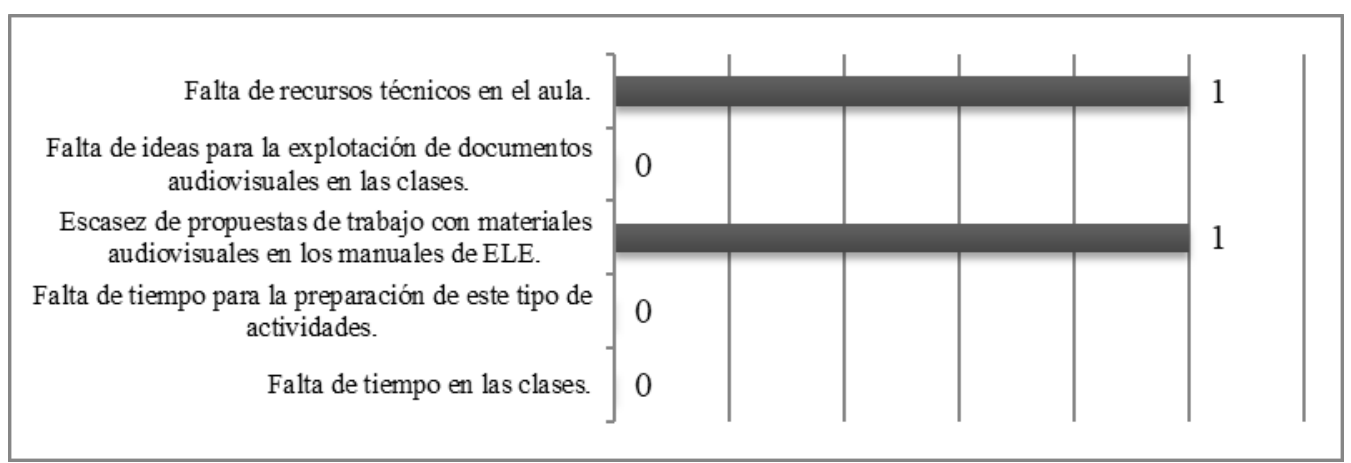

Figura 2. Motivos por los que los profesores declaran no trabajan con documentos audiovisuales en el aula de ELE.

3. En caso afirmativo en la pregunta 1, por favor, indique con qué frecuencia:

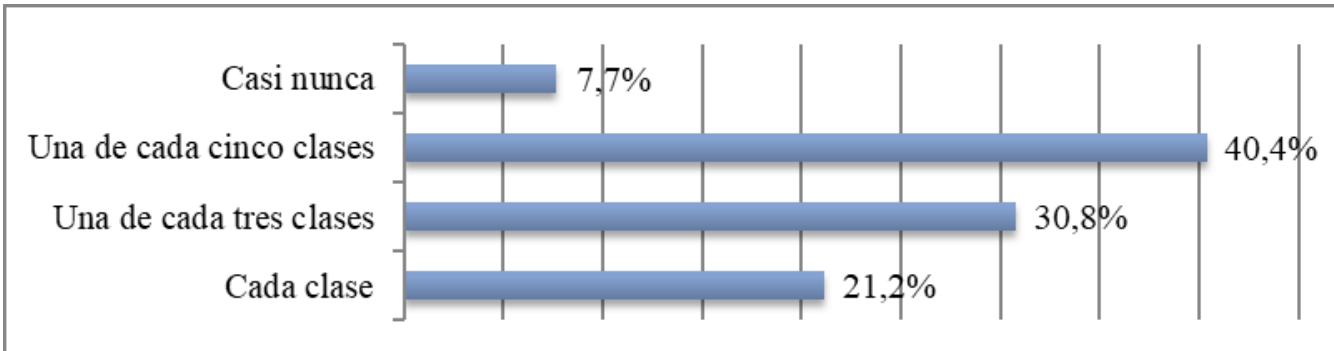

Figura 3. Frecuencia con la que los profesores declaran trabajar con documentos audiovisuales en el aula de ELE.

4. En caso afirmativo en la pregunta 1, por favor, señale qué porcentaje aproximado de la clase suele dedicar a que los alumnos realicen actividades con este tipo de documento:

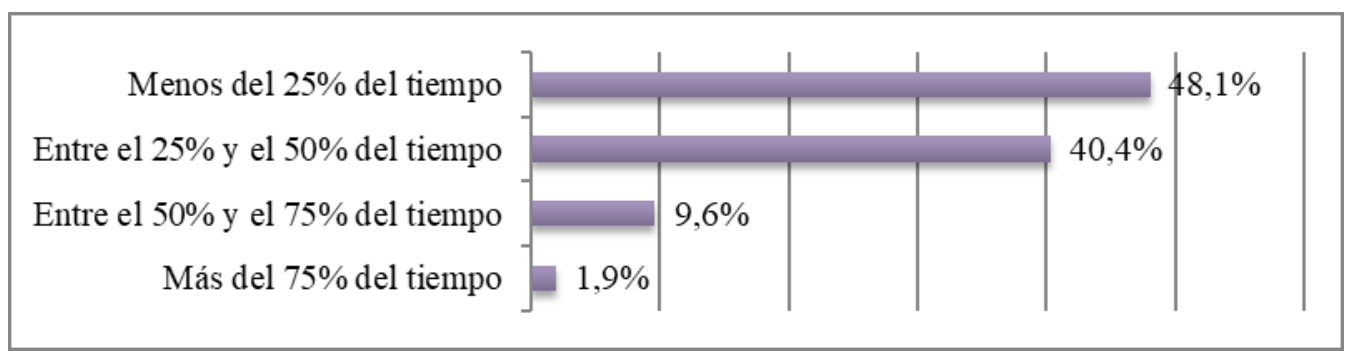

Figura 4. Porcentaje aproximado del tiempo de clase que los profesores declaran dedicar a que los alumnos realicen actividades con documentos audiovisuales. 
5. En caso afirmativo en la pregunta 1, por favor, indique con qué frecuencia utiliza los siguientes documentos audiovisuales o fragmentos de los mismos:

\subsection{Programas de televisión:}

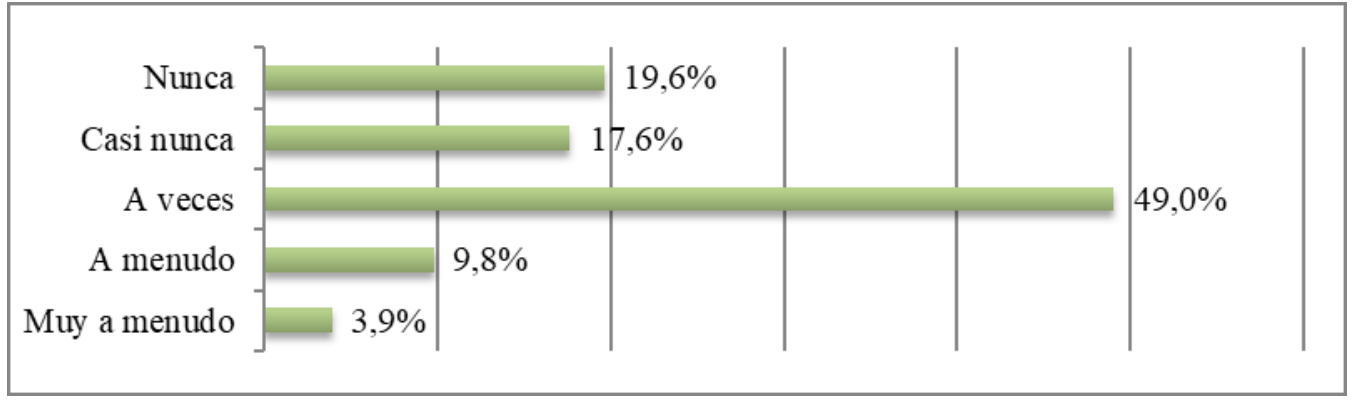

Figura 5. Frecuencia con la que los profesores declaran utilizar programas televisivos en el aula de ELE.

\subsection{Anuncios publicitarios}

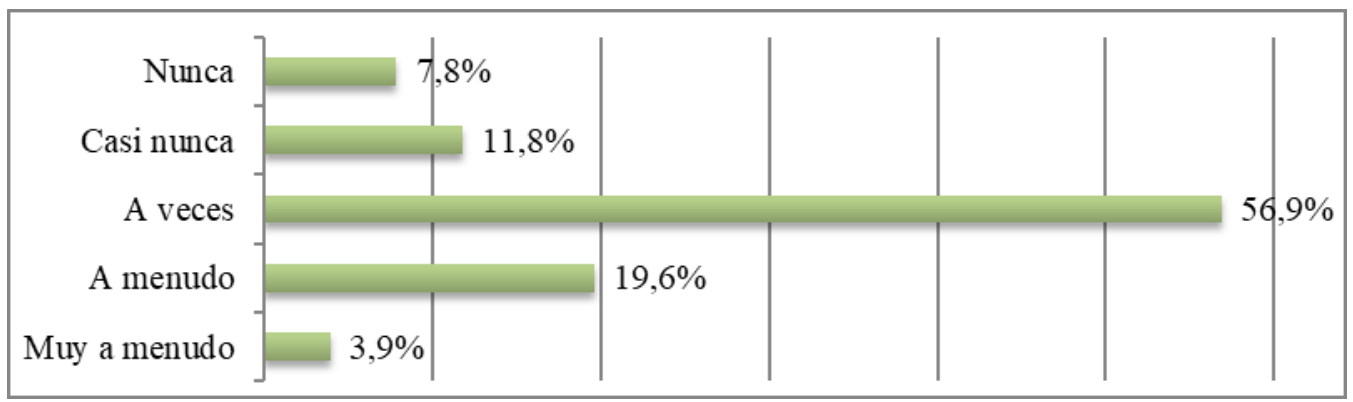

Figura 6. Frecuencia con la que los profesores declaran utilizar anuncios publicitarios en el aula de ELE.

\subsection{Películas}


EL PROGRAMA TELEVISIVO COMO RECURSO PARA LA

ENSEÑANZA/APRENDIZAJE DE ESPAÑOL LENGUA EXTRANJERA

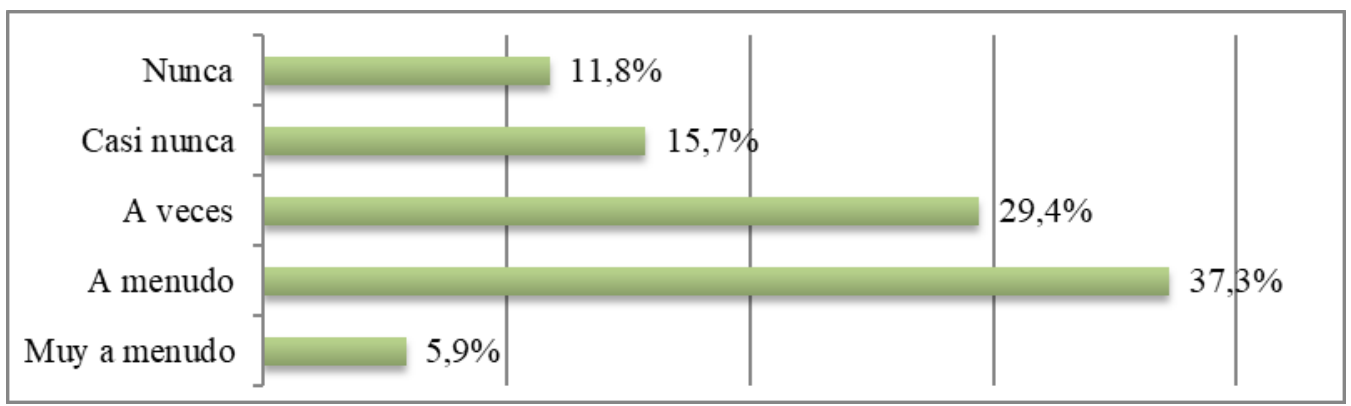

Figura 7. Frecuencia con la que los profesores declaran utilizar programas televisivos en el aula de ELE.

\subsection{Tráiler}

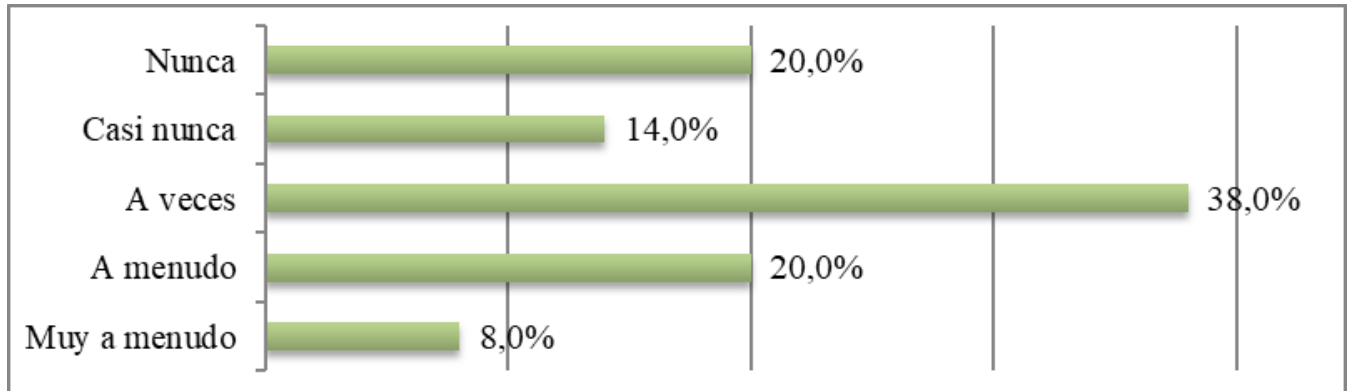

Figura 8. Frecuencia con la que los profesores declaran utilizar tráileres en el aula de ELE.

\subsection{Cortometrajes}

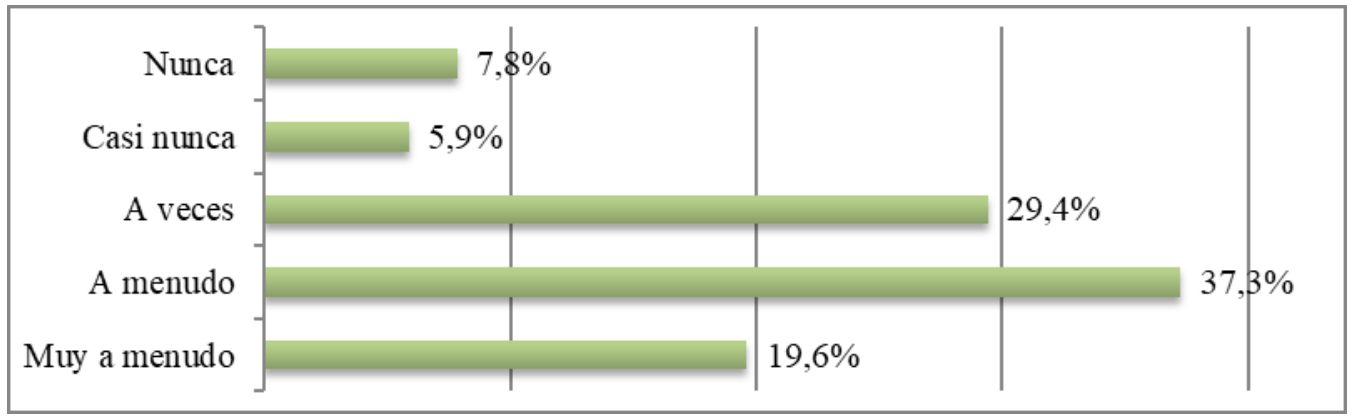

Figura 9. Frecuencia con la que los profesores declaran utilizar cortometrajes en el aula de ELE. 
6. En caso de utilizar programas televisivos en sus clases, por favor, indique qué tipos de programas utiliza y con qué frecuencia:

6.1. Informativos (Telediario, reportajes de actualidad, tertulias, el tiempo...)

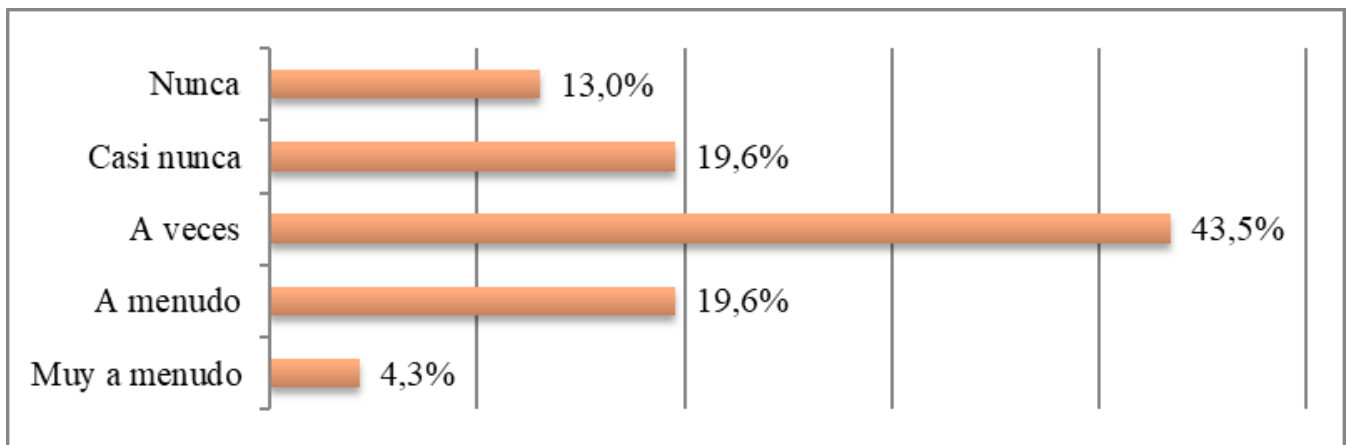

Figura 10. Frecuencia con la que los profesores declaran utilizar programas televisivos informativos en el aula de ELE.

\subsection{Culturales (Documental, educativo...)}

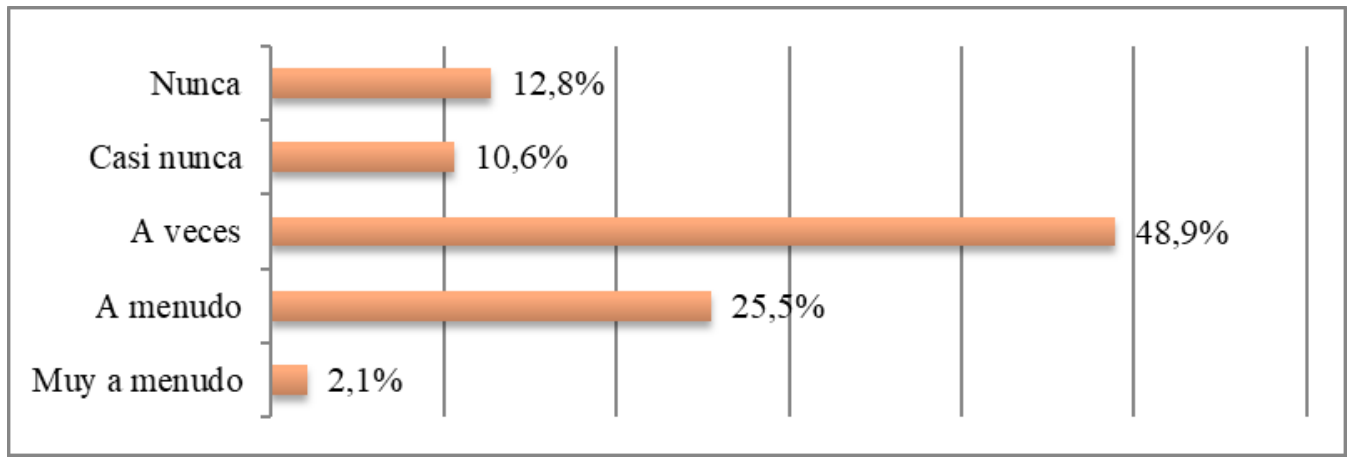

Figura 11. Frecuencia con la que los profesores declaran utilizar programas televisivos culturales en el aula de ELE.

\subsection{Ficción (Series, miniseries, telenovelas...)}




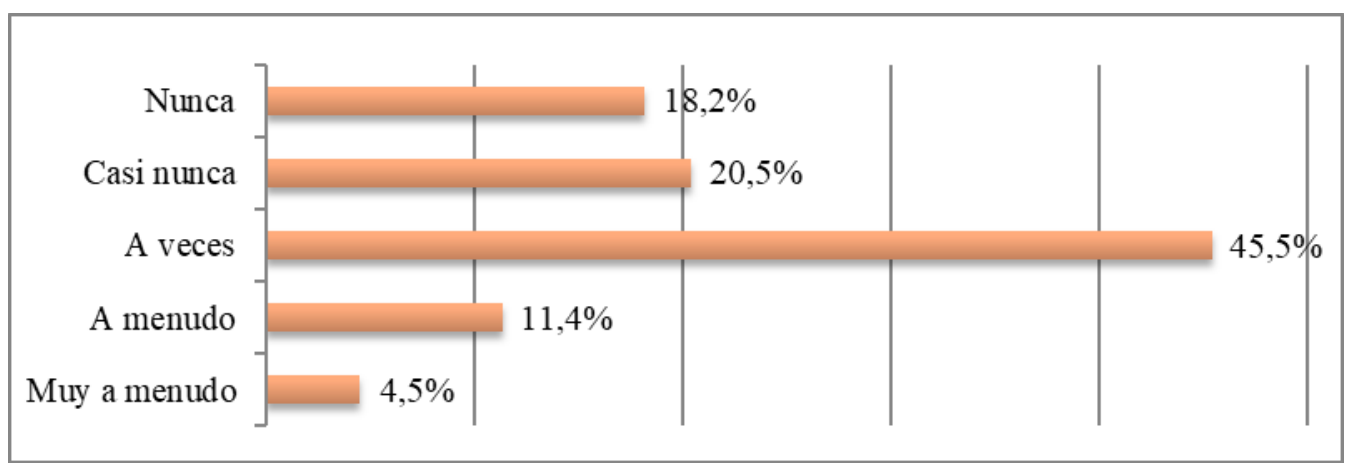

Figura 12. Frecuencia con la que los profesores declaran utilizar programas televisivos de ficción en el aula de ELE.

\subsection{Entretenimiento (Talk-shows, reality-shows, magacines, concursos, galas...)}

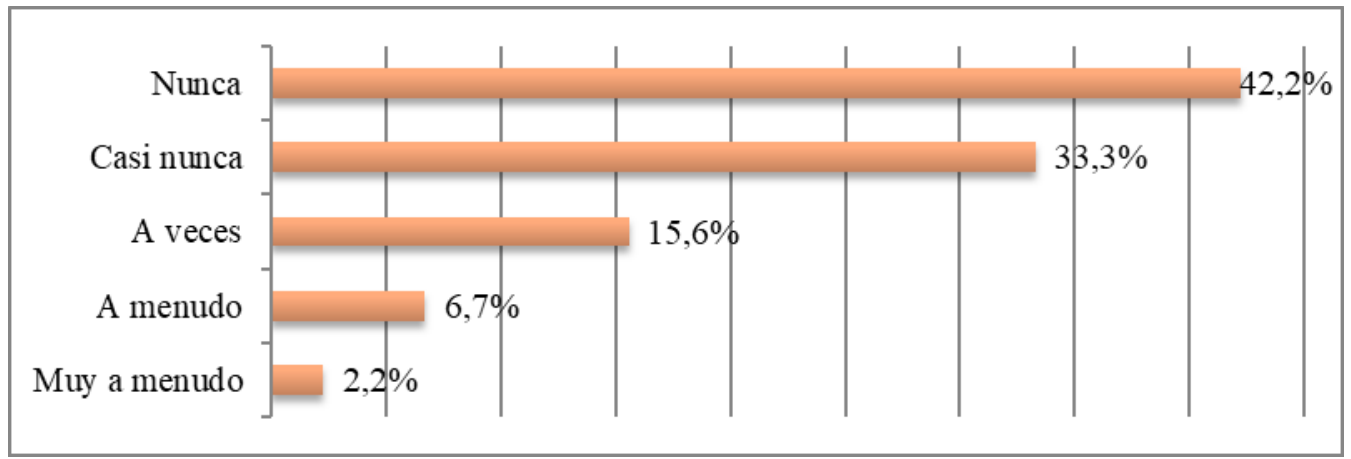

Figura 13. Frecuencia con la que los profesores declaran utilizar programas televisivos de entretenimiento en el aula de ELE.

\subsection{Deportes (Programas específicos, retransmisiones de competiciones, eventos especiales...)}

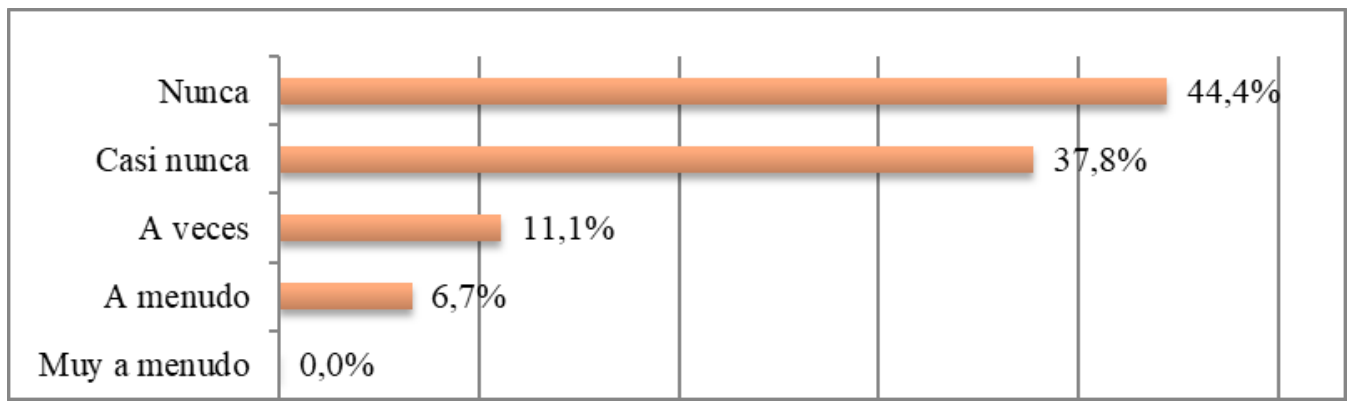

Figura 14. Frecuencia con la que los profesores declaran utilizar programas televisivos de deportes en el aula de ELE. 
7. En cualquier caso, por favor, indique con qué frecuencia trabaja en clase con estos otros medios de comunicación:

\subsection{Radio}

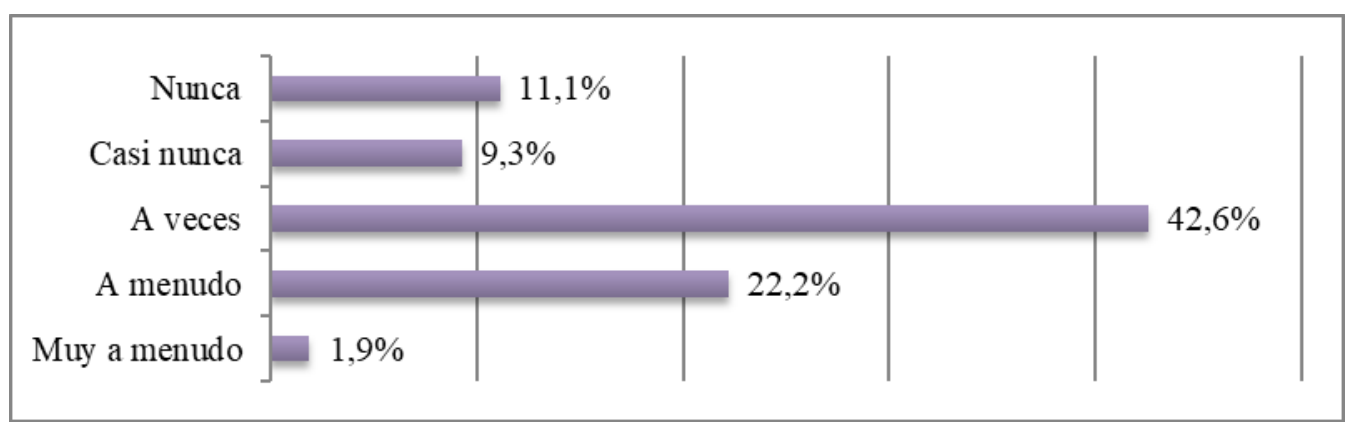

Figura 15. Frecuencia con la que los profesores declaran trabajar con documentos radiofónicos en el aula de ELE.

\subsection{Periódicos}

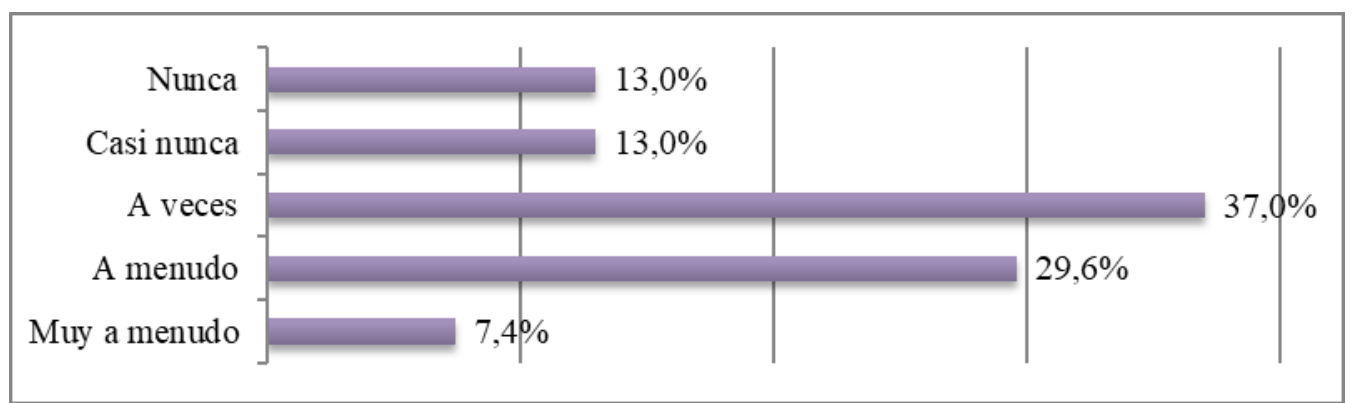

Figura 16. Frecuencia con la que los profesores declaran trabajar con periódicos en el aula de ELE.

\subsection{Revistas}




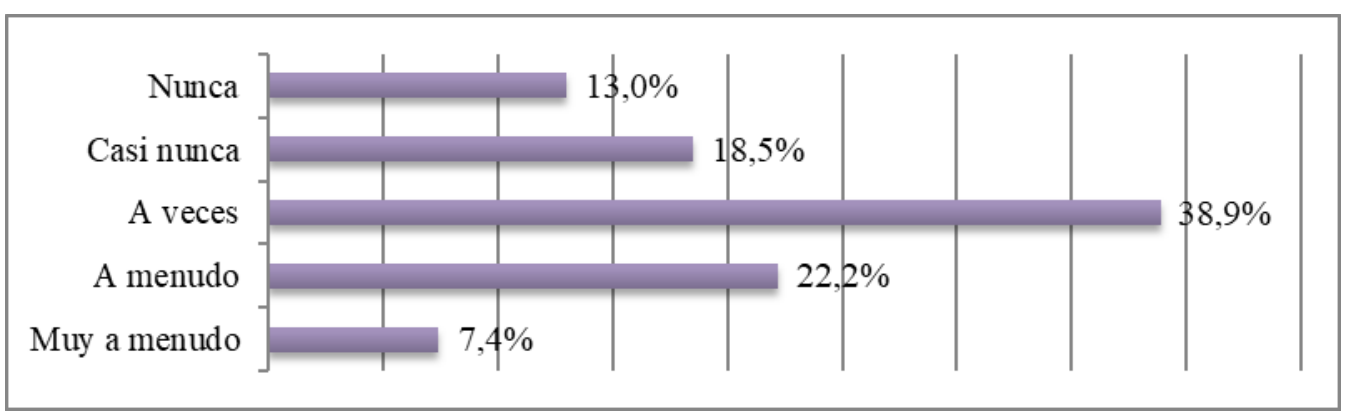

Figura 17. Frecuencia con la que los profesores declaran trabajar con revistas en el aula de ELE.

\subsection{Redes Sociales}

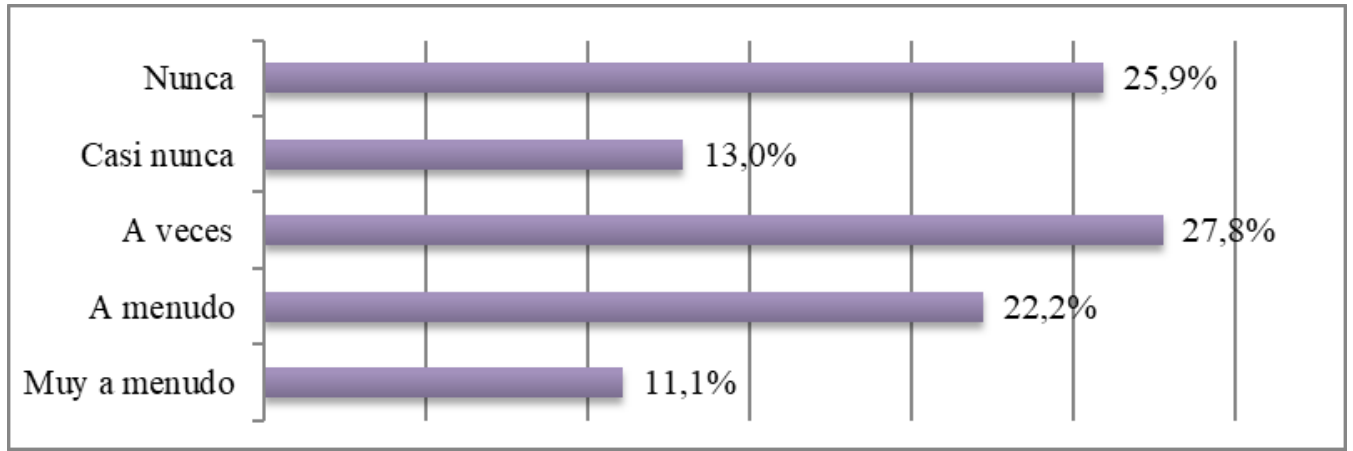

Figura 18. Frecuencia con la que los profesores declaran trabajar con redes sociales en el aula de ELE.

\section{Si no ha trabajado en el aula con programas televisivos, ¿cree que sería útil hacerlo? ¿Por qué ${ }^{72}$ ?}

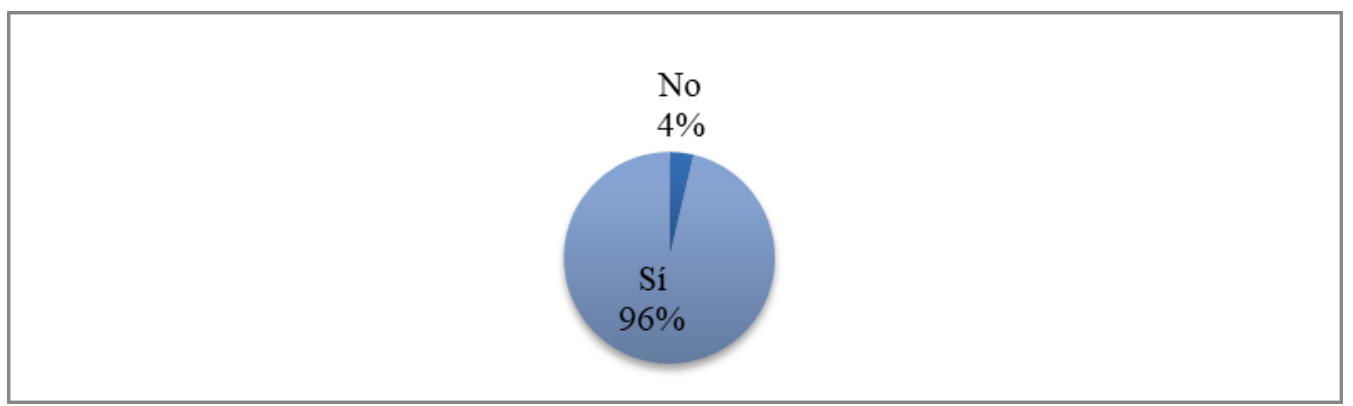

Figura 19. Porcentaje de profesores que consideraría útil trabajar con programas televisivos.

\footnotetext{
${ }^{72}$ Las respuestas de los alumnos a las preguntas abiertas se muestran a continuación.
} 


\section{9. ¿Qué aspectos cree que se podrían trabajar mediante la explotación didáctica de un programa televisivo? (Puede señalar una o varias respuestas)}

a) Desarrollo de las actividades comunicativas de la lengua

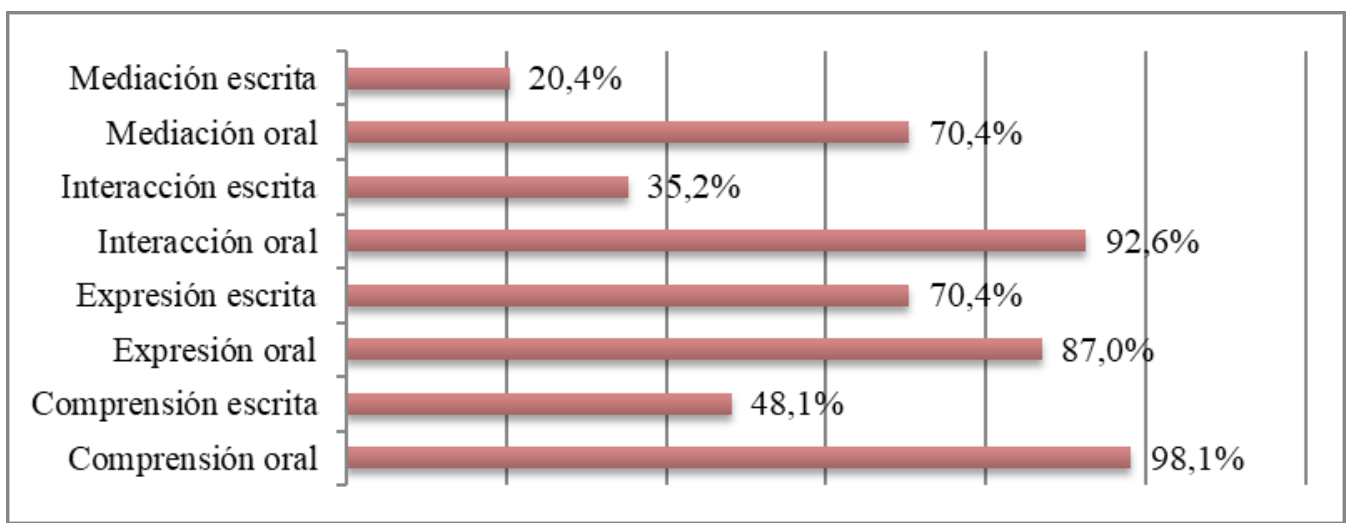

Figura 20. Aspectos que los profesores consideran que se podrían trabajar mediante la explotación didáctica de un programa televisivo.

b) Desarrollo de las competencias de la lengua

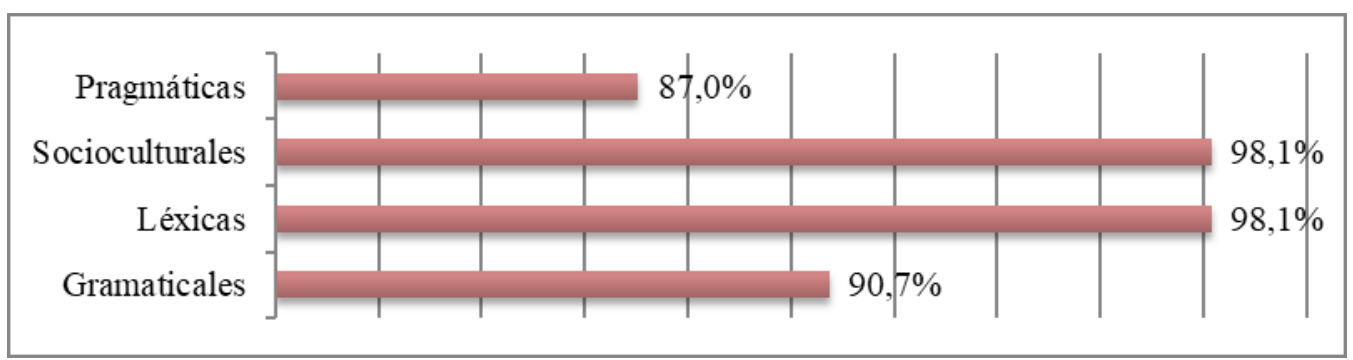

Figura 21. Competencias de la lengua que los profesores consideran que se podrían trabajar mediante la explotación didáctica de un programa televisivo.

c) Desarrollo de la capacidad de autoaprendizaje del alumno 


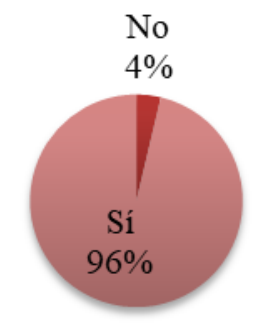

Figura 22: Porcentaje de profesores que considera que se podría desarrollar la capacidad de autoaprendizaje del alumno mediante la explotación didáctica de un programa televisivo.

Algunos de los comentarios que recogimos en la pregunta 8 «si no ha trabajado en el aula con programas televisivos, ¿cree que sería útil hacerlo?, ¿por qué?», fueron los siguientes:

1. Es un recurso donde la cultura está siempre presente.

2. He trabajado poco con programas televisivos. Me parece interesante porque son muestras de lengua reales. Muchos son explotables didácticamente, pero supone mucho tiempo de preparación y pocas veces dispongo de él.

3. Algunos programas televisivos son una herramienta complementaria para las clases de ELE porque son buenas muestras de lengua en uso.

4. Trabajar con documentos audiovisuales sobre temas de interés para los estudiantes hace que los alumnos se interesen más por el idioma.

5. Es una manera de acercarse al mundo del alumno y motivarlo.

6. Son muy útiles para trabajar el lenguaje tal y como se usa en la vida real.

7. Es otro recurso a tener en cuenta para facilitar el aprendizaje de los alumnos.

8. Son útiles para trabajar la expresión oral y escrita.

9. Siempre es útil emplear documentos reales para la enseñanza, puesto que generan especial interés en los estudiantes y, por otra parte, los preparan para un uso del lenguaje que es necesario para dominar una lengua. Si no se usan más es porque en la mayor parte de los casos son dificiles de adaptar o de preparar para el aula, es decir, realizar una actividad que desarrolle el conjunto o un buen número de destrezas y competencias lleva tiempo. En todo caso, en niveles altos me parecen un material muy interesante y más sencillo de adaptar.

10. Pueden oír diferentes dialectos, ver temas culturales, practicar la comprensión y expresión y mejorar el vocabulario.

11. Considero la inclusión de este tipo de material realmente beneficioso y atractivo para los estudiantes. Además, usar programas de televisión reales fomenta la inclusión de los extranjeros en nuestra cultura y sociedad. Solo un dato, mis estudiantes no tienen acceso a la televisión en español.

12. En mi caso particular, el aula no dispone de proyector $u$ ordenador.

13. Creo que puede ser otra variación de método de enseñanza que quizás aumente el interés y la atención de los alumnos durante la clase. 
14. En la televisión española actual no hay una programación muy atractiva ni siquiera como entretenimiento, menos aún para usarla de forma educativa. Además, el uso de un programa supondría emplear mucho tiempo en el aula.

15. Para poder analizar un documento auténtico para hablantes nativos.

16. Se emiten programas de gran variedad y pueden explotarse como recurso para la clase de español.

17. Las series serían útiles en momentos puntuales porque permiten contextualizar mucho la cultura y los concursos sirven para crear una dinámica de juego y aprendizaje, sin embargo, en principio no utilizaría los demás formatos televisivos.

18. Sí que he trabajado con programas de la televisión, puesto que se incluyen en ellos los documentales.

19. Ayudan a entender otros acentos.

20. El material real siempre es útil para clase. Además, si se trata de programas actuales, es una manera de que los alumnos aprendan sobre lo que interesa a los españoles hoy en día, $y$ asi poder entender mejor la realidad española.

21. Hoy día vivimos en una sociedad en la que las imágenes tienen mucho valor y es muy interesante para los alumnos que puedan conocer la sociedad y cultura española a través de este medio, al tiempo que aprenden el idioma.

22. En ocasiones resulta una forma atractiva de mostrar habilidades y contenidos. A veces se aprende más y mejor a través de contenidos audiovisuales porque potencian la destreza auditiva, y también sirven como modelo lingüistico para los alumnos, quienes se fijarán en la forma de expresarse de los hablantes que aparecen en dicho contenido audiovisual.

23. Es material de actualidad con muchas posibilidades de explotación didáctica.

24. Es un material real y una manera muy buena de estar en contacto con la cultura y la sociedad en la que se habla el idioma que se está estudiando.

25. Con una cuidada selección del tiempo y del fragmento, pueden ser útiles como muestras reales del uso de la lengua.

26. Para que nuestros alumnos interioricen cómo es la vida de los españoles y de los hispanoamericanos.

27. Con una buena preparación del material, sería susceptible de incluirse en un programa de clase, no al azar o sin conexión con el programa. El problema es que si el tema es de actualidad o su información perderá interés con el tiempo, puede ocurrir que al profesor no le compense preparar un material que vaya a quedar obsoleto pronto. Elegir un contenido recurrente es esencial para aprovechar el tiempo dedicado a su preparación.

28. Es útil porque son materiales reales, actualizados, dinámicos y con una variedad temática infinita. Además, suponen una conexión con la vida diaria del estudiante, ya que trabajamos con materiales que él mismo puede encontrar en su entorno para un estudio autónomo.

Algunos de los comentarios que recogimos a través de la última pregunta del cuestionario, en la que invitamos a los profesores a manifestar su opinión respecto al uso de programas televisivos en la clase de español, fueron los siguientes:

1. Es una idea que probablemente a nadie se le haya ocurrido.

2. Hace falta mucho tiempo tanto para la preparación (selección del programa, y del fragmento, si es el caso, y preparación de actividades). Es verdad que, en el desarrollo 


\section{EL PROGRAMA TELEVISIVO COMO RECURSO PARA LA ENSEÑANZA/APRENDIZAJE DE ESPAÑOL LENGUA EXTRANJERA}

de la clase, los profesores también sentimos que nos falta tiempo para hacer este tipo de cosas, y que no siempre el aprendizaje obtenido es directamente proporcional al tiempo de preparación y al de realización en el aula.

3. He utilizado en nivel de B2 fragmentos de la serie "Cuéntame cómo pasó ${ }^{73 " . ~ S i n ~}$ embargo, ahora enseño A1 - A2, y lo utilizo menos. Creo que hay poco material para esos niveles en relación a los programas televisivos.

4. Uso mucho la serie "El Internado 74 ". ;Les encanta!

5. Me parece un tema muy interesante. Trabajo mucho con informativos, pero muy poco con otro tipo de programas, como magacines o talk-shows. Creo que pueden tener un potencial enorme.

6. Cuando no tienen un nivel aceptable (B1 o B2, por ejemplo) les resulta muy difícil y no es posible encontrar con subtitulos lo que queremos trabajar.

7. Un comentario que me hacen los estudiantes es que hablan muy rápido y no pueden comprender lo que dicen, lo cual no los motiva.

8. Tengo varias clases y unidades desarrolladas con secuencias de "Yo soy Bea", especialmente para el curso de español de los negocios (entrevista de trabajo, CV, relaciones informales, formales en una empresa) y también algunos con "Cuéntame ${ }^{76 \text { ". }}$ Se pueden complementar las actividades con la página web de los programas.

9. Creo que usar programas televisivos durante las clases de español puede ser útil y productivo si estos se adecuan al nivel de los alumnos.

\subsection{Análisis de los datos extraídos del cuestionario realizado por los profesores}

- Casi la totalidad de los profesores encuestados (96\%) utiliza documentos audiovisuales en el aula de español, y más de la mitad lo hace de manera más o menos frecuente —una de cada tres o cinco sesiones $(70 \%)$ - Sin embargo, la gran mayoría ( $88 \%$ ) solo les dedica el $25 \%$ o el $50 \%$ del tiempo de la clase. Respecto a los dos profesores que indicaron no utilizarlos, estos declararon no hacerlo por falta de recursos técnicos en el aula o por escasez de propuestas de trabajo con materiales audiovisuales en los manuales de ELE (esta última información pudo ser contrastada gracias al análisis de manuales también llevado a cabo en este proyecto de investigación).

\footnotetext{
73 Serie de televisión española que narra las vivencias de una familia de clase media-baja durante los últimos años del franquismo y los comienzos de la Transición Española.

${ }^{74}$ Serie de televisión española que narra la historia de dos hermanos gallegos, cuyos padres han desaparecido, que ingresan en el internado Laguna Negra, donde empezarán a suceder extraños acontecimientos.

75 Telenovela española que cuenta cómo una chica joven, poco agraciada pero muy inteligente, entra a trabajar en una famosa revista de moda, donde se enamora de su jefe.

${ }^{76}$ Véase nota 73.
} 
- Los documentos audiovisuales más utilizados son, de mayor a menor, cortometrajes (el 57\% los utiliza a menudo o muy a menudo) películas (el $66 \%$ los utiliza a menudo o a veces), anuncios publicitarios (un 76\% los utiliza a veces o a menudo), tráiler (un 58\% los utiliza a veces o a menudo), y en último lugar, los programas de televisión (el 59\% los utiliza a veces o a menudo). Cabe destacar que el $20 \%$ declaró no utilizar nunca ni tráileres ni programas televisivos en sus clases.

- Los programas televisivos más utilizados son, de mayor a menor, los culturales (el 74\% los utiliza a veces o a menudo), los informativos (el 63\% los utiliza a veces o a menudo) y los programas de ficción (54\% los utiliza a veces o a menudo). Sin embargo, la mayoría declaró no utilizar nunca o casi nunca programas de deportes (el 82\%) ni programas de entretenimiento (el $75 \%)$.

- Por lo que se refiere a otros medios de comunicación, los más utilizados son, de mayor a menor, aunque con similares porcentajes, la radio (el 64\% la utiliza a veces o a menudo), los periódicos (el 63\% los utiliza a veces o a menudo) y las revistas (el 61\% las utiliza a veces o a menudo). Es curiosa la disparidad que presentan los resultados relativos al uso de las redes sociales, pues la mitad de los encuestados declaró utilizar este recurso a veces o a menudo (un 50\%), mientras que una considerable parte de ellos afirmó no utilizarlas nunca (un 26\%).

- El 96\% defiende la rentabilidad didáctica del programa televisivo. Las razones que más se repitieron entre nuestros encuestados fueron: su alto contenido cultural y social, su carácter de material real y auténtico, su capacidad para motivar e interesar a los alumnos, y su posible uso para mejorar, entre otras, la destreza auditiva. No obstante, también pudimos recoger algunos comentarios que reflejan los inconvenientes que los profesores encuentran en este tipo de documento audiovisual: implican mucho tiempo de preparación y su carácter de material actual puede hacer que el contenido preparado se vuelva obsoleto al poco tiempo, son difíciles de adaptar a los diferentes niveles y pueden desmotivar a los alumnos de los niveles más básicos, y la ausencia o escasez de programas interesantes en la televisión española.

- Los profesores encuestados consideran que los aspectos que más y mejor se pueden trabajar mediante la explotación didáctica de los programas 


\section{EL PROGRAMA TELEVISIVO COMO RECURSO PARA LA ENSEÑANZA/APRENDIZAJE DE ESPAÑOL LENGUA EXTRANJERA}

televisivos son la compresión oral (un 98\%), la interacción oral (el 92\%), la expresión oral (un 87\%), y la mediación oral y la expresión escrita (ambas un $70 \%$ ). Sin embargo, muchos también creen que es posible trabajar la comprensión escrita, la interacción escrita y la mediación escrita.

- La gran mayoría opina que, mediante la explotación didáctica de los programas televisivos, se pueden trabajar las competencias sociocultural (98\%), léxica (98\%), gramatical $(90 \%)$ y pragmática $(87 \%)$ de la lengua. También la mayoría (el 96\%) considera que es una herramienta útil para fomentar la capacidad de autoaprendizaje del alumno.

\subsection{Conclusiones}

Los datos obtenidos nos llevaron a inferir que la mayoría de los encuestados considera que el uso del programa televisivo es o podría ser útil para la consecución de diferentes objetivos de aprendizaje, por su alto contenido cultural y social, su carácter de material real y auténtico, su capacidad de motivar e interesar a los alumnos y su posible uso para mejorar varias destrezas. También pudimos comprobar que muchos profesores se limitan a utilizar en sus clases programas televisivos culturales o informativos, por considerarlos más educativos, y muy pocos explotan otro tipo de programas, como los de entretenimiento, que en nuestra opinión podrían despertar aún más la motivación de los alumnos, al mismo tiempo que contribuyen a su formación.

Según los objetivos con los que los encuestados llevarían explotaciones de programas televisivos al aula, se distinguen tres categorías: el desarrollo de principalmente tres de las actividades comunicativas de la lengua - la comprensión oral, la interacción oral, y la expresión oral—, el desarrollo de cuatro de las competencias de la lengua ${ }^{77}$ — sociocultural, léxica, gramatical y pragmática-, y el desarrollo del perfil del alumno como aprendiente

\footnotetext{
${ }^{77}$ En la pregunta relativa a las competencias de la lengua que se podrían trabajar mediante la explotación didáctica de un programa televisivo, en el cuestionario se dio la opción de seleccionar entre competencias gramaticales, léxicas, socioculturales y pragmáticas. Decidimos no incluir las competencias estratégicas y discursivas porque, como pudimos comprobar al realizar el análisis de manuales, estas no suelen tratarse como competencias independientes. No obstante, en este trabajo, también analizamos estas dos competencias y diseñamos actividades, basadas en el uso de programas televisivos, a través de las cuales se pueden desarrollar.
} 
autónomo. Más adelante en este trabajo, demostraremos que a través de este formato, se pueden diseñar y realizar actividades enfocadas a trabajar no solo las tres actividades comunicativas de la lengua y las cuatro competencias señaladas por los profesores.

De entre los obstáculos que encuentran los profesores a la hora de trabajar con programas televisivos en el aula, y para los que más adelante ofreceremos algunas soluciones, destacan la necesidad de tiempo para su preparación previa, su carácter de material actual — que puede hacer que el contenido preparado se vuelva obsoleto al poco tiempo - su difícil adaptación a los diferentes niveles y la posible desd que esto puede provocar entre los alumnos de los niveles más básicos y, finalmente, la ausencia o escasez de programas interesantes en la televisión española.

Como venimos señalando, todos los datos recogidos en este análisis se tomaron en consideración en el diseño de las propuestas didácticas para la explotación de programas televisivos en la clase de ELE presentadas al final de esta tesis doctoral. 
EL PROGRAMA TELEVISIVO COMO RECURSO PARA LA ENSEÑANZA/APRENDIZAJE DE ESPAÑOL LENGUA EXTRANJERA

6. DETERMINACIÓN DEL CORPUS DE PROGRAMAS TELEVISIVOS EMPLEADO COMO RECURSO DIDÁCTICO 


\subsection{Metodología y criterio de selección de los programas televisivos incluidos en las propuestas didácticas}

A la hora de seleccionar los vídeos que utilizamos para elaborar nuestras propuestas didácticas, tuvimos en cuenta los factores que a continuación explicamos.

- Con el fin de demostrar que es posible trabajar varios aspectos de la competencia comunicativa - registros lingüísticos, variantes lingüísticas del español, cuestiones culturales, etc.- utilizando diversos formatos televisivos, utilizamos un programa de televisión diferente en cada una de nuestras propuestas didácticas: un programa de información meteorológica, un programa informativo, un programa de información deportiva, un programa de cocina, un programa documental, un programa de ficción, un programa de entretenimiento, un concurso de televisión, una emisión puntual y un programa de humor.

- En todas nuestras propuestas quisimos utilizar vídeos completos a los que se pudiera acceder de forma fácil y gratuita en Internet a través de los enlaces que incluimos en el apartado Actividades durante el visionado. Nuestro objetivo es demostrar que, aunque siempre es posible utilizar solo ciertos minutos o partes de un vídeo, también es posible encontrar vídeos en los que tanto el contenido como la duración no requieren ninguna modificación, pues este es un factor que puede facilitar la tarea del profesor.

- La duración media de los vídeos que seleccionamos es de dos minutos y medio. Con ello queremos demostrar que no es necesario recurrir a una película de dos horas o a un cortometraje de veinte minutos cuando se quiere utilizar un recurso audiovisual en clase para trabajar uno o varios aspectos de la competencia comunicativa. En nuestras propuestas didácticas queda reflejado que con cada uno de estos vídeos es posible diseñar actividades mediante las que se pueden trabajar no solo uno, sino varios aspectos de la competencia comunicativa.

- Algunos de los vídeos que decidimos no incluir fueron rechazados por su falta de adecuación. En la televisión es posible que a veces se traten temas que puedan molestar a un determinado público, bien por cuestiones culturales, políticas o religiosas; del mismo modo, cuando se trata de muestras de lenguaje coloquial, ocurre con frecuencia que los hablantes 


\section{EL PROGRAMA TELEVISIVO COMO RECURSO PARA LA ENSEÑANZA/APRENDIZAJE DE ESPAÑOL LENGUA EXTRANJERA}

utilizan expresiones o palabras que resultan inadecuadas en un contexto académico como es el de la clase de español. Consideramos que es importante tener estos dos aspectos en cuenta a la hora de seleccionar las muestras que se van a llevar al aula.

- Dado que otro de nuestros objetivos era diseñar propuestas didácticas dirigidas a niveles diferentes, desde básicos hasta avanzados, elegimos los vídeos y diseñamos las actividades teniendo en cuenta la duración, los temas, la variedad lingüística — diafásica ${ }^{78}$, diastrática ${ }^{79}$, diatópica ${ }^{80}$ y diacrónica ${ }^{81}$ _ , la velocidad de habla, la dificultad general y los posibles contenidos y destrezas que se pueden trabajar, así como los descriptores de la escala ilustrativa para Ver televisión y cine disponible en el apartado Actividades de comprensión audiovisual del MCER (2002: 73), que incluimos en el apartado 6.1 de esta tesis.

\subsection{Descripción de los programas televisivos incluidos en las propuestas didácticas}

A continuación incluimos una descripción detallada de cada uno de los programas televisivos de los que fueron extraídos los vídeos utilizados en las propuestas didácticas presentadas en el sexto apartado de esta tesis.

1. Programa de información meteorológica: Agencia EFE.

La Agencia Efe es una agencia de noticias internacional fundada en Burgos (España) en 1939. Efe es una empresa informativa que cubre todos los ámbitos de la información en los soportes de prensa escrita, radio, televisión e Internet. Opera 24 horas al día en más de 180 ciudades de 110 países y con cuatro mesas de edición en Madrid, Bogotá, El Cairo (árabe), y Río de Janeiro (portugués). Fue la primera agencia española en tener delegaciones en todas las Comunidades y ciudades autónomas españolas, contribuyendo a la vertebración informativa del territorio nacional ${ }^{82}$.

\footnotetext{
${ }^{78}$ Variedades funcionales o registros.

${ }^{79}$ Variedades socioculturales.

${ }^{80}$ Variedades geográficas o dialectos.

${ }^{81}$ Variedades históricas.

${ }^{82}$ Información extraída de: http://www.efe.com/
} 
2. Programa informativo: RT en español.

$R T$ en español, también conocida como Actualidad $R T$, es una cadena de televisión de noticias en idioma español con sede en Moscú (Rusia). Fue lanzada en 2009 y tiene corresponsalías permanentes en Miami, Madrid, Buenos Aires,.Caracas y La Habana. Es la versión en español de $R T$ (anteriormente Russia Today), que también transmite en ruso, inglés y árabe. Actualmente la plantilla de $R T$ en español cuenta con unas 200 personas, incluidos periodistas extranjeros de España, Argentina, México, Estados Unidos, Chile y Venezuela. También cuenta con periodistas provenientes de Rusia y Serbia, que hablan español ${ }^{83}$.

3. Programa de información deportiva: Informe Robinson.

Informe Robinson es un programa de televisión de deportes dirigido y presentado por el exjugador de fútbol Michael Robinson. Se ha destacado su exhaustividad en la investigación y recolecta de información. El programa comenzó a emitirse en 2007 con una duración de unos 25 minutos por emisión. El programa obtuvo el Premio Ondas ${ }^{84} 2009$ a mejor programa de entretenimiento o de cobertura especial. También ha sido nominado en dos ocasiones a los Premios $\mathrm{ATV}^{85}$ en la categoría de mejor programa documental $(2012 \text { y 2013) })^{86}$.

4. Programa de cocina: Karlos Arguiñano en tu cocina.

Karlos Arguiñano en tu cocina es un programa de televisión de cocina presentado por el cocinero vasco Karlos Arguiñano, quien se hizo muy popular en España a comienzos de los años noventa por sus programas de cocina en televisión, realizados tanto en el canal público como en canales privados, y galardonados con varios premios. Este cocinero y presentador también destaca por haber promocionado la cocina en general y la española en particular por diferentes países, entre ellos, Argentina, Estados Unidos, México, Suecia, Italia, Suiza, Alemania y Francia, impartiendo clases de

\footnotetext{
${ }^{83}$ Información extraída de: https://actualidad.rt.com/

${ }^{84}$ Galardones entregados a los profesionales de radio, televisión, cine y música. Son los primeros galardones de radio y televisión instituidos en España.

${ }^{85}$ Premios anuales de la Academia de las Ciencias y las Artes de Televisión de España.

${ }^{86}$ Información extraída de: http://www.plus.es/cero/informerobinson
} 


\section{EL PROGRAMA TELEVISIVO COMO RECURSO PARA LA \\ ENSEÑANZA/APRENDIZAJE DE ESPAÑOL LENGUA EXTRANJERA}

cocina, cursillos, participado en jurados gastronómicos, conferencias, charlas, etc. ${ }^{87}$.

5. Programa documental: Españoles en el Mundo.

Españoles en el mundo es un programa de televisión de tipo documental, que empezó a emitirse en España en 2009 (también se emiten versiones propias en otros países como Argentina, Brasil o México) en el que un presentador/a muestra cómo es la vida de algunos españoles que viven en otros países. Tanto el presentador como los propios españoles entrevistados cuentan a los espectadores hechos históricos, aspectos culturales y características de la ciudad y país en el que viven. En cada programa, de alrededor de una hora de duración, intervienen en torno a unos seis españoles $^{88}$.

6. Programa de ficción: Camera Café.

Camera café es un formato de serie de televisión de humor, originario de Francia, emitido con el mismo título en países como Italia, Portugal, Polonia, Chile, Colombia y, desde 2005, España. Se trata de episodios de corta duración (de 4 a 6 minutos) compuestos por un prólogo, varios sketches y un epílogo. En España se agrupan varios episodios formando un bloque; en ellos se ven, a modo de cámara oculta en la propia máquina de café, distintas situaciones de empleados que acuden a «escaquearse» del trabajo. Cada personaje de los diecisiete que componen el reparto cumple un rol distinto ${ }^{89}$.

7. Programa de entretenimiento: El hormiguero.

El hormiguero es un talk-show de televisión de creación española estrenado en 2006. Sus contenidos giran alrededor del humor, las entrevistas y los experimentos de divulgación científica. Está presentado y dirigido por el presentador, humorista y locutor de radio valenciano Pablo Motos, junto con las marionetas Trancas, Barrancas y Petancas. En cada programa también participan uno o varios invitados (personajes famosos tanto de

\footnotetext{
${ }^{87}$ Información extraída de: http://www.antena3.com/programas/karlos-arguinano/

${ }^{88}$ Información extraída de: http://www.rtve.es/television/espanoles-en-el-mundo/

${ }^{89}$ Información extraída de: http://www.telecinco.es/cameracafe/
} 


\section{DETERMINACIÓN DEL CORPUS DE PROGRAMAS TELEVISIVOS EMPLEADOS COMO RECURSO DIDÁCTICO}

ámbito nacional como internacional) y varios colaboradores encargados de presentar diferentes secciones del programa ${ }^{90}$.

8. Concurso de televisión: MasterChef.

MasterChef es un programa de televisión gastronómico de tipo concursoreality-show que busca al mejor cocinero amateur de España. El formato está basado en un espacio de televisión británico de cocina con el mismo título. En España el programa se empezó a emitir en 2013 y está conducido por la presentadora sevillana Eva González. Los tres chefs que juzgan los platos de los aspirantes son Jordi Cruz, cocinero con tres estrellas Michelin ${ }^{91}$, Samantha Vallejo-Nágera, directora de una empresa de catering, y Pepe Rodríguez, propietario de un restaurante con una estrella Michelín ${ }^{92}$.

9. Emisión puntual: Campanadas de fin de año.

Campanadas de fin de año es un programa especial retransmitido la noche del 31 de diciembre, en Televisión Española, cada año desde 1958. El evento se televisa desde la Puerta del Sol de Madrid (España). En él, dos presentadores, normalmente un hombre y una mujer (aunque no necesariamente los mismos cada año), describen a los espectadores el momento de «las campanadas»: treinta y cinco segundos antes de las doce, una bola en lo alto del reloj baja, sonando un carillón; después, suenan cuatro campanas dobles representando los cuatro cuartos; y por último, a las doce en punto comienzan las doce campanadas, una cada tres segundos aproximadamente. Al finalizar los presentadores suelen brindar y desear un feliz año nuevo a los televidentes ${ }^{93}$.

10. Programa de humor: El club de la comedia.

El club de la comedia es un formato de televisión del género stand up comedy ${ }^{94}$ en el que monologuistas profesionales y actores invitados se enfrentan al público en directo con un monólogo de entre 8 y 10 minutos de duración. Cuenta hasta la fecha con 10 temporadas emitidas en dos etapas

\footnotetext{
${ }^{90}$ Información extraída de: http://www.antena3.com/programas/el-hormiguero/

${ }^{91}$ Galardones otorgados por la guía de viajes Michelín a aquellos restaurantes destacados por tener una calidad excepcional.

92 Información extraída de: http://www.rtve.es/television/masterchef/

93 Información extraída de: http://www.rtve.es/alacarta/videos/campanadas-de-fin-deano/campanadas-repaso-historia-campanadas/361861/

${ }^{94}$ Estilo de comedia donde el comediante se dirige directamente a una audiencia en vivo.
} 
EL PROGRAMA TELEVISIVO COMO RECURSO PARA LA ENSEÑANZA/APRENDIZAJE DE ESPAÑOL LENGUA EXTRANJERA

diferentes (1999-2005, 2011-presente), la mayoría de ellas presentadas por la cómica segoviana Eva Hache, que también interviene en el programa realizando monólogos $\operatorname{cortos}^{95}$.

${ }^{95}$ Información extraída de: http://www.lasexta.com/programas/club-de-la-comedia/ 
PROPUESTAS DIDÁCTICAS PARA LA EXPLOTACIÓN DE PROGRAMAS DE TELEVISIÓN EN CLASE DE ELE

\section{PROPUESTAS DIDÁCTICAS PARA LA EXPLOTACIÓN} DE PROGRAMAS DE TELEVISIÓN EN LA CLASE DE ELE 


\section{EL PROGRAMA TELEVISIVO COMO RECURSO PARA LA \\ ENSEÑANZA/APRENDIZAJE DE ESPAÑOL LENGUA EXTRANJERA}

\subsection{Recomendaciones para la utilización de este formato en los diferentes niveles del MCER}

En el apartado Actividades de comprensión audiovisual, incluido en el MCER (2002: 73), se proporciona una escala ilustrativa para Ver televisión y cine, cuyos descriptores de los diferentes niveles sirven de orientación y referencia a la hora de diseñar actividades basadas en estos formatos.

Tabla 8

Escala para ver televisión y cine en clase de ELE según el MCER (2002)

\section{VER TELEVISIÓN Y CINE}

C2 Como C1.

C1 Comprende películas que emplean una cantidad considerable de argot o lenguaje coloquial y de expresiones idiomáticas.

B2 Comprende la mayoría de las noticias de televisión y de los programas de temas actuales. Comprende documentales, entrevistas en directo, debates, obras de teatro y la mayoría de las películas en lengua estándar.

B1 Comprende la mayoría de los programas de televisión que tratan temas de interés personal, como, por ejemplo, entrevistas, breves conferencias e informativos, cuando se articulan de forma relativamente lenta y clara.

Comprende muchas películas donde los elementos visuales y la acción conducen gran parte del argumento y que se articulan con claridad y con un nivel de lengua sencillo. Capta las ideas principales de programas de televisión que tratan temas cotidianos cuando se articulan con relativa lentitud y claridad.

A2 Identifica la idea principal de las noticias de televisión que informan de acontecimientos, accidentes, etc., cuando hay apoyo visual que complemente el discurso.

Es capaz de saber cuándo han cambiado de tema en las noticias de televisión y de formarse una idea del contenido principal.

A1 No hay descriptor disponible.

Datos según el MCER (2002) 


\section{PROPUESTAS DIDÁCTICAS PARA LA EXPLOTACIÓN DE PROGRAMAS \\ DE TELEVISIÓN EN CLASE DE ELE}

A falta de descriptor para el nivel A1 en el MCER y dado que los profesores encuestados ${ }^{96}$ destacaban —entre los obstáculos que encuentran a la hora de trabajar con programas televisivos en el aula- su difícil aplicación en los niveles iniciales, procedemos a incluir algunas recomendaciones al respecto:

- Incluir subtítulos o mostrar/proporcionar la transcripción del vídeo a los alumnos.

- Poner especial énfasis en las actividades de previsionado.

- Las actividades deben ser sencillas y estar enfocadas a trabajar las competencias propias del nivel.

- Recordar que la comprensión auditiva no es el objetivo principal de trabajar con este material.

\subsection{Parámetros de clasificación de las propuestas didácticas}

A continuación incluimos una propuesta didáctica compuesta de varias actividades de previsionado, posvisionado y durante el visionado, para cada uno de los vídeos extraídos de programas televisivos seleccionados y descritos en el apartado anterior.

Al principio de cada una de estas propuestas didácticas, incluimos una tabla como la que se muestra a continuación, en la que se clasifica la propuesta de acuerdo con los siguientes parámetros:

- el nivel del MCER para el que está dirigida: A1, A2, B1, B2, C1, C2;

- las competencias de la lengua que se trabajan: Competencias Gramaticales, Competencias Léxicas, Competencias Socioculturales, Competencias Pragmáticas, Competencias Estratégicas, Competencias Discursivas;

- las actividades comunicativas de la lengua que se llevan a cabo: Compresión Oral, Comprensión Escrita, Expresión Oral, Expresión Escrita, Interacción Oral, Interacción Escrita, Mediación Oral, Mediación Escrita.

\footnotetext{
96 Véase el apartado 5.5. Datos extraídos del cuestionario realizado por los profesores de la sección 5. Análisis de manuales y extracción de datos
} 
EL PROGRAMA TELEVISIVO COMO RECURSO PARA LA

ENSEÑANZA/APRENDIZAJE DE ESPAÑOL LENGUA EXTRANJERA

Tabla 9

Tabla modelo de clasificación de las propuestas didácticas

\begin{tabular}{lll}
\hline Nivel del MCER & Competencias & Actividades comunicativas \\
\hline$\square$ A1 & $\square$ Gramaticales & $\square$ Compresión Oral \\
$\square$ A2 & $\square$ Léxicas & $\square$ Comprensión Escrita \\
$\square$ B1 & $\square$ Socioculturales & $\square$ Expresión Oral \\
$\square$ B2 & $\square$ Pragmáticas & $\square$ Expresión Escrita \\
$\square \mathrm{C} 1$ & $\square$ Estratégicas & $\square$ Interacción Oral \\
$\square \mathrm{C} 2$ & $\square$ Discursivas & $\square$ Mediación Escrita Oral \\
& & $\square$ Mediación Escrita
\end{tabular}

Fuente: elaboración propia 


\subsection{Propuesta de actividades para la explotación de un programa de información meteorológica}

Tabla 10

Clasificación de la propuesta de actividades para la explotación de un programa de información meteorológica

\begin{tabular}{lll}
\hline Nivel del MCER & Competencias & Actividades comunicativas \\
\hline \# A1 & \# Gramaticales & \# Compresión Oral \\
$\square$ A2 & \# Léxicas & $\square$ Comprensión Escrita \\
$\square$ B1 & \# Socioculturales & \# Expresión Oral \\
$\square$ B2 & \# Pragmáticas & $\square$ Expresión Escrita \\
$\square$ C1 & \# Estratégicas & \# Interacción Oral \\
$\square \mathrm{C} 2$ & \# Discursivas & $\square$ Interacción Escrita \\
& & $\square$ Mediación Oral \\
& & $\square$ Mediación Escrita
\end{tabular}

Fuente: elaboración propia

\subsubsection{Actividades de previsionado}

1) ¿ $\mathrm{Te}^{97}$ gusta informarte sobre el tiempo que va a hacer en tu ciudad o en tu país? ¿Cómo sueles informarte: viendo la previsión del tiempo en la televisión, buscándola en Internet, a través de una aplicación en tu móvil? Coméntalo con tus compañeros.

2) Aquí tienes la previsión del tiempo para el domingo 29 de mayo y para el resto de la semana. Adivina a qué día de la semana se refieren las siguientes descripciones.

\footnotetext{
97 Optamos por utilizar el tuteo en todas las actividades porque están dirigidas a estudiantes universitarios, ya que el estudio empírico se realizó en una universidad americana.
} 
EL PROGRAMA TELEVISIVO COMO RECURSO PARA LA

ENSEÑANZA/APRENDIZAJE DE ESPAÑOL LENGUA EXTRANJERA

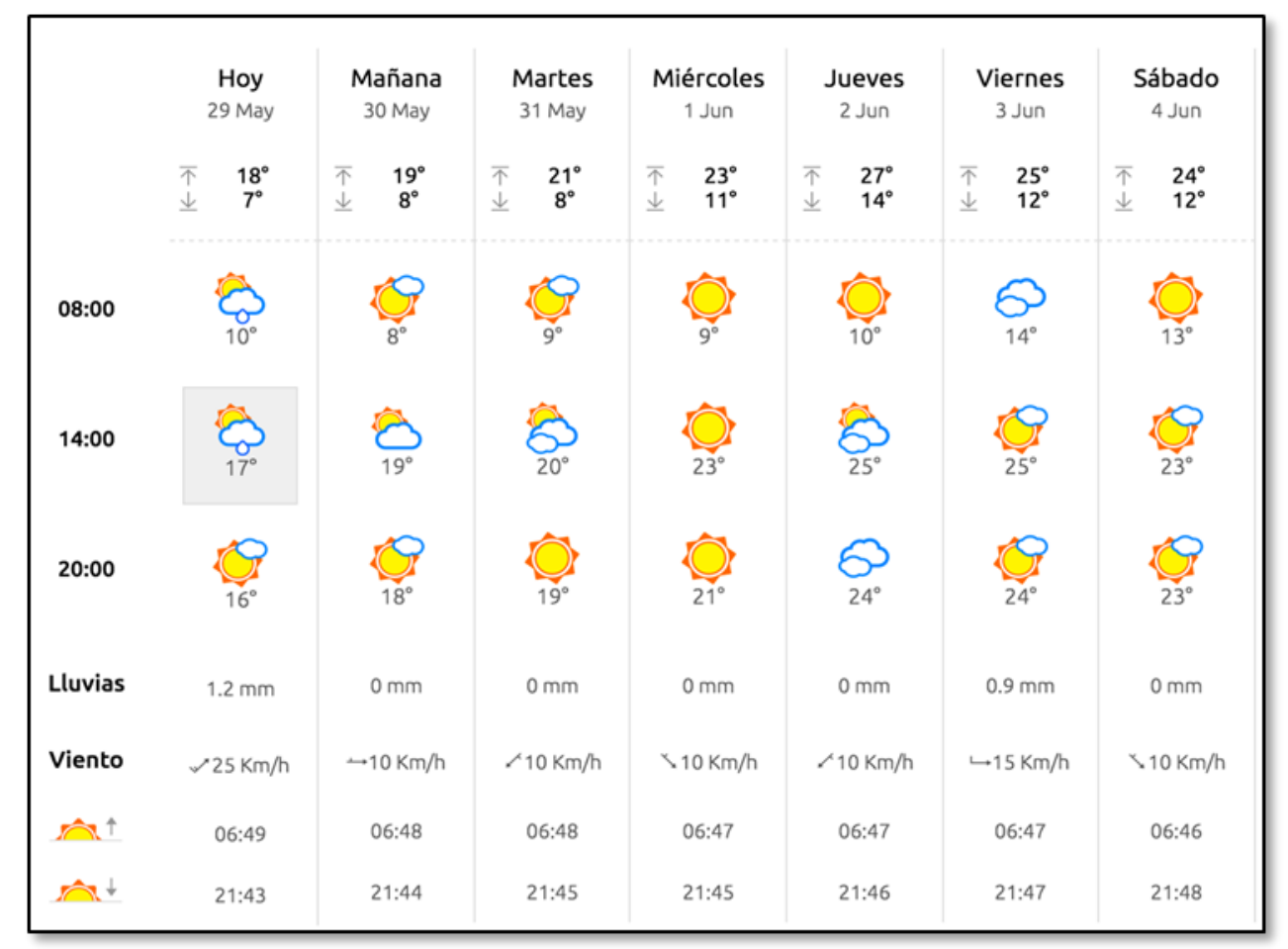

Fuente: eltiempo.es

- El va a hacer sol todo el día.

- El va a llover por la mañana y al mediodía.

- El el cielo va a estar nublado por la tarde.

- El la temperatura mínima va a ser de 7 grados.

- $\mathrm{El}$ la temperatura máxima va a ser de 17 grados.

- El va a hacer viento fuerte.

- $\mathrm{El}$ el sol va a salir a las 6:46 horas.

- El el sol se va a poner a las 21:43 horas.

3) Muchas personas de otros países piensan que en España casi siempre hace sol y calor y que no llueve mucho. ¿Crees que esto es cierto? 
A continuación, observa este mapa con la información meteorológica del 28 de mayo de 2016 y contesta a las siguientes preguntas, ayudándote de los puntos cardinales que hay junto al mapa.

- ¿En qué zonas del país las temperaturas van a ser más altas?

- ¿En qué zonas del país va a llover más?

- ¿Cuál es la temperatura más alta que aparece en el mapa? ¿y la más baja?

- ¿Qué temperatura va a hacer en las islas?

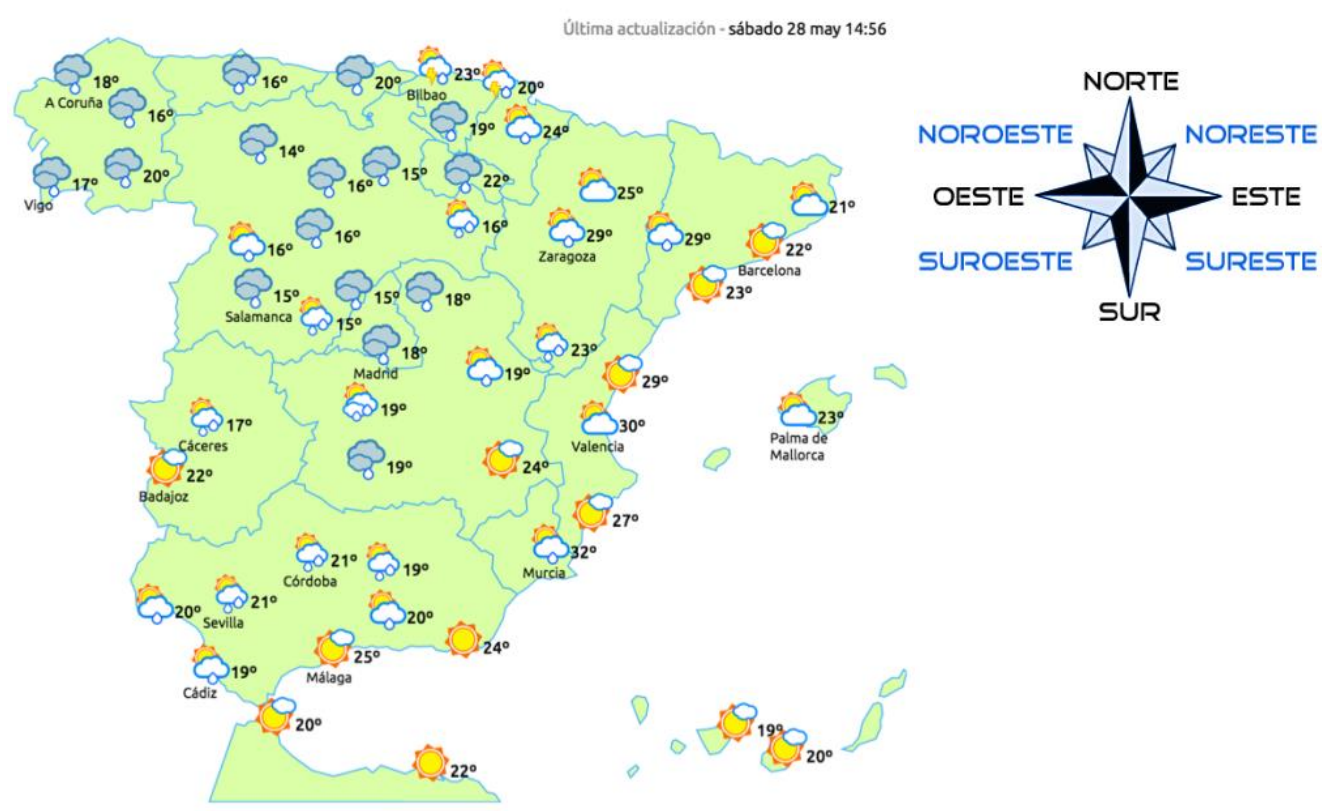

Fuente: eltiempo.es

4) Ahora vas a realizar el mismo ejercicio pero utilizando los nombres de las ciudades que vas a encontrar en el siguiente mapa. Fíjate en el ejemplo, utiliza la construcción ir a + infinitivo como has visto en el ejercicio anterior. 
EL PROGRAMA TELEVISIVO COMO RECURSO PARA LA

ENSEÑANZA/APRENDIZAJE DE ESPAÑOL LENGUA EXTRANJERA

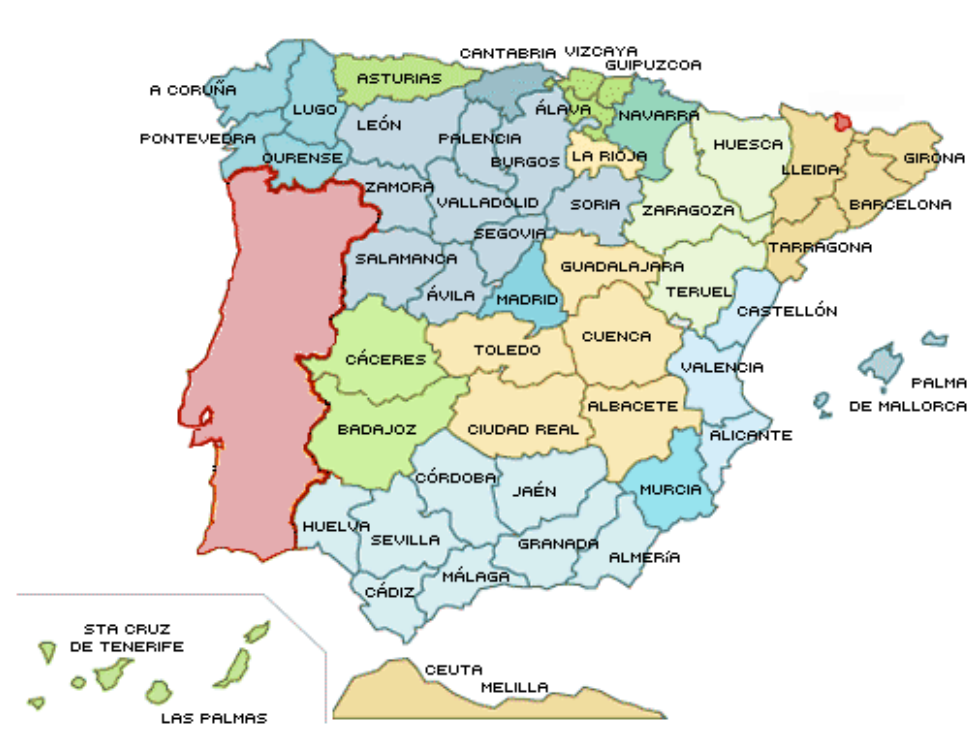

¿Qué tiempo va a hacer en Teruel?

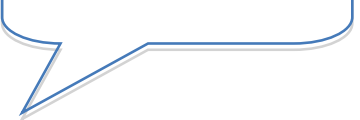

En Teruel el cielo va a estar nublado y va a llover

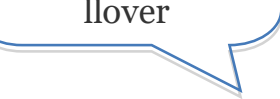

5) Relaciona las siguientes acciones con el tiempo atmosférico al que corresponden.

\begin{tabular}{|c|c|c|c|}
\hline ir a la playa & coger el paraguas & tomar el sol & ir a esquiar \\
\hline quedarse en casa & salir a dar un paseo & mojarse & ir a la piscina \\
\hline comer un helado & $\begin{array}{c}\text { ponerse gafas y } \\
\text { gorra }\end{array}$ & pisar un charco & ponerse crema \\
\hdashline $\begin{array}{c}\text { hacer un muñeco de } \\
\text { nieve }\end{array}$ & $\begin{array}{c}\text { sentarse en una } \\
\text { terraza }\end{array}$ & $\begin{array}{c}\text { tomar un chocolate } \\
\text { caliente }\end{array}$ & $\begin{array}{c}\text { ir a un centro } \\
\text { comercial }\end{array}$ \\
\hline
\end{tabular}

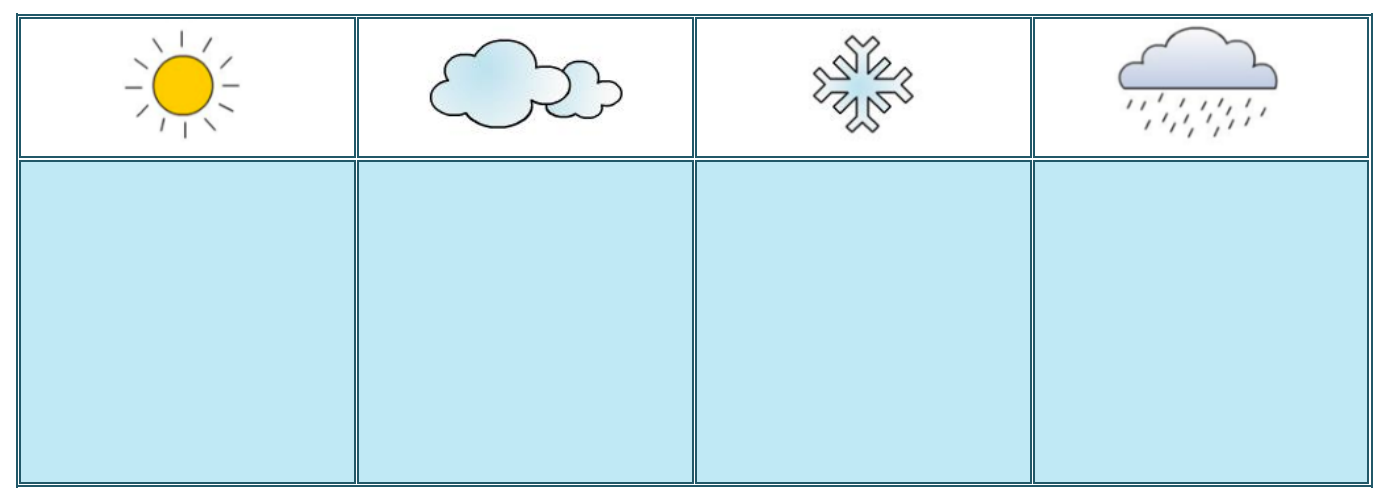


6) ¿Cómo terminan las siguientes expresiones relacionadas con el tiempo?

Hacer un frío...

Hacer un sol...

Llover...

Hacer un calor...
... que pela

... de justicia

... a cántaros

... infernal

\subsubsection{Actividades durante el visionado}

Ahora vas a ver un vídeo que habla sobre la "ola de calor" que vivimos en verano casi cada año en España.

Vídeo disponible en: https://www.youtube.com/watch?v=ObRqlCbqETU

1) ¿Cómo se llama este objeto? ¿para qué sirve? ¿se utiliza en tu país? ¿crees que se utiliza en otros países además de en España?

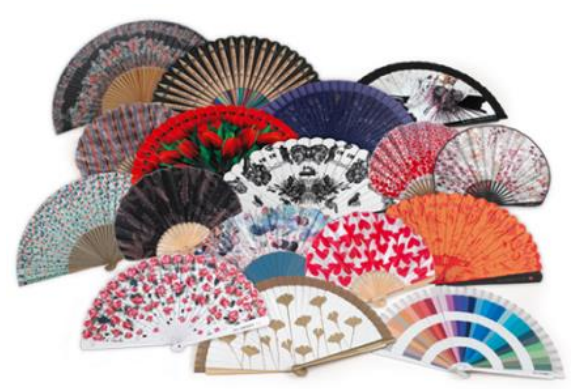

2) Completa las siguientes frases extraídas del vídeo.

$\checkmark$ Los son, estos días, tendencia en la totalidad de la $\mathrm{p}$ 
EL PROGRAMA TELEVISIVO COMO RECURSO PARA LA

ENSEÑANZA/APRENDIZAJE DE ESPAÑOL LENGUA EXTRANJERA

$\checkmark \quad$ Los C despejados en la mayor parte del $\mathrm{p}$ han favorecido temperaturas que, en c como Z y G_ han alcanzado máximas históricas.

$\checkmark$ "Hace mucho calor, esto es inaguantable, ya podían bajar un poquito las t___

$\checkmark$ Aunque las temperaturas descenderán a lo largo del d en el área del $m$ y archipiélagos, cada uno tiene sus trucos para soportar el c

$\checkmark$ Esta ola de calor nos acompañará, al menos, hasta la s que viene.

3) ¿Qué consejos para soportar el calor se mencionan en el vídeo?

\begin{tabular}{|l|l|l|l|}
\hline beber mucha agua & ir a trabajar & \\
\hline llevar ropa ligera & & hacer surf & \\
\hline ducharse con agua fría & & usar aire acondicionado & \\
\hline bañarse en la piscina & & usar el ventilador & \\
\hline
\end{tabular}

\subsubsection{Actividades de posvisionado}

1) Ahora vosotros vais a ser "el hombre/la mujer del tiempo". En parejas, elegid una comunidad autónoma de España (podéis verlas en el mapa que hay a continuación) y buscad el tiempo que va a hacer allí cada día de la próxima semana. Tenéis que grabar un vídeo para un programa informativo, podéis utilizar algunas de las expresiones que habéis aprendido y, lo más importante, tenéis que darle vuestro "toque personal". En clase votaremos el vídeo que más nos guste. 
PROPUESTAS DIDÁCTICAS PARA LA EXPLOTACIÓN DE PROGRAMAS DE TELEVISIÓN EN CLASE DE ELE

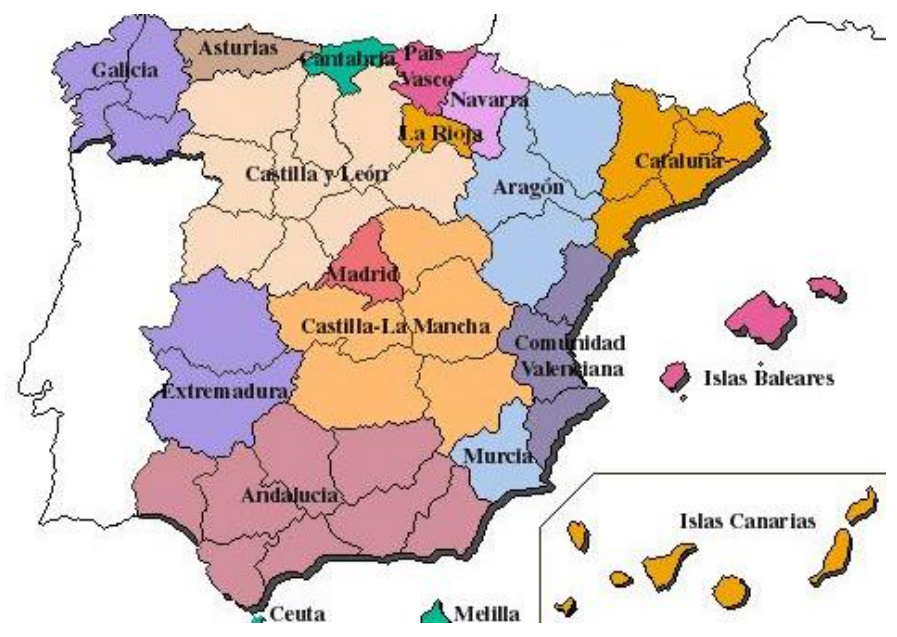


EL PROGRAMA TELEVISIVO COMO RECURSO PARA LA

ENSEÑANZA/APRENDIZAJE DE ESPAÑOL LENGUA EXTRANJERA

\subsection{Propuesta de actividades para la explotación de un programa informativo}

Tabla 11

Clasificación de la propuesta de actividades para la explotación de un programa informativo

\begin{tabular}{lll}
\hline Nivel del MCER & Competencias & Actividades comunicativas \\
\hline$\square$ A1 & \# Gramaticales & \# Compresión Oral \\
\# A2 & \# Léxicas & \# Comprensión Escrita \\
\# B1 & \# Socioculturales & \# Expresión Oral \\
$\square$ B2 & \# Pragmáticas & $\square$ Expresión Escrita \\
$\square$ C1 & \# Estratégicas & \# Interacción Oral \\
$\square$ C2 & \# Discursivas & $\square$ Interacción Escrita \\
& & $\square$ Mediación Oral \\
& & $\square$ Mediación Escrita
\end{tabular}

Fuente: elaboración propia

\subsubsection{Actividades de previsionado}

1) Uno de los temas sobre el que más se ha hablado este y el pasado año en todos los programas informativos de España ha sido las elecciones a la presidencia del gobierno español. ¿Podrías decir cuál ha sido uno de los temas más tratados en tu país estos últimos meses?

2) El lenguaje de la política siempre tiene algunos términos un poco complicados. ¿Sabrías encontrar su definición? Este ejercicio te ayudará a comprender mejor las siguientes actividades y el vídeo que verás a continuación. 
PROPUESTAS DIDÁCTICAS PARA LA EXPLOTACIÓN DE PROGRAMAS

DE TELEVISIÓN EN CLASE DE ELE

\begin{tabular}{|c|c|c|c|c|c|}
\hline escaño & comicios & pacto & disolver & oposición & $\begin{array}{l}\text { partido } \\
\text { político }\end{array}$ \\
\hline escrutar & sondeo & $\begin{array}{l}\text { mayoría } \\
\text { absoluta }\end{array}$ & diputado & coalición & legislatura \\
\hline
\end{tabular}

: Elecciones para designar cargos políticos

: asiento de los parlamentarios en las cámaras

: tratado entre dos o más partes

: deshacer algo

: en el gobierno, la minoría

: contar los votos

: investigación de la opinión mediante encuestas

: mayoría que consta de más de la mitad de votos

: persona nombrada por elección popular como

representante en una cámara legislativa

: unión temporal de grupos políticos

: grupo organizado de personas que comparten objetivos y

opiniones políticas

: tiempo durante el cual funciona un gobierno

3) Aquí puedes ver algunos de los titulares que se han publicado en la edición online del periódico español El País ${ }^{98}$ con respecto a este tema.

- Primero, intenta ordenarlos, observa la fecha de publicación para que te resulte más fácil.

- Después, comenta con tus compañeros y tu profesor cómo se ha desarrollado la situación.

${ }^{98}$ Disponible en: elpaís.com 
EL PROGRAMA TELEVISIVO COMO RECURSO PARA LA

ENSEÑANZA/APRENDIZAJE DE ESPAÑOL LENGUA EXTRANJERA

\begin{tabular}{|ll|}
\hline 15/03/2016 & L9.92\% de \\
L2:39 CET & Los partidos ensayan cómo quitarse la culpa de repetir las elecciones \\
& JUAN JOSÉ MATEO, FRANCESCO MANETTO, JOSÉ MARCOS, NATALIA JUNQUERA \\
& intereses personales \\
\hline
\end{tabular}

08/01/2016
17:58 CET
euro
Goldman Sachs da prácticamente por segura la repetición de las elecciones generales y en Cataluña. Las buenas
perspectivas que los analistas otorgaban a la economía dejan paso a la prudencia

\begin{tabular}{|c|c|}
\hline $22 / 12 / 2015$ & 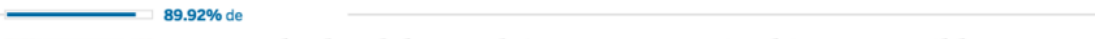 \\
\hline 09:38 CET & 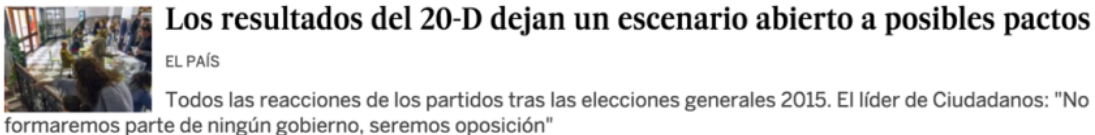 \\
\hline
\end{tabular}

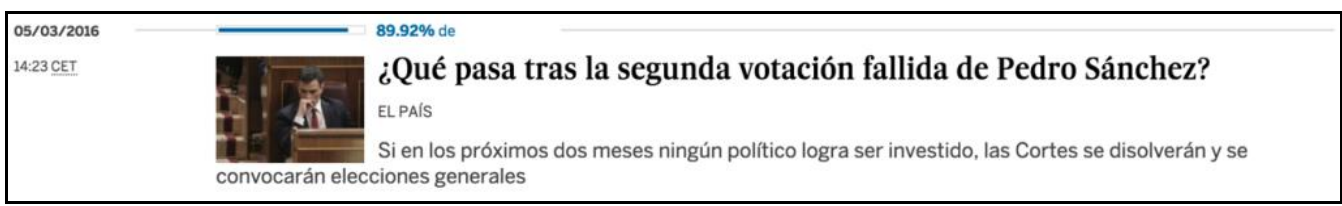

27/04/2016
00:40 CEST
junio de
Felipe VI constata, tras recibir a los líderes de los partidos, la imposibilidad de un acuerdo para formar Gobierno. Los
nuevos comicios serán el 26 de junio

\begin{tabular}{lll} 
12:18 CET & 89.92\% de \\
& ¿Qué pasa si no hay mayoría suficiente para formar gobierno? \\
Cortes se disolverían y se convocarían nuevas elecciones generales & Si pérez \\
\hline
\end{tabular}

\begin{tabular}{|ll} 
16/05/2016 & 89.92\% de \\
12:21 CEST & Unidos Podemos, el nombre de la coalición de Podemos e IU \\
FRANCESCO MANETTO, ELSA GARCIA DE BLAS \\
Podemos e IU pactan el nombre de la coalición con la que concurren a las generales
\end{tabular}

\begin{tabular}{|ll} 
20/12/2015 & 89.92\% de \\
19:14 CET & Elecciones generales 2015: La jornada electoral \\
GEMA GARCIA \\
Un total de 517.374 ciudadanos en calidad de miembros o suplentes forman parte de las 57.486
\end{tabular}

Fuente: elpais.com 


\section{PROPUESTAS DIDÁCTICAS PARA LA EXPLOTACIÓN DE PROGRAMAS \\ DE TELEVISIÓN EN CLASE DE ELE}

4) Aquí tienes una gráfica con los resultados de las elecciones del 20 de diciembre del 2015. Obsérvalo y completa el siguiente cuadro:
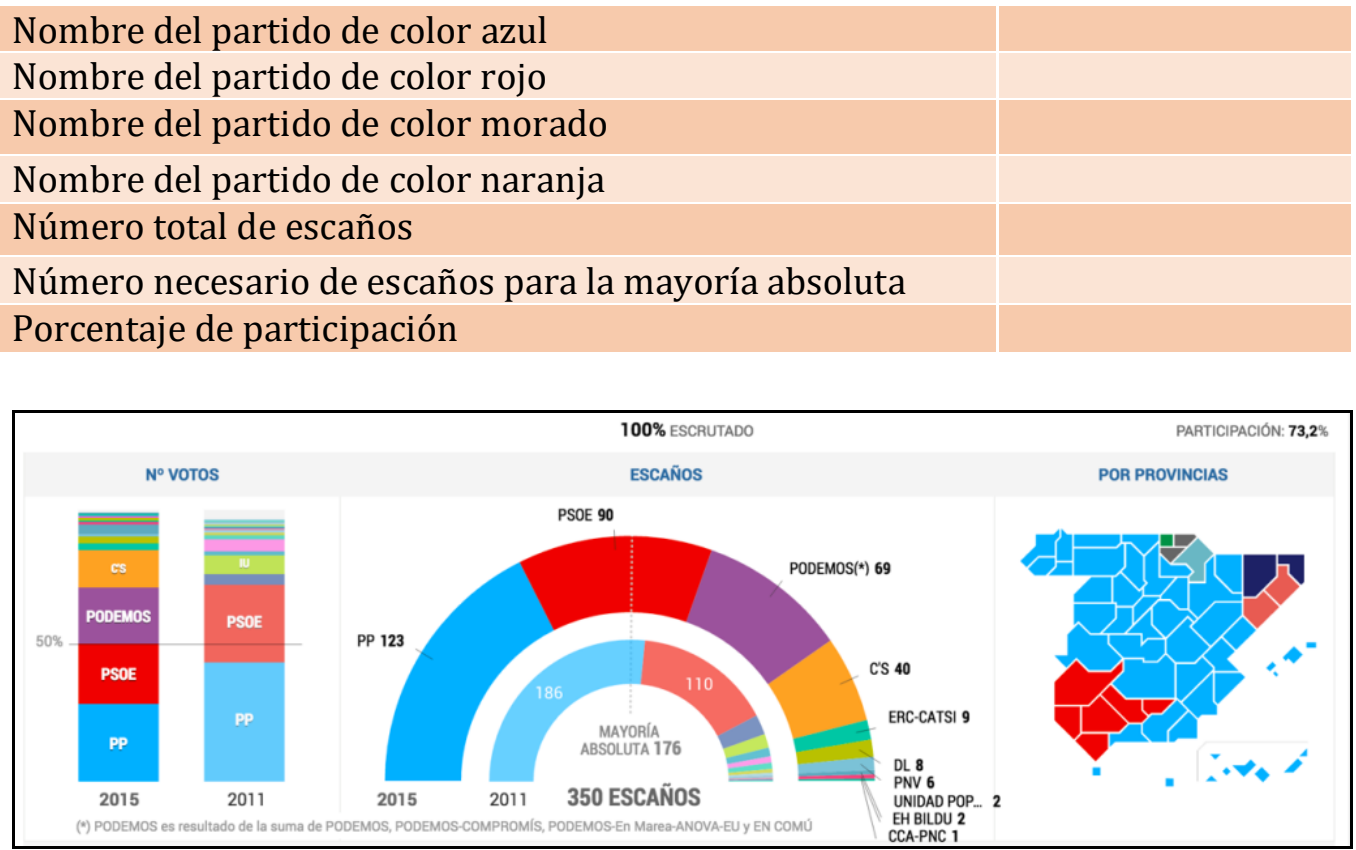

Fuente: elpais.com

- ¿Qué diferencias observas entre los resultados de 2011 y de 2015? Coméntalo con tus compañeros y con tu profesor.

\subsubsection{Actividades durante el visionado}

Ahora vas a ver un vídeo extraído de un programa informativo español, retransmitido inmediatamente después de las elecciones del 20 de diciembre de 2015.

Video disponible en: https://www.youtube.com/watch?v=t57INC84MfA

1) Relaciona los candidatos a la presidencia con sus partidos correspondientes y escribe sus nombres. 


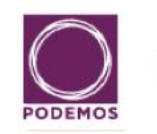

Podemos

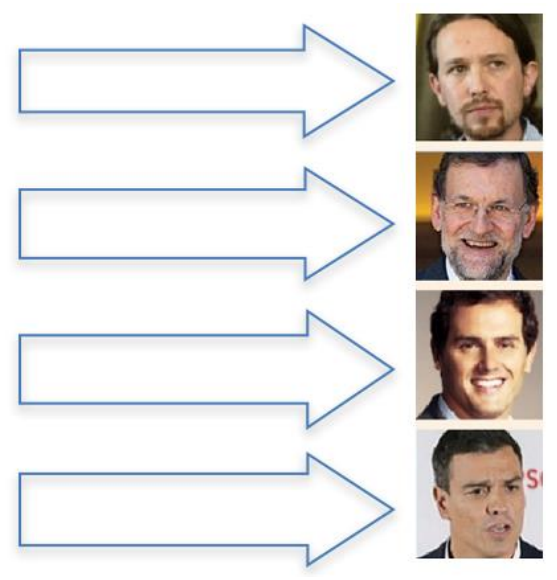

Partido Popular

2) ¿Qué candidato dice cada una de las siguientes frases?

\begin{tabular}{|c|c|c|c|c|}
\cline { 3 - 4 } & & & & \\
\hline "Nosotros salimos a ganar las elecciones" & & & & \\
\hline "España ha votado cambio de sistema" & & & & \\
\hline "Creo que España necesita un gobierno estable" & & & & \\
\hline "El nuevo centro político..." & & & & \\
\hline "Los españoles han hecho muchos esfuerzos" & & & & \\
\hline "Desgraciadamente, no ha sido así" & & & & \\
\hline "Es verdad que España quiere cambiar" & & & & \\
\hline "Esto tiene una serie de implicaciones" & & & & \\
\hline
\end{tabular}

3) Contesta verdadero o falso a las siguientes afirmaciones.

\begin{tabular}{|l|c|c|}
\cline { 2 - 3 } \multicolumn{1}{c|}{} & V & F \\
\hline Los nuevos partidos son Podemos y PSOE. & & \\
\hline La participación este año ha sido menor que en años anteriores. & & \\
\hline La última legislatura fue complicada. & & \\
\hline El PSOE es un partido de derechas. & & \\
\hline Ciudadanos es un partido de izquierdas. & & \\
\hline En España nunca antes ha habido un gobierno de coalición. & & \\
\hline
\end{tabular}




\subsubsection{Actividades de posvisionado}

1) Como ahora sabes, las últimas elecciones en España se tuvieron que repetir unos meses después, el 26 de julio de 2016. Aquí tienes un gráfico con los escaños que obtuvieron los diferentes partidos en las segundas votaciones.

Ahora, en grupos, tenéis que representar un programa informativo en el que habléis sobre esta noticia, siguiendo el estilo del vídeo que habéis visto antes.

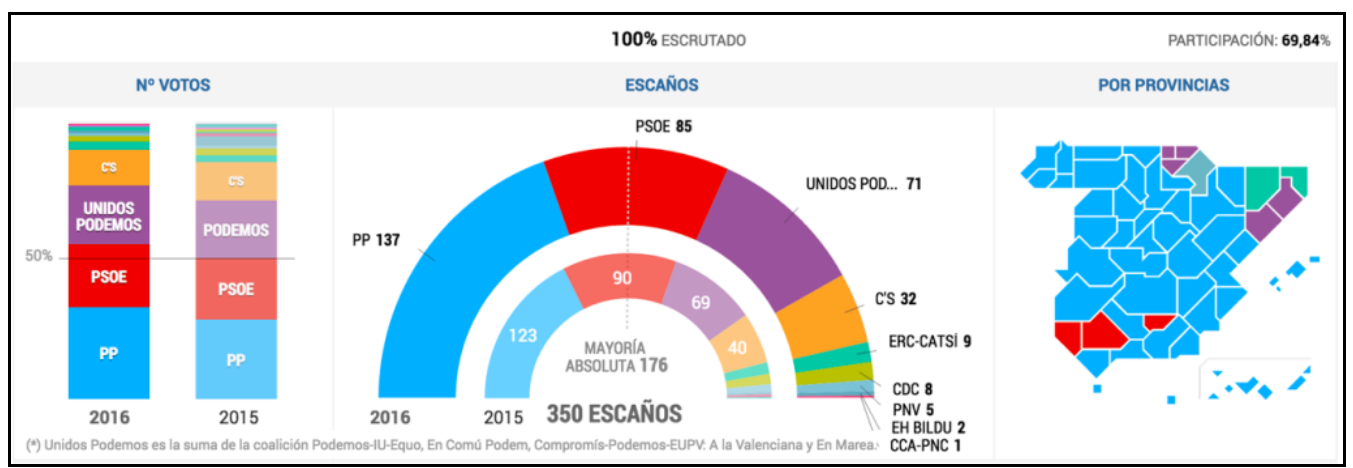

Fuente: elpais.com 
EL PROGRAMA TELEVISIVO COMO RECURSO PARA LA

ENSEÑANZA/APRENDIZAJE DE ESPAÑOL LENGUA EXTRANJERA

\subsection{Propuesta de actividades para la explotación de un programa de información deportiva}

Tabla 12

Clasificación de la propuesta de actividades para la explotación de un programa de información deportiva

\begin{tabular}{lll}
\hline Nivel del MCER & Competencias & Actividades comunicativas \\
\hline$\square$ A1 & \# Gramaticales & \# Compresión Oral \\
\# A2 & \# Léxicas & \# Comprensión Escrita \\
\# B1 & \# Socioculturales & \# Expresión Oral \\
$\square \mathrm{B} 2$ & \# Pragmáticas & $\square$ Expresión Escrita \\
$\square \mathrm{C} 1$ & \# Estratégicas & \# Interacción Oral \\
$\square \mathrm{C} 2$ & \# Discursivas & $\square$ Interacción Escrita \\
& & $\square$ Mediación Oral \\
& & $\square$ Mediación Escrita
\end{tabular}

Fuente: elaboración propia

\subsubsection{Actividades de previsionado}

1) ¿Qué sabes del deporte español? ¿Qué deportistas españoles conoces? ¿Crees que España es un país conocido por sus deportistas?

2) Relaciona las imágenes con estos artículos ${ }^{99}$ que relatan algunos de los acontecimientos más importantes del deporte Español de los últimos años. 


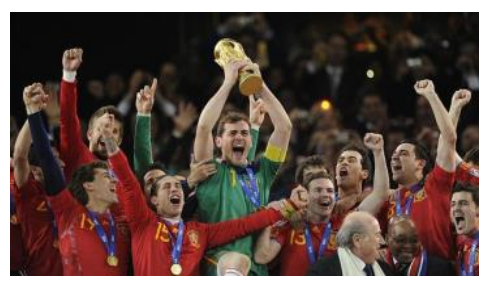
Fernando Alonso, campeón del mundo de F-1

El 25 de septiembre de 2005, tras acabar el Gran Premio de Brasil, el piloto asturiano no puede contener su alegría. Fernando Alonso gana el campeonato del mundo por primera vez y expande el dominio del deporte español al complejo mundo de la Fórmula 1.

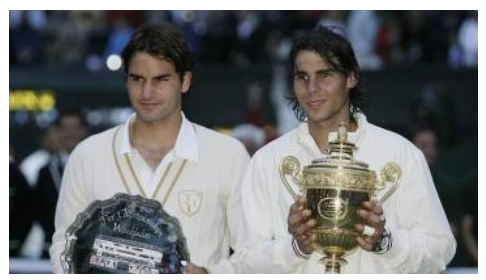

\section{Los chicos de oro del baloncesto español}

El baloncesto es un deporte que ha dado muchas alegrías a los aficionados españoles.

En el Mundial de Japón 2006, el equipo español consiguió el oro. Luego llegaron dos

Europeos y dos platas olímpicas para una historia que aún no ha finalizado.

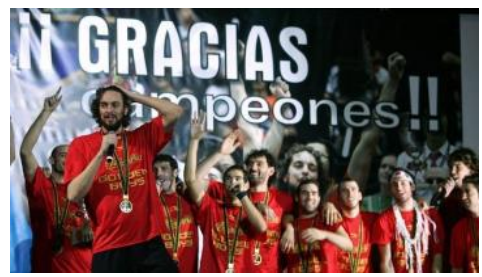

Mundial de Sudáfrica 2010

El 11 de julio de 2010, Andrés Iniesta, en la final contra Holanda, marca el gol que concede el triunfo a la selección española de fútbol en el Mundial de Sudáfrica. España, campeona de

Europa en 2008 y de nuevo en 2012, acaba para siempre con su "leyenda negra".

\section{Nadal gana el mejor partido de la historia}

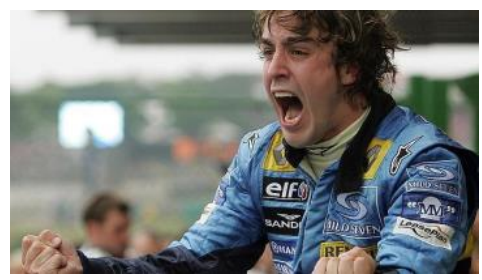

Ganador de 14 Grand Slams. Probablemente sus 9 victorias en Roland Garros sean las más conocidas, pero la victoria en Wimbledon 2008 ante Roger Federer es probablemente su punto álgido: muchos especialistas consideran aquel duelo el mejor de la historia.

3) Encuentra las palabras correspondientes a las siguientes definiciones de términos deportivos, hay una en cada línea horizontal. 
EL PROGRAMA TELEVISIVO COMO RECURSO PARA LA ENSEÑANZA/APRENDIZAJE DE ESPAÑOL LENGUA EXTRANJERA

\begin{tabular}{|llllllllllllll|}
\hline$T$ & $G$ & $K$ & $S$ & $W$ & $I$ & $T$ & $P$ & $E$ & $R$ & $D$ & $E$ & $R$ & $E$ \\
$Y$ & $Y$ & $A$ & $R$ & $B$ & $I$ & $T$ & $R$ & $O$ & $J$ & $T$ & $O$ & $U$ & $I$ \\
$A$ & $A$ & $J$ & $J$ & $Y$ & $C$ & $A$ & $N$ & $A$ & $S$ & $T$ & $A$ & $Q$ & $L$ \\
$P$ & $R$ & $O$ & $R$ & $R$ & $O$ & $G$ & $A$ & $I$ & $Y$ & $R$ & $K$ & $A$ & $S$ \\
$L$ & $E$ & $V$ & $A$ & $U$ & $P$ & $I$ & $S$ & $T$ & $A$ & $Z$ & $E$ & $V$ & $G$ \\
$D$ & $S$ & $S$ & $I$ & $A$ & $L$ & $E$ & $P$ & $E$ & $L$ & $O$ & $T$ & $A$ & $O$ \\
$L$ & $P$ & $I$ & $S$ & $C$ & $I$ & $N$ & $A$ & $Q$ & $P$ & $B$ & $U$ & $E$ & $C$ \\
$E$ & $N$ & $P$ & $K$ & $B$ & $Y$ & $P$ & $O$ & $R$ & $T$ & $E$ & $R$ & $I$ & $A$ \\
$P$ & $E$ & $N$ & $A$ & $L$ & $T$ & $I$ & $O$ & $C$ & $J$ & $E$ & $I$ & $O$ & $O$ \\
$E$ & $N$ & $T$ & $R$ & $E$ & $N$ & $A$ & $D$ & $O$ & $R$ & $B$ & $E$ & $G$ & $E$ \\
$J$ & $Q$ & $Q$ & $I$ & $M$ & $Q$ & $W$ & $A$ & $G$ & $A$ & $N$ & $A$ & $R$ & $K$ \\
$Z$ & $C$ & $E$ & $V$ & $E$ & $C$ & $A$ & $M$ & $P$ & $O$ & $I$ & $R$ & $J$ & $S$ \\
$N$ & $H$ & $R$ & $A$ & $Q$ & $U$ & $E$ & $T$ & $A$ & $Q$ & $U$ & $M$ & $S$ & $D$ \\
$E$ & $M$ & $P$ & $A$ & $T$ & $A$ & $R$ & $U$ & $L$ & $A$ & $E$ & $Q$ & $H$ & $P$ \\
\hline
\end{tabular}

Obtener igual puntuación en una competición.

Máxima sanción que se aplica a ciertas faltas del juego cometidas por un equipo.

Tiempo que se añade en una competición cuando existe un empate.

Marco rectangular por el que ha de entrar el balón para marcar tantos.

En baloncesto, aro por el que ha de entrar el balón para marcar tantos.

Terreno donde se practican deportes como, por ejemplo, el fútbol o el baloncesto.

Persona que, en las competiciones, aplica el reglamento y sanciona.

Persona que entrena a deportistas.

No conseguir la victoria.

Conseguir la victoria.

Instrumento formado por un mango y una superficie circular que se emplea para golpear una pelota.

Sinónimo de balón.

Construcción que contiene gran cantidad de agua y que se destina al baño, a la natación y a otros deportes.

Espacio destinado a practicar deportes, por ejemplo, el tenis o el hockey. 


\subsubsection{Actividades durante el visionado}

Ahora vas a ver un vídeo en el que algunos de los jugadores de la selección española cuentan cómo vivieron el gol que les hizo ganar la copa del mundo de fútbol en 2010.

Vídeo disponible en: https://www.youtube.com/watch?v=bVN5zo4KHR4

1) Aquí tienes la transcripción del vídeo. Coloca las palabras y expresiones específicas del ámbito del fútbol que faltan.

\begin{tabular}{|c|c|c|c|}
\hline balón & gol & medio campo & tacón \\
\hline desmarque & lateral & banda & rebote \\
\hline
\end{tabular}

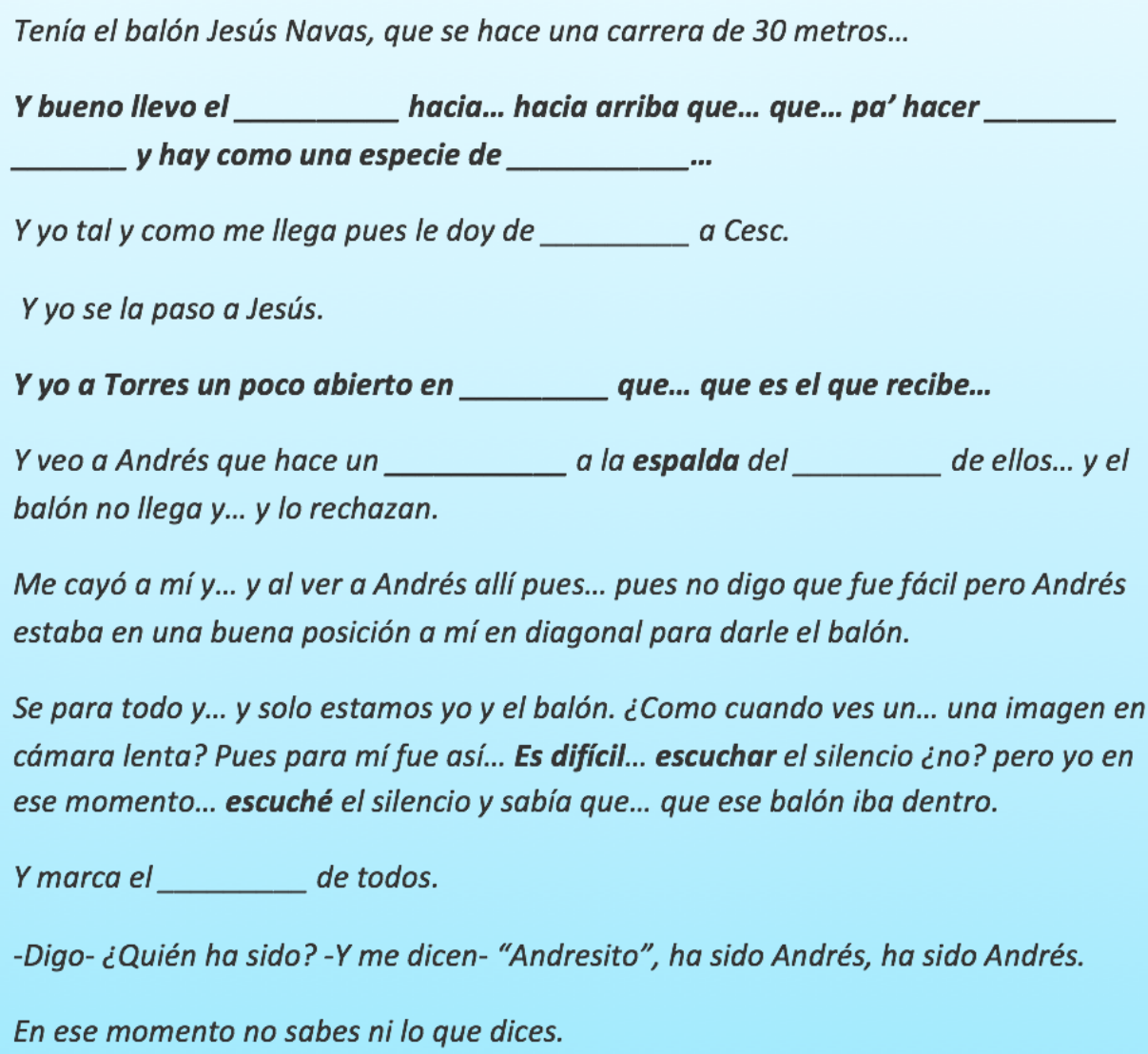




\section{EL PROGRAMA TELEVISIVO COMO RECURSO PARA LA ENSEÑANZA/APRENDIZAJE DE ESPAÑOL LENGUA EXTRANJERA}

2) ¿Qué notas en la pronunciación de las partes y palabras que aparecen en negrita? ¿A qué crees que se debe esta pronunciación "diferente"?

3) Fíjate en la palabra "Andresito". ¿Sabes cuándo se utiliza el sufijo -ito/a en español? Fíjate en estos otros sufijos y relaciónalos con su uso y significado.

-ete

-illo/a

$-\mathbf{a z 0} / \mathbf{a}$

-ón/ona

-ote/a

-orro/a
Sufijo aumentativo ('grande') utilizado principalmente para halagar con un matiz de cariño. Se utiliza, por ejemplo, con el adjetivo bueno.

Tiene valor aumentativo ('grande') y puede tener un matiz tanto halagador, por ejemplo, con la palabra madre, como despectivo, por ejemplo, con la palabra mano.

Se utiliza solo con valor halagador, por ejemplo, con la palabra vida.

Tiene carácter afectivo. Se utiliza prácticamente solo su forma masculina, por ejemplo, con la palabra majo.

Utilizado sobre todo en el sur de España. Quiere decir "pequeño" y también tiene un carácter afectivo. Se utiliza, por ejemplo, con la palabra chico.

Puede tener un matiz tanto despectivo como afectivo. Se utiliza, por ejemplo, con la palabra amigo. 


\subsubsection{Actividades de posvisionado}

1) Ahora, en parejas, vais a preparar una entrevista de unos cinco minutos. Uno será el entrevistador y otro el entrevistado. El entrevistado representará al deportista famoso que elija. Ambos tendréis unos minutos para informaros sobre los éxitos de ese deportista, sin embargo, solo podréis preparar tres preguntas relacionadas con ese tema, jel resto las tendréis que improvisar! Al final votaremos la entrevista más interesante, divertida, original, natural... 
EL PROGRAMA TELEVISIVO COMO RECURSO PARA LA

ENSEÑANZA/APRENDIZAJE DE ESPAÑOL LENGUA EXTRANJERA

\subsection{Propuesta de actividades para la explotación de un programa de cocina}

Tabla 13

Clasificación de la propuesta de actividades para la explotación de un programa de cocina

\begin{tabular}{lll}
\hline Nivel del MCER & Competencias & Actividades comunicativas \\
\hline \# A1 & \# Gramaticales & \# Compresión Oral \\
\# A2 & \# Léxicas & \# Comprensión Escrita \\
$\square$ B1 & \# Socioculturales & \# Expresión Oral \\
$\square$ B2 & \# Pragmáticas & \# Expresión Escrita \\
$\square \mathrm{C} 1$ & \# Estratégicas & \# InteracciónOral \\
$\square \mathrm{C} 2$ & \# Discursivas & $\square$ Interacción Escrita \\
& & \# Mediación Oral \\
& & $\square$ Mediación Escrita
\end{tabular}

Fuente: elaboración propia

\subsubsection{Actividades de previsionado}

1) ¿Te gusta cocinar o te gustaría aprender? ¿Por qué? ¿Qué formas hay de aprender a cocinar? ¿Cuál crees que es la más efectiva? ¿Qué crees que es necesario para ser un buen cocinero?

2) Aquí tienes una serie de platos típicos españoles. ¿Sabrías decir a qué zona de España corresponde cada uno y en qué consisten? 
PROPUESTAS DIDÁCTICAS PARA LA EXPLOTACIÓN DE PROGRAMAS DE TELEVISIÓN EN CLASE DE ELE
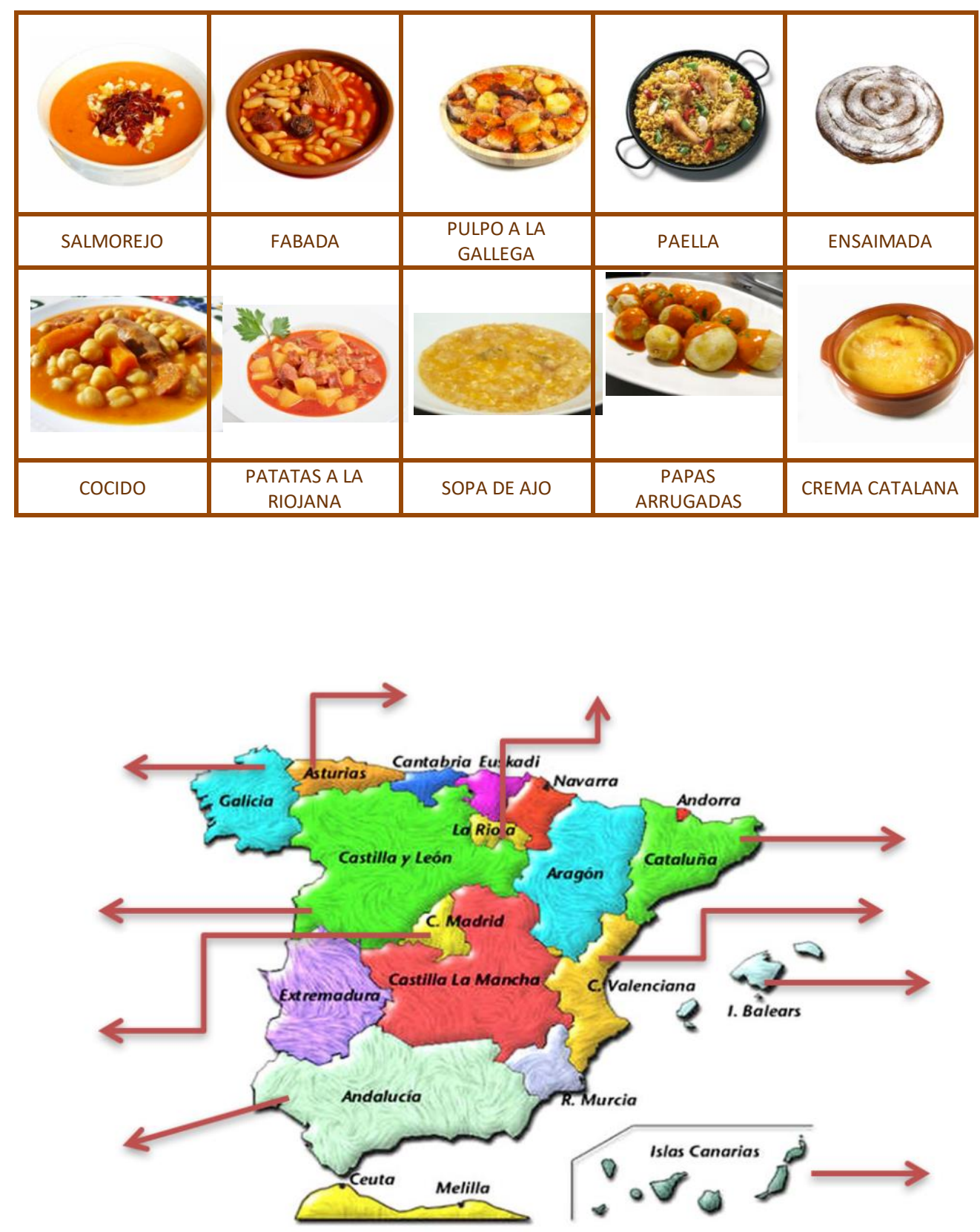

3) Aquí tienes la receta del salmorejo. Conjuga los verbos con la segunda persona del imperativo. 


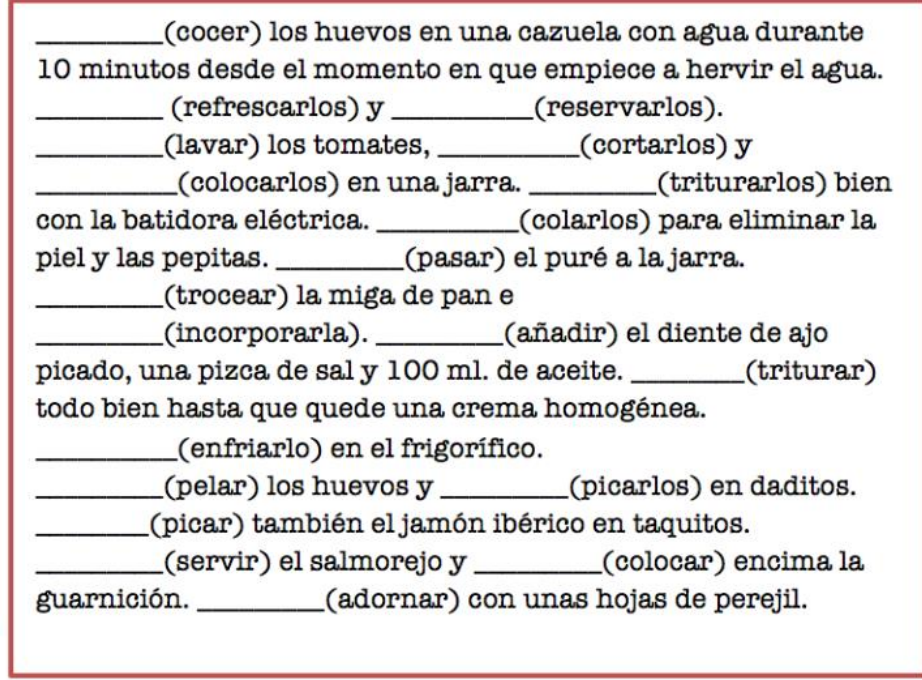

\subsubsection{Actividades durante el visionado}

Ahora vas a ver un vídeo de un programa de cocina de la televisión española presentado por el famoso cocinero español Karlos Arguiñano. En este programa vemos cómo se elabora el plato de "Patatas a la riojana".

Vídeo disponible en: https://www.youtube.com/watch?v=_nHjHFE5E7o

1) Aquí tienes la receta del plato patatas a la riojana. Ayúdate del vídeo para completarla con sus ingredientes. 


\begin{tabular}{|ll|}
\hline Ingredientes para 4-6 \\
personas: \\
$\checkmark$ & 6 patatas \\
$\checkmark$ & 3 chorizos \\
$\checkmark$ & 1 cebolla \\
$\checkmark$ & 1 pimiento verde \\
$\checkmark$ & 2 pimientos \\
& choriceros \\
$\checkmark$ & 1 cabeza de ajos \\
$\checkmark$ & agua \\
$\checkmark$ & aceite de oliva \\
$\checkmark$ & sal \\
$\checkmark$ & 2 hojas de laurel \\
$\checkmark$ & 1 guindilla \\
$\checkmark$ & perejil (para \\
& decorar) \\
& \\
\hline
\end{tabular}

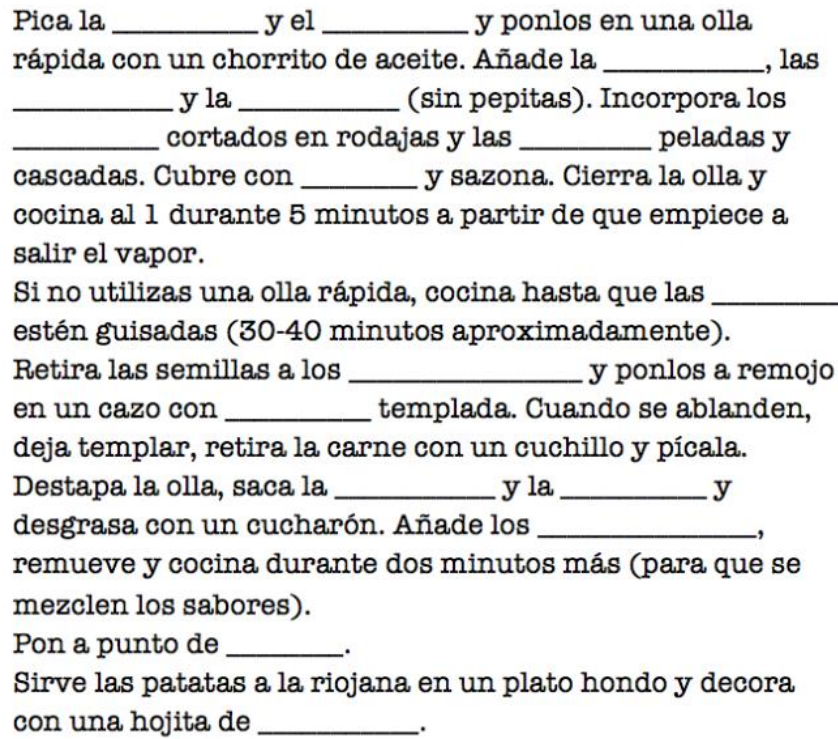

2) El cocinero utiliza algunas metáforas y expresiones mientras está cocinando. ¿Sabes a qué se refiere cuando dice...?

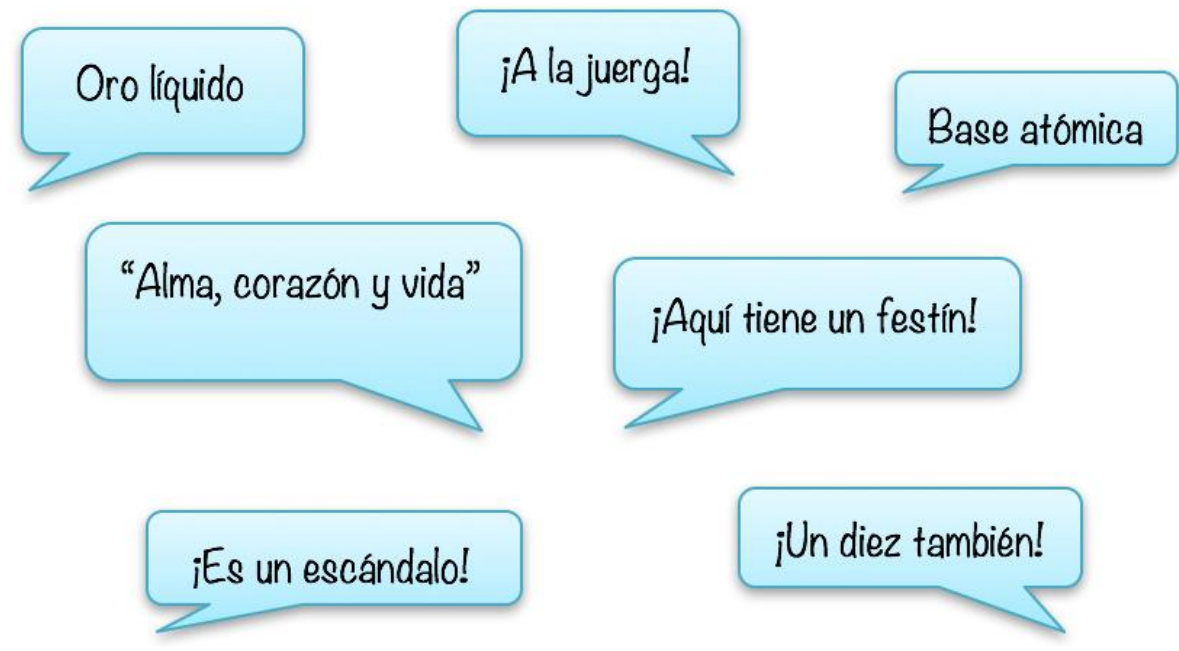

3) En la cocina se utiliza mucho el diminutivo -ito/a. ¿Cuántas veces lo has escuchado a lo largo del vídeo? Anota algunas de ellas. 
4) ¿Qué consejo da el cocinero para que el plato sea más ligero y engorde menos?

5) Fíjate en cómo pronuncia el cocinero la palabras desgrasado. ¿De qué zona de España crees que es esta característica?

\subsubsection{Actividades de posvisionado}

1) Ahora, en parejas, vais a escribir la receta de un plato típico de vuestro país. Recordad utilizar la segunda persona del singular de imperativo para las instrucciones.

2) Después, vais a grabar un vídeo explicando la elaboración de la receta que habéis elegido. El vídeo tiene que durar unos 3 minutos, por lo que no solo tendréis que explicar la receta sino también "entretener a vuestros espectadores", como hacía el cocinero en el vídeo que hemos visto antes. No tenéis que cocinar de verdad, podéis hacer todo con mímica. Luego veremos los vídeos en clase y votaremos el que más nos haya gustado. 


\subsection{Propuesta de actividades para la explotación de un programa documental}

Tabla 14

Clasificación de la propuesta de actividades para la explotación de un programa documental

\begin{tabular}{lll}
\hline Nivel del MCER & Competencias & Actividades comunicativas \\
\hline$\square$ A1 & \# Gramaticales & \# Compresión Oral \\
$\square$ A2 & \# Léxicas & \# Comprensión Escrita \\
\# B1 & \# Socioculturales & \# Expresión Oral \\
\# B2 & \# Pragmáticas & \# Expresión Escrita \\
$\square$ C1 & \# Estratégicas & \# Interacción Oral \\
$\square$ C2 & \# Discursivas & $\square$ Interacción Escrita \\
& & $\square$ Mediación Oral \\
& & \# Mediación Escrita
\end{tabular}

Fuente: elaboración propia

\subsubsection{Actividades de previsionado}

1) ¿Te gusta viajar? ¿Alguna vez has viajado a algún sitio y has pensado que te gustaría vivir allí? ¿Dónde? ¿Por qué?

2) A estas personas les gustaría mudarse a otro país. ¿Qué país le recomendarías a cada una de ellas teniendo en cuenta sus preferencias? Recuerda utilizar el condicional para hacer las recomendaciones. 


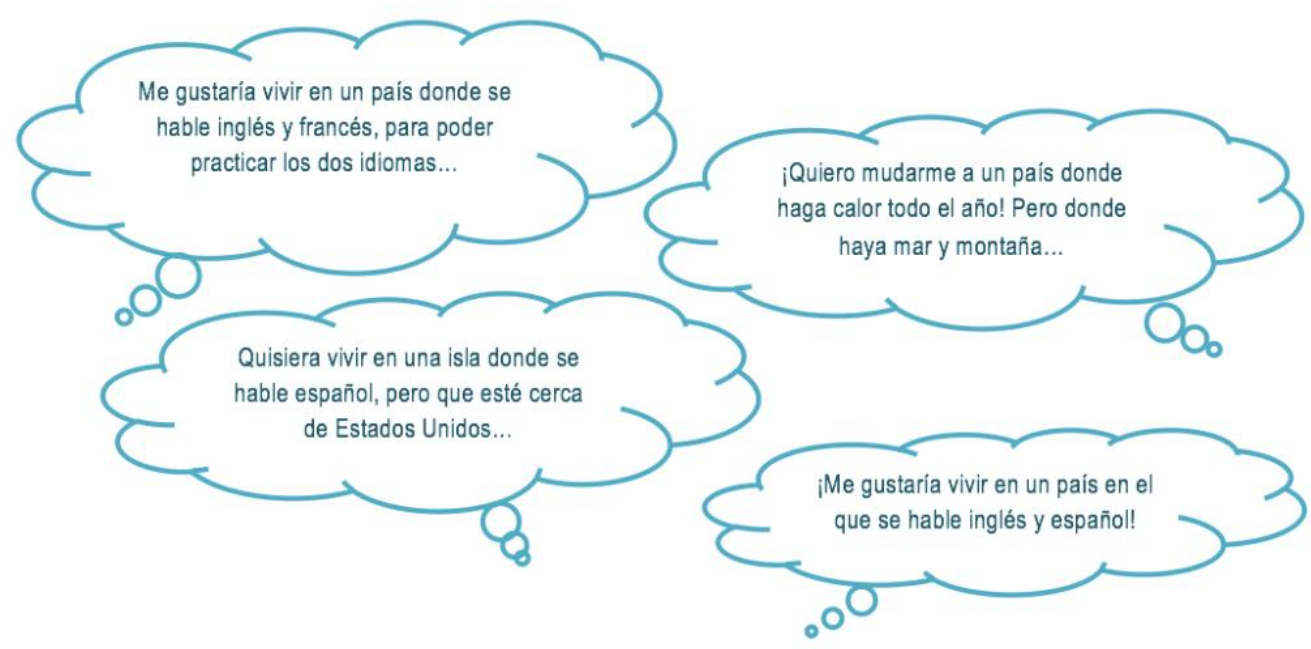

3) Lee el texto y explica, en unas líneas y con tus propias palabras, la diferencia entre los términos Hispanoamérica, Iberoamérica y Latinoamérica.

¿Hispanoamérica, Iberoamérica o Latinoamérica?

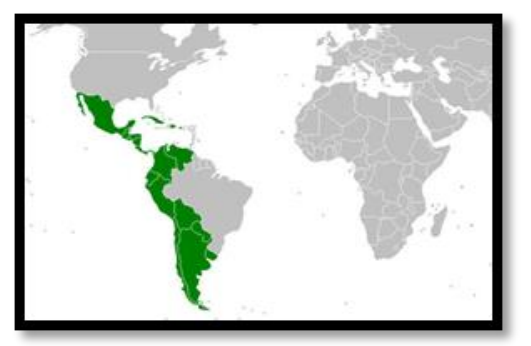

Hispanoamérica o América hispana es una región cultural integrada por los estados americanos donde se habla español; su gentilicio es hispanoamericano. Se trata de un territorio integrado por veinte países que suman una población total de unos 400 millones de habitantes. En la mayoría de ellos, el español es el idioma oficial o cooficial, aunque en algunas comunidades, principalmente indígenas, se hablan también lenguas propias como guaraní, aimara, quechua, náhuatl, maya, wayú y mapudungún. Los países que forman Hispanoamérica son : Nicaragua, Panamá, Paraguay, Perú, Guatemala, Honduras, México, Puerto Rico, República Dominicana, Uruguay, Venezuela, Argentina, Bolivia, Chile, Colombia, Costa Rica, Cuba, Ecuador, El Salvador. 


\section{PROPUESTAS DIDÁCTICAS PARA LA EXPLOTACIÓN DE PROGRAMAS \\ DE TELEVISIÓN EN CLASE DE ELE}

Por otro lado, Iberoamérica está constituida por los países sudamericanos que tienen como lengua oficial el español o el portugués. Aquí se incluye, además de la américa hispanohablante, a Brasil.

Finalmente, América Latina o Latinoamérica es un concepto aparecido en el siglo XIX para identificar una región del continente americano de habla española y portuguesa como lenguas oficiales o mayoritarias, también incluye los territorios o países de habla francesa. Siempre se considera parte de América Latina a Argentina, Bolivia, Brasil, Chile, Colombia, Costa Rica, Cuba, Ecuador, El Salvador, Guatemala, Haití, Honduras, México, Nicaragua, Panamá, Paraguay, Perú, República Dominicana, Uruguay y Venezuela. Sin embargo, se debate la inclusión de Belice, la región francófona de Canadá, los estados y posesiones hispanohablantes de Estados Unidos, en especial Puerto Rico e Islas Vírgenes, y las posesiones francesas en América (Guadalupe, Guayana Francesa, Martinica, San Bartolomé y San Martín).

\subsubsection{Actividades durante el visionado}

Ahora vas a ver un extracto de un programa-documental de la televisión española llamado Españoles por el Mundo, en el que algunos españoles que viven en otros países cuentan y muestran cómo es su vida allí.

Vídeo disponible en: https://www.youtube.com/watch?v=uD9jk3MqVn0

1) Completa la siguiente información sobre la española entrevistada. 


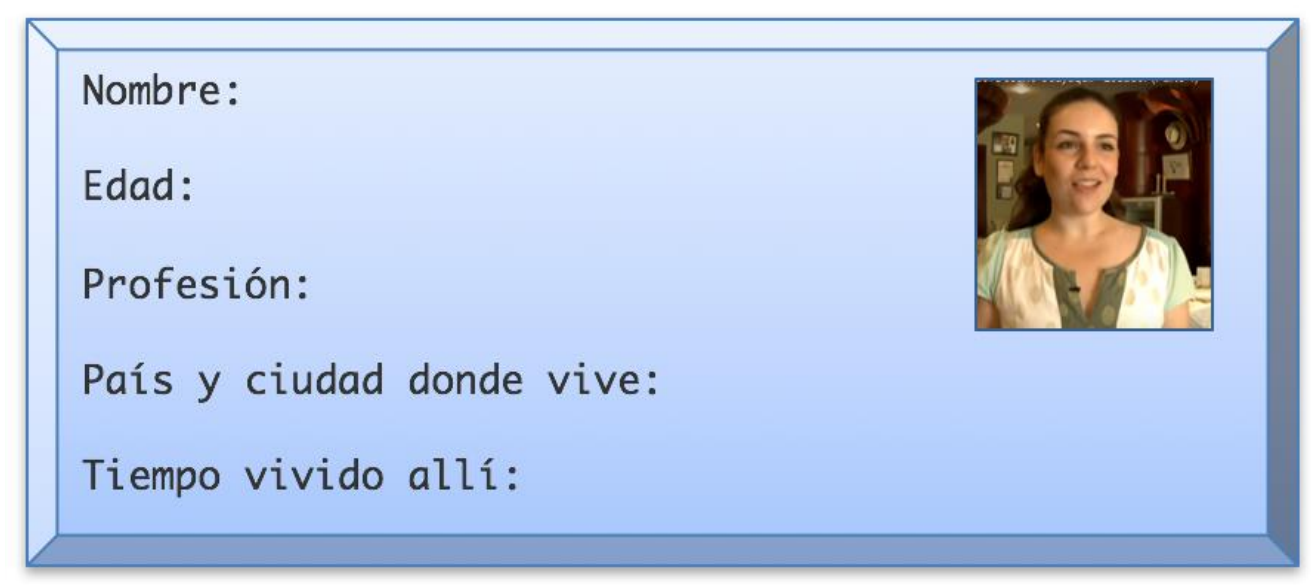

2) Completa estas frases con la información que falta, la escucharás al principio del vídeo.

$\checkmark$ El restaurante se llama la Tasca de por el de Alicia.

$\checkmark$ El restaurante lleva abierto meses.

$\checkmark$ La madre de Alicia está allí de

$\checkmark$ Alicia vivió en Ecuador hasta los años, y volvió de nuevo hace años, regresó cuando tenía de Alicia también trabaja en año.

$\checkmark \mathrm{El}$ de Alicia también trabaja en el restaurante.

$\checkmark$ En el restaurante se pueden comer las típicas españolas pero también cocina innovadora.

$\checkmark$ El plato estrella del restaurante es la

3) Indica si la siguiente información que se da sobre el cultivo del chocolate en Ecuador es verdadera o falsa.

\begin{tabular}{|c|c|c|}
\hline & \\
\hline & $\mathbf{V}$ & $\mathbf{F}$ \\
\hline $\begin{array}{l}\text { El color morado del fruto significa que el cacao está listo para ser } \\
\text { recogido. }\end{array}$ & & \\
\hline Las pepas del fruto del cacao son de color marrón. & & \\
\hline En Ecuador hay dos variedades de cacao. & & \\
\hline Fueron los aztecas quienes descubrieron el cacao. & & \\
\hline $\begin{array}{l}\text { En Europa, fueron los belgas quienes empezaron a fabricar } \\
\text { chocolate. }\end{array}$ & & \\
\hline El olor del cacao es dulce. & & \\
\hline El proceso de elaboración del cacao tiene cuatro pasos. & & \\
\hline
\end{tabular}

4) ¿Qué echa de menos Alicia de España? 


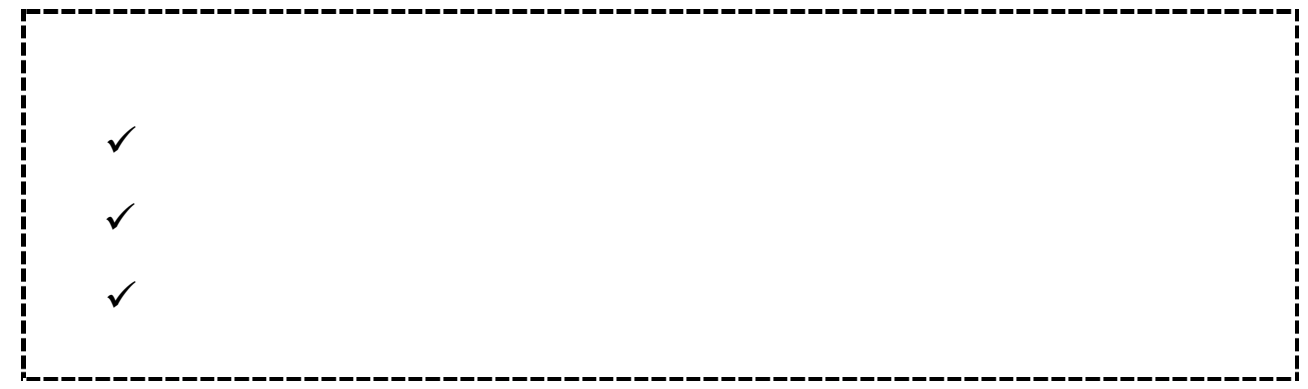

5) ¿Qué quiere hacer Alicia en el futuro?

6) ¿Qué notas en el acento de Alicia? ¿Te parece un acento español o ecuatoriano? ¿Por qué?

\subsubsection{Actividades de posvisionado}

1) Elabora un breve texto con información sobre un país hispanoamericano. Recuerda hablar de su geografía, cultura, comida y acento o palabras propias del país, entre otros aspectos. Después, se lo leerás a tus compañeros en clase.

2) ¡Ahora vais a hacer vosotros un minidocumental! Individualmente o en parejas vais a hacer un vídeo de 2 o 3 minutos en el que vais a presentar vuestra ciudad y vuestra universidad. Imaginad que es un vídeo para promocionar vuestra ciudad y vuestra universidad en otros países para que vengan estudiantes internacionales a estudiar un curso allí. Debéis buscar información real en Internet para incluir en vuestro vídeo y grabar el vídeo desde algún lugar de la ciudad o de la universidad. 
EL PROGRAMA TELEVISIVO COMO RECURSO PARA LA

ENSEÑANZA/APRENDIZAJE DE ESPAÑOL LENGUA EXTRANJERA

\subsection{Propuesta de actividades para la explotación de un programa de ficción}

Tabla 15

Clasificación de la propuesta de actividades para la explotación de un programa de ficción

\begin{tabular}{lll}
\hline Nivel del MCER & Competencias & Actividades comunicativas \\
\hline$\square$ A1 & \# Gramaticales & \# Compresión Oral \\
$\square$ A2 & \# Léxicas & \# Comprensión Escrita \\
$\square$ B1 & \# Socioculturales & \# Expresión Oral \\
$\square \mathrm{B} 2$ & \# Pragmáticas & \# Expresión Escrita \\
\# C1 & \# Estratégicas & \# Interacción Oral \\
\# C2 & \# Discursivas & $\square$ Interacción Escrita \\
& & \# Mediación Oral \\
& & \# Mediación Escrita
\end{tabular}

Fuente: elaboración propia

\subsubsection{Actividades de previsionado}

1) ¿Conoces la miniserie de televisión Camera Café? ¿De qué crees que trata y dónde crees que se desarrolla? ¿Qué programas televisivos de humor te gustan más?

2) Lee esta entrevista digital ${ }^{100}$ hecha a Arturo Valls, uno de los actores de la versión española de Camera Café, por algunos de sus fans a través de la página web del periódico español El País. Después, basándote en las

\footnotetext{
${ }^{100}$ Extraída de:

http://cultura.elpais.com/cultura/2015/07/15/actualidad/1436954400_1436965962.html
} 
preguntas y las respuestas, escribe un artículo sobre él (en tercera persona).

- ¿Qué te gusta más, presentar o actuar?

Lo considero igual. El presentador de televisión es un personaje. Estoy actuando. Imaginate que hablara asi y contara esos chistes tan malos en la vida real. Nota: en la vida soy mucho más gracioso.

- ¿Qué es lo que más te gusta de ser actor de cine?

Digamos que los proyectos son más pensados y pausados que la televisión, que tiene más premura e inmediatez. Los tiempos del cine te permiten disfrutar más el personaje.

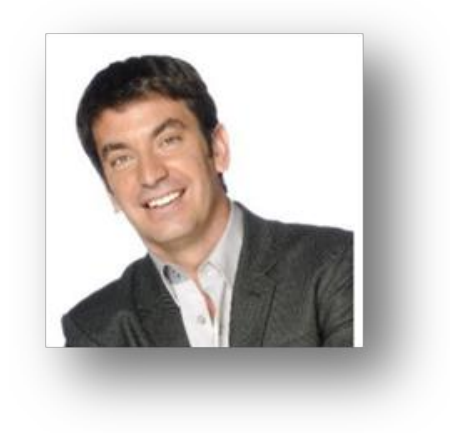

- ¿Para cuándo un papel serio?

No hay ansiedad por hacer un papel serio. Parece que cuando haces un drama eres mejor actor y yo no lo creo así. Si alguien, un productor o un director de cine me ofrece un papel dramático pues ahi me lanzaría. Pero no por demostrar nada, sino por afrontar un nuevo reto. Resumiendo: cuando alguien me lo proponga.

- ¿Se rie de sí mismo?

Hombre, ipor supuesto! Es fundamental como terapia y para hacer la vida más llevadera. Si empiezas por reirte de ti mismo es más difícil hacer comedia.

- ¿Dónde se le ocurren las mayores payasadas?

La verdad que grabando los programas. Porque luego cuando uno está en casa, está saturado de tanta chorrada. Desconectas un poco el modo humor. Asi pasa que luego los taxistas no distinguen entre la persona y el personaje, y me piden chistes en todo momento. Es verdad que luego con amigos, según qué momentos, con una paella y y unos gintonics, uno improvisa muy bien. 


\section{Arturo Valls}

\subsubsection{Actividades durante el visionado}

Ahora vas a ver un vídeo de uno de los programas de Camera Café emitidos en España.

Vídeo disponible en: https://www.youtube.com/watch?v=wUMxFehGTSo

1) Fíjate en las siguientes palabras y expresiones que has escuchado en el vídeo. ¿Qué crees que significan? Coméntalo con tus compañeros y tu profesor.

\begin{tabular}{|l|l|}
\hline - Le voy a preparar una buena a mi suegro & \\
\hline - Un coñazo & \\
\hline - iQué “pringao"! & \\
\hline - ¿Qué le tienes preparado? & \\
\hline - Hacerme pasar por el director & \\
\hline - iA ver quién es más "pringao"! & \\
\hline - Se lo voy a decir a toda la peña & \\
\hline - Que me sigan el rollo & \\
\hline - Lo que te dé la gana & \\
\hline - Fue de un día para otro & \\
\hline - Menudo eres tú & \\
\hline - “Con mano dura pero con guante de seda” & \\
\hline
\end{tabular}




\begin{tabular}{|l|l|}
\hline - iQué desastre! & \\
\hline - Hala, ilárgate! & \\
\hline - Será que no hay puestos... & \\
\hline - Ya me contarás... & \\
\hline - El de la cara de “amargao" & \\
\hline - Yo ahora mismo estoy perdido & \\
\hline - La que se ha “liao" & \\
\hline - iToma! & \\
\hline - Como se pensaba que tenía un pie en la & \\
tumba... & \\
\hline - Yademás de forrarse, ¿qué impresión se llevó? & \\
\hline
\end{tabular}

2) Fíjate en cómo pronuncian en el vídeo las palabras pringado, amargado y liado. ¿Crees que se pronuncian así en toda España o solo en algunas zonas? ¿Y siempre o solo a veces?

\subsubsection{Actividades de posvisionado}

1) En parejas, responded por escrito a las siguientes preguntas. Después compararemos y comentaremos las respuestas con el resto de la clase.

$\checkmark$ ¿Dónde se sitúa la acción?

$\checkmark$ ¿Quiénes son los personajes?

$\checkmark \quad$ ¿Qué le ocurre al protagonista en este vídeo?

$\checkmark$ ¿Por qué se trata de un vídeo de humor? ¿Qué bromas has percibido?

$\checkmark$ ¿Crees que se refleja cómo es el escenario de trabajo de una empresa en España? ¿Por qué?

$\checkmark \quad$ ¿Cómo es el lenguaje utilizado por los trabajadores?

$\checkmark \quad$ ¿Crees que es el lenguaje empleado normalmente en el ambiente de trabajo? ¿Por qué? 
$\checkmark \quad$ ¿Cómo es el ambiente de trabajo en las empresas de tu país? ¿Qué semejanzas o diferencias crees que pueden existir?

2) Completa este crucigrama con algunas de las palabras y expresiones del vídeo que hemos comentado antes.

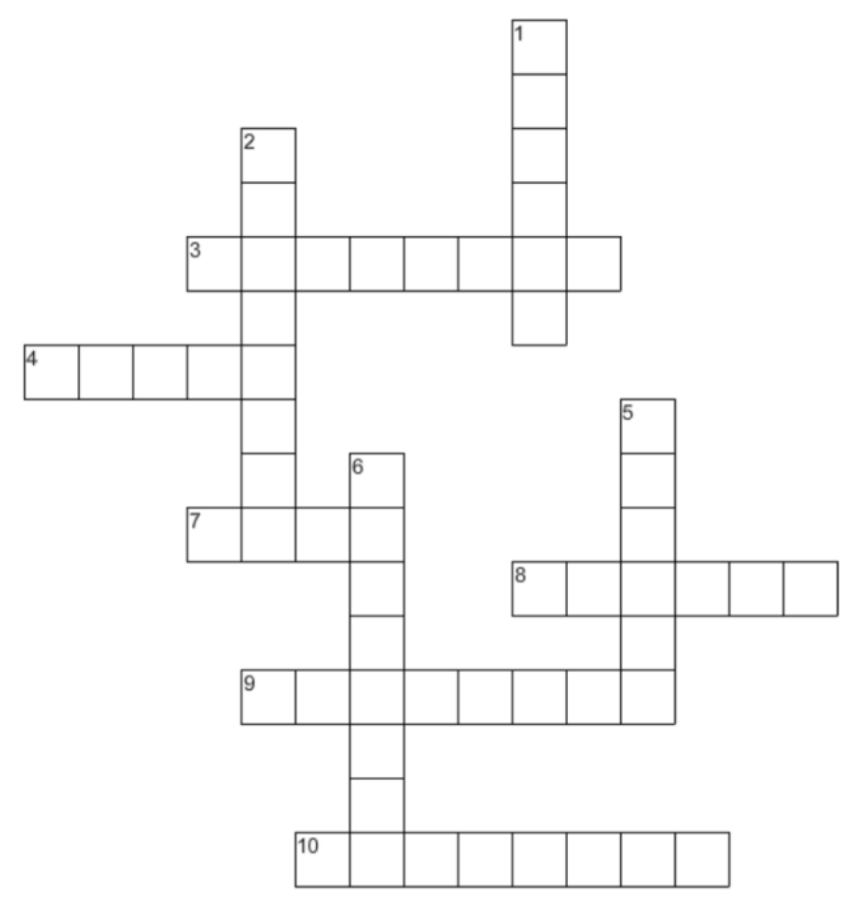

HORIZONTAL

3. Persona que se deja engañar fácilmente

4. Lugar en el que está enterrado un cadáver

7. Grupo de amigos

8. Volverse complicada una situación

9. Persona frustrada

10. Algo que sale muy mal

\section{VERTICAL}

1. Adjetivo que sirve para enfatizar lo que le sigue

2. Enriquecerse

5. Persona o cosa insoportable

6. Irse

3) En grupos de 5 o 6, vais a representar el vídeo que habéis visto pero lo tenéis que transformar de "informal" a "formal", como si se tratara de una situación real y no de un vídeo de humor. Al final, votaremos la representación que mejor haya hecho la adaptación. 


\subsection{Propuesta de actividades para la explotación de un programa de entretenimiento}

Tabla 16

Clasificación de la propuesta de actividades para la explotación de un programa de entretenimiento

\begin{tabular}{lll}
\hline Nivel del MCER & Competencias & Actividades comunicativas \\
\hline$\square$ A1 & \# Gramaticales & \# Compresión Oral \\
$\square$ A2 & \# Léxicas & \# Comprensión Escrita \\
$\square$ B1 & \# Socioculturales & \# Expresión Oral \\
\# B2 & \# Pragmáticas & \# Expresión Escrita \\
\# C1 & \# Estratégicas & \# Interacción Oral \\
$\square$ C2 & \# Discursivas & $\square$ Interacción Escrita \\
& & $\square$ Mediación Oral \\
& & \# Mediación Escrita
\end{tabular}

Fuente: elaboración propia

\subsubsection{Actividades de previsionado}

1) ¿Qué tipo de música te gusta? ¿Tocas algún instrumento musical? ¿A qué edad y dónde aprendiste?

2) Ayudándote de las imágenes, busca en esta sopa de letras vocabulario relacionado con la música.

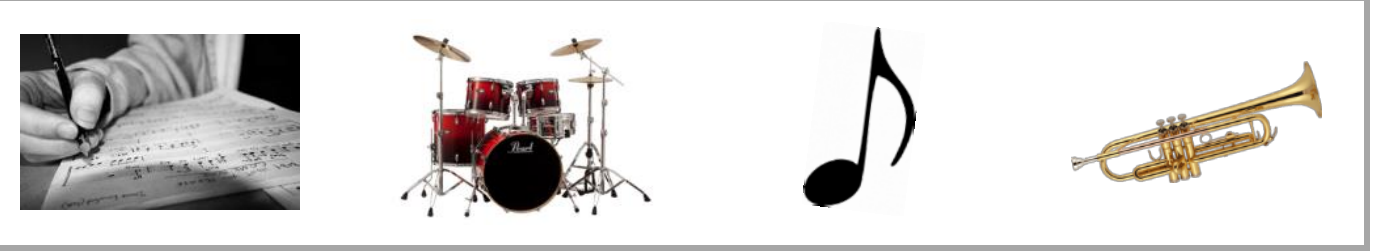




\section{$\xi$}
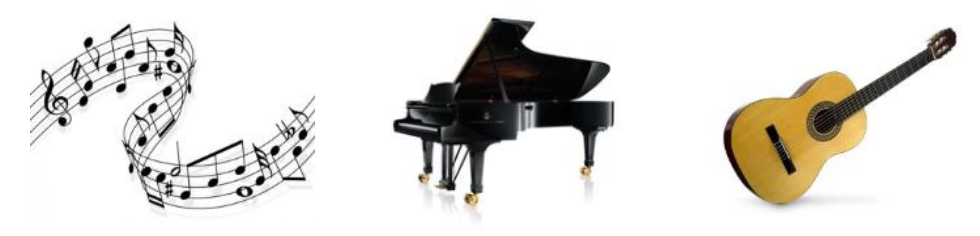

$\begin{array}{llllllllllllll}G & U & I & T & A & R & R & A & X & K & U & D & O & I \\ C & O & M & P & O & N & E & R & J & O & J & U & D & Y \\ D & O & E & E & C & N & S & D & Y & F & N & O & C & A \\ U & J & U & W & E & N & Q & W & Z & O & M & E & U & S \\ C & K & S & B & B & V & H & W & L & Y & N & U & Z & X \\ J & T & R & O & M & P & E & T & A & S & H & H & T & I \\ P & E & N & T & A & G & R & A & M & A & S & X & G & A \\ G & U & I & T & A & R & R & A & V & E & B & C & F & C \\ A & O & C & L & A & V & E & D & E & S & O & L & E & N \\ P & I & A & N & O & D & E & C & O & L & A & B & H & O \\ A & P & J & R & U & Q & G & E & Y & C & Z & M & A & Z \\ O & E & C & S & C & X & K & Z & N & N & Y & E & L & A \\ G & N & U & C & H & V & E & L & V & T & G & D & P & Y \\ B & A & T & E & R & I & A & C & O & R & C & H & E & A\end{array}$

3) Ahora lee el siguiente artículo ${ }^{101}$ relacionado con la música y realiza un resumen utilizando tus propias palabras. 


\section{¿Qué le hace la música a nuestro cerebro?}

"Somos lo que somos con la música y por la música", argumenta el autor, neurólogo y neurocientífico

\section{0}

FACUNDO MANES

BuenOS Aires 14 SEP 2015 - 11:39 CEST

Los seres humanos convivimos con la música en todo momento. Es un arte que nos hace disfrutar de tiempos agradables, nos estimula a recordar hechos del pasado, nos hace compartir emociones en canciones grupales, conciertos o eventos deportivos. Pero esto que resulta natural, se produce a través de complejos y sorprendentes mecanismos neuronales. Es por eso que desde las neurociencias nos hacemos muchas veces esta pregunta: ¿qué le hace la música a nuestro cerebro?

El área de la salud se vale de la música con el fin de mejorar, mantener o intentar recuperar el funcionamiento cognitivo, físico, emocional y social, y ayudar a lentificar el avance de distintos problemas de salud. La musicoterapia, a través de la utilización clínica de la música, intenta activar procesos fisiológicos y emocionales que permiten estimular funciones disminuidas o deterioradas. Se han observado importantes resultados en pacientes con trastornos del movimiento, dificultad en el habla producto de un accidente cerebrovascular, demencias, trastornos neurológicos y en niños con capacidades especiales, entre otros.

La música puede ser una herramienta poderosa en el tratamiento de trastornos cerebrales y lesiones adquiridas ayudando a los pacientes a recuperar habilidades lingüísticas y motrices, ya que activa a casi todas las regiones del cerebro. Estudios muestran que tanto al escuchar como al hacer música se estimulan conexiones en regiones cerebrales normalmente relacionadas con la emoción, la recompensa, la cognición, la sensación y el movimiento. Las nuevas terapias basadas en la música pueden favorecer la neuroplasticidad -nuevas conexiones y circuitos- que compensa en parte las deficiencias en las regiones dañadas del cerebro. La música anima a la gente a moverse con el ritmo. Cuanto más destacado es el ritmo, más radical es el movimiento del cuerpo. El ejercicio físico puede ayudar a mejorar la circulación, a proteger el cerebro y facilitar la función motora. La música induce estados de ánimo positivos y aumenta la excitación, lo que a su vez puede ayudar a la rehabilitación.

Emoción, expresión, habilidades sociales, teoría de la mente, habilidades lingüísticas y matemáticas, habilidades visoespaciales y motoras, atención, memoria, funciones ejecutivas, toma de decisiones, autonomía, creatividad, flexibilidad emocional y cognitiva, todo confluye en forma simultánea en la experiencia musical compartida. Las personas cantan y bailan juntas en todas las culturas. Sabemos que lo hacemos hoy 
y lo seguiremos haciendo en el futuro. Podemos imaginar que lo hacían también nuestros ancestros, alrededor del fuego, hace miles de años. Somos lo que somos con la música y por la música, ni más ni menos.

\subsubsection{Actividades durante el visionado}

Ahora vas a ver un vídeo de un extracto un talk-show emitido en la televisión española llamado El Hormiguero. En esta sección, vemos a su presentador, Pablo Motos, al famoso invitado al programa, Emilio Aragón, y a una niña.

Vídeo disponible en: https://www.youtube.com/watch?v=nkJeTtXRW_4

1) ¿Qué es lo que tiene que hacer el invitado? Señala la respuesta correcta.

\begin{tabular}{|l|l|}
\hline Tiene que componer una canción e interpretarla con el piano. & \\
\hline Tiene que tocar con el piano la canción que va a componer una niña. & \\
\hline $\begin{array}{l}\text { Tiene que ayudar a una niña a componer una canción y luego } \\
\text { interpretarla con el piano. }\end{array}$ & \\
\hline
\end{tabular}

2) Indica quién dice las siguientes frases, el presentador, el invitado o la niña. Después, comenta su forma, sentido y significado con tus compañeros y tu profesor. 


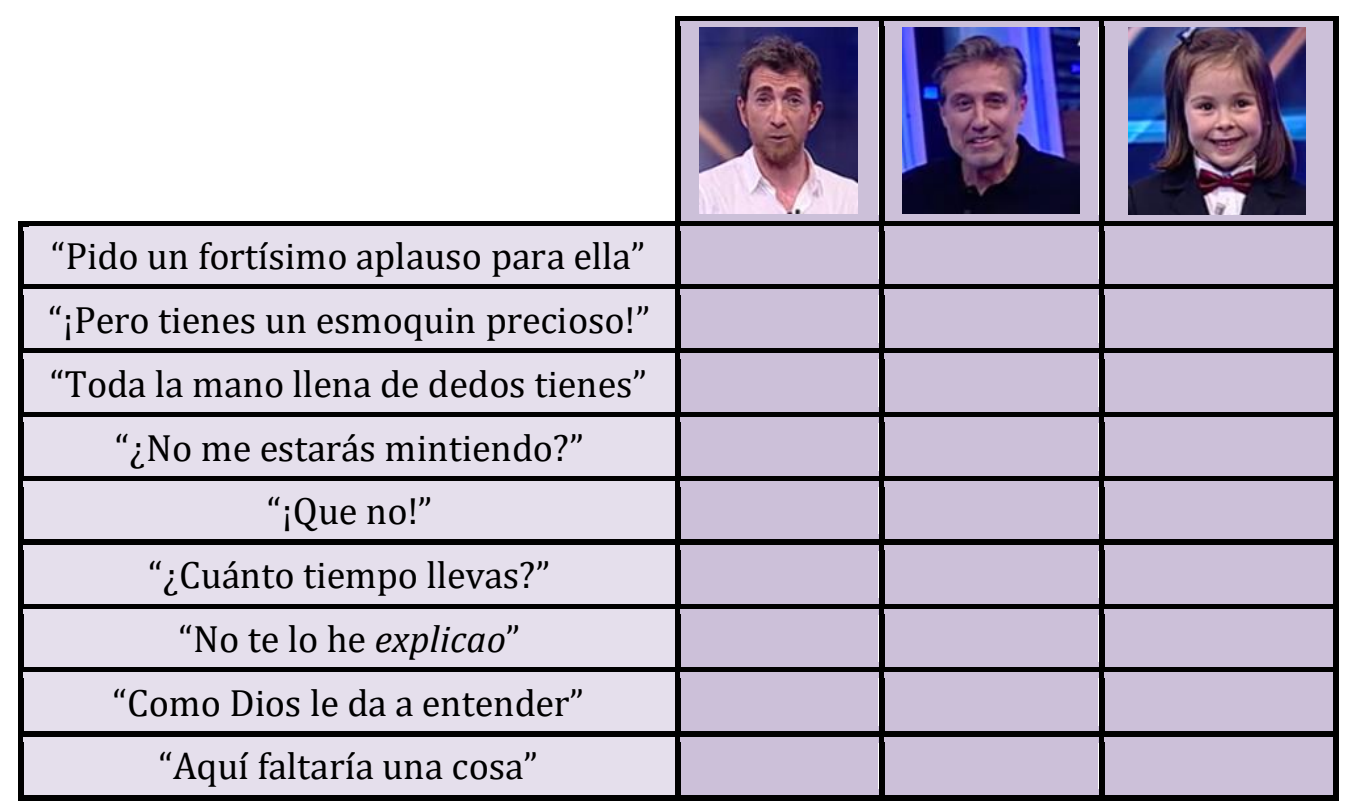

3) Hacia la mitad del vídeo, se escuchan unas voces diferentes, estas corresponden a los colaboradores del programa, llamados Trancas y Barrancas. Aquí tienes una foto de ellos, ¿sabes qué son? Si recuerdas el título del programa, podrás averiguarlo. Coméntalo con tus compañeros.

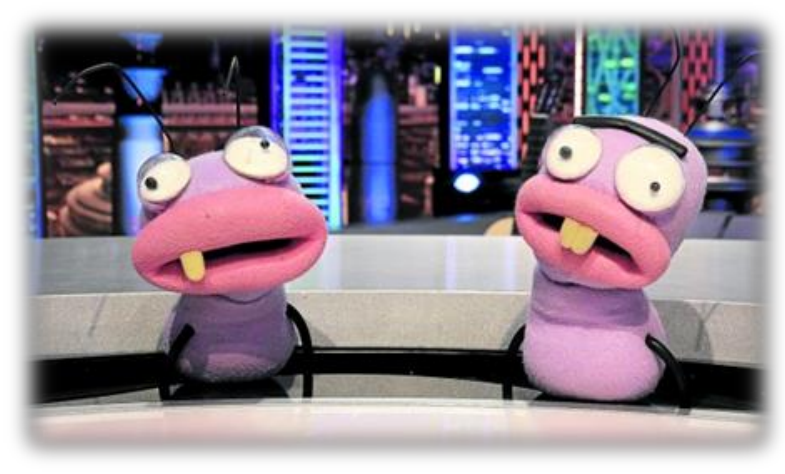

4) Trancas y Barrancas hacen algunos comentarios humorísticos. ¿Entiendes su sentido y significado? Coméntalo con tus compañeros y tu profesor. 


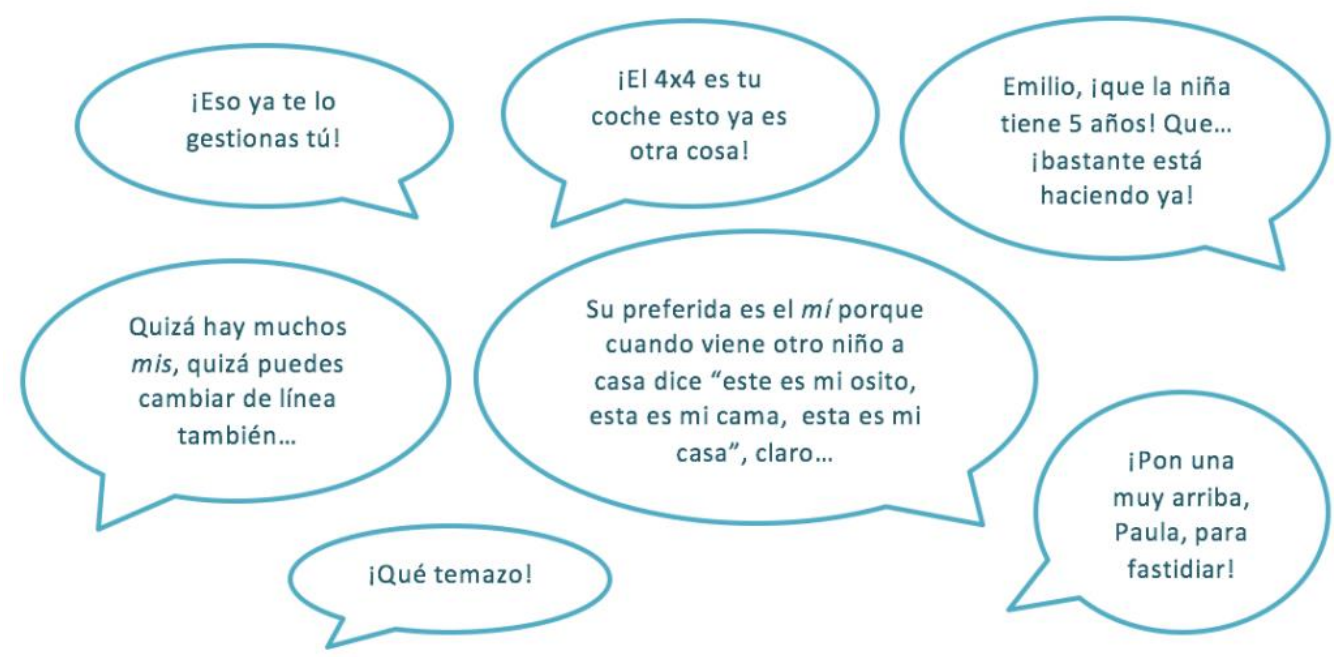

\subsubsection{Actividades de posvisionado}

1) En el vídeo, el presentador dice: "Emilio tiene que tocar lo que tú compongas" y "tú tienes que tocar lo que ella componga".

Como ya has estudiado, las formas componga y compongas están en presente de subjuntivo. Repasa este tiempo completando las siguientes frases.

$\checkmark \quad$ Mis padres quieren que (estudiar) medicina, pero yo prefiero estudiar derecho.

$\checkmark$ Espero que (tener) tiempo de venir a visitarme. Te echo de menos.

$\checkmark$ Le han pedido que (hacer) una presentación en la universidad.

$\checkmark$ Dudo que esta noche (poner) algo interesante en la tele.

$\checkmark$ A mis compañeros de piso les parece bien que mi hermana (dormir) unos días aquí.

$\checkmark$ Les alegra mucho que su hijo (ir) a vivir a Estados Unidos.

$\checkmark$ Mi entrenador me ha aconsejado que (comer) un poco más.

$\checkmark \quad$ Esperamos que este número nos (traer) buena suerte. 
PROPUESTAS DIDÁCTICAS PARA LA EXPLOTACIÓN DE PROGRAMAS

DE TELEVISIÓN EN CLASE DE ELE

$\checkmark$ No creo que ___ (sentir) nada de dolor, vamos a ponerle anestesia.

$\checkmark \quad$ Es posible que el tren (salir) con un poco de retraso.

2) ¡Ahora vosotros vais a ser los compositores, pero de una historia! Dividiremos la clase en grupos de 4-5 personas. Cada grupo escribirá seis palabras en un papel, con ellas, otro equipo tendrá que inventar y escribir una historia. El profesor recogerá y mezclará todos los papeles con las seis palabras y repartirá uno a cada grupo. Tendréis 20 minutos para escribir la historia. Después, cada grupo leerá la suya en alto y votaremos la que más nos haya gustado. 
EL PROGRAMA TELEVISIVO COMO RECURSO PARA LA

ENSEÑANZA/APRENDIZAJE DE ESPAÑOL LENGUA EXTRANJERA

\subsection{Propuesta de actividades para la explotación de un concurso de televisión}

Tabla 17

Clasificación de la propuesta de actividades para la explotación de un concurso de televisión

\begin{tabular}{lll}
\hline Nivel del MCER & Competencias & Actividades comunicativas \\
\hline$\square$ A1 & \# Gramaticales & \# Compresión Oral \\
$\square$ A2 & \# Léxicas & \# Comprensión Escrita \\
\# B1 & \# Socioculturales & \# Expresión Oral \\
\# B2 & \# Pragmáticas & \# Expresión Escrita \\
$\square$ C1 & \# Estratégicas & \# Interacción Oral \\
$\square$ C2 & \# Discursivas & $\square$ Interacción Escrita \\
& & $\square$ Mediación Oral \\
& & \# Mediación Escrita
\end{tabular}

Fuente: elaboración propia

\subsubsection{Actividades de previsionado}

1) ¿Te gustan los concursos de televisión? ¿Qué concursos de televisión son populares en tu país? ¿Cuáles son tus favoritos? ¿Por qué?

2) Relaciona las descripciones con el concurso de televisión al que corresponden ${ }^{102}$.

${ }^{102}$ Información e imágenes extraídas de http://www.tvguia.es/ 
PROPUESTAS DIDÁCTICAS PARA LA EXPLOTACIÓN DE PROGRAMAS

DE TELEVISIÓN EN CLASE DE ELE

\begin{tabular}{|c|c|c|}
\hline $\begin{array}{l}\text { Concurso gastronómico de tipo reality } \\
\text { show en el que un jurado compuesto por } \\
\text { tres chefs profesionales busca al mejor } \\
\text { cocinero amateur de España. }\end{array}$ & $\begin{array}{l}\text { Concurso de talentos que consiste en } \\
\text { elegir entre un grupo de concursantes a } \\
\text { aquellos que destaquen por sus } \\
\text { cualidades vocales sin que su imagen } \\
\text { influya en la decisión del jurado. }\end{array}$ & $\begin{array}{l}\text { Concurso diario en el que los tres } \\
\text { participantes deben demostrar sus } \\
\text { conocimientos y agilidad mental a la } \\
\text { hora de contestar a un auténtico } \\
\text { bombardeo de preguntas. }\end{array}$ \\
\hline $\begin{array}{l}\text { Concurso de tipo reality show en el que } \\
\text { diez parejas deben recorrer } 10.000 \mathrm{~km} \\
\text { para ganar un premio de } 100.000 \text { euros, } \\
\text { además del dinero que vayan } \\
\text { consiguiendo en cada etapa. }\end{array}$ & $\begin{array}{l}\text { Concurso en el que los participantes } \\
\text { intentan acumular segundos a lo largo } \\
\text { de diversas pruebas, con el fin de tener } \\
\text { más tiempo para la prueba final: El } \\
\text { Rosco. }\end{array}$ & $\begin{array}{l}\text { Programa en el que los participantes se } \\
\text { enfrentan en una lucha contra reloj. Si } \\
\text { no dan con la respuesta correcta en el } \\
\text { tiempo marcado, lo pierden todo y la } \\
\text { trampilla sobre la que están } \\
\text { posicionados se abre y caen al vacío. }\end{array}$ \\
\hline
\end{tabular}
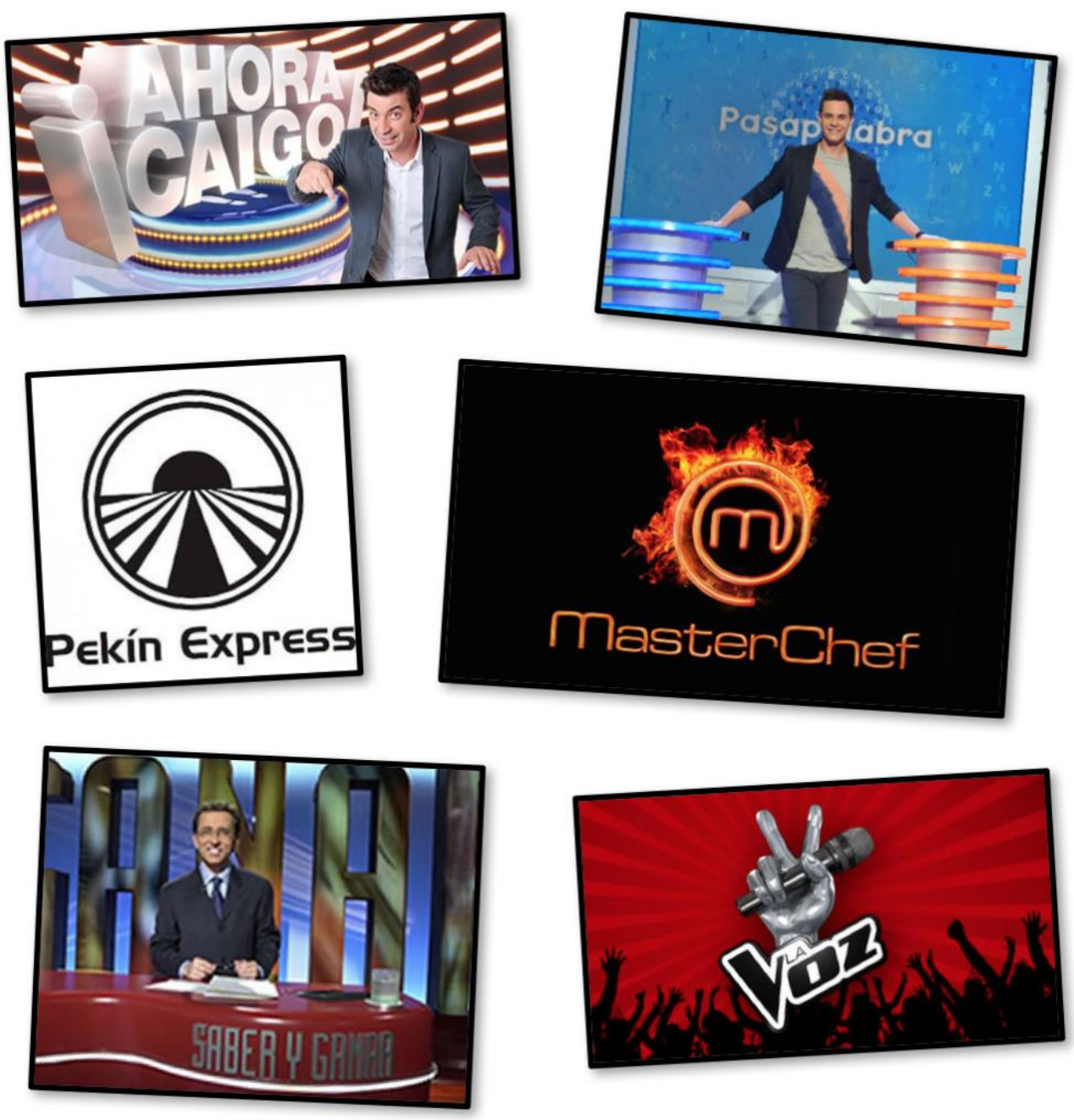
3) Lee el siguiente artículo ${ }^{103}$ sobre una de las ganadores de MasterChef en España y escribe un resumen de su entrevista transformando las frases en discurso directo (entrecomilladas) en discurso indirecto.

SERIES QUINTA TEMPORADA PROGRAMAS COMUNICACIÓN CRITICA TV AVANCES PROGRAMACIÓN TV

\section{Virginia, de "MasterChef: "Mi hija me apuntó al programa, ya no podré reñirle nunca más"}

La ganadora de la cuarta edición del programa cuenta que fue su niña quien la inscribió a escondidas tras una discusión con ella para alejarla de casa

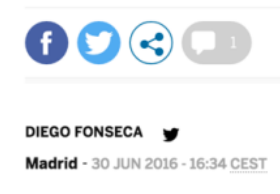

La nueva vida de Virginia empezó cuando Paula, su hija de 15 años, malhumorada y harta después de una riña de su madre, la apuntó en el programa mientras veía MasterChef Junior y en la pantalla de la televisión aparecía la información para presentarse como candidato. "Después de una discusión conmigo, mi niña, que estaba en una edad muy, muy difícil, lo que pensó fue: '¿Cómo me puedo quitar a mi madre de en medio? ¡Pues a MasterChef la mando, que son muchas semanas", bromea Virginia.

Lo que llegó después de que su pequeña le cogiese el móvil y el DNI a escondidas para apuntarla en un programa de la tele, terminó en la con un premio de 100.000 euros, un máster en el Basque Culinary Center y la publicación de su propio libro de recetas. "A mi niña ya le he dicho que no le voy a poder reñir más en la vida. Va a ser muy complicado echarle la bronca ahora", continúa Virginia, medio en broma, medio en serio.

Virginia no puede decir el momento exacto en el que comenzó su relación con la cocina. "A mí es que siempre me ha gustado comer y cocinar. Eso es muy importante, porque te tienen que gustar las dos cosas. Son un tándem. En las cenas familiares pensaba 'hoy voy a sorprender', y buscaba recetas en Internet, en libros, iba buscando y viendo que las cosas que iba haciendo me iban saliendo bien", cuenta. Su mayor metedura de pata en casa, recuerda, fue hace años, la primera vez

\footnotetext{
103 Adaptado de:

http://cultura.elpais.com/cultura/2016/06/30/television/1467283015_125593.html
} 


\section{PROPUESTAS DIDÁCTICAS PARA LA EXPLOTACIÓN DE PROGRAMAS \\ DE TELEVISIÓN EN CLASE DE ELE}

que intentó hacer sushi, y el arroz que salió estaba incomible: "Mi familia me preguntaba qué podíamos hacer con eso, si pegar carteles, si pintar la pared... Por eso yo siempre digo que la cocina es como un laboratorio, donde hay cosas que te salen estupendas y otras que más vale tirarlas".

Con el premio, a esta jerezana le gustaría montar su propia empresa, una firma de catering o de restaurantes, pero todavía sabe que le falta mucho para poder llevar bien su propio negocio.

\subsubsection{Actividades durante el visionado}

Ahora vas a ver un vídeo extraído de la versión española del famoso concurso de televisión MasterChef. En él, los miembros del jurado valoran el plato elaborado por uno de los concursantes del programa.

Vídeo disponible en: https://www.youtube.com/watch?v=6VS3PS4zMv8

1) ¿Cómo es la valoración de los jueces sobre el plato que ha elaborado el concursante?

\begin{tabular}{|l|l|l|l|l|l|l|l|}
\hline Muy mala & & Mala & & Buena & & Muy buena & \\
\hline
\end{tabular}


2) ¿Cuáles de estas frases dicen los miembros del jurado en el vídeo y cuáles no?

\begin{tabular}{|c|c|c|}
\hline & sí & NO \\
\hline \multicolumn{3}{|c|}{ "Este plato es el mejor plato que se ha cocinado en MasterChef } \\
\hline \multicolumn{3}{|l|}{ "Me parece un plato muy original" } \\
\hline \multicolumn{3}{|l|}{ "La idea es muy buena, pero se puede mejorar" } \\
\hline \multicolumn{3}{|l|}{ "Me encanta el picante" } \\
\hline \multicolumn{3}{|l|}{ "Me guardo el pan para el siguiente plato" } \\
\hline \multicolumn{3}{|l|}{ "Has logrado un muy buen mousse y está superrico" } \\
\hline \multicolumn{3}{|l|}{ "Quizá está un poco picante para mi gusto" } \\
\hline \multicolumn{3}{|c|}{ "Es uno de los mejores platos que he probado en mi vida" } \\
\hline \multicolumn{3}{|l|}{ "Pero tú sabes que esto está muy bueno" } \\
\hline \multicolumn{3}{|l|}{ “Cocinando así, llegarás a la final” } \\
\hline "A mí me gusta el sabor ese ácido a limón" & & \\
\hline
\end{tabular}

3) Algunas de las expresiones que has escuchado en el vídeo son un poco coloquiales, aquí tienes las palabras que necesitas para completarlas. Después, comenta su sentido y significado con tus compañeros y tu profesor.

\begin{tabular}{|c|c|c|c|c|c|}
\hline chispa & flojo & subidón & mula & afilado & rollo \\
\hline crack & cazurro & soy & enrollar & descarao & chapó \\
\hline
\end{tabular}

o "Y tú , que eres más que nadie...”

○ "Si es que eres un $"$

○ "La haces a tu " 
PROPUESTAS DIDÁCTICAS PARA LA EXPLOTACIÓN DE PROGRAMAS

DE TELEVISIÓN EN CLASE DE ELE

○ "Yo súper de limón, de vinagre... me gusta que tenga

○ "No me voy a más,

○ “¿Me crees un ?

○ "Pero ay amigo... el paladar lo tengo muy

○ "Esto es un

○ "Eres un auténtico

4) Fíjate en la pronunciación de la palabra 'descarado'. ¿En qué zonas de España crees que se pronuncia así? ¿Crees que depende de la formalidad de la situación?

5) Cuando el último de los miembros del jurado procede a valorar el plato del concursante, todos ríen. ¿Has entendido la broma que surge entre el concursante y el miembro del jurado? Coméntalo con tus compañeros y tu profesor.

\subsubsection{Actividades de posvisionado}

1) Ahora vosotros vais a ser el jurado. El plato que ves en esta imagen fue presentado en uno de los programas de MasterChef por uno de sus concursantes, quien lo llamó "León come gamba". Escribe en el bocadillo lo que le habrías dicho tú, como juez, al concursante. 
EL PROGRAMA TELEVISIVO COMO RECURSO PARA LA

ENSEÑANZA/APRENDIZAJE DE ESPAÑOL LENGUA EXTRANJERA
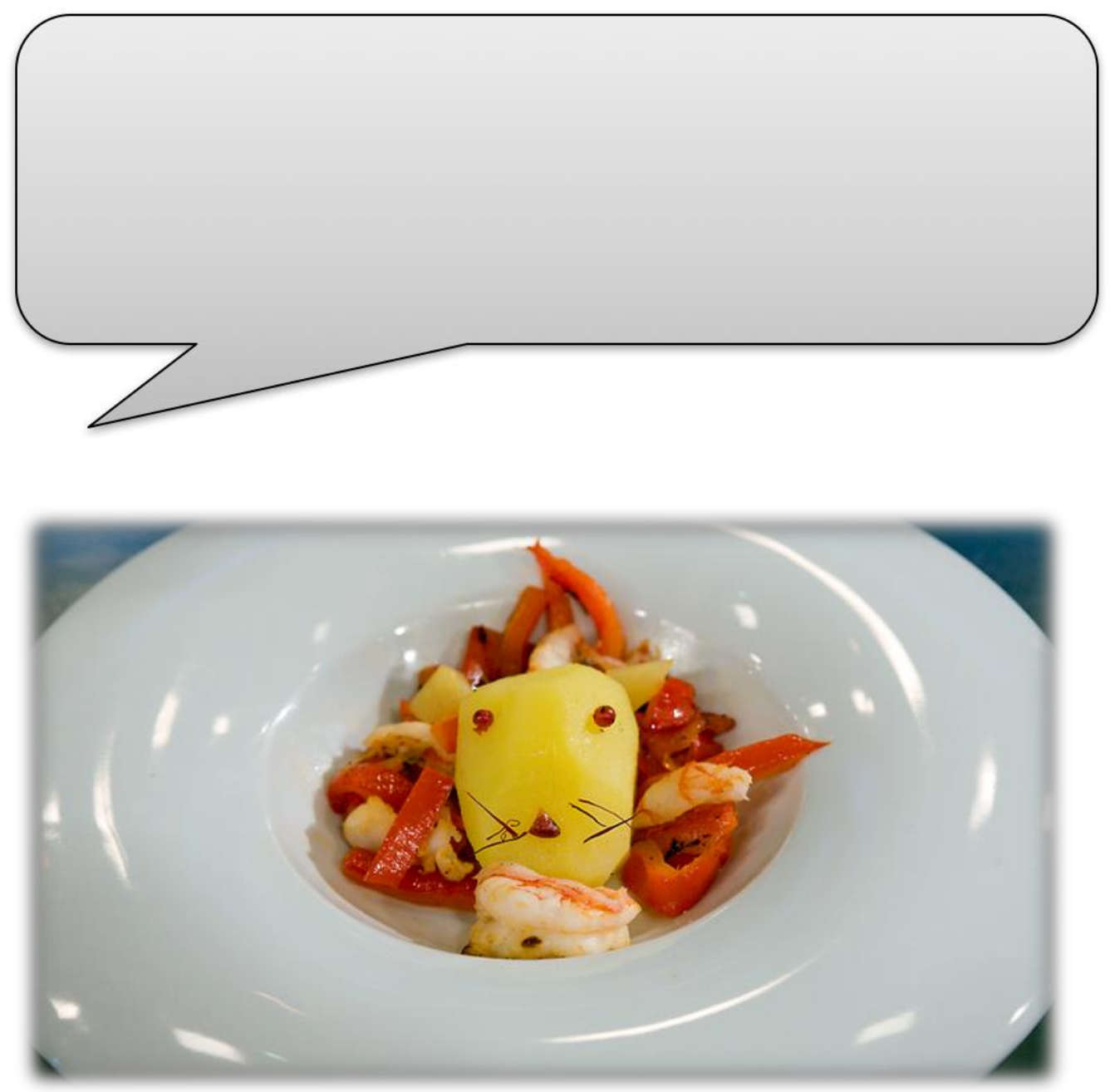

Fuente: rtve.es

2) En grupos de cuatro, vais a diseñar un concurso de televisión que nunca antes se haya visto. Tenéis que decidir:

$\checkmark$ ¿Cómo se llamaría?

$\checkmark$ ¿En qué consistiría y dónde se desarrollaría?

$\checkmark$ ¿Cuántos concursantes habría y cuál sería su perfil?

$\checkmark$ ¿Cómo serían eliminados los concursantes?

$\checkmark$ ¿Cuál sería el premio final? 
PROPUESTAS DIDÁCTICAS PARA LA EXPLOTACIÓN DE PROGRAMAS DE TELEVISIÓN EN CLASE DE ELE

Para explicar todo esto, haréis una presentación de unos 2 minutos en clase. Después, todos votaremos la propuesta que más nos haya gustado. 
EL PROGRAMA TELEVISIVO COMO RECURSO PARA LA

ENSEÑANZA/APRENDIZAJE DE ESPAÑOL LENGUA EXTRANJERA

\subsection{Propuesta de actividades para la explotación de una emisión puntual}

Tabla 18

Clasificación de la propuesta de actividades para la explotación de una emisión puntual

\begin{tabular}{lll}
\hline Nivel del MCER & Competencias & Actividades comunicativas \\
\hline$\square$ A1 & \# Gramaticales & \# Compresión Oral \\
$\square$ A2 & \# Léxicas & \# Comprensión Escrita \\
\# B1 & \# Socioculturales & \# Expresión Oral \\
\# B2 & \# Pragmáticas & \# Expresión Escrita \\
$\square$ C1 & \# Estratégicas & \# Interacción Oral \\
$\square$ C2 & \# Discursivas & $\square$ Interacción Escrita \\
& & $\square$ Mediación Oral \\
& & \# Mediación Escrita
\end{tabular}

Fuente: elaboración propia

\subsubsection{Actividades de previsionado}

1) ¿Cómo y dónde sueles celebrar la noche de fin de año? ¿Lo haces con tu familia o con tus amigos? ¿Es una noche especial para ti? ¿Por qué?

2) ¿Hay alguna tradición especial en tu país para esa noche? Cuéntaselo a tus compañeros. Después, intenta adivinar a qué países corresponden las siguientes tradiciones ${ }^{104}$. 104 Adaptado de: http://listas.20minutos.es/lista/como-se-celebra-el-fin-de-ano-en-diferentes-
paises-267097/ 


\section{PROPUESTAS DIDÁCTICAS PARA LA EXPLOTACIÓN DE PROGRAMAS DE TELEVISIÓN EN CLASE DE ELE}

Aquí algunas personas han adoptado la tradición de comer

lentejas en el momento de la medianoche. Hay muchas tradiciones, una de ellas es la quema de monigotes, que consiste en que durante la medianoche del cambio de año se quema un monigote realizado con materiales desechables, principalmente papel y ropa vieja. Esta costumbre se da especialmente en las regiones del norte de este país.

Los habitantes de este país cantan, bailan y se divierten hasta altas horas de la madrugada para despedir el año, claro que ellos combinan estas celebraciones con algunas tradiciones peculiares. Hay quien acostumbra a barrer la casa esa noche para que el nuevo año solo traiga suerte "limpia"; otros aseguran que pasearse esa noche con una maleta favorecerá los viajes en los meses siguientes; otros insisten en llevar ropa interior roja para encontrar el amor.

No importa dónde o con quién te pille la Nochevieja. Lo que más cuenta es lograr comer doce uvas al ritmo de las doce campanadas que indican la llegada del nuevo año. Y es que la tradición asegura que quien complete la operación sin atragantarse tendrá suerte en los doce meses siguientes. Como acompañamiento, una copita de cava para brindar por el Año Nuevo y ayudar a pasar mejor las uvas.

En este país el año nuevo se celebra comiendo doce uvas a las 12 de la noche del 1 de Enero. Se queman los tradicionales "años viejos", que consiste en escribir y quemar las cosas malas que pasaron en el 2010. Hay fuegos artificiales, especialmente a las doce (llamado "La hora de la Luz") y también se hacen desfiles de coches decorados con el tema del año nuevo.

La tradición manda despedir el año con fuego. Por una parte, están los cohetes y demás elementos pirotécnicos; por otra, los muñecos de madera, tela y papel, que los habitantes de este país

construyen con la mejor de las intenciones pese a saber que acabarán siendo pasto de las llamas; y es que quemar estos muñecos es un rito purificador, una forma de deshacerse de todo lo malo que ha traído el año que acaba.

Nochevieja es el momento perfecto para que los habitantes de este país estrechen lazos de amistad con quienes les rodean. Y nada mejor que la "hallaca", un plato especial que ellos mismos preparan. Regalarlo es una forma de desear buena suerte para el año que llega. También es costumbre escribir los deseos en una carta que, ya en enero, cada uno quema para asegurarse de que nadie más pueda leerla.

\section{VENEZUELA}

\section{ARGENTINA Y URUGUAY}

\section{PERÚ}




\section{EL PROGRAMA TELEVISIVO COMO RECURSO PARA LA \\ ENSEÑANZA/APRENDIZAJE DE ESPAÑOL LENGUA EXTRANJERA}

En este país es tradición crear muñecos o monigotes que representan el año viejo. Cuando llega la medianoche, se suele quemar uno de estos monigotes y se lee su testamento. Está celebración suele estar acompañada de fuegos artificiales (los populares "castillos", estructuras de madera llenas de artefactos

COLOMBIA pirotécnicos).También se debe llevar ropa interior de color amarillo y del revés.

El 31 de diciembre, en este país los protagonistas son los agüeros, o lo que es lo mismo, una serie de tradiciones populares destinadas a cargar las pilas con energía positiva para el año que comienza. Las hay para todos los gustos: recibir la medianoche de pie para tener suerte y salud; dar un portazo cuando el reloj da las doce para alejar de la casa a los malos espíritus; o besar en primer lugar a una persona del sexo opuesto para obtener buena fortuna.

3) Quizás te estarás preguntando cuál es el origen de la tradición de comer doce uvas la noche de fin de año. ¡Lee el siguiente artículo105 para averiguarlo! Después, imagina que has pasado la noche de fin de año en España y escribe una postal a un amigo para contarle cómo ha sido y desearle un feliz año nuevo.

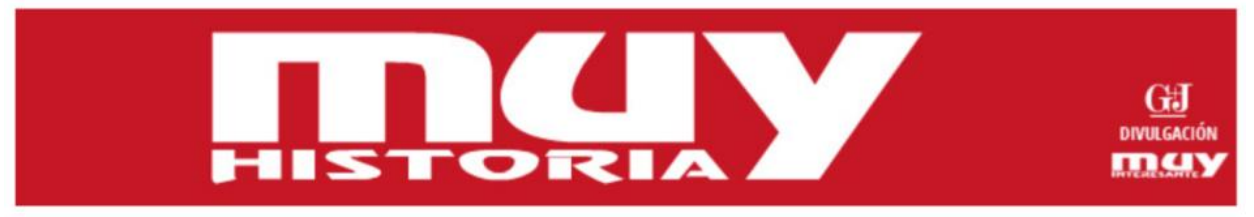

\section{¿Por qué tomamos doce uvas en Nochevieja?}

Las doce uvas "de la suerte" comenzaron a tomarse de manera masiva en España en la Nochevieja de 1909, ante un excedente de la cosecha en Alicante. Sin embargo ya en el siglo XIX existía la costumbre entre los burgueses españoles de comer uvas y brindar con champán para despedir el año.

Las doce uvas "de la suerte" comenzaron a tomarse de manera masiva en España en la Nochevieja de 1909, debido a un excedente de la cosecha en Alicante. Sin embargo ya en el siglo XIX existía la costumbre entre los burgueses españoles de comer uvas y brindar con champán para despedir el año.

105 Extraído de: http://www.muyhistoria.es/curiosidades/preguntas-respuestas/ipor-quetomamos-doce-uvas-en-nochevieja\# 


\section{PROPUESTAS DIDÁCTICAS PARA LA EXPLOTACIÓN DE PROGRAMAS \\ DE TELEVISIÓN EN CLASE DE ELE}

Según la tradición, en la mesa se colocan 12 uvas delante de cada comensal que simbolizan los 12 meses del año y que deben comerse con cada una de las campanadas del reloj.

En otros países también existen alimentos típicos para dar la bienvenida al nuevo año. En Grecia suelen cocinar un pastel llamado Vassilopitta en cuyo interior se coloca una moneda de oro o de plata. El que encuentre la moneda en su plato será la persona con más buena suerte en el año que se avecina. Y en Italia y algunos países sudamericanos es tradición comer un plato de lentejas estofadas tras las campanadas de media noche para atraer la prosperidad y la fortuna en el año entrante.

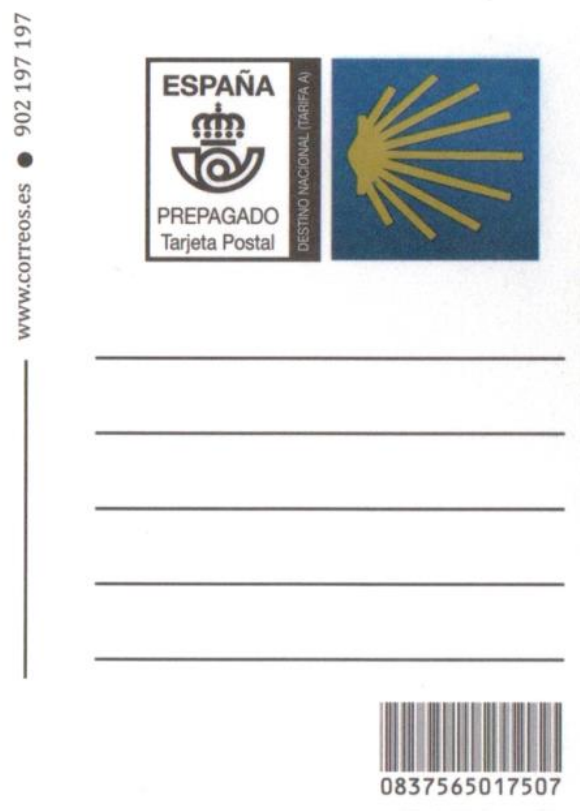

\subsubsection{Actividades durante el visionado}

Ahora vais a ver un vídeo extraído del programa que ven cada 31 de diciembre por la noche los españoles en sus casas: las Campanadas de fin de año.

Vídeo disponible en: https://www.youtube.com/watch?v=uIJCJqzVQvk

1) Completa las siguientes frases extraídas del vídeo.

$\checkmark \quad$ Ese reloj de la 
EL PROGRAMA TELEVISIVO COMO RECURSO PARA LA

ENSEÑANZA/APRENDIZAJE DE ESPAÑOL LENGUA EXTRANJERA

$\checkmark$ Si alguien se despista, que no se

$\checkmark$ Un consejo en casa, vayan

$\checkmark$ Algunas niñas esta mañana me han dicho que

$\checkmark 30$ segundos aproximadamente para que ese carillón empiece a

$\checkmark$ Atención porque va a bajar la bola.

$\checkmark$ Estamos cambiar de año y dar la

al 2016 .

$\checkmark$ Decía que se acuerden si quieren de poner el pie

$\checkmark$ Ahora los

$\checkmark$ Para todos ustedes este primer

2) La noche de Fin de Año, también es tradición llevar un vestido o un traje "de fiesta". Describe con detalle cómo van vestidos los presentadores.

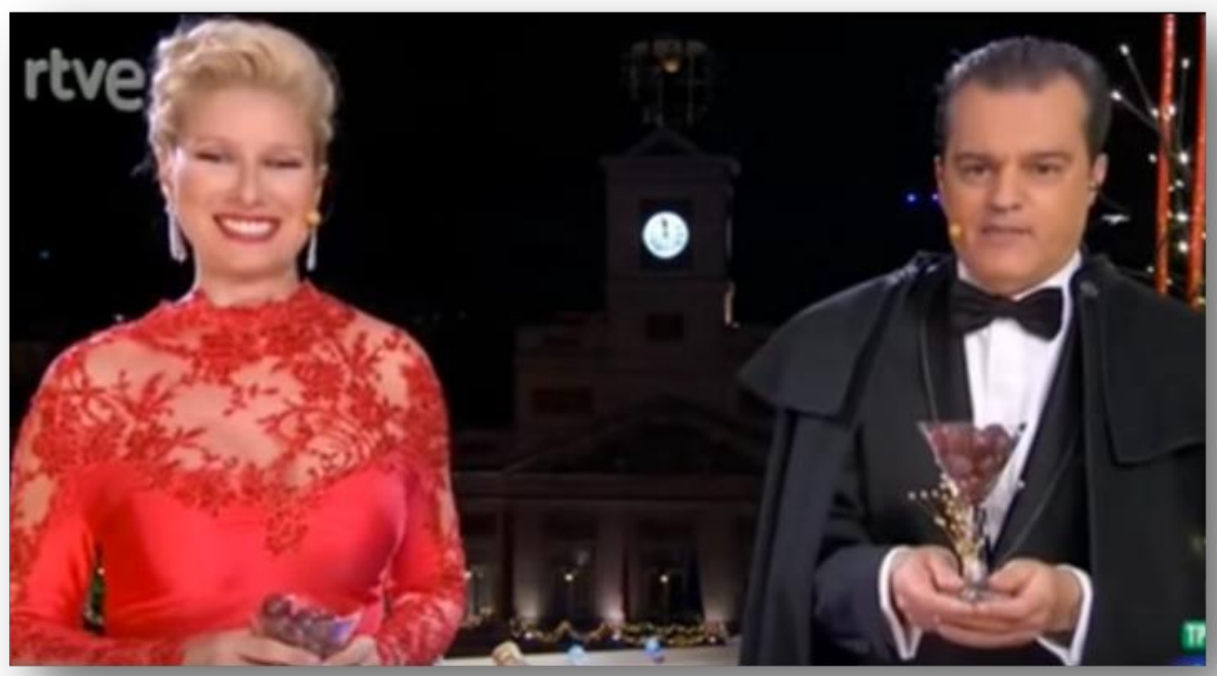

\section{La presentadora lleva....}




\subsubsection{Actividades de posvisionado}

1) Completa este crucigrama con el vocabulario que has aprendido.

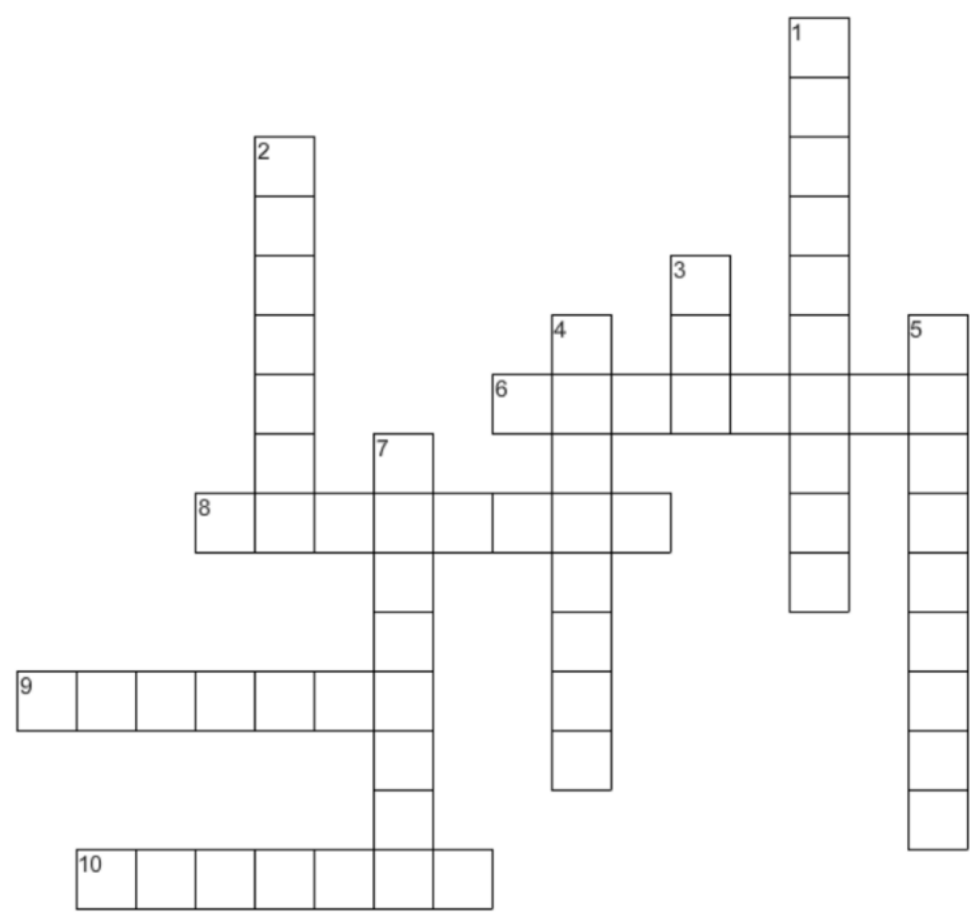

HORIZONTAL

6. Corbata que se anuda en forma de lazo corto.

8. Prenda masculina de etiqueta.

9. Vino espumoso, blanco o rosado, originario de Francia.

10. Manifestar, al beber una bebida alcohólica, el bien que se desea a alguien.
1. Última noche del año.

2. Cuatro campanadas que suenan los últimos 4 segundos antes de comenzar las 12 .

3. Fruto de la vid, que forma racimos.

4. Grupo de campanas en una torre. 
EL PROGRAMA TELEVISIVO COMO RECURSO PARA LA

ENSEÑANZA/APRENDIZAJE DE ESPAÑOL LENGUA EXTRANJERA

5. Sonido producido por una campana.

7. Golosina blanda masticable,

generalmente recubierta de azúcar.

2) Ahora, en parejas de dos, vais a grabar un vídeo de unos 2 minutos como si fuerais los presentadores del programa de Fin de Año en España. Tendréis que explicar a la audiencia en qué consisten las doce campanadas, representar ese momento, brindar, y desear un feliz año a los espectadores. Después, veremos los vídeos en clase y votaremos el que más nos haya gustado. 


\subsection{Propuesta de actividades para la explotación de un programa de humor}

Tabla 19

Clasificación de la propuesta de actividades para la explotación de un programa de humor

\begin{tabular}{lll}
\hline Nivel del MCER & Competencias & Actividades comunicativas \\
\hline$\square$ A1 & \# Gramaticales & \# Compresión Oral \\
$\square$ A2 & \# Léxicas & \# Comprensión Escrita \\
$\square$ B1 & \# Socioculturales & \# Expresión Oral \\
$\square$ B2 & \# Pragmáticas & \# Expresión Escrita \\
\# C1 & \# Estratégicas & \# Interacción Oral \\
\# C2 & \# Discursivas & $\square$ Interacción Escrita \\
& & $\square$ Mediación Oral \\
& & $\square$ Mediación Escrita
\end{tabular}

\subsubsection{Actividades de previsionado}

1) Lee el siguiente texto ${ }^{106}$ y asigna uno de los títulos que hay en el recuadro a cada uno de los párrafos.

\begin{tabular}{|c|c|c|c|c|}
\hline $\begin{array}{l}\text { La } \\
\text { exageración }\end{array}$ & $\begin{array}{l}\text { La comedia } \\
\text { es ritmo }\end{array}$ & $\begin{array}{l}\text { breve dos } \\
\text { veces bueno }\end{array}$ & La actualidad & $\begin{array}{c}\text { Escribir para } \\
\text { otros }\end{array}$ \\
\hline Las rimas & $\begin{array}{l}\text { Conectar con } \\
\text { el público }\end{array}$ & $\begin{array}{l}\text { La risa } \\
\text { sincera }\end{array}$ & El toque fin & $\begin{array}{l}\text { La ve } \\
\text { nos ha }\end{array}$ \\
\hline
\end{tabular}

\footnotetext{
${ }^{106}$ Adaptado de: http://www.miproyectopersonal.es/guia-para-escribir-monologos-comicos-en10-pasos/\#
} 


\section{CÓMO HACER UN BUEN MONÓLGO EN 10 PASOS}

Un chiste solo es divertido si eres capaz de entenderlo. A la hora de escoger un tema para un monólogo, conviene que sea una experiencia compartida por la mayoría de los espectadores, así se sentirán identificados y será más fácil que les enganche la historia. Si hablamos de cosas muy específicas corremos el riesgo de que mucha gente no entienda la broma, por muy buena que sea.

En la mayoría de programas de humor que se pueden ver hoy en televisión se usan temas o personajes de actualidad para satirizarlos o verlos desde una perspectiva cómica. Esto es una buena idea que encaja con el punto anterior, ya que mientras ese personaje o tema está de moda, es conocido por un gran número de personas. El problema de los temas o personajes de actualidad es que pasan de moda con rapidez, y lo que es gracioso hoy puede que no lo sea en unos meses; esto es lo que se llamaría "material de usar y tirar".

No hay un máximo en lo exagerado que puedes ser en tus comparaciones, llévalas al límite y cuando creas que no puedes exagerar más, ¡exagéralo todavía más!, no hay tope con esta regla porque no hay exageración demasiado exagerada; la única norma es que resulte gracioso.

Esta idea es en la que se basan todos los programas de vídeos caseros de tortas, caídas y resbalones. El padre enseña al niño a jugar al béisbol y el niño intenta golpear la bola con toda su fuerza pero lo único que consigue es golpear la entrepierna de su padre. Sí, sentimos pena por el padre, pero nos reímos. Esta estructura se encuentra en la mayoría de chistes y bromas que contamos o escuchamos todos los días, sin embargo, no necesariamente tiene que tener un contenido sádico.

Si consigues incluir rimas dentro de tu monólogo conseguirás hacerlo entre un 5 y un $10 \%$ más divertido; vale, no es mucho, ipero es mejor que nada! Aunque no hay que confundirse, se trata de hacer reír y, aunque la rima nos puede ayudar, en algunos casos no podemos restarle espacio a los chistes. Así que, como norma general, debemos usar la rima solo si ayuda al efecto cómico.

Tanto en monólogos, como en sketch como en películas o programas de televisión de humor, observaréis que funcionan con un ritmo rápido o muy rápido. El ritmo es la esencia de la comedia y en la medida que aprendas a controlarlo llegarás a la maestría de este arte. El caso de los monólogos funciona igual, normalmente apuran la sonrisa conseguida con un gag para unirlo con el siguiente, consiguiendo un efecto cómico y de sorpresa más grande. 


\section{PROPUESTAS DIDÁCTICAS PARA LA EXPLOTACIÓN DE PROGRAMAS DE TELEVISIÓN EN CLASE DE ELE}

Para comprobar si el texto que estoy escribiendo resulta gracioso uso mi honestidad y mi propia risa. Es muy fácil, cojo el texto en cuestión, lo leo con tranquilidad y en voz alta y si lo que estoy leyendo me hace sonreír quiere decir que funciona (si me hace reír a mí, puede que funcione con otra persona ¿no?) Sin embargo, si me resulta monótono, difícil de explicar o es demasiado lento, es el momento de una revisión y un recorte del texto.

Esta es otra de esas verdades universales de las que no es fácil escapar. Si tienes un texto de 20 minutos que no es muy gracioso, intenta reducirlo a 10 minutos o incluso a 8 intentando conservar todos sus gags. No te garantizo que tu producto se vuelva un $200 \%$ más gracioso, solo te puedo decir que seguro que se vuelve más divertido y, por lo menos, sí te puedo asegurar que lo que has conseguido es hacerlo un 50\% menos aburrido; lo que tus espectadores te agradecerán.

Si escribes para otros intenta estar presente cuando el actor dé vida al texto porque comprobar la calidad de tu producto también es parte del trabajo. Si es posible, retoca el texto después de cada función hasta que quede completamente "redondo". Para esto es importante escuchar al actor y al público. Si escribes para interpretarlo tú mismo la cosa es más fácil, pues siempre tendrás la libertad de cambiar o modificar lo que has escrito, además de comprobar de una manera más real si tu creación "funciona".

La reescritura es parte de este trabajo y repasar, modificar y afinar es nuestro pan de cada día. A veces tienes que dejar fuera gags o ideas que te resultaban geniales porque, al final, tienes que pensar en el resultado como "producto" más que en tu propia satisfacción. No tengas miedo de borrar y escribir de nuevo por que todo ello servirá para mejorar tu producto final.

2) Aquí tienes la biografía 107 de Eva Hache, una famosa humorista española a la que luego veremos interpretar un monólogo. Adivina las palabras que han sido eliminadas del texto.

\section{Eva Hache}

Eva María Hernández Villegas, conocida Eva

Hache (Segovia, 7 de agosto de 1972) es una actriz, cómica y presentadora de televisión española. Vivió

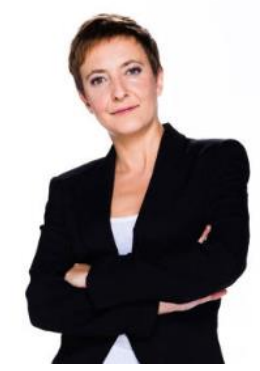

${ }^{107}$ Adaptada de: http://hoycinema.abc.es/perfil-cine/eva-hache-128616/biografia.html 


\section{EL PROGRAMA TELEVISIVO COMO RECURSO PARA LA ENSEÑANZA/APRENDIZAJE DE ESPAÑOL LENGUA EXTRANJERA}

los siete años en Valdepeñas (Ciudad Real) y varios años $\mathrm{Su}$ juventud en Cuéllar (Segovia). estudiar Filología inglesa, su carrera como actriz se inició teatro. Representó obras clásicas la compañía del director Juan Antonio Quintana en el Aula de Teatro la Universidad de Valladolid. Tras cuatro años trabajo, decidió tomarse una temporada viajar el mundo. Consiguió participar monologuista en algunos programas de la cadena humorística Paramount Comedy, hasta en 2003 ganó el IV Certamen de Monólogos de El club de la comedia. En 2005 ganó el Premio Iris (concedido la Academia de la Televisión), la categoría de Mejor Comunicadora de Programas de Entretenimiento. Ese año, también fue nominada al TP de Oro (premio otorgado mediante votación de la audiencia) Mejor Presentadora de Programas de Entretenimiento. En enero de 2011, comenzó presentar en La Sexta nueva edición de El Club de la Comedia, precisamente el programa de monólogos Eva se hizo famosa.

\subsubsection{Actividades durante el visionado}

Ahora vais a ver un vídeo extraído del programa de televisión español $E l$ club de la comedia en el que la presentadora del programa realiza un monólogo.

Vídeo disponible en: https://www.youtube.com/watch?v=mx_DfIklOac

1) ¿Cuál crees que es el título de este monólogo? Selecciona la respuesta correcta.

\begin{tabular}{|l|l|}
\hline Nuestros padres siempre se quejan de nuestra forma de vestir & \\
\hline Nuestros padres nunca dejarán de tratarnos como niños & \\
\hline Nuestros padres siempre quieren elegir nuestro trabajo & \\
\hline
\end{tabular}


2) Según la humorista, ¿qué es lo que siempre dice la madre cuando la hija va a comer a casa?

3) Según la humorista, ¿qué es lo que siempre dicen el padre sobre la forma de vestir de la hija?

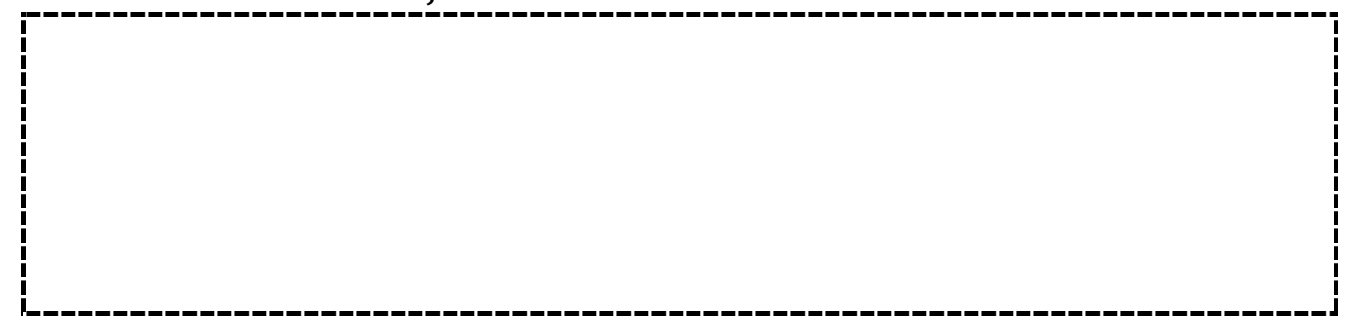

4) ¿Por qué la humorista menciona las profesiones de notario y controlador aéreo?

5) Completa las siguientes frases extraídas del monólogo y comenta su forma y significado con tus compañeros y tu profesor.

$>$ Tu madre, , te va a decir: ¡cómete eso!

$>$ iQue en ná, raquítica perdida, que

$>$ Yo, , he llegado a comerme la fruta sin pelar.

$>$ Un padre ¡tápate, tápate, tápate! 
Desde la maternidad ya

bombones.

Ya con eso toda tu existencia.

Yo no voy a ser la típica madre pesada que vaya a estar todo el día ahí insistiendo y para que sea notario.

Este se hace controlador aéreo

Eva.

\subsubsection{Actividades de posvisionado}

1) ¿Qué opinas del tema del monólogo? ¿Estás de acuerdo con lo que cuenta la humorista? Coméntalo con tus compañeros.

2) Ahora vosotros, individualmente, vais a escribir y ensayar un monólogo de unos dos minutos para presentarlo en clase. Tendréis que elegir un tema y un título e intentar seguir los consejos que habéis leído antes. Después, haremos nuestro propio programa de monólogos y al final votaremos los que más nos hayan gustado. 


\section{ESTUDIOS EMPÍRICOS}




\section{EL PROGRAMA TELEVISIVO COMO RECURSO PARA LA \\ ENSEÑANZA/APRENDIZAJE DE ESPAÑOL LENGUA EXTRANJERA}

\subsection{Estudio empírico de la propuesta didáctica para la explotación de un programa de cocina}

Con el objetivo de demostrar la efectividad de una de las propuestas didácticas dirigidas a estudiantes de español de nivel básico presentadas en esta tesis —en este caso la propuesta didáctica para la explotación de un programa televisivo de cocina ${ }^{108}$ —, se llevó a la práctica una serie de actividades en dos clases de dos cursos de español de nivel básico en la universidad West Virginia University $^{109}$.

Para realizar este estudio empírico en Estados Unidos fue necesario contar con la aprobación del Institutional Review Board (IRB) ${ }^{110}$ y del Department of World Languages, Literatures, and Linguistics ${ }^{111}$ de la universidad ${ }^{112}$.

Esta propuesta se llevó a cabo al final del semestre de primavera en dos cursos de nivel básico no inicial. Estos cursos se imparten tres días a la semana en clases de cincuenta minutos. Por ello, fue necesario adaptar este estudio empírico a dicha duración. Los cincuenta minutos de la clase se distribuyeron de la siguiente forma: durante los cinco primeros minutos, los alumnos completaron un cuestionario ${ }^{113}$ online, diseñado a través de Google Docs, cuyas preguntas intentaban sondear, en primer lugar, su nivel de consumo habitual de programas televisivos en su lengua materna; y en segundo, lugar, sus hábitos y experiencia en cuanto al visionado de programas televisivos en español. La propuesta didáctica $^{114}$ —actividades de previsionado y actividades durante el visionado ${ }^{115}$ - se llevó a cabo durante los cuarenta minutos siguientes. Aunque las actividades se realizaron en grupo por cuestiones de tiempo, cada alumno fue completando su hoja de preguntas individualmente. Finalmente, durante los

\footnotetext{
108 Véase el apartado 7.6. Propuesta de actividades para la explotación de un programa de cocina de la sección 7. Propuestas didácticas para la explotación de programas de televisión en la clase de ELE.

109 Universidad pública, fundada en 1887, ubicada en Morgantown, Virginia Occidental, Estados Unidos.

110 En Estados Unidos, comité encargado de la aprobación y seguimiento de cualquier investigación que involucre a personas.

${ }^{111}$ Departamento de Lenguas del Mundo, Literaturas y Lingüística.

112 Véase Anexo IV y Anexo V.

113 Véase Anexo II (inglés) o Anexo III (español).

${ }^{114}$ Véase nota 108.

115 Por limitaciones de tiempo, las actividades de posvisionado - que en esta propuesta didáctica consisten en escribir una receta y grabar un vídeo explicándola, y cuyo objetivo es desarrollar la compresión y la expresión escrita, y por último la expresión oral— se propusieron como una actividad optativa fuera de clase.
} 


\section{ESTUDIOS EMPÍRICOS}

últimos cinco minutos, los alumnos rellenaron un segundo cuestionario en el que se les pedía que valoraran la formación que acababan de recibir y su reciente experiencia trabajando con programas televisivos en la clase de español. En cuanto a las actividades de posvisionado, estas se propusieron - de nuevo por limitaciones de tiempo- como práctica optativa para realizar fuera de clase ${ }^{116}$. Los alumnos que las llevaron a cabo completaron, posteriormente, un tercer y último cuestionario que nos permitió obtener también una valoración de estas actividades.

La muestra total recogida nos permitió analizar las respuestas de 40 estudiantes, 22 alumnas y 18 alumnos, en su mayoría estadounidenses ${ }^{117}$ de 18 a 21 años ${ }^{118}$. En cuanto a su nivel de español, basándonos en el criterio de admisión de este curso, podemos confirmar que se trata de un nivel básico no inicial, equivalente al nivel A2 del MCER (2002). El requisito mínimo para que el alumno pueda matricularse en esta asignatura es que haya cursado y aprobado, al menos, el curso inicial de español — de un semestre de duración - impartido también en la universidad, o que haya pasado un examen de nivel establecido por el departamento de español. No obstante, a la hora de analizar las respuestas obtenidas a través de los cuestionarios y de elaborar conclusiones, tuvimos en cuenta la formación previa de cada alumno, pues algunos de ellos declararon haber aprendido español en el instituto y, en el caso de los alumnos de origen hispano, haber escuchado español en el entorno familiar.

Entre las cuestiones básicas, destacamos aquellas que hacen referencia al reconocimiento por parte de los propios alumnos de la utilidad de los programas televisivos como herramienta para su aprendizaje del español como lengua extranjera: para mejorar su comprensión oral, aprender gramática, vocabulario, expresiones, rasgos de la pronunciación, conocer la cultura española e incluso para animarse a ver programas televisivos en español fuera de clase.

Los datos obtenidos nos llevaron a confirmar que una gran mayoría de alumnos, además de disfrutar trabajando con este material, considera que el programa televisivo es un recurso de utilidad para el aprendizaje de español por varios y diversos motivos. La lectura de los datos obtenidos en el análisis de los cuestionarios de los alumnos nos sirvió para demostrar que la propuesta didáctica utilizada en este estudio permite desarrollar actividades comunicativas

\footnotetext{
${ }^{116}$ Las actividades de posvisionado fueron puestas en práctica por 9 estudiantes, 5 alumnas y 4 alumnos, del total de 40 que asistieron a la clase experimental.

117 Solo 3 de los alumnos declararon ser de origen hispano.

${ }^{118}$ En concreto cuatro alumnos de 18 años, diez de 19, dieciocho de 20 y ocho de 21.
} 
de la lengua, tanto de comprensión como de expresión; competencias de la lengua — léxicas, gramaticales, socioculturales y pragmáticas-; así como la capacidad de autoaprendizaje del alumno.

\subsubsection{Datos extraídos del cuestionario realizado por los alumnos ${ }^{119}$}

\section{APARTADO I. TU CONSUMO HABITUAL DE PROGRAMAS TELEVISIVOS}

1. ¿Con qué frecuencia ves el siguiente contenido audiovisual?

\subsection{Programas de televisión}

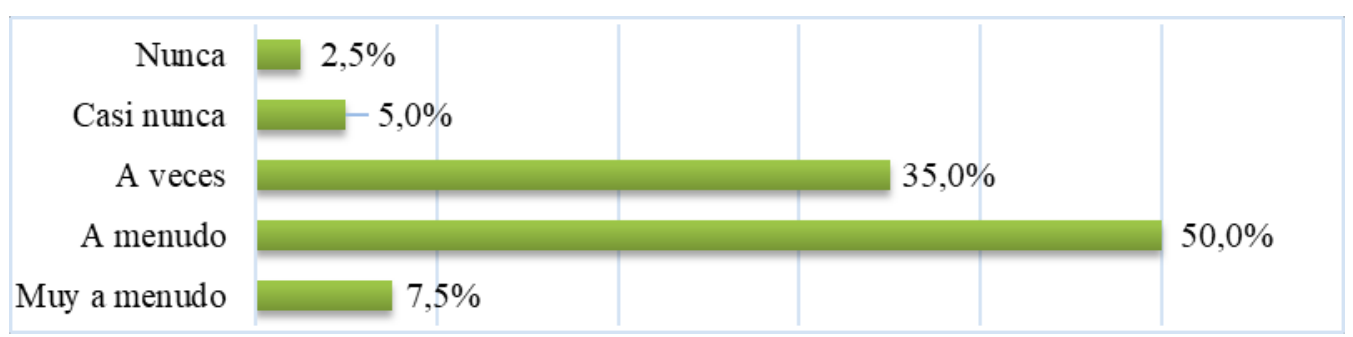

Figura 23. Frecuencia con la que los alumnos declaran ver programas de televisión.

\subsection{Anuncios publicitarios}

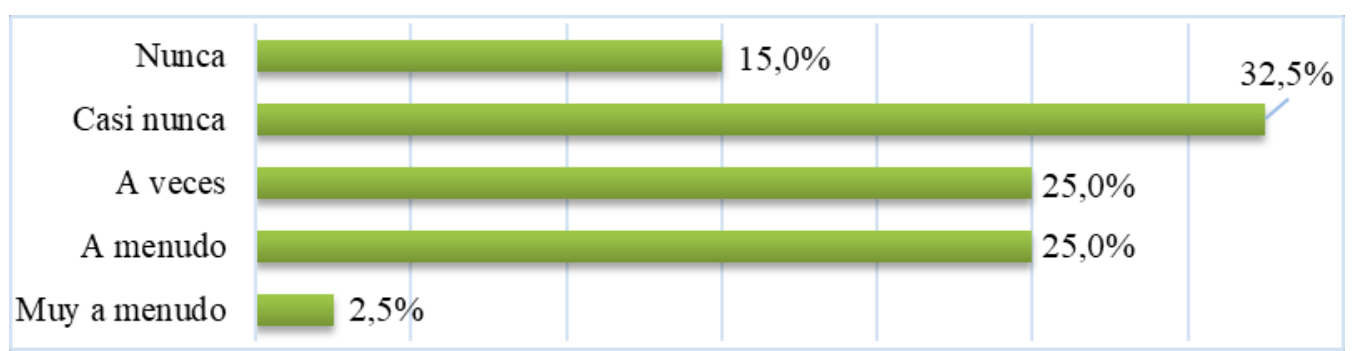

Figura 24. Frecuencia con la que los alumnos declaran ver anuncios publicitarios.

\footnotetext{
${ }^{119}$ Las preguntas y respuestas del cuestionario original son en inglés.
} 


\subsection{Películas}

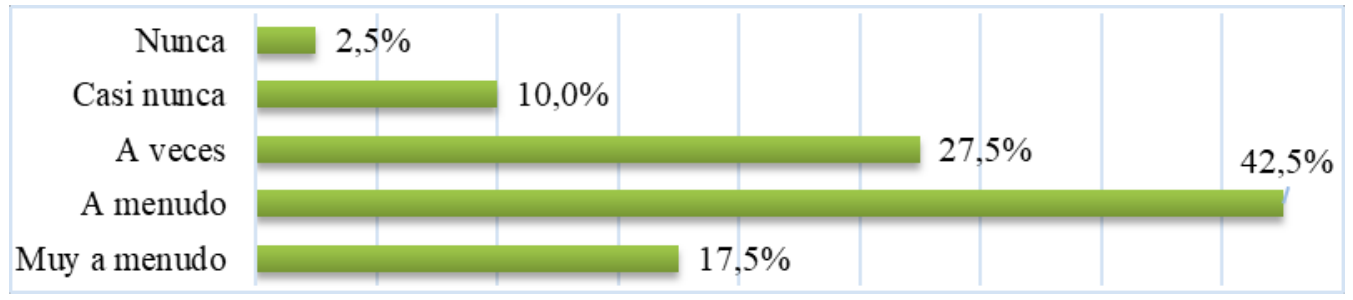

Figura 25. Frecuencia con la que los alumnos declaran ver películas.

\subsection{Tráiler}

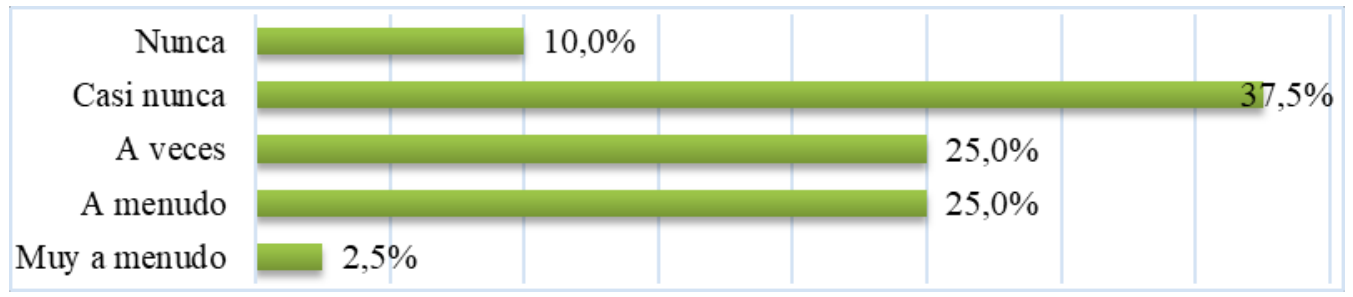

Figura 26. Frecuencia con la que los alumnos declaran ver tráileres.

\subsection{Cortometrajes}

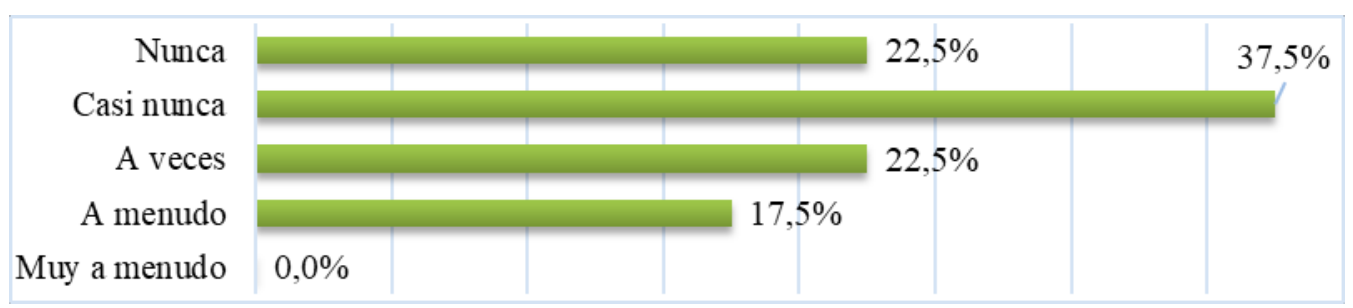

Figura 27. Frecuencia con la que los alumnos declaran ver cortometrajes.

2. Aproximadamente, ¿cuántos programas de televisión ves en tu lengua materna? 
EL PROGRAMA TELEVISIVO COMO RECURSO PARA LA

ENSEÑANZA/APRENDIZAJE DE ESPAÑOL LENGUA EXTRANJERA

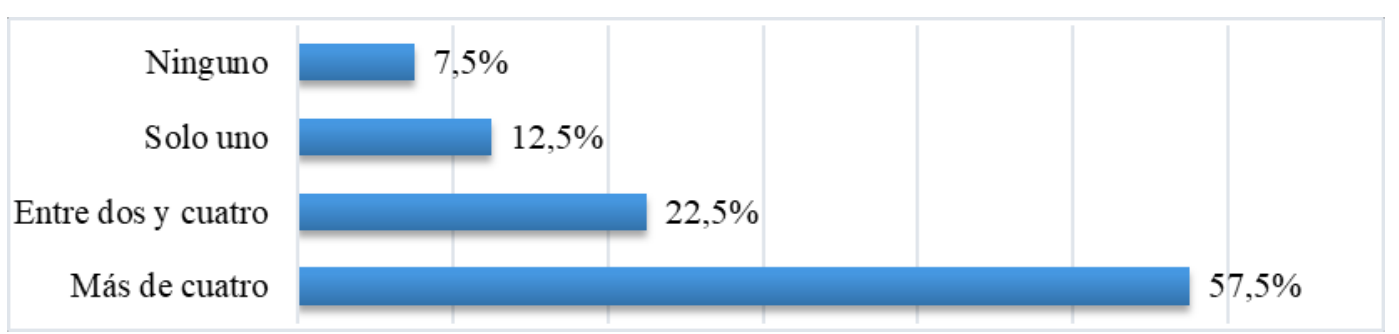

Figura 28. Número de programas de televisión que los alumnos declaran ver en su lengua materna.

3. ¿Cuáles de los siguientes tipos de programas televisivos ves y con qué frecuencia?

3.1. Informativos (Telediario, reportajes de actualidad, tertulias, el tiempo...)

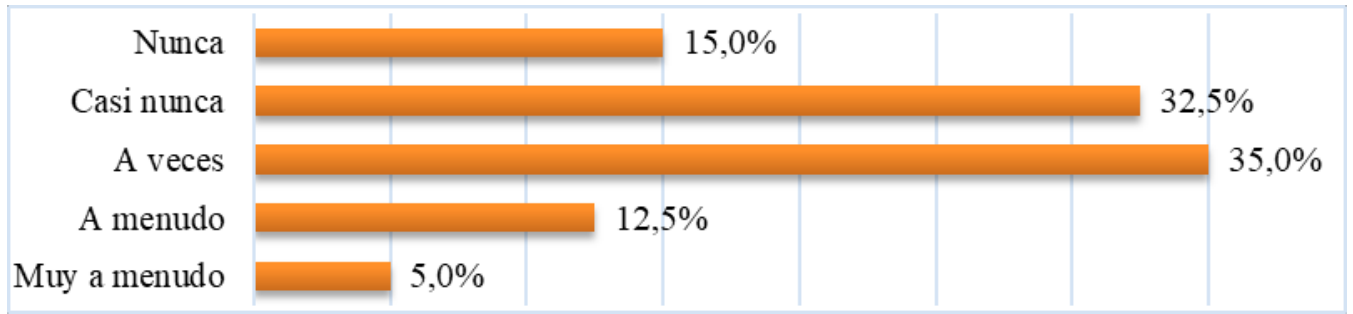

Figura 29. Frecuencia con la que los alumnos declaran ver programas televisivos informativos.

\subsection{Culturales (Documental, educativo...)}

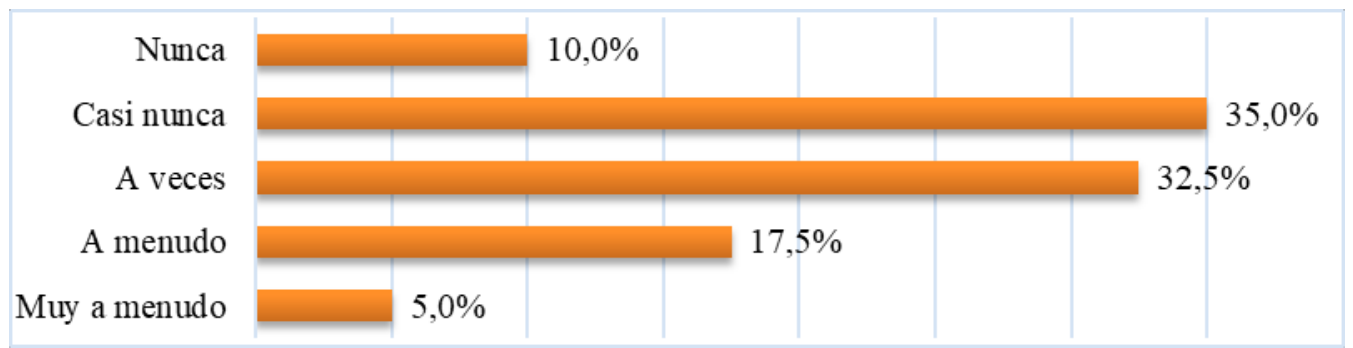

Figura 30. Frecuencia con la que los alumnos declaran ver programas televisivos culturales.

\subsection{Ficción (Series, miniseries, telenovelas...)}




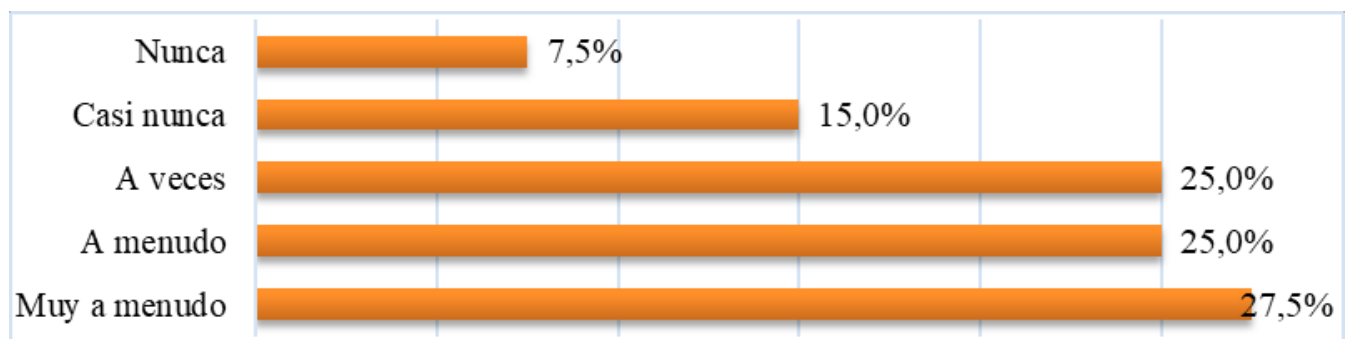

Figura 31. Frecuencia con la que los alumnos declaran ver programas televisivos de fícción.

3.4. Entretenimiento (talk-shows, reality-shows, magacines, concursos, galas...)

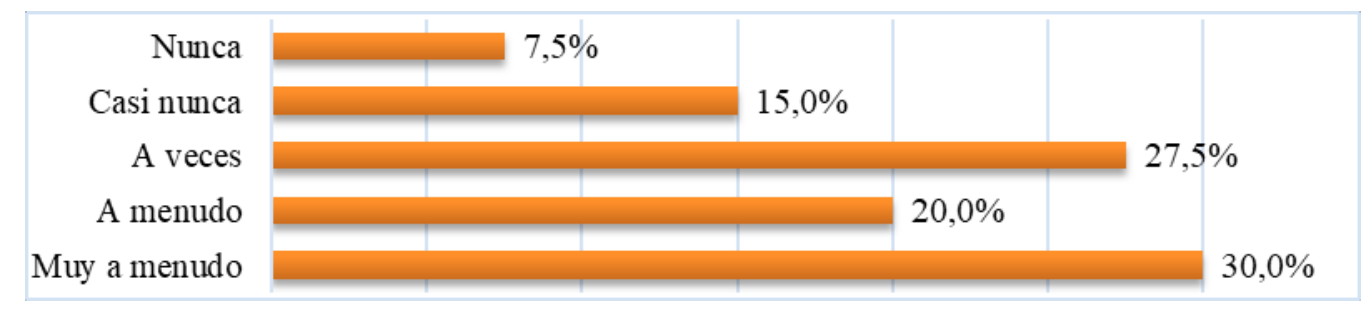

Figura 32. Frecuencia con la que los alumnos declaran ver programas televisivos de entretenimiento.

\subsection{Deportes (Programas específicos, retransmisiones de competiciones, eventos especiales...)}

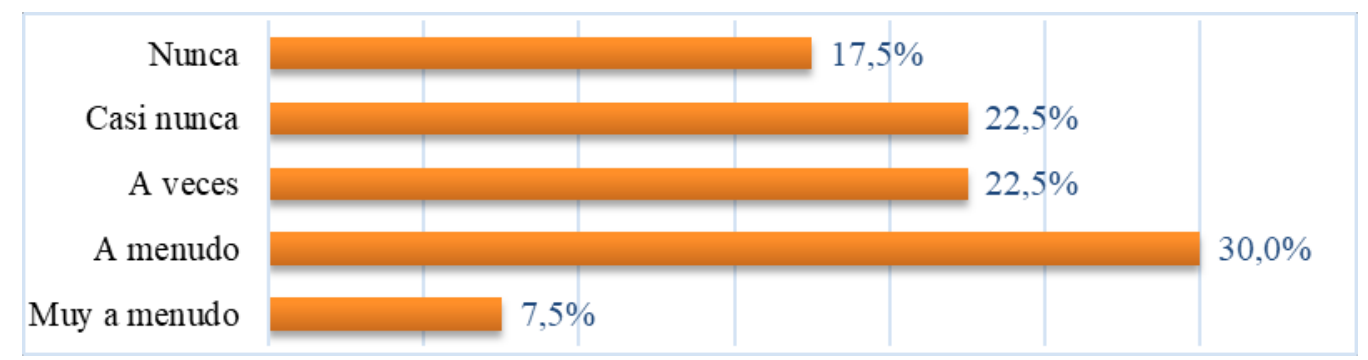

Figura 33. Frecuencia con la que los alumnos declaran ver programas televisivos de deportes.

\section{APARTADO II. TUS HÁBITOS COMO ESTUDIANTE DE ESPAÑOL EN CUANTO AL USO DE PROGRAMAS TELEVISIVOS}

15. ¿Sueles ver programas televisivos en español? 


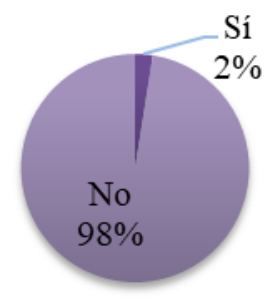

Figura 34. Porcentaje de alumnos que declara ver programas televisivos en español.

\section{Si tu respuesta fue sí, ¿para qué crees que son útiles?}

29. Para aprender vocabulario y mejorar mi acento. ${ }^{120}$

\section{Si tu respuesta fue no, ¿para qué crees que podrían ser útiles?}

1. Me podrían ayudar a aprender español más rápidamente.

2. Para poner en contexto lo que estamos aprendiendo.

3. Creo que ayudarían mucho para aprender español.

4. Para aprender gramática y vocabulario.

5. Ayudarian a entender el idioma que estamos intentando aprender.

6. Para mejorar mi comprensión oral.

7. Para aprender las diferencias culturales de los shows de Latinoamérica o España.

8. Me ayudarían a acostumbrarme a escuchar cómo habla español la gente nativa.

9. Para mejorar mi pronunciación.

10. Entendería mejor cómo se usan los verbos.

11. Podría entender las noticias de otras partes del mundo y las retransmisiones de fútbol.

12. Para aprender español fuera de clase.

13. Para escuchar conversaciones reales.

14. Para aprender a distinguir las diferentes variedades de español.

15. Para aprender sobre otras culturas.

16. Para recibir noticias de otras fuentes, especialmente si se trata de noticias internacionales.

\footnotetext{
${ }^{120}$ De los cuarenta participantes, solo una alumna de 25 años de origen brasileño respondió sí a esta pregunta.

${ }^{121}$ Todas las preguntas del cuestionario en las que se invita al alumno a justificar su respuesta son de tipo opcional. Aquí incluimos una selección de comentarios.
} 


\section{6. ¿Alguna vez has tenido una clase de español que incorporara programas televisivos?}

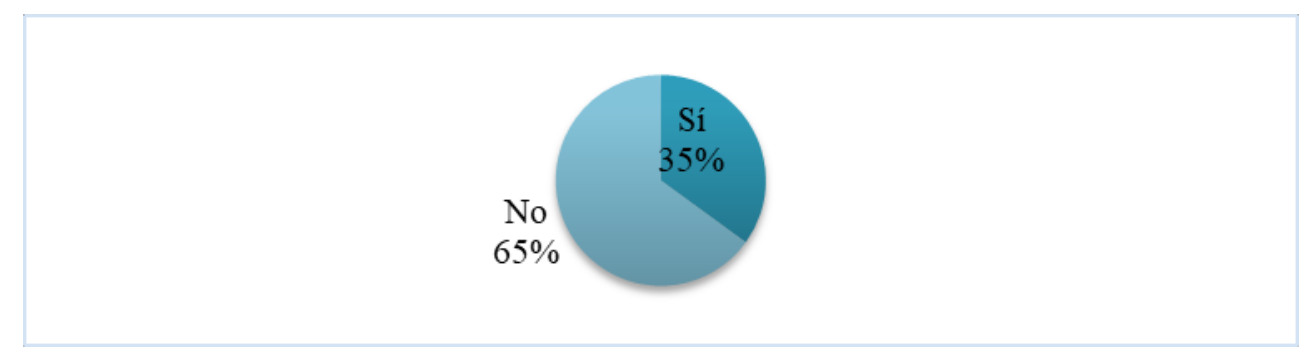

Figura 35. Porcentaje de alumnos que declara haber tenido alguna vez una clase de español que incorporara programas televisivos.

\section{Si tu respuesta fue sí, ¿te pareció útil?, ¿por qué?}

1. Ayudó mucho, fue interesante e hizo la clase menos aburrida.

2. Fue una forma divertida de aprender.

3. Me pareció muy interesante y me ayudó a aprender.

4. Me ayudó a fijarme en la pronunciación.

5. Me ayudó a mejorar mi comprensión oral.

6. Fue en la escuela primaria así que me gustó mucho porque era un programa de televisión.

7. En la secundaria, tuve clases de español dos años. La profesora era fantástica y nos enseñó mucho. Algunos días nos ponía un programa muy bueno de la BBC (no recuerdo el nombre) que además tenía versiones en varios idiomas. Me parecía un método muy bueno para aprender.

8. Me sirvió para aprender algunos patrones y expresiones.

\section{Si tu respuesta fue no, ¿te gustaría trabajar con programas televisivos en tus clases de español?, ¿por qué?}

1. Sí, sería muy útil porque así puedes oír cómo la gente habla normalmente en vez de solo estudiar con un libro.

2. Sí, para aprender más palabras y expresiones coloquiales que usan los hablantes de español y para oír la velocidad a la que hablan.

3. Sí, me gustaría porque he visto algunas películas en español y me gustaron mucho. Fui capaz de entender lo que estaba pasando por el contexto y aprendi nuevas palabras.

4. Sí, para oír a una variedad más grande de hablantes y su tono según lo que quieren expresar.

5. Sí, me ayudaría a poner en contexto la gramática y el vocabulario que hemos aprendido.

6. Sí, porque me acostumbraría a oír conversaciones reales en español. 
7. Sí, sería algo nuevo con lo que aprender.

8. Sí, sería una forma diferente de aprender.

9. No, no me parecería útil porque en el programa quizá utilicen palabras que aún no he aprendido.

10. Solo me gustaría si también hay subtitulos.

11. Aún no, todavía no tengo nivel suficiente para entenderlos.

12. No estoy seguro porque nunca lo he experimentado.

\section{APARTADO III ${ }^{122}$. TU RECIENTE EXPERIENCIA COMO ESTUDIANTE DE ESPAÑOL EN CUANTO AL USO DE PROGRAMAS TELEVISIVOS}

\section{1. ¿Te ha gustado esta clase? Clasifica tu respuesta de 1 (no me ha} gustado) a 10 (me ha gustado mucho).

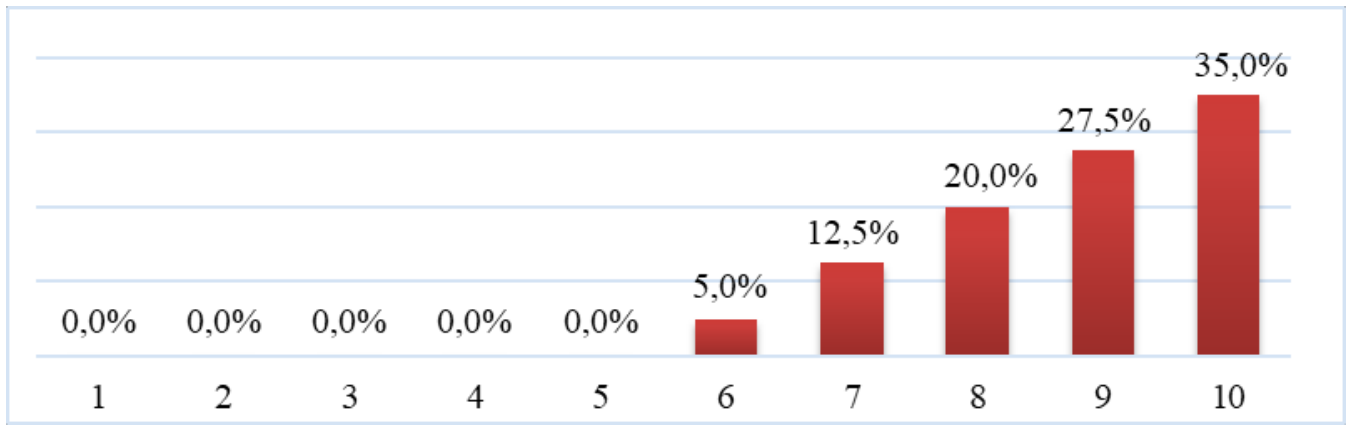

Figura 36. Valoración general de los alumnos (de 1 a 10) de la clase recibida en este estudio empírico.

\section{¿Por qué?}

1. Sí, el vídeo me permitió escuchar a un hablante nativo hablando como lo haría a otros hablantes nativos.

2. Sí, fue interesante e interactivo.

3. Sí, fue algo diferente.

${ }^{122}$ Apartado a contestar al final de la clase experimental. 


\section{ESTUDIOS EMPÍRICOS}

4. Si, fue divertido y aprendimos mucho.

5. Sí, ayuda mucho tener en papel delante de ti el material que estás viendo y escuchando.

6. Sí, fue divertido, aprendimos nuevas expresiones y participamos.

7. Sí, fue muy interesante.

8. Sí, ver el vídeo fue divertido y útil.

9. Sí, me gusta cuando utilizamos vídeos en clase.

10. Sí, fue muy bueno para recordar el vocabulario que hemos aprendido.

11. Aprender español es duro pero la clase fue muy buena.

12. No mucho porque no soy suficientemente bueno en español.

13. No mucho porque fue difícil.

\section{2. ¿Te ha parecido útil esta clase? Clasifica tu respuesta de 1 (no me ha gustado) a 10 (me ha gustado mucho).}

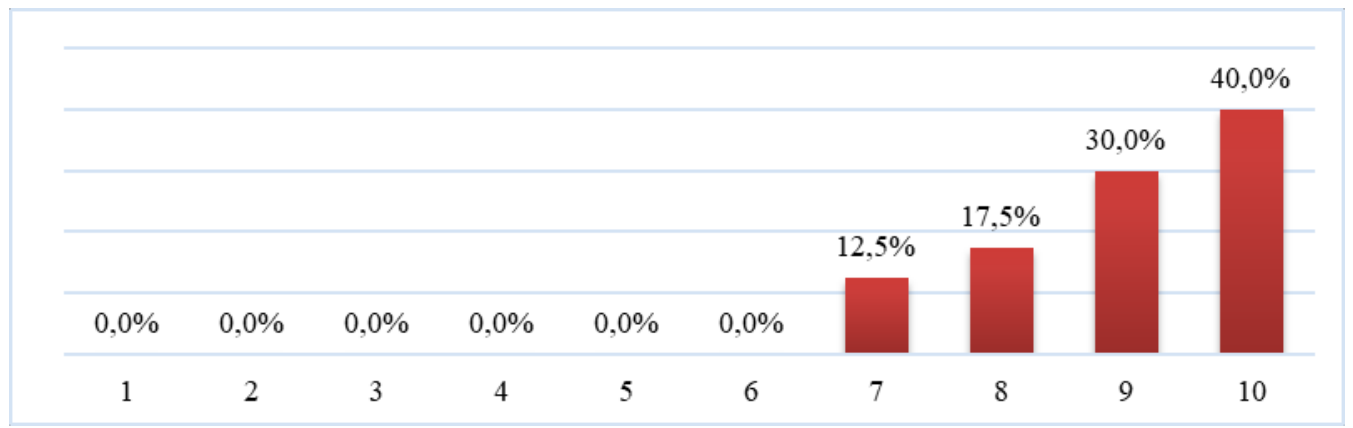

Figura 37. Valoración de los alumnos (de 1 a 10) de la utilidad de la clase recibida en este estudio empírico.

\section{¿Por qué?}

1. Sí, ha hecho que me interese ver programas de televisión en español para aprender más español.

2. Si, ha ayudado a mejorar mis conocimientos de español.

3. Sí, he aprendido mucho.

4. Sí, porque hemos hecho muchas actividades utilizando el contenido del vídeo.

5. Si, porque hemos aprendido nuevas palabras y expresiones.

6. Sí, porque he aprendido algo nuevo a pesar de que se me dé fatal el español.

7. Sí, porque ha sido una buena forma de hacerme prestar atención.

8. Sí, porque he aprendido muchos verbos nuevos.

9. Sí, porque he aprendido cosas nuevas y he recordado cosas que habia olvidado. 


\section{EL PROGRAMA TELEVISIVO COMO RECURSO PARA LA \\ ENSEÑANZA/APRENDIZAJE DE ESPAÑOL LENGUA EXTRANJERA}

\section{3. ¿Te han parecido útiles las actividades de previsionado? Clasifica tu respuesta de 1 (no me ha gustado) a 10 (me ha gustado mucho).}

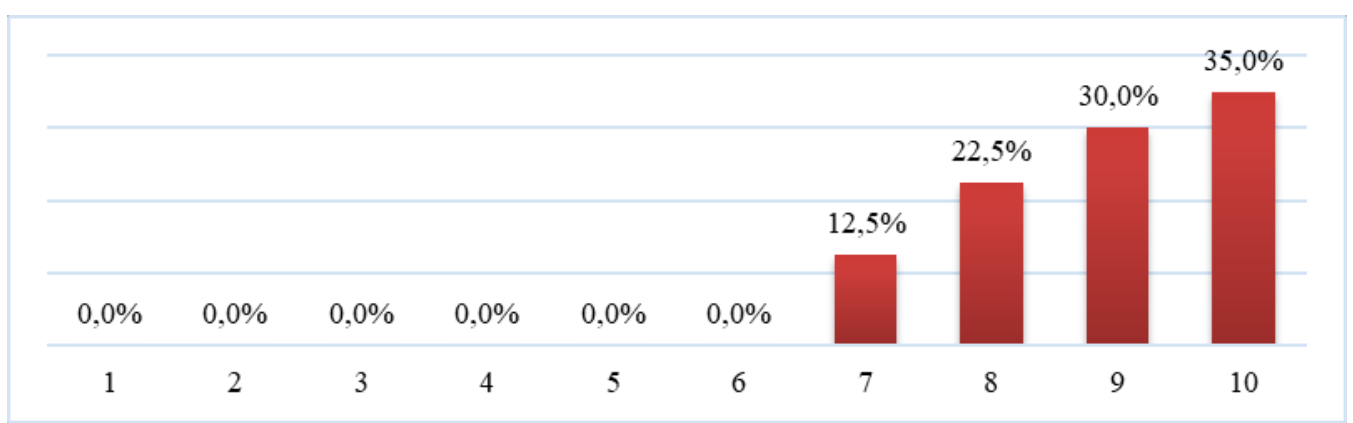

Figura 38. Valoración de los alumnos (de 1 a 10) de las actividades de previsionado de la propuesta didáctica empleada en este estudio empírico.

\section{¿Por qué?}

1. Sí, porque me han ayudado a entender el vídeo mucho mejor.

2. Sí, porque nos han preparado para el vídeo.

3. Sí, porque en estas actividades hemos visto el vocabulario y los verbos que usaban en el vídeo.

4. Sí, porque nos han expuesto a lo que ibamos a escuchar.

5. Sí, porque me han ayudado a hacerme una idea general antes de ver el vídeo.

6. Sí, porque nos han ayudado a familiarizarnos con el contenido antes de escucharlo.

7. Sí, porque fueron como una introducción antes de ver el vídeo.

8. Sí, porque pudimos practicar un poco antes de ver el vídeo.

9. Sí, me ayudaron a mentalizarme antes de ver el vídeo.

4. Después de esta clase, ¿para qué crees que es útil ver programas televisivos en la clase de español? (Puedes señalar una o varias respuestas) 


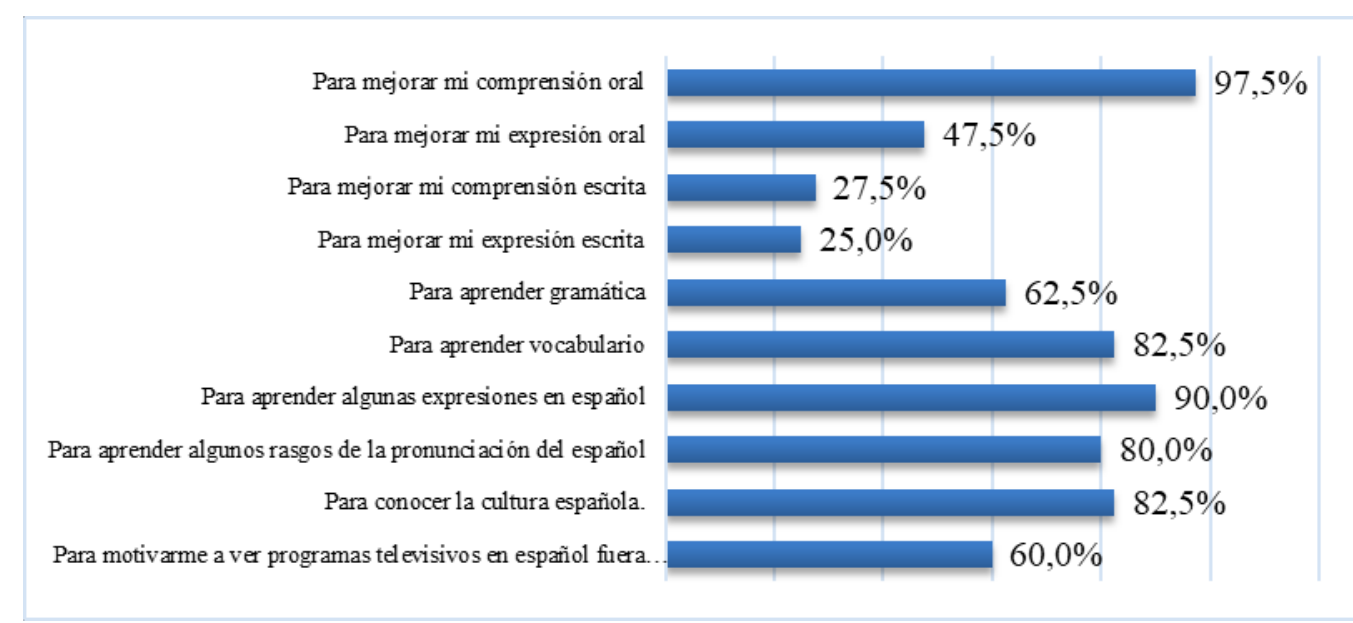

Figura 39. Aspectos que los alumnos consideran que se podrían trabajar mediante la visualización de programas televisivos en la clase de español

\section{APARTADO IV ${ }^{123}$. TU RECIENTE EXPERIENCIA COMO ESTUDIANTE DE ESPAÑOL EN CUANTO AL USO DE PROGRAMAS TELEVISIVOS FUERA DE CLASE}

1. ¿Te ha parecido útil la actividad de posvisionado de escribir una receta? Clasifica tu respuesta de 1 (no me ha parecido útil) a 10 (me ha parecido muy útil).

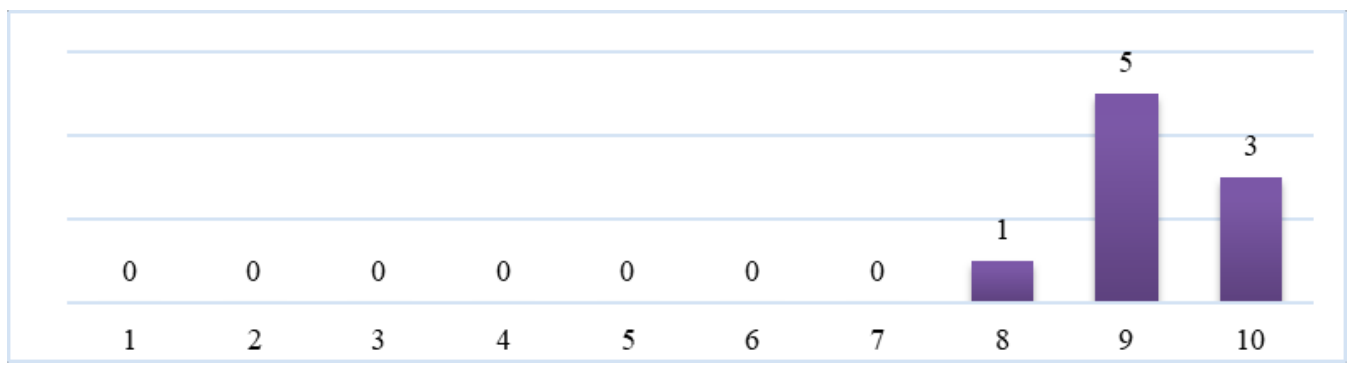

Figura 40. Valoración de los alumnos (de 1 a 10) de la actividad de posvisionado consistente en escribir una receta de cocina.

${ }^{123}$ A responder tras haber realizado las actividades de posvisionado. 


\section{EL PROGRAMA TELEVISIVO COMO RECURSO PARA LA \\ ENSEÑANZA/APRENDIZAJE DE ESPAÑOL LENGUA EXTRANJERA}

\section{¿Por qué?}

1. Sí, porque me ha permitido usar tanto mis conocimientos de vocabulario como de gramática para ayudarme a entender en español algo que ya conozco en inglés.

2. Si, me ha servido para fijarme en la estructura de las frases y verbos.

3. Sí, creo que escribir los pasos y lo que quería decir en el vídeo me ha ayudado a mejorar mi forma de expresarme. En las composiciones que hemos escrito este semestre escribia para ser correcta no para hablar de forma coloquial y agradable.

4. Sí, porque me ha ayudado a hablar español.

5. Sí, porque me ha ayudado a ver y aplicar lo que he aprendido este año en un estilo diferente y en una forma que permite sentir la cultura.

6. Sí, me ha ayudado con mi escritura y mi pronunciación en español.

7. Sí, porque hemos tenido que pensar para escribir las frases correctamente y hemos aprendido nuevas palabras.

8. Sí, me ha ayudado mucho a aprender cómo explicar pasos y a mejorar mis conocimientos de vocabulario.

9. Sí, porque al escribir la receta he aprendido algunos verbos nuevos.

\section{2. ¿Leíste algunas recetas en español antes de escribir la receta?}

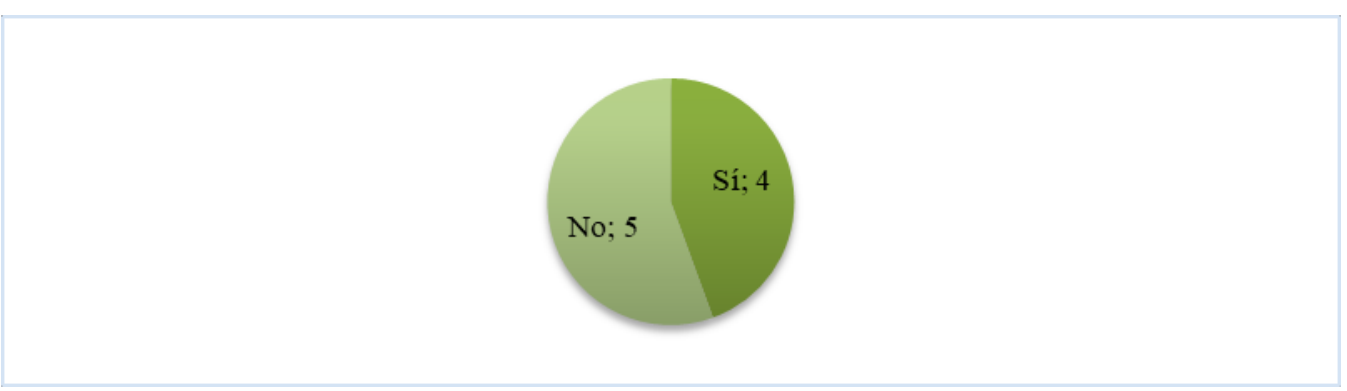

Figura 41. Número de alumnos que declaró haber leído algunas recetas en español antes de escribir su receta.

\section{¿Por qué?}

1. Sí, para ayudarme a entender mejor cómo escribir la receta.

2. Sí, intenté buscar la receta en internet pero todos los resultados que encontré eran en inglés. Así que no encontré la receta en español pero sí encontré saqué una lista de palabras usadas en recetas de un proyecto escolar.

3. Sí, porque tenía algo de un trabajo que hice en el instituto.

4. Sí, para entender mejor la disposición.

5. No, solo busqué la que elegimos.

6. No, solo recordé la receta que hicimos en clase y me pareció que con eso tenía conocimientos suficientes para escribir la mía. 


\section{ESTUDIOS EMPÍRICOS}

7. No, solo usé mis conocimientos de lo que había aprendido en clase.

8. No, porque no tuve tiempo de buscar.

9. No, sinceramente porque no tuve tiempo de buscar.

\section{3. ¿Te ha parecido útil la actividad de posvisionado de grabar un vídeo? Clasifica tu respuesta de 1 (no me ha parecido útil) a 10 (me ha parecido muy útil).}

\begin{tabular}{|c|c|c|c|c|c|c|c|c|c|}
\hline & & & & & & & 3 & 3 & 3 \\
\hline 0 & 0 & 0 & 0 & 0 & 0 & 0 & & & \\
\hline 1 & 2 & 3 & 4 & 5 & 6 & 7 & 8 & 9 & 10 \\
\hline
\end{tabular}

Figura 42. Valoración de los alumnos (de 1 a 10) de la actividad de posvisionado consistente en grabar un vídeo de sí mismos explicando una receta de cocina.

\section{¿Por qué?}

1. Sí, me ha ayudado a hablar en español y a mejorar mi forma de hablar.

2. Sí, porque he podido hablar español con un verdadero propósito y con objetos físicos en la mano.

3. Sí, me ha ayudado a hablar pero grabar el vídeo me ha resultado un poco raro. Creo que si hiciéramos esta actividad en clase resultaría menos raro y podríamos mejorar aún más nuestra expresión oral.

4. Sí, hablar en español sobre un tema totalmente nuevo es muy útil.

5. Si, ha sido una forma divertida de combinar el leer y entender con el hablar.

6. Sí, ha sido bueno para practicar el hablar en español.

7. Si, me ha hecho esforzarme en pronunciar las palabras correctamente.

8. Sí, me ha parecido una oportunidad estupenda para reflexionar sobre lo que he aprendido.

9. Sí, creo que obligar a los alumnos a hablar en español es muy importante para el proceso de aprendizaje. No tenemos muchas oportunidades de practicar en clase.

\section{4. ¿Esta fue la primera vez que te grabaste hablando en otro idioma?}




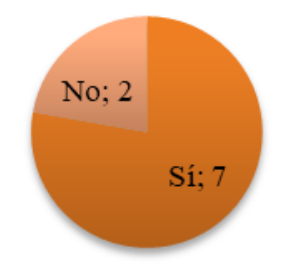

Figura 43. Número de alumnos que declaró haberse grabado por primera vez hablando en otro idioma al realizar esta actividad de posvisionado.

\section{¿Cómo te sentiste?}

1. Sí, estaba nerviosa y un poco incómoda porque no era natural para mí pero una vez que empecé me sentí como si realmente conociera muy bien el material.

2. Sí, me resultó raro escucharme hablar en español pero me pareció que hablaba clara y coherentemente.

3. Sí, me senti rara y nerviosa pero no me gusta nada hablar en clase. Me he dado cuenta de que nunca antes me habian mandado algo que hiciera hincapié en que hablara español (tras dos años de clases de español en el instituto).

4. Sí, me parece que grabarte te ayuda a darte cuenta de si estás pronunciando las palabras correctamente.

5. Sí, me dio un poco de vergüenza pero creo que solo es porque necesito trabajar en ello.

6. Sí, estaba muy nerviosa pero luego me di cuenta de que no era para tanto.

7. Sí, fue un poco raro pero la verdad es que me gustó porque fue como una demostración para mi misma de que he aprendido mucho este año.

8. No, ya lo había hecho antes así que solo me sentí un poco nervioso.

9. No, yo me sentí cómodo pero puede que sea porque tenía escrito delante de mí lo que quería decir asi que solo tenía que leerlo.

\section{5. ¿Para qué crees que fueron útiles estas actividades de posvisionado?}




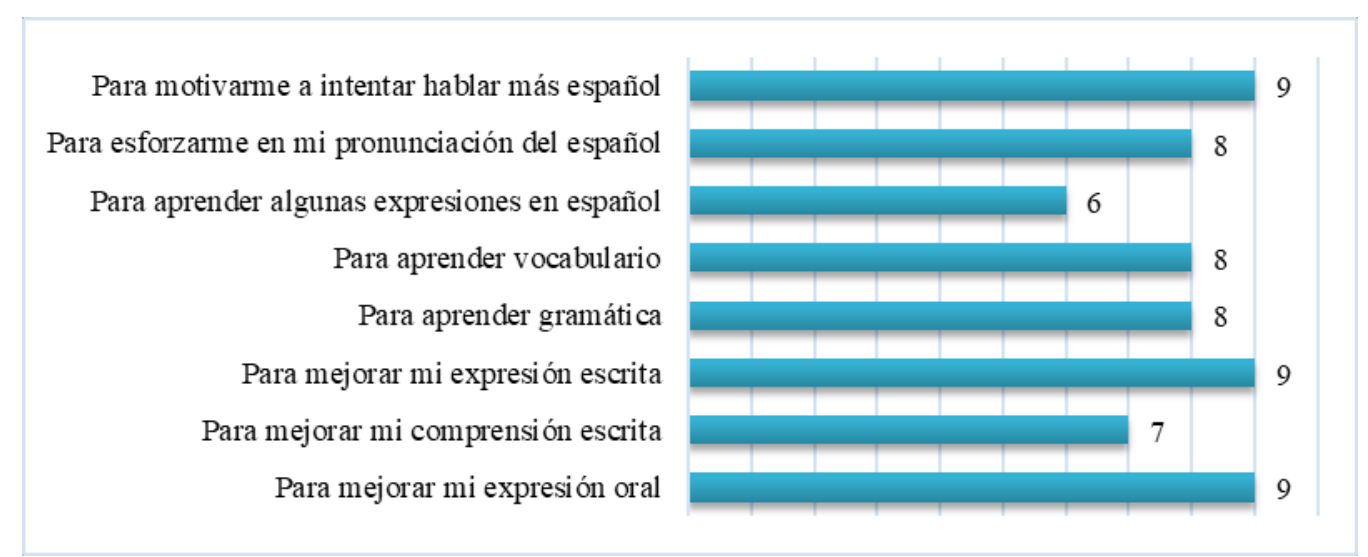

Figura 44. Aspectos que los alumnos consideran haber trabajado a través de las actividades de posvisionado de la propuesta didáctica de este estudio empírico.

\subsubsection{Análisis de los datos extraídos del cuestionario realizado por los alumnos}

- Los documentos audiovisuales de los que se registró un mayor consumo por parte de los estudiantes son, de mayor a menor, películas (el $60 \%$ las ve a menudo o muy a menudo) programas de televisión (el 57,5\% los ve a menudo o muy a menudo), tráiler (un $50 \%$ los ve a menudo o a veces), anuncios publicitarios (también un $50 \%$ los ve a menudo o a veces) y, en último lugar, los cortometrajes (el $40 \%$ los ve a veces o a menudo pero nadie afirma verlos muy a menudo). Cabe destacar que solo un 2,5\% declaró no ver nunca ni programas televisivos ni películas. Este dato no resulta sorprendente ya que, hoy en día, la mayoría de los jóvenes tiene una $o$ varias televisiones en casa o dispone de conexión a Internet para acceder a estos formatos de entretenimiento.

- En cuanto al número de programas de televisión (en su lengua materna) que ven normalmente los alumnos, registramos los siguientes datos: la mayoría (un 57,5\%) confiesa ver más de cuatro programas televisivos diferentes y un $22,5 \%$ declara ver entre dos y cuatro programas. Tan solo un $12,5 \%$ ve solo un programa y un $7,5 \%$ no ve ninguno.

- Los programas televisivos más populares entre los estudiantes son, de mayor a menor, los de ficción (el 52,5\% los ve muy a menudo o a menudo), los de entretenimiento (el $50 \%$ los ve muy a menudo o a menudo) y los programas de deportes (el 52,5\% los ve a menudo o a veces). Sin embargo, 


\section{EL PROGRAMA TELEVISIVO COMO RECURSO PARA LA ENSEÑANZA/APRENDIZAJE DE ESPAÑOL LENGUA EXTRANJERA}

la mayoría declara solo ver a veces o casi nunca programas culturales (el $67,5 \%$ ) y programas informativos (también el 67,5\%). Esto demuestra que las series de televisión y los programas de entretenimiento, como los talkshows o los reality-shows, son los programas televisivos preferidos por los jóvenes.

- Por lo que se refiere a sus hábitos de uso de programas televisivos en español, la gran mayoría (el 98\%) confesó no ver nunca programas televisivos en español. La única estudiantes que afirmó verlos, una joven de 25 años de origen brasileño, explicó que le resultan útiles para aprender vocabulario y mejorar su acento. Sin embargo, muchos de los alumnos que declararon no verlos admitieron que esta práctica podría ayudarles a aprender español más rápidamente, entender mejor el idioma (especialmente a los nativos), poner en contexto lo aprendido en clase, aprender vocabulario y gramática, mejorar su pronunciación, aprender a distinguir variedades de español, darse cuenta de diferencias culturales, aprender español fuera de clase, e incluso a poder informarse a través de otras fuentes de información.

- Siguiendo con los hábitos de estos alumnos en cuanto al uso de programas televisivos en español, la mayoría (el 65\%) declaró no haber tenido nunca una clase de español en la que se trabajara con programas televisivos. Los que sí han tenido esta experiencia (el 35\%), comentaron que les ayudó a aprender algunas estructuras y expresiones, a prestar atención a la pronunciación, y a mejorar su comprensión oral. Además, les pareció muy interesante e hizo la clase más divertida. La mayoría de los que aún no han experimentado el hecho de trabajar en clase de español con este tipo de recurso, afirmaron que les gustaría hacerlo porque les permitiría escuchar una variedad más amplia de hablantes nativos —incluyendo diferentes variedades de español - hablar "a velocidad normal", acostumbrarse a oír diálogos reales, aprender más palabras y expresiones coloquiales, y poner en contexto la gramática y el vocabulario que conocen. Además, opinaron que sería una forma nueva y diferente de aprender español. Por otro lado, uno de los alumnos encuestados expresó su incertidumbre al no haber experimentado nunca el hecho de trabajar con programas televisivos en clase, otro comentó que solo le gustaría trabajar con ellos si estos incluyen 


\section{ESTUDIOS EMPÍRICOS}

subtítulos y, finalmente, un par de estudiantes explicaron que creían no tener aún nivel suficiente para entenderlos ${ }^{124}$.

- Al final de la clase experimental —en la que los alumnos realizaron la propuesta didáctica descrita anteriormente-, la gran mayoría (un 82,5\%) afirmó haber disfrutado mucho de la clase (calificándola con un 8, 9 o 10 sobre 10). Algunos de los comentarios que aportaron para justificar su respuesta fueron que la clase les pareció interesante, interactiva, divertida, diferente y útil, y que les sirvió para ampliar y recordar el vocabulario que habían aprendido recientemente. Además, comentaron que les había ayudado mucho el tener la hoja de actividades con ellos mientras veían el vídeo. Por otro lado, los alumnos que confesaron no haber disfrutado tanto de la clase (un $5 \%$ que la calificó con un 6 sobre 10) justificaron su respuesta añadiendo que su nivel no era suficientemente bueno o que el material les había resultado difícil ${ }^{125}$.

- Tras la clase experimental, la gran mayoría de los alumnos (un 87,5\%) opinó que la clase le había parecido muy útil (calificándola con un 8, 9 o 10 sobre 10). Algunos de los comentarios que aportaron fueron que habían aprendido mucho - por ejemplo, nuevas palabras, verbos y expresiones-, que habían recordado cosas que habían olvidado, y que el vídeo y las actividades les habían hecho prestar atención. Además, algún alumno comentó que a través de esta experiencia le había surgido el interés de ver programas televisivos en español para aumentar su aprendizaje.

- En cuanto a las actividades de previsionado ${ }^{126}$, la gran mayoría de alumnos (el 87,5\%) coincidió en que les habían parecido muy útiles (calificándolas con un 8, 9 o 10 sobre 10). Los alumnos destacaron que estas actividades les habían preparado y ayudado a familiarizarse con el contenido del vídeo y a entender el programa televisivo mucho mejor. Algunos también comentaron que les había parecido una muy buena introducción para mentalizarse y a hacerse una idea general antes de ver el vídeo.

- Al final de la clase experimental, los participantes concluyeron que ver programas televisivos en la clase de español es útil para mejorar su comprensión oral (un 97,5\%), aprender algunas expresiones en español (el $90 \%$ ), aprender vocabulario (un 82,5\%), conocer la cultura española (un

\footnotetext{
124 Estos alumnos declararon contar solo con la formación de español que les había proporcionado el curso inicial, de cinco meses de duración, impartido en la universidad.

${ }^{125}$ Véase nota 124.

${ }^{126}$ Véase el apartado 7.6.1. Actividades de previsionado de la sección 7. Propuestas didácticas para la explotación de programas de televisión en la clase de ELE.
} 


\section{EL PROGRAMA TELEVISIVO COMO RECURSO PARA LA \\ ENSEÑANZA/APRENDIZAJE DE ESPAÑOL LENGUA EXTRANJERA}

$82,5 \%$ ), aprender algunos rasgos de la pronunciación del español (un 80\%), aprender gramática (el 62,5\%) y para motivarles a ver programas televisivos en español fuera de clase (el 60\%). Sin embargo, no tantos consideraron que el uso de programas televisivos en clase sea útil para mejorar su expresión oral (un 47,5\%), y muy pocos lo consideraron útil para mejorar su comprensión escrita (el 27,5\%) y su expresión escrita (el 25\%). Como veremos más adelante, los participantes que realizaron las actividades de posvisionado, incluidas en nuestra propuesta, sí declararon también haber mejorado estas tres competencias.

- En cuanto a la actividad de posvisionado ${ }^{127}$ que consistía en escribir una receta, los 9 alumnos que la llevaron a cabo la calificaron como muy útil (valorándola con un 8 , un 9 o un 10 sobre 10). Estos alumnos comentaron que el hecho de escribir en papel lo que iban a explicar en el vídeo les había ayudado a prestar atención a la forma de expresarse, la estructura de las frases y la pronunciación de las palabras. Algunos añadieron que esta actividad también les había permitido conocer nuevas palabras y verbos, además de aplicar lo aprendido hasta el momento. Uno de los factores que contribuyó a esto fue el hecho de que algunos decidieran buscar una o varias recetas para utilizarlas como modelo antes de escribir la suya, o que releyeran y se fijaran en la estructura de las recetas con las que se había trabajado en la clase experimental.

- Respecto a la actividad de posvisionado ${ }^{128}$ que consistía en grabar un vídeo de sí mismos explicando la receta que previamente habían redactado, también los 9 alumnos que llevaron a cabo esta propuesta la calificaron como muy útil (otorgándole un 8 , un 9 o un 10 sobre 10). Algunos de los argumentos que aportaron para justificar su respuesta fueron que esta actividad les había permitido hablar en español con un verdadero propósito - una oportunidad que, comentaron, no suelen tener en clase-, sobre un tema nuevo, y que, entre otras cosas, les había hecho esforzarse en su pronunciación. Algunos también comentaron que la actividad les había resultado divertida y les había parecido una gran oportunidad para reflexionar sobre sus conocimientos. Para la mayoría (7 de los 9 alumnos que realizaron la actividad), esta era la primera vez que se grababa hablando en otro idioma. En general, los alumnos comentaron que, aunque al principio se habían sentido un poco nerviosos e incómodos porque el hecho

\footnotetext{
${ }^{127}$ Véase el apartado 7.6.3. Actividades de posvisionado de la sección 7. Propuestas didácticas para la explotación de programas de televisión en la clase de ELE.

${ }^{128}$ Véase nota 127.
} 


\section{ESTUDIOS EMPÍRICOS}

de grabarse hablando español no les resultaba natural, una vez que empezaron a hablar se sintieron cómodos, seguros e incluso orgullosos de su trabajo. Un estudiante también señaló que le había ayudado mucho el haber escrito primero lo que quería decir.

- Tras haber puesto en práctica las dos actividades de posvisionado propuestas, los 9 participantes se mostraron de acuerdo en que la combinación de ambos ejercicios es útil para mejorar su expresión escrita y su expresión oral, y para motivarles a intentar hablar más español. La mayoría ( 8 de los 9 participantes) también consideraron que estas dos actividades son útiles para aprender vocabulario y gramática, y para esforzarse en su pronunciación del español. Finalmente, también la mayoría - no solo los alumnos que decidieron buscar otras recetas antes de escribir la suya- opinó que estas actividades también son útiles para mejorar su comprensión escrita ( 7 de los 9 participantes) y para aprender algunas expresiones en español ( 6 de los 9 participantes).

\subsubsection{Conclusiones}

Los datos obtenidos nos llevan a inferir que la mayoría de los estudiantes encuestados - al igual que los profesores encuestados ${ }^{129}$ - considera que el uso del programa televisivo es o podría ser útil para la consecución de diferentes objetivos de aprendizaje, por su alto contenido cultural y social, su carácter de material real y auténtico, su capacidad de motivarles e interesarles y su posible uso para mejorar varias destrezas. En los datos obtenidos a través del cuestionario realizado a profesores, comprobamos que muchos docentes se limitan a utilizar en sus clases programas televisivos culturales o informativos, por considerarlos más educativos, y muy pocos explotan otro tipo de programas, como los de entretenimiento. Sin embargo, como vimos en uno de los apartados de este análisis, los materiales audiovisuales preferidos por los alumnos son las películas y los programas televisivos, especialmente, de ficción y entretenimiento.

\footnotetext{
129 Véase el apartado 5.5. Datos extraídos del cuestionario realizado por los profesores de la sección 5. Análisis de manuales y extracción de datos.
} 


\section{EL PROGRAMA TELEVISIVO COMO RECURSO PARA LA ENSEÑANZA/APRENDIZAJE DE ESPAÑOL LENGUA EXTRANJERA}

Por otro lado, el hecho de que la mayoría de los alumnos encuestados declare no haber tenido nunca una clase de español en la que se trabajara con programas televisivos, nos permite confirmar el escaso uso que aún se hace de este recurso en la enseñanza de español como lengua extranjera. Del mismo modo, el hecho de que la inmensa mayoría de los alumnos confiese no ver programas televisivos en español, en un país donde el español es el segundo idioma más hablado y donde es muy fácil acceder a contenido audiovisual en este idioma, hace evidente la necesidad de exponer y acercar este recurso a los alumnos, de forma práctica y motivadora. En el caso de Estados Unidos, esto también contribuye a eliminar los prejuicios y las actitudes negativas hacia el español que, por motivos de integración, surgieron y, en cierta manera, aún permanecen entre los inmigrantes hispanos.

Como demostramos en este estudio empírico, es posible elaborar una propuesta didáctica basada en el uso de programas televisivos que permita a los alumnos mejorar la comprensión y expresión oral, la comprensión y expresión escrita, aprender gramática, vocabulario, expresiones en español y rasgos de la pronunciación del español, conocer la cultura española, e incluso motivar a los alumnos tanto a ver programas de televisión en español fuera de clase como a intentar expresarse en la lengua que están aprendiendo. De este modo, este estudio empírico nos permite confirmar que a través del formato del programa televisivo, se pueden diseñar y realizar actividades enfocadas a trabajar no solo las tres actividades comunicativas de la lengua - la comprensión oral, la interacción oral, y la expresión oral- y las cuatro competencias ${ }^{130}$ señaladas por los profesores encuestados ${ }^{131}$ —sociocultural, léxica, gramatical y pragmática一.

En cuanto a los obstáculos que los profesores encuestados dijeron encontrar a la hora de trabajar con programas televisivos en el aula - la necesidad de tiempo para su preparación previa, su carácter de material actual, su difícil adaptación a los diferentes niveles y la posible desmotivación que esto puede provocar entre

\footnotetext{
${ }^{130}$ En el cuestionario a profesores, en la pregunta relativa a las competencias de la lengua que se podrían trabajar mediante la explotación didáctica de un programa televisivo, se dio la opción de seleccionar entre competencias gramaticales, léxicas, socioculturales y pragmáticas. Decidimos no incluir las competencias estratégicas y discursivas porque, como pudimos comprobar al realizar el análisis de manuales, estas no suelen tratarse como competencias independientes. No obstante, la propuesta didáctica empleada en este estudio empírico incluye actividades, basadas en el uso de programas televisivos, a través de las cuales se pueden desarrollar también estas dos competencias.

${ }^{131}$ Véase nota 129.
} 


\section{ESTUDIOS EMPÍRICOS}

los alumnos de los niveles más básicos $\mathrm{y}$, la ausencia o escasez de programas interesantes en la televisión española-, los resultados de este estudio empírico nos permiten concluir que es posible trabajar con programas televisivos atemporales, como es el caso del programa de cocina utilizado en nuestra propuesta didáctica, y a la vez interesantes para los alumnos; y que una serie de actividades basada en el uso de programas televisivos es fácil de adaptar y posible de utilizar hasta en los niveles más básicos, sin perjudicar la motivación de alumnos.

Como señalamos anteriormente, todos los datos recogidos, tanto del análisis de manuales didácticos como de los resultados obtenidos a través del cuestionario dirigido a profesores de español como lengua extranjera, fueron tomados en consideración para el diseño de la propuesta didáctica utilizada en este estudio empírico. 


\section{EL PROGRAMA TELEVISIVO COMO RECURSO PARA LA \\ ENSEÑANZA/APRENDIZAJE DE ESPAÑOL LENGUA EXTRANJERA}

\subsection{Estudio empírico de la propuesta didáctica para la explotación de un programa documental}

Con el objetivo de demostrar la efectividad de una de las propuestas didácticas dirigidas a estudiantes de español de nivel intermedio-alto presentadas en esta tesis - en este caso la propuesta didáctica para la explotación de un programa televisivo documental ${ }^{132}$ - , una serie de actividades se llevó a la práctica en dos clases de dos cursos de español de nivel intermedio-alto en la universidad West Virginia University ${ }^{133}$.

Para realizar este segundo estudio empírico en Estados Unidos también fue necesario contar con la aprobación del Institutional Review Board (IRB) ${ }^{134}$ y del Department of World Languages, Literatures, and Linguistics ${ }^{135}$ de la universidad $^{136}$.

Esta propuesta se llevó a cabo al final del semestre de otoño en dos cursos de nivel intermedio-alto. Estos cursos se imparten tres días a la semana en clases de cincuenta minutos. Por ello, fue necesario adaptar también este estudio empírico a dicha duración. Los cincuenta minutos de la clase se distribuyeron del mismo modo que en el primer estudio empírico: durante los cinco primeros minutos, los alumnos completaron un cuestionario ${ }^{137}$ online, diseñado a través de Google Docs, cuyas preguntas intentaban sondear, en primer lugar, su nivel de consumo habitual de programas televisivos en su lengua materna; y en segundo, lugar, sus hábitos y experiencia en cuanto al visionado de programas televisivos en español. La propuesta didáctica ${ }^{138}$ — actividades de previsionado y actividades durante el visionado ${ }^{139}$ — se llevó a cabo durante los cuarenta minutos siguientes. Aunque las actividades se realizaron en grupo por

\footnotetext{
132 Véase el apartado 7.7. Propuesta de actividades para la explotación de un programa documental de la sección 7. Propuestas didácticas para la explotación de programas de televisión en la clase de ELE.

133 Universidad pública, fundada en 1887, ubicada en Morgantown, Virginia Occidental, Estados Unidos.

134 En Estados Unidos, comité encargado de la aprobación y seguimiento de cualquier investigación que involucre a personas.

${ }^{135}$ Departamento de Lenguas del Mundo, Literaturas y Lingüística.

${ }^{136}$ Véase Anexo IV y Anexo V.

${ }^{137}$ Véase Anexo II (inglés) o Anexo III (español).

${ }^{138}$ Véase nota 132.

139 Por limitaciones de tiempo, las actividades de posvisionado - que en esta propuesta didáctica consisten en escribir una receta y grabar un vídeo explicándola, y cuyo objetivo es desarrollar la compresión y la expresión escrita, y por último la expresión oral— se propusieron como una actividad optativa fuera de clase.
} 


\section{ESTUDIOS EMPÍRICOS}

cuestiones de tiempo, cada alumno fue completando su hoja de preguntas individualmente. Finalmente, durante los últimos cinco minutos, los alumnos rellenaron un segundo cuestionario en el que se les pedía que valoraran la formación que acababan de recibir y su reciente experiencia trabajando con programas televisivos en la clase de español. En cuanto a las actividades de posvisionado, estas se propusieron - de nuevo por limitaciones de tiempocomo práctica optativa para realizar fuera de clase ${ }^{140}$. Los alumnos que las llevaron a cabo completaron, posteriormente, un tercer y último cuestionario que nos permitió obtener también una valoración de estas actividades.

La muestra total recogida nos permitió analizar las respuestas de 42 estudiantes $^{141}$, 29 alumnas y 13 alumnos, en su mayoría estadounidenses ${ }^{142}$ de 19 a 23 años ${ }^{143}$. En cuanto a su nivel de español, basándonos en el criterio de admisión de este curso, podemos confirmar que se trata de un nivel intermedioalto, equivalente al nivel B2 del MCER (2002). El requisito mínimo para que el alumno pueda matricularse en esta asignatura es que haya cursado y aprobado, al menos, tres cursos de español — de un semestre de duración cada unoimpartidos también en la universidad, o que haya pasado un examen de nivel establecido por el departamento de español. No obstante, a la hora de analizar las respuestas obtenidas a través de los cuestionarios y de elaborar conclusiones, tuvimos en cuenta la formación previa de cada alumno, pues muchos de ellos, 25 concretamente, declararon haber aprendido español en la secundaria.

Entre las cuestiones básicas, destacamos aquellas que hacen referencia al reconocimiento por parte de los propios alumnos de la utilidad de los programas televisivos como herramienta para su aprendizaje del español como lengua extranjera: para mejorar su comprensión oral, aprender gramática, vocabulario, expresiones, rasgos de la pronunciación, conocer la cultura española e incluso para animarse a ver programas televisivos en español fuera de clase.

Los datos obtenidos en este segundo estudio nos llevaron a confirmar de nuevo que una gran mayoría de alumnos, además de disfrutar trabajando con este

\footnotetext{
${ }^{140}$ Las actividades de posvisionado fueron puestas en práctica por 11 estudiantes, 6 alumnas y 5 alumnos, del total de 42 que asistieron a la clase experimental.

${ }^{141}$ Ninguno de estos alumnos participó en el primer estudio empírico descrito en el apartado 7.1. Estudio empírico de la propuesta didáctica para la explotación de un programa de cocina de esta tesis, por lo que la muestra total de alumnos participantes en esta investigación fue de 82.

${ }^{142}$ Solo 1 de los alumnos declaró ser de origen hispano (colombiano).

${ }^{143}$ En concreto cinco alumnos de 19 años, trece de 20, trece de 21, cinco de 22 y seis de 23.
} 
material, considera que el programa televisivo es un recurso de utilidad para el aprendizaje de español por varios y diversos motivos. La lectura de los datos obtenidos en el análisis de los cuestionarios de los alumnos nos sirvió para demostrar que la propuesta didáctica utilizada en este estudio permite desarrollar actividades comunicativas de la lengua, tanto de comprensión como de expresión; competencias de la lengua -léxicas, gramaticales, socioculturales y pragmáticas-; así como la capacidad de autoaprendizaje del alumno.

\subsubsection{Datos extraídos del cuestionario realizado por los alumnos \\ APARTADO I. TU CONSUMO HABITUAL DE PROGRAMAS TELEVISIVOS}

\section{4. ¿Con qué frecuencia ves el siguiente contenido audiovisual?}

\subsection{Programas de televisión}

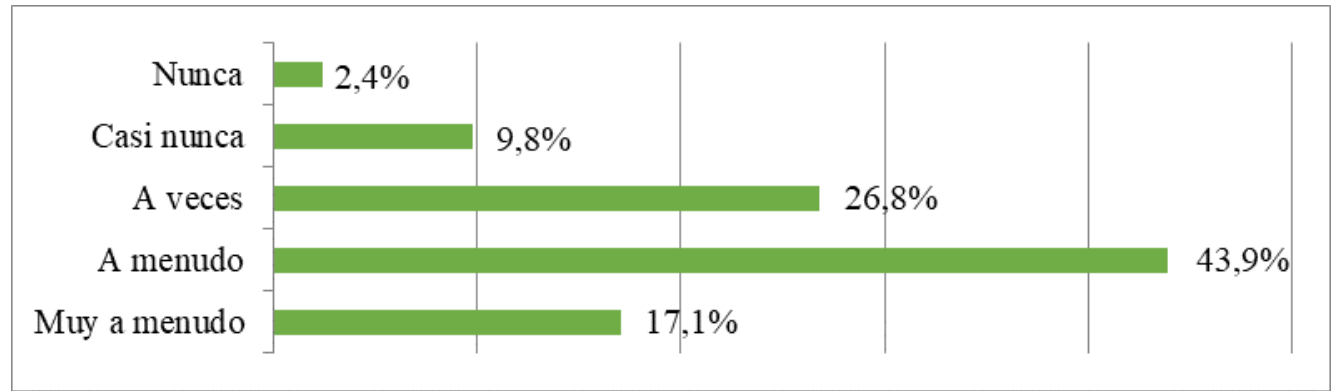

Figura 45. Frecuencia con la que los alumnos declaran ver programas de televisión.

\subsection{Anuncios publicitarios}




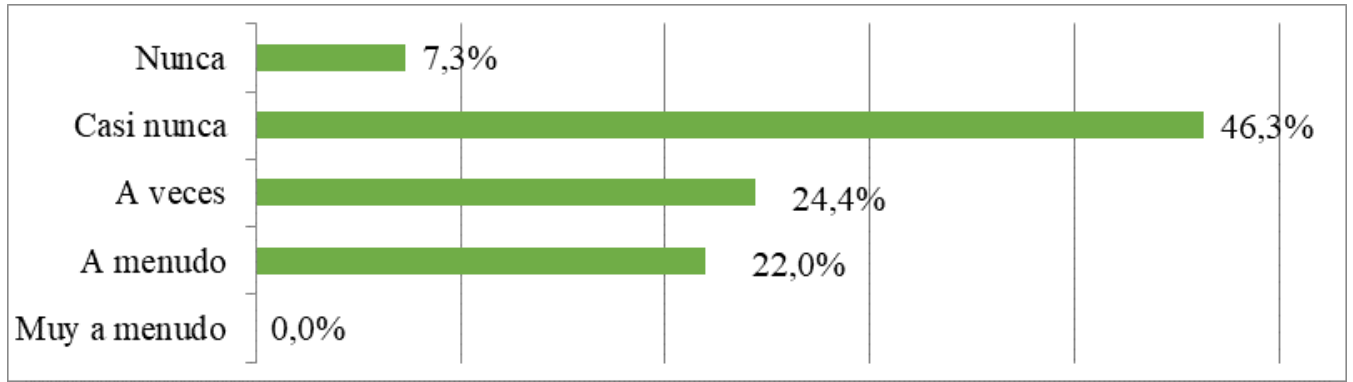

Figura 46. Frecuencia con la que los alumnos declaran ver anuncios publicitarios.

\subsection{Películas}

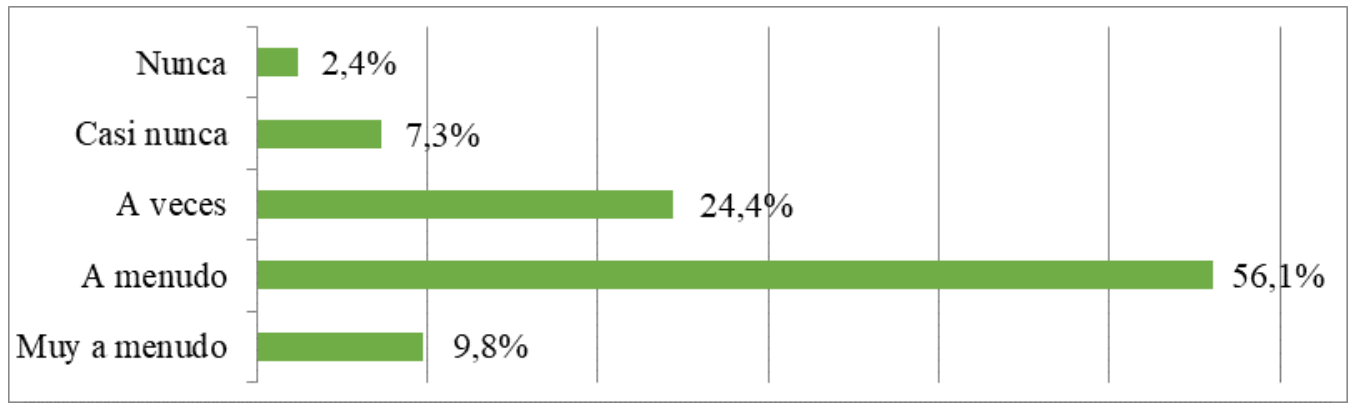

Figura 47. Frecuencia con la que los alumnos declaran ver películas.

\subsection{Tráiler}

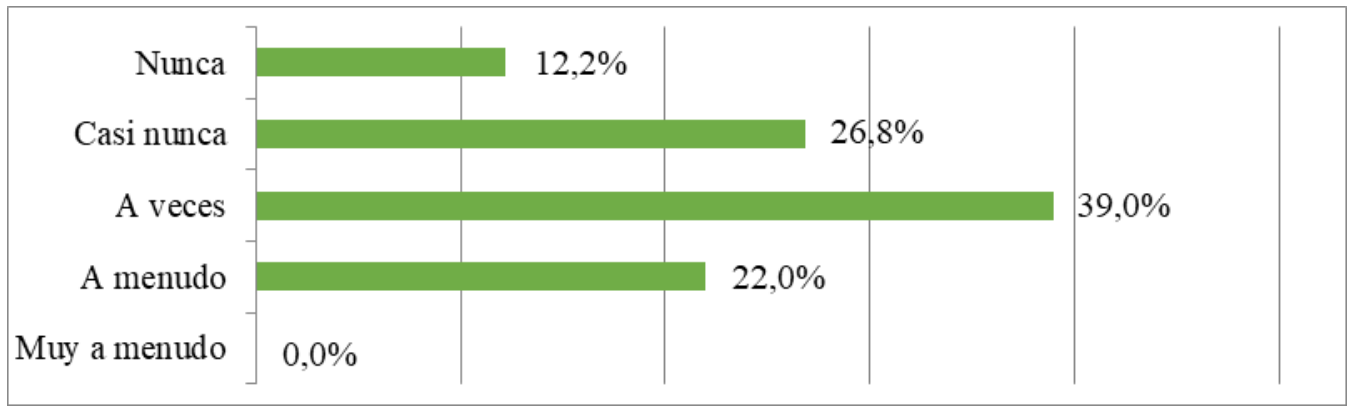

Figura 48. Frecuencia con la que los alumnos declaran ver tráileres.

\subsection{Cortometrajes}


EL PROGRAMA TELEVISIVO COMO RECURSO PARA LA

ENSEÑANZA/APRENDIZAJE DE ESPAÑOL LENGUA EXTRANJERA

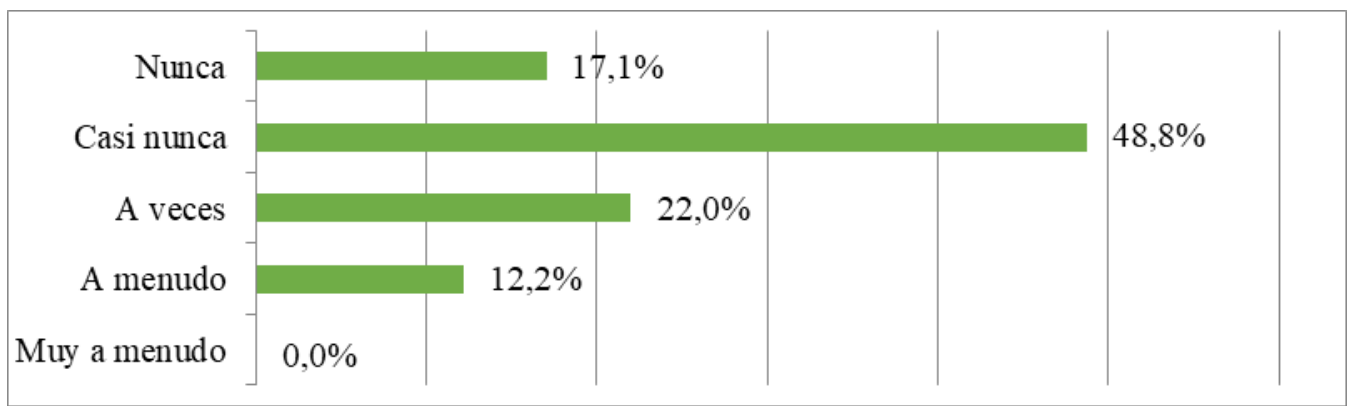

Figura 49. Frecuencia con la que los alumnos declaran ver cortometrajes.

5. Aproximadamente, ¿cuántos programas de televisión ves en tu lengua materna?

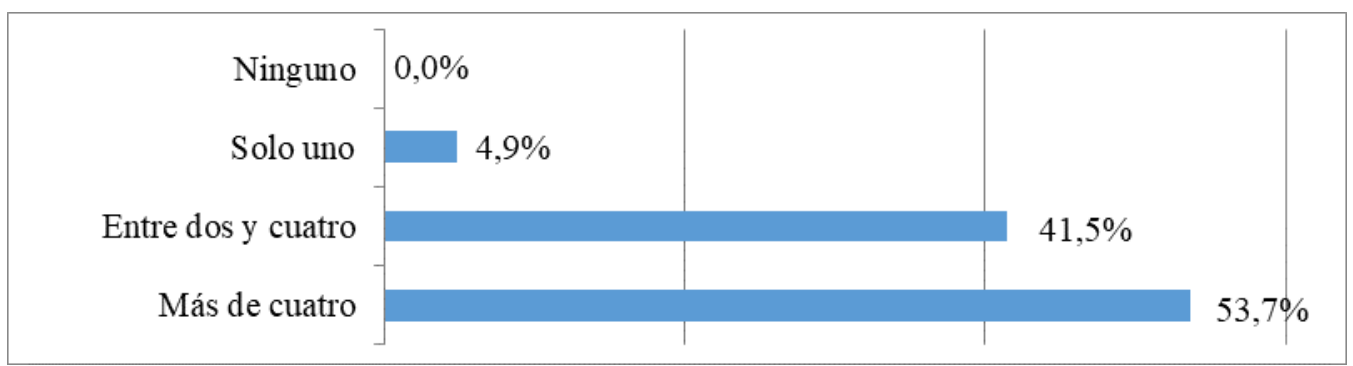

Figura 50. Número de programas de televisión que los alumnos declaran ver en su lengua materna.

6. ¿Cuáles de los siguientes tipos de programas televisivos ves y con qué frecuencia?

3.1. Informativos (Telediario, reportajes de actualidad, tertulias, el tiempo...)

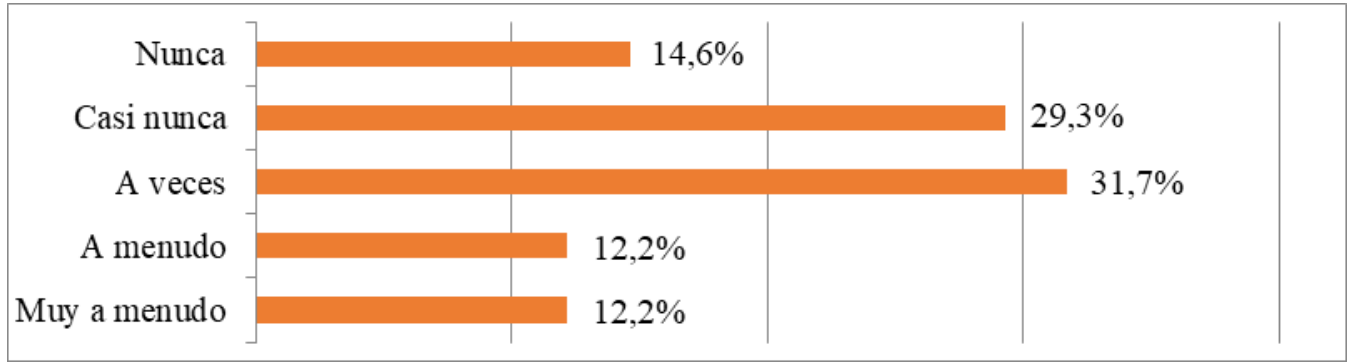

Figura 51. Frecuencia con la que los alumnos declaran ver programas televisivos informativos. 


\subsection{Culturales (Documental, educativo...)}

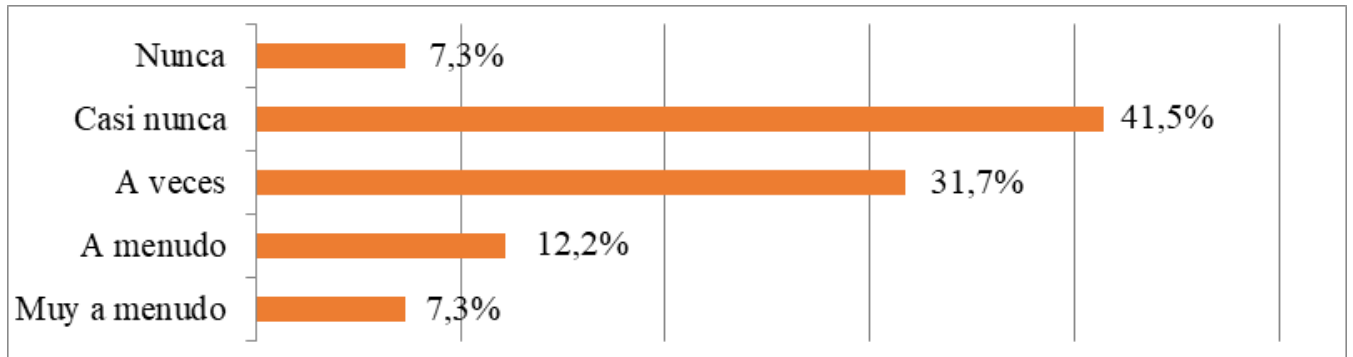

Figura 52. Frecuencia con la que los alumnos declaran ver programas televisivos culturales.

\subsection{Ficción (Series, miniseries, telenovelas...)}

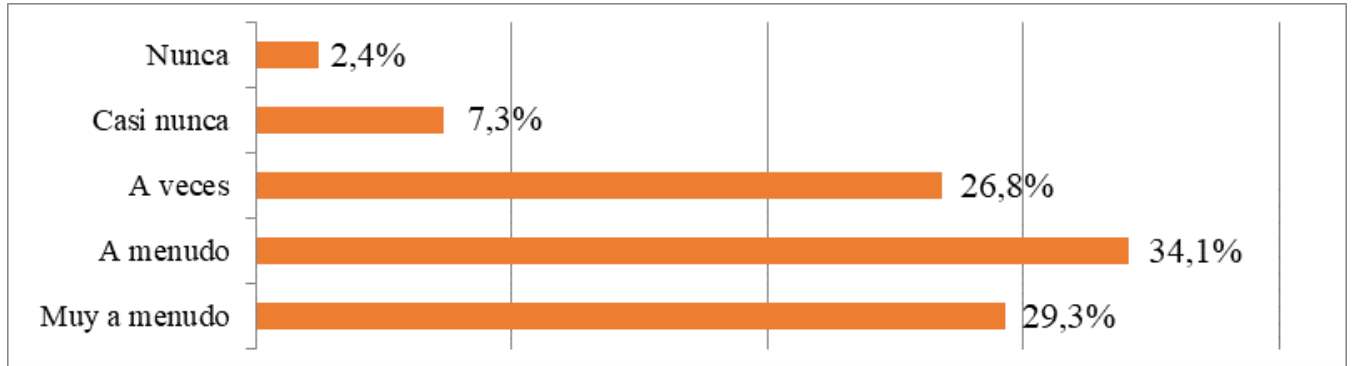

Figura 53. Frecuencia con la que los alumnos declaran ver programas televisivos de ficción.

\subsection{Entretenimiento (talk-shows, reality-shows, magacines, concursos, galas...)}

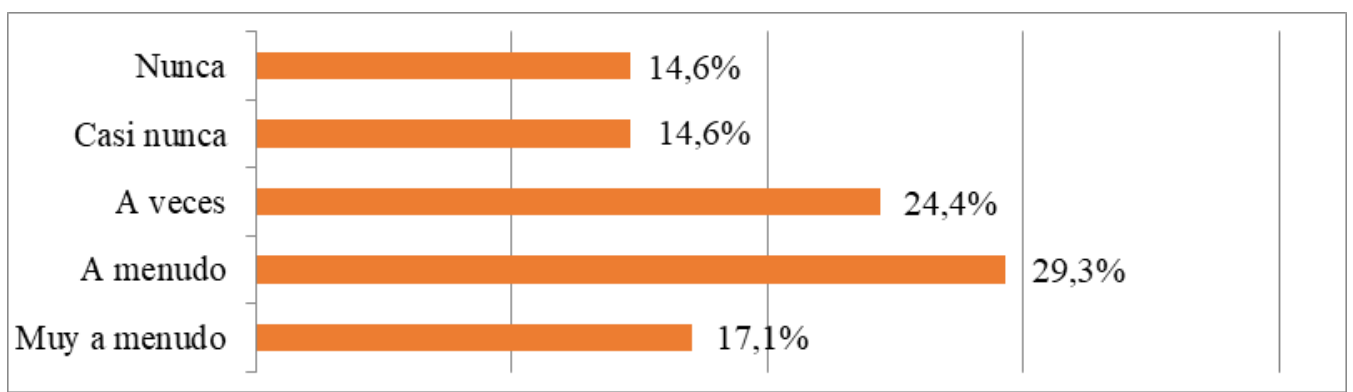

Figura 54. Frecuencia con la que los alumnos declaran ver programas televisivos de entretenimiento. 
3.4. Deportes (programas específicos, retransmisiones de competiciones, eventos especiales...)

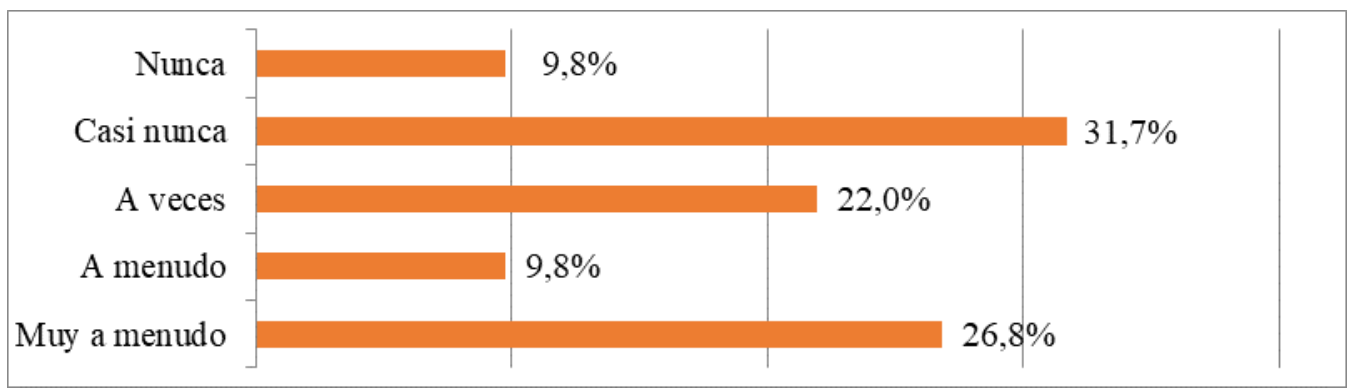

Figura 55. Frecuencia con la que los alumnos declaran ver programas televisivos de deportes.

\section{APARTADO II. TUS HÁBITOS COMO ESTUDIANTE DE ESPAÑOL EN CUANTO AL USO DE PROGRAMAS TELEVISIVOS}

17. ¿Sueles ver programas televisivos en español?

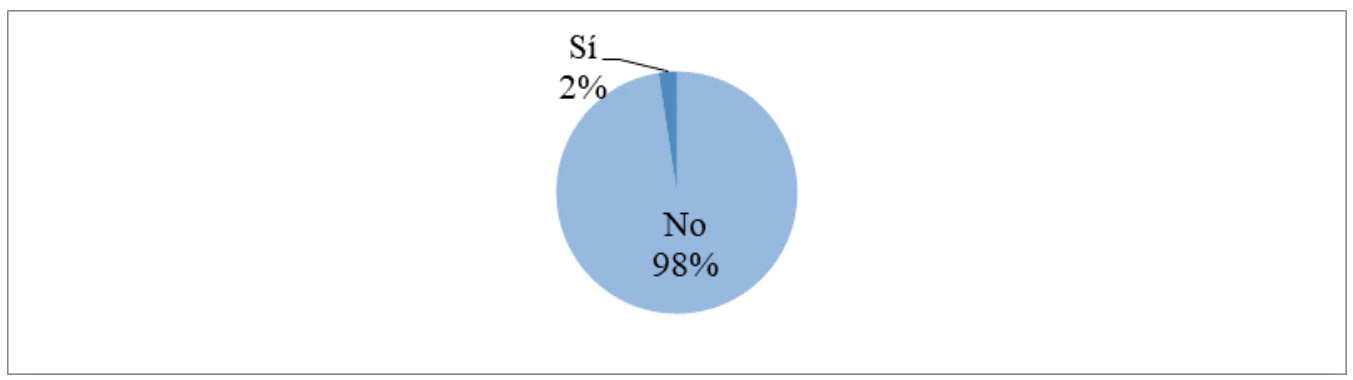

Figura 56. Porcentaje de alumnos que declara ver programas televisivos en español.

Si tu respuesta fue sí, ¿para qué crees que son útiles?

1. La exposición a conversaciones reales en español facilita el aprendizaje. ${ }^{144}$

\footnotetext{
${ }^{144}$ De los cuarenta y dos participantes, solo un alumno estadounidense de 23 años respondió sía esta pregunta. Esta cifra coincide con la obtenida en el primer estudio empírico.
} 


\section{ESTUDIOS EMPÍRICOS}

\section{Si tu respuesta fue no, ¿para qué crees que podrían ser útiles? ${ }^{145}$}

1. Para practicar y mejorar mis habilidades en español.

2. Cuanto más te expones al idioma, mejor lo entiendes.

3. Es bueno ver programas en español para aprender el idioma escuchando a más personas que lo hablan.

4. Para aumentar mis conocimientos sobre la cultura española.

5. Para aprender el idioma en contexto.

6. Ver el idioma "en acción" ayuda a aprender.

7. Para aprender el lenguaje conversacional.

8. Podrían ser útiles si estuvieran relacionados con temas que realmente nos interesen.

9. Para ayudarme a mejorar el acento.

10. Para ver cómo hablan los hablantes nativos de español y fijarme en su pronunciación.

11. Para ayudarme a familiarizarme con el idioma y ver cómo se usa en conversaciones.

12. Para ayudarme a retener mis conocimientos de español.

13. Para familiarizarme con la cultura española.

14. Para entender el acento y aprender el idioma en contexto.

15. Para ayudarme a entender a los hablantes de español cuando hablan con fluidez.

16. Para ver cómo usan el idioma los hablantes nativos.

17. Para entender el español hablado a ritmo rápido.

18. Para ver el idioma en situaciones reales.

19. Para aprender la pronunciación adecuada.

\section{8. ¿Alguna vez has tenido una clase de español que incorporara programas televisivos?}

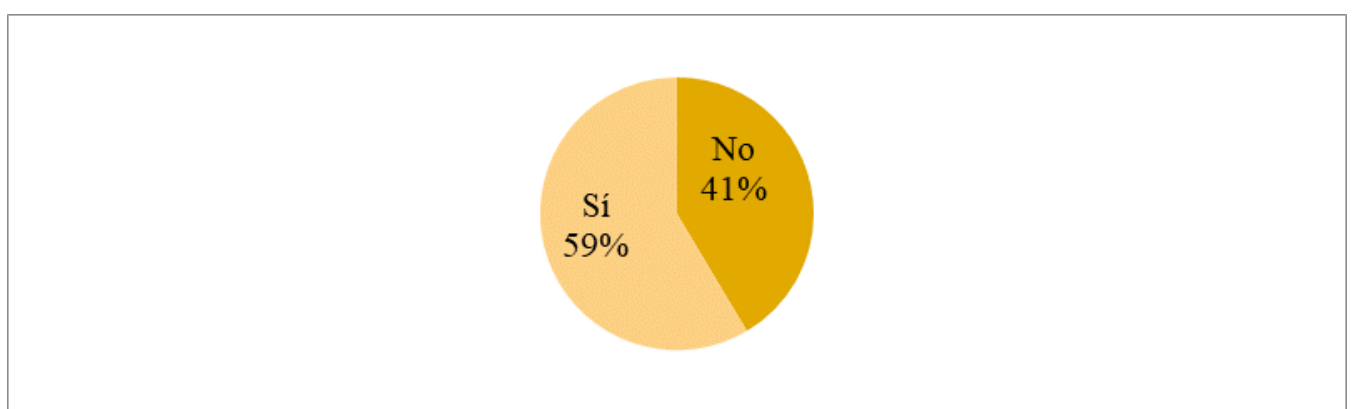

Figura 57. Porcentaje de alumnos que declara haber tenido alguna vez una clase de español que incorporara programas televisivos.

\section{Si tu respuesta fue sí, ¿te pareció útil?, ¿por qué?}

\footnotetext{
145 Todas las preguntas del cuestionario en las que se invita al alumno a justificar su respuesta son de tipo opcional. Aquí incluimos una selección de comentarios.
} 


\section{EL PROGRAMA TELEVISIVO COMO RECURSO PARA LA ENSEÑANZA/APRENDIZAJE DE ESPAÑOL LENGUA EXTRANJERA}

1. Fue divertido y nos ayudó a captar la verdadera esencia de la cultura popular de Latinoamérica.

2. La clase captó mi atención y disfruté.

3. Fue interesante ver conversaciones reales en vez de tener otra clase normal y corriente.

4. Nos ayudó mucho con la comprensión auditiva incluso aunque no fuéramos capaces de entenderlo todo.

5. Me ayudó con mis conocimientos de gramática.

6. Escuchar a otros ayuda mucho.

7. Podías entender mejor lo que estaba pasando gracias a las imágenes.

8. Como era para nuestro nivel de español fue fácil seguirlo y me ayudó mucho a aprender palabras y expresiones.

9. Me ayudó a entender el ritmo y la pronunciación más difíciles del español.

10. Fue útil escuchar diferentes dialectos del español.

11. En el instituto solíamos ver películas españolas actuales con subtitulos en inglés. Me parecía útil porque era entretenido y a la vez estábamos escuchando español, así que estábamos aprendiendo.

\section{Si tu respuesta fue no, ¿te gustaría trabajar con programas televisivos en tus clases de español?, ¿por qué?}

1. Sí, porque me ayudaría a expresarme mejor en español.

2. Sí, porque si te interesa un programa televisivo es más probable que te esfuerces en entender lo que se está diciendo.

3. Sí, porque ayudaría a dar sentido a las frases.

4. Sí, creo que sería divertido y entretenido.

5. Sí, creo que escuchar y leer subtítulos puede ayudar.

6. Sí, nos podría enseñar a pronunciar correctamente.

7. Sí, creo que mejoraría la experiencia del aprendizaje del idioma.

8. Sí, porque nos ayudaría mucho con nuestra comprensión y expresión orales.

9. Sí, creo que nos haría involucrarnos más en la clase.

\section{APARTADO III ${ }^{146}$. TU RECIENTE EXPERIENCIA COMO ESTUDIANTE DE ESPAÑOL EN CUANTO AL USO DE PROGRAMAS TELEVISIVOS}

${ }^{146}$ Apartado a contestar al final de la clase experimental. 


\section{5. ¿Te ha gustado esta clase? Clasifica tu respuesta de 1 (no me ha gustado) a 10 (me ha gustado mucho).}

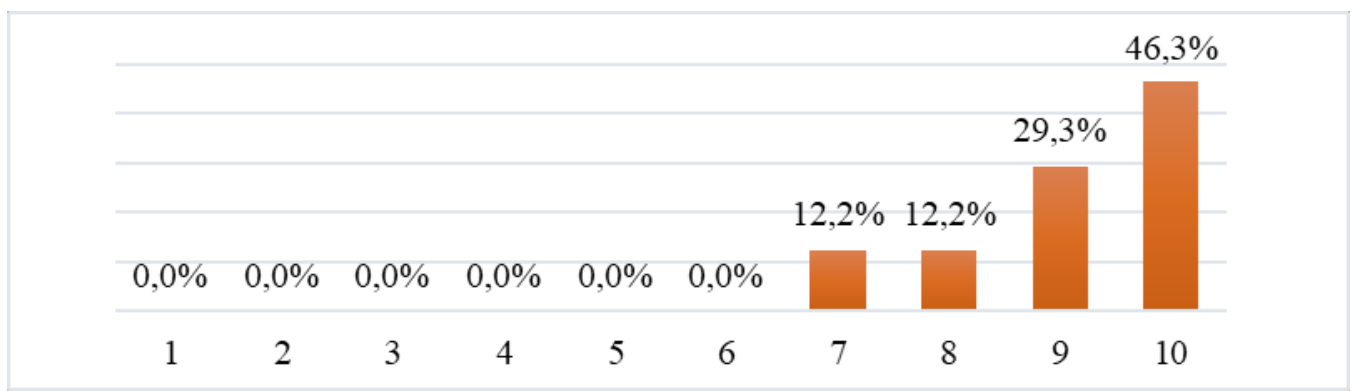

Figura 58. Valoración general de los alumnos (de 1 a 10) de la clase recibida en este estudio empírico.

\section{¿Por qué?}

1. Sí, fue más realista e interactivo.

2. Sí, fue muy divertido e interesante.

3. Sí, fue muy útil y disfruté mucho.

4. Sí, la clase fue interactiva y muy estimulante.

5. Sí, aunque en el vídeo hablaban rápido, fue muy interesante y pude entender mejor según me iba acostumbrando a ello.

6. Sí, fue difícil de entender pero aun así muy útil.

7. Si, me gusta escuchar a otras personas hablar en español con otros acentos.

8. Sí, me dio la oportunidad de escuchar español como lo hacen los nativos.

9. Sí, fue una nueva experiencia.

10. Sí, fue difícil pero creo que aprendí mucho.

11. Sí, la clase se me hizo mucho más interesante.

\section{6. ¿Te ha parecido útil esta clase? Clasifica tu respuesta de 1 (no me ha gustado) a 10 (me ha gustado mucho).}

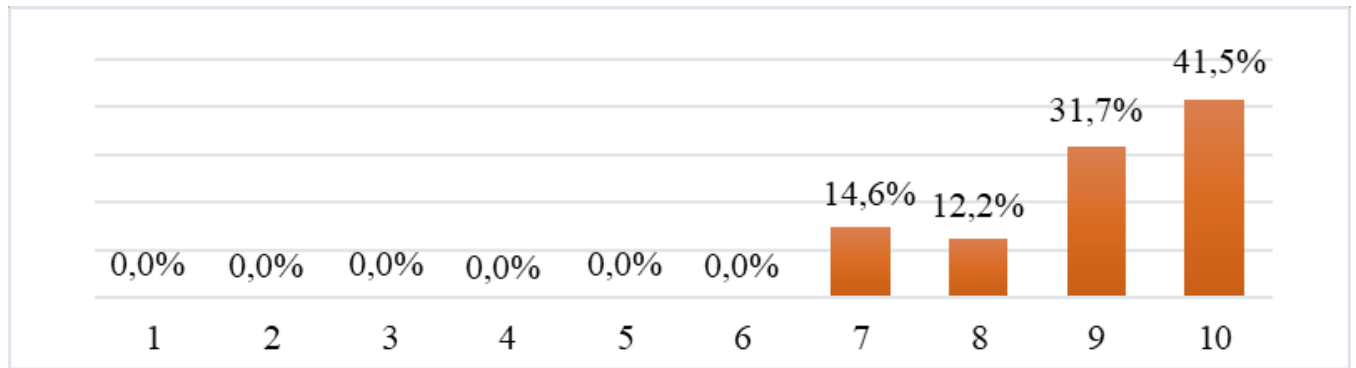

Figura 59. Valoración de los alumnos (de 1 a 10) de la utilidad de la clase recibida en este estudio empírico. 


\section{EL PROGRAMA TELEVISIVO COMO RECURSO PARA LA \\ ENSEÑANZA/APRENDIZAJE DE ESPAÑOL LENGUA EXTRANJERA}

\section{¿Por qué?}

1. Sí, porque ha sido más realista.

2. Sí, porque Sara ha parado y repetido las partes del vídeo que más nos costaba entender y asi hemos podido aprender al ritmo que necesitábamos.

3. Sí, porque he aprendido algo más de la cultura española.

4. Sí, porque he entendido más de lo que esperaba.

5. Sí, porque escuchar hablantes nativos de español te ayuda a entender cómo sería estar en un país de habla hispana.

6. Sí, porque nos ha permitido aprender con un contexto.

7. Sí, porque he escuchado español a su velocidad normal.

8. Sí, porque hemos aprendido de una forma entretenida.

9. Sí, porque me ha hecho darme cuenta de lo rápido que hablan los hablantes nativos de español.

10. Sí, porque esta experiencia ha sido muy interesante.

\section{7. ¿Te han parecido útiles las actividades de previsionado? Clasifica tu respuesta de 1 (no me ha gustado) a 10 (me ha gustado mucho).}

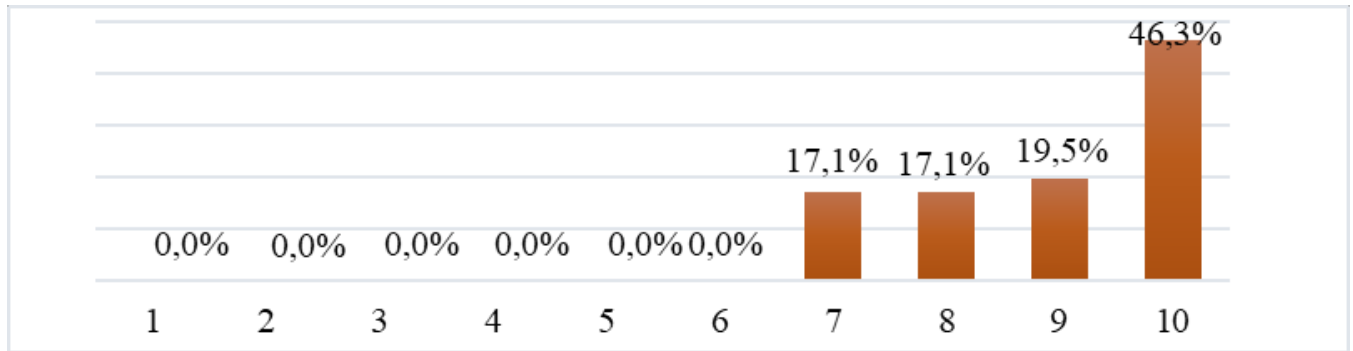

Figura 60. Valoración de los alumnos (de 1 a 10) de las actividades de previsionado de la propuesta didáctica empleada en este estudio empírico.

\section{¿Por qué?}

1. Sí, porque me han puesto en situación antes de ver el vídeo.

2. Sí, porque te ayudan a prepararte para la clase.

3. Sí, porque te ayudan a escuchar con más atención.

4. Sí, porque nos han estimulado a pensar en viajar y a tener la mentalidad adecuada para ver el vídeo.

5. Sí, porque ha sido otra forma de practicar.

6. Sí, porque nos han mostrado la diferencia entre leer y escuchar. 
7. Sí, porque me han ayudado a ampliar mis conocimientos geográficos sobre los países hispanos.

8. Si, porque ha sido como un calentamiento para ver el vídeo y nos ha ayudado a prepararnos para prestar atención.

8. Después de esta clase, ¿para qué crees que es útil ver programas televisivos en la clase de español? (Puedes señalar una o varias respuestas)

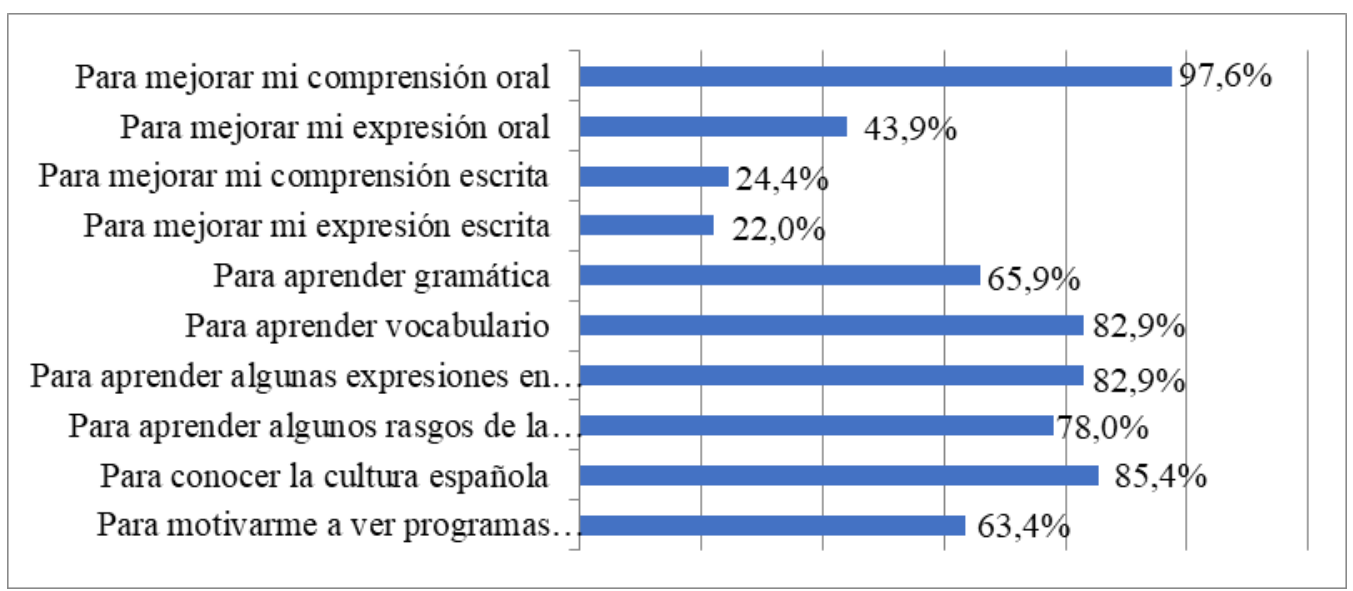

Figura 61. Aspectos que los alumnos consideran que se podrían trabajar mediante la visualización de programas televisivos en la clase de español.

\section{APARTADO IV ${ }^{147}$. TU RECIENTE EXPERIENCIA COMO \\ ESTUDIANTE DE ESPAÑOL EN CUANTO AL USO DE PROGRAMAS TELEVISIVOS FUERA DE CLASE}

6. ¿Te ha parecido útil la actividad de posvisionado de escribir un texto sobre un país hispanoamericano? Clasifica tu respuesta de 1 (no me ha parecido útil) a 10 (me ha parecido muy útil).

${ }^{147}$ A responder tras haber realizado las actividades de posvisionado. 
EL PROGRAMA TELEVISIVO COMO RECURSO PARA LA

ENSEÑANZA/APRENDIZAJE DE ESPAÑOL LENGUA EXTRANJERA

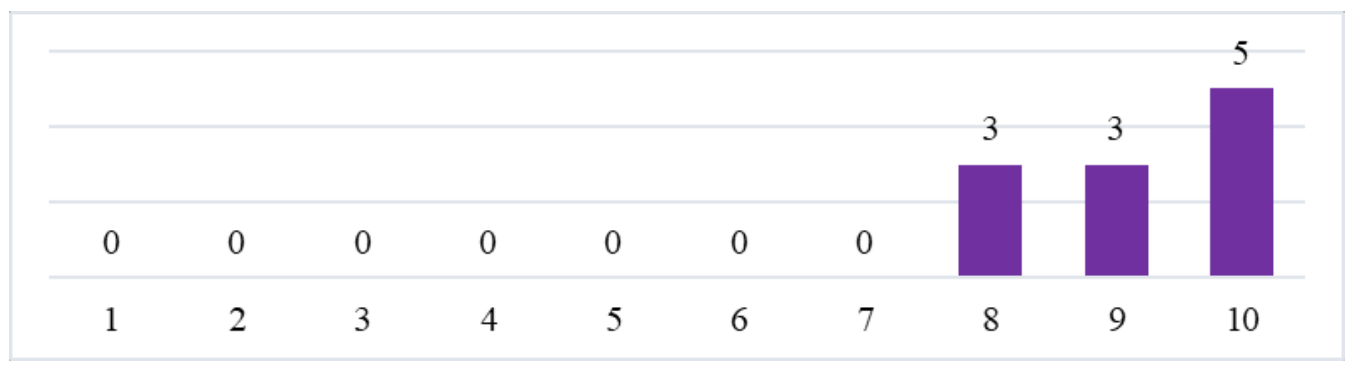

Figura 62. Valoración de los alumnos (de 1 a 10) de la actividad de posvisionado consistente en escribir una receta de cocina.

\section{¿Por qué?}

1. Sí, porque me ha parecido una forma interesante de aprender sobre otra cultura.

2. Sí, porque dentro de unas semanas voy a viajar a Ecuador, así que me ha venido muy bien escribir un texto sobre ese país para aprender cosas que me van a ser útiles en el viaje.

3. Sí, porque se aprende sobre el país a la vez que se aprende a escribir en español.

4. Sí, porque he podido aprender sobre la cultura y la tradición del país que he escogido.

5. Si, porque he aprendido algo más sobre un país de Hispanoamérica.

6. Sí, porque he aprendido muchas cosas sobre Argentina que no sabia.

7. Sí, porque he aprendido más sobre mi cultura. ${ }^{148}$

8. Sí, porque he aprendido sobre la cultura de México.

9. Sí, porque me ha ayudado a mejorar mi escritura en español.

\section{7. ¿Leíste información en español antes de escribir el texto?}

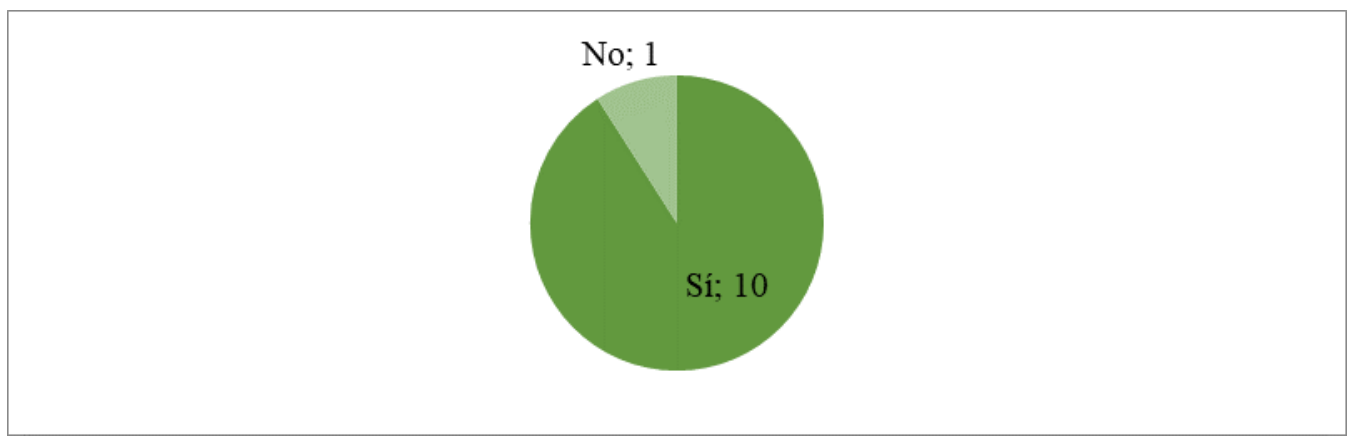

Figura 63. Número de alumnos que declaró haber leído algunas recetas en español antes de escribir su receta.

${ }^{148}$ Comentario del alumno de origen hispano (colombiano). 


\section{ESTUDIOS EMPÍRICOS}

\section{¿Por qué?}

1. Sí, porque necesitaba información sobre el país que escogí.

2. Sí, porque no conocía toda la información antes de crear el texto.

3. Sí, porque me ayudó a entender lo que quería decir.

4. Sí, porque necesitaba saber de lo que iba a hablar.

5. Sí, porque así era más fácil escribir el texto.

6. Sí, porque necesitaba tener de referencia la estructura de las frases en español. Me cuesta mucho eso y leer antes de escribir me ayuda.

7. Sí, porque quería comprobar si estaba escribiendo las palabras correctamente.

8. Sí, porque quería que la información fuera precisa.

9. Sí, porque quería recopilar información para escribir el texto.

10. No, no lei ninguna información en español, la lei en inglés y la traduje.

\section{8. ¿Te ha parecido útil la actividad de posvisionado de grabar un vídeo? Clasifica tu respuesta de 1 (no me ha parecido útil) a 10 (me ha parecido muy útil).}

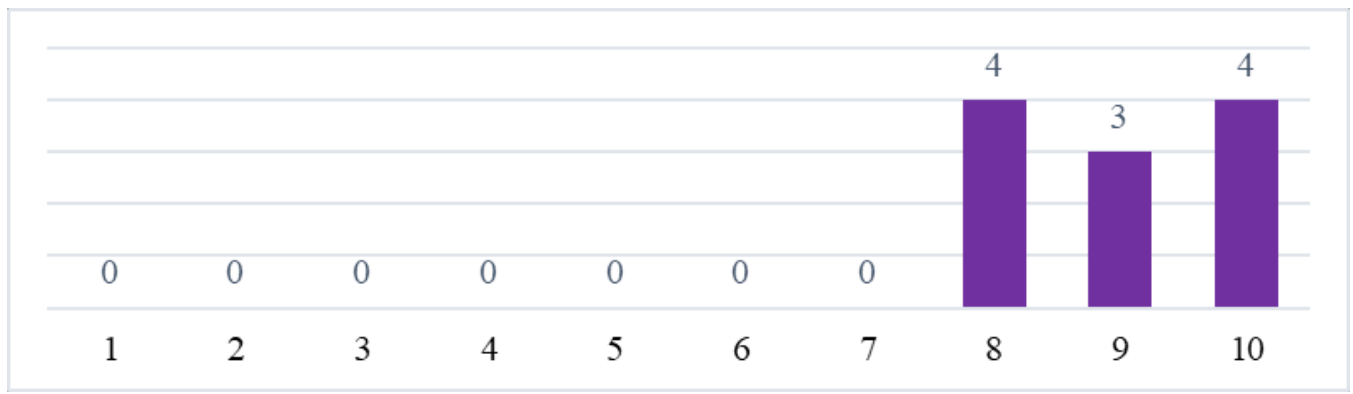

Figura 64. Valoración de los alumnos (de 1 a 10) de la actividad de posvisionado consistente en grabar un vídeo de sí mismos explicando una receta de cocina.

\section{¿Por qué?}

1. Sí, porque hablar en español me ayuda a solidificar mis conocimientos del idioma.

2. Sí, porque fui capaz de hablar sobre mi ciudad en español de forma natural.

3. Sí, porque me motivó a hablar y a esforzarme en mi acento.

4. Sí, porque me dio la oportunidad de hablar español y eso es mejor que solo leer y escribir.

5. Sí, porque me hizo sentirme más cómodo al hablar.

6. Sí, porque hablar en alto ayuda a conectar frases y oraciones.

7. Sí, porque hablar en español me cuesta mucho. Tuve que grabar el vídeo más de cuatro veces porque metía la pata.

8. Sí, porque me di cuenta de que me gusta el español más de lo que pensaba.

9. Sí, porque fue divertido. 


\section{EL PROGRAMA TELEVISIVO COMO RECURSO PARA LA \\ ENSEÑANZA/APRENDIZAJE DE ESPAÑOL LENGUA EXTRANJERA}

10. Sí, porque ha sido una oportunidad de practicar y de mejorar nuestra pronunciación en un ambiente cómodo y relajado.

\section{9. ¿Esta fue la primera vez que te grabaste hablando en otro idioma?}

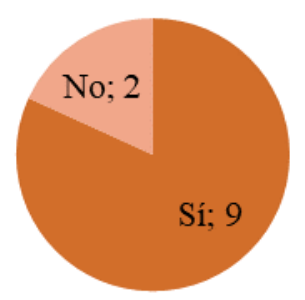

Figura 65. Número de alumnos que declaró haberse grabado por primera vez hablando en otro idioma al realizar esta actividad de posvisionado.

\section{¿Cómo te sentiste?}

1. No, al principio me sentí rara pero se volvió más natural a medida que hablaba. Y tuve que hacerlo por lo menos cinco veces.

2. No, fue duro al principio pero fue muy gratificante darme cuenta de que podía hacerlo.

3. Sí, sentí que de verdad estaba practicando.

4. Sí, me gustó porque me di más cuenta de lo que estaba diciendo mal.

5. Sí, al principio me sentí rara pero después de varios intentos de grabación me acostumbré.

6. Sí, me sentí cómoda.

7. Sí, me sentí un poco rara y nerviosa pero solo al principio.

8. Sí, me sentí un poco nerviosa pero también intrigada.

\section{0. ¿Para qué crees que fueron útiles estas actividades de posvisionado?}




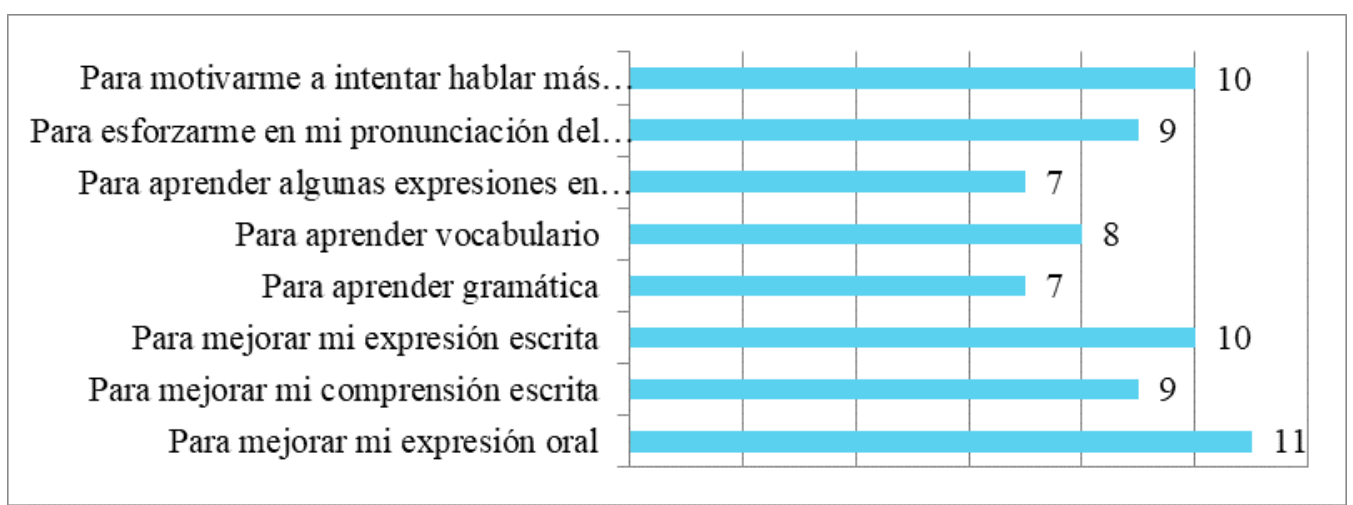

Figura 66. Aspectos que los alumnos consideran haber trabajado a través de las actividades de posvisionado de la propuesta didáctica de este estudio empírico.

\subsubsection{Análisis de los datos extraídos del cuestionario realizado por los alumnos}

- Los documentos audiovisuales de los que se registró un mayor consumo por parte de los estudiantes son, de mayor a menor, películas (el 65,9\% las ve a menudo o muy a menudo) programas de televisión (el 61\% los ve a menudo o muy a menudo), tráiler (también el $61 \%$ los ve a menudo o a veces), anuncios publicitarios (un $46 \%$ los ve a menudo o a veces) y, en último lugar, los cortometrajes (el $34 \%$ los ve a veces o a menudo pero nadie afirma verlos muy a menudo). Cabe destacar que solo un $2,4 \%$ declaró no ver nunca ni programas televisivos ni películas. Tanto el orden de consumo de los documentos audiovisuales propuestos, como el escaso porcentaje de alumnos que no ven nunca ni programas televisivos ni películas coinciden con los del primer estudio empírico ${ }^{149}$.

- En cuanto al número de programas de televisión (en su lengua materna) que ven normalmente los alumnos, registramos los siguientes datos: la mayoría (un 53,7\%) confiesa ver más de cuatro programas televisivos diferentes y un $41,5 \%$ declara ver entre dos y cuatro programas. Tan solo un 4,9\% ve solo un programa y ningún alumno afirmó no ver ninguno. Estos datos también son similares a los registrados en el primer estudio empírico.

- Los programas televisivos más populares entre los estudiantes son, de mayor a menor, los de ficción (el 63,4\% los ve muy a menudo o a menudo), los de entretenimiento (el $46,4 \%$ los ve muy a menudo o a menudo) y los programas de deportes (el $36,6 \%$ los ve muy a menudo o a menudo). Sin

\footnotetext{
149 Véase el apartado 8.1. Estudio empírico de la propuesta didáctica para la explotación de un programa de cocina.
} 


\section{EL PROGRAMA TELEVISIVO COMO RECURSO PARA LA ENSEÑANZA/APRENDIZAJE DE ESPAÑOL LENGUA EXTRANJERA}

embargo, la mayoría declara solo ver a veces o casi nunca programas culturales (el 73,2\%) y programas informativos (el 61\%). El hecho de que estos datos también coincidan con los del primer estudio demuestra nuevamente que las series de televisión y los programas de entretenimiento, como los talk-shows o los reality-shows, son los programas televisivos preferidos por los jóvenes.

- Por lo que se refiere a sus hábitos de uso de programas televisivos en español, la gran mayoría (el 98\%, cifra que coincide con la obtenida en el primer estudio empírico) confesó no ver nunca programas televisivos en español. El único estudiante que afirmó verlos, un joven estadounidense de 23 años, comentó que exponerse a conversaciones reales en español le facilita el aprendizaje. Sin embargo, muchos de los alumnos que declararon no verlos, admitieron que esta práctica podría ayudarles a entender mejor el idioma, familiarizarse con él, mejorar su acento, aumentar sus conocimientos sobre la cultura española, ver cómo se usa el idioma en conversaciones reales, y para acostumbrarse a la fluidez y rapidez con la que hablan los hablantes nativos, entre otros aspectos.

- Siguiendo con los hábitos de estos alumnos en cuanto al uso de programas televisivos en español. En este estudio empírico, a diferencia del primero, la mayoría (el 59\%) afirmó haber tenido una clase de español en la que se trabajara con programas televisivos. Puede que el incremento de este porcentaje, respecto al obtenido en el primer estudio, se deba al nivel intermedio-alto de los alumnos participantes. El hecho de haber recibido más clases de español aumenta la probabilidad de que alguna de estas haya incluido programas televisivos, especialmente alguna de las clases que han recibido en sus últimos años de estudios. Los alumnos que respondieron afirmativamente comentaron que la clase captó su atención y les hizo disfrutar, les ayudó a entender el ritmo y pronunciación "más difíciles" del español, y les permitió aumentar sus conocimientos culturales y gramaticales. Algunos también comentaron que las imágenes les ayudaron a comprender y que, incluso sin ser capaces de entenderlo todo, mejoraron su comprensión auditiva. Aquellos que aún no han experimentado el hecho de trabajar en clase de español con este tipo de recurso, afirmaron que les gustaría hacerlo porque les ayudaría a comprender y expresarse mejor en español, a pronunciar correctamente y a dar sentido a las frases. Además, destacaron que sería una forma interesante, divertida y entretenida de aprender, y que incluso les haría involucrarse más en la clase. A diferencia de los participantes en el primer estudio, ninguno de estos alumnos comentó no tener el nivel suficiente para trabajar con programas televisivos en 


\section{ESTUDIOS EMPÍRICOS}

español o necesitar subtítulos para hacerlo. De nuevo, estas diferencias entre ambos grupos de estudio se pueden explicar por sus diferentes niveles de español. Recordemos que los alumnos que participaron en el primer estudio contaban con un nivel básico-inicial, mientras que en este segundo estudio todos los participantes habían alcanzado un nivel intermedio-alto.

- Al final de la clase experimental —en la que los alumnos realizaron la propuesta didáctica descrita anteriormente-, la gran mayoría (un $87,8 \%$ ) afirmó haber disfrutado mucho de la clase (calificándola con un 8,9 o 10 sobre 10). Algunos de los comentarios que aportaron para justificar su respuesta fueron que la clase les pareció realista, interactiva, estimulante, divertida e interesante. Incluso los alumnos que comentaron haber tenido dificultad para comprender el vídeo, valoraron positivamente esta experiencia argumentando que había sido muy útil e interesante, y que les había permitido aprender mucho. Esta valoración general tan positiva por parte de los alumnos también coincide con la obtenida al final de la clase experimental llevada a cabo en el primer estudio empírico.

- Tras la clase experimental, la gran mayoría de los alumnos (un 85,4\%) opinó que la clase le había parecido muy útil (calificándola con un 8, 9 o 10 sobre 10). Algunos de los comentarios que aportaron fueron que esta experiencia les había permitido aprender con un contexto, les había hecho darse cuenta de la velocidad a la que pueden llegar a hablar los hablantes nativos, y les había acercado a la cultura hispana. Algunos alumnos también confesaron haber entendido el vídeo mejor de lo que pensaban, gracias a las pausas y repeticiones que se hicieron a lo largo del visionado. Esta valoración tan positiva acerca de la utilidad de la clase también fue la que se registró en el primer estudio empírico.

- En cuanto a las actividades de previsionado ${ }^{150}$, la gran mayoría de alumnos (el 82,9\%) coincidió en que les habían parecido muy útiles (calificándolas con un 8,9 o 10 sobre 10). Los alumnos comentaron que estas actividades les habían servido de "calentamiento" para prepararse y prestar atención pues, en este caso, les habían estimulado a pensar en viajar y a tener la mentalidad adecuada activada para ver el vídeo. Algún alumno también concluyó, correctamente, que uno de los objetivos de estas actividades era el de practicar otras destrezas lingüísticas. En el caso de estas actividades, también coincide esta valoración general positiva con la obtenida en el primer estudio empírico. Cabe destacar dicha coincidencia, pues las

\footnotetext{
${ }^{150}$ Véase el apartado 7.7.1. Actividades de previsionado de la sección 7. Propuestas didácticas para la explotación de programas de televisión en la clase de ELE.
} 


\section{EL PROGRAMA TELEVISIVO COMO RECURSO PARA LA ENSEÑANZA/APRENDIZAJE DE ESPAÑOL LENGUA EXTRANJERA}

actividades de previsionado de este segundo estudio empírico no estaban tan orientadas a facilitar la comprensión del vídeo como las incluidas en la propuesta didáctica utilizada en el primer estudio empírico. De nuevo, esta diferencia en el diseño de las mismas se hizo teniendo en cuenta el nivel de los estudiantes.

- Al final de la clase experimental, los participantes concluyeron que ver programas televisivos en la clase de español es útil para mejorar su comprensión oral (el 97,6\%), conocer la cultura española (el 85,4\%), aprender algunas expresiones en español (un 82,9\%), aprender vocabulario (también un 82,9\%), aprender algunos rasgos de la pronunciación del español (un 78\%), aprender gramática (el 65,9\%) y para motivarlos a ver programas televisivos en español fuera de clase (el 63,4\%). Sin embargo, no tantos consideraron que el uso de programas televisivos en clase sea útil para mejorar su expresión oral (un 43\%), y muy pocos lo consideraron útil para mejorar su comprensión escrita (el 24,4\%) y su expresión escrita (el $22 \%$ ). Todos estos datos coinciden con los registrados en el primer estudio empírico. Finalmente, como veremos más adelante, y al igual que ocurrió en el primer estudio, los participantes que realizaron las actividades de posvisionado incluidas en esta propuesta declararon haber mejorado también estas tres competencias.

- En cuanto a la actividad de posvisionado ${ }^{151}$ que consistía en escribir una texto sobre un país hispanoamericano ${ }^{152}$, los 11 alumnos que la llevaron a cabo la calificaron como muy útil (valorándola con un 8 , un 9 o un 10 sobre 10). Estos alumnos comentaron que les había parecido una forma interesante de conocer otra cultura, y destacaron el hecho de haber aprendido algo sobre un país hispano al mismo tiempo que se esforzaban en escribir en español. Además, el que se les diera a los alumnos la libertad de elegir el país hispanoamericano sobre el que escribir su texto, hizo que esta actividad les resultara aún más motivadora. Por ejemplo, un alumno de origen hispano que escribió sobre Colombia señaló que con esta actividad había aprendido algo más sobre su cultura, mientras que otra alumna que habló de Ecuador comentó que lo que había aprendido escribiendo sobre ese país le iba a resultar muy útil en su próximo viaje a este destino. Estos

\footnotetext{
${ }^{151}$ Véase el apartado 7.7.3. Actividades de posvisionado de la sección 7. Propuestas didácticas para la explotación de programas de televisión en la clase de ELE.

152 Recordemos que una de las actividades de previsionado llevada a cabo en la clase experimental consistía en leer y resumir un texto sobre los términos 'Hispanoamérica', 'Iberoamérica' y 'Lationamérica'.
} 


\section{ESTUDIOS EMPÍRICOS}

resultados coinciden con los del primer estudio empírico, lo que es destacable teniendo en cuenta la variación del tema de la actividad de expresión escrita.

- Respecto a la actividad de posvisionado ${ }^{153}$ que consistía en grabar un vídeo de sí mismos presentando la ciudad y la universidad donde estudian ${ }^{154}$, también los 11 alumnos que llevaron a cabo esta propuesta la calificaron como muy útil (otorgándole un 8 , un 9 o un 10 sobre 10). Algunos de los argumentos que aportaron para justificar su respuesta fueron que esta actividad les había permitido hablar sobre su ciudad en español de forma natural —un 'tema' con el que están familiarizados - esforzarse en su acento, y practicar, ya que algunos confesaron haber grabado el vídeo varias veces. Además, destacaron el hecho de haber podido hablar de forma cómoda y relajada, pues aunque algunos grabaron su vídeo desde algún lugar de la ciudad o de la universidad, otros lo hicieron desde su casa. Para la mayoría (9 de los 11 alumnos que realizaron la actividad), esta era la primera vez que se grababa hablando en otro idioma. En general, los alumnos comentaron que, aunque al principio se habían sentido un poco 'raros' y nerviosos, esa sensación se había ido transformando en naturalidad y comodidad a medida que iban hablando; incluso afirmaron sentirse orgullosos del resultado. También comentaron que esta actividad les había permitido practicar 'de verdad' y darse cuenta de sus errores. Una vez más, estos resultados son similares a los del primer estudio empírico, lo que también es destacable en este caso por la variación de tema de la actividad de expresión oral.

- Tras haber puesto en práctica las dos actividades de posvisionado propuestas, los participantes se mostraron de acuerdo en que la combinación de ambos ejercicios es útil para mejorar su expresión escrita y su expresión oral, y para motivarlos a intentar hablar más español. La mayoría también consideró que estas dos actividades son útiles para aprender vocabulario (8 de los 11 participantes) y gramática ( 7 de los 11), y para esforzarse en su pronunciación del español. Finalmente, también la mayoría opinó que estas actividades también son útiles para mejorar su comprensión escrita ( 9 de los 11 participantes) y para aprender algunas expresiones en español ( 7 de los 11 participantes). Esta valoración general también coincide con la obtenida en el primer estudio empírico, lo que demuestra la efectividad no solo de las

\footnotetext{
${ }^{153}$ Véase nota 151.

${ }^{154}$ Recordemos que en este caso se trata de alumnos que asisten a la universidad West Virginia University, situada en la ciudad de Morgantown, en el estado de West Virginia (EEUU).
} 


\section{EL PROGRAMA TELEVISIVO COMO RECURSO PARA LA ENSEÑANZA/APRENDIZAJE DE ESPAÑOL LENGUA EXTRANJERA}

actividades de pre y durante el visionado, sino también de las actividades de posvisionado propuestas en esta tesis.

\subsubsection{Conclusiones}

El hecho de que los resultados de este segundo estudio empírico coincidan con los del primero, nos permite reafirmar las conclusiones elaboradas en el apartado 7.1.3 de esta tesis. De nuevo, podemos afirmar que la mayoría de los estudiantes encuestados ${ }^{155}$-al igual que los profesores encuestados ${ }^{156}$ considera que el uso del programa televisivo es o podría ser útil para la consecución de diferentes objetivos de aprendizaje, por su alto contenido cultural y social, su carácter de material real y auténtico, su capacidad de motivarlos e interesarles, y su posible uso para mejorar varias destrezas. En los datos obtenidos a través del cuestionario realizado a profesores, comprobamos que muchos docentes se limitan a utilizar en sus clases programas televisivos culturales o informativos, por considerarlos más educativos, y muy pocos explotan otro tipo de programas, como los de entretenimiento. Sin embargo, ambos estudios empíricos han revelado que los materiales audiovisuales preferidos por los alumnos son las películas y los programas televisivos, especialmente, de ficción y entretenimiento.

Por otro lado, el hecho de que en este segundo estudio empírico — realizado con alumnos de nivel intermedio-alto-, a diferencia del primero - llevado a cabo con estudiantes de nivel básico-, la mayoría de los alumnos encuestados afirmara haber tenido una clase de español en la que se trabajara con programas televisivos, nos lleva a deducir que la mayoría de profesores de español reserva este formato para las clases de nivel avanzado. Sin embargo, el hecho de que en ambos estudios la inmensa mayoría de los alumnos confesara no ver programas televisivos en español, en un país donde el español es el segundo idioma más hablado y donde es muy fácil acceder a contenido audiovisual en este idioma, reafirma la necesidad de exponer y acercar este recurso a los alumnos, de forma práctica y motivadora. Como ya comentamos, en el caso de Estados Unidos, esto también contribuye a eliminar los prejuicios y las actitudes negativas hacia

\footnotetext{
${ }^{155}$ Recordemos que los estudiantes encuestados en ambos estudios suman un total de 82 .

${ }^{156}$ Véase el apartado 5.5. Datos extraídos del cuestionario realizado por los profesores de la sección 5. Análisis de manuales y extracción de datos.
} 


\section{ESTUDIOS EMPÍRICOS}

el español que, por motivos de integración, surgieron y, en cierta manera, aún permanecen entre los inmigrantes hispanos.

Con este segundo estudio empírico hemos querido volver a demostrar que es posible elaborar una propuesta didáctica basada en el uso de programas televisivos que permita a los alumnos mejorar la comprensión y expresión oral, la comprensión y expresión escrita, aprender gramática, vocabulario, expresiones en español y rasgos de la pronunciación del español, conocer la cultura española, e incluso motivar a los alumnos tanto a ver programas de televisión en español fuera de clase como a intentar expresarse en la lengua que están aprendiendo. De este modo, ambos estudios nos permiten confirmar y reafirmar que, a través del formato del programa televisivo, se pueden diseñar y realizar actividades enfocadas a trabajar no solo las tres actividades comunicativas de la lengua - la comprensión oral, la interacción oral, y la expresión oral- y las cuatro competencias ${ }^{157}$ señaladas por los profesores encuestados $^{158}$ — sociocultural, léxica, gramatical y pragmática-.

En cuanto a los obstáculos que los profesores encuestados dijeron encontrar a la hora de trabajar con programas televisivos en el aula - la necesidad de tiempo para su preparación previa, su carácter de material actual, su difícil adaptación a los diferentes niveles y la posible desmotivación que esto puede provocar entre los alumnos de los niveles más básicos y, la ausencia o escasez de programas interesantes en la televisión española-, los resultados obtenidos en este segundo estudio empírico nos han permitido demostrar, de nuevo, que es posible trabajar con programas televisivos atemporales, como es el caso del programa documental utilizado en nuestra propuesta didáctica, y a la vez interesantes para los alumnos; y que una serie de actividades basada en el uso de programas televisivos es fácil de adaptar y posible de utilizar, desde los niveles más básicos hasta los más avanzados, sin perjudicar la motivación de alumnos.

\footnotetext{
${ }^{157}$ En el cuestionario a profesores, en la pregunta relativa a las competencias de la lengua que se podrían trabajar mediante la explotación didáctica de un programa televisivo, se dio la opción de seleccionar entre competencias gramaticales, léxicas, socioculturales y pragmáticas. Decidimos no incluir las competencias estratégicas y discursivas porque, como pudimos comprobar al realizar el análisis de manuales, estas no suelen tratarse como competencias independientes. No obstante, la propuesta didáctica empleada en este estudio empírico incluye actividades, basadas en el uso de programas televisivos, a través de las cuales se pueden desarrollar también estas dos competencias.

${ }^{158}$ Véase nota 156.
} 


\section{EL PROGRAMA TELEVISIVO COMO RECURSO PARA LA \\ ENSEÑANZA/APRENDIZAJE DE ESPAÑOL LENGUA EXTRANJERA}

Como última reflexión, es importante comentar que, dado que en el primer estudio empírico observamos que los estudiantes tenían dificultad para realizar las actividades de 'durante el visionado' al mismo tiempo que se reproducía el vídeo, en este segundo estudio empírico decidimos pausar y repetir aquellos fragmentos del vídeo relevantes para completar dichas actividades. Esta dinámica demostró tener más éxito que la anterior, y fue mejor valorada por los estudiantes. No hay que olvidar que el objetivo principal de trabajar con este tipo de formato es favorecer y potenciar el aprendizaje de los alumnos, no examinarlos y menos aún desmotivarlos.

Finalmente, todos los datos recogidos, tanto del análisis de manuales didácticos como de los resultados obtenidos a través del cuestionario dirigido a profesores de español como lengua extranjera, fueron tomados en consideración también para el diseño de la propuesta didáctica utilizada en este segundo estudio empírico. 
ESTUDIOS EMPÍRICOS 


\section{CONCLUSIONES}

En esta tesis doctoral hemos abordado el tema del uso del programa televisivo como recurso didáctico en el aula de ELE. En primer lugar, hemos aportado una base científica para dar coherencia y sentido a la propuesta de técnicas docentes para la explotación de dicho recurso. A continuación, hemos demostrado la rentabilidad didáctica de los programas televisivos en un contexto de enseñanza de una lengua extranjera. Por último, hemos presentado y llevado a la práctica, en un contexto académico real, actividades de explotación didáctica para estudiantes de español como lengua extranjera a partir de este tipo de programas.

La parte teórica de esta tesis nos ha permitido estudiar el estado de la cuestión - la competencia comunicativa en la enseñanza de segundas lenguas, el programa televisivo como recurso didáctico, y los aspectos de la competencia comunicativa que se pueden trabajar con programas de televisión-; mientras que la segunda, práctica, nos ha permitido obtener datos recientes y extraer conclusiones sobre el uso que se le da a este recurso, a través de dos pruebas diagnósticas. Por un lado, se han analizado las actividades basadas en programas televisivos que aparecen en los manuales de ELE, teniendo en cuenta los siguientes parámetros: objetivos, contenidos, soportes y destrezas. Esto nos ha permitido determinar cómo se integra actualmente este recurso. Para complementar esta información, se ha realizado un cuestionario a una muestra de profesores de ELE, cuyas preguntas nos han permitido sondear cómo y con qué frecuencia los docentes de ELE trabajan con programas televisivos en sus clases, así como su opinión acerca de dicho recurso. Consecuentemente, se ha elaborado una explicación y ofrecido una serie de recomendaciones sobre cómo utilizar los programas televisivos para trabajar el enfoque comunicativo en la clase de ELE: criterios de selección del material, aspectos que se pueden abordar —aspectos gramaticales, léxicos, socioculturales, pragmáticos, estratégicos y discursivos- y actividades de lengua que se pueden diseñar y realizar.

La parte práctica nos ha permitido demostrar la rentabilidad didáctica de este recurso en diferentes niveles y confirmar cómo el uso de programas televisivos en clase favorece la adquisición de ciertas competencias y destrezas, además de ser un material muy motivador para los alumnos. Por un lado, se han diseñado diez propuestas didácticas con actividades para realizar antes, durante y después del visionado, utilizando un formato televisivo diferente para cada una de ellas: 
informativos, culturales/divulgativos, ficción, entretenimiento y deportes. Por otro lado, se han realizado dos estudios empíricos en una universidad norteamericana con el objetivo de poner en práctica dos de estas propuestas didácticas — una diseñada para alumnos de nivel básico y otra dirigida a alumnos de nivel intermedio-alto - y de llevar a cabo un análisis de resultados de los datos obtenidos a través de los cuestionarios completados por los alumnos participantes.

El enfoque que hemos adoptado y mantenido a lo largo de este trabajo ha sido el enfoque comunicativo, ya que es una metodología con la que se pretende capacitar al alumno a que consiga una comunicación real, oralmente y por escrito, con otros hablantes de la lengua meta. Para lograr este fin, dicha metodología propone que se utilicen documentos auténticos — como son los programas televisivos - durante el proceso de aprendizaje. A través de las propuestas didácticas y de los estudios empíricos incluidos en esta tesis se ha demostrado cómo el material audiovisual sirve tanto para la enseñanza de la imagen como para la enseñanza con imágenes, pues los alumnos participantes en el estudio no solo realizaron actividades antes y durante el visionado del vídeo en cuestión, sino que también se grabaron y visualizaron a sí mismos como actividad de posvisionado.

Dentro de esta visión comunicativa y a la vez pragmática en la enseñanza de ELE, hemos podido constatar que los textos, tanto orales como escritos, extraídos de situaciones comunicativas reales —como es el caso de los programas televisivos - resultan ser un material adecuado para trabajar la competencia gramatical. Así, a través del texto, el estudiante extrae desde una situación discursiva, las intenciones comunicativas con sus exponentes funcionales, además de las estructuras gramaticales. En este sentido, hemos demostrado que se pueden realizar actividades de dos tipos: que contribuyan a desarrollar las nociones gramaticales en los alumnos de manera inconsciente; o que estén orientadas a trabajar y practicar en contexto las nociones ya aprendidas. Puesto que la enseñanza de la competencia gramatical es uno de los retos fundamentales que los profesores de español encuentran en su práctica cotidiana, hemos insistido en la importancia de tener en cuenta diferentes recursos a la hora de trabajar esta competencia, entre ellos, el programa televisivo.

Del mismo modo, hemos justificado cómo el material audiovisual también puede ejercer un papel importante en la adquisición del léxico. El programa televisivo aporta una gran información contextual, fundamental para la comprensión, y presenta otros elementos no lingüísticos que, sin embargo, son 


\section{EL PROGRAMA TELEVISIVO COMO RECURSO PARA LA \\ ENSEÑANZA/APRENDIZAJE DE ESPAÑOL LENGUA EXTRANJERA}

fundamentales en toda interacción, como los gestos y las características suprasegmentales, la entonación y el acento. Este formato proporciona a los alumnos información contextualizada del léxico —reducción y selección del léxico común; palabras comodines o proformas; léxico formal y coloquial; léxicos especiales, argóticos, extranjerismos...; metáforas de la vida cotidiana; expresiones intensificadoras (y todo ello de acuerdo con la variación geográfica)—, mediante la creación de tareas, en las que se integre el nuevo léxico, que sean significativas y que favorezcan el proceso de adquisición.

Como hemos visto, desde una perspectiva comunicativa, también es necesario abordar la competencia cultural, pues no basta con que el estudiante tenga conocimientos sobre la sociedad, sino que estos deben servirle para actuar en ella o con los individuos que hacen uso de la lengua meta. Para conseguir transmitir todos estos contenidos socioculturales a los alumnos, es importante que el profesor de ELE sea capaz de hacerlos visibles, por lo que el programa televisivo también es una buena herramienta para conseguir este fin. Hemos comprobado que los alumnos valoran el hecho de trabajar en clase con materiales que forman parte de la vida cotidiana de los hablantes nativos y este aspecto acerca su aprendizaje a la realidad. Además, existe la posibilidad de realizar un trabajo de comparación y contraste sociocultural a través de los programas televisivos, por ejemplo, entre la versión del país de origen de los estudiantes y la versión española del mismo formato, pues cada una de ellas estará adaptada al público del país donde se retransmiten.

Por medio del programa televisivo, también es posible ofrecer a los estudiantes de ELE muestras de las diferentes modalidades discursivas orales: se puede trabajar tanto el registro coloquial como el formal mediante el visionado y análisis de debates, entrevistas, reportajes, anuncios, reality-shows, etc. Entre otros aspectos pragmáticos, a través de este formato se puede facilitar la comprensión por parte del alumno de la cortesía; la ironía; la toma de turno, la dinámica de la conversación; la atenuación; la intensificación y las estrategias conversacionales en español. Cuanto más variado y más diverso es el input, más fácil es alcanzar estos objetivos. Los programas televisivos deben presentar variaciones de registro, de acentos regionales, de género..., para potenciar la capacidad sociolingüística del alumno. Como ha quedado reflejado en nuestras propuestas didácticas, de cara a la competencia socio-pragmática esto supone la presencia de actividades basadas en esa amplia variedad de muestras orales en las que el alumno se ve obligado a reflexionar sobre lo que se dice, el cómo se dice, y sobre cuál es la intención comunicativa de los hablantes. 
Asimismo, a través de un medio audiovisual, como es el programa televisivo, se puede ayudar al aprendiente de español a desarrollar varias estrategias, en especial, estrategias de comprensión y expresión orales —estas últimas también llamadas estrategias comunicativas - . Como hemos explicado, a través del visionado de este tipo de formato, se pueden percibir, analizar, y comentar en clase las estrategias comunicativas a las que los propios hablantes nativos, y también no nativos, recurren en unas $\mathrm{u}$ otras situaciones comunicativas. Con ello se estimula a los alumnos a que aprendan y usen la lengua sin miedo, de la manera que les resulte más útil y efectiva, en un esfuerzo por conocer y aplicar las estrategias comunicativas más adecuadas para posibles situaciones y contextos problemáticos. Con el empleo de estos recursos, los alumnos activan su propio aprendizaje y adquieren cada vez más autonomía para desenvolverse eficazmente en la lengua meta.

Los programas televisivos, sobre todo los no guionados, como las entrevistas, también suponen una buena muestra de cómo los hablantes nativos de español se sirven de la entonación, los alargamientos silábicos, la pronunciación enfática y marcada, las partículas discursivas y los conectores pragmáticos, los deícticos y el orden de las palabras, entre otros aspectos discursivos, para favorecer y enriquecer la comunicación oral. A través de las muestras de lengua extraídas de programas televisivos, también es posible trabajar con los alumnos, mediante análisis comparativos y contrastivos, las características psicosociales y culturales de diferentes hispanohablantes. Esto contribuye a que el estudiante aprenda a distinguir, comprender y respetar las diferentes variedades del español. Las actividades enfocadas a trabajar los aspectos discursivos de la lengua oral deben consistir en capacitar a los alumnos para formar frases, comprender mensajes, seguir el hilo de una conversación o contar de forma comprensible una experiencia o una película, es decir, a defenderse discursivamente sobre un tema, incluso con escasos recursos lingüísticos.

Una de las ventajas que hemos destacado de trabajar con programas televisivos es que el material audiovisual motiva a los estudiantes y los moviliza como espectadores audiovisuales expertos. Esta motivación también viene dada por la aportación de variedad a la dinámica de la clase para salir de la monotonía. Además, como hemos comprobado, la mayoría de las imágenes televisivas pueden servir como programa motivador, basta con que tengan capacidad de seducción y que el profesor sepa integrarlas en una unidad didáctica. Otra de las grandes ventajas que hemos señalado es que el alumno tiene la posibilidad de seguir mejorando su capacidad de comprensión audiovisual de manera autónoma con un producto fácilmente adquirible. 


\section{EL PROGRAMA TELEVISIVO COMO RECURSO PARA LA ENSEÑANZA/APRENDIZAJE DE ESPAÑOL LENGUA EXTRANJERA}

A través de nuestra serie de propuestas didácticas, hemos demostrado que el programa televisivo, al ser un material auténtico, incluye contenidos sociales, culturales, políticos, pragmáticos, etc. del país originario de la lengua que se estudia, lo que permite conocer esta cultura de una forma amena y dinámica. Asimismo, al transmitir ejemplos de comunicación auténtica y espontánea, presenta muestras reales de lengua. La íntima relación de los programas televisivos con el contexto social y cultural conlleva que normalmente el lenguaje utilizado sea muy coloquial y expresivo, reflejo de lo que el alumno se va a encontrar en la calle. También ofrece al espectador diversos registros lingüísticos, una amplia tipología textual, y pone en contacto al estudiante con diferentes variantes lingüísticas del español. Del mismo modo, ofrece la posibilidad de tratar en la clase de ELE cuestiones como los estereotipos, los clichés uniformados, las costumbres idealizadas, los modelos contraculturales, etc.

Otra de las ventajas que hemos mencionado - y la que nos ha permitido realizar ambos estudios empíricos en clases de tan solo cincuenta minutos- es su corta duración, que permite trabajar con agilidad y rapidez, variando las actividades y practicando varias destrezas. La mayoría tienen pocos diálogos, lo que nos permite realizar actividades sencillas de audición. Igualmente, no implica el esfuerzo de atención y comprensión, por parte de los alumnos, que exigen otro tipo de materiales audiovisuales como los documentales o las películas; recordemos que estos últimos no muestran actos comunicativos espontáneos porque proceden de guiones.

En cuanto a la tipología de actividades susceptibles de ser diseñadas a partir de programas televisivos o fragmentos de estos, se han explicado las distintas variables que intervienen en su diseño: el tipo de proceso de comprensión que se requiere, el tipo de labor que se fija en cada una, el modelo pedagógico en que se basa el diseño, o el nivel lingüístico que se quiere trabajar. Dado que el programa televisivo es un documento de tipo audiovisual, la destreza de la que hemos partido para posteriormente diseñar actividades con las que trabajar los diferentes aspectos de la competencia comunicativa — aspectos gramaticales, léxico, socioculturales, pragmáticos, estratégicos y discursivos-, ha sido la comprensión auditiva. Por lo que respecta a las actividades de posvisionado, hemos defendido que las más adecuadas y rentables para trabajar con este formato son las actividades de expresión e interacción orales porque el input del que se parte es de tipo oral. En esta clasificación, se han incluido los diálogos, las entrevistas y encuestas, los monólogos, los debates, y los relatos y anécdotas; aunque como ha quedado reflejado en la propuestas didácticas 
incluidas en esta tesis, también es posible diseñar otro tipo de actividades.

Como hemos explicado, cuando utilizamos el vídeo en clase con fines didácticos, debemos asegurarnos de que la actitud del alumno sea activa, pues el alumno está acostumbrado a ver la televisión o el cine como medio de entretenimiento y relajación, por lo que podemos calificar su actitud como pasiva. Para ello, se debe preparar una serie de materiales complementarios que despierten su interés y le motiven a participar en la actividad. Esto es lo que hemos querido conseguir con las propuestas didácticas presentadas en esta tesis. Por otro lado, también queremos recordar que no se debe confundir lo oral con lo coloquial. El programa televisivo supone una muestra real de ambos, por lo que nuestras propuestas didácticas incluyen una muestra de actividades enfocadas a trabajar tanto el registro coloquial como el formal.

De este modo, a lo largo de este trabajo de investigación hemos defendido de forma objetiva que los programas televisivos, a pesar de las duras críticas que la gran mayoría recibe, representan, desde un punto de vista lingüístico, una variedad de lengua de enorme riqueza. Los estudiantes de español necesitan conocer las variedades de la lengua, más allá de la norma culta que suelen aprender en clase, y una de las labores de los profesores de ELE es proporcionarles este tipo de información de una forma lo más atractiva y eficaz posible.

Como hemos expuesto, el recurso del programa televisivo para la enseñanza/aprendizaje del español como lengua extranjera puede resultar de gran ayuda, pues representa el puente de unión ideal entre el aprendizaje tradicional en el aula y el momento de la práctica real en lugares de habla hispana. Además, es un material que destaca por su alto contenido cultural y social, su carácter real y auténtico, su capacidad de motivar e interesar a los alumnos y su posible uso para mejorar varias destrezas. Por otro lado, como hemos señalado, a la hora de introducir material audiovisual en el aula, es preferible comenzar por programas de televisión y dejar los cortometrajes y largometrajes para una segunda etapa, ya que estos suelen presentar una variedad de lengua más elaborada y requieren una atención más enfocada al contenido.

La reticencia y el rechazo aún mostrado hacia este medio - recordemos que la mayoría de los alumnos encuestados declaró no haber tenido nunca una clase de español en la que se trabajara con programas televisivos - ha hecho que hasta el momento no se hayan podido explotar a fondo todas sus potencialidades ni se hayan podido sistematizar las actividades como base para una eficaz utilización 


\section{EL PROGRAMA TELEVISIVO COMO RECURSO PARA LA \\ ENSEÑANZA/APRENDIZAJE DE ESPAÑOL LENGUA EXTRANJERA}

didáctica. Sin embargo, en este trabajo hemos querido demostrar que la mayoría de los inconvenientes señalados por los detractores se pueden resolver con una propuesta didáctica adecuada que permita trabajar varios de los componentes de la competencia comunicativa - aspectos gramaticales, léxicos, socioculturales, pragmáticos, estratégicos y discursivos-, a través de actividades que ejerciten de forma integrada distintas habilidades comunicativas - comprensión oral, comprensión escrita, expresión oral, expresión escrita, interacción oral, interacción escrita, mediación oral y mediación escrita-

El análisis de manuales nos ha llevado a determinar que en la mayoría de las actividades cuyo soporte es el programa de televisión, este solo es utilizado como herramienta para introducir los contenidos temáticos de una unidad, o trabajar contenidos léxicos o gramaticales. Además, tanto el análisis de manuales como el de los datos obtenidos a través del cuestionario realizado a profesores, nos han permitido comprobar que muchos docentes se limitan a utilizar en sus clases programas televisivos culturales o informativos, por considerarlos más educativos, y muy pocos explotan otro tipo de programas, como los de entretenimiento. No obstante, los datos extraídos del cuestionario realizado a alumnos han reflejado que los materiales audiovisuales preferidos por estos son las películas y los programas televisivos, especialmente, de ficción y entretenimiento.

Ambos estudios empíricos nos han permitido demostrar que es posible elaborar una propuesta didáctica basada en el uso de programas televisivos que permita a los alumnos mejorar la comprensión y expresión oral, la comprensión y expresión escrita, aprender gramática, vocabulario, expresiones en español y rasgos de la pronunciación del español, conocer la cultura española, e incluso motivar a los alumnos tanto a ver programas de televisión en español fuera de clase como a intentar expresarse en la lengua que están aprendiendo. De este modo, ambos estudios nos han permitido confirmar y reafirmar que, a través del formato del programa televisivo, se pueden diseñar y realizar actividades enfocadas a trabajar no solo las tres actividades comunicativas de la lengua - la comprensión oral, la interacción oral, y la expresión oral- y las cuatro competencias señaladas por los profesores encuestados-sociocultural, léxica, gramatical y pragmática-.

Teniendo en cuenta todos estos factores, gran parte de este trabajo se ha centrado en la estructuración, diseño y presentación de actividades que permitan explotar mucho más este recurso. Finalmente, ha quedado demostrado que es posible trabajar con programas televisivos atemporales y a la vez 
interesantes para los alumnos, y que una serie de actividades basada en el uso de programas televisivos es fácil de adaptar y posible de utilizar hasta en los niveles más básicos, sin perjudicar la motivación de alumnos. Las propuestas didácticas aquí incluidas admiten muchas variantes y modificaciones, por lo que aquellos profesores de ELE que se animen a utilizarlas en sus clases podrán adoptar las que mejor se adapten a las expectativas y necesidades de sus alumnos. 


\section{CONCLUSIONS}

This doctoral thesis has approached the use of television programs as a teaching resource in the Spanish-as-a-second-language classroom. First, we have provided a scientific basis to prove the practical nature of this learning proposal for using these types of resources. Next, we have demonstrated the usefulness of television programs for teaching a foreign language. Lastly, we have presented and put into practice, in a real academic context, a learning proposal for Spanish-as-a-second-language students based on this resource.

The theoretical part of this thesis has allowed us to study the status of the issue - communicative competence in second-language teaching, television programs as a teaching resource, and aspects of communicative competence that can be worked on with the help of television programs - while the second, practical part has allowed us to collect recent data and draw conclusions about the use of this resource by means of two diagnostic tests. On the one hand, we have analyzed several activities based on television programs in Spanish-as-asecond-language manuals, considering the following parameters: objectives, contents, means and skills. This has allowed us to determine how this resource is currently integrated. To complement this information, we have distributed a questionnaire among several Spanish teachers. Its questions have allowed us to sound out how and how often Spanish teachers use television programs in their classes, as well as their opinion on this teaching resource. Consequently, we have offered an explanation and a series of recommendations for using television programs to develop the communicative approach in the Spanish-asa-second-language classroom: guidelines for choosing the material, aspects to work on -grammatical, lexical, sociocultural, pragmatic, strategic and discursive aspects - and learning activities to be designed and carried out.

The practical part has allowed us to prove the teaching profitability of this resource in different levels and to confirm how the use of television programs in class favors the acquisition of certain competences and skills, in addition to being a very motivating material for the students. On the one hand, we have designed ten teaching proposals with activities to do before, during and after the viewing, using a different television program format for each of them: informative, cultural, fiction, entertaining and sports. On the other hand, we have carried out two empirical studies in a North American university with the aim of putting into practice two of these teaching proposals - one designed for beginner-level students and another one for intermediate-high level students- 
and to perform an analysis of the data obtained through the questionnaires completed by the participating students.

The approach that we have adopted and maintained throughout this work has been the communicative approach, since it is a methodology that tries to help the student acquire real oral and written communication skills. To this end, this methodology proposes using authentic documents — such as television programs - during the learning process. The teaching proposals and the empirical studies included in this thesis show that audiovisual contents are useful to teach both about and with images, since the participating students not only engaged in the pre-view and during-view activities but also recorded and watched themselves in the post-view activity.

From this communicative and at the same time pragmatic perspective of Spanish-as-a-second-language teaching, we have been able to confirm that texts, both oral and written, taken from real communicative situations —as is the case of television programs - are a suitable material to work on grammatical competence. This way, through the text, the student deduces from a discourse situation the communicative intentions with its functional exponents, in addition to the grammatical structures. In this regard, we have demonstrated that it is possible to do two types of activities: to contribute to the unconscious development of the students' grammatical notions; or to work and practice in context with the notions already learned. Since teaching grammatical competence is one of the main challenges that Spanish teachers meet daily, we have insisted on the importance of taking into account different resources when working on this competence, the television program among them.

By the same token, we have explained how audiovisual material can also play an important role in lexical acquisition. The television program provides great contextual information fundamental to understanding, and shows other nonlinguistic elements which are nevertheless integral to all interactions, such as gestures and suprasegmental characteristics, intonation and accent. This format provides students with contextualized information on the vocabulary reduction and selection of common vocabulary; general-purpose words; formal and colloquial vocabulary; technical vocabulary, slang, borrowings...; daily life metaphors; intensifying expressions (and all this according to geographical variation) - by creating tasks which include the new vocabulary, and which are meaningful and favor the acquisition process.

As we have seen, from a communicative perspective, it is also necessary to address cultural competence. It is not enough for the student to simply have general knowledge of the society, but this knowledge must help him to behave 


\section{EL PROGRAMA TELEVISIVO COMO RECURSO PARA LA \\ ENSEÑANZA/APRENDIZAJE DE ESPAÑOL LENGUA EXTRANJERA}

in it or towards the individuals who use the target language. In order to succeed at teaching all this sociocultural knowledge to the students, it is important that the Spanish teacher is able to make them visible. The television program is a useful tool to achieve this aim. We have verified that students appreciate working in class with materials that are part of the native speakers' daily lives because this brings their learning closer to reality. Besides, there is a possibility of comparing and contrasting sociocultural aspects through television programs, for example, between the students' homeland version and the Spanish version of the same format. Both of them are to be adapted to the audience of the country in which they are broadcasted.

Television programs also offer Spanish-as-a-second-language learners a sample of different discursive modalities. It is possible to work on both the colloquial and the formal registers by viewing and analyzing debates, interviews, reports, commercials, reality-shows, etc. Among other pragmatic aspects, this format helps students to understand courtesy, irony, turn-taking, conversational dynamics; attenuation; intensification and conversational strategies in Spanish. The more varied and diverse the input is, the easier it is for the student to achieve these goals. Television programs must show register, accent and gender variations to develop the student's sociolinguistic skills. As our teaching proposal has shown, with regard to socio-pragmatic competence this involves designing activities based on this large variety of oral samples. This makes the student think about what it is said, the way it is said, and about the speakers' communicative intentions.

Likewise, through an audiovisual aid, such as the television program, we can help the Spanish learner to develop several strategies, especially listening and speaking strategies - the latter also called communicative strategies. As we have explained, by viewing this type of format, the communicative strategies which native and non-native speakers use in certain communicative situations can be perceived, analyzed and discussed in class. This motivates students to learn and use the language fearlessly, in the most useful and effective way for them, in an effort to explore and implement the most appropriate communicative strategies for problematic situations and contexts. By working with these resources, students boost their own learning and gain more autonomy to efficiently navigate within the target language.

Television programs, especially the unscripted ones, such as interviews, are a good sample of how Spanish native speakers use intonation, syllable lengthening, emphatic pronunciation, discourse particles and pragmatic connectors, deixis and word order, among other discourse aspects, to favor and 
enrich oral communication. By using language samples taken from television programs and doing comparative and contrastive analyses, it is also possible to work with the students on the psychosocial and cultural characteristics of different Spanish speakers. This helps the student learn to distinguish, understand and respect the different varieties of Spanish. The activities focused on working on the discourse aspects of the oral language must consist of preparing the students to make sentences, understand messages, follow conversations or relate an experience or a movie in a comprehensible way. In other words, to discursively manage to talk about a topic even with limited linguistic resources.

One of the advantages of working with television programs which we have highlighted is that the audiovisual material motivates the students and mobilizes them as an expert audiovisual audience. This motivation also comes from bringing variety to the classroom in order to escape monotony. In addition, as we have proved, most television images can be motivating. All they need is to be appealing and well integrated by the instructor in the teaching unit. Another main advantage of those we have pointed out is that the student has the possibility to continue improving his listening skills by himself and with an easy-to-acquire product.

Through our series of teaching proposals, we have demonstrated that the television program, as an authentic material, includes social, cultural, political, pragmatic, and other content from the country or countries where the target language is spoken, which makes it possible to get to know the culture in an enjoyable and dynamic way.

Additionally, it shows real language samples in that it transmits examples of real and spontaneous communication. The close relation between television programs and the sociocultural context implies that the language used is usually very colloquial and expressive, a reflection of what the student will hear in the streets. It also provides the spectator with different linguistic registers, a wide textual typology, and puts the student in contact with different linguistic varieties of the Spanish language. In the same way, it offers the possibility of addressing issues in class such as stereotypes, clichés, customs, countercultural models, etc.

Another advantage that we have mentioned - and the one which has allowed us to carry out both empirical studies in fifty-minute lessons - is their short duration, which makes it possible to quickly work with different activities and on different skills. Most of them have few dialogues, which allows us to do simple listening activities. Likewise, they do not require the effort and attention 


\section{EL PROGRAMA TELEVISIVO COMO RECURSO PARA LA \\ ENSEÑANZA/APRENDIZAJE DE ESPAÑOL LENGUA EXTRANJERA}

that other types of audiovisual materials do, like documentaries or movies; let us remember that the latter do not show spontaneous acts of communication because they are scripted.

With regard to the typology of activities which can be designed by using television programs, we have explained the different variables that take part in their design: the type of understanding process it requires, the work invested in them, the pedagogical model on which the design is based, or the linguistic level on which it will be applied. Since the television program is an audiovisual aid, we have based our design on the listening skills and subsequently designed activities to work on the different aspects of communicative competence grammatical, lexical, sociocultural, pragmatic, strategic and discursive aspects. With regard to post-view activities, we have stated that speaking activities are the most appropriate and fruitful to work with this format due to its oral input. In this list we can include dialogues, interviews and surveys, monologues, debates, short stories and anecdotes. However, as our teaching proposals show, it is also possible to design other types of activities.

As we have explained, when we use video in class with an educational purpose, we must ensure that the student's attitude is active. Since the student is used to watching television programs or movies as entertainment, his attitude might be passive. Consequently, we must prepare a series of complementary materials which stimulate his interest and motivate him to participate in the activity. This is what we have aimed to achieve with the teaching proposals presented in this thesis. On the other hand, let us recall that we must not confuse oral with colloquial. The television program is a real sample of both. Therefore, our teaching proposals include a sample of activities designed to work on both the colloquial and the formal registries.

In this way, throughout this study we have objectively defended that television programs, in spite of the criticism that most of them receive, represent, from a linguistic point of view, an enormously rich language variety. Spanish learners need to experience the language beyond the standard form normally taught in the classroom, and one of the Spanish teachers' tasks is to provide them with this information in the most appealing and effective manner.

As we have discussed, television programs can be very useful as a teaching resource to teach Spanish as a second language because they serve as an ideal "missing link" between traditional lessons in the classroom and real life practice in places where Spanish is spoken. In addition, this material stands out on account of its high cultural and sociocultural content, its authenticity, its 
ability to motivate and interest students and its potential use to improve several language skills. On the other hand, as we have pointed out, when it comes to using audiovisual material in the classroom, it is preferable to start with television programs and to save short films and feature length movies for a later stage, since they generally exhibit greater language variety and they require more content-focused attention.

Furthermore, the results of the student poll showed that the majority of Spanish teachers are reticent to incorporate television programs in the classroom. This rejection has kept television-based resources from reaching their full potential as a part of the repertoire of tools available to the modern language teacher. However, this thesis aimed to demonstrate that most of the issues highlighted by the detractors of this approach can be resolved with a suitable pedagogical design which addresses several aspects of communicative competence (the grammatical, lexical, sociocultural, pragmatic, strategic and discursive aspects) through a series of activities that integrates various communicative skills (listening, oral, reading and writing).

The analysis of manuals led us to determine that, in most of the activities based on television programs, this resource is only used to introduce the thematic content of the unit or to work on lexical or grammatical aspects. Both the analysis of manuals and the analysis of the data obtained from the questionnaires completed by the teachers allowed us to confirm that many instructors only use cultural or informative television programs because they consider them more educational, while very few use other types of programs, such as entertainment programs. Nevertheless, the data collected from the questionnaires completed by the students showed that the audiovisual materials that they prefer are movies and television programs, particularly, fiction and entertainment programs.

Both empirical studies have allowed us to demonstrate that it is possible to create a teaching proposal based on the use of television programs, which allows students to improve their listening, speaking, reading and writing skills, as well as to learn grammar, vocabulary, Spanish expressions and features of Spanish pronunciation, to get to know the Spanish culture and even to motivate the students to watch Spanish television programs outside of class as well as to attempt expressing themselves in the language. In this way, both studies have allowed us to confirm and reaffirm that television programs are a valuable tool to design and carry out activities to hone not only the two communicative language activities — listening and speaking — but also the four competences 


\section{EL PROGRAMA TELEVISIVO COMO RECURSO PARA LA \\ ENSEÑANZA/APRENDIZAJE DE ESPAÑOL LENGUA EXTRANJERA}

pointed out by the teachers polled - sociocultural, lexical, grammatical and pragmatic.

Considering all these factors, a significant part of this study has been focused on structuring, designing and presenting activities which allow a better and greater use of this resource. Finally, it has been demonstrated that it is possible to work with timeless television programs that are also interesting for the students, and that a series of activities based on a television program is easy to adapt and might be used even at the lowest levels without diminishing the learner's motivation. The teaching proposals included here allow for variation and modification. Therefore, those instructors who decide to incorporate them into their lessons may take the ones that best fit their students' needs and expectations. 


\section{BIBLIOGRAFÍA}

Adam, J. M. (1992). Les textes: types et prototypes. Récit, description, argumentation, explication et dialogue. París: Nathan.

Adam, J. M. (1999). Linguistique textuelle. Des genres de discours aux textes. París: Nathan/HER

Aguaded Gómez, J. I. (1993). Comunicación audiovisual en una enseñanza renovada. Propuestas desde los medios. Huelva: Prensa y Educación.

Albelda, M. (2007). La intensificación como categoría pragmática: revisión y propuesta. Frankfurt am Main: Peter Lang.

Albelda, M. y Fernández, M. J. (2006). "La enseñanza de los registros en ELE. Una aplicación al español coloquial”. Marcoele, n. 3, pp. 1-31.

Anderson, J. R. (1985). Cognitive Psychology and its implication. New York, W.H: Freeman and Company (2. ${ }^{\mathrm{a}}$ ed.).

Aparici, R. y García Matilla, A. (1987). Imagen, vídeo y educación. México: Fondo de Cultura Económica.

Bachman, L. (1990). Fundamental considerations in language teaching. Oxford: Oxford University Press.

Bajtín, M. (1952-53). "El problema de los géneros discursivos”. En M. Bajtín, Estética de la creación verbal, pp. 248-293. México: Siglo XXI, 1979.

Balboni, P. E. (1999). Dizionario de Glottodidattica. Perugia: Guerra.

Ballesteros, C. (2013). El vídeo en la enseñanza y la formación, en Barroso, J. y Cabero, J. (coord.). Nuevos escenarios digitales. Las tecnologías de la información y la comunicación aplicadas a la formación y desarrollo curricular, pp.167-185. Madrid: Pirámide.

Ballesteros, C. (2016). "Los medios audiovisuales: funciones didácticas y principios metodológicos para su integración en los procesos de enseñanza y aprendizaje". International Journal of Educational Research and Innovation (IJERI), n.6, 58-70

Baralo, M. (2000). "La construcción del lexicón en español/ LE: transferencia y construcción creativa”. En Zorraquino y Pelegrín (eds.) ¿Qué Español 
Enseñar? Norma y Variación Lingüisticas en la Enseñanza del Español a Extranjeros. Actas del XI Congreso Internacional de ASELE, pp. 165174. Zaragoza: Universidad de Zaragoza.

Barroso, C. (2000). "El desarrollo de la interacción oral mediante las estrategias de comunicación (algunas propuestas para trabajar la fluidez oral en clase dentro del español con fines específicos". En Zorraquino y Pelegrín (eds.), ¿Qué español enseñar?: norma y variación lingüísticas en la enseñanza del español a extranjeros: Actas del XI Congreso Internacional de ASELE, pp. 175-180. Zaragoza: Universidad de Zaragoza.

Bermúdez L. y González, L. (2011). "La competencia comunicativa: elemento clave en las organizaciones", Quórum Académico, n. 1 (8), pp. 95-110. Universidad del Zulia: Facultad de Humanidades.

Bonch-Bruevich, X. (2006). "Prácticas actuales y direcciones futuras para la enseñanza de la comprensión auditiva a los hablantes de inglés en el ambiente multimedia”. RedELE, n. 7. Madrid: Ministerio de Educación y Ciencia.

Bosch, M. (1999). "Desarrollo de la autonomía en el aprendizaje de lenguas". Didáctica del español como lengua extranjera: Actas de Expolingua desde 1996 a 1998 (4). Madrid: Fundación Actilibre.

Bou, P. (1992). Estrategias de comunicación y secuencias tópicas en el discurso conversacional de estudiantes españoles de inglés [Tesis doctoral no publicada], Universidad de Valencia.

Brandimonte, G. (2003). "El soporte audiovisual en la clase de E/LE: el cine y la televisión”. En Perdiguero y Álvarez (eds.), Medios de Comunicación y Enseñanza del Español como Lengua Extranjera: XIV Congreso Internacional de ASELE, pp. 870-88. Burgos: Universidad de Burgos.

Briz, A. (2010). "Lo coloquial y lo formal, el eje de la variedad lingüística". De moneda nunca usada, pp. 125-133. Zaragoza: Universidad autónoma de Nuevo León.

Briz, A. y grupo Val.Es.Co. (2002). "Corpus de conversaciones coloquiales". Anejo de la Revista Oralia. Madrid: Arco-Libros.

Briz, A., coord. (1995). "La conversación coloquial (Materiales para su estudio)". Anejo XVI de la Revista Cuadernos de Filología. Valencia: Universidad de Valencia.

Bygate, M. (1987). Speaking. Oxford: Oxford University Press. 


\section{EL PROGRAMA TELEVISIVO COMO RECURSO PARA LA \\ ENSEÑANZA/APRENDIZAJE DE ESPAÑOL LENGUA EXTRANJERA}

Cabello, M. (1998). La comprensión auditiva en ELE. Colección Aula de Español. Madrid: Universidad Antonio de Nebrija.

Cabero, J. (2004). "El uso del vídeo en la enseñanza”. En Cabero, J. y Romero, R. (coord.), Nuevas Tecnologías en la práctica educativa, pp.77-104. Granada: Arial.

Cabero, J. (2007). "El vídeo en la enseñanza y formación”. En Cabero, J. (coord.), Nuevas Tecnologías Aplicadas a la Educación, pp.129-149. Madrid: McGraw-Hill.

Calsamiglia, H. y Tusón, A. (1999). Las cosas del decir. Manual de análisis del discurso. Barcelona: Ariel.

Campbell, R. y Wales, R. (1970). "The study of language acquisition". En J. Lyons (ed.), New Horizons in Linguistics, pp. 242-260. Harmondsworth: Penguin.

Canale, M. (1983). "From Communicative Competence to Communicative Language Pedagogy". En J. C. Richards, y R. Schmidt (eds.), Language and Communication. London: Longman. (Trad. esp. de J. Lahuerta, en VV.AA. (1995: 63-81)

Canale, M. y Swain, M. (1980). "Theoretical bases of communicative approaches to second language teaching and testing". Applied Linguistics, n. 1, pp. $1-47$.

Celce-Murcia, M.; Brinton, D. y Goodwin, J. (1996). "The History and Scope of Pronunciation Teaching". Teaching Pronunciation: A Reference for Teachers of English to Speakers of other Languages, pp. 2-13. Cambridge: CUP.

Cenoz, J. (1996). "La competencia comunicativa: su origen y componentes". En J. Cenoz y J. Valencia (eds.), La Competencia Pragmática: Elementos Lingüísticos y Psicosociales, pp. 95-114. Lejona: Universidad del País Vasco.

Centro Virtual Cervantes (1997-2018). Diccionario de términos clave de ELE.

Cervero M. J. y F. Pichardo (2000). Aprender y enseñar vocabulario. Madrid: Edelsa.

Cesteros, A. M. (1999). Comunicación no verbal y enseñanza de lenguas extranjeras. Madrid: Arco/Libros. 
Cook, V. (2001). Second Language Learning and Teaching. Londres: Hodder Arnold.

Corpas Pastor, G. (1996). Manual de fraseología española. Madrid: Gredos.

Corral Esteves, C. y Fernández López, X. (2009). "El tratamiento de los contenidos pragmáticos en el aula de ELE: reflexión o intuición". Anuario Brasileño de Estudios Hispánicos XIX, pp. 121-137.

Cortés Rodríguez, L. (1991), "Sobre conectores, expletivos y muletillas en el español hablado", Cuadernos de lingüistica, n.10. Málaga: Librería Ágora.

Coste, D. et al. (1976). Un Niveau Seuil. Estrasburgo: Consejo de Europa.

Chomsky, N. (1957). Syntactic Structures (Estructuras sintácticas), Buenos Aires: Siglo XXI, 1999.

Chomsky, N. (1965). Aspects of the theory of sintax. Cambridge, Mass.: MIT Press.

Ellis, N. y Beaton, A. (1993). "Psycholinguistic Determinants of Foreign Language Vocabulary Learning”. Language Learning, n. 43 (4), pp. 559617.

Ellis, R. (1992). Second Language Acquisition and Language Pedagogy. Clevedon: Multilingual Matters.

Escandell, M. V. (1998). "Politeness: A Relevant Issue for Relevance Theory". Revista Alicantina de Estudios Ingleses, n. 11, pp. 45-57.

Escandell, M. V. (2004). “Aportaciones de la pragmática”. En J. Sánchez e I. Santos (coords.), Vademécum para la formación de profesores. Enseñar español como segunda lengua (L2)/lengua extranjera (LE), pp. 179-198. Madrid: SGEL.

Estaire, S. y Zanón, J. (1990). "El diseño de unidades didácticas mediante tareas: principios y desarrollo". Comunicación, Lenguaje y Educación, 78. La Rioja: Universidad de la Rioja.

Fernández López, M. C. (2004). "Principios y criterios para el análisis de materiales didácticos". En J. Sánchez \& I. Santos (eds.), Vademécum para la formación de profesores, pp. 715-734. Madrid, España: SGEL.

Ferrer Plaza, C. (2009). "Reflexiones sobre el uso de documentos auténticos en la clase de E/LE". En S. Rojo et al. (eds.), Anais do V Congresso 


\section{EL PROGRAMA TELEVISIVO COMO RECURSO PARA LA ENSEÑANZA/APRENDIZAJE DE ESPAÑOL LENGUA EXTRANJERA}

Brasileiro de Hispanistas e I Congresso Internacional da Associaçâo Brasileira de Hispanistas, pp. 2363-2368. Belo Horizonte: Faculdade de Letras da Universidade Federal de Minas Gerais.

Ferrés Prats, J. (1994). Televisión y educación. Barcelona: Paidós.

Flowerdew, J. y Miller, L. (2005). Second language listening: theory and practice, Cambridge: Cambridge University Press.

García-Page Sánchez, M. (2008). Introducción a la fraseología española. Estudio de las locuciones. Barcelona: Anthropos.

Gil-Torresano, M. (2004). "La comprensión auditiva". Vademécum para la formación de profesores. Enseñar español como L2/LE, pp. 899-915. Madrid: SGEL.

Giovannini, A. et al. (1996b). "Vocabulario", Profesor en acción 2, pp. 43-70. Madrid: Edelsa.

Giovannini, A.; Martín Peris, E.; Rodríguez, M.; y Simón, T. (1996a). "La comprensión oral", Profesor en acción, n. 3. Madrid: Edelsa.

Glisan, E. W. (1985). "The effect of word order on listening comprehension and pattern recognition: an experiment in spanish as a foreign language", Language Learning, n. 3 (35), pp. 443-472.

Gómez del Estal , M. y Zanón, J. (1999). "Tareas formales para la enseñanza de la gramática en clase de español”, La enseñanza del español mediante tareas, pp. 73-99. Madrid: Edinumen.

Gómez Molina, J. R. (2000). "Las unidades fraseológicas en español: una propuesta de clasificación para la enseñanza de locuciones en la clase de ELE”. En Coperías Aguilar, M... J., J. Redondo Sánchez y J. Sanmartín Sáez (eds.), Aprendizaje y enseñanza de una segunda lengua, pp. 111134. Valencia: Universidad de Valencia.

González Rey, M. I. (2006). “A fraseodidáctica e o Marco europeo común de referencia para as linguas". Cadernos de Fraseoloxía Galega, n. 8, pp. 123-145.

Goodman. L. A. (1961). "Snowball sampling". Annals of Mathematical Statistics, n. 32, pp. 148-170.

Gregory, M. y Carroll, S. (1978). Lenguaje y situación. Variedades del lenguaje y sus contextos sociales. México: Fondo de Cultura Económica, 1986. 
Grotjahn, R. (1987). "On the Methodological Basis of Introspective Methods". En C. Faerch \& G. Kasper (Eds.), Multilingual matters, No. 30. Introspection in second language research. Clevedon, England: Multilingual Matters, pp. 54-81.

Gumperz, J. J. (1972). "Introduction". En J. J. Gumperz (ed.), Directions in Sociolinguistics: The Ethnography of Communication, pp.1-25. New York: Blackwell.

Gutiérrez Ordóñez, S. (2004). “La subcompetencia pragmática”. En J. Sánchez e I. Santos (coords.), Vademécum para la formación de profesores de profesores. Enseñar español como segunda lengua (L2)/ lengua extranjera (LE), pp. 533-552. Madrid: SGEL.

Halliday, M. A. K. (1978). El lenguaje como semiótica social. La interpretación social del lenguaje y del significado. México: Fondo de Cultura Económica, 1982.

Halliday, M. A. K. (1982). El lenguaje como semiótica social. México: Fondo de Cultura Económica.

Halliday, M. A. K.; McIntosh, A. y Strevens, P. (1964). The Linguistic Sciences and Language Teaching. Londres, Nueva York: Longman.

Hernández Sacristán, C. (1999). Culturas y acción comunicativa. Introducción a la pragmática intercultural. Barcelona: Octaedro.

Hernández, M. J. y Zanón, J. (1990). "La enseñanza de la comunicación en la clase de español”. Cable, n. 5, pp. 12-18. Madrid: Equipo Cable.

Hidalgo, A. (1997). "La entonación coloquial. Función demarcativa y unidades de habla". Anejo XXI de Cuadernos de Filología. Valencia: Universidad de Valencia.

Hymes, D. (1971). "Foundations in sociolinguistics: an ethnographic approach", International Journal of Cross Cultural Management (6), (Reprinted in 2001) London: Routledge.

Hymes, D. (1972). "On communicative competence". En J. B. Pride y J. Holmes (eds.), Sociolinguistics, pp. 269-285. Harmondsworth: Penguin.

Instituto Cervantes (2006). Plan curricular del Instituto Cervantes. Niveles de referencia para el español (3 volúmenes). Madrid: Biblioteca Nueva.

Kasper, G. (1992). "Pragmatic transfer". Second Language Research, n. 8 (3), pp. 203-231. 


\section{EL PROGRAMA TELEVISIVO COMO RECURSO PARA LA ENSEÑANZA/APRENDIZAJE DE ESPAÑOL LENGUA EXTRANJERA}

Kasper, G. (1997). “Can pragmatic competence be taught?". NFLRC Network, n. 6. Honolulu: University of Hawaii, Second Language Teaching \& Curriculum Center.

Krashen, S. D. y Terrel, T. D. (1983). The Natural Approach: Language Acquisition in the Classroom. Oxford: Pergamon.

Lakoff, R. (1973). "The Logic of Politeness, or Minding your P's and Q's". Proceedings of the Ninth regional Meeting of the Chicago Linguistic Society, pp. 345-356.

Landone, E. (2009). "Reflexiones sobre la cortesía verbal en la enseñanza/aprendizaje del ELE”. MarcoEle, n. 8, pp. 1-23.

Leal Riol, M. J. (2013). "Estrategias para la enseñanza y aprendizaje de la fraseología en español como lengua extranjera", Paremia, n. 22, pp. 161170.

Leech, G. (1983/1998). Principios de pragmática. Logroño: Universidad de La Rioja.

Leontaridi, E.; Ruiz Morales, M. y Peramos Soler, N. (2009). “Aprender no es un juego... ¿o sí?: El componente lúdico en la práctica de la destreza escrita en la clase de E/LE”. J.F. Barrio Barrio (coord.), Actas de las Jornadas de Formación del Profesorado en la Enseñanza de L2/ELE y la Literatura Española Contemporánea. Sofía: Ministerio de Educación de España y Universidad de Sofía "San Clemente de Ojrid", pp. 151162.

Leontaridi, E.; Ruiz Morales, M. y Peramos Soler, N. (2009). "Las unidades fraseológicas del español: su enseñanza y adquisición en la clase de ELE”. J.F. Barrio Barrio (coord.), Actas de las Jornadas de Formación del Profesorado en la Enseñanza de L2/ELE y la Literatura Española Contemporánea. Sofía: Ministerio de Educación de España y Universidad de Sofía "San Clemente de Ojrid”, pp. 185-204.

Littlewood, W. (1981). La enseñanza comunicativa de idiomas; introducción al enfoque comunicativo. Cambridge: Cambridge University Press.

Lonergan, J. (1984). Video in Language Teaching. Cambridge: Cambridge University Press.

Lonergan, J. (1985). El vídeo en la enseñanza de idiomas. León: Editorial Academia. 
Llurda, E. (2000). "On competence, proficieny and communicative language ability”, International Journal of Applied Linguistics, n. 10, pp. 85-95.

Maiguashca, R. (1993). "Teaching and learning vocabulary in a second language: past, present, and future directions". The Canadian Modern Language Review/La Revue canadiense des langues vivantes, n. 50 (1), pp. 83-100.

Manchón Ruiz, R. M. (1993). "La evaluación del componente estratégico del aprendizaje de lenguas", Didáctica del español como lengua extranjera (1), pp. 151-165. Madrid: Fundación Actilibre.

Marques Branco Sanches, G. M. y de Amorim Barbieri Durão, A. B. (2003). "La televisión y la enseñanza de español como lengua extranjera en Brasil ¿Por qué no? XIV Congreso Internacional de ASELE. Burgos: Universidad de Burgos, pp. 976-995.

Martín Leralta, S. (2009). "Competencia estratégica para la comprensión auditiva en español como lengua extranjera", ASELE Colección Monografias (12). Madrid: Ministerio de educación y ciencia.

Martín Peris, E. (1991). "La didáctica de la comprensión auditiva”, Cable, n. 8. Madrid: Equipo Cable.

MCER (2002). Marco Común Europeo de Referencia para las Lenguas: aprendizaje, enseñanza y evaluación. Madrid: Anaya.

McLaughlin, B. (1990). “Restructuring”. Applied Linguistics, 11, pp. 113-128.

Meyer, M. (1994). "Developing transcultural competence: Case studies of advanced language learners", F. Genesee. Educating Second Language Children the whole child, the whole curriculum, the whole community, pp. 159-182. New York: Cambridge University Press.

Miguel García, M. L. (2005). "La enseñanza del léxico del español como lengua extranjera. Resultados de una encuesta sobre la metodología aplicada en el aula". MarcoELE, n.1, pp. 1-21.

Miquel, L. y Sans, N. (1992). "El componente cultural: un ingrediente más de la clase de lengua”, Cable, n. 9, pp. 15-21. Madrid: Equipo Cable.

Morante, R. (2004). "Modelos de actividades didácticas para el desarrollo léxico", RedELE, n. 4. Madrid: Ministerio de Educación y Ciencia.

Morante, R. (2005). El desarrollo del conocimiento léxico en segundas lenguas, Madrid: Arco/Libros. 


\section{EL PROGRAMA TELEVISIVO COMO RECURSO PARA LA ENSEÑANZA/APRENDIZAJE DE ESPAÑOL LENGUA EXTRANJERA}

Moreno Fernández, F. (2007). "Adquisición de segundas lenguas y sociolingüística”. Revista de Educación, n. 343, pp. 55-70.

Muñoz, C. (2000). Segundas Lenguas. Adquisición en el aula. Barcelona: Ariel.

Naiman, N.; Fröhlich, M.; Stern, H. H.; y Todesco, A. (1978). "The Good Language Learner". Research in Education Series, n. 7. Toronto: Ontario Institute for Studies in Education.

Nation, I.S.P. (1990)."What is involved in learning a word?". Teaching and Learning Vocabulary, pp. 29-50. Rowley, Mass.: Newbury House.

Nisbet, J. y Shucksmith, J. (1991). Estrategias de aprendizaje. Madrid: Santillana, 1994.

Nunan, D. (1989). El diseño de tareas para la clase comunicativa. Cambridge: Cambridge University Press, 1997.

O'Malley, J. y Chamot, A-U. (1990). Language Learning Strategies. Cambridge: Cambridge University Press.

Ogalde, I. (2000). Los Materiales didácticos. México: Trillas.

Olaeta Rubio, R. (1997). "Las paremias, un recurso didáctico para la enseñanza de la lengua española". Paremia, n. 6, pp. 451-458.

Oxford, R. (1990). Language Learning Strategies. What Every Teacher Should Know. Nueva York: Newbury House.

Palacios, I. (2007). Diccionario de enseñanza y aprendizaje de lenguas. Madrid: EnClave ELE.

Pardinas, F. (1991). Metodología y técnicas de investigación en ciencias sociales. México: Siglo XXI.

Pardo Díaz, I. (2000). "Integración de destrezas en la producción de un cortometraje en clase de ELE”. En Zorraquino y Pelegrín (eds.) ¿Qué Español Enseñar? Norma y Variación Lingüisticas en la Enseñanza del Español a Extranjeros. Actas del XI Congreso Internacional de ASELE, pp. 247-255. Zaragoza: Universidad de Zaragoza.

Penadés, I. (1999). La enseñanza de las unidades fraseológicas. Madrid: Arco/Libros.

Pinilla, R. (2000). "La competencia estratégica en las destrezas de los 
estudiantes de E/LE: caracterización de las estrategias de comunicación". En ELR Ediciones, Cuadernos Cervantes de la lengua española, pp. 2027. Logroño: Universidad de la Rioja.

Pinilla, R. (2006). "La competencia estratégica del estudiante de ELE en su producción oral: algunas consideraciones para su evaluación". En E. Balmaseda Maestu (ed.), Las destrezas orales en la enseñanza del español L2-LE: XVII Congreso Internacional ASELE, pp. 89-96. Logroño: Universidad de la Rioja.

Pinilla, R. (2010). "Tipos de interacción oral y entornos situacionales: una tipología de las actividades de comunicación oral". Monográficos MarcoELE, n. 10, pp. 97-104.

Poch, D. (1993). "La corrección fonética en español lengua extranjera". En L. Miquel y N. Sans (eds.), Didáctica del español como lengua extranjera (1), pp. 193-200. Madrid: Fundación Actilibre.

Poch, D. (1999). Fonética para aprender español: pronunciación. Madrid: Edinumen.

Poch, D. (2001). "Sensación física y realidad mental: de la onda sonora al significado de los enunciados". VVAA, El desarrollo de la comprensión auditiva en el aula de español como lengua extranjera, Carabela, 2 a etapa, n. 49, pp. 5-15. Madrid: SGEL.

Poyatos, F. (1994). La comunicación no verbal I. Cultura, lenguaje y conversación. Madrid: Istmo.

Poyatos, F. (1994). La comunicación no verbal II. Paralenguaje, kinésica e interacción. Madrid: Istmo.

Preston, D. (2000). "Three kinds of sociolinguistics and SLA: A psycholinguistic perspective". En B. Swierzbin et al. (eds.): Social and Cognitive Factors in SLA, pp. 3-30. Somerville, MA: Cascadilla Press.

Pujol Berché, M. (2002). "La enseñanza de la expresión oral en el ámbito universitario. Necesidades orales de los estudiantes y propuestas de actividades", Frecuencia L, n. 21, pp. 11-19.

RAE-ASALE (2014). Diccionario de la Lengua Española (vigésimotercera edición). Madrid: Espasa-Calpe.

Raga Gimeno, Francisco. (2006). Culturas cara a cara: Relatos y actividades para la comunicación intercultural. Madrid: Edinumen. 


\section{EL PROGRAMA TELEVISIVO COMO RECURSO PARA LA ENSEÑANZA/APRENDIZAJE DE ESPAÑOL LENGUA EXTRANJERA}

Richards, J. C. (1976). "The Role of Vocabulary Teaching". TESOL Quarterly, n. $10(1)$, pp. $77-89$.

Richards, J. C. (1983). "Listening comprehension: approach, design, procedure", TESOL Quarterly, n. 2 (17), pp. 219-240.

Riley, P. (1989). «"Well, don't blame me" on the interpretation of pragmatic errors». En W. Olesky (ed.), Contrastive Pragmatics, pp. 231-249. Amsterdam: John Benjamins.

Rost, M. (2002). Teaching and researching listening. London: Pearson Education.

Ruiz Fajardo, G. (1994). "Vídeo en clase: virtudes y vicios”. En L. Miquel y N. Sans (eds.), Didáctica del español como lengua extranjera: actas de Expolingua desde 1990 a 1993. (Cuadernos de tiempo libre Expolingua. E/LE 2), pp. 141-164. Madrid: Fundación Actilibre.

Ruiz Gurillo, L. (2001). Las locuciones en español actual. Madrid: Arco/Libros.

Sánchez Pérez, A. (1992). Historia de la enseñanza del español como lengua extranjera. Madrid: SGEL.

Sánchez Sarmiento, R. (2005). "El reflejo de la competencia sociopragmática en materiales de ELE". En A. Álvarez et al. (eds.), La competencia pragmática y la enseñanza del español como lengua extranjera. Actas del XVI Congreso Internacional de ASELE, pp. 585-593. Oviedo: Ediciones de la Universidad de Oviedo.

Sanjuan, M. (1991). "Qué significa 'conocer' una palabra: la complejidad de la competencia léxica". Cuadernos de Investigación Filológica, n. 17 (1-2), pp. 89-101.

Santaella Esquinas, M. (2010). "El uso del tráiler cinematográfico en el aula de ELE". [Memoria de Máster]. En EdiEle-Letra 25 (eds.), Colección ASELE.

Savignon, S. (1983). Communicative Competence: Theory and Classroom Practice. Reading, Mass.: Addison-Wesley.

Saville-Troike, M. (1989). The Ethnography of Communication: An Introduction. Londres: Blackwell.

Schiffrin, D. (1987). Discourse Markers. Cambridge: Cambridge University 
Press.

Schmitt, N. (1995). "A fresh approach to vocabulary: using a word knowledge framework". RELC Journal, n. 26 (1), pp. 86-94.

Searle, J. R. (1975). "Una taxonomía de los actos ilocucionarios", Teorema, n. 6 (1), pp. 43-77.

Sierra Bravo, R. (1994). Técnicas de investigación social. Teoría y ejercicios. Madrid: Paraninfo, pp. 304-350.

Sierra Plo, J. M. (1990). "El vídeo: presupuestos teóricos y técnicas prácticas", VV. AA. Didáctica, pp. 194-219.

Soler, L. (1988). La televisión. Una metodología para su aprendizaje. Barcelona: Gustavo Gili.

Soriano Fernández, S. (2009). "Cortos y sin cortes. Una propuesta didáctica para el uso del cortometraje en la clase de ELE." [Memoria de Máster], Revista MarcoELE, n.10.

Swales, J. (1990). Genre Analysis: English in Academic and Research Settings. Cambridge: CUP.

Taylor, D. S. (1988). "The meaning and use fo the term competence in linguistics and applied linguistics", Applied Linguistics, n. 9, pp.148-168.

Thomas, J. (1983). “Cross-cultural Pragmatic Failure”. Applied Linguistics, n.4, pp. 91-112.

Tomlinson, B. (1998). Materials Development in Language Teaching. Cambridge: Cambridge University Press.

Trubetzkoy, N. S. (1939). "Gründzuge der Phonologie", Travaux du Cercle Linguistique de Prague, n. 7. Traducción al español, D. García Giordiano (1973), Principios de fonología. Madrid: Cincel.

Van Dijk, T. (1980). Estructuras y funciones del discurso. Una introducción interdisciplinaria a la lingüística del texto y a los estudios del discurso. México: Siglo XXI editores.

Van Ek, J. (1986). Objectives for Foreign Language Learning (1). Estrasburgo: Consejo de Europa.

Van Ek, J.A., y Trim, J. L. M. (1991). Threshold Level 1990. Cambridge: CUP. 


\section{EL PROGRAMA TELEVISIVO COMO RECURSO PARA LA \\ ENSEÑANZA/APRENDIZAJE DE ESPAÑOL LENGUA EXTRANJERA}

Van Ek, J.A., y Trim, J. L. M. (1991). Waystage 1990. Cambridge: CUP.

Van Ek, J.A., y Trim, J. L. M. (1997). Vantage Level. Cambridge: CUP.

Villanueva, M. L. \& Navarro, I. (1997). Los estilos de aprendizaje de lenguas. Castellón de la Plana: Publicaciones de la Universitat Jaume I.

Vogely, A. (1995). "Percived strategy use during performance on 3 authentic listening comprehension tasks", The Modern Language Journal, n. 79, pp. 41-56.

Vygotsky, L. (1962). Thought and Language. Cambridge, Mass.: MIT Press.

Wenden, A. y Rubin, J. (eds.). (1987). Learner Strategies in Langauge Learning. Nueva Jersey: Prentice Hall.

Werlich, E. (1975). Typologie der Texte, Múnich: Fink.

Widdowson, H. G. (1995). "Conocimiento de la lengua y habilidad para usarla”. En M. Llobera (ed.), Competencia comunicativa, pp. 83-90. Madrid: Edelsa.

Wilson, J. J. (2008). How to teach listening. Harlow: Pearson Education.

Zanón, J. (1990). "Los enfoques por tareas para la enseñanza de las lenguas extranjeras", Cable, n. 5, pp. 19-27. Madrid: Equipo Cable.

\section{MANUALES ANALIZADOS}

Cerrolaza Aragón, M.; Cerrolaza Gili, O. Llovet Barquero, B. (2008). Pasaporte Nivel 3 (B1). Español Lengua Extranjera. Madrid: Edelsa. 
Cerrolaza Aragón, M.; Cerrolaza Gili, O. Llovet Barquero, B. (2010). Pasaporte Nivel 4 (B2). Español Lengua Extranjera. Madrid: Edelsa.

Cerrolaza Aragón, M.; Cerrolaza Gili, O.; Justo Muñoz, P. (2007). Pasaporte Nivel 1 (A1). Español Lengua Extranjera. Madrid: Edelsa.

Cerrolaza Aragón, M.; Cerrolaza Gili, O.; Llovet Barquero, B. (2008). Pasaporte Nivel 2 (A2). Español Lengua Extranjera. Madrid: Edelsa.

Moreno, C.; Zurita, P.; Moreno, V. (2010). Nuevo Avance 3 (B1.1). Curso de español. Madrid: SGEL.

Moreno, C.; Zurita, P.; Moreno, V. (2010). Nuevo Avance Básico A1-A2. Curso de español. Madrid: SGEL.

Moreno, C.; Zurita, P.; Moreno, V. (2011). Nuevo Avance 5 (B2.1). Curso de español. Madrid: SGEL.

Moreno, C.; Zurita, P.; Moreno, V. (2014). Nuevo Avance Superior (B2). Curso de español. Madrid: SGEL.

VV. AA. (2003). Prisma Bl Progresa. Método de español para extranjeros. Madrid: Edinumen.

VV. AA. (2003). Prisma B2 Avanza. Método de español para extranjeros. Madrid: Edinumen.

VV. AA. (2011). Nuevo Prisma C1. Curso de español para extranjeros. Madrid: Edinumen.

VV. AA. (2011). Vía Rápida (A1-B1). Curso intensivo de español. Barcelona: Difusión.

VV. AA. (2012). Gente Hoy 1 (A1-A2). Curso de español. Barcelona: Difusión.

VV. AA. (2012). Nuevo Prisma A1. Curso de español para extranjeros. Madrid: Edinumen.

VV. AA. (2012). Nuevo Prisma C2. Curso de español para extranjeros. Madrid: Edinumen.

VV. AA. (2013). Aula Internacional 1 (A1). Curso de español. Nueva Edición. Barcelona: Difusión.

VV. AA. (2013). Aula Internacional 2 (A2). Curso de español. Nueva Edición. Barcelona: Difusión. 
EL PROGRAMA TELEVISIVO COMO RECURSO PARA LA

ENSEÑANZA/APRENDIZAJE DE ESPAÑOL LENGUA EXTRANJERA

VV. AA. (2013). Aula Internacional 4 (B2.1). Curso de español. Nueva Edición. Barcelona: Difusión.

VV. AA. (2013). Nuevo Prisma A2. Curso de español para extranjeros. Madrid: Edinumen.

VV. AA. (2014). Aula Internacional 3 (B1). Curso de español. Nueva Edición. Barcelona: Difusión.

VV. AA. (2014). Aula Internacional 5 (B2.2). Curso de español. Nueva Edición. Barcelona: Difusión.

VV. AA. (2014). Gente Hoy 2 (B1). Curso de español. Barcelona: Difusión. 


\title{
EL PROGRAMA TELEVISIVO COMO RECURSO PARA LA ENSEÑANZA/APRENDIZAJE DE ESPAÑOL LENGUA EXTRANJERA
}

\section{CUESTIONARIO PARA PROFESORES}

\begin{abstract}
El siguiente cuestionario está destinado a desarrollar una investigación doctoral sobre El programa televisivo como recurso didáctico en el aula de ELE. Su colaboración será de gran utilidad. Se trata de un cuestionario anónimo y los datos serán tratados con total confidencialidad.
\end{abstract}

Tipo de centro (y país) en el que trabaja:

Años de experiencia en la enseñanza de ELE:

¿Formación especializada en la didáctica de ELE?
a) Sí
b) No

1. ¿Trabaja con documentos audiovisuales en el aula de ELE?
a) Sí
b) No

2. En caso de respuesta negativa en la pregunta 1 , por favor, señale sus motivos:
a) Falta de tiempo en las clases.
b) Falta de tiempo para la preparación de este tipo de actividades.
c) Escasez de propuestas de trabajo con materiales audiovisuales en los manuales de ELE.
d) Falta de ideas para la explotación de documentos audiovisuales en las clases.
e) Falta de recursos técnicos en el aula. 
3. En caso afirmativo en la pregunta 1, por favor, indique con qué frecuencia:
a) Cada clase
b) Una de cada tres clases
c) Una de cada cinco clases
d) Casi nunca

4. En caso afirmativo en la pregunta 1, por favor, señale qué porcentaje aproximado de la clase suele dedicar a que los alumnos realicen actividades con este tipo de documento:
a) Menos del $25 \%$ del tiempo
b) Entre el 25\% y el 50\% del tiempo
c) Entre el $50 \%$ y el $75 \%$ del tiempo
d) Más del 75\% del tiempo

5. En caso afirmativo en la pregunta 1, por favor, indique con qué frecuencia utiliza los siguientes documentos audiovisuales o fragmentos de los mismos:

\begin{tabular}{|l|l|l|l|l|l|}
\hline & Nunca & Casi nunca & A veces & A menudo & $\begin{array}{c}\text { Muy a } \\
\text { menudo }\end{array}$ \\
\hline $\begin{array}{l}\text { Programas de } \\
\text { televisión }\end{array}$ & & & & & \\
\hline Anuncios publicitarios & & & & & \\
\hline Películas & & & & & \\
\hline Tráiler & & & & & \\
\hline Cortometrajes & & & & & \\
\hline
\end{tabular}

6. En caso de utilizar programas televisivos en sus clases, por favor, indique qué tipos de programas utiliza y con qué frecuencia:

\begin{tabular}{|l|l|l|l|l|l|}
\hline & Nunca & Casi nunca & A veces & A menudo & $\begin{array}{c}\text { Muy a } \\
\text { menudo }\end{array}$ \\
\hline $\begin{array}{l}\text { Informativos } \\
\text { (Telediario, reportajes de } \\
\text { actualidad, tertulias, el } \\
\text { tiempo...) }\end{array}$ & & & & & \\
\hline $\begin{array}{l}\text { Culturales } \\
\text { (Documental, educativo...) }\end{array}$ & & & & & \\
\hline $\begin{array}{l}\text { Ficción } \\
\text { (Series, miniseries, } \\
\text { telenovelas...) }\end{array}$ & & & & & \\
\hline $\begin{array}{l}\text { Entretenimiento } \\
\text { (Talk-shows, reality-shows, } \\
\text { magacines, concursos, galas...) }\end{array}$ & & & & & \\
\hline $\begin{array}{l}\text { Deportes } \\
\text { (Programas específicos, }\end{array}$ & & & & & \\
\hline
\end{tabular}


EL PROGRAMA TELEVISIVO COMO RECURSO PARA LA

ENSEÑANZA/APRENDIZAJE DE ESPAÑOL LENGUA EXTRANJERA

7. En cualquier caso, por favor, indique con qué frecuencia trabaja en clase con estos otros medios de comunicación:

\begin{tabular}{|l|l|l|l|l|l|}
\hline & Nunca & Casi nunca & A veces & A menudo & $\begin{array}{c}\text { Muy a } \\
\text { menudo }\end{array}$ \\
\hline Radio & & & & & \\
\hline Periódicos & & & & & \\
\hline Revistas & & & & & \\
\hline Redes Sociales & & & & & \\
\hline
\end{tabular}

8. Si no ha trabajado en el aula con programas televisivos, ¿cree que sería útil hacerlo?, ¿por qué?
a) Sí
b) No

Por favor, explique el motivo:

9. ¿Qué aspectos cree que se podrían trabajar mediante la explotación didáctica de un programa televisivo? (Puede señalar una o varias respuestas)

d) Desarrollo de las actividades comunicativas de la lengua

\begin{tabular}{|c|c|c|c|c|c|c|c|}
\hline $\begin{array}{c}\text { Comprensión } \\
\text { oral }\end{array}$ & $\begin{array}{c}\text { Comprensión } \\
\text { escrita }\end{array}$ & $\begin{array}{c}\text { Expresión } \\
\text { oral }\end{array}$ & $\begin{array}{c}\text { Expresión } \\
\text { escrita }\end{array}$ & $\begin{array}{c}\text { Interacción } \\
\text { oral }\end{array}$ & $\begin{array}{c}\text { Interacción } \\
\text { escrita }\end{array}$ & $\begin{array}{c}\text { Mediación } \\
\text { oral }\end{array}$ & $\begin{array}{c}\text { Mediación } \\
\text { escrita }\end{array}$ \\
\hline & & & & & & & \\
\hline
\end{tabular}

e) Desarrollo de las competencias de la lengua

\begin{tabular}{|c|c|c|c|}
\hline Gramaticales & Léxicas & Socioculturales & Pragmáticas \\
\hline & & & \\
\hline
\end{tabular}

f) Desarrollo de la capacidad de autoaprendizaje del alumno 
10. Si quiere, puede recoger aquí cualquier otro comentario en relación al uso de programas televisivos en la clase de español:

MUCHAS GRACIAS POR SU INESTIMABLE COLABORACIÓN 
EL PROGRAMA TELEVISIVO COMO RECURSO PARA LA ENSEÑANZA/APRENDIZAJE DE ESPAÑOL LENGUA EXTRANJERA 


\begin{abstract}
ANEXO II
USE OF TELEVISION PROGRAMS IN SPANISH LESSONS

STUDENT QUESTIONNAIRE I

The following questionnaire is part of a doctoral investigation regarding the use of television programs in Spanish lessons. Your collaboration will be highly useful. This questionnaire is anonymous and your personal data will remain strictly confidential.
\end{abstract}

Thanks for your cooperation.

Center and country where you study Spanish:

Nationality:

Gender:

Age:

How long you have been studying Spanish (in years/months):

Level of Spanish:

A1 or Breakthrough

B1 or Threshold

$\mathrm{C} 1$ or Effective

A2 or Waystage

B2 or Vantage

C2 or Mastery

\title{
SECTION I. YOUR HABITUAL VIEWING OF TELEVISION PROGRAMS
}

7. How often do you watch the following audiovisual materials?

\begin{tabular}{|c|l|l|l|l|l|}
\hline & Never & Hardly ever & Sometimes & Often & Very often \\
\hline Television Programs & & & & & \\
\hline Commercials & & & & & \\
\hline Movies & & & & & \\
\hline Movie trailers & & & & & \\
\hline Short movies & & & & & \\
\hline
\end{tabular}

8. Approximately, how many television programs in your mother tongue do you watch?

None.

Only one. 
EL PROGRAMA TELEVISIVO COMO RECURSO PARA LA

ENSEÑANZA/APRENDIZAJE DE ESPAÑOL LENGUA EXTRANJERA

Between two and four.

More than four.

9. Which of the following types of television programs do you watch and how often?

\begin{tabular}{|l|l|l|l|l|l|}
\hline & Never & Hardly ever & Sometimes & Often & Very often \\
\hline $\begin{array}{l}\text { Informative } \\
\text { (The news, news reports, the } \\
\text { weather forecast...) }\end{array}$ & & & & & \\
\hline $\begin{array}{l}\text { Cultural } \\
\text { (Documentaries, educational TV } \\
\text { programs...) }\end{array}$ & & & & & \\
\hline $\begin{array}{l}\text { Fiction } \\
\text { (TV series, TV mini-series, soap } \\
\text { operas...) }\end{array}$ & & & & & \\
\hline $\begin{array}{l}\text { Entertaining } \\
\text { (Talk-shows, reality-shows, TV } \\
\text { magazines, game shows...) }\end{array}$ & & & & & \\
\hline $\begin{array}{l}\text { Sports } \\
\text { (Sports talk-show, broadcasts of } \\
\text { games, broadcasts of special } \\
\text { sporting events...) }\end{array}$ & & & & & \\
\hline
\end{tabular}

\section{SECTION II. YOUR HABITS AS A SPANISH LEARNER REGARDING THE USE OF TELEVISION PROGRAMS}

\section{Do you usually watch TV programs in Spanish?}

Yes.

What do you find them useful for?

\section{No.}

What do you think they could eventually be useful for?

20. Have you ever had a Spanish class that incorporated a television program? Yes. 
Did you find it useful? Why?

No.

Would you like to work with television programs in your Spanish lessons? Why?

SECTION III ${ }^{159}$. YOUR RECENT EXPERIENCE AS A SPANISH LEARNER REGARDING THE USE OF TELEVISION PROGRAMS IN THE CLASSROOM

9. Have you enjoyed this class? Rank your answer from 1 (not enjoyed it) to 10 (enjoyed it very much).

\begin{tabular}{|l|l|l|l|l|l|l|l|l|l|}
\hline 1 & 2 & 3 & 4 & 5 & 6 & 7 & 8 & 9 & 10 \\
\hline & & & & & & & & & \\
\hline
\end{tabular}

Why?

10. Have you found this class useful? Rank your answer from 1 (not useful at all) to 10 (very useful).

\begin{tabular}{|l|l|l|l|l|l|l|l|l|l|}
\hline 1 & 2 & 3 & 4 & 5 & 6 & 7 & 8 & 9 & 10 \\
\hline & & & & & & & & & \\
\hline
\end{tabular}

Why?

11. Have you found the pre-view activities useful? Rank your answer from 1 (not useful at all) to 10 (very useful).

\begin{tabular}{|l|l|l|l|l|l|l|l|l|l|}
\hline 1 & 2 & 3 & 4 & 5 & 6 & 7 & 8 & 9 & 10 \\
\hline
\end{tabular}

${ }^{159}$ To be answered at the end of the experimental class. 


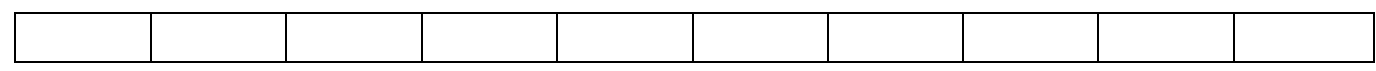

Why?

21. After this class, what do you think watching television programs in the Spanish classroom is useful for?

\begin{tabular}{|l|l|}
\hline Developing my listening skills. & \\
\hline Developing my oral skills. & \\
\hline Developing my reading skills. & \\
\hline Developing my writing skills. & \\
\hline Learning grammar. & \\
\hline Learning vocabulary. & \\
\hline Learning some Spanish expressions. & \\
\hline Learning some features of the Spanish pronunciation. & \\
\hline Getting to know the Spanish culture. & \\
\hline Motivating me to watch Spanish television programs outside of class. & \\
\hline
\end{tabular}

SECTION IV ${ }^{160}$. YOUR RECENT EXPERIENCE AS A SPANISH LEARNER REGARDING THE USE OF TELEVISION PROGRAMS OUTSIDE OF THE CLASSROOM

1. Have you found the post-view activity of writing a recipe useful? Rank your answer from 1 (not useful at all) to 10 (very useful).

\begin{tabular}{|l|l|l|l|l|l|l|l|l|l|}
\hline 1 & 2 & 3 & 4 & 5 & 6 & 7 & 8 & 9 & 10 \\
\hline & & & & & & & & & \\
\hline
\end{tabular}

Why?

2. Did you read some recipes in Spanish before writing the recipe?

${ }^{160}$ To be answered after having done the post-view activities. 
Why?

3. Have you found the post-view activity of recording a video useful? Rank your answer from 1 (not useful at all) to 10 (very useful).

\begin{tabular}{|l|l|l|l|l|l|l|l|l|l|}
\hline 1 & 2 & 3 & 4 & 5 & 6 & 7 & 8 & 9 & 10 \\
\hline & & & & & & & & & \\
\hline
\end{tabular}

Why?

4. Was this your first time recording yourself speaking another language?

How did you feel about it?

\section{What do you think these post-view activities were useful for?}

\begin{tabular}{|l|l|}
\hline Developing my oral skills. & \\
\hline Developing my reading skills. & \\
\hline Developing my writing skills. & \\
\hline Learning grammar. & \\
\hline Learning vocabulary. & \\
\hline Learning some Spanish expressions. & \\
\hline Making me work on my Spanish pronunciation. & \\
\hline Motivating me to try to speak more Spanish. & \\
\hline
\end{tabular}


EL PROGRAMA TELEVISIVO COMO RECURSO PARA LA ENSEÑANZA/APRENDIZAJE DE ESPAÑOL LENGUA EXTRANJERA 


\begin{abstract}
ANEXO III
USO DE PROGRAMAS TELEVISIVOS EN LAS CLASES DE ESPAÑOL

\section{CUESTIONARIO PARA ALUMNOS I}

El siguiente cuestionario está destinado a desarrollar una investigación doctoral sobre el uso de programas televisivos en las clases de español. Tu colaboración será de gran utilidad. Se trata de un cuestionario anónimo y los datos serán tratados con total confidencialidad.
\end{abstract}

Gracias por tu colaboración.

Centro y país en el que estudias español:

Nacionalidad:

Sexo:

Edad:

Tiempo que llevas estudiando español (en años/meses):

Nivel de español:

A1 o Acceso

B1 o Intermedio

C1 o Dominio Operativo Eficaz

A2 o Plataforma

B2 o Intermedio Alto

C2 o Maestría

\title{
APARTADO I. TU CONSUMO HABITUAL DE PROGRAMAS TELEVISIVOS
}

15. ¿Con qué frecuencia ves el siguiente contenido audiovisual?

\begin{tabular}{|c|l|l|l|l|c|}
\hline & Nunca & Casi nunca & A veces & A menudo & $\begin{array}{c}\text { Muy a } \\
\text { menudo }\end{array}$ \\
\hline Programas televisivos & & & & & \\
\hline Anuncios publicitarios & & & & & \\
\hline Películas & & & & & \\
\hline Tráiler & & & & & \\
\hline Cortometrajes & & & & & \\
\hline
\end{tabular}

16. Aproximadamente, ¿cuántos programas de televisión ves en tu lengua materna? 
EL PROGRAMA TELEVISIVO COMO RECURSO PARA LA

ENSEÑANZA/APRENDIZAJE DE ESPAÑOL LENGUA EXTRANJERA

Ninguno.

Solo uno.

Entre uno y cuatro.

Más de cuatro.

17. ¿Cuáles de los siguientes tipos de programas televisivos ves y con qué frecuencia?

\begin{tabular}{|l|l|l|l|l|l|}
\hline & Nunca & Casi nunca & A veces & A menudo & $\begin{array}{c}\text { Muy a } \\
\text { menudo }\end{array}$ \\
\hline $\begin{array}{l}\text { Informativos } \\
\text { (Telediario, reportajes de } \\
\text { actualidad, tertulias, el } \\
\text { tiempo...) }\end{array}$ & & & & \\
\hline $\begin{array}{l}\text { Culturales } \\
\text { (Documental, educativo...) }\end{array}$ & & & & & \\
\hline $\begin{array}{l}\text { Ficción } \\
\text { (Series, miniseries, } \\
\text { telenovelas...) }\end{array}$ & & & & & \\
\hline $\begin{array}{l}\text { Entretenimiento } \\
\text { (Talk-shows, reality-shows, } \\
\text { magacines, concursos, galas...) }\end{array}$ & & & & & \\
\hline $\begin{array}{l}\text { Deportes } \\
\text { (Programas específicos, } \\
\text { retransmisiones de } \\
\text { competiciones, eventos } \\
\text { especiales...) }\end{array}$ & & & & & \\
\hline
\end{tabular}

APARTADO II. TUS HÁBITOS Y EXPERIENCIA COMO ESTUDIANTE DE ESPAÑOL EN CUANTO AL USO DE PROGRAMAS TELEVISIVOS

22. ¿Sueles ver programas televisivos en español?

Sí.

¿Para qué crees que son útiles?

No.

¿Para qué crees que podrían ser útiles? 
23. ¿Alguna vez has tenido una clase de español que incorporara programas televisivos?

Sí.

¿Te pareció útil? ¿Por qué?

No.

¿Te gustaría trabajar con programas televisivos en tus clases de español?, ¿por qué?

APARTADO III ${ }^{161}$. TU RECIENTE EXPERIENCIA COMO ESTUDIANTE DE ESPAÑOL EN CUANTO AL USO DE PROGRAMAS TELEVISIVOS EN CLASE

12. ¿Te ha gustado esta clase? Clasifica tu respuesta de 1 (no me ha gustado) a 10 (me ha gustado mucho).

\begin{tabular}{|l|l|l|l|l|l|l|l|l|l|}
\hline 1 & 2 & 3 & 4 & 5 & 6 & 7 & 8 & 9 & 10 \\
\hline & & & & & & & & & \\
\hline
\end{tabular}

¿Por qué?

13. ¿Te ha parecido útil esta clase? Clasifica tu respuesta de 1 (no me ha parecido útil) a 10 (me ha parecido muy útil).

\begin{tabular}{|l|l|l|l|l|l|l|l|l|l|}
\hline 1 & 2 & 3 & 4 & 5 & 6 & 7 & 8 & 9 & 10 \\
\hline & & & & & & & & & \\
\hline
\end{tabular}

¿Por qué?

${ }^{161}$ A responder al final de la clase experimental. 
14. ¿Te han parecido útiles las actividades de previsionado? Clasifica tu respuesta de 1 (no me han parecido útiles) a 10 (me han parecido muy útiles).

\begin{tabular}{|l|l|l|l|l|l|l|l|l|l|}
\hline 1 & 2 & 3 & 4 & 5 & 6 & 7 & 8 & 9 & 10 \\
\hline & & & & & & & & & \\
\hline
\end{tabular}

¿Por qué?

15. Después de esta clase, ¿para qué crees que es útil ver programas televisivos en la clase de español?

\begin{tabular}{|l|l|}
\hline Para mejorar mi comprensión oral. & \\
\hline Para mejorar mi expresión oral. & \\
\hline Para mejorar mi comprensión escrita. & \\
\hline Para mejorar mi expresión escrita. & \\
\hline Para aprender gramática. & \\
\hline Para aprender vocabulario. & \\
\hline Para aprender algunas expresiones en español. & \\
\hline Para aprender algunos rasgos de la pronunciación del español. & \\
\hline Para conocer la cultura española. & \\
\hline Para motivarme a ver programas televisivos en español fuera de clase. & \\
\hline
\end{tabular}

\section{APARTADO IV ${ }^{162}$. TU RECIENTE EXPERIENCIA COMO ESTUDIANTE DE ESPAÑOL EN CUANTO AL USO DE PROGRAMAS TELEVISIVOS FUERA DE CLASE}

\section{1. ¿Te ha parecido últil la actividad de posvisionado de escribir una} receta? Clasifica tu respuesta de 1 (no me ha parecido útil) a 10 (me ha parecido muy útil).

\begin{tabular}{|l|l|l|l|l|l|l|l|l|l|}
\hline 1 & 2 & 3 & 4 & 5 & 6 & 7 & 8 & 9 & 10 \\
\hline
\end{tabular}

${ }^{162} \mathrm{~A}$ responder tras haber realizado las actividades de posvisionado. 


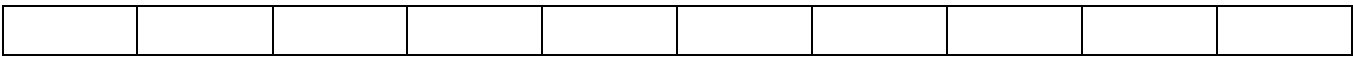

¿Por qué?

12. ¿Leíste algunas recetas en español antes de escribir la receta?

¿Por qué?

13. ¿Te ha parecido últil la actividad de posvisionado de grabar un vídeo? Clasifica tu respuesta de 1 (no me ha parecido útil) a 10 (me ha parecido muy útil).

\begin{tabular}{|l|l|l|l|l|l|l|l|l|l|}
\hline 1 & 2 & 3 & 4 & 5 & 6 & 7 & 8 & 9 & 10 \\
\hline & & & & & & & & & \\
\hline
\end{tabular}

¿Por qué?

14. ¿Esta fue la primera vez que te grabaste hablando en otro idioma?

¿Cómo te sentiste?

15. ¿Para qué crees que fueron útiles estas actividades de posvisionado?

\begin{tabular}{|l|l|}
\hline Para mejorar mi expresión oral. & \\
\hline Para mejorar mi comprensión escrita. & \\
\hline Para mejorar mi expresión escrita. & \\
\hline Para aprender gramática. & \\
\hline Para aprender vocabulario. & \\
\hline Para aprender algunas expresiones en español. & \\
\hline Para esforzarme en mi pronunciación del español. & \\
\hline Para motivarme a intentar hablar más español. & \\
\hline
\end{tabular}


EL PROGRAMA TELEVISIVO COMO RECURSO PARA LA ENSEÑANZA/APRENDIZAJE DE ESPAÑOL LENGUA EXTRANJERA 


\author{
ANEXO IV \\ WestVurginiaUniversity. \\ Office of Research Integrity and Compliance \\ Approval Letter Expedited

$\begin{array}{ll}\text { Action Date } & 03 / 07 / 2017 \\ \text { To } & \text { Maria Amores-Aguera } \\ \text { From } & \text { WVU Office of Research Integrity and Compliance } \\ \text { Approval Date } & 03 / 07 / 2017 \\ \text { Expiration Date } & 03 / 06 / 2018 \\ \text { Subject } & \text { Protocol Approval Letter } \\ \text { Protocol Number } & 1612373439 \\ \text { Title } & \text { USE OF TELEVISION PROGRAMS IN SPANISH LESSONS }\end{array}$

The above-referenced research study was reviewed by the West Virginia University Institutional Review Board IRB and was approved in accordance with 46 CFR $46.101 \mathrm{~b}$.

It has been determined that this study is of minimal risk and meets the criteria as defined by the expedited categories listed below:

- Category 6. Collection of data from voice, video, digital, or image recordings made for research purposes.

- Category 7. Research on individual or group characteristics or behavior (including, but not limited to, research on perception, cognition, motivation, identity, language, communication, cultural beliefs or practices, and social behavior) or research employing survey, interview, oral history, focus group, program evaluation, human factors evaluation, or quality assurance methodologies. [NOTE: Some research in this category may be exempt from the DHHS regulations for the protection of human subjects. See Exempt Categories and 45 CFR 46.101(b)(2) and (b)(3). This listing refers only to research that is not exempt.]

Documents reviewed and/or approved as part of this submission:

CoverLetter_Modified_SaradelValle.pdf: 2017-03-01-05:00

TeachingProposal_Spanishversion_SaradelValle.pdf: 2017-02-04-05:00

TeachingProposal_Englishversion_SaradelValle.pdf: 2017-02-04-05:00

Questionnaire_Students_SaradelValle.pdf: 2017-02-04-05:00 
EL PROGRAMA TELEVISIVO COMO RECURSO PARA LA ENSEÑANZA/APRENDIZAJE DE ESPAÑOL LENGUA EXTRANJERA 
ANEXO V

Dear Students,

In this class, we are conducting a research project designed to evaluate the efficiency of using videos from Spanish television programs as a teaching resource in the Spanish-as-a-second-language classroom. The objective of this study is (i) to provide a scientific basis to prove the practical nature of this learning proposal for using these types of resources, (ii) to demonstrate the usefulness of television programs for teaching a foreign language, (iii) to present and put into practice, in a real academic context, a learning proposal for Spanish-as-a-second-language students based on this resource. With this letter, we would like to invite you to participate in this research project by providing us with your perspective on learning Spanish through the use of videos taken from Spanish television programs.

All of you will participate in the lesson featuring a video from a television program as part of your normal class instruction; however, you may choose not to participate in the questionnaires for the purpose of this project. The inclusion of your feedback is completely voluntary. The data collected for this project will be kept confidential, and all data will be reported by using non-traceable identifiers (numbers). No names will be used in the final reporting. You must be 18 years of age or older to participate. In one of the activities that we will carry out in this lesson, you will be asked to videotape yourselves as a way to develop your oral skills. Tapes will be sent to Sara del Valle Revuelta and will be watched exclusively by her. Tapes will be deleted from her personal computer right after the end of this study, since their only objective is to make the students experience the process of recording and reviewing themselves speaking Spanish.

Your class standing (grades, etc.) will not be affected if you decide not to have your feedback included or to withdraw it later from the study.

This project has been approved by the West Virginia University's Institutional Review Board. The project is being conducted by Sara del Valle Revuelta (in Spanish 102 and 204) for the purposes of her $\mathrm{PhD}$ thesis research.

Your participation in this project is greatly appreciated. We hope that you will consider including your data in the project because it could be beneficial in understanding what motivates students in language classes and what helps their learning.

Should you have any questions about this letter or the research project, please feel free to contact Sara del Valle Revuelta by email at sd0033@mix.wvu.edu or Dr. Maria Amores at mamores@wvu.edu.

For information regarding you rights as a research subject, to discuss problems, concerns, or suggestions related to the research, to obtain information or offer input about the research, contact the Office of Research Integrity \& Compliance at (304) 293-7073.

Thank you for your time and help with this project.

Sincerely,

Sara del Valle, PhD student in Spanish and Linguistics, and

Dr. Maria Amores, Associate Professor of Spanish

DEPARTMENT OF WORLD LANGUAGES, LITERATURES, AND LINGUISTICS 


\section{ANEXO VI}

\begin{tabular}{|c|c|}
\hline \multicolumn{2}{|c|}{$\begin{array}{l}\text { PROPUESTA DE ACTIVIDADES PARA LA EXPLOTACIÓN DE UN PROGRAMA } \\
\text { DE INFORMACIÓN METEOROLÓGICA }\end{array}$} \\
\hline Soporte & $\begin{array}{l}\text { Programa de información meteorológica: Agencia } \\
\text { EFE. }\end{array}$ \\
\hline Nivel & A1 \\
\hline Duración & 75 minutos \\
\hline - Actividades de previsionado & - 40 minutos ( 6 actividades) \\
\hline - Actividades durante el visionado & - 15 minutos ( 3 actividades) \\
\hline - Actividades de posvisionado & - 20 minutos ( 1 actividad) \\
\hline Dinámica & Individual, en parejas y en grupo. \\
\hline Objetivos & $\begin{array}{l}\text { Comprender un programa de información } \\
\text { meteorológica; trabajar con vocabulario relativo al } \\
\text { tiempo atmosférico, los días de la semana, los } \\
\text { números y las horas; familiarizarse con el mapa de } \\
\text { España; utilizar la construcción ir a }+ \text { infinitivo; } \\
\text { relacionar actividades y acciones con tiempo } \\
\text { atmosférico; aprender expresiones relacionadas con } \\
\text { el tiempo atmosférico; hablar del tiempo } \\
\text { atmosférico. }\end{array}$ \\
\hline Contenidos & $\begin{array}{l}\text { Gramaticales, léxicos, socioculturales, pragmáticos, } \\
\text { estratégicos y discursivos. }\end{array}$ \\
\hline Destrezas & Comprensión oral, expresión oral e interacción oral. \\
\hline Tarea final & $\begin{array}{l}\text { Grabar un vídeo para un programa de información } \\
\text { meteorológica: elegir una comunidad autónoma de } \\
\text { España e informar del tiempo que va a hacer. }\end{array}$ \\
\hline
\end{tabular}

\begin{tabular}{|ll|}
\hline \multicolumn{1}{|c|}{ PROPUESTA DE ACTIVIDADES PARA LA EXPLOTACIÓN DE UN PROGRAMA } \\
INFORMATIVO
\end{tabular}




\begin{tabular}{|ll|}
\hline Contenidos & noticia. \\
\hline Destrezas & $\begin{array}{l}\text { Gramaticales, léxicos, socioculturales, pragmáticos, } \\
\text { estratégicos y discursivos. }\end{array}$ \\
\hline Tarea final & $\begin{array}{l}\text { Comprensión oral, comprensión escrita, expresión } \\
\text { oral e interacción oral. }\end{array}$ \\
\hline & $\begin{array}{l}\text { Grabar un vídeo representando un programa } \\
\text { informativo: informar de una noticia relacionada } \\
\text { con la política. }\end{array}$ \\
\hline
\end{tabular}

\begin{tabular}{|ll|}
\hline \multicolumn{1}{|c|}{ PROPUESTA DE ACTIVIDADES PARA LA EXPLOTACIÓN DE UN PROGRAMA } \\
DE INFORMACIÓN DEPORTIVA
\end{tabular}

\begin{tabular}{|ll|}
\hline \multicolumn{1}{|l|}{ PROPUESTA DE ACTIVIDADES PARA LA EXPLOTACIÓN DE UN PROGRAMA } \\
DE COCINA
\end{tabular}




\begin{tabular}{|ll|}
\hline \multirow{3}{*}{ Objetivos } & $\begin{array}{l}\text { Comprender un programa de cocina; conocer platos } \\
\text { típicos españoles e identificar la región a la que } \\
\text { pertenecen; trabajar con vocabulario relativo a las } \\
\text { recetas de cocina: ingredientes, cantidades y } \\
\text { elaboraciones; utilizar el modo imperativo; conocer } \\
\text { expresiones relacionadas con la comida; aprender el } \\
\text { uso y significado del diminutivo -ito/-ita; percibir } \\
\text { rasgos de la pronunciación del español del norte de } \\
\text { España; escribir y explicar la receta de un plato } \\
\text { típico del país de origen. }\end{array}$ \\
\hline Gramaticales, léxicos, socioculturales, pragmáticos, \\
estratégicos y discursivos.
\end{tabular}

\begin{tabular}{|ll|}
\hline PROPUESTA DE ACTIVIDADES PARA LA EXPLOTACIÓN DE UN PROGRAMA \\
DOCUMENTAL
\end{tabular}




\begin{tabular}{|ll|}
\hline $\begin{array}{l}\text { PROPUESTA DE ACTIVIDADES PARA LA EXPLOTACIÓN DE UN PROGRAMA } \\
\text { DE FICCIÓN }\end{array}$ \\
\hline Soporte & Programa de ficción: Camera Café. \\
\hline Nivel & C1/C2 \\
\hline Duración & 75 minutos \\
- Actividades de previsionado & -20 minutos (2 actividades) \\
- Actividades durante el visionado & -20 minutos (2 actividades) \\
\hline Actividades de posvisionado & -35 minutos (3 actividades) \\
\hline & Individual, en parejas y en grupo. \\
Objetivos & $\begin{array}{l}\text { Comprender un programa de ficción; trabajar con } \\
\text { vocabulario relativo a la televisión; comprender una } \\
\text { entrevista; utilizar el discurso indirecto; aprender } \\
\text { expresiones coloquiales; percibir rasgos de la } \\
\text { pronunciación coloquial; comparar la ficción y la } \\
\text { realidad; entender el humor español; convertir un } \\
\text { registro informal en un registro formal. }\end{array}$ \\
\hline Contenidos & $\begin{array}{l}\text { Gramaticales, léxicos, socioculturales, pragmáticos, } \\
\text { estratégicos y discursivos. }\end{array}$ \\
\hline \multirow{2}{*}{ Destrezas } & $\begin{array}{l}\text { Comprensión oral, comprensión escrita, expresión } \\
\text { oral, expresión escrita, interacción oral, mediación } \\
\text { oral y mediación escrita. }\end{array}$ \\
\hline \multirow{2}{*}{ Tarea final } & $\begin{array}{l}\text { Representar el vídeo de ficción visualizado como si } \\
\text { se tratara de una situación real: utilizar el registro } \\
\text { formal. }\end{array}$ \\
\hline
\end{tabular}

\begin{tabular}{|ll|}
\hline \multicolumn{1}{|c|}{$\begin{array}{l}\text { PROPUESTA DE ACTIVIDADES PARA LA EXPLOTACIÓN DE UN PROGRAMA } \\
\text { DE ENTRETENIMIENTO }\end{array}$} \\
\hline Soporte & Programa de entretenimiento: El hormiguero. \\
\hline Nivel & B2/C1 \\
\hline Duración & 85 minutos \\
- Actividades de previsionado & -25 minutos (3 actividades) \\
- Actividades durante el visionado & -30 minutos (4 actividades) \\
- Actividades de posvisionado & -30 minutos (2 actividades) \\
\hline Dinámica & Individual, en parejas y en grupo. \\
\hline & $\begin{array}{l}\text { Comprender un programa de entretenimiento; } \\
\text { trabajar con vocabulario relativo a la música; } \\
\text { Comprender un artículo periodístico y resumirlo; } \\
\text { aprender expresiones coloquiales; entender el humor } \\
\text { español; utilizar el presente de subjuntivo; crear y } \\
\text { escribir una historia. }\end{array}$ \\
\hline Contenidos & Gramaticales, léxicos, socioculturales, pragmáticos, \\
& estratégicos y discursivos. \\
\hline Destrezas & Comprensión oral, comprensión escrita, expresión \\
\hline
\end{tabular}


EL PROGRAMA TELEVISIVO COMO RECURSO PARA LA

ENSEÑANZA/APRENDIZAJE DE ESPAÑOL LENGUA EXTRANJERA

\begin{tabular}{|ll|}
\hline & $\begin{array}{l}\text { oral, expresión escrita, interacción oral y mediación } \\
\text { escrita. }\end{array}$ \\
\hline Tarea final & $\begin{array}{l}\text { Crear y escribir una historia a partir de una serie de } \\
\text { palabras. }\end{array}$ \\
\hline
\end{tabular}

\begin{tabular}{|ll|}
\hline \multicolumn{1}{|c|}{ PROPUESTA DE ACTIVIDADES PARA LA EXPLOTACIÓN DE UN CONCURSO } \\
DE TELEVISIÓN
\end{tabular}

\begin{tabular}{|ll|}
\hline \multicolumn{2}{|c|}{ PROPUESTA DE ACTIVIDADES PARA LA EXPLOTACIÓN DE UNA EMISIÓN } \\
PUNTUAL
\end{tabular}




\begin{tabular}{|ll|}
\hline & $\begin{array}{l}\text { periodístico; escribir una postal de navidad; } \\
\text { describir un atuendo; representar la noche de fin de } \\
\text { año en España. }\end{array}$ \\
\hline Contenidos & $\begin{array}{l}\text { Gramaticales, léxicos, socioculturales, pragmáticos, } \\
\text { estratégicos y discursivos. }\end{array}$ \\
\hline Destrezas & $\begin{array}{l}\text { Comprensión oral, comprensión escrita, expresión } \\
\text { oral, expresión escrita, interacción oral y mediación } \\
\text { escrita. }\end{array}$ \\
\hline Tarea final & $\begin{array}{l}\text { Grabar un vídeo representando la emisión de fin de } \\
\text { año en España. }\end{array}$ \\
\hline
\end{tabular}

\begin{tabular}{|ll|}
\hline \multicolumn{1}{|l|}{ PROPUESTA DE ACTIVIDADES PARA LA EXPLOTACIÓN DE UN PROGRAMA } \\
DE HUMOR
\end{tabular}

